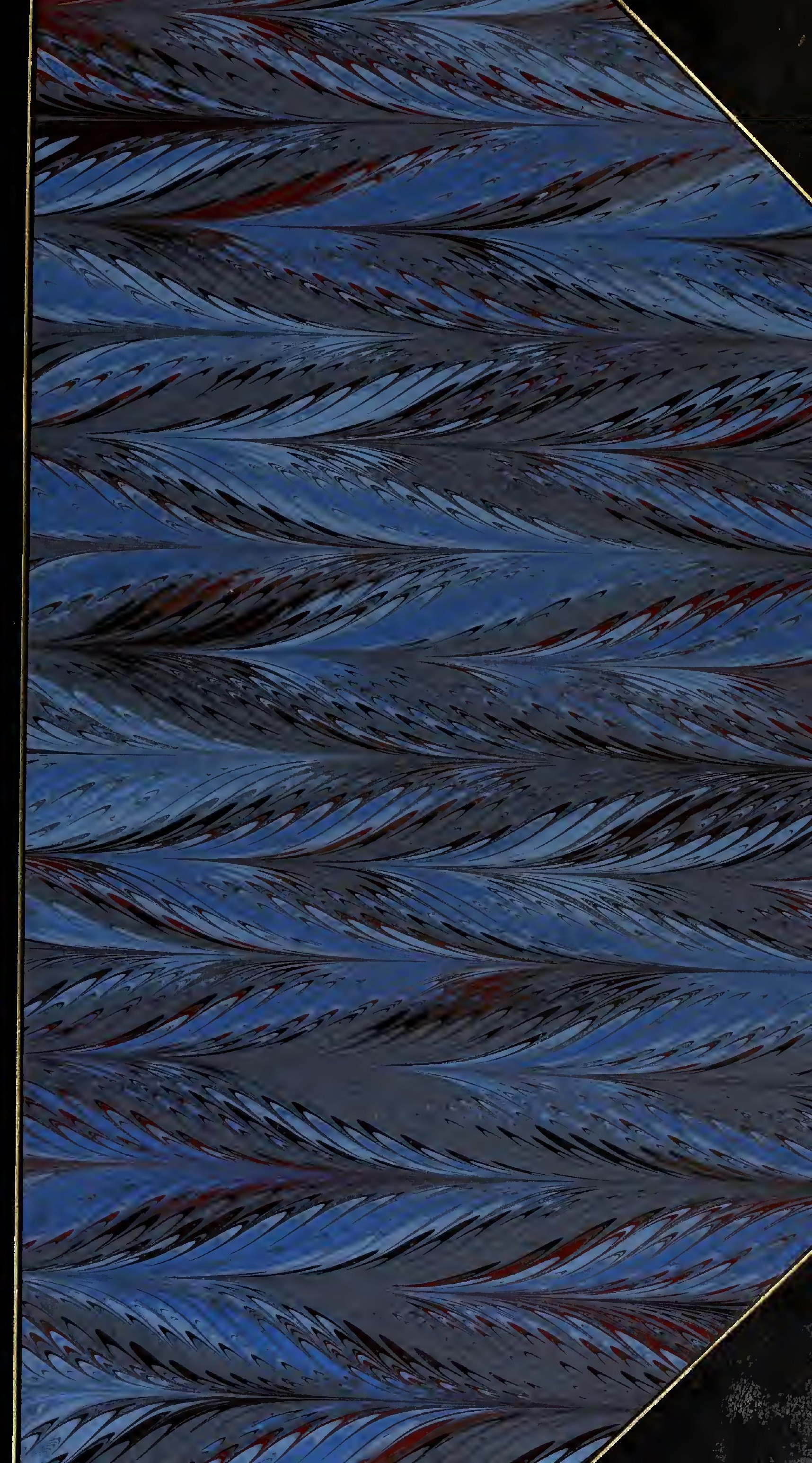









\section{MONOGRAPHIES}

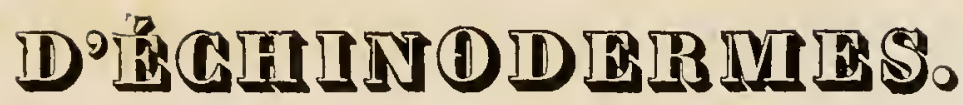





\section{MONOGRAPHIES}

D'ÉCHINODERMES

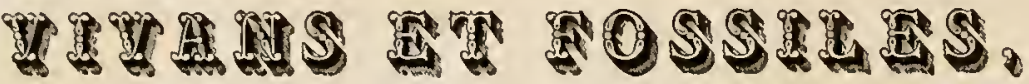

$P, 1 R$

\section{LOUIS AGASSIZ,}

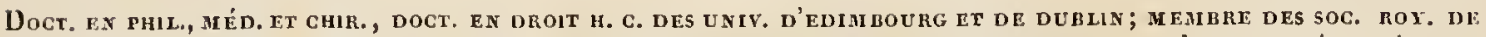
LOADRES ET D'EDIMBOURG, DES ACAD. ROY. DES SCIENCES DE STOCKHOLM ET DE TURIN, DE I'AC. IMP. LÉOP. CÉS. DES CUR. DE L.I NAT., DE LA SOC. IMP. DES NIT. DE MOSCOU, DE LA SOC. PHILOM. DE PARIS, DES AC. DE PHILADELPHIE ET IDU

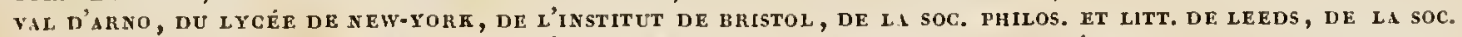
GÉOL. DE PRANCE, DE L'ASSOC. BRITT. POUR L'AYANCEMENT DES SCIENCES, DEś SOC. HELVÉT. ET GERMAN. DES SC. NAT. ET MÉW., DE LA SOC. DES ANTIQ. DU NORD A COPENHAUE, DE CELLE DES SC. PHYS., CHIM., ARTS AGRIC. ET INIUSTR. 1)E FRANCE, DES SOC. D'HIST. NAT. DE BERLIN, FRANCFORT, PRAGUE, HEIDFLBERG, STKASBOURG, SILÉSIE, HILTE, FRIBOURG, 7.URICH, BALE, FTC. ; PROFESSEUR D'HISTOIRE NATUR ELLE A NEUCHATEL.

\section{NEUCHATEL EN SUISSE,}

AUX FRIS DE L'AUTEUR.

\section{8.}





\section{VALENGIENNES,}

PROFESSEUR DE ZOOLOGIE AU JARDIN DES PLANTES,

I.

\section{PAUL DESHAYES,}

PROFESSEL DE CONCHILIOLOGIE, A PARIS,

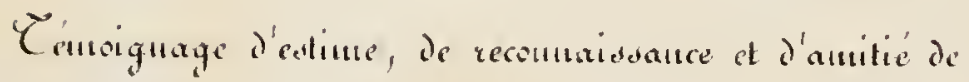

IOY nenc. 



\section{PREACA.}

La nature des résultats généraux auxquels l'étude des poissons fossiles m'a conduit; la certitude que j'ai aequise par là que les ehangemens que eette elasse a subis à travers l'ensemble des formations géologiques, présentent une sorte de transformations progressives, annonçant un ordre de choses supéricur, accompli dans l'époque actuelle aree l'apparition de l'homme; le désir d'apprendre à connaître les tendances diverses qui se sont manifestées dans le développenent des autres embranehemens du règne animal; enfin le besoin toujours plus pressant d'embrasser d'un coup-d'ocil général les rapports qui existent entre tous les êtres vivans dans leur apparition sur la terre, toutes ees considérations m'ont engagé à faire des recherches sur plusieurs elasses d'animaux dont je m’étais occupé moins spécialement jusqu'alors.

La classe des Echinodermes m'a paru d'abord devoir mériter une attention toute particulière. La solidité du test de la plupart des espèces, à laquelle il faut attribuer la conservation souvent très-parfaite de nombreux débris de ees animaux, dans toutes les eouches de l'écorce de notre globe qui eontiennent des fossiles, me donnait par avanee la ecrtitude de pouvoir examiner les earactères de ees animaux sur l'éehelle la plıs étendıe, en même temps que la nature compliquée de ees enveloppes solides me promettait de nombreux termes de comparaison et par eonséquent la possibilité d'une étude plus eomplète et plus siguifieative de leur organisation que ne l'eủt offert l'examen des eoquilles des Mollusques. Une autre circonstance me paraissait encore, de prime abord, devoir faciliter des recherches dans cette classe, et conduire plus promptement à des résultats certains : e'était le nombre comparativement moins considérable d'espèces eonnues. Cependant, je m'aperẹus bientôt qul'à cet égard je m'étais singulièrement trompé; car à mesure que jẹ me mis 
à eomparer entre elles les espèces provenant de différentes localités et qui avaient été envisagées comme identiques par suite de déterminations faites la plupart d'après des figures, ou même d'après de simples descriptions, j'acquis la eertitude que non-seulement ees espèces étaient fréquemment différentes, mais encore qu'elles appartenaient même quelquefois à des genres différens. La néccssité de revoir avec plus de soin la elasse tout entière, me fut dès-lors démontrée, et je fis tous mes efforts pour réunir les matériaux nécessaires pour une eomparaison directe de toutes les espèces décrites ou signalées par les auteurs. Il me parut également essentiel de remonter aux sources premières pour établir la synonymie d'une manière authentique, et pour éviter ces doubles-emplois trop fréquens dans les ourrages de pure eompilation, et aussi funestes anx progrès de la science que l'énumération de toutes ees espèces nominales dont l'existence ne repose, le plus souvent, que sur des indications superficielles, ou sur de mauvaises deseriptions applicables à plusieurs espèces à-la-fois, ou sur le peu de soin que l'on met généralement à comparer les ouvrages anciens.

Afin d'atteindre plus sûrement mon but, et pour éviter, autant qu'il dépendrait de moi, les diverses sources d'erreurs que je viens de signaler, je me rendis à Paris, peu de temps après la publication de mon Prodrome d'une Monographie des Radiaires ou Echinodermes (inséré dans le I ${ }^{\text {er }}$ vol. des Mémoires de la Soc. des sc.nat. de Nenchâtel 1836), pour y étudier en détail la collection d'Echinodermes du Muséum, la plus eonsidérable qui existe en Europe. Encouragé dans mes recherches par l'obligeante anitié de M. Valenciennes qui voulut bien mettre à ma disposition la collcetion entière, j'en examinai une à une les différentes espèces, que je déterminai pour la plupart et parmi lesquelles j'en distinguai un grand nombre de nouvelles ainsi que plusieurs genres entièrement nouveaux. J'y r'etrouvai surtout les originaux de presque toutes les espèces de Lamarck, portant pour la plupart encore des étiquettes de sa main. Un grand nombre d'espèces déerites par M. de Blainville, dans le nouveau Dictionnaire des sciences naturelles, s'y trouve également, avec des étiquettes de la main de l'auteur. Grâce au zèle persévérant de M. Valenciennes, eette elasse de Rayonnés est maintenant en progrès d'arrangement dans les galeries du Huséum; de sorte que ecux qui voudront en faire une étude approfondie y trouveront toutes les 
facilités désirables. Les excmplaires sont montés d'une manièrc très-ingénicuse et propre à mettre cn évidenee les earactères des espèces.

M. Brongniart m’a également communiqué, avee son obligeance aceoutumée, les espèces fossiles qu'il a déerites ou indiquées dans ses différens ouvrages; je dois aussi à M. Defranee la connaissanee de toutes les espèces fossiles qu'il a déerites. J'examen de ees collections originales a eu d'autant plus de prix pour moi, que c'est aux ouvrages de ees auteurs que se rattachent les travaux plus récents qui ont été faits sur les Eehinodermes, et qu'avant d'avoir vu les originaux dc leurs deseriptions, il pouvait me rester des doutes graves sur l'identité de leur's espèces avec eelles qui ont été déerites plus tard par MII. Gray, Goldfuss, le comte de Münster et Ch. DesMoulins.

Outre ces espèces originales, j’ai rencontré dans ces eollections un grand nombre d'espèces nouvelles qui ont été miscs à ma disposition avee la mème libéralité. Mais e’est à M. Desllayes en particulier que j’ai dû la communication du plus grand nombre d'espèces nouvelles, surtout de fossiles. On aura de la peine à eroire que sa seule collection renferme plus de ecnt espèees d'Echinites qui ne sont cneore mentionnées dans aueun des nombreux ouvrages qui traitent de l'histoire des Eehinodermes. Mu par eetie noble eonfiance qui earactérise les naturalistes dont le but unique est de favoriser les progrès de la science, M. Desllaycs a eu la bonté de me eonfier toutc sa eolleetion en m'autorisant à la garder aussi long-temps qu'clle me serait nécessaire dans mon travail. J'ai trouvé le même empressement à mettre à ma disposition tout ee qui pouvait être de quelque intérêt pour na publieation, ehez la plupart des géologues et naturalistes français, qui possèdent des eollections. M. Elie de Beaumont m'a remis plusieurs espèces alpines trèsintéressantes quant à leur giscment; M. Voltz, différens Oursins du néocomien de Bourgogne et du midi de la Franec; M. Milne-Edward, des espèees d'Italic et d'Egypte; M. Alcide d'Orljigny de superbes Oursins de la eraie, du grès-vert et du coral-rag de l'ouest de la Franee, et quelques espèees vivantes de l'A mérique du sud; il possède en outre une eollection remarquable de Crinoïdes. M. Miehelin m'a eonfié les exemplaircs les plus intéressans de sa magnifique eollection d'Echinitcs vivans et fossiles, renfermant des espèces de diverses localités et de différens terrains. J'ai vu chez M. de Verneuil une 
fort belle eolleetion de Crinoïdes, surtout du Mountain-Limestone; M. Dutressier, de Besanęon, m'a communiqué un nombre assez considérable de Cidarides fossiles avee lcurs baguettes à-peu-près intactes, M. Leymeric des Diadèmes de l'époque triasique, et M. Deslongchamps, de Cacn, une trèshelle suite d'espèces provenant des terrains de Normandic. Précédemment déjà j’avais examiné à Londres les espèces du Musée Britannique décrites par M. König dans ses Icones sectiles, et par M. Gray dans différentes notices; eelles de la colleetion de M. Stockes, qui est très-riehe en espèees vivantes, et unc partie de celles de la Société géologique, recueillies dans tous les terrains d'Angleterre. A Brighton j'ai vu celles de la collection de M. Mantell, provenant pour la plupart, du terrain erétacé. A Bristol, j’ai examiné la magnifique collection de Crinoïdes de Miller, qui se trouve au Musée de cette ville, et les espèces que M. Cumberland a découvertes. Plusieurs espèees nouvelles de la collection de Sir Philipp Egerton, et celles du Musée de Scarborough, offrent également un grand intérèt. Hais j'ai été surtout réjoui de retrouver au Mnsée de Cambridge les espèces figurées dans Ag. Scilla. En Suisse, M. Studer a mis à ma disposition la magnifique collection d'espèces fossiles du Musée de Berne; celle du Musée de Soleure m’a été communiquée par M. Ilugi, celle de Bâle par M. Mérian. Lors de la réunion de la Soc. géol. de France à Porrentruy, j’ai examiné la plupart des espèces mentionnées par M. Thurmann. Enfin, M. Gressly m’a remis toutes les espèces nouvelles qu’il a découvertes en explorant le Jura suisse, y joignant en même temps des obscrvations précieuses sur leur gisement et en particulier sur leur association avec d'autres fossiles, circonstance bien digne de l'attention des géologues et sur laquelle il a le premier insisté d'une manière préeise comme devant surtout contribuer à éelairer l'histoire du globe terrestre.

Déjà les tableaux synonymiques des Echinites de M. DesMonlins m'ont été de la plus grande utilité, comme résumé de nos connaissances sur eet ordre de la elasse, à l'époque de leur publication. J'apprécic d'autant plus ce travail, que j'ai pu me convainere des diffieultés sans nombre qu'il présente lorsque, de mon eôté, j’ai rédigé de semblahles tableaux pour mon usage particulier. Je me félicite d'ètre par là en grande partic dispensé d'en publier les détails, et de pouvoir me borner à signaler les différenees que je trouve entre sa synonymie et eelle que j’avais établic. 
Si j’ai mentionné tontes les faeilités qui mont été offertes pour mon travail, ce n'est point pour en faire parade; c'est au eontraire un sentiment de justice, qui un'a déterminé à rendre un hommage public à la libéralité de tous eeux qui ont contribué à me mettre en état de donner à mou ouvrage une extension qu’il n'anrait jamais eue si j’avais été réduit à travailler sur les seuls matériaux que possède le Musée de Neuchâtel. J'ai d'ailleurs la conviction que ce n'est qu'en indiquant fidèlement toutes les sources où l'on a puisé, en rendant à chaeun ee qui lui est dù, en ne elıerchant jamais à usurper une priorité qui ne serait pas justement méritée, en ne visant pas à une suprématic tyrannique dans la science, que l'on peut mériter de ses eontcmporains une eonfiance sans laquelle les travaux scientifiques les plus eonsidérables perdent de leur autorité, et que la scule position d'un savant dans le monde ne saurait ni lui donner ni lui conserver. Et puis il y a si rarement de notre fait dans les cireonstances favorables dans lesquelles nous pouvons nous trouver, qu'il serait ridicule de vouloir nous en glorifier.

Pour eompléter l'inspection des eollections originales, il me reste encore à voir ou à revoir avec plus de soin les espèces décrites par Goldfuss, eelles du eomte de Münster, eelles de MII. Ch. DesMoulins et Grateloup, eelles de MIM. Plilipps, Risso, Marcel de Serres, et celles de M. Roemer. Dès que mes oceupations me le permettront, je m'empresserai de terminer ectte partie de la tàehe que je me suis imposée pour compléter, autant que possible, l'histoire naturelle de eette classe. Les relations que je soutiens avec la plupart de ces savans me donnent la certitude que je trouverai ehez cux les mêmes faeilités que j’ai déjà r'eneontrées ailleurs dans la suite de mes recherehes.

Qu'il me soit permis d'ajouter encore quelques mots sur le plan de eet ouvrage. Mon intention est de décrire et de représenter toutes les espèces nouvelles ou peu connues, ct mème eelles qui ont été mal figurées jusqu'à présent. Mais ne pouvant, dans l'intérêt mème de cet ouvrage, m'astreindre à un mode de publication régulier, et afin de réussir à mettre au jour, en premier lieu, les parties de mes recherches sur lesquelles j'ai réuni le plus de matériaux nouveaux et les renseignemens les plus complets, je publierai sueessivement de petites monographies embrassant chacune un groupe naturel et formant ainsi des touts complets, dont l'ordre de sue- 
ccssion devient dès-lors asscz indifférent, mais qui se lieront en dernière analysc par les considérations généralcs qui tcrmineront cet ouvrage. Ces monographies, dont l'étcndue sera proportionnée à leur contenu, paraîtront à des époques irrégulières. C'est, jc crois, la seule marche qu'un auteur qui doit publier par livraisons puisse suivre, sans encourir des reproches eontinucls de négligence et de lentcur, souvent si peu mérités. De cette manière, cet ouvragc pourra être envisagé, en quclque sortc, pcndant toute la duréc de sa publication, comme un journal ou unc revue destinée à l'étude de la classe entière des Echinodermes. Je me ferai un plaisir d'y consigner tous les faits nouveaux que l'on voudra me transmcttre. Les espèces nouvcllcs, qui n'auront point été mentionnées au ehapitre du genre dont elles font partie, seront décrites dans des supplémens qui accompagneront les monographies chaque fois qu'il y aura licu.

Désirant mettre tous les naturalistes en état de vérifier l'exactitude de mes indications et de contrôler directement la valeur des caractères que j'ai assignés à mcs nouveaux genres et aux espèces nonvelles que j’ai distinguées, je les ai fait mouler en plàtre toutes les fois que l'état des cxcmplaires le permettait, et j'offre ces collections anx Musées qui désirent les possédcr, dans l'espoir d'obtcnir' en échangc de nouvcaux matériaux pour mon travail.

Pour ne pas prolonger indéfiniment cette publication, et pour en achever plutôt les détails descriptifs, j'ai associé à mon travail un de mes amis, M. Desor, qui a fait, sous ma direction, unc étude très-approfondic des Echinodermes, et qui déjà s'est cliargé dı soin de la rédaction de mes notes et de la direction des artistcs occupés à dessiner lcs matériaux considérables que j'ai maintenant sous les ycux.

Nenchâtel, le 22 décembre 1838 .

L. Agnssiz. 


\section{ÉCHINITES.}

FAMILLE DES CIDARIDES.

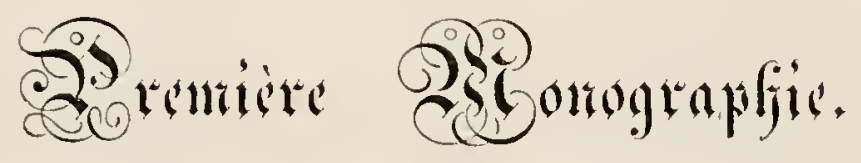

DES SALÉNIES. 



\section{QUELQUES OBSERVATIONS SUR LES SALENIES EN GENERAL.}

A mesure que, depuis Linnée, l'ou a commencé à subdiviser les Oursins en plusieurs genres, on a reconwu la nécessité de restreindre les caractères génériques à des particularités d’organisation auxquelles on n’avait d'ahord attaché que peu d'importance. Néanmoins, le nombre de genres que l'on admet maintenant dans la famille des rais Oursins, est encore peu considérable; et cependant les différences organiques qui existent entre les espèces qu’on a laissées dans le genre Echimes, ont souvent une valeur générique aussi grande que les caractères d’ạpès lesquels on a distingué les genres adoptés jusqüici, savoir, les genres Cidaris, Diadema, Arbacia (Gray) ou Echinocidaris (Desmoulins), Salenia, Echinometra et Echinus. En effet, c'est surtout à cause de la structure de leurs ambulacres, composés, comme dans les Cidaris, de deux paires de pores seulement, que l'on a détaché les Arbacia et les Salenia du genre Echinus; et les grands tubercules ambulacraires des Cidaris ont servi à les distinguer des Diadèmes. Or, si l'on examine altentivement les espèces placées dans chacun de ces genres, on sera frappé des différences qu elles présentent, et l'on éprouvera une très-grande difficulté à y introduire un grand nonbre d'espèces inédites, dont l'examen, loin de faire naitre l'idée de réunir derechef des genres déjả établis, fait plutòt sentir le besoin d'en créer de nouveaux, avec des limites plus étroites qui permettent de grouper plus naturellement les espèces suivant leurs affinités les plus intimes. C'est surtout l'étude des espèces fossiles qui fait sentir le besoin de multiplier les goenres; car à mesure qu'on les comuaît mieux, on s'aperçoit qu'elles cadrent mal avee les espèces vivantes auxquelles oll a l'labitude de les associer ; par exemple, le Cidaris cremularis, placé successivement dans les genres Cidaris et Diadema, est le type dun genre particulier que jappellerai IIemicidaris, dont les piquans sont si bizarres que souvent mème ils ont été envisagés comme des polypiers. Je ronnais maintenaut une dizaine d'espèces inédites de ce genre. Un autre genre également nouveau, el voisin des Hemicidaris, est celui des Gymmocidaris, caractérisé par l’absence à-peu-pris complèle de gros tubercules à la face supérieure du test. Daus les collections de Paris, jai re- 
comnu un genre tout nouvean, voisin des Cidaris, que jappellerai Acrocidaris, et dont les piquans me sont également eonmus; ils ressemblent à eeux de l'Echinometra mammillata. D’autres lypes gélériques voisins des Cidaris semblent indiqués par les piquans que l'on eonfond sous le nom de Cidaris glandifera, et dont je eonnais einq ou six espéees distinetes, des terrains jurassiques et erélaés. Les piquans dont on a fait le Cidaris Schmidelii, paraissent aussi se rapporter à un geure partieulier. Il en est de même d'une espèee inédite de l'oolithe inférieure, dont les piquans se terminent en larges lames spatuliformes. Eı résunı́, le nombre des espéees de Cidaris, dans le sens le plus étendu de ee genre, que je eonnais maintenant et que jai examinées en nature, est au moins triple de eelui qu'ont signalé les auteurs.

Quant aux Diadèmes, il est évident pour moi que les fossiles jurassiques et erétaeés que l'on a rapportés à ee genre, diffèrent génériquement des Diadèmes vivaus, tant par la strueture de leur test, que par la nature de leurs piquans. Jaì eru en eouséquenee devoir reporter ees derniers dans le genre Asteropyga, établi par Gray. Mais je ne me suis pas arrêté là : j’ai encore été eonduit à admettre plusieurs eoupes génériques dans les fossiles, en séparant des vrais Diadèmes trois genres nouveaux, les Tetragramma, les Acropeltis et les Pedina; le prenier earactérisé par la présenee de quatre rangées de tubereules primeipaux sur les aires interambulacraires, le seeond par un appareil ovidueal tout partieulier, analogue a eelui des Salénies, et le troisième par sa forme généralement aplatie et la disposition de ses ambulaeres.

Les espèces à tubereules non perforés, qu'on avait jusqüiei confondues parmi les Diadémes, ne pouvaient dès lors plus rester réunies à ee genre, quelle que füt l'analogie de leurs formes. J'en ai fait plusieurs genres distinets : le genre Cyphosoma, à ambulaeres sintples avee deux rangées de tubereules prineipaux sur les aires ambulaeraires et interambulaeraires; le genre $C_{a-}$ lopleurus, dont les aires anbulaeraires sont épineuses, les interambulaeraires, au eontraire, dépourvues de tubereules daus toute la partie supérieure du test, et les genres Echinopsis, Codiopsis et Terina. Malgrẻ ces restrietions, il me reste eneore dans les vrais Diadémes einq tois plus d'especees qu'on l'en a déerit jusqu'a présent.

Les Arbacia vivantes diffèrent génériquement des espèees jurassiques que j’avais rangẻes dans ce genre. Le nombre des espèees s'est aussi doublé depuis la publieation de mon Prodrome.

Mais e'est dans le groupe des Salenia que jai fait le plus d'aequisitions ; ear le nombre en a èté quintuplé, et jai reeontu trois genres nouveaux qui étaient eonfondus dans eette division.

Je n'étendrai pas plus loin mes indieations sur les additions que la elasse des Eelinodermes est sur le point de reecoir. Je me bornerai seulement à faire remarquer à cette oceasion, com- 
bien nos connaissances en paléontologie sont encore incomplètes, puisque dans une classe dont on s'est tant occupé depuis Lamarek, et sur laquelle il a paru des travaux si remarquables, quelques visites dans les collections existantes mont fourni une pareille masse de matériaux nouveaux, et conbien les résultats scientifiques présentẻs jusqu’à présent subiront probablement de modifications. Ne voulant moccuper, pour le moment, que des Salénies et des genres qui s'en rapprochent le plus, je vais indiquer les caractères généraux de ce groupe; jentrerai plus tard dans des détails très-circonstanciés sur les genres Echinometra et Echimus proprement dits, qu’il faut également subdiviser en plusieurs genres, mais dont l’énumération m’entrainerait au delà de nıon but actuel.

Les S.úxics, telles que Gray les a caractérisées (Proced. of the Zool. Soc. 1835, p. 58), et telles quion les a envisagées jusqu’ici, sont des Oursins à aires ambulacraires plus étroites que les interambulacraires, n'ayant qu'un gros tubercule inıperforé sur cliaque plaque coronale, et dont les plaques ovariales et interovariales, sondées entre elles de manière à ne pas se disloquer facilement, forment un disque saillant traversé par l'appareil anal dont l'ouverture est tantòt centrale, tantôt antérieure et tantôt postérieure. En examinant cependant attentivement ce groupe, j’ai reconnu des différences notables dans la structure de l'appareil oviducal; et comme, par une particularité digne de remarque, cet appareil se trouve conservé dans tous les exemplaires tant soit peu reconnaissables, au point que lorsqu'il s'agirait de déterminer un oursin qui réunirait tous les caractères des Salénies, mais auquel il manquerait l’appareil oviducal, on pourrait sans crainte de se tromper le rapporter à d'autres genres, j'ai cru devoir attacher une importance toute particulière à cette partie du test, et diviser le groupe des Salénies en quatre genres suivant les modifications qu'elles présentent. Ce sont : $1^{\circ}$ le genre Salenia proprement dit, $2^{\circ}$ le genre Goniopygus, $3^{\circ}$ le genre Pellastes et $4^{\circ}$ le genre Goniophorus, qui tous paraissent particuliers aux terrains crétacés, puisqu'on n’en a jusqu'à présent trouvé ancune espèce ni daus les terrains plus anciens, ni dans les plus récens. Goldfuss à la vérité cite aussi son Cidarites scutiger dans la formation jurassique, mais cette indication mérite confirmation.

Comme les Salénies sont généralement de petite taille, et leurs caractẻres par conséquent difficiles à saisir à l'oeil nu, j’ai eu soin de faire représenter les différentes parties du test grossies à côté des figures de grandeur naturelle. Cliaque espèce se voit de profil et par les faces supérieure et iuférieure; les parties grossies sont, pour chaque espèce, une aire ambulacraire et une interambulacraire, le pourtour de l'ouverture inférieure du test, l'appareil oviducal et un tubercule vu de profil. 


\section{CHAPITRE I.}

DU GENRE SALENIA Gray. ( Ag. )

Le genre Salenia, restreint aux limites que je lui assigne maintenant, est earaetérisé par une plaque impaire, placée au milieu de l'appareil oviducal, que j’appellerai la plaque suranale et qui, suivant sa position vis-à-vis de l'ouverture anale, rend l'anus toujours exeentrique, le rejetant tantôt en avaut, tantòt en arrière. Cette plaque surauale est ordinairement de même grantdeur que les plaques ovariales, et forme avee elles, ainsi qu'avee les eiluq interovariales, un disune circulaire diversement éelıaneré dans son pourtour. Les plaques elles-mênes ont leurs bords ou tronqués, ou dentelés, ou lobẻs, ee qui eonstitue des différenees spérifiques très-importantes. Lorsque la plaque suranale est placée en avant de l'anus, les trois plaques ovariales postérieures sout ordinairement uı peu plus grandes que les deux antérieures; et au eontraire lorsqu'elle est reportée en arrière et rapprochée de l'aire interambulacraire postérieure, ec sont les quatre plaques ovariales paires qui sont les plus grandes. Les aires interambulacraires sont fort larges, composées d'un petit nombre de plaques sur le milieu desquelles s’èlève un large còne, entouré d'une zone lisse qui est bordée d'autres petits tubercules. Ce cône est surmonté d’un mamelon articulaire, au sonmet duquel il n'y a point d'impression foraminiforme, conme dans les espèces de la tribn des Cillaris. L'étranglement qui sépare le mamelon articulaire de la base du cône tuberculaire, est utarqué d"impressions rayonnées qui, d’après l'observalion que M. de Buelı en a faile pour les Cidaris, servent à fixer les baguettes et à rẻgulariser leurs moureuens. Jusqu'ì présent je u’ai eu oceasion d'observer les baguettes d'aucune espèce de Salenia. Les aires ambulaeraires portent deux rangées de tubercules principaux, séparés quelquefois par de petites granulations verruqueuses plus ou noins nombreuses, mais en général plus rapprochées que dans le genre Diaulema; elles sont bordées de claque eôté d'une double rangée de pores disposés par paires obliques simples, et très-rapprochés des petits tubercules que portent les plaques ambulaeraires. Le nombre de ees paires de pores est eonstammen! 
plus considérable et souvent triple de celui des tubercules. L'ouverture de l'appareil buccal est toujours plus petite que le disque formé par l'appareil oviducal, bien que dans des proportions diflërentes. Dans quelques exemplaires brisés de diverses espèces, jai pu remarquer que le test des Salenia est fort épais, proportionnellement à leur taille, et que les supports auxquels l'appareil buccal est fixé sont très-courts. Toutes les espèces que je connais sont de petite taille, les unes ayant à peine un tiers de pouce, les autres un demi-pouce de diamètre. Elles proviennent toutes des terrains crétacés, depuis le terrain néocomien jusqu’à la craie blanche inclusivenent. D’après la position de l'anus, jai divisé ce genre en deux sections : la première comprend les espèces oủ l'anus est antérieur, la seconde celles oủ il est postérieur.

\section{Salénies ayant l'ouverture anale en avaut.}

I. Silexid persoxitd $\Lambda$ g. Tal). 1. fig. 1-8.

Cidaris personata Defrance, Msc.

Sa forme est orbiculaire, avec un fort aplatissement à la face inférieure fiğ. 2 et 3 . Louverture buccale est plus petite que l'appareil oviducal et légèrement rentrante; son pourtour est circulaire, quoique pourvu de petites échancrures placées à égale distance les unes des autres, de manière que le bord des aires ambulacraires et celui des aires interambulacraires ont á-peu-près la nême étendue; seulement ce dernier est droit, tandis que le bord des aires ambulacraires est caractérisé par une dentelure médiane plus petite, qui correspond ả la jonction des deux rangẻes de tubercules, fig. 3 et $\mathbf{T}$. L'appareil oviducal occupe à-peu-près la moitié de la surface supérieure du test. Les plaques dont il se compose sont proprement lisses, mais comme elles s'articulent en lignes sinueuses, et qu'elles sont déprimées au point de jonction, il en résulte que l'appareil entier offre un aspect très-raboteux qui a valu à l'espèce le nom de personata. Les plaques ovariales diffèrent essentiellement des interovariales par leurs dimensions et leur structure; ce sont de larges écussons trilobés, percés d'un petit trou an milieu. Les interovariales sont sensiblement plus petites et allongées dans le sens du diamètre transversal; enfin la plaque suranale affecte une forme toute particulière: elle ressemble a un large croissant embrassant toute la moitié postérieure de l'ouverture anale, qu'elle rend par là même plus saillante que la partie antérieure, bordée par la base des deux plaques ovariales de devant. L'ouverture anale elle-même est orale dans le sens du diamètre transversal de l'animal, fig. 1 et 6. 
Les aires ambulacraires, quoique très-étroites, au point de ne laisser aucun espace libre pour de plus petites verrues entre les deux rangées principales de tubercules, sont cependant plus larges dans la partie inférieure que dans la partie supérieure du disque, et convergent en ligne légèrement sinueuse de la base au sommet; elles se composent de deux rangées de tubercules simples, assez petits, auxquelles s'adosse, de chaque côté, une ligne de double pores, disposés par paires obliques, comme les tubercules, fig. 5. Sur les aires interambulacraires, qui sont très-larges, on remarque deux séries de quatre gros tubercules coniques, dont les plus saillans occupent le milieu de la circonférence; leur base est parfaitement lisse, mais le sommet présente un étranglenent assez prononcé, avec de petiles crénelures articulaires tout autour du mamelon qui termine le cône, fig. 8. Autour de chaque gros tubercule viennent se grouper en cercle, en dehors d'une zone lisse et assez large, de plus petits tubercules semblables à ceux des ambulacres, fig. 2 et 4 .

L'étiquette des exemplaires que je dois à l'obligeance de M. Defrance, indique comme origine Minorque, et comme gisement le grès-vert. M. Valenciennes m’en a communiqué un exemplaire du Muséun, portant les mêmes indications. J'en dois d'autres à l'obligeance de M. DesHayes; leur origine niest inconnue.

\section{Salexu scripti Ag. Tab. 1. fig. 9-16.}

On peut considérer cette espèce comme intermédiaire entre les $S$. personata et petalifera. Son carac tère essentiel consiste dans la structure de l'appareil oviducal, fig. 9 et 14 , et en particulier dans la manière dont les différentes plaques se soudent entre elles. Les sutures représentent de fines lignes, traversées elles-mêmes par de petites dépressions perpendiculaires, qui passent des bords d'une plaque à ceux des plaques adjacentes, et sont surtout apparentes sur les sulures qui unissent la grande plaque surauale aux trois ovariales postérieures. Les plaques ovariales sont toutes percées d'un petit trou au milieu, mais elles diffërent entre elles de forme et de grandeur selon leur position : celles du côté postérieur ressemblent à de grands écussons en forme d'eptagones irréguliers, plus larges à leur bord interne qu'à leur bord externe, tandis que celles du rôté antéricur affectent jusqu’à un certain point la forme de croissant, et sont réduites par le pourtour de lanus qui est subcentral et porté en avant. La plaque suranale qui forme la bordure immidiate de l'ouverture anale du côté postérieur, est très-épaisse et très-saillante ; clle diffire des ovariales par ses plus grandes dimensions et par sa base plus concave. Les interova- 
riales débordent quelque pen les ovariales; clles sont irrégulièrement losangées ef finement dentelées à leur bord externe. L'ouverture anale est ovale, allongée dans le sens du diamètre transtersal. Liouverture inférieure n’est pas très-grande, fig. 11. On remarque sur son pourtour, aux augles des aires ambulacraires, des crénelnres assez profondes placées à-peu-près a comale distance les nues des autres; mais le bord des aires ambulacraires differe du borl des aires interambulacraires, en ce qüil présente une pelite crénelure secondiare correspondant à la réunion des deux séries de tubercules, tandis que le dernier est à-peu-près droit, figg. 11 et 15. Les aires ambulacraires sont très-étroites, et leurs tubercules très-petits; cependant on aperegit encore eả et lá quelques petites granulations verruqueuses entre les deux rangées de tubercules. Les aires interambulacraires sont larges, fig. 10, i tubercules assez apparens, qui ont cela de remarquable, que leur mamelon articulaire est proportionnellement trẻs-petil, lig. 16. Autour de chaque gros tulherenle on remarque également, conme dans la plupart des especes de ce genre, un cerde de plus petits tubercules mamelonnes. D'autres, plus petits encore, viemnent prendre place entre ces diflèrens cereles et forment une zone sinueuse assez large entre les rangées de grands tubercules. Le seul exemplaire parfait que je connaisse de cette espèce, fait partie de la collection du Muséum de Paris, el m’a été communiqué par M. Valenciennes. Son origine est inconnue.

III. S.levil pethlifeli Ag. Tal. 1. fig. 17-2'

Echimus petaliferus DesII. (Defrance, Dicl. Sc. nat. Tom. 37, p. 101.

Des.I. Echin. p. 304.

La disposition de l'appareil oviducal, qui se détache sensiblement de la face supérieure du lest, et le nombre assez considerable de petiles verrues entre les deux rangées de tubereules des aires ambulacraires, constituent le caractere le plus saillant de cette espèce, fig. 18 el 21 . Sa forme circulaire, très-aplatie au côté inférieur, la rapproche de la $S$. scripta et de la $S$. geometrica. L'ouverture inférieure est assez grande et rentrante; les entailles de son pourtour sont larges et profomles, el l'on remarque que le bord des aires ambulacraires eutre deux crénelures est anssi zrand, sinon plus grand que celui des aires interambulacraires. La différence consiste en ceci, rest que ce dernier est taillé en saillie, taudis que celui des aires ambulacraires est échancré, fig. 19 et 23 . Les aires ambulacraires forment une bande lógèrenent sinueuse, composée do deux séries de tubercules principaux, qui convergent en se resserrant de la base au sommet, 
mais qui sont cependant assez distantes, surtout vers la face inférieure, pour pernteltre l'insertion de deux autres rangées de plus petites verrues. Les pores sont disposés par paires oblíques sur deux lignes trẻs-rapprochées qui s’adossent immédiatement, de chaque còté, a la bande tuberculeuse, fig. 18 et 21. Autant qu'il m’a été possible de m'en assurer sur des tests fossiles, jai cru reconnaître qu’il n’y en a guère qu'une paire pour une plaque de l'aire ambulacraire. Les aires interambulacraires sont larges et pourvues de deux rangées d'environ cinq gros tubercules assez raides, ef surmontés d'un assez gros mamelon qu'entourent, au-dessous du col du tubercule, de très-petits sillons articulaires, fig. 20 et 2\%. Les plus gros tubercules sont placés au-dessus de la partie la plus renflée du test; plus bas ils diminuent sensiblement de grosseur à mesure qu’ils approchent de l'ouverture inférieure. Chaque tubercule principal est entouré d'un cercle complet de plus petites verrues dépourvues de mamelon et assez analogues aux tubercules des aires ambulacraires. D’autres granulations veriuqueuses, plus petites encore, viennent remplir l'espace entre ces cercles et forment ainsi plusieurs lignes sinueuses de bas en haut, fig. 18 et 20.

L'appareil oviducal est à-peu-près circulaire, et très-détaché : il occupe environ le tiers de la face supérieure du test. Les cinq plaques ovariales, de forme plus ou moins régulière suivant leur position en avant ou en arrière de l'ouverture anale, sont percées chacune d'un pelit trou au nilieu ; les interovariales sont plus petites, en forme de triangles allongés et ondulés a leur lord externe; la plaque suranale, enfin, est en forme de croissant irrégulier, placée entre les cvariales postérieures et l'ouverture anale dont elle forme le bord immédiat qui est trés-saillant. Toutes ces plaques sont lisses et unies entre elles par des sutures très-distinctes sur lesquelles apparaissent d'espace en espace de petits points creux qui donnent aux plaques un air tant soit peu découpé et persillé. Le pourtour de l’appareil entier présente une ligne uniformément onlulée, résultant de ce que les plaques ovariales et interovariales ne se dépassent point les unes les autres. L'ouverture anale est subcentrale, penchant vers le còtẻ antérieur, fig. 17 et 22. Le test, en général, est d’une épaisseur moyenne; sa structure est très-ćlégante et très-délicate. Parni les exemplaires que jai eus à ma disposition, deux mont été communiqués par M. DesIIayes, un par MI. Defrance et deux par M. Brongniart, dont l'un provient du cap La Hère et l'autre de Longleat. 
IV. Silexin gionetuci Ig. Tab. I. fig. 25-32.

C'est la plus grande des espèces de ce genre connues jusqu’ả présent. Sa forme élevée, presque sphéroülale, faiblement aplatie à la face supérieure et inférieure, l'étroitesse des aires ambularraires et les sutures rectilignes de l'appareil oviducal (qui mont engagé à lui donner le noun ('i-dessus), serviront toujours à la distinguer de prime abord de la plupart de ses congénères.

L'ouverture inférieure est plus petite que l'appareil oviducal. Son pourtour est circulaire, bien que légèrement échancré entre les aires ambulacraires et les aires interambulacraires. Comme dans la $S$. personata, le bord de ces dernières est presque droit, tandis que celui des aires ambulacraires présente une légère inflexion correspondant au point de jonction des denx séries de tubercules; et il est digne de remarque que malgré la grande diffërence de largeur des aires ambulacraires et interambulacraires, les échancrures qui les séparent sur le pourtour de l'ouverture buceale soient à égale distance, fig. 27 et 31.

Les aires ambulacraires, très-étroites et légèrement sinueuses, portent deux séries de tubercules tellement rapprochés, qu'il ne reste point d'espace libre entre elles pour de plus petites verrues; c'est à peine s̈il en existe quelques-unes très-petites près de l'ouverture inférieure. Les pores forment de chaque côté de l'aire ambulacraire une double série parallèle aux rangées de tubercules , fiğ. 26 et 29 . Les aires iuterambulacraires, également larges du côté anal et du côté buccal, sout formées d'un petit nombre de grandes plaques portant clacune un tubercule très-saillant, entouré d'un cercle de plus petites verrues. Les plus gros tubercules sont placés au-dessus du milieu de la circonférence; tous, sans exception, s’ëlèvent du milieu d’une large zone lisse et sont couronnés d'un mamelon articulaire trẻs-apparent, quoique petil comparalivement à la largeur de la base, fig. 28 et 32 . Les petites crénelures articulaires du mamelon se roient très-bien au-dessous du col des tubercules; enfin l'espace entre les deux séries de gros tubercules est parsemé, comme dans l'espèce précédente, mais en nombre moins considérablr, de très-petites granulations qui ont étè omises par erreur dans le dessin.

Les plaques ovariales et interovariales et la placue suranale sont également lisses. L'ourerture anale est subcentrale, légẻrement saillante et bordée daus sa moitié postérieure par la grande plaque suranale qui occupe le centre du disque supérieur : cette dernière est de forme hexagonale à base concave. Les ovariales sont irrégulièrement hexagonales, allongées et rétrícies en dehors, avec un petil trou au milieu. Leur bord extérieur est tronqué et arrondi: mais 


\section{$-12-$}

il ne depasse pas le bord des plaques interovariales, ce qui rend le disque apicial circulaire et issez régulier. Les plaques interovariales sont en forme de triangles irréguliers; leur plus grand rôté est tourné en-dehors et lígèrement ondulé. Les sutures qui unissent toutes ces plaques représentent des lignes droites interrompues d'espace en espace par de petites impressions anguleuses, fig. 25 et 30. M. dOrbigny a eu Cobligeance de me communiquer plusieurs exemplaires très-bien conservés de cetle espèce, provenant des conches inférieures de la craie de Saintes, près de la Charente, dans le département de la Charente-Inférieure. Un autre, non moins parfait, m’a été confié par M. Desllayes.

V. Silexiı scctigerı Gray. Tab. 2 , fig. $1-8$.

Cidarites scutiger. Münst. (Goldl. Tal. 49. fig. $4 a$ et 4 b.)

Jai cru devoir reporter cette espẻce, du genre Cidaris on l'a placée $\mathrm{M}$. Le comte de Miinster, dans le genre Salenia, parce qu'elle n’a point les tubercules perforés. M. Gray, et d’aprés lui II. Deshoulins la confondent avec la $S$. petalifera (Echinus petaliferus Des.I.), mais il est plısieurs particularités de structure qui l'en distinguent suffisamment pour qu'on puisse l'envisager comme spécifiquement différente: éest entre autres l'étroitesse des aires ambulacraires et la disposition des plaques composant l'appareil oviducal, fig. 1, 2 et 6.

J'ai ru plusieurs exemplaires de cette espèce, dont deux trouvés par M. Coulon dans la pierre jaune (ćtage moyen du terrain néocomicn), an Roc pris de Neuchàtel, et deux provenant du grrẻs-rert d'Angleterre, dont l'un m’a été conmmuniqué par M. Brongniart et l'autre par M. Defrance. On en a cité également dans plusieurs autres localités, mais je doute que tous soient spérifiquement identiques avec mon espèce, notamment ceux que M. Goldfuss dit avoir été trouvés dans le terrain jurassique. En revanche, la figure publiée par cet auteur de l'exemplaire du conte de Munster, provenant du grès-rent de Kehlheim, ne ne paraît pas en différer.

Le pourtour de l'ouverture inférieure est circulaire, légèrement crénclé à l'angle des aires ambulacraires tont le bord dépasse tant soit peu celui des aires interambulacraires, fig. 3 et 7 . Les pores sont disposés par paires simples de chaque còté de l'aire ambulacraire et convergent, comme celle-ci, uniformément vers le sommet, fig. 2 et 5 . Les aires interambulacraires, fig. 4, sont parsemées d'une masse de tubercules, dont deux rangées de très-gros, à base lisse et à sommet étranglé el plissé au-dessous de l'étranglement, fig. 8. Un cercle très-serré de tubercules 
plus petits entoure les gros, et lespace entre ces différens cercles est en outre occupe par diautres tubereules encore phus petits, également nombreux sur toute la surface du disque.

Lappareil oviducal, fig. I et 6 , parfaitement conservé dans l'exemplaire du grès-vert d'Angleterre, que je dois a lobligeance de II. Defrance, est heaucoup plus grand que l'ouverture infërieure: son pourtour est légèrement sinueux. Les plaques ovariales sont grandes, ilrondies i leur bord externe, fortement crénclées à leur bord interne et percées chacune d'un tron. Les plaques interovariales sont moins grandes ot allongées transversalement; les ovariales s'articulent entre elles et avec la grande plaque suranale qui forme le bord postérieur inmédiat de l'anus, par des lignes droites marquées de petits points creux. L'ouverture anale est circulaire, rejetée en avant et légérement relevée sur ses bords. Toutes les plaques de l'appareil oviducal sont lisses.

VI. Salevin gibia Ag. Tab. 2. fig. $9-16$.

Cefte espece se fait remarquer entre toutes ses congénères par la très-forte saillie de son appareil oviducal, fig. 10, qui lui donne une forme à-peu-près conique de bas en haut. Les aires ambulacraires, comme dans la $S$. geometrica, se distinguent par leur étroitesse extrême ; all point qüil n'y a pas même de place pour les plus menues granulations entre les deux rangées de tubercules: ceux-ci ne sont eux-mêmes pas plus gros que les verrues secondaires qui bordent les gros tubercules des aires interambulacraires, fig. 10 et 13. Les aires interambulacraires, fig. 10 et 12 , sont proportionnellement aussi larges que les ambulacraires sont étroites. Les gros tubercules sont au nombre de quatre ou cinq dans chaque rangée, entourés rhacun d'un cercle très-prononcé de plus petites verrues, et surmontés d'un mamelon articulaire très-apparent, fig. 16.

L'ouverture inférieure a son pourtour garni de petites échancrures, qui en font un polygone à-peu-près équilatéral, fig. 11 et 15.5.

l'ar la structure de l'appareil oviducal, fig. 14, cette espece se rapproche assez de la $S$. personata ot de la $S$. petalifera; seulement les dépressions sur les lignes de sutures sont ici plus profondes. Les plaques ovariales ont, jusquà un certain point, la forme d'une feuille de vigne, tandis que les interovariales sont plutot triangulaires. La plaque suranale est proportionnellement trẻs-large, de manière que l'ouverture anale se trouve considérablement 
rejetée en avant ; et cette circonstance, jointe à l'élévation de tout l'appareil, détermine cet aspect irrégulier et bossu qui a valu à l'espèce son nom.

Les exemplaires que j’ai sous les yeux mont été communiqués l’un par M. Hichelin, et l'autre par M. d'Orbigny, qui l'a trouvé dans le grès-vert de l'ìle d'Aix, à l'embouchure de la Charente.

VII. Sulesu thigovitı Ag. Talo. 2, fig. 17-21.

La structure de lappareil oviducal et la taille des tubercules des aires interambulacraires , qui est plus considérable que dans les autres espèces, fig. 22 el 20 , constituent le caractère distinctif de la $S$. trigonala, qui d'ailleurs se rapproche assez, par son aspect général, de la $S$. personata. Sa forme est sphérique avec un aplatissement assez considérable au côté inférieur, fig. 18. L'ouverture inférieure est circulaire, moins grande que l'appareil ovidural et légèrement échancrée sur son pourtour, de manière que les bords des aires ambulacraires et interambulacraires sont à-peu-près égaux, fig. 23. Les aires ambulacraires portent, conme daus la $S$. personata, deux rangées de petits tubercules assez rapprochées pour qu’il ne reste point de place entre elles pour de plus petites verrues, fig. 18 et 21 . Les pores sont disposés par paires simples de chaque côté des aires ambnlacraires, fig. 21. Les aires interambulacraires, comme nous venons de l'observer, sont remarquables par leurs grands tubercules. La zone lisse qui entoure leur hase est trẻs-grande, et le sommet du cône, fig. 2ł, forme une forte aréole articulaire entourée de petits plis rayonnés dont on aperçoit surtout bien la disposition lorsque le mamelon qui les surmonte est enlevé. Un cercle de six à sepl petiles verrues entoure la zone lisse de la base des gros tubercules, et un certain nombre de granulations plus petites encore, et fréquentes surtont près de l'ouverture buccale, viennent remplir l'espace entre les différens cercles, fig. 20.

L'appareil oviducal, fig. 17 et 22 , est à-peu-près circulaire, les angles des plaques inter"variales ne déhordant que légèrement les ovariales. Leurs sutures sont marquées d'espace ril espace par de petites dépressions triangulaires assez profondes. Les ovariales sont généralement plus grandes que les interovariales, en particulier celles du borl postérieur qui ont la forme de fleurs de lis, tandis que les antérieures paraissent atrophiées et sont i-peu-prés Iriangulaires: les interovariales sont en forme de triangles isocẻles, ayant leur hase droite et tournée vers les ambulacres. Enfin la plaque suranale, en forme de croissant irrégulier, 


\section{$-13-$}

forme du còté postérieur la bordure immédiate de l'ouverture anale, qui se trouve ainsi refoulée en avant du côté de l'ambulacre impair. Sur cette plaque naissent des côtes rayonnées qui sétendent sur les plaques ovariales avoisinantes, et forment, avec d'autres cotes transversales, des triangles plus marqués dans les jeunes exemplaires que dans les vieux, ou ils sont à peine sensibles. Louverture anale elle-même est insensiblement allongée dans le sens du diamétre transversal ; ses bords sont renflés el saillans. Les exemplaires que jai eus a ma disposition proviennent des environs de Tours. Ils font partie de la collection de M. Michelin.

\section{Salénies ayant l'onreptnie anale en arpière.}

Vili. Silevil stellulita $\Lambda \mathrm{g}$. Tab. 2, fig. 2j-32.

L'appareil oviducal atteint dans celte espèce des développemens considérables : il occupe plus de la moitié de la face supérieure du test, et présente un aspect persillé qui le rend trẻs-apparent, quoiqu'il ne soit que peu saillant, fig. 30. La forme générale du test est circulaire, fortement aplatie en dessous, légèrement déprimée en dessus, fig. 26. Les aires ambulacraires portent deux séries de petits tubercules qui se resserrent légèrement à mesure qüils s’éloigneut du milieu de la circonférence, pour se rapprocher de l'appareil buccal ou de l'appareil anal. Les pores ambulacraires sont disposés par simples paires obliques de chaque côté des tubercules, fig. 26 et 29 . Les aires interambulacraires sont fort larges et garnies de deux rangées de gros tubercules coniques à hase lisse, mais sillonnés de petits plis articulaires rayonnés autour de létranglement. On remarque, en outre, autour de chaque gros tubercule, un cercle le petils tubercules à-peu-près de même grandeur que ceux des aires ambulacraires, fig. 28 et 32. Mais comme l'appareil oviducal occupe, en grande parlie, la face supérieure du test, et que par consérfuent ni les uns ni les autres ne dépassent guère le milieu de la circonférence, il en résulte que, vue d'en-haut, cette espèce parait porter beaucoup moins de tubercules que la plupart de ses congénères.

L'ouverture inférieure est circulaire, et son pourtour présente des crénelures analogues à celles que nous arons sigualées dans toutes les espèces précédentes, fig. 27 et 31 . L'ouverture anale est presque circulaire, subcentrale, refoulée en arrière par la plaque suranale qui s'articule avec les deux playues ovariales antérieures, formant ainsi de ce côté le bord de l'ouverture, qui est 
plus relevé que du côté postérieur. Les plaques ovariales et interovariales sont profondément dentelées dans tout leur pourtour, et cette particularité détermine l'aspeet persillé et étoilé de la plupart de ces plaques, auquel il est facile de reconnâitre l'espèce et qui lui a valu son nom. Les ovariales antérieures sont plus grandes que les postérieures, tontes sont percées d’un trou au milieu. Les interovariales sont en forme de triangles irréguliers. La surface des unes et des autres est lisse, fig. 25 et 30 .

Le plus bel exemplaire que jaie vu de cette espèce appartient á $\mathbf{M}$. Cél. Nicolet, qui l'a trouvé dans le terrain néoconien des environs de la Cliaux-de-Fonds. Un autre exemplaire ma iti communiqué par M. Defrance: il provient du grès-vert de Wiltshire.

\section{Salewis areoliti Ag. Talo. 3, fig. 1-8.}

Forme circulaire, aplatie au còté inférieur, moins déprimée au côté supérieur, fig. 2. Lionverture inférieure, fig. 3 et 7 , est moins grande que l'appareil oviducal; cependant la différence entre leurs dimensions relatives est moins considérable que dans la $S$. stellulata. Son pourtour offre des crénelures au point de contact des aires interambulacraires avec les aires ambula(raires, et, comme d'ordinaire, l'espace compris entre deux crénelures est toujours plus grant en fare des aires ambulacraires qu en face des aires interambulacraires, quoique celles-ci soient beaucoup phus larges dans tout le reste de la périphérie. L'appareil oviducal ne diffère guère, dans sa forme générale, de celui de la $S$. stellulata. Les plaques ovariales et interovariales présentent, sur leurs points de jonction, de petites dépressions qui donnent à l'appareil entier un aspect inegal et raboteux, et aux plaques ovariales en particulier, une forme assez semblable a nne feuille de chêne. Les interovariales sont petiles et assez régulièrement triangulaires. La plaque suranale enfin est en forme de croissant irrégulier. Louverture anale est fortement allongée dans le sens du diamètre transversal, et son bord antérieur est plus saillant que le bord postorieur, fig. 1 et 6.

Les aires ambulacraires sont pourvues de deux rangées simples de tubercules de noyenne grandeur, plus grands, proportionnellement, que dans le $S$. stellutua, surtout à la face inférieure du test. Les pores sont rangés sur deux lignes de chaque côté de l'aire ambulacraire, qu ils accompagnent dans toute son étendue, fig. 5. Les aires interambulacraires sont fort larges et ornées de deux rangées de quatre à cinq tubercules de plus en plus gros, depuis les plaques qui entourent l'ouverture inférieure jusqu’a celles qui se forment en arant de 
lappareil oviducal, et entourés chacun d'un cercle de plus petits tubercules, à-peu-pris de même dimension que ceux des aires ambulacraires, fig. 2 el 4. Leur mamelon articulaire, fig. S, est plus gros, proportionnellement, que dans la $S$. stellulata. Comme dans toutes les vraies Salénies, ces gros tubercules sont lisses à leur base et étranglés à leur sommet, qui est entouré d'un cercle de petits plis rayonnés. Les petits tubercules, placés en cercle autour des gros, étant plus nombreux au nilieu de l'aire interambulacraire que du côté des anbulacres, il en résulte une sorte de double ligne sinueuse an milieu des deux rangées de gros tubercules.

Jusqü̈ici cette espèce ne s'est encore rencontréce que dans le terrain néocomien; M. Coulon e'I a trouvé un exemplaire dans la pierre jaune du Roc, et 11 . DuBois un second dans la marnière de Ilauterive, prìs de Neuchàtel.

A l'occasion des genres Salenia et Arbacia, bualis par M. Gray et pour lesquels II. DesMoulins réclame la priorité, ce dernier a élevé des doutes, dans ses études sur les Echinides, pag. 207, sur la date de mon Prodrome d'une Monographie des Radiares ou Echinodermes, lu à la Société des Sciences naturelles de Neuchàtel le 10 février 183ł, imprimé pendanı l'liver de 1835 à 1836 et publié en juillet 1836. Il se fonde sur ce que jai introduit daus mon énumération des genres publiës par 1I. Gray en 1835, imprimis dans les Proceedings de la Société zoologique de Londres en avril (et non en octobre, comme M. DesMloulins le croit), et que je n'aurais par conséquent pu connaître en 183\%. Il n'en est cependant pas moins vrai que j’ai connu les genres de M. Gray des 183 i, ce savant ayant eu l'obligeance de nien communiquer les caractères avant la publication de ses notes. Comme il ne sagit pas ici pour noi d'une question de priorití, mais d'une justice à rendre à l'auteur des genres Salenia el Arbacia, j’ai dù faire voir fu'en conservant les noms de M. Gray je suivais la riggle généralement admise, sans faire aucun tort ì $\mathbf{M}$. Desiloulins, dont les noms ne sauraient être conservés dans ce cas, puisque son ouvrage a paru en aoù 1835 , c'est-à-dire plus fard que celui de M. Gray. Il n’en est pas moins vrai, cependant, que MI. Des.Ioulins a très-bien établi ces groupes à une époque où il ne pouvail pas avoir connaissance du travail de M. Grily. En indiquant comment, de mon côte, je les ai connus plus tòt, jai simplement eu lüntention de me disculper des reproches que ce rapprochement de dates semblait faire peser sur moi. Des collisions semblables ì celles que je viens de signaler entre M. Gray et M. DesMoulins, se reproduiront pour plusieurs geures que jai établis ou modifiés dans le même sens que II. Des.Ioulins. Nattachant pas une grande importance à des questions de ce genre, et pour ne pas abuser de la priorité que me donne la lecture de mon mémoire en 18.3 je me bornerai à conserver ma nomenclature lorsquelle me paraitra préférable à celle de 
II. DesMoulins. Je le ferai d'autant plus volontiers que les tableaux de ce savant ont le grand avantage sur mon Prodrome, de présenter une synonymie complète et généralement très-bien faite de toutes les espèces connues jusqu'ici.

Dans mon Prodrome, etc. ,jai cité sous les noms de Salenia hemisphœrica et Salenia IIoffmanni, deux espèces que j’avais cru pouvoir rapporter à ce genre, d'après les caractères qu'en donne M. Rœener. N'ayant point eu l'occasion de voir depuis les originaux de ces espèces, je me suis abstenu de les mentionner dans cette monographie, dans la crainte de confondre dans un même genre des types différens, quoique voisins, comme sont, par exemple, les genres Cyphosoma, Acropeltis et Salenia. Le fait seul que ces espèces proviennent des terrains jurassiques me fait douter que ce soient de véritables Salẻnies; car, ainsi que je l'ai dit p. 5 et 7 , toutes les espèces que je possède et dont l'origine est connue appartiennent au terrain crétacé.

$\Lambda$ u moment de mettre sous presse, je reçois un envoi de fossiles de M. Røemer, parmi lesquels se trouve un exemplaire de son Cidarites Hoffmanni, le Salenia Hoffmanni de mon Prodrome, qui est une fort jolie espèce de mon genre Hemicidaris, dont je donnerai une description détaillée dans ma Monographie de ce groupe. Il ne reste donc maintenant de donteux que ma Salenia hemispharica, le Cidariles homisphoricus de M. Rømer, que j'espère recevoir aussi avant de publier la Monographie des Hemicidaris, dans laquelle je pense qu'elle derra prendre place, à en juger d'après sa grande ressemblance avec le Cidariles Hoffmanni. 


\section{CHAPITRE II.}

\section{DU GENRE GONIOPYGUS Ag.}

Je comprends dans ce genre toutes les espèces de la famille des Salénies dont l'appareil oviducal est dépourvu de cette plaque suranale qui, daus les trois autres genres, reporte l'ouverture anale tantòt en avant, tantôt en arrière, suivant qu'elle est placée en arrière ou en avant de soll orifice. Les plaques ovariales ne sont point soudées dans toute leur longueur aux interovariales, d'où il résulte que l'appareil oviducal présente constamment une rosette décagonale plus ou moins distincte. L'ouverture anale est centrale, tantôt circulaire, tantôt anguleuse, suivant les espèces. Quelquefois elle est triangulaire, carrée ou pentagonale, et l'on voit ordinairement surgir de lintérieur de ces angles d'autres petites plaques plus ou moins distinctes. Les dimensions des espèces de ce genre sont soumises à des variations notables, depuis le $G$. major qui atteint un diamètre d'un et un quart de pouce et au-delà, jusqu'au $G$. intricatus qui n’a guère qu'un quart de pouce dans son plus grand diamètre (voy. tab. 3 et 4.) La structure générale du test est à peu de chose près la même que dans les vraies Salénies; les pores sont disposés par simples paires, d'où il résulte que les ambulacres proprement dits doivent être très-étroits. Les aires interambulacraires sont bien moins tuberculeuses que dans les autres genres de cette famille; dans la partie supérieure du test, les plaques coronales ne portent souvent qu'mn seul gros tubercule sans granulations accessoires. Enfin un dernier caractère particulier à ce genre et qui à lui seul suffirait pour le distinguer des trois autres, c'est l'absence de sillons rayonnés sur les tubercules des aires interambulacraires. On connait jusqu'à présent deux sortes de piquans de Goniopygus, provenant toutes deux du terrain néocomien, et que je crois pouvoir rapporter avec assez de certitude aux $G$. peltatus et intricatus, auxquels ils sont ordinairement associés. En général, tous les Goniopygus dont l’origine est connue appartiennent aux terrains crétacés ; il n’en existe à ma connaissance aucune espèce, ni dans les terrains plus anciens, ni dans les 
terrains plus rẻcens; et dans la création actuelle on ne rencontre aucun type qui s'en rapproche, même de loin.

I. Goniongets peltates Ag. Tab. 1, fig. 9-18.

Salenia peltuta Agass. Mém. de la Soc. des sc. nat. de Neuchâtel, tom. I. Echinus peltatus DesM. Echin., p. 30 \%.

Jusqu'à présent cette espèce n'a été tronvéc que dans le terrain crétacé du Jura neuchâtelois (terrain néocomien), où elle est assez fréquente. Sa forme est circulaire, fortement aplatie en dessous, et sensiblement dẻprimẻe en dessus, fig. 10. L’ouverture inférieure est proportionnellement plus grande que daus aucune autre espèce; elle occupe ì-peu-près les deux tiers de la face inférieure du disque, fig. 11; son pourtour est régulièrement ichancré au point de contact des aires ambulacraires avee les aires interambulacraires, et l'espace compris entre deux échancrures (le nombre total est de dix, puisqu’il y a cinq aires ambulacraires et cinf interambulacraires) est toujours plus petit à l'extrémité des aires interambulacraires qu'au bord des aires ambulacraires, fig. 11 et 15 . En général, ces dernières ne se rétrécissent que peu ou point à l'approche de louverture inférieure, tandis que le conIraire a lieu pour les interambulacraires : ce sont celles-ci qui, en s'étalant, produisent le renflement du test.

L'appareil oviducal est étoilé et bien moins grand que l'ouverture inlérieure, fig. 9. Les plaques dont il se compose sont lisses à leur surface et échancrées à leur bord; on remarque très-distinctement les sutures qui les unissent. Les ovariales, en forme de feuille de vigne et percées d'un trou au milieu, se soudent toutes entre elles pour former la bordure immédiate de l'ouverture anale. Les interovariales sont plus petites, tronquées à leur bord extérieur, arrondies à leur bord interne; la plaque ovariale de l'aire interambulacraire impaire est, comme dans la plupart des espèces, un peu plus grande que les autres. Les aires ambulacraires, composées de deux simples rangées de tubercules, se détachent fortement de la surlace du test et se rétrécissent sensiblement vers l'appareil oviducal, fig. 10 et 13 ; quoique assez distantes, surtout vers le milieu de la circonfërence, on ne remarque cependant point de tubercules plus petits entre les deux rangées. Les pores sont disposés par paires obliques de chaque côté des aires ambulacraires. Les aires interambulacraires portent denx séries de six à sept gros tubercules surmontés 


\section{$-21-$}

d'un fort mamelon articulaire, fig. 12 et 16. Les pelites verrues qui ordinairement recouvrent tout l'espace entre les gros tubercules, sont ici trẻs-rares; l'on n'en remarque que quelquesunes très-petites à la surface infërienre, figg. 11 .

Bagcetres. On ne saurait douter que les baguettes qui accompagnent habituellement les exeniplaires de cette cspèce, et dont la décourerte est due à MI. DuBois de Montpéreux, i’en soient les véritables piquaus. Ces baguettes sont éminemment claviformes, fortement striées longitudinaleuent dans leur partie supérieure, lisses dans la partie inférieure jusqu'au tiers de la hau teur, fig. 18. Elles sont, en outre, dépourvues de ce que l'on appelle communément la tête du piquant, ćest-ìdire de ce renflement eu forme d'anneau qui, dans les baguefles des Cidaris, succède à la facette articulaire. Celle-ci est une simple petite cavité, fig. 17, dépourvne de deutelures comme le col du tubercule arec lequel elle a dù s'articuler. Cette figure est la projection d'une baguette, vue d'en bas. Toutes les baguettes ont à-peu-près les mèmes dimensions, environ un demi-pouce de long et deux à trois lignes de diamètre dans la partic la plus bombée.

II. Govioprges mernicates $\mathrm{Ag}$. Tab. 3, fig. 19-28.

C'est la plus petite espèce que je connaisse de tout le groupe des Salénies ef même de toute la famille des Cidarides. Par sa forme et par sa structure, elle se rapproclie beaucoup du G. peltatus; mais, d'uu autre còté, elle est plus tuberculeuse, et les dimensions de l'appareil oviducal sont proportionuellement plus grandes, fig. 19 et $2 \%$. Les aires ambulacraires, fig. 20 et 23 , sout assez larges, sans pour cela que les deux rangées de tubercules qu'on y disingue soient séparées par de plus petites verrues. Les aires interambulacraires, fig. 20 et 22 , sont pourvues de deux rangées de gros tubercules parfaitement lisses, qui deviennent surtout saillans sur le milieu de la circonférence, fig. 26. Les pores, disposés par paires sinples le long des aires, sont si petits qu'on a de la peine à les reconnaître. L'ouverture inférieure, fig. 21 et 25 , est fort grande et échancrée dans son pourtour; elle occupe plus de la moilié de la face inférieure du test.

L'ouverture anale est petite, tuberculée, ef placéc. au milieu de l'appareil oviducal, qui est lui-même très-grand quoique peu appareut, à raison de sa faible saillie au-dessus du test. Les plaques ovariales forment de grands lobes allongés, dentelés sur leurs bords et percés d’un petit trou, tandis que les interovariales sont en forme de triangles assez ríguliers, fig. 19 et $2 \%$.

Bıgretres, fig. 27 et 28 . Les baguetles de celte espèce ont été découvertes simultanément avec celles du G. peltalus, dans la pierre jaune (étage moyen du néocomien) du Merdasson, par 
M. DuBois de Montpéreux. Elles diffèrent de ces dernières par leur plus petite taille et par l'absence de plis dans la partie supérieure. La baguette entière est plus uniforme avec un très-léger rétrécissement près de sa base, qui, comme dans le $G$. peltatus, est dépourvue d'un renflenent annulaire, et de crénelures à sa facette articulaire. La fig. 27 est la projection du rayon, vu d'en bas.

III. Goxiopygus Mexand Ag. Tab. 3, fig. 29-36.

Echinus Menardi Desm. (Defrance, Dict. sc. nat., tom. 37, p. 101.)

Sa forme est circulaire, aplatie à la face inférieure, un peu déprimée à la face supérieure. Les diamètres longitudinal et transversal sont à-peu-près doubles du diamètre vertical. L'ouverture inférieure, fig. 31 et 35 , est centrale, assez grande, plus grande même que l'appareil oviducal, de sorte qu'elle occupe la majeure partie de la face inférieure. Son pourtour, quoique circulaire, offre de petites échancrures qui correspondent aux sutures des bandes ambulacraires et interambulacraires. Il en résulte un décagone dont les plus grands côtés sont au bord des aires ambulacraires, et les plus petits en face des interambulacraires. Outre ces échancrures au point de contact des aires ambulacraires et interambulacraires, on en remarque d'autres plus petites au milieu du bord des aires ambulacraires, là où les deux rangées de tubercules se rencontrent. Quoique à peine visibles, leur existence est constante.

L'appareil oviducal, fig. 29 et 34, composé de plaques entièrement lisses et fortement soudées entre elles, forme une rosetle peu proéminente au-dessus du test. Les plaques ovariales sont en forme d'eptagones allongés ayant leur angle le plus saillant tourné en dehors; elles sont toutes dégale dimension. Les plaques interovariales sont de moitié moins grandes, pentagonales, ayant, à l'inverse des ovariales, le plus grand côté tourné en dehors, de manière à déborder considérablement le sommet des ambulacres; ce mème côté est en outre légèrement concave, landis que les autres côtés du polygone s'articulent par des lignes droites avec les ovariales. Enfin l'ouverture anale mérite une attention toute particulière, à cause de sa forme triangulaire. Dans l'origine, j’élais disposè à l'attribuer à une brisure, mais l'ayant rencontrée depuis sur un nombre considérable d’exemplaires, je ne puis plus douter que ce ne soit un caractère particulier à cette espèce.

Les aires ambulacraires, fig. 30 et 33, portent deux rangées de tubercules qui, quoique assez distantes, notamment vers l'ouverture inférieure et sur le milieu de la circonférence, ne sont 
cependant point séparées par de plus petits tubercules. Les pores sont très-apparens, disposés par paires obliques simples, contiguës aux tubercules de l'aire ambulacraire et convergeant de la bouche au sommet sans se rétrécir beaucoup. Les aires interambulacraires, fig. 30 et 32 , sont larges, munies de deux séries de gros tubereules à base lisse, et entourés, sur la moitié inférieure du test seulement, d'un cercle de plus petits tubercules. Les gros tubereules les plus saillans oecupent le milieu de la cireonférenee du disque. Le mamelon articulaire qui en forme le sommet est très-gros et très-apparent, fiğ. 36 .

J'ai sous les yeux plusieurs exemplaires de eette espèce, appartenant, l'un à M. Defrance, l'autre à M. Brongniart. M. d'Orbigny m'en a communiqué d'autres beaucoup plus grands, provenant du grès-vert de l'embouchure de la Charente, que je rapporte à la même espèce, quoique l'appareil oviducal soit à-peu-près de même grandeur, malgrẻ la différence de taille. Je pense que ee sont de simples variélés.

\section{Gonopyges meteropygts Ag. Tab. 4. fig. $1-8$.}

Il est diffieile, au premier coup-d'oeil, de ne pas confondre ectte espèce avee le G. Menardi. Cependant il existe quelques différences d'organisation qui obligent à les séparer spécifiquement: c'est entr'autres la forme de l'ouverture anale, qui, au lieu d'être triangulaire comme dans le G. Menardi, est earréc. Les aires ambulacraires sont aussi plus saillantes, et leurs tubercules proportionnellement plus gros, fig. 3 et 5. L'appareil ovidueal a à-peu-près les mèmes dimensions que l'ouverture inférieure. Les plaques ovariales sont toutes d'égale grandeur; leur forme est eelle d'un pentagone allongé, ayant son angle le plus aigu tourné en delors. Leur base, qui forme la bordure immédiate de l'ouverture anale, est fortement concave, el c'est du milieu de eette coneavité que s'élèvent ces petites plaques ou verrues qui sont partieulières à la plupart des espèces de ee genre. La base de la plaque de l'aire interambulacraire impaire est seule droite et n'a par conséquent point de petite plaque additionnelle, ce qui réduit le nombre de ces dernières à quatre. Les plaques interovariales sont pentagonales, comme dans le $G$. Menardi, et s’insèrent par leur sommet entre les ovariales; léur base présente un léger renflement au milieu. Toutes ees plaques sont parfaitement lisses, et les sutures qui les unissent sont indiquées par des lignes droites, fig. 1 et 6.

Les deux rangées de tubereules ambulacraires sont trop serrées pour qu'il puisse y avoir de plus petites rerrues entre elles, fig. 2 et 5 . Les tubereules des aires interambulacraires 


\section{$-\quad 24$}

sont très-saillans, lisses el élranglés au milieu du cône, de manière ả former un très-gros mamelon articulaire, fig. 8. Les ${ }^{\circ}$ petites verrues qui les accompagnent n'existent guère qu’à la parlie inféricure du test et jusqu'au milien de la circonférence, fig. 3 et 4 . Les pores ambulauraires sont disposés par paires obliques, sur deux rangées simples, de chaque côté de l'ambulacre. Le seul exemplaire parfail de cette espèce que j’aie rencontré, m’a été communiqué par M. DesIlayes. Il provient des cuvirons de Tours.

\section{Gonioprgus globoses Ag. Tal. 4. fig. 9-16.}

Les dimensions de cette espèce sont considérables, son dianètre transversal étant d'environ un pouce, sur un demi-pouce el au-dela de hauteur; sa forme est circulaire, aplatie en dessous, légèrement déprimée en dessus, fig. 9 et 10.

L'ouverture inférieure est d'une grandeur extraordinaire, occupant au moins la moitié de la face inférieure; les échancrures de son pourtour sont assez profondes, el les espaces compris cutre deux crénclures sont toujours moins grands au bord des aires interambulacraires qu'au hord des aires ambulacraires, pourvu qu'on ne tienne pas compte d'un léger enfoncement au unilieu de ces dernières, fig. 11 et 16.

L'appareil oviducal, moins grand que l'ouverture inférieure, se compose, comme dans toutes les espéces de ce genre, de cinq plaques ovariales de forme pentagonale, ayant leur angle le plus aigu tourné en dehors, et de cinq interovariales igalement pentagonales ou plutòt subpentagonales, plus larges que longues, et sinsérant par leur sommet entré- les ovariales. Les ovariales ne déborilent que trìs-peu les interovariales; mais ces dernières, à raison de leur moindre étendue, n'atteiguent point l'ouverture anale; celle-ci est triangulaire, bordée uniquement par les ovariales, qui présentent à cet effet alternativement une base droite ef une base concalve. En avant de clacune des trois plaques a base concave, on aperçoit a lintërieur de l'ouverture anale une espèce de petite plaque ou verrue particulière, qui semble naître de dessous les plaques principales. Toutes les plaques sont lisses ou très-légèrement rugrueuses, et s'articulent par des lignes droites ou à-peu-près, fig. 9 et 15 .

Les aires ambulacraires sout remarquables par leur largeur; elles portent deux simples rangées de tubercules qui se rétrẻcissent légèrement vers leur sommet, oủ ils s’arrondissent en se terminant. Quoique ces deux rangées de tubercules soient assez distantes, on ne roit cependant point s'élever entre elles de plus petites verrues. Les pores ambulacraires sont très-apparens, disposés par 


\section{$-23-$}

paires obliques simples de chaque côté de l'aire ambulacraire, fig. 10 et 13 . Les aires interambulacraires sout pourvues de deux rangées de gros tubercules lisses ì leur base, et surmontés d'un gros mamelon articulaire, fig. 14; autour de chacun de ces gros tubercules, on apergoit un cercle plus on moins complet de plus petites verrues qui sont surtout visibles au milieu de la circonférence, là oú sont aussi placés les plus gros tubercules. Je n’ai vu quiun exemplaire bien conservé de cette espèce; il provient de l'ile d'Aix (département de la Charente-Inférieure) et mia été communiqué par M. Alex. Brongniart, dans la collection duquel il se trouvait sous le nom d'Echimus Menardi.

\section{Gonopyges mujor $\Lambda$ g. Tab. 4, fig. 17-22.}

C'est la plus grande espèce que je connaisse dans le groupe des Salénies. I'ar sa forme générale, et par la disposition de ses tubercules, elle se rapproche de certains types de Cidaris ; mais un examen attentif de la structure de son test, de lappareil oviducal et surtout des tubercules qui ne sont ni perforés ni entourés de sillons articulaires, la fera toujours reconnaitre pour ce qu'elle est réellement, c’est-à-dire pour un Goniopygus. Je n’en ai vu jusqu’à prẻsent qu'un seul exemplaire bien conservé, provenant de la craie inférieure du port des Barques, a l'embouchure de la Charente, que M. d'Orbigny a hien voulu me communiquer.

Cette espece se distingue arant tout du $G$. globosus par sa forme plus conique, fig. 18 ; son diamètre bucco-anal égale a-peu-près la moitié du plus grand dianètre, qui est d'un pouce et demi. L'ouverture inferieure n'est pas assez bien conservée pour pouvoir être décrite en détail; on ne peut guère déterminer que sa position centrale, son pourtour circulaire et son diamètre, qui égale à-peu-près le tiers du plus grand diamétre du test. Son pourtour parait offrir quelques légères échancrures, qui correspondent aux sutures des aires ambulacraires et interambulacraires, fig. 19.

L'appareil oviducal forme une rosette decagonale autour de l'ouverture anale, comme dans le G. globosus, mais avec cette différence que les plaques ovariales sont notablement plus effiléeset débordent sensiblement les interovariales. Toutes les ovariales ont à-peu-près la même forme : elles sont pentagonales, très-allongées à leur sommet et concares à leur base. Leurs bords ne sont pas parfaitement droits, mais tous à-peu-près d'égale longueur, sans crẻnelures suturales et entièrement lisses. Les interovariales sont igalement pentagonales, mais beaucoup plus larges que hautes et légèrenent renflées au bord externe, qui dẻborde considèrablement 


\section{$-26-$}

le sommet des ambulacres, au dessus desquels il se trouve placé comme un chapeau à deux cornes. Lenr sommet s'enchasse entre les côtés des ovariales, et les sutures qui unissent ces deux systèmes de plaques sont indiquées par des lignes légèrement déprimées. La surface de toutes ces plaques n'est que très-légèrement granuleuse, sinon entièrement lisse. L'ouverture anale est pentagonale, et en avant de la base concave de chaque plaque ovariale naît une autre petite plaque de mème nature que celles que nous avons signalées dans le $G$. globosus; il est digne de remarque que dans cette espèce elles sont au nombre de cinq, tandis qu’il n'y en avait que Irois dans la précédente, fig. 17 et 22.

Les aires ambulacraires très-apparentes ont à-peu-près la moitié de la largeur des aires interambulacraires. Leurs deux rangées de tubercules, assez distantes à l'origine, se resserrent eu approchant du sonmet. Ies tubercules eux-mêmes sont très-saillans, surtout sur le milieu de la circonférence et à la partie inférienre du test, oủ ils atteignent presque la même grosseur que ceux des aires interambulacraires. Ce qui mérite surtout d'être remarqué, c'est que, de mème que ces derniers, ils sont étranglés vers leur sommet et terninẻs par un mamelon articulaire. De plus petits tubercules ne se voient entre les deux rangées principales qu'à la face inférieure du test. Les pores ambulacraires sont très-distincts et placés en alternance sur deux lignes at-peu-près parallèles; a chaque paire de tubercules correspondent de chaque côté trois paires de pores, fig. 17, 18 et 21 .

Les aires interambulacraires se composent de plaques très-distinctes, fort grandes sur le milieu de la périphérie, et entourées de granulations tuberculeuses parfaitement distinctes et trèsproéminentes. Clacune de ces plaques donne naissance à un très-fort tubercule conique, entouré d'une large zone lisse el portant un mamelon articulaire un peu aplati, qui n'est séparé du tubercule que par un léger étranglement sans plis rayonnés, fig. 17, 18 et 20 .

Les piquans ne sont pas connus. 


\section{CIIAPITRE III.}

DU GENRE PELTASTES Ag.

La forme toute particuliẻre qu'affecte l'appareil ovidueal dans plusieurs espèees du groupe des Salénies mia engagé à les élever à la dignité d’un genre que jappelle Pelcastes, à eause de la ressenthanee de cet appareil avec un bouclier. Les plaques ovariales s'étendent en lobes allongés sur une portion considérable des aires interambulacraires, bordées de chaque côté par les plaques inter"rariales auxquelles elles sont soudées dans toute leur longueur; de manière qu'au lieu d'une atoile à dix rayons nous avons ici une simple rosette pentagonale. Outre les cinq plaques ovariales et les cing interovariales, il y a, comme dans les vrais Salénies, une plaque suranale placée entre les ovariales du côté antérieur et l’ouverture anale, de sorte que cette dernière se trouve refoulée en arriẻre comme dans la $S$. areoluta et la $S$. stellulata.

Les espéces comnues de ce genre sont de petite taille, mais d'une strueture trés-élégante. L'ouverture inférieure est constamment plus petite que l'appareil oviducal. Les aires ambulacraires, quoique trés-étroites comparativement aux aires interambulaeraires, sont cependant très-apparentes. Les zones porifères on les ambulacres proprement dits sont très-étroits, et 'pnoiquïil soit fort difficile de reconnaître les pores dans les exemplaires que je possède de ce „renre, je suis cependant porté à croire quils sont généralement disposés par simples paires comme dans toute la famille des Salénies. Enfun les aires interambulacraires sont remar(juables par leurs tubercules trẻs-saillans qui súlèrent en cònes raides du milieu d'une zone lisse, ef sont surmontẻs, comme dans toutes les Salénies en général, d'un mamelon articulaire non perforé, qu'entoure, au dessous de l'étranglement, un eercle de petits plis rayonnés.

I. Peltistes pechellus Ag. Tah. 5, fig. 1-8.

11. Charles DesHoulins cite cette espèee dans ses Tableanx synonymiques, p. 302, sous le nom d'Echimus acanthoides. Du moins je pense que son Echimus acanhoides se rapproche plus 
de mon Peltastes pulchellus que du P. marginalis; n'ayant pas vu l'original de M. DesMoulins, je ne puis cependant l'affirmer positivement.

Sa forme est circulaire, fortement aplatie à la face inférieure et légèrement déprimée à la face supérieure; de maniẻre que le diamètre vertical égale à-peu-près la moitié du diamètre transversal, fig. 1 et 2. L'ouverture inférieure, de moyenne grandeur, est sensiblement rentrante, et son pourtour présente de petites crénelures comme dans la plupart des Salénies, mais aree cette diffẻrence qu’ici le bord des aires ambulacraires est plus saillant et plus étroit que celui des aires interambulacraires, fig. 3 et 7 . Les aires ambulacraires portent deux rangées de petits tubercules assez saillans, qui se resserrent sensiblement de la base au sommet; l'espace intermédiaire est parsemé de petites granulations verrnqueuses à peine visibles à l'œil nu. Les pores paraissent disposés par simples paires de cliaque côté et tout le long de l'aire ambulacraire, fig. 5. Les aires interambulacraires sont fort larges et surtout remarquables en ce qu'elles sont couvertes, dans toute la partie supérienre du disque, de petites verrues uniformes, les gros tubercules ne dépassant guère le milieu de la circonférence. Ces derniers augmentent en grosseur depuis le bord de l'ouverture inférieure jusqu’à la moitié de la lıateur du test, oủ ils se distinguent par la raidenr du cône, fig. 1 et 8 . Tous s'élévent du milien d'une zone lisse que borde 1 cercle de petits tubercules placés á égale distance les uns des autres. Le sommet du cône est terminé par un mamelon articulaire remarquable par sa petitesse et entouré d'un cercle de très-petits plis rayonnés qu'on ne distingue guère qu’à la loupe, fig. 4 et 8.

L'appareil oviducal ne fait qu'une légère saillie au dessus de la face supérieure du test ; mais en revanche sa structure est assez compliquée et sourent difficile à reconnaitre, à cause des hachures transverses qui se croisent avec les lignes de suture, d'autant plus que celles-ci sont ordinairement très-fines et même quelquefois imperceptibles à l'œil nu. Les plaques ovariales sont trẻs-allongées, crénelées à leur bord externe et considérablement plus grandes que les interovariales, qui s'insẻrent en fornte de croissans très-étroits entre les intervalles de leurs sommets. La plaque suranale, qui refoule l'ouverture anale en arrière, est subpentagonale et a base concave: l'on remarque sur les sutures qui l'unissent aux interovariales antérieures les mèmes hachures transverses qu'entre les ovariales et les interovariales. Ses dimensions ne sont pas trèsconsidérables. Toutes ces plaques sont parfaitement lisses, et l'aspect rugueux de l'appareil enlier ne provient absolument que des hachures que je viens de signaler, fig. 1 et 6.

J'ai vu deux exemplaires de cette espèce, parfaitement conservés et provenant du département du Var; l’un m’a été communiqué par M. Studer, et lautre par M. Desllayes. 
II. Peltastes margivilis Ag. Tal, 5, fig. $9-16$.

Tris-voisine du $P$. pulchellus, par sa forme comme par sa structure. Cependant, en l'étudiant attentivement, on ne tarde pas à lui reconnaitre des différences spécifiques incontestables: et d'abord l'appareil oviducal est proportionnellement beaucoup phus grand, les plaques ovariales sont plus larges, moins resserries au milieu, et leur bord externe forme un angle obtus iu lieu d'ètre dentelé comme dans le $\boldsymbol{P}$. pulchellus. Les plaques interovariales sont en revanche plus petites et plus arquées, et les hachures qu’on remarque sur les sutures qui les unissent aux ovariales et celles-ci à la plaque suranale sont moins profondes et plus rẻgulières; au lieu de sillons transverses ce sont de petits points creux placés à égale distance les uns des autres. L'ouverture anale est allongée dans le sens du diamètre transversal, et son bord antérieur, formé par le còté interne de la plaque suranale, est très-relevé. Cette plaque suranale est assez régulièrement pentagonale, à l'exception de sa base qui est concave, fig. 9 et 14.

L'ouverture inférieure est fortement rentrante, et l'on remarque que les crénelures de son pourtour sont disposées de la même manière que dans l'espèce précédente, c’est-à-dire que le bord des aires ambulacraires est plus saillant et plus étroit que celui des interambulacraires, fig. 11 et 15 .

Les aires ambulacraires comptent deux rangěes de tubercules entre lesquels naissent, sur toute la partie inférieure, de très-petites granulations. Les pores se rangent par simples paires de claque côté de l’aire ambulacraire, fig. 13.

Les aires interambulacraires sont larges et munies de très-gros tubercules qui cependant ne dépassent pas le milieu de la circonférence. Ĺa face supérieure du test est uniformément couverte de petites granulations. Les gros tubercules sont comme d'ordinaire lisses à leur base, et entourés d'un cercle de plus petits tubercules simples; le mamelon arliculaire qui couronne leur sommet, ainsi que les plis rayonnés au-dessous, sont plus apparens que dans l'espèce précédente, fig. 10, 12 et 16. L'espace entre les rangées principales est aussi parsemé de petites granulations comme la face supérieure; en général, on en voit surgir partout oủ les gros tubercules ou l'appareil oviducal ont laissé quelque espace libre.

Cette espèce m’a été communiquée par M. Michelin; elle provient de Caussolś, département du Var. 


\section{CHAPITRE IV.}

\section{DU GENRE GONIOPIIORUS $A_{g}$}

Ce gुenre, très-voisin des vraies Salénies, s’en distingue, comme les deux précédens, essentiellement par la forme de l'appareil oviducal. La structure de cet appareil est en effet très-bizarre : au premier coup-d'oil on serait tentẻ de croire qu'il n'est composé que de plaques interovariales; et re u'est qu'en l'examinant avec altention, qu'on s'apercoit que les côtes raides et saillantes de sa surface ne sont point des sutures, celles-ci étant à peine visibles à l'œil nu. Outre les plaques ovariales et interovariales, il y a aussi une grande plaque suranale qui, placée, comme dans les Peltastes et les Salénies de la seconde division, entre les ovariales antérieures et l'ouverture anale, refonle cette dernière en arrière La forme de l'appareil entier est celle d'un pentagone régulier, dont les angles saillans sont formés par les plaques iuterovariales.

Je ne connais-encore que deux espèces de ce genre. L'une et l'autre se font remarquer par l'élévalion de leur test, ce qui est le résultat de la hauteur extraordinaire des plaques interambulacraires proportionnellement à leur nombre qui n'est guẻre que de quatre à cinq dans une série. Les ambulacres ou zones porifères sont peu apparens, formés de deux rangées de pores disposés par paires simples, de manière qu'il y a i-peu-près autant de paires de pores quill y a de tubercules sur les aires ambulacraires. Ces dernières sont d'une étroitesse extrême. Les aires interambulacraires, au contraire, sont fort larges, munies de deux rangées de tubercules principaux qui s'élèvent du milieu d’une large zone lisse bordée d'un cercle de plus petiles verrues. Louverture inférieure est de grandeur moyenne et crénelée sur son pourtour.

\section{Gonophonds lendutus Ag. Tab. 5, fig. 17-2\%.}

Jolie petite espèce it-peu-près aussi haute que large avec un léger aplatissement à la face inférieure, fig. 17. L'ouverture inféricure est très-petite, néannoins l'on distingue fort bien les petites crénclures de son pourtour, qui sont placées à distance égale les unes des autres, de 


\section{$-51-$}

maniẻre que les bords des aires ambulacraires et interambulacraires sont a-pen-près égaux, si toutefois l'on fait abstraction d'une autre petite dentelure an milien du bord de chaque aire ambulacraire, fig. 19 et 23.

Les aires ambulacraires sont remarquables par leur étroitesse et la petitesse de leurs tubercules; et depuis la base jusqu'au sommet il ne reste aucun espace lihre pour de plus petites verrues, entre les deux rangées principales. Les pores sont disposés par paires obliques sur les cótés de l'aire ambulacraire, et comme celle-ci convergent uniformément vers le sommet, fig. 18 et 21 .

Les aires interambulacraires sont fort larges, munies de deux rangẻes de tubercules principaux dont les plus gros occupent le milieu de la circonfërence; mais ils dimimuent brusquement de grosseur à mesure quils approchent de l'ouverture inférieure ou de l'appareil anal. Cliacun de ces tubercules a une large zone lisse à sa base, et est en outre entouré d'un cercle de plus petites rerrues; celles-ci sont mème plus apparentes que dans beaucoup dautres espéces. Le mamelon articulaire qui termine le cône, est renarquable par sa grosseur. Les plis rayonnés autour de l'étranglement sont également très-apparens, fig. 20 et $2 \%$.

Lappareil oviducal occupe le tiers de la face supérieure du test. Les lignes de suture entre les diverses plaques dont il se compose sont tellement fines, que l'on a souvent de la peine ì les recounaitre, d'autant plus que l'on est naturellement porté ì les confondre aree les côtes, quỉ sont plus prononcèes dans cette espèce que dans aucune autre. Cependant, si l'on examine attentivement, on trouvera que les plaques ovariales antérieures sont assez régulièrement pentagronales et que les deux postéricures qui touchent immédiatement ả l'ouverture anale sont seules comprimées et allongées; ce qui tient uniquement à la position de la plaque suranale qui, en s̈insérant entre les deux ovariales antérieures et louverture anale, refoule cette dernière en arrière et rétrécit par cet effet les deux ovariales postérieures. La plaque suranale elle-mène est en forme de pentagone allongé embrassant a-peu-près la moitié de l'ouverture anale. Les plaques interovariales sont de petits triangles à base convexe et à sommet arrondi, qui sünsèrent entre les ovariales et forment ainsi les angles du pentagone oviducal, fig. 17 et 22.

Les còtes de l'appareil oviducal se croisent en tous sens avec les sutures des plaques; elles sont en général, plus apparentes en avant qu'en arrière de l'ouverture anale, et forment ici trois triangles i-peu-près égaux. Les bords de l'appareil entier, ainsi que les bords de l'ouverture anale, sont très-saillans.

Je ne connais encore qu'un seul exemplaire hien conservè de cette espèce. It provient du cap la Hève et m’a été communiqué par MI. LeSueur. 
II. Goxiophonus apicclates Ag. Tab. 5, fig. 25一-32.

Il est très-facile, au premier abord, de confondre cetle espèce avec la précédente, dont elle se rapproche beaucoup. Maís, d'un autre côté, elle en diffère à plusieurs égards : ainsi l'appareil oviducal, quoique disposé de la même manière que dans le G. lumulatus, a cependant ses bords et ses còtes bien moins saillans; ce qu'on ne saurait expliquer par une variété d’àge, puisque l'exemplaire que j'ai sous les yeux est à-peu-près du double plus grand que le G. lumulatus figuré: or, on ne peut raisonnablement admettre qu'ils se soient atténués par l'àge, fig. 25 et 30 ; il en est de même des tubercules qui sont moins saillans et moins gros. En outre, l'ouverlure anale est moins centrale, plus grande, plus allongée, et ses bords sont plus tranchans. L'ouverture inférieure est circulaire et crénelée à-peu-près comme dans l'espèce précédente, fig. 27 et 31.

Les aires ambulacraires sont étrnites et peu prénminentes, composées de deux rangées simples de petits tubercules sans granulations intermédiaires; de chaque côté s'adossent deux séries sinıples de petits pores disposés par paires obliques, fig. 26 et 29 .

Les aires interambulacraires sont larges, munies de deux rangées de forts tubercules, dont ceux qui occupent le milieu de la circonférence sont beaucoup plus grands que ceux qui entourent l'ouverture buccale. La zone lisse, qui occupe la plus grande partie de chaque plaque, s'élève en forme de cône plus aplati que dans le $G$. lunulatus; le mamelon articulaire dont il est surnonté est également plus petit, fortement étranglé et entouré, à la base de l'étranglemınt, d'une rosette de petits plis rayonnés, fig. 28 et 32 . La forme et la disposition de l'appareil oviducal sont absolument les mènes que dans le G. lumulatus, si ce n'est que ses bords sont un peu plus droits et plus saillans. Il en est de même des côtes, qui, partant du trou dont chaque ovariale est percée, se dirigent dans tous les sens; d'où résultent ces triangles que l'on prend si facilement pour les sutures des plaques. Les ovariales postérieures sont considérablement atténuées par l'ouverture anale qui penche sensiblement de ce côté, ce qui fait aussi que les còtes y disparaissent complètement. La plaque suranale est proportionnellenent plus étroite et plus allongée; sa forme est un pentagone irrégulier ì base concave, fig. 25 et 30.

C'est à lobligeance de mon ami M. Valenciennes, qui a bien voulu me communiquer toutes les espèces d'Echinodernes de la collection du Muséum, dont je ne possède pas moi-même ḍoriginanx, que je dois de pouvoir donner la description de cette espèce. 


\section{CONSPECTUS GENERUM ET SPECIERUM SALENARUM.}

Character gentis Suleniarum e famitia Cidaridum. Ambulacra simplicia, interambulacris angustiora; tubercula majora non perforata; discus ovarialis prominulus, assulis firmis, intime conjunctis.

I. Gemus SALENI A Gray. Ag. Discus ovarialis circularis , plus minusve emarginat us, assulis ovarialibus et interovarialibus quinque, assula undecima, supraanali, antica, rel postica : tubercula collo crenulato.

๘. Species ano antico.

1. Salenia personata Ag. Disco ovariali inæquo, suturis assularum depressis; zonis ambulacralibus angustis; tuberculis majoribus ( $\left.{ }^{1}\right)$.

2. Salenia scripta Ag. Suturis assularum disci ovarialis transverse insectis; ano prominulo; tuberculis minimis; zonis ambulacralibus angustissinis.

3. Salenia petalifera $\mathrm{Ag}$. Disco ovariali equo, angulis assularum depressis, zonis ambulacralibus amplioribus; apertura inferiore magna, margine alte inciso.

4. Salcria geometrica Ag. Orbicularis; disco ovariali aequo, suturis assularum linearibus.

5. Salenia scutigera Gray. Ag. Disco ovariali subplano, margine apertura analis lumido, prominulo; tuberculis ninoribus.

6. Salenia gibba Ag. Disco ovariali conico, angulis assularum truncatis, depressis.

7. Salevia trigonata $\mathrm{Ag}$. Disco ovariali costulis triangulos conferentilus predito.

B. Species ano postico.

8. Salenia stellulata Ag. Depressa, disco ovariali amplissimo, assulis in margine crenulatis.

9. Salenia areolata $\mathrm{Ag}$. Depressa ; disco ovariali inæquo, assulis in margine depressis; zonis ambulacralibus angustissimis.

II. Genus Goviopygus $\mathbf{A g}$. Discus ovarialis stellatus, assulis orarialibus et interovarialibus quinque, supraanali deficiente. Tubercula collo lavi.

(') En parcourant les planches de cette monographie, depuis qu'elle a paru, je me suis aperçu que sur un certinin nombre d'exemplaires de la $1^{\text {re }}$ planche, les tubercules grossis paraissent perforés. Cette erreur de grarure corrigée à l'épreure s'est en partie reproduite an tirage. Il m’a paru important de signaler cette inexactitude que j’aurais réparíe en supprimant les épreures, si je l'avais a perçue avant 'jue les pierres fussent effacées.

(Ag.) 
1. Gomiopygus peltatus Ag. Facie inferiore plana, apertura maxima; assulis ovarialibus acuninatis; margine apertura analis subpentagonali. Spinis clavatis, sulcatis.

2. Gomiopygus intricatus Ag. Depressus, minimus; apertura inferiore magna; assulis ovarialibus margine crenulatis. Spinis obtusis, lavibus.

3. Goniopygus Menardi Ag. Disco ovariali assularum margine lineari. Margine aperturæ analis trigonato.

4. Gomiopygus leteropygus $\mathrm{Ag}$. Margine aperturæe analis quadrato, inaquo.

5. Gomiopygus globosus Ag. Suborbicularis; apertura inferiore magna; ano trigonato.

6. Gomiopygus major $\Lambda \mathrm{g}$. Subconicus; disco ovariali minore; assulis ovarialibus valde acuminatis. Apertura anali pentagonali.

III. Genus PELTASTES Ag. Discus ovarialis pentangulatus; assulis ovarialibus prominentibus, assulas interovariales emarginatas amplectentibus. Assula supraanali antica.

1. Peltastes pulchellus $\mathrm{Ag}$. Disco ovariali minore, assulis margine crenulatis, ovarialibus apice lissis ; tuberculis parvis, maxime prominentibus.

2. Peltastes marginalis $\mathrm{Ag}$. Disco ovariali majore, assulis in angulis depressis, ovarialibus in apice integris.

IV. Genus GONIOPIORUS Ag. Discus ovarialis marginibus rectis, pentangulatus, costatus, assulis interovarialibus prominentibus, angulos referentibus.

1. Goniophorus lumulatus Ag. Costis disci ovarialis crassis; aperlura inferiore minima.

2. Goniophorus apiculatus $\mathrm{Ag}$. Globosus; disco ovariali majore, costis tenuioribus.

Species omnes simili modo a facie superiore, laterali et inferiore delineata sunt. Partes aucte sunt : discus ovarialis, tuberculum spiniferum, apertura inferior, zona interambulacralis et ambulacralis.

Mandato jam typis loc opusculo et amicis doctissimis proposito, clariss. Bronn speciem novam e gente Saleniarum mecum communicavit, qua eo magis interest mea, quod probet non solam Saleniam scutigeram in Germania occurrere. Ad genus Goniopygorum pertinet; aliàs accuratam ejus descriptionem cum figuris in lucem proferam. Ad Goniopygum Menardi proxime accedit; a quo tamen differt assulis disci ovarialis acutioribus, et inde disco in margine valde serrato. Apertura analis transversin ovata. Gomiopygus Bronnii dicendus. E stratis cretaceo-margaceis Wesiphalia. 

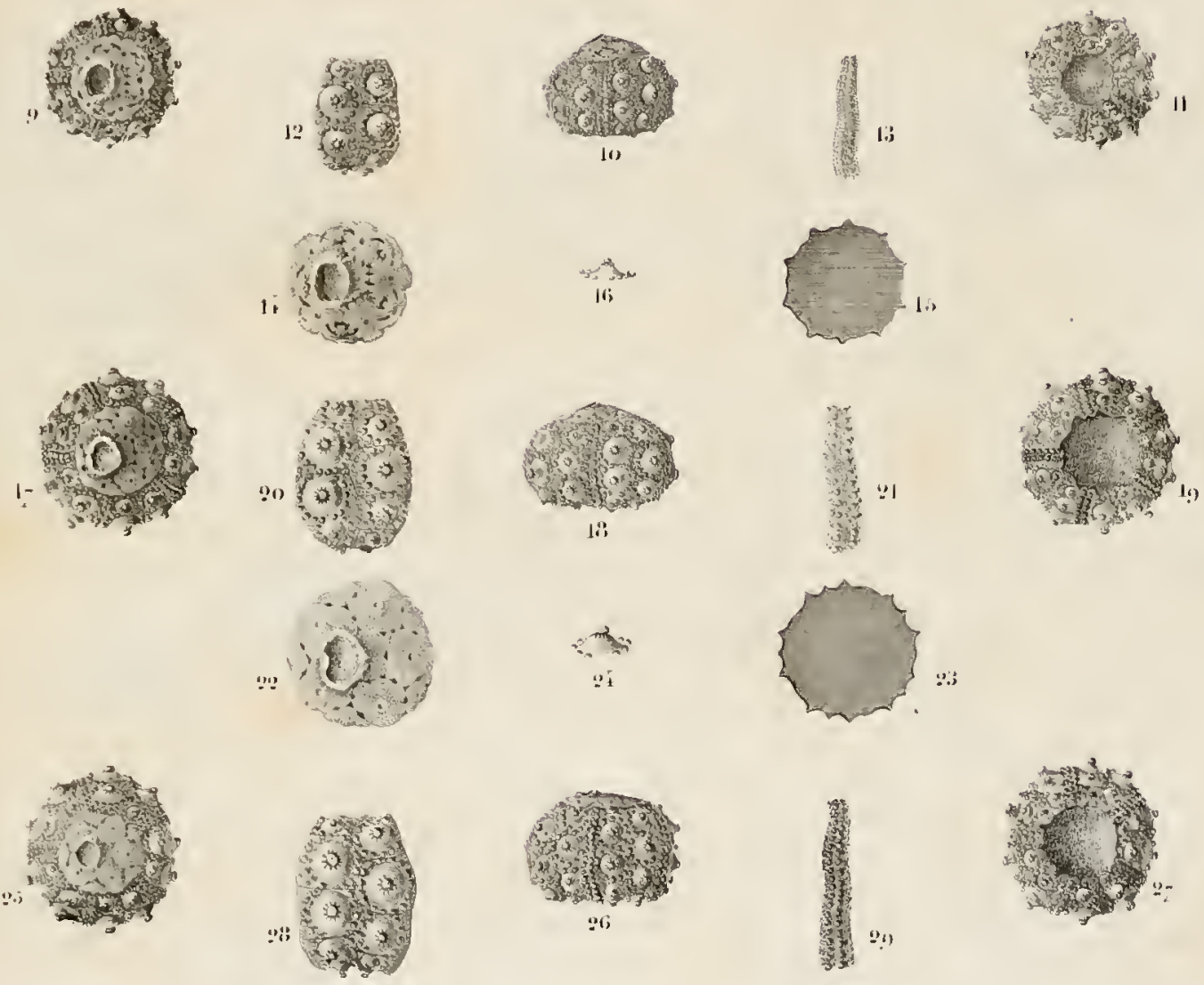

of
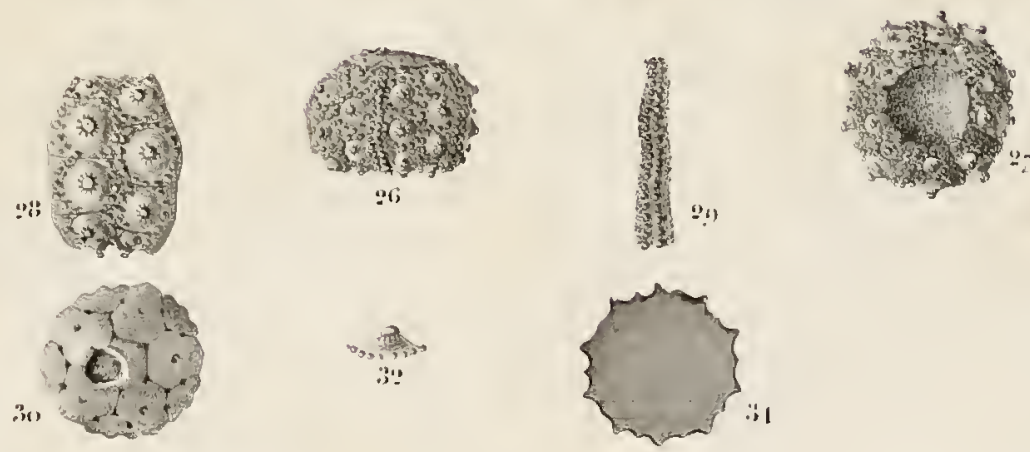

$-1 / 1,5,=\cdot$

"1ify, :? 


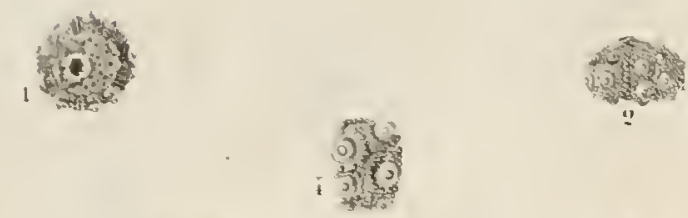

is

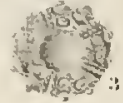

(1)

, A
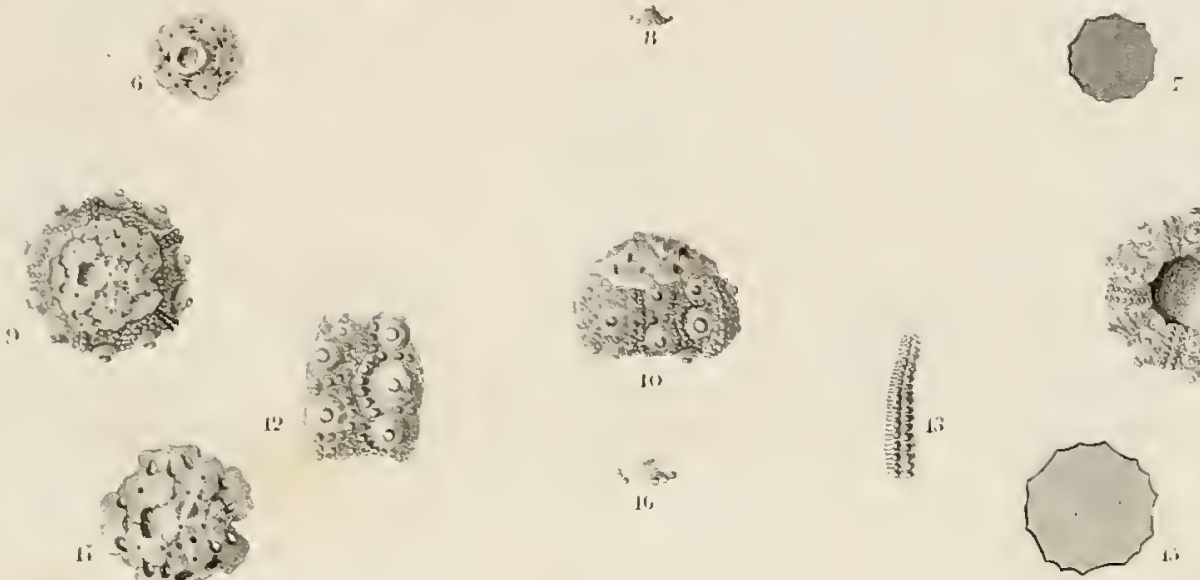

(1)

影

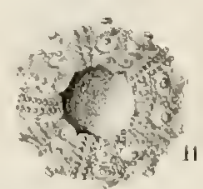

(1)<smiles>C1CCCCCCCCCCC1</smiles>

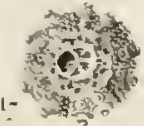

3
5
0
0

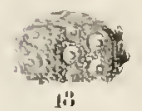

II

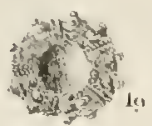

3,7

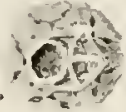

$\because$
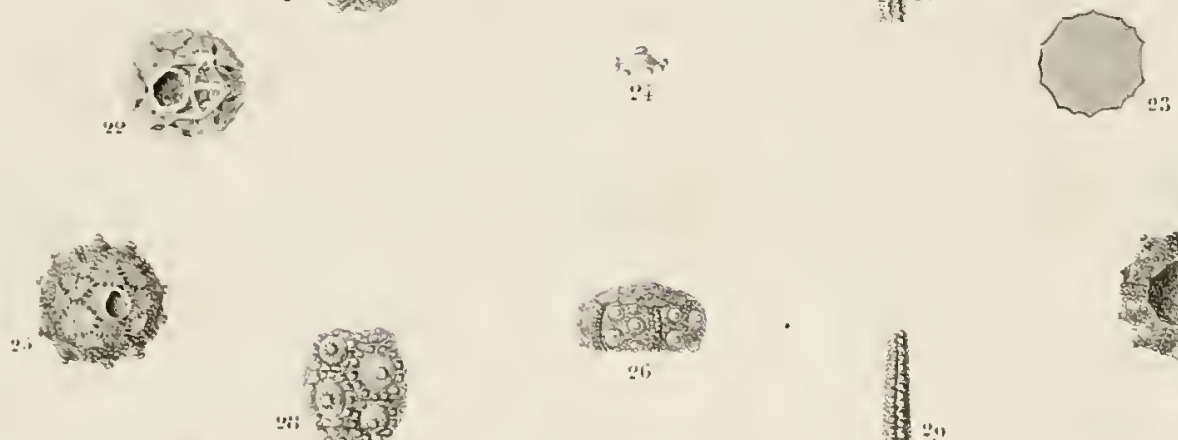

䨽
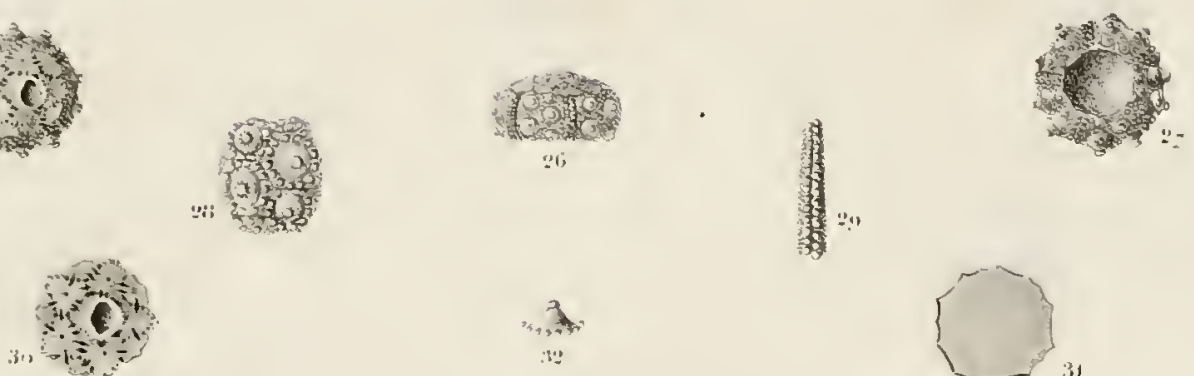

ㄱ.

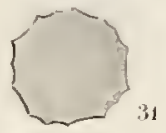



sillinic.

Tal...

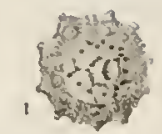

6 that

?

0

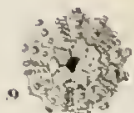

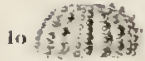

ํํㄴ

11

(1)

1- 5

留

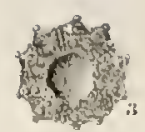

繁

का

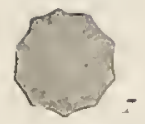

16.

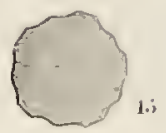

and

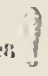

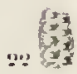

2- 2

桑:

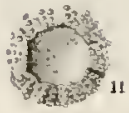

1.)

$2+1$

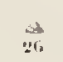
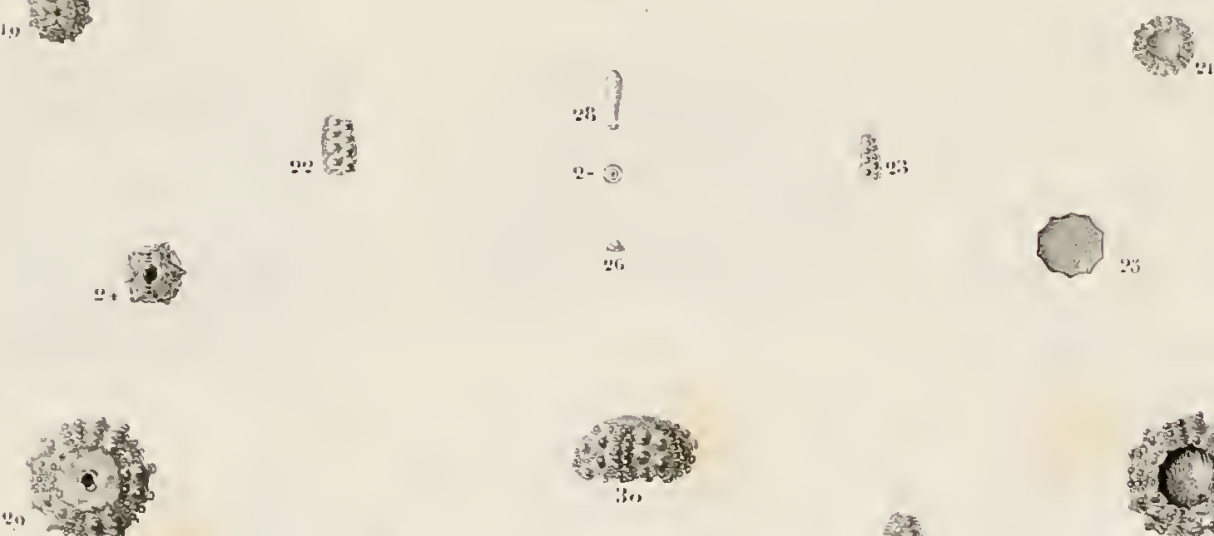

40

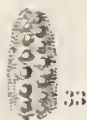

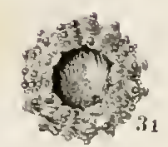

, 3

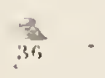

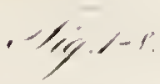
Yig:-1
- Ior Ily-2,
Wer by=ir 

salenir..
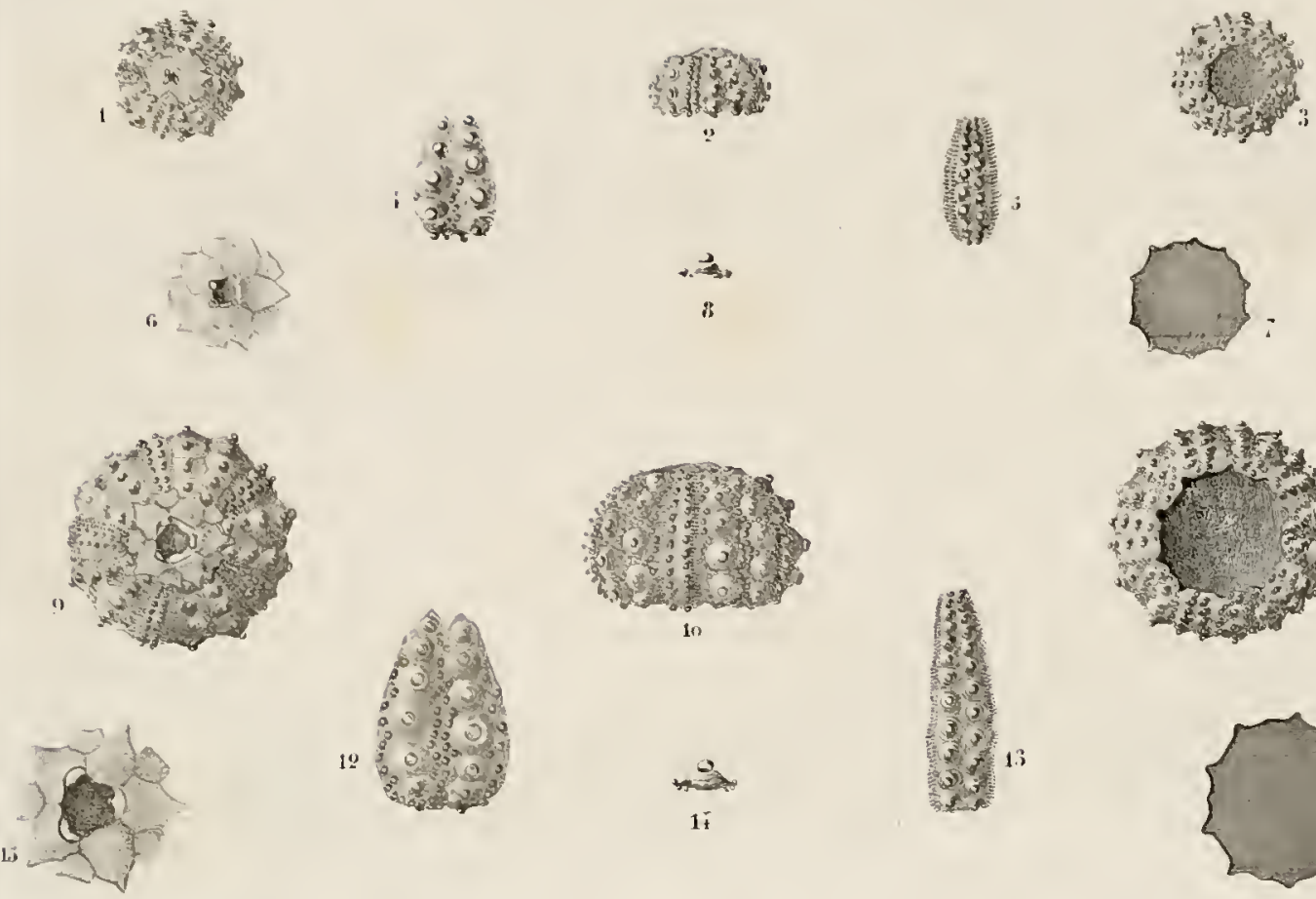

8
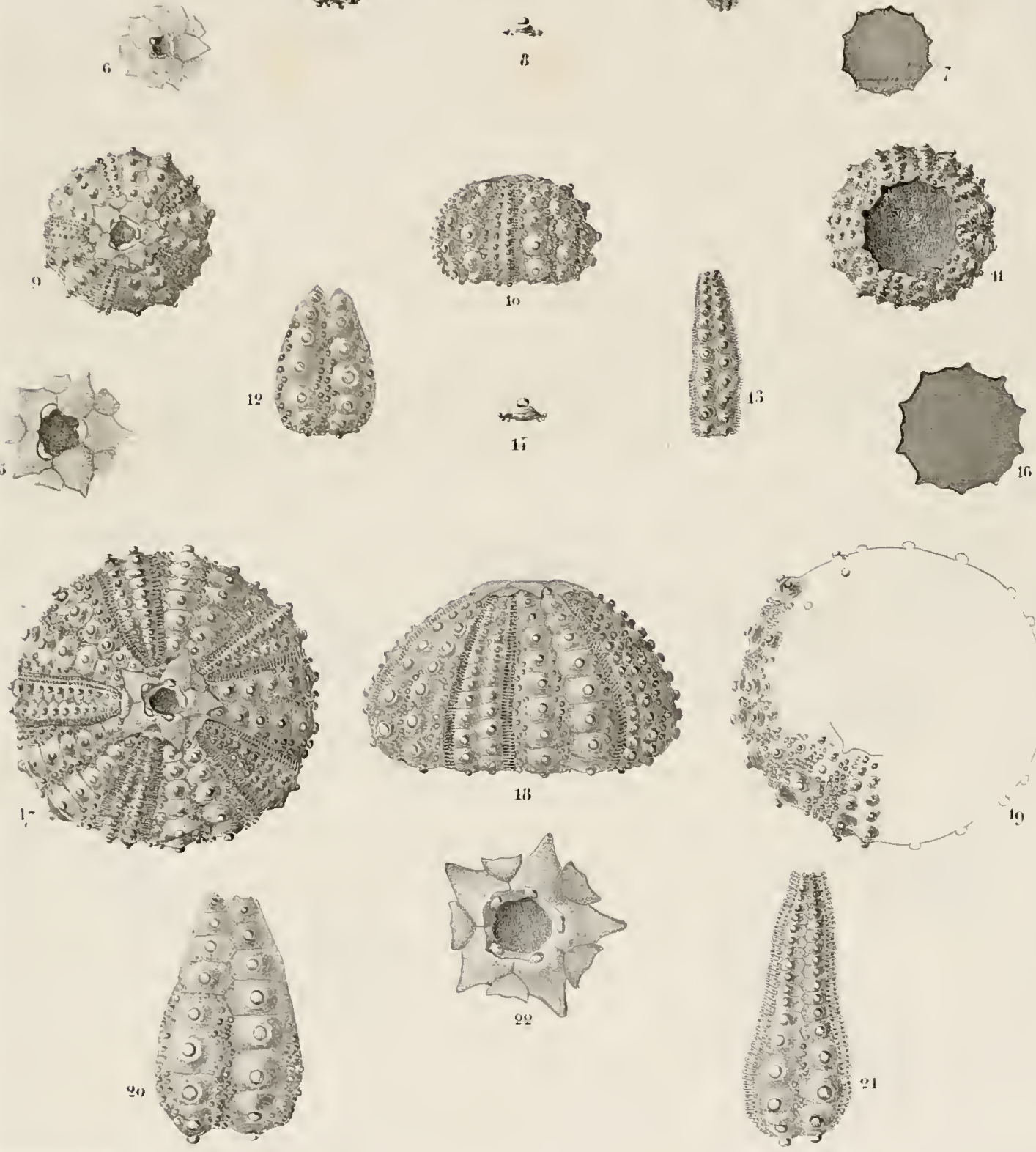

$,-1,-$,

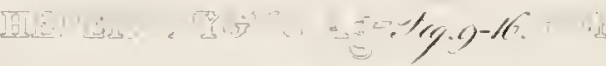

- "Niy.y-PR. 



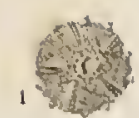

1.

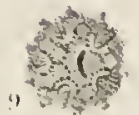

18
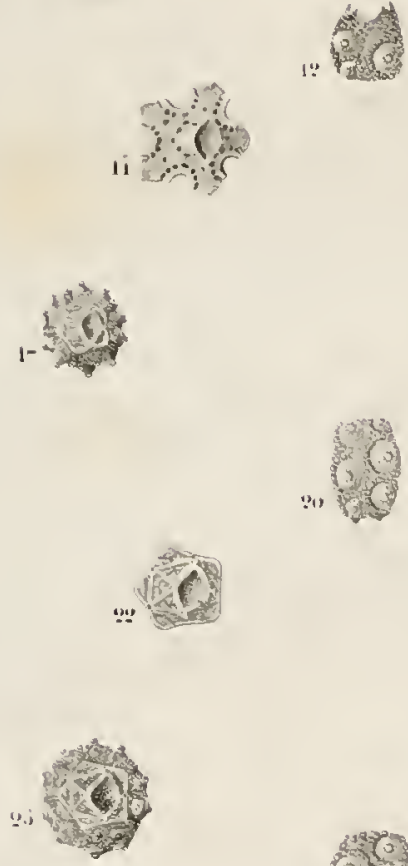

;)

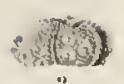

,

is

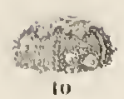

依

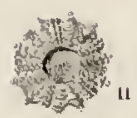

ii<smiles>C1CCCCC1</smiles>
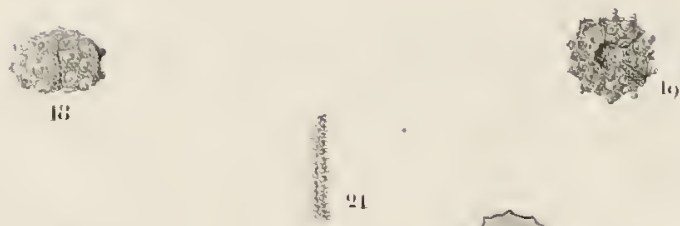

$\prod_{1}^{3}$
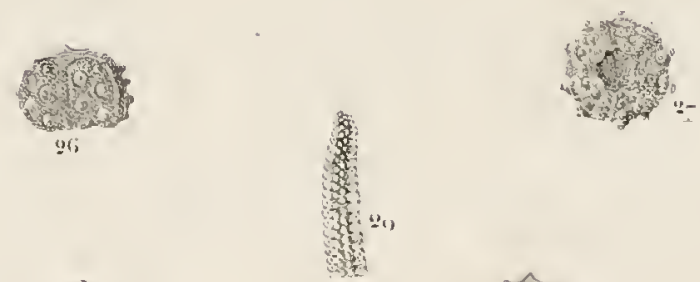

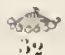
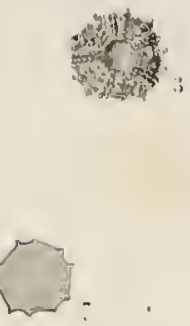

等这

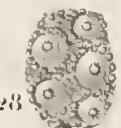
1 1yy - 1.
' Yiy :y-11
toys is
Iry sis 



\section{CONSPECTUS GENERUM ET SPECIERUM SALENIARUM.}

\section{Cimpacter gextis Silexinden e fanili Cidiridum.}

Ambulacra simplicia, interambulacris angustiora ; tubercula majora non pèrforata ; discus ovarialis prominuius, assulis firmis, intime conjunctis.

I. Genus SILENIA Gray. Ag. Discus ovarialis circularis, plus minusve emarginatus, assulis orarialibus et interovarialibus quinque, assula undecima, supraanali, antica, vel postica ; tubercula collo crenulato.

a. Spccies ano antico.

1. Salenia personata $\mathrm{Ag}$. Disco ovariali inaquo, suturis assularum depressis; zonis ambulacralibus angustis; tuberculis majoribus (").

2. Salenia scripta $\mathrm{Ag}$. Suturis assularum disci ovarialis transrerse insectis ; ano prominulo ; tuberculis minimis; zonis ambulacralibus angustissimis.

3. Salcmia petalifera $\mathrm{Ag}$. Disco ovariali aequo, angulis assularum depressis, zonis ambulacralibus amplioribus; apertura inferiore magna, margine alte inciso.

4. Salcnia gcometrica Ag. Orbicularis; disco ovariali iequo, suturis assularum linearibus.

5. Salenia scutigcra Gray. Ag. Disco ovariali subplano, margine aperture analis tumido, prominulo; tuberculis minoribus.

6. Salenia gibba Ag. Disco ovariali conico, angulis assularum truncatis, depressis.

7. Salcnia trigonata $\mathrm{Ag}$. Disco ovariali costulis triangulos conferentibus predito.

B. Spccies ano postico.

8. Salenia stellulata $\mathrm{Ag}$. Depressa; disco ovariali amplissimo, assulis in margine crenulatis.

9. Salenia areolata $\mathrm{Ag}$. Depressa ; disco ovariali inaquo, assulis in margine depressis; zonis ambulacralibus angustissimis.

II. Genus GONIOPYGUS Ag. Discus ovarialis stellatus, assulis ovarialibus et interovarialibus quinque, supraanali deficiente. Tubercula collo lævi.

(') En parcourant les planches de cette monographie, dẹuis qu'elle a paru, je me suis aperçu que sur un certain nombre d'exemplaires de la $1^{\text {re }}$ planche, les tubercules grossis paraissent perforés. Cette erreur de gravure, corrigée a l'épreuve, s'est en partie reproduite au tirage. Il m'a paru important de signaler cette inexactitude, que j’aurais réparẻe en supprimant les épreures, si je l'avais aperçuc avant que les pierres fussent effacées. 
1. Goniopygus pellatus Ag. Facie inferiore plana, apertura maxima; assulis ovarialibus acuminatis; margine aperturæ analis subpentagonali. Spinis clavatis, sulcatis.

2. Goniopygus intricatus Ag. Depressus, minimus; apertura inferiore magna ; assulis ovarialibus margine crenulatis. Spinis obtusis, lavibus.

Goniopygus Menardi Ag. Disco ovariali assularum margine lineari. Margine apertura analis trigonato.

4. Goniopygus heteropygus $\mathrm{Ag}$. Margine apertura analis quadrato, inxquo.

5. Goniopygus globosus Ag. Suborbicularis; apertura inferiore magna; ano trigonato.

6. Goniopygus major $\mathrm{Ag}$. Subconicus; disco ovariali minore; assulis ovarialibus valde acuminatis. Apertura anali pentagonali.

III. Genus PELT ASTES Ag. Discus ovarialis pentangulatus; assulis ovarialibus prominentibus, assulas interovariales emarginatas amplectentibus. Assula supraanali antica.

1. Peltastes pulchellus Ag. Disco ovariali minore, assulis margine crenulatis, ovarialibus apice fissis ; tuberculis parvis, maxime prominentibus.

2. Peltastes marginalis $\mathbf{A g}$. Disco ovariali majore, assulis in angulis depressis, ovarialibus in apice integris.

IV. Genus GONIOPHORCS Ag. Discus ovarialis marginibus rectis, pentangulatus, costatus, assulis interovarialibus prominentibus, angulos referentibus.

1. Gonioplorus lumulatus Ag. Costis disci ovarialis crassis; apertura inferiore minima.

2. Goniophorus apiculatus Ag. Globosus; disco ovariali majori, costis tenuioribus.

Species ommes simili modo a facie superiori, laterali et inferiore delineata sunt. Partes aucta sunt: discus ovarialis, tuberculum spiniferum, apertura inferior, zona interambulacralis et ambulacralis.

Mandato jam typis loc opusculo et amicis doctissimis proposito, clariss. Bronn speciem novam e gente Saleniarum mecum communicavit, qua eo magis interest mea, quod probet non solam Saleniam scutigeram in Germania occurrere. Ad genus Goniopygorum pertinet; alias accuratam ejus descriptionem cum figuris in lucem proferam. Ad Goniopygum Ienardi proxime accedit; a quo tamen differt assulis disci ovarialis acutioribus, et inde disco in margine valde serrato. Apertura analis transyersim ovata. Goniopygus Brommii dicendus. E. stratis cretaceomargaceis Westphalia. 


\section{MONOGRAPHIES}

\section{D'LGIINDDERIIRE。}





\section{OBSERVATIONS SUR LES PROGRES RECENS DE L'HISTOHE NATURELLE DES ECHIXODERHES.}

Pour eompléter l'apercu que j’ai donné de mes recherehes sur les Echinodermes dans la préface de la première livraison de ces monographies, je crois devoir présenter ici quelques observalions sur les progrès réeens de l'histoire naturelle des Eehinodermes.

Les travaux qui ont été publiés depuis quelques années, on qui se publient encore dans ee moment sur ces animaux, sont assez nombreux. Ils embrassent, soit leur classification en général et l'histoire naturelle deseriptive des genres et des espèees, soit leur anatomic deseriptive et comparée, soit l'étude des nombreux fossiles qui ont représenté ectle elasse aux différentes époques dı développement de la vie organique. C'est aussi dans eet ordre que nous allons les passer en revue; puis je terminerai par quelques renseignemens sur les collections quej'ai examinécs dans ees derniers temps.

Autant ees diverses branches de l'histoire naturelle des Eehinodermes ont fait de rapides progrès, autant il est à regretter que la connaissance de leurs mours, de leur mode d'alimentation, de leur développement, des fonetions de leurs organes, ete., ete., soit restée en quelque sorte stationnaire, à l'exeeption de quelques remarques détachées sur les espèces européennes.

Le scul ourrage qui embrasse toute la elasse des Echinodermes est le charmant volume que M. E. Forbes a publié par livraisons sur les Eehinodermes d'Angleterre, en 1840 et 1841, sous le titre de History of british Starfishes and other animals of the class Echinodermata. Il les divise en six ordres, savoir: I les Pinnigrades ou Crinoïles; $2^{\circ}$ Ies Spinigrades ou Ophiurides, qu'il subdivise en Ophiures proprement dites et en Euryales; $3^{\circ}$ les Cirrhigrades ou Astériades, qu'il subdivise en Urastéries, Solastéries, Goniastéries et Astéries proprement dites; $4^{\circ}$ les Cirrhi-spinigrades on Echinides, pour lesquels il adopte les subdivisions que j’ai proposées dans mon Prodrome; 
$5^{\circ}$ les Cirrhi-vermigrades ou Holothuries, dont il fait quatre familles, les Psolides, lcs Pentactes, les Thyones et les Synaptes, et enfin $6^{\circ}$ les Vermigzades ou Siponculides, qu'il subdivise encore en trois familles: Ies Siponculacées, les Priapulacées et les Thralassenuacées. Il place ainsi au même rang, comme ordres, les Crinoïdes, les Ophiurides ct les Astéries, que j'avais laissés dans unseul ordre, dans mon Prodrone d'une histoire naturelle des Echinodermes; et il réunit aux Echinodermes les Siponcles que j’en avais éloignés pour les réunir aux vers. Je me suis, en effet, convaincu, à la vue des préparations que m'ont fait voir à L'dimbourg MM. Forbes et Goodsir, que les Siponclcs sontréellement des Echinodermes. Les descriptions que M. Forbes donne des espèces d'Angleterre sont beaucoup plus complè tes que toutes celles que l'on possédait jusque là, et il en a considérablement augmenté le nombre, surtout dans la famille des Holothuries et des Siponcles; il a en outre établi, en partie conjointement avec son ami M. Goodsir, les deux nouveaux genres Psolinus et Ocnlis, et circonscrit d'une manière plus rigoureuse mes genres Uraster ct Cribrella, de la famille des Astćries. Plusieurs des espèces dćcrites par M. Eorbes ont été découvertes par M. Thompson, de Belfast, et par M. Ball, de Dublin. Précédemment, MI. Forbes avait déjà publié, dans le $8^{e}$ volume des Transactions de la Société wernérienne d'Edimbourg, un mémoire sur les Astéries de la mer d'Irlande, dans lequel il a établi deux genres nouveaux (Solaster et Luidia) ct décrit plusieurs espèces nouvelles.

MM. J. Müller et Troschel ont entrepris une révision de la famille des Astéries, qu'ils ont d'abord subdivisée en quatorze et puis en scize gemres basés pour la plupart sur des caractères nou veaux et généralement circonscrits dans de justes limites. Ce sont les genres : Asteracanthion M. ct Tr. (Stellonia Nard. Forbes, Uraster Ag.); Pisaster M. et Tr.; Stichaster M. ct Tr.; Echinaster M. et Tr.; Crossaster M. et Tr. (Solaster Forbes); Chretaster M. etTr.; OphidiasterAg.; Linchia Nard. (MI. et Tr.); GoniasterAg.; Platy aster DeBl. (Scutasterias DeBl.); Asterope M. et Tr.; Culcita Ag.; Asteriscus M. etTr. (Asterina Nard., Palmipes Link); Archaster M. et Tr.; Asterias Ag. (Astropecten Link, Stellaria Nard.), Hemicnemis. M. et Tr. (Luidia Forbes). Leur travail, qui n'est encore publié que par extraits insérés dans les Bulletins de l'Académie de Berlin, du mois d'arril 1840, et dans les Archives d'his- 
toire naturelle de Wiegmann pour 1840, p. 318 et 367 , renferme de précieux détails sur l'organisation de ces animaux. Plus tard, ees messieurs ont étendu lenrs reeherehes aux Ophiures et publié un aperçu très intéressant des genres de eette famille, qu'ils portent maintenant à huit (Arehives d'histoire naturelle de Wiegmann 1840 , p. 326 et 368), savoir les genres Ophiolepis M. et Tr., Ophiopholis M. et Tr., Ophiocoma Ag., Ophiothrix M. et Tr., Ophioderna M. et Tr. (Ophiura Lam.), Ophionyx M. et Tr., Ophionuyxa M. et Tr. et Ophiocnemis M. et Tr., sans eompter les genres que j'ai établis pour des espèees fossiles.

M. J. E. Gray a publié un travail très important et très étendu sur les Astéries dans les eahiers de novembre et de déecmbre des Anuals and Magazine of Natural History. La tendanee de ee mémoire est toute différente de eelle de la publieation de MII. Müller et Trosehel. Tandis que les naturalistes de Berlin avaient surtout en vue d'étudier les détails de l'organisation des Astéries, M. Gray eherehait plutôt à grouper de la manière la plus naturelle et d'après leurs affinités les plus étroites, l'ensemble des espèces qu'il a eu l'oeeasion d'examiner et qui sont très nombreuses, partieulièrement dans la seetion des Pentacérotides. M. J. E. Gray a établi uniquement parmi les Astéries proprement dites, quarante-einq genres, (sans eompter les nombreux sous-genres) qu'il répartit en quatre familles, cornme suit :

Astertadae Gr. : Asterias Gr. (Pentasterias DeBl., Stellonia Nardo, Forbes, Uraster Ag., Asteraeanthion M. et Tr.) ; Heliaster Gr. (Solasterias DeBl.); Tonia Gr. (Stiehaster M. et Tr.).

Astropectrudae Gr. : Nanticia Gr. (Arehaster M. et Tr.); Astropecten Link (Asterias I. Ag.; Crenaster Link, Stellaria Nardo;) avee le sousgenre Astropus Gr. Luidia Forbes (IIemienemis M. et Tr.); Petalaster Gr.; Solaster Forbes (Crossaster MI. et Tr.), avee les sous-genres Endeca Gr. et Polyaster Gr.; Henricia Gr. (Linekia Forbes, Cribrella Ag. , Forb.).

Pextacenotidae Gr. ${ }^{\circ}$ Pentacerotina: Culcita Ag.; Pentaceros Link, Gr. (Goniaster Ag.), avee le sous-genre Nidorellia Gr.; Stellaster Gr.; ComptoniaGr.; GymnasteriaGr. (Asterope M. et Tr.); PanliaGr., RandasiaGr.; Anthenea Gr. ; Hosia Gr.; Hippasteria Gr.; Calliaster Gr.; Goniaster Ag. (Gr.); 
(Gr.); Pentagonaster Gr.; TosiaGr.-2 Echinasterina: Echinaster Gr. (non M. et Tr.).- $3^{\circ}$ Cribellina: Othilia Gr. (Echinaster M. et Tr.); Metrodira Gr. (Chistaster M. et Tr.); Rhopia Gr. (Lchinaster M. et Tr.); Ferdina Gr.; Dactylosaster Gr. (Ophidiaster Ag.); Tantaria Gr.; Cistina Gr.; Ophidiaster Ag. avec les sou s-genres Hacelia Gr. et Pharia Gr.; Linckia Nardo, Gr., avec les sous-genres Phataria Gr. et Acalia Gr.; Froulia Gr. (Linckia Nardo), Gonnophia Gr.; Nardoa Gr. (Linckia Nardo); Narcissia Gr.; Nectria Gr.; Nepanthia Gr.; Mithrodia Gr.; Uniophora Gr.

Asternida Gr.: Palnipes Linck(Anseropoda Nardo, Palmasterias DeBl., Asteriscus M. et Tr.) ; Porania Gr. (Goniaster Forb.); Asterina Nardo (Ctemaster Ag., Asteriscus M. et Tr., Pentaceros Linck); Patiria Gr.; Socomia $\mathrm{Gr}$.

Quelque nombreuses qu'elles soient, la plupart de ces coupes m'ont paru naturelles, et je pense qu'elles devront ètre adoptées après quelques rectifications dans les noms, qui font souvent double emploi avec ceux de MM. Müller et Troschel et autres, comme on peut s'en assurer par la synonymie que j'ai jointe en parenthèse aux noms de M. Gray. Il est vraiment à regretter quc ce dernier n'ait pas connu à temps le travail de MM. Müller et Troschel, qui a cependant six mois de priorité sur le sien. M. Gray fait des Astéries une classe à part sous le nom d'Hrpostona; mais je ne crois pas que cette sćparation des autres Echinodermes puisse ètre justifiéc anatomiquement, ni même zoologiquement. En effet, le caractère sur lequel on a le plus insisté jusqu'ici pour distinguer les Astéries des Oursins est fictif, puisque la plupart des Astćries ont un anus, comme l'a fait connaître le premier M. J. Müller.

Les études sur les Echinides de M. Cl. DesMoulins ćtant un ouvrage qui doit se trouver entre les mains de tous ceux qui s'occupent de l'histoire naturelle des Echinodermes, je puis me dispenser d'en rendre ici un compte détaillé. Je me borncrai à rappeler que $\mathrm{m}$. DesMoulins n'admet que dixsept genres dans l'ordre des Echinites, savoir : les genres $C l y p e a s t e r, S c u-$ tella, Fibularia, Cassidulus, Galerites, Pyrina, Echinounetra, Echinus, Echinocidaris, Diadeuna, Cidaris, Echinoneus, Echinolampas, Nucleolites, Collyrites, Ananchytes et Spatangus. Antérieurement à cette publication, M. Ch. DesMoulins avait déjà publié un catalogue descriptif 
des Stellérides vivantes et fossiles de la Gironde, avec deux planches (Actes de la Soc. liméenne de Bordeaux, Tom. 5).

Parmi les travaux plus spéciaux, je citerai la monographie des Astéries voisines de l'Asterias aurantiaca que M. Philippi a publice dans les Archives d'histoire naturelle de Wiegmann pour l'année 1837, vol. 1., p. 193, et la description d'un genre nouveau de Crinoïde vivant, des plus curicux, nommé Holopus, par M. Alc. d'Orbigny, qui l'a publié dans le Magasin de Zoologic de Guérin, de 1837.

Dans un travail encore inédit sur les espèces vivantes de l'ancien genre Echinus, travail que je me propose de publier prochainement, j’ai établi les conpes suivantes, dont je me borncrai à citer ici les types: Temnopleurus (E. torcumaticus), Pleurechinus (E. bothryoides), Microcyphus (E. versicolor), Tripneustes (E. ventricosus), Amblypneustes (E. griseus), Toxopneustes (E. pilcolus), Stomopneustes (E. variolaris). J'ai également cru devoir subdiviser le genre Arbacia en trois, laissant ce nom aux petites espèces fossiles, pour appeler Tetrapygus celles qui ont l'anus fermé par quatre valves, et $A$ garites celles dont les aires interambulacraires sont en partic dépourvues de tuhercules et de piquans.

Les Holothurics sont toujours la division des Echinodermes dans laquelle il reste le plus à faire. La difficulté d'observer ces animaux nous a privés jusqu'à présent de planches qui satisfissent aux cxigences de la science. Il n'y a que cclles qui ont été puhliées par MM. Quoy et Gaimard, dans l'Atlas zoologique de l'Astrolabe, qui, à cet égard, ne laissent rien à désirer. Quant à lcur délimination en genres, il reste encore beaucoup de vague et dincertitude dans les caractères sur lcsquels on a fait reposer ees groupes.

Oken (Lehrbuch der Naturgeschichte 1815) a été le premier à subdiviser les Holothuries en quatre genres qu'il appclle Thyone, Subuculus, Holothuria et Psolus. Lamarck n'a admis que deux genres dans cettc famille, les Holothuries et les Fistulaires; eneore ces genres sont-ils mal délimités. Cuvier, sans donner des noms génériques à ses divisions, a cependant établi dès la $1^{\text {re }}$ édition du Règne animal, six sections très naturelles dans le genre Holothuria, dont la première correspond au genre Psolus d'Oken, la seconde au genre Cuvieria de Péron; les $3^{\mathrm{e}}$ et $4^{\mathrm{e}}$ aux vraies Holothuries; la $5^{\mathrm{e}}$ au genre Subuculus d'Oken, qui est en mème temps le genre Cucumaria des 
auteurs ou Pentacta de Goldfuss; la $6^{\mathrm{c}}$ enfin correspond au genre Thyone d'Oken, que de son eôté M. Fleming a nommé Mïlleria dans son History of british Animals, mais qui n'est point le genre Mülleria de Jrger. Plus tard, Esehseholtz établit, dans l'Atlas zoologique du seeond voyage autour du monde dı eapitaine de Kotzebue, deux genres nouveaux sous les noms de Synapta et Chirodota, qui eorrespondent au genre Tiedentannia de Leuekardt (Isis 1831 , eompte-rendu de la réunion des naturalistes allemands à Ilambourg). M. Leuekardt a en outre établi les genres Phascolosoma et Ochetostoma de la famille des Siponeulacées; le premier dans son adresse pour le jubilé de Blumenbaeh, le seeond eonjointement avee M. Ruppell dans l'atlas qui aecompagne le voyage dans le nord de l'Afrique.

Dans sa dissertation sur les Holothuries (Zurich 1833, in-4º), M. Jæger a établi trois nouvelles coupes sous les noms de Mïlleria, Bohadschia et Trepang; mais son genre Mülleria n'est point, comme il le pense, identique avee eelui de Fleming. La seeonde partie de eette dissertation renferme des détails anatomiques. Dans mon Prodrome d'une monographie des Radiaires ou Echinodermes, j’ai dû me borner, pour l'ordre des Holothuries, à énumérer ee qui avait été publié . n'ayant pas alors d'observations qui me fussent propres sur ces animaux.

Le travail le plus étendu qui ait paru depuis long-temps sur les Holothuries est de Brandt; il fait partie de son Prodromus descriptionis animalium. $a b$ H. Mertensio observat. ete., inséré dans le reeueil des Aetes de la séanee publique de l'Aead. des se. de St Pétersbourg, de 1835. L'auteur divise d'abord cette famille en deux grands groupes, les Pedatce et les Apodes; puis il subdivise les Perlatce en Homoiopodes et en Heteropodes; les Ilomoiopodes se subdivisent à leur tour en Dendropnenmones et en Apneumones; les Dendropneumones sont ensuite Peripodes ou Hypopodes, et les Peripodes Pentasticha ou Sporadipodes; puis les Pentasticha sont Adetopneumones avee les genres Cladodactyla $\mathrm{Br}$. (et les sous genres Polyclados Br. Holigoclados Br.), et Dactylota Br. ou Detopneunones avee le genre Aspidochir Br. I.es Sporadipodes ne eomprennent que le genre Sporadipus Br. avee les sous-genres Colpochirota $\mathrm{Br}$. et Acolpos $\mathrm{Br}$. Les Hypopodes qui sont toutes Platygastricae, comprennent les genres Psolus Oken (Jæg.) et Cuvieria Pér. 
el les Apneumones le seul genre Oncinolabes Br. Quant aux Heteropodes, il les subdivise en Stichoporles Br. avec les genres Stichopus Br. (qui renferme les sous-genres Perideris Br. et Gymnochirota Br.), et Diploperideris $\mathrm{Br}$. et en Sporadipodes Br., qui sont ou Aspidochirotce Br. avec les genres Holothuria Lin. (Br.) (et les sous-genres Thtelenota Br., Camarosoma Br., Platysoma Br. et. Microthele Br.) Bohadschia Jxger, Mülleria Jager, Trepang Jeger ou Dendrochirota, avec le genre Cladolabes Br. Le $2^{\mathrm{e}}$ grand groupe, les Apodes, se subdivise en Pneunonophorce avee les gemres Liosoma Br. et Chiridota Esch. et en Apmeumones avee le genre Synapta Eschsch. Cet aperçu systématique est accompagné de la description d'un grand nombre d'espèces, la plupart observées par Mertens.

Brandt déerit ensuite trois espèces nouvelles de Sipunculus et un Echiurus. Dans l'ordre des Echinites enfin il établit les genres suivans: Strongylocentrotus pour des espèces nouvelles, Heterocentrotus pour les espèees dont jai fait mon genre Acrocladia, Colobrocentrotus pour eelles que je range dans mon genre Podophora et Pleyllacantluts pour les Cidaris à grosses baguettes cylindriques et tuberculeuses.

II. de Blainville, dans le $60^{\mathrm{e}}$ vol. du Dict. des sciences naturelles, n'admettait que les einq genres suivans de la famillle des Iolothuries: Cuvieria, Holothuria, Thyoue, Fistularia el Cucumaria; mais dans le supplément à son Manuel d'Actinologie, il les divise en six groupes, dans lesquels il admet une partie des genres de ses prédécesseurs. Ses articles sur les Echinodermes, dans le Dictionnaire des sciences naturelles, et son Manuel d'Actinologie, qui en est un recueil systématique, renferment une foule de renseignemens précieux sur l'ensemble de ees animaux. Enfin les nombreuses notes que M. Dujardin a ajoutées au $3^{\text {e }}$ vol. de la seconde édition des animaux sans vertèbres de Lamarck, ont mis, dans cet ouvrage, la classe des Echinodermes au niveau actuel de la science.

A ma sollicitation M. le Professeur Valentin a bien voulu entreprendre pour eet ouvrage une révision générale de l'anatomie des Echinodermes. Déjà la première monographie de ce travail, qui comprend l'anatomie du genre Echinus, est achevée. Huit planches in-folio, dessinées sous les yeux de M. Valentin, par un artiste très-habile, M. Diclimann, sont déjà lithogra- 
phiées, et le texte s'imprime dans ce moment. Le monde scientifique sait ce que l'on peut attendre du scalpel et de la plume de M. Valentin; je me bornerai donc ì dire ici, pour rendre justice à son désintéressement, que M. Valentin a fait, à ses propres frais, un voyage sur les bords de la Méditerranéc, dans le but spécial de se livrer aux recherches nécessaires pour compléter une pareille entreprise. Des monographies sur l'organisation de ces animaux sont d'autant plus nécessaires maintenant, que depuis la publication des travaux de Tiedemann et de Delle Chiaje, la plupart des recherches qui ont été faites dans ce domaine de la science, concernent des points de délail. L'article Echinodermata, par Sharpey, dans l'Encyclopédic anatomique et physiologique de Todd, contient seul un résumé complet de l'état de nos connaissances sur l'organisation de l'ensemble de ces animaux.

Quelques monographies sont en outre venues étendre ce domaine tout récemment. C'est ainsi que M. Grube a publié une description anatomique très-complète du Sipunculus nudus, accompagnée de planches très-bien faites (Arehives de Müller, 1837, pag. 237). M. Krohn (ibid., 1839, pag. 348) a ajonté quelques détails sur le système nerveux de cet animal, qui avaient échappé à MI. Grube.

M.J. Müller a étudié avec benucoup de détails et d'une manière comparative l'or'ganisation du Pentacrinus Caput Medusae, dont il est parvenu à se procurer un cxemplaire conservé dans l'esprit de vin. La publication de son mémoire sera une précieuse addition à nos connaissances sur l'anatomie des Echinodermes; malheureusement il n'en a encore paru qu'un extrait dans les Bulletins de l'Académic de Berlin, du mois d'avril 1840, tellement concis et si riche en faits nouveaux, qu'il faudrait le reproduire en entier pour en donner une juste idée. Ce qui s'y trouve déjà relaté est d'un haut intérêt, non seulement sous le point de vuc anatomique, mais encore sous le point de vue zoologique. M. J. Mülller abandonnant, dans sa description des partics solides de cet animal, la nomenclature bizarre employée d'abord par Miller, puis par tous ceux qui ont décrit des Crinoïdes depuis lui, propose une terminologie beaucoup plus simple de toute cette charpente si compliquée.

Plusicurs points de détail de l'anatomie des Echinodermes ont également été éclairés. MI. Krohn a publié un mémoire très-intéressant sur le système 
nerveux des Echinides et des Holothuries (Areh. de Müller, I841, p. 1), que M. van Beneden a observé de son eôté clıez les Oursins (Instit. n²73, p. 96.). Ehrenberg a le premier déeouvert les yeux dans les Astéries (Arch. de Müller, 1834, p. 570), et déerit leur connexion avec les uerfs des rayons; ils se voient très-facilement dans beaueoup d'espèces, mème à l'état see. M. Forbes les a cnsuite signalés dans les Oursins (Ilist. of british Starfishes, ete., pag. 152); je les ai vus après lui dans plusicurs espèces. MM. Ehrenberg (Areh. de Müller 1\$34, p. 580), de Sicbold (ibid. 1836, p. 291), Valentin (Repert. 2 vol. p. 26) et J. Müller (Bull. de l'Aead. de Berlin, 1840) ont donué des renscignemens détaillés sur les réseaux caleaires dont sc eompose la charpente solide des Eehinodermes. De mon eòté j’ai eherché à préeiser les lois de la disposition et de l'accroissement de ees plaques et leur analogie dans différentes familles (Mémoires de la Soe. des seienees natur. de Neuehìtel, tom. 1, p. 2-6 et 7-11), contre lesquels M. Philippi a présenté quelques objections (Wiegmann Archiv. 1837, vol. 1, p. 194). M. Duvernoy a communiqué à l'Académic des seienees de Paris ses idées sur la charpente solide de ees animaux (Institut $1837, N^{\circ} 216$, p. 208), auxquels il attribue un squelette intéricur, mais périphérique (Oursins), tandis qu'il enrisage les Astéries comme formées de la réunion de plusieurs individus soudés autour d'une bouche commune. Dans une notiee sur quelques points de l'organisation des Euryales, etc. ( $2^{\mathrm{e}}$ vol. des Mém. de la Soc. des se. nat. de Neuchàtel) j’ai donné des détails eirconstanciés sur la strueture et la disposition des parties solides de ees animaux, et déerit deux espèces eomparativement.

MI. Sars et Forbes ont revu ce que Otto Fr. Müller avait dit sur les Pédicellaires des Eehinodermes et ajouté de nouvelles observations sur ces organisations bizarres (Hist. of brit. Starf. p. 155 ).

Dans mon Prodrome j'avais élevé des doutes contre la part que les tubes membraneux des ambulaeres des oursins prennent à leurs mouvemens, m'appuyant sur quelques observations que j'avais faites sur les eòtes sableuses de la Normandie, et sur l'assertion bien positive d'Aristote qui dit qu'ils se meuvent avec leurs piquans et que l'on distingue mème à l'état des piquans leur habileté à se monvoir $\left({ }^{*}\right)$. Mais M. Forbes a rectifié cette ma-

(*) Lirr. 4. Chap. 5. 
nière de voir en démontrant qu'ils se meuvent également à l'aide des tubes membraneux des ambulaeres, surtout lorsqu'ils vivent sur des surfaces solides. J'en ai vu ehez M. Forbes grimper à l'aide de ees tubes le long des parois vertieales d'un boeal en verre parfaitement lisse. On ne saurait plus révoquer le fait en doute; reste à savoir si ehez les Cidaris à longs piquans ees baguettes ne sont pas le prineipal organe du mouvement, et si ehez les oursins à soies très eourtes ee ne sont pas les tubes ambulaeraires qui remplissent essentiellement eette fonetion. MI. de Siebold mentionne l'existence de fils mieroscopiques dans l'intérieur de ces tentaeules et de leurs ampoules (Areh. de Muller 1836, p. 295).M. Ehrenberg, d'un autre eòté, déerit des monvemens vibratoires dans la peau des piquans de l'Eehinus saxatilis (mouvemens qui sont niés par MI. Forbes) et indique l'existenee d'une cireulation intéricure de eorpuseules semblables aux globules de sang dans tous les tentaeules rétractiles de la face dorsale de l'Asterias violacea : il ajoute en ontre que la surfaee de ees tentacules est toute converte de eils vibratoires (Areh. de Muller 1834, p. 577). M. Volkmann a aussi donné des détails nouveaux sur la eirenlation des Astéries, mais je ne eonnais son travail que par extraits (Areh. de Wiegmann 1838, vol. 2, p. 333.)

L'histoire du développement des Echinodermes s'est enriehie de plusieurs faits importans. M. Sars a fait eonnaittre les ehangemens que subit l'Asterias sanguinolenta Müller pendant les premiers temps de son existenee.

M. Thompson, de Cork, une douzaine d'années après avoir déerit son Pentacrinus europaus, publia un seeond mémoire sur eet animal, dans lequel il l'envisage comme le jeune état du Comatula rosacea. Cette opinion a été pleinement confirmée par MII. Forbes, Thompson de Belfast et Ball, qui ont vu le Pentacrinus europæus vivant se détacher de sa tige et nager librement sous la forme d'une petite Comatule. Les renseignemens que M. Forbes a donnés sur le développement de eette Comatule sont très-eurieux.

M. de Siebold a signalé l'existenee de la vésieule et de la tache germinative ehez toutes les Astéries qu'il a examinées (Areh. de Mïller 1836, p. 29т.). M. J. Müller a également déerit la vésieule et la tache germinative des Comatules et des Ophiures. MI. Peters (Areh. de Miiller 1840, p. 143) annonce que les oursins ont des sexes distincts. Ils ne diffèrent pas, il 
est vrai, extérieurement; les organes sexuels des mâles et ceux des femelles ont la nème apparence; mais chez les femelles des Echinus purpureus et Melo, les glandes sexuelles sont rouges et renferment des oeufs où l'on distinguc le vitellus et la vésicule germinative, tandis que chez les mâles elles sont blanches et remplies de spcrmatozoaires. MM. Valentin et R. Wagner ont également remarqué une scmblable duplicité de sexes chez les Holothuries, et M. Rathke chez les Astéries. MI. J. Müller fait observer en outre qu'il en est probablement de mème des Crinoïdes ou du moins des Comatules (Arch. de Mü̈ller 1840, p. 144.) MII. Valentin et Miescher ont observé des spermatozoaires dans le Spatangus purpureus (Repert. de Valentin 1840, pag. 301 ). M. Milne-Edwards a confirmé ces faits par de notwelles observations.

Dans un mémoire spécial, inséré dans les Archives d'histoire naturelle de Wicgmann (1837, vol. I, p. 241), M. Philippi a décrit deux monstruosités d'Echinus et de Spatangus. MII. II. de Mcyer et Agassiz ont aussi fait connaittre diverses monstruosités par défaut et par excès.

Plusieurs mémoires étendus ont été publiés sur les Echinodermes fossiles, et un bon nombre d'espèces se trouvent déerites dans divers ouvrages généraux de géologic et de paléontologic. Mais ces travaux manquent encore d'ensemble, la plupart des autcurs divergeant d'opinion sur les limites à assigner aux genres. Ceux qui ont été établis depuis Miller dans la famille des Crinoïdes, et qui sont assez nombreux, paraissent surtout avoir besoin d'une révision. M. Alcide d'Orbig̣ny vient d'entreprendre cette tâche diflicile cn publiant son Histoire natnrelle des Crinö̈des vivans et fossiles, travail qui repose sur l'examen critique d'une collection très-considérable. Le grand mérite de cette monographic me paraît consister dans l'arrangement méthodique des genres, qui sont ici distribués par familles naturelles; tandis que jusqu'à présent on les avait placés pèle-mêle à la suite les uns des autres. Déjà trois livraisons de cet intćressant ouvrage ont paru; elles renferment la description des genres Guettarlicrinus, Apiocrinus et Millericrinus de la famille des Apiocrinidées. Il est à regretter seulement que M. d'Orbigny n'ait pas tenu compte des travaux de M. Ch. König qui, dans ses Incones sectiles, a déjà établi depuis longtemps plusieurs genres, ses Ceriocrinus, Pomatocrimus et Symplytocrinus, qui me paraissent en partic faire double emploi avec ceux 
que M. d'Orbigny propose. M. L. de Bucl vient également de publier dans les bulletins de l'Aeadémie de Berlin un travail critique sur les Sphaeronites, groupe peu connu de Crinoïdes, dont la véritable structure avait échappé aux auteurs qui s'en étaient occupés jusqu’à lui. Le mémoire de M. de Buch est accompagné de très-belles figures. Pander, dans ses Beytraege zur Geognosie des russischen Reichs, donne aussi quelques renseignemens sur ces fossiles, aceompagnés de figures. M. Goldfuss, dans un mémoire spécial sur les Crinoïdes fossiles, inséré dans les Acta nova Academ. caesar. Leop. Carol. Nature Curiosortum, T. 19, ete., a fait connaître un nouveau genre sous le nom de Gasterocoma et donné d'excellentes figures et de très-bonnes descriptions d'un nombre assez considérable d'espèces qui ne figuraient point encore dans son grand ouvrage sur les fossiles d'Allemagne. M. le comte de Münster a aussi décrit plusicurs Crinoïdes nouveaux des terrains de transition, dans ses Beytraege zur Petrefactenkunde, parmi lesquels il y a trois genres nouveaux, très-remarquables par la disposition des parties de leur calice qui, déviant du type quinaire, qui est le plus fréquent dans ce groupe d'animaux, présente des nombres inusités dans la elasse des Echinodermes. 11 appelle ees genres: Dichocrinus, Triacrinus et Asterocrinus. Dans le même ouvrage M. le comte de Münster a en outre établi son genre Comaturella et déerit plusieurs espèces nouvelles de genres déjà connus. H. Herm. de Meyer a aussi établi deux genres nouveaux de Crinö̈des dans le Museum Sentenbergianum de 1837, sous les noms d'Isocrinus et de Chelocrinus. M. Bronn a décrit le genre Ctenocrinus dans le Jahrbuch für Mineral. u. Petref. de 1840; M. Steininger le genre Halocrinites dans les volumes 8 et 9 dı Bulletin de la société géologique de France, et dans le premier volume des Mémoires de cette Société. MI. Quenstedt (Wiegmann, Archiv. 1835) et Bronn (Jahrb. für Min. 1837) ont déerit de nouvelles espèces d'Encrinus du Nuschelkalk; ensorte que l'on connait maintenant trois espèces distinctes de ce genre remarquable.

M. Philipps, dans la seconde partie de sa géologie du Yorkshire, a aussi établi deux genres de Crinoïdes provenant des terrains houillers et qu'il désigne sous les noms d'Euryocrinus et de Gilbertsocrinus, et décrit plusicurs espèces nouvelles de genres déjà connus. Dans le grand ouvrage sur le sys- 
tème silurien de M. Murchison, M. Philipps a en outre décrit un grand nombre de Crinoïdes nouveaux, provenant des terrains fossiliferes les plus anciens, parmi lesquels se trouvent encore plusicurs genres nouveaux, qu'il nomme Marsupiocrinites, Iypanthocrinites et Dimerocrinites. Ic genre Ischadites de M. König (Murehison Silurian system pl. 26, fig. 11) appartient aussi aux Crinoïdes; M. de Buch l'cnvisage comme identique avec le $S$ phacronites Aurantium. Sous le nom de Scyphocrinites, M. Zcnker a décrit une forme particulière de ces animaux, dans son Naturgeschichte der Urwelt. Enfin M. de Ilagenow a fait connaitre un genre nouveau voisin des Solanocrinus, qu'il nomme Kertha, et plusicurs espèces nouvelles de Crinoïdes et d'Echinites.

Je mentionnerai encore les genres Glenotremites de Goldfuss et Gany-meda de Gray, quoique j'aie acquis la certitude qu'ils ont été établis d'après des axes de Crinoïdes de la famille des Comatules et qu'ils doivent par conséquent ètre supprimés. Quant aux genres Caryocrinites de Say et Trianisites de Rafinesque, ils ne me sont connus que par des citations nominales. Le genre Marsupites de M. Mantell (Marsupinum König) est déjà trop connu pour ètre encore mentionné parmi les nouvelles acquisitions de la palćontologie.

II. Römer dans son ouvrage sur les fossiles du terrain jurassique du nord de l'Allemagne ct dans son second ouvrage sur les fossiles du terrain crétacé des mèmes contrćes, décrit un nombre asscz considérable d'espèces nouvelles d'Echinodermes, de l'ordre des Echinites et des Crinö̈des. MM. Koch et Dunker ont aussi décrit plusicurs Echinites nouvcaux dans leur supplément au premier ouvrage, et M. Hinsinger tous ceux des terrains de la Suède, dans son Lethaea suecica, accompagnés de très-bonnes figures.

La famille des Crinoïdes mérite d'autant plus de fixer l'attention des naturalistes, qu'clle donncra la clef du dévcloppcment de toutc la classe des Echinodermes à raison des formes variées qu'elle renferme; ce sont en quelque sorte les précurscurs des Comatules, des Astéries et des Echinites, dont ils affectent mème quelquefois déjà les formes. A cet égard, le plus curicux de tous les genres est celui que je décrirai sous le nom d'Echinocrinus et qui a tout-à-fait la forme sphérö̈dale des oursins avec des ambulacres ćtroits et de longs piquans épineux comme certains Cidaris. L'analogic avec ces der- 
niers est si frappante, que des fragmens détachés de ce gemre, qui est circonscrit dans les terrains de transition et dans les tcrains lıouillers, ont réellemont déjà été décrits comme des Cidaris; tels sont entre autres lc Cidaris Urii de Fleming, et lcs Cidarites Nerei, Protei et priscus du Comte de Münster ct quelqucs espèces inéditcs.

Les Astéries et les Ophiures fossiles sont cncore très-peu connues; on n'en a mèmc signalé qu'un petit nombre, parmi lesquellcs je citcrai comme nouvelles eelles que M. Williamson a décritcs dans le Magasin d'histoire natırelle de Loudon pour 1836 ct eclles de la collcction de Lord Enniskillen et de Sir Philippe Egerton déeritcs par MI. Broderip dansle $5{ }^{\mathrm{e}}$ volume des Transaetions de la société géologique de Londres, sans comptcr celles qu'ont déerites M. le Comte de Münster, M. Goldfuss, M. DesMoulins et M. Agassiz. Mais le nombrc en cst assez considćrable, et je mc plais à annoncer sur ce sujet 1 th travail spécial de M. Dixon, qui doit embrasser toutes les espèces d'Angletcr'e.

Dans l'atlas de son voyage en Crimée, ctc., M. Frédćric Dubois de Montpéreux a préludé à la publieation des magnifiques collections de fossiles qu'il a rapportées de ees contrées, par l'émission d'une grande planehe d'Echinites très-intéressans. Dans le $4^{\mathrm{e}}$ vol. de la $2^{\mathrm{e}}$ série dcs mémoires de l'Acadćmic des sciences de Turin, M. le docteur Sismonda a publié une monographie complètc des Echinites fossiles du Piémont, dans laquclle il décrit un genre nouveau sous le nom d'Anaster, ct un grand nombre d'espèccs nouvcllcs accompagnées de bonnes figures. M. Grateloup a aussi publié un mémoirc spćcial sur les oursins fossiles qui sc rencontrent dans les terrains calcaires des environs de Dax (Actes de la soc. lin. de Bordcaux, tom. 8, accompagnés de nombreuscs figurcs.) M. Lcymcrie a décrit plusieurs cspèces intércssantes de Diadèmes dans le $3^{\mathrm{e}}$ vol. des mémoircs de la Soe. géologique de Franee. Dans İ mème recueil, tom. 2, M. Dujardin a également décrit un oursin nouveau de la craie. M. DeFrance a donnć, dans lc Dictionnaire des sciences naturelles de Lcvrault, de nombreux articlcs sur les divers genres d'Echinodermes fossiles, qui font eonnaîtrc l'état de la sciencc sur ce sujct à l'époque de la publication de cc recucil encyclopédique. Quoiqu'il embrassc l'ensemblc des fossiles, lc 
grand onvrage de Goldfuss sur les pétrifications d'Allemagne sera encore pendant longtemps l'ouvrage capital pour l'étude des Echinodermes fossiles.

Moi-même j'ai fait connaitre les Echinites fossiles de la Suisse dans deux mémoires insérés dans les Nouveaux mémoires de la société helvétique des sciences uaturelles, tom. 2 et 4; mes descriptions sont aceompagnées de figures, qui représentent toutes les espèees sous plusieurs faces. Dans ee mémoire, j’aićtabli les genres nouveaux suivans: Hyboclypus, Py gorhyuchus, Conoclypus, Pygurns, Hemicidaris, Acrocidaris, Acrosalenia, Tetragranma, Pedina, et Clypticus. Précédemment, j’avais déjà publić à part une notice sur les espèces du terrain néocomien, insérée dans le $1^{\text {er }}$ rol. des Mémoires de la soc. des sc. luat. de Nenchâtel. A la suite de mon Catalogue systématique des moules des Oursins fossiles du Musée de Neuchàtel*, j'ai publié les caractères diagnostiques des genres nouveaux on encore peu connus que j’ai établis jusqu’à ee jonc parmi les Echinites; les genres suivans s'y trouvent earactérisés pour la première fois: Toxaster Ag., Brissopsis Ag. , Nucleopysus Ag., Globator Ag., Caratomus Ag., Amblypygus Ag., Heliophora ${ }^{* *}$ Ag., Ampliope Ag., Encope Ag., Echinopsis Ag., Cyphosoma Ag. Acropeltis, Colopleurus, Codiopsis, Podophora, Acrocladia. L'émission de plusieurs collections de ees moules a donné à l'eusemble de mon travail sur les Echinites fossiles une première publicité qui eontribuera, je l'espère, à avaneer nos comnaissances de ces fossiles et à faciliter l'identification d'exemplaires appartenant à des espèces qui ne sont encore ni figurées ni mème décrites. J'ai mis par là en circulation des représentations aussi fidèles qu'il est possible de les obtenir, d'un grand nombre d'échantillons uniques ou dans un état parfait de conservation.

Depuis la publication de ma première monographie des Echinodermes, en 1838 , les matériaux dont je dispose se sont considérablement augmentés. Une quantité d'espèces nouvelles appartenant à tous les ordres de la classe des Echinodermes mont été eonfiées par les nombreux amis de la science qui ont eompris que réunir en un même faisceau le plus de données possibles, c’est le plus sùr moyen de la servir avantageusement. Je me fais par conséquent

\footnotetext{
*) Catalogus System. Ectyporum Echinodermatum fossilium MIIsei neocomensis. $\mathbf{1}^{3} \mathbf{1 8} \mathbf{4 0 .}$

(**) Ce genre a repris plus tard le nom de Rolula que lui arait donné Kilein, il y a dẹja plus d'un siécle, et dont personne n’a teun compte. 
un devoir et un plaisir de consigner ici les noms de tous ceux qui se sont acquis de nouvcaux droits à ma reconnaissance, soit en me communiquant des originaux, soit en me fournissant des renseignemens sur la répartition ou le gisement des espèces.

II. le professeur MLérian de Bâle m'a confié tous les originaux de la belle collection du muséc de Bâle, dans laquelle j’ai retrouvé des originaux de plusieurs espèces figurées et décrites dans le grand ouvrage de Knorr. M. André Deluc que j'eus l'avantage de voir à Genève en 1839, a bien voulu me permettre d'emporter toutes les espèces nouvelles contenues dans sa célèbre collection, l'une des plus belles qui existent. ML. Valeneiennes m'a donné le même témoignage de bienveillance, en mettant à ma disposition un grand nombre d'espèces fort rares du Muséum de Paris. MIM. DesHayes et Michelin ont continué de me fairc part avec un génércux empressement de toutes les espèces nouvelles dont se sont cnriehies leurs collections. J'ai reçu en communication de MI. Elic de Beaumont plusieurs espèces fort intéressantes de la craie et des terrains pisolitiques de Vérone. M. le professeur Pictet de la Rive m'a communiqué plusieurs espèces nouvelles du musée de Genève. M. Walchner, directeur de l'Ecole polytechnique de Carlsruhc, m'a confié de fort beaux oursins recucillis par lui dans la chaine du Sentis et en Allemagne. II. Alex. Brongniart a bien voulu m'adresser un second envoi d'oursins provenant des terrains crétacés de France. M. le comte de Mandelslohe et II. Røemer m'ont confié chacun leurs eollections pour me faciliter la comparaison des espèces du Jura Wurtembergeois et du Nord de l'Allemagne avec cclles du Jura suisse. M. Rechsteiner de Tcuffen, canton d'Appenzell, m'a cnvoyé plusicurs espèces très-précieuses recueillics par lui dans le néocomien et dans la craic marneuse des Alpes de St-Gall. M. Chavannes de Lausanne m'a confié plusieurs espèces fort intéressantes du musée de Lausanne. Lcs oursins de la collcetion de feu M. Renaud-Comtc, contenant des espèces fort intéressantes des terrains jurassiques et néocomicns, m’ont été communiqués au nom de la famille du défunt, par M. Nicolet, qui y a joint plusieurs espèces nouvelles trouvécs par lui dans la molasse ct dans le néocomien du canton de Neuehâtel et du département du Doubs. M. le doctcur Mayor de Genève et $\mathrm{M}$. Alphonse Favre-Bertrand m'ont remis de nombreux oursins de la 
montagne des Fis, du Saxomnet, du Reposoir, du Salève et de la perte du Rhòne, qui serviront, je l'espère, à fixer d'une manic̀re de plus en plus préeise Jes rapports qui existent entre les terrains fossilifères de ees intéressantes loealités et les terrains erétacés de France et de Suisse. M. Strohmeyer, curé à Obergosschen, dans le eanton de Soleure, m'a envoyé plusieurs espèccs fort rares de l'oolite du Jura sole urois et bernois. MI. Voltz, dont la science déplorera longtcmps la perte, m'a envoyé en eommunieation, dans le eourant de l'ćté 1839 , les Eehinodermes fossiles de l'Eeole des mines de Paris, parmi lesqnels sc trouvent des espèees fort remarquables d'ćtoiles de mer. M. DesMoulins m'a confié l'original de l'une de ses espèees nouvelles de Seutelles, aeeompagné de nouveaux renseignemens sur lcs Seutelles. M. Leymerie m'a adressé les originaux de tontes les espèees de Diadèmes décrites et figurćes dans son mémoire sur lc terrain seeondaire des environs de Lyon. M. J. Müllcr de Berlin m'a envoyé un nombre eonsidérable de beaux cxemplaires d'oursins des tcrrains jurassiques et erétaeés. Je dois aussi à MM. Alex. et Max Braun la communication de plusieurs espèces jurassiques et crétacécs, et à M. de Bueh la connaissance d'une espèee nouvelle de Dysaster. Enfin MII. Gressly, Coulon père et fils, Parandier et Escher de la Linth ont continué de me faire part dc toutcs lcs cspèees nouvclles qu'ils ont reeueillies dans ees dcrnic̀res années.

Mais e'est surtout dans mon dernier voyagc en Anglcterre que j’ai reeueilli le plus de matériaux pour mon travail. M. le marquis de Northampton daigna me confier lcs exemplaires les plus préeicux d'un grand nombre d'espèees jurassiques et erétacées de la Grande Bretagnc.

Je dois à l'obligeanee de MM. Forbes, Thompson de Belfast et Ball de Dublin une eolleetion à peu près complète des Eehinodermes vivans observés jusqu'à ec jour sur les eôtes des Iles britanniques. Ces matériaux ont pour moi une valeur inappréeiable, puisqu'ils me serviront à fixer les limites de l'identité des espèees du nord de l'Europe avec celles de la Méditcrranée. M. le $D^{r}$ Flcming m'a rendu un serviee non moins grand en me communiquant les exemplaires origginaux de plusieurs espèces qu'il a le premier déerites dans son histoire naturelle des animaux de la Grande Bretagne. M. Stokes a également mis à ma disposition sa magnifique eollection d'oursins et d'é- 
toiles de mer vivans et de Crinoïdes fossiles. M. Wood m'a communiqué toutes les espèces du erag qui se trouvent dans sa belle collection. MI. Banbury, secrétaire de la société géologique de Londres, a mis à ma disposition une foule d'espèces de Dover et de Warminster, et M. Bowerbank toute une série provenant du crag, de l'argile de Londres et de la craie. M. Woodward et M. Dixon m'ont confié de fort belles espèces du crag et de la craic. Je dois aussi à l'obligeante amitié de Lord Enniskillen, de Sir Philip Egerton, de M. Lyell et de M. Hibbert la communication d'une foule d'espèces provenant de tous les terrains fossilifères. M. Austin m'a communiqué une espèce nouvelle d'un genre fort remarquable, que j'ai appelé Echinocrinus. J'ai en outre puisé de précieux renseignements sur les rapports géologiques des espèces et des genres, dans la riche collection de la société géologique. A Edimbourg, MI. le professeur Jameson, de son còté, m'a offert toutes les facilités désirables pour étudier la riche eollection du Musée de cette ville; les Ophiures surtout y sont d'une rare beauté. MII. Drummond et Patterson de Belfast m'ont communiqué plusieurs espèces d'Oursins et de Crinoïdes. J'ai les mèmes obligations à M. Portlock et à M. Goodsir qui posséde une fort belle série d'Holothuries. Enfin M. Gray a mis à ma disposition tous les matériaux du musée britannique, qui est surtout riche en Astéries, comme le prouve le travail remarquable de ce savant zoologiste sur cette famille, travail qui repose essentiellement sur l'examen des espèces dı Musée britannique. MI. Gray ayant donné son assentiment à mon projet de faire dessiner toutes les espèces nouvelles qu'il a décrites, j’ai la certitude de pouvoir rendre eette partie de mon ouvrage aussi complète qu'il est possible maintenant, d'autant plus que M. Valenciennes un'a donné la même assurance à l'égard des espèces du Musée de Paris, et M. J. Muller pour celles qui font la base de son travail.

Fort du concours de tant de naturalistes distingués, j'espère rendre mes Monographics toujours plus dignes de l'accueil bienveillant qu'elles ont reçu.

Neuchıatel, en juillet 1841 .

$\mathrm{L}^{5} \Lambda_{\mathrm{gassiz}}$ 


\section{ÉCHINITES.}

PAIIILLE DES CLYPÉASTROIDES:

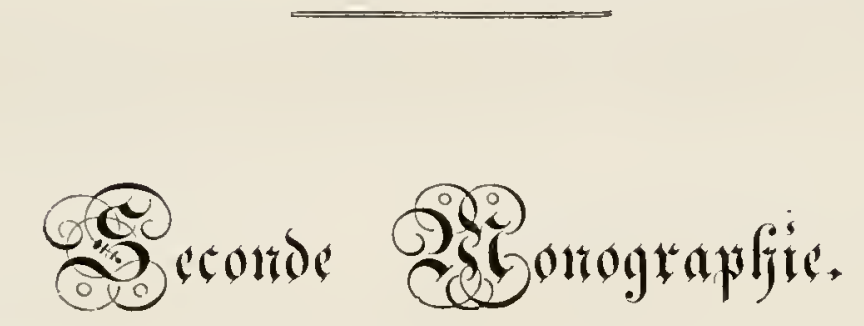

DES SCUTELLES.

1841. 


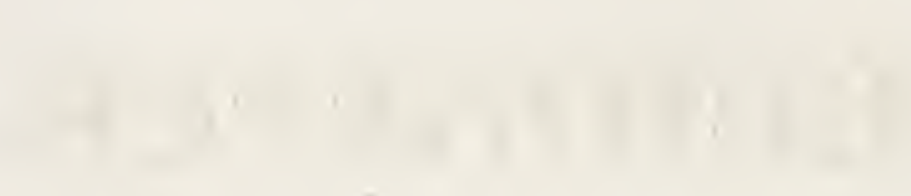




\section{PRÉ I CE.}

Partant du point de vue que les organismes fossiles sont intimement liés aux organismes vivaus, et que pour arriver à l’intelligence complète des rapports qui cxistent entre les divers membres d'une famille d'animaux, il faut en poursuivre le développement dans les différentes périodes de l'histoire de la terre, j’ai réuni dans cette monographie les espèces fossilcs et vivantes du groupe des Scutelles, dont j'ai pu me procurer des exemplaires, et j'ai lieu d'espérer que pour les géologues, commc pour les zoologistes, l'étude des modifications que ce type remarquable a subies depuis sa premièrc apparition à la surface de la terre jusqu'à nos jours, ne sera point la partie la moins inléressante de ce mémoire.

Malgré l'intérêt tout particulier qui semble se rattacher aux Scutelles, à cause de leur forme bizarre ct de leur grande taille, ces animaux n'en sont pas moins fort rares; ce qui se comprend en quelque sorte, lorsqu'on songe que les espèces vivantes habitent pour la plupart les mers tropicales, d'où ellcs n'ont été rapportées que par quelques uaturalistes, et que les fossiles sont restreintes pour la plupart aux terrains tertiaires. Aussi n’aurais-je pas pu songer à souncttre cette tribu à un travail monographique, si je n'avais eu le bonheur de rencontrer chez tous ceux de mes collègues qui sont possesscurs ou directeurs de collections, le plus généreux empressement à scconder mon cntreprise, soit en mc confiant les originaux dont ils disposent, soit en me permeltant de les faire dessiner. Les amis de la science ne s'étonneneront pas de m'entendre nommer encore ici, comme ayant droit à ma plus entière reconnaissance, les noms de 1111. Valenciennes, Gray, Stokes, Ilichelin, DeslIayes. Je dois aussi des remercicmens tout particuliers à 
M. Alex. Brongniart, à M. le Doct. Mayor de Genève, à M. Pictet de la Rive, à M. Alcide d'Orbignny, et à M. Mérian de Bâle.

Dans la synonymie des espèces, je n'ai mentionné que ceux des auteurs qui ont étudié les Scutclles sur des originaux : les principaux sont Klein, Leske, Lamarck, DeBlainville, Gray et DesMoulins. Les ouvrages de ces auteurs, auxquels se rapporte ma synonymie, sont: de Lamarck, la seconde édition de son Histoire naturelle des animanx sans vertèbres; de Charles DesMoulins ses Etudes sur les Echinides, extraites des Actes de la Société Linnéenne de Bordealtx, et plus particulièremcnt son troisic̀me mémoire intitulć Tableaux synonymiques des Echinides, Tom. IX, $2^{\mathrm{e}}$ livr. des Actes ci-dessus; de M. DeBlainville, son article Zoophytes, dans le Dictionnaire des sciences naturelles de Lcvrault, et son article $\boldsymbol{S}$ cutelle dans le mêmc dictionnaire; de M. Gray, son mémoire extrait des Annals of Plilosophy et ayant pour titre An Attempt to divide the Echinida or Sea Eggs into natural Families; enfin mon Prodrome d'une Monographie des Radiaires inséré dans les Mémoires de la société des sciences naturelles de Neuchâtel, Tom. I.

J'ai donné des figures coloriécs de toutes les espc̀ces vivantes dont les teintes m'ont paru n'être que peu ou point altérées. Malhcurcusement le nombre n'en est pas considérable. 


\section{IVTRODLLCTIOI.}

\section{DU GROUPE DES SCUTELLES EN GENERAL.}

Le groupe des Scutelles dont il est traité dans cette monographie, fait partie de la division des Echinites que jai désignée dans mon Prodrome sous le nom de Clypéaströ̈des et dont le caractère est d'avoir la bouche centrale, tandis que l'anus est subcentral, tantôt supère, tantôt infëre, et tantôt marginal. A côtẻ de ces caractères généraux, les genres que je range dans le groupe des Scutelles se distinguent de tons les autres Clypéastroïdes par une physionomic particulière, qui résulte de la combinaison de plnsieurs caractères constans, dont le plus remarquable est l'aplatissement extraordinaire du test. Ce dernier caractère suffirait à lui seul pour distinguer les Scutelles de tous les autres types de la famille des Clypéastroïdes. Mais cette forme aplatie se retrourant dans tontes les espèces de ce groupe, quelle que soit d'ailleurs leur structure et leur dimension, je ne pense pas qu'on doive l'envisager comme un simple caractère générique, ainsi que l'ont fait Lamarck et Des.Ioulins. Je la considère au contraire comme un caractère distinctif de tout le groupe, de même que j’ai envisağẻ la forme écussonnée et saillante de l'appareil oviducal dans les Salénies, comme un des caractères significatifs de toute cette tribu *.

Les Scutelles ont de tout temps fixé l'attention des naturalistes. Nous les trouvons figurées et mentionnées dans les plus anciens ouvrages d'histoire naturelle. Les auteurs systématiques du commencement du siècle passé les ont même déjả divisées en plusieurs genres, qui, qnoique circonscrits d’une manière très-naturelle, n’ont cependant pas été admis par les modernes. Klein 
dont l'ouvrage parut en 173\%" divise les Scutelles en quatre genres qu'il désigne sous les noms de Mellita, Laganum, Rotula et Arachnö̈lcs. Avant Klein, Breynius "* avait déjả décrit et figuré plusieurs espèces de Scutelles sous le nom d'Echinodiscus. Rumphius *** leur donna des noms hollandais, qui rappellent d'une manière plus ou moins précise la forme extérieure de ces animaux. Van Phelsum "*** remplaça le genre Rotula de Klein par son genre Echinotrochus, mais en lui associant à tort le Mellita hexapora. Il créa en outre le genre Echinoglycus qui correspond à peu près au genre Mellita de Kílein, c'est à dire qu'il comprend des Lobophores, des Encopes et des vraies Mellites. Son genre Echinarachius correspond aux Arachnö̈des de Kilein; mais comme il renferme deux types distinets, j’ai conservé pour l'un le nom de Klein et pour l'autre celui de van Phelsum. Enfin c'est a van Phelsum que remonte le genre Echinocyamus 'jui comprend a la fois les Fibulaires et les vrais Echinocyames. Davila *...* divise les Scutelles en deux genres, Placenta et Rotula, le premier embrassant les genres Mellita, Laganum et Arachnoïdes de Klein; le second correspondant à son genre Rotula.

Leske, le commentateur de KKlein, réunit toutes les Scutelles, à l'exception des Echinocyames, en un seul genre, sous le nom d'Echinodiscus que lui avait donné Breynius. Linné, selon son habitude de ne tenir aucun compte des travaux de ses devanciers, supprima tous ces genres en les réunissant à son genre Echinus dans lequel il comprenait tous les Echinites. Lamarck sentit le besoin de nouvelles coupes dans les Echinites et établit son genre Scutella qui a été admis par Cuvier et par la plupart des auteurs modernes, mais qui en délinitive n’est autre chose que le genre Echinodiscus de Breynius et deLeske, car il comprend des espèces d'à peu près tous les types du groupe des Scutelles. Dans ces derniers temps II. Gray a de nouveau réintégrẻ les genre Lagana, Echinodiscus et Echinocyamus, que II. De Blainville a également maintenus, en conservant toutefois le nom d'Echinodiscus pour le genre Echinarachuius, et celui de Scutella pour les vraies Scutelles, que Gray laisse dans le genre Echinodiscus avec les Mellites et les Rotules. MI. Chr. Des Moulins, dans son travail sur les Echinites, n’a point admis cette réintégration, mais s'en est tenu aux genres Scutelle et Fibulaire de Lamarck.

(") J. T. Klein Naturalis dispositio Echinodermatum, in- $\iota^{2}$. Edit. anct. a Nath. God. Leske; Lipsiæ 1778.

$\left.{ }^{\star \star \star}\right)$ J. P. Erejnii Dissertatio plysica de Polythalamis, Gedani 1732, in-4*.

$\left(^{* \star \star}\right)$ G. E. Rumph. d'Amboinscle Rariteitkammer. Amsterdam, 1705 Fol.

$\left(^{* \star \star *}\right)$ Murc, van Phelsum Brief aan Cornelius Nozemann over de Gewelvslekken of Zee-egelen. Rotterdau, 177 .

("***) Davila Catalogue systématique, etc. Paris, 1767, in. $8^{\circ}$. 


\section{Division des Scutelles.}

Ces nombreuses oscillations dans la délinitation des genres de ee groupe sont une preure de la difficulté qu’il y a à bien saisir leurs caractères généraux, lorsquon n’a pour se guider que la forme el la structure extérieure du test. Un coup d'eil jeté sur les planches qui accompagnent ce mémoire suffit, il est vrai, pour faire sentir que les diverses espèces qui y sont figurées, quoique toutes construites sur le même plan, n'en forment pas moins plusicurs types très-distincts. Qu'y a-t-il de commun entre une Encope et un Echinocyame, entre une Rotule et une vraic Scutelle? Mais ces différences en apparence si tranchées s'effacent en quelque sorte, à mesure que l'on pénètre dans les détails des espèces, et les types les plus dissemblables se lient par des espèces intermédiaires, qui en rendent la délimitation des plus difficiles. On comprend dès-lors, que des auteurs, d'ailleurs fort exacts, aient élé conduits à établir des coupes très-peu naturelles, pour avoir accordé une valeur trop exclusive à certains caractères extérieurs. D’autres, plus circonspects, ont préféré réunir toutes les Scutelles en un seul genre, tels que Leslie, Lamarck et Cl. Des Noulins. Pour arriver à une appréciation plus rigoureuse de la valeur des divers caractères que l'on avait envisagés comme génériques et des limites dans lesquelles ils peuveut varier, il importait d'ètudier leurs rapports avec l'organisation entière de l'animal et surtuut avec les principaux organes intérieurs, ce qui me fut d'autant plus facile que je possédais des doubles d'espèces appartenant à la plupart des types. Celte étude m'ayant fait connaître des différences d'organisation profondes dans la structure intérieure d'espèces dont l'apparence exlérieure est très-semblable, j’ai dì réintẻgrer en partie les genres des auteurs anciens et en élablir en outre plusieurs nouveaux; ensorte que le groupe des Scutelles, tel qu'il est circonscrit dans celte monographic, comple treize genres qui sont les suivans: Rotula Kl. (Echinotrochus van Phels). - Runa Ag. - Mellita Kil. (Ag.) (Echinoglycus van Phels). - Encope Ag. - Lobophora Ag. - Amphiope Ag. - Scutclla Lam. (Ag.) (Echinodiscus Breyn., Gray). - Echina-

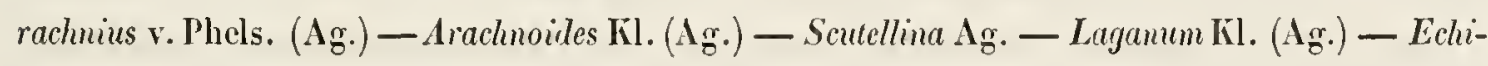
nocyamus van Phels. (Fibularia Lam.) - Moulinia Ag. - Chacun de ces genres se distingue par un ensemble de caractères constans et précis, tirés essentiellement de la structure de lintérieur combinée arec les principaux traits de la surface du test. Pour ne laisser aucun doute sur la valeur de ces caractères, jai eu soin de donner des figures comparatives de lintérieur du test, dans les genres les plus ressemblans; el j’ai lieu d'espérer que, sous ce rapport au moins, les 
coupes génériques que je propose seront pleinement justifiées, quelque nombreuses qu'elles puissent paraitre au premier abord. La forme générale, la disposition le l'apparcil oviducal et de l'éloile ambulacraire, la position de l'anus, la structure de l'appareil masticatoire et de la cavilé intẻrieure du test, sont autant de caractères dont les combinaisons variées donnent à chaque genre sa physiononie particulière, ct qui devront, par conséquent, servir de guides dans l'étude des genres et des cspèces.

J'ai préféré, en général, conserver les noms des auteurs anciens toutes les fois que jai pu le faire sans craindre de donner lieu à des confusions, que d'introduire des noms nouveaux, comme ce n'est que trop lhabitude des modernes, qui se croient en droit de ne tenir aucun compte des travaux de leurs devanciers, lorsqu'ils ne cadrent pas avec leur systc̀me.

Klein déjả avait fort bien saisi les caractères génériques des Scutelles, quoiqu'il n'en connùt qu'un petit nombre d'espèces, et la manière dont il les classe prouve qu il avait une connaissance assez exacte de l'organisation intime de ces animaux. La séparation qu’il établit entre les espèces à bords entiers qu'il désigne sous le nom de Lagamum, et celles dont le test est entamé par les lunules ou des vacuoles, ne repose pas seulement sur la forme extérieure, elle est encore justifiée par la nature des organes intérieurs qui présentent une disposition fort diffẻrente, ainsi que nous le verrons plus bas. Son genre Rolula, circonscrit d'une manière très-précise, comprend les espèces dont le bord postérieur est orné de digitations. Aussi me suis-je fait un devoir de le rẻintëgrer dans le même sens que l'avait défini son auteur. Son genre Mellita est moins précis ; il réunit sous ce nom toutes les Scutellcs à bords sinueux ayant deux ou plusieurs ouvertures, ¿́est-ä-dire des espèces appartenant à des types diffërens. En circonscrivant d'une manière plus naturelle ces différens genres, jai conservé le nom de Mcllita aux espèces pourvues d'au moins quatre vacuoles ambulacraires trés-étroites, d'une lunule scmblable dans l'aire interambulacrairc postéricure, mais dont l'appareil oviducal n'a que quatre trous oviducaux. J'ai en outre élabli trois genres nouveaux parmi les espèces dont le test est entamé : ce sont lcs genres Encope, Lobophora et Amphiope. Le premier comprend les grandes espèces du type du Scutella emarginata ayant cinq vacuoles ambulacraircs et une grande lune dans l'aire interambulacraire postérieure. Le second est composé d'espèces ayant deux vacuoles allongẻes dans les aires ambulacraires postérieures, et un appareil masticatoire d'une structure particulière. Les Ampliopes enfin ont, au lieu de vacuoles allongées, deux ouvertures circulaires dans les aires ambulacraires posléricures.

Parmi les espèces dont le test est entier, j'ai conservé le nom de Scutelles à celles qui ont l'a- 
uus à la face inférieure, en prenant pour type du geure le Scutelle subrotundu de Lamarck. Jai divise les Echinarachnius en trois genres, en conservant le nom d'Echinarachius proprement dit aux espèces du type de l'E. parma; j’en ai éloigné les petites espèces, telle que l'E. lenticularis et l'E. mummularius des auteurs, dont j'ai fait un nouveau genre sous le nom de Scutellina. Enfin , j'en ai aussi éloigné l'espèce connue sous l'ancien nom d'E. placenta que j'envisage comme le type d'un genre a part, auquel jai conservẻ le nom d'Arachoidcs. J'ai restreint le genre Lagamum aux especes de forme allongée et subpentagonale et à bords entiers. J'ai conservé le nom d'Echinocyamus de van Phelsum aux espèces it test pyriforme ou subpentagonal, ayant les ambulacres légèrement arrondis et les quatre pores génitaux très-rapprochés. J'en ai complètement ċloigné les petites espèces globulaires, que Lamarck avait réunies à tort aux Echinocyames et que je crois devoir être associées au groupe des Galérites à raison de la structure particulière de l'intèrieur du test. Le genre Runa qui ne compte encore que deux espèces, remarquables par les proportions des aires ambulacraires comparíes aux aires interambulacraires, et le genre Moulinia qui se distingue par la structure de la surface de son test, sont tous deux nouveaux. Le premier de ces deux genres établit un passage entre les Scutelles à bords entiers et celles qui ont des entailles.

Noublions cependant pas de faire remarquer qu'il existe dans le groupe des Scutelles, tel qu’il est ici limité, deux grands types assez tranchés : l’un qui comprend les genres à test circulaire ou elliptique, tels que les Rotules, les Mellites, les Encopes, les Lobophores, les Anphiopes, les vraies Scutelles, les Echinarachnius et les Arachnoïdes ; et l'autre qui embrasse les genres à test pentagonal ou anguleux, c'est-à-dire, les Laganes et les Echinocyames. Ces derniers semblent au premier abord bien plus voisins des Clypéastres que des Scutelles, d'autant plus que leurs tubereules et leurs soies ne présentent pas cette forme et cet arrangement variés qui caractérisent tous les genres circulaires; la forme de la bouche rappelle aussi davantage celle des Clypéastres, surtout dans les Echinocyames. Mais d'un autre côté, il existe des passages incontestables d'un type à l'autre, dans les deux genres Arachnoides et Echinarachnius, qui ont la forme circulaire des Scutelles et l'aspect uniforme des Laganes. Ajoutons à cela que l'intérieur du test est construit de la même manière que dans les Scutelles; c'est la même disposition de lintestin, la même structure celluleuse des bords du test et à peu de chose près la mème structure de l'appareil masticatoire. Néanmoins je me suis demandé plusieurs fois, s’il ne conviendrait pas de faire des Laganes un petit groupe à part, intermédiaire entre les Scutelles et les Clypéastres. Peut-être cela deviendra-t-il nécessaire, lorsqu'on aura fait une étude comparative des parties 
molles de tous ces genres. En attendant, il m'a semblé que les ressemblances l'emportaient sur les différences, au moins en ce qui concerne les parties solides et particulièrement la structure de la carité intérieure; en conséquence, j’ai réuni les Laganes au groupe des Scutelles. M. Gray va plus loin encore; il joint mème les vrais Clypéastres et les Cassidules au groupe des Scutelles; mais ces rapprochemens sont exagérés, surtout ce dernier.

\section{De la forme générale.}

La forme aplatie est, comme nous l'avons dit plus haut, un caractère commun à tout le groupe des Scutelles. A part quelques petites espices d'Echinocyames, la hauteur égale á peu prés le sixième de la longueur dans la plupart des genres. La face supérieure est en général Jombée, à l'exception de quelques espèces de Laganes et d'Echinocyames dont les bords sont trèsrenflés. Le plus grand renflement coïncide ordinairement arec le sommet apicial, excepté dans les Encopes et les Mellites, oủ il est à la région postérieure. La face inférieure est plate. Le pourtour du test est tantôt circulaire ou suborbículaire ( dans les Rotules, les Mellites, les rraies Scutelles, les Echinarachnius), tantôt allongé ou subpentagonal (dans les Encopes, les Laganes les Echinodiscus, etc). Dans les espèces à test subcirculaire, c’est ordinairement le diamètre lon gitudinal qui l'emporte sur le diamètre transversal; quelquefois aussi c'est le contraire qui a lieu, témoíns les vraies Scutelles et plusieurs espèces de Mellites. Souvent le bord postérieur est plus ou moins tronqué, tandis que le bord antẻrieur est rostré. C'est en particulier le cas des Laganes et des Echinocyames. Plusieurs genres se font en outre remarquer par des entailles, des lunules et des vacuoles de forme diverse; il y en a dont le pourtour n'est pour ainsi dire composé que de digitations, résultant des découpures qui entament le disque, par exemple dans les Rotules. Ordinairement ces vacuoles affectent de préférence les aires ambulacraires, et même daus les genres dont le test n'offre aucune solution de continuité, on remarque souvent en face des ambulacres, un sinus ou une échancrure, qui semblent indiquer un moindre développement dans ces parties du test que dans les aires interambulacraires. Il n'y a que les Rotules qui fassent exception à cette rẻgle, en ce que les vacuoles sont plus considérables dans les aires interambulacraires que dans les aires ambulacraires. 


\section{De Ia structure du test.}

Le test des Scutelles se divise, comme celui de tous les Echinides, en dix aires, dont cinq ambulacraires et cing interambulacraires. Chacune de ces aires est composée de deux sèries de plaques principales qui sont souvent si intimement soudées qu'on a de la peine à reconnaitre les sutures qui les unissent, surtout dans les vieux individus. Dans les jeunes, l'articulation est plus distincte. Le nombre normal des plaques principales est par conséquent de vingt, en faisant abstraction des plaques porifères, dont nous traiterons à l'article des ambulacres. Sur le pourtour immédiat de l'ourerture buccale, on ne compte ordinairement que dix plaques et quelquefois seulement cinq au lieu de vingt. Leur forme diffère complètement de celle des plaques qui composent le reste du test; au lieu d'ètre carrées, elles sont cunéiformes, et de leur disposition en cercle autour de la bouche résulte une rosette très-élégante que je désignerai sous le nom. de rosette buccale. Cette rosette est plus ou moins distincte, suivant que la couche tuberculifére est mince ou épaisse. Il m’a éte impossible de la reconnaître dans les Echinocyames et dans plısieurs Laganes; cependant je ne doute pas qu'elle n'existe comme dans les autres genres. Quant aux vacuoles et aux entailles, M. DesMoulins a fait l'observation trés-juste que loin de s'ouvrir dans les plaques, elles sont toujours le résultat d'une disjonction et d'un élargissement de la suture, dans les aires ambulacraires comme dans les aires interambulacraires. Il en est de même de l'ouverture anale.

Lorsque les soies qui recourrent le test des Scutelles sont enlevées (comme c'est le cas de lil plupart des exemplaires qu'on voit dans les collections et particulièrement des espèces fossiles), la surface entière du test apparait revètue de petits tubercules d'apparence trẻs-lomogène, mais qui, lorsquion les examine a la loupe, n’en présentent pas moins des diffërences très-notables. Il y en a de gros distinctement mamelonnés et perforés, qui portent les soies les plus développèes; ce sont ceux que M. DesMoulins appelle tubcrcules spiniféres. A côté de ceux-ci, on en remarque une foule d'autres beaucoup plus petits, mais également mamelonnés, quoique à peine visibles à l'oil nu; ce sont les tubercules miliaires de M. Ch. DesMoulins. La fig. 9 de Pl. 2, qui représente une portion de la face supérieure du Mcllita Augusti Kkl. sous un grossissement de plusieurs diamètres, donnera une idée de cette disposition. $\boldsymbol{\Lambda}$ la face inférieure, l'arrangement des tubercules est ordinairement plus varié qu’ả la face supérieure. Les gros tubercules et notamment ceux des aires interambulacraires y sont moins serrés et leaucoup plus dé- 
veloppés, les petits au contraire y sont excessivement nombreux : de lả cet aspect élégant que présente la face inférieure dans la plupart des genres et notamment dans les Encopes, les Mellites, les Lohophores et les vraies Scutelles.

\section{Des ambulacres.}

Les ambulacres sont d'une importance capitale pour l'étude des Scutelles et de tous les Oursins en génẻral, à cause des variations nombreuses qu’ils subissent suivant le genre et les espéces, et des caractères précis qu'ils fournissent au zoologiste. Dans beaucoup d'espèces et uotamment dans les fossiles, qui ne pernettent pas une inspection de l'intérieur du test, les caractères qui se tirent de ces organes sont mème toujours de première valeur.

Je n'essaierai pas d'entrer en discussion sur la nature et l'usage des ambulacres dans les Scutelles, persuadé que les difficultés qui se sont élevées à ce sujet, ne pourront être résolues que lorsque l'on aura étudié ces animaux sur le vivant ou du moins sur une série d'espèces bien conservées dans de l'esprit-de-vin *. Je m’en tiendrai par conséquent ici uniquement aux caractères zoologiques.

Les Scutelles ont, comme la plupart des Clypéastroïdes, les ambulacres bornés, c'est-à-dire, que les séries de pores, au lieu de s'étendre d'une manière uniforme de la bouche au sommet, affectent une disposition toute particulière à la face supérieure en y formant une rosette composée de cinq rayons que j’appelle pétales ambulacraires, à cause de leur forme pétaloïde. Cette disposition des ambulacraires est fort différente de celle que nous voyons dans les Cidarides et mème dans plusieurs groupes de la famille des Clỵpéastroïdes, tels que les Pygaster, les Discoïdées et jusqu'à un certain point dans les Galérites. Dans ceux-ci, les zoues porifères ou ambulacres proprement dits, sont composées de pores ouverts dans de petites plaques à part, que je désigne par cette raison sous le nom de plaques porifêres, et qui forment une ou plusieurs ran-

* D’après ce quc j’ai pu observer sur un exemplaire très-bien conservé, quoique desséclié, de Laganum rostratum Tab. 25 , fig. 5 , l'espace compris entre les deux rangées de pores des pétales ambulacraires, est revêtu à l'intérieur d'un renflement d’apparence spongieuse, composé de lamelles verticales placées les unes à côté des autres, et qui évidemment communiquent avec les pores. Or, comme il m'est dénıontré, par l'anatomie du genre Echinus ( voy. la $4^{c}$ Livr. de ces monographies par M. Valentin), qu'il existe une communication directe entre les pores ambulacraires et les organes de la respiration, je ne doute pas que ces lamelles juxtaposées ne soient les squelettes des feuillets branchiaux des Scutelles. Examinés isolément au microscope, ils se montrent composés d'un tissu calcaire très-ćlègamment réticulẻ. 
gées continues dans toute la longueur de l'Oursin. Il n'en est pas de même des Scutelles et des genres à ambulacres bornés : ceux-ci n'ont de plaques porifères, proprement dites, qu’à la face supérienre. An-deli des pétales ambulacraires, les pores disparaissent généralenient ou du moins ne s'ouvrent point dans des plaqnettes à part. Cette disposition implinge une grande inégalité dans la forme et les dimensions des plaques principales du test. Prenons pour exemple l’Éncope emarginata figurée sur la PI. 10 ; nous y verrons qu’au delả des pétales, les plaques des aires ambulacraires sont grandes et de forme à peu prẻs carrée. Dans l’intérieur des pétales, au contraire, elles sont fort petites, beancoup plus larges que hautes, formant deux rangées qui s'articulent sur la ligne médiaire de l'aire ambulacraire; mais au lieu de se prolonger jusqu'i l'aire interambulacraire, ces plaquettes sont limitées à la rangée interne des pores, et l'espace sillonné transversalement qui les borde est composé de plaquettes indépendantes, ayant à peu près la mème largeur que celles de lespace intermédiaire. Au premier abord, on est naturellement porté à prendre les sillons qui unissent les deux séries, pour les sutures des plaques porifères; mais sil’on vient à les examiner de près, on acquiert bientot la certitude qu'ils ne sont que superficiels. Javoue que jai ignoré pendant long-temps la véritahle disposition de ces plaquettes et leur mode d'articulation. C'est en étudiant les Spatangoüles que j’ai trouvé la clef de l'énigme. J'ai reconnu distinctement les sutures sur l'espace intermédiaire entre les sillons, et plus tard je les ai retrouvées dans la même position sur les Clypéastres. Il est plus difficile de les observer dans les Scutelles, a cause des tubercules trèsserrés qui les recourrent. Cependant, je ne doute pas qu'elles ne soient disposées de la même maniere.

Cette forme des ambulacres est commune aux Echinolanpes, aux Nucléolites, aux Clypeus, aux Clypéastres, et, dans la famille des Spatangoïdes, à tous les genres dont les ambulacres sont bornés. Nais un caractire propre au groupe des Scutelles, et plus particulièrement aux genres Mellita, Encope, Lobophora, Amphiope et Scutella, c'est la forme qu'affectent les ambulacres à la face inférieure. Ce sont des sillons très marqués qui se ramifient en tous sens dans leur trajet du centre à la périphérie, et déterminent ainsi des ondulations nombreuses et fort élégantes. Si l'on examine ces sillons de près, on les trouve criblés d'une multitude de petits pores jusque dans leurs dernières ramifications. Diverses opinions ont été émises sur la nature et l'usage de ces petits pores; quelques auteurs, eu égard à leur extrême petitesse qui les rend mème imperceptibles dans plusieurs genres tels que les Laganes, les Echinodiscus et les Echinocyames, ont douté qu'ils donnassent passage ả des suçoirs. Il importait dẻs lors de soumettre ces organes à un examen minutieux. C'est ce que je fis de concert avec mon ami M. Valentin. Nous déta- 
clàmes du test d'un exemplaire de Lagamum Bonani líl. conservé dans l'esprit de vin, quelques parcelles de l'épiderme qui recouvrail les sillons de la face inférieure, nous l'examinâmes au microscope, et nous y reconmùmes effectivement une quantitẻ depetits suçoirs très caractéristiques. La fig. 29 de Pl. 22 représente un de ces suçoirs sous un grossissement de 102 fois le diamètre, d'après un dessin de .I. Valentiı.

Il est donc démontré par cette observation que les organes ambulacraires (sucoirs ou tentacules) existent à la face inférieure comme à la face supérieure. Reste à savoir maintenant šils sont de même nature. C'est ce que je n'ai pu observer jusqu’ici, faute d'exemplaires assez bien conservés. En tous cas la grande différence qui existe, sous le rapport des dimensions el du nombre, entre les pores de la face supérieure et ceux de la face inférieure, établit une séparation tranchée entre les Scutelles et tous les genres à ambulacres bornés d'une part, et les genres dont ces zones porifères sont uniformes dans toute leur longueur, tels que les Galérites, les Pygastres, etc., d'autre part. Dans tous les genres de Scutelles, et même dans presque tous les Clypéastroïdes à ambulacres bornés, les pores de la rangèe interne des pétales ambulacraires sont circulaires et plus petits que ceus de la rangée externe, qui sont en général obliques*

\section{De la rosette apiciale.}

Il existe dans les Scutelles, comme dans tous les Clypéaströ̈des el les Spatangoüdes, à l’opposite de la bouche, au sommet du disque, une rosette de forme généralement anguleuse ou étoilée à laquelle viennent aboutir les pétales ambulacraires, et que j’ai désignée jusqu'ici sous le nom d'appareil ovichucal, parce que les pores génitaux s'ourrent à l'entour. Cependant les recherches

(*) M. DesMoulins, dans son premier Mémoire sur les Fchinites (p. 70), donnc unc description détaillće du système am. bulacraire de l'Encope (Scutella) tetrapora, dans laquelle il démontre l'existence de dix canaux (dont un sous chaque uroitić des cinq a mbulacres), crcusés daus la masse calcaire et celluleuse qui remplit le test. a Le toit de chaque canal, * dit-il, est strié transversalcment par des sillons plus larges quc ceux du delors de l'ambulacre, et ces sillons sont sépa* rés par des côtes trancliantes et denticulẻes... Les parties molles du système consistent dans des membranes roses, * très-minces, fixées parallèlcmcut et verticalement comme autant de cloisons sur le dos de chaque côte, et elles com. " muniquent par les trous dont ce sillon est percé (les pores ambulacraires) avec le derme externe de l'animal. Ces mem"branes sont parcourues par une infinité de nervurcs en relief (vaisseaux), et portent les suçoirs dont on aperçoit les "restes dans les pores."

Je n'ai pas eu l'occasion de constatcr cette disposition des membranes, ni leurs rapports avec les côtes qui séparent les sillons de la face inférieure, dans l'E. tetrapora, mais j’ai rencontré une structure analoguc à l'intérieur des Encopes dans plusieurs autres espéces. 
plus suivies que j'ai faites depuis lor's, sur la structure du test des Scutelles et la découverte que M. Forbés vient de faire sur les Echimus, et que jai constatée sur plusieurs espèces de ce genre, de la présence d'yeux dans les petits pores situés au sommet des ambulacres et généralenent connus sous le nom vague de pores interoviducaux ou intergénitaux, ces faits joints à l'autres considèrations tirées de la structure de ce même appareil dans l’intérieur, n’ont engagé à clıanger la dénomination trop restreinte d'appareil oviducal en celle de roselle apiciule, qui au moins ne donnera pas lieu à des équivoques. Cette rosette se compose de trois organes, qui sont : le corps madréporiforme, les plaques génitales et les plaques ocellaires. Dans la plupart des genres, ces trois plaques sont si intimement articulées entr'elles qu'on n’y distingue aucune trace de suture; jen étais même à me demander si peut-être les pores génitaux et ocellaires ne s'ouvraient pas dans le corps madréporiforme lui-même, lorsque je reconnus dans le Lagamum decagonum une articulation distincte entre les diverses plaques de la rosette apiciale.

Le corps madrẻporiforme est un bouton plus ou moins développé, mais d’une apparence diffèrente de celle du reste du test, et qui, lorsqu'on l'examine à la loupe, montre une quantité de petits pores très-semblables aux cellules de certains petits coraux microscopiques. De là sans doute le nom de corps madréporiforne qu’on lui a donné. Mais cette structure celluleuse n’est qu’extérieure. A l'intérieur le sommet du test se présente sous la forme d'une ètoile très-compacte et pourvue de cinq rayons grèles et saillans, destinée sans doute à protéger l'oviducte ou le canal spermatique, qui passe sous ces saillies avant d'arriver a la surface. De mème qu’i l'extérieur, on n'y distingue pas la moindre trace de suture. Pendant la vie de l'animal, l'ésophage est fixé au milieu de cette étoile apiciale interne, dans une petite cavité qui est ouverte dans la direction de l'intestin.

Les pores génitatx s'ourrent tantòt à l'extrémité des rayons de la rosette apiciale, tantôt dans les sinus intermédiaires. Dans ce dernier cas, ils sont toujours très rapprochìs, par exemple, dans les Rotules. Le nombre normal de cinq pores génitaux est réduit á quatre dans la plupart des genres du groupe des Scutelles, par exemple dans les Rotules, les Mellites, les Lobophores, les Amphiopes, les vraies Scutelles, les Echinarachnius, les Echinocyames et dans une partie des Laganes. Je ne saurais dire si cette absence du cinquième pore dépend réellement, comme le veut M. Deslloulins, de l'avortement du cinquiẻme ovaire, par suite de la direction de l'intestin. En tous cas je ne pense pas qu'on puisse l'envisager à bon droit comme un caractère essenticl; car lorsqu'on vient à examiner la rosette intérieure, on trouve le rayon de l'aire interambulacraire impaire construit de la mème manière que ceux des interambulacraires 
paires; sauf qu'il n'y a point de trou. Les recherches anatomiques ultérieures nous apprendront si cette particularité correspond à une différence capitale dans l'organisation, ou non.

Les pores ocellaires acquerront dorénavant une grande importance, s’il est vrai, comme je n'en doute pas, qu'ils servent aussi dans les Scutelles, à loger les organes de la vision. Pour s'en assurer, il faudrait avoir à sa disposition des individus vivans, ce qui est lien difficile en Enrope, en sorte que nous devons nous contenter pour le moment des preuves tirées de l'analogie; et je crois qu'en général on peut leur accorder une valeur d'autant plus grande que les organes principaux sont construits sur le même plan général dans toute la classe des Echinodermes. Il n'y a jamais moins de cing trous ocellaires; mais quelquefois ils sont si petits, qu'on a de la peine à les distinguer même à la loupe. Ils sont invariablenent placés au sommet les ambulacres, et pénétrent le test de part en part, de même que les pores génitaux.

\section{Des piquans.}

Les Scutelles portent, comme tous les Clypéaströ̈des, de petits piquans qui s'articulent aux tubercules de la surface du test. Ces piquans sont de forme très-variable, suivant les genres et les espèces, et mème dans les individus d'une mème espèce, ils présentent des diffẻrences trèsnotables, suivant qu'ils sont à la face supérienre ou à la face inférieure. Ceux de la face supérieure sont en général courts et clavellés; ceux de la face inférieure, grèles et aciculaires. Enfin, plusieurs espèces de Mellites et d'Eucopes en portent d'une troisième espèce sur le pourtour des lunules : ce sont des piquans assez développés et aplatis à leur extrémité. A l'état vivant, l'animal meut ces piquans à son gré dans toutes les directions; mais dans les individus morts, on les trouve toujours inclinés de la même manière. Ceux de la face infẻrieure sont dirigés, dans les aires interambulacraires postérieures, du bord vers le centre, et dans les aires ambulacraires antérieures, du centre vers le bord. Cette disposition me frappa vivement lorsque je l'observai pour la première fois dans le Mcllita testudinata; mais plus tard je l'ai retrouvée dans toutes les espèces dont les soies sont conservées. Il n'y a que les Echinarachuius et les Laganes qui semblent faire exception à celte règle; car leurs soies ne présentent point une disposition bien régulière.

Lorsqu'on examine ces divers piquans au microscope, on est tout étonné de leur trouver la mème structure qu'aux piquans des vrais oursins. Au lieu d'être lisses, comme on le suppose naturellement, ils sont fortement plissés dans le sens de la longueur, et ces plis sont en outre liérissés d'une quantité de petites épines. (Voy. Tab. 4 a, fig. 7, 11 et 12. Tab. 6 a, fig. 4 et 7 ; Tab. $10 a$, fig. 1 et 2 ; Tab. 20 , fig. 7,8 el 13, et Tab. 22 , fig. 28. 


\section{De la coulcur.}

La couleur est rarement conservée; elle paraît mẻme ètre très-fugace. J'ai vu dans ma propre collection des exemplaires du Mellita pentapora, d'une teinte très-vive, pàlir en peu de mois. Aussi, parui les exemplaires qu'on conserve dans les collections, la plupart sont-ils décolorés ì tel point que l'on ne peut pas deviner quelle a été leur teinte à l'état vivant. Les couleurs qui prédominent paraissent être le vert et le violet; le rert dans les Rotules, les Mellites, et le violet dans les Encopes, les Lobophores et les Echinarachnius. Jai vil des Encopes, de toutes les nuanres, depuis le cramoisi jusqu'au rouge-brun. Quelquefois la couleur se maintient, alors mème que les soies sont enlevées; et même dans les exemplaires qui ne les ont conservées que partiellement, on remarque la mème teinte sur les endroits garnis de cils comme sur ceux qui en sont dépourvus. Au reste, les Scutelles sont en général unicolores; et si parfois l'une des faces est plus claire ou plus foncée que l'autre, cette différence ne porte que sur les nuances d'une seule et mème couleur. Je n’ai jamais rencontré une Scutelle bigarrée.

\section{He la borche.}

La bouclie est centrale comme dans tous les Clypéastroïdes, et proportionellement plus petite que dans aucun autre groupe de cette famille. Son pourtour est ordinairemeut subcirculaire ou sul,pentagonal, et revêtı, pendant la vie de l'animal, de nombreuses soies plus grandes que celles dı reste du test, qui s'entrecroisent dans tous les sens, de manière à en masquer souvent l'ouverture. Dans la plupaat des genres, on remarque sur le pourtour de la bouclie, à l'extrémité ou plutòt à l'origine des sillons ambulacraires, de petits renflemens qui font saillie dans l'ouverture buccale, et qui, lorsqu'on vient à les examiner de près, se présentent sous la forme de tubes ayant une ou plusieurs ourertures à leur extrémité. J'envisage ces tubes comme les cavités destinées à loger les branchies buccales, qui en tout cas ont dù être très-petites. Lorsque ces tubes manquent, comme c'est par exemple le cas des Laganes, des Eclinocyames et des Echinodiscus, le pourtour de la boucle n'en est pas moins pentagonal; mais sa forme rappelle darantage celle des rrais Clypéastres. 


\section{De l'orifice anal.}

La forme et la position de l'orifice anal méritent une grande attention dans l'étude de ces aṇimaux, à cause des rapports intimes de cet organe avec l'intestin. Aussi nous fournit-il en général de bons caractères génériques. Cependant il ne faut pas lui attribuer une valeur trop exclusive, comme l'ont fait quelques auteurs qui ont rangé dans des familles différentes certaines espèces d'ailleurs très-roisines, par la raison que dans les unes l'anus est marginal, tandis que dans d'autres il est supère ou infère. Ce serait à mon avis une erreur de vouloir ćloigner les Echinarachnius des autres Scutelles, parce qülls ont l'anus supra-marginal ; tandis que les vraies Scutelles l'ont a la face inféricure. Dans les genres qui ont une entaille ou une lunule dans l'aire interambulacraire impaire, l'anus est généralement plus rapproché de la bouche que dans les genres à bords entiers. Sa forme est tantòt circulaire, tantòt elliptique, jamais anguleuse. Pendant la vie de l'animal, l'orifice anal est fermé par une membrane revêtue de petites plaques calcaires d’inégale grandeur, qu'on trouve quelquefois conservée dans les exemplaires desséchés, par exemple dans le Laganum depressum, figuré Pl. 23, fig. 6.

\section{De l'inténiene du test.}

L'intérienr des Scntelles ne présente point une cavité uniforme, comme celui des Spatangoïdes, des Cidarides et de la plupart des Clypéastroïdes. Il est au contraire diversement accidenté par des cloisons, des piliers et des réseaux calcaires, dont la forme, la structure et la disposition, très-variées dans les dicers types du groupe, suffraient, à elles seules, pour justifier la plupart des coupes génériques que j'admets ici ". L'espace central qui contient l'appareil masticatoire, et que j’appelle la cavité buccale, est distinct de la cavité intestinale qui s'étend tout alentour. Le plus souvent, il est vrai, la cloison qui les sépare n'est qu'une cloison membraneuse (dans les Rotules, les Lobophores, les vraies Scutelles, les Lagranes, etc.); mais quelquefois aussi c'est une cloison calcaire continue ( par exemple dans les Encopes ), ou bien ce sont des piliers qui sëlèrent des aires interambulacraires, et antour des-

(†) L’intérieur du test des vrais Cly péastres est construit à peu près de la même manière que celui des Scutelles; et l'on y distingue de plus une quantité de fines aiłruilles lrès-acérées que je n’ai jamais rencontrées dans les Scutelles. M. DesMoulins dit en avoir observé de trés-fines dans un exemplaire du Scutella (Encope) cmarginata. 
quels est étendue une membrane, par exemple, dans les Mellites. Quant à la cloison lorizontale, qui sépare le test en deux étages superposés, elle n'existe que dans les Encopes (voyez l'article du genre Ėncope), et c'est sans doute pour n'avoir eu à sa disposition que les espéces le ce genre que M. Des.loulins en parle comme d'un caractere commun à tout le groupe.

Les bords sont ordinairement très-caverneux à l’intérieur, parfois même ils ne présentent qưun réseau continu et très-compliqué de cellules qui pénètrent la substance calcaire du test comme une p'ponge; d'autres fois, et le plus souvent, ce sont des canaux flexueux qui cireulent entre des piliers verticaux massifs, et dans lespuels vont se loger les appendices cécaux du canal intestinal. Les genres Scutelline et Echinocyame sont remarquables en ce que les aires ambulacraires sont séparées des aires interambulacraires par des lames calcaires saillantes, qui s'étendent du centre au bord. En reranche, les bords eux-mêmes ne sont ni caverneux, ni celluleux. Le principal carnetère qui distingue les Echinocyames des vraies Fibulaires avec lesquels on les a confondus jusqüici, consiste précisément dans ces cloisons, qui les rattaclıent aux Scutelles, tandis que les Fibulaires n'ont ni cloisons, ni cellnles, ni piliers.

Les Scutelles ont en outre, comme tous les autres Clypéastroïdes, ciṇ auricules ou supports calcaires fixes, placés autour de l'ouverture buccale et destinés à faciliter le jeu des mâclıoires. Ils sont moins développés que dans les Cidarides. Leur forme, leurs dimensions et même leur disposition varient plus ou moins dans les diffërens genres. Ils sont petits et très-rapprochés lorsquils servent de pivôts aux màchoires, comme c'est le cas des Lobophores; ils sont au contraire très-développés lorsqu'ils leur servent de contreforts, comme par exemple dans les Laganes.

\section{De I'appareil masticatoire.}

Cet appareil, ordinairement trẻs-développé et mobile, est construit sur le même plan que celui des Clỵpéastres, dont M. Des\loulins a domné une description détaillée, accompagnée de figures dans ses Etudes sur les Echinites, avec cette diffërence cependant qu'il n'y a point de rotules *, et que les dents, au lieu d'être fixées verticalement à l'extrémité des mâchoires, sont, au contraire, implantées horizontalement à la face supérieure de ces dernières. Les eing mìchoires, qui composent l'appareil masticatoire des Scutelles, sont triangulaires, et ressemblent,

(*) M. Des Ioulins a donné le nom de rotules à cinq petites pièces alternant avec les dents, et destinćes, seion lui ,à faciliter l'indépendance de mourement de chacune des mâchoires. Yoyez. Des Moulins p. 66. 
comme celles des Clypéastres, ì un V trẻs-ouvert, ou a un compas placé horizontalement (voy. Tab. 8, fig. 3 et 4 et Tab. 6, fig. 7-9). Toutes ont à la face supérieure, sur la ligne médiane, un sillon, dans lequel se fixent les dents, dont l'extrémité fait saillie au delá des mâcloires. La face inférieure est ordinairement renflée sur la ligne médiane, et lorsque les dents pivotent sur les auricules, conme c'est le cas des Lobophores, on y remarque en outre une petite dépression, que M. DesMoulins a appelée fossette naviculaire.

Les différences, parfois très-frappantes, que présentent les màchoires dans les divers genres, sont plus apparentes que réelles, et en rósımé, les màchoires des Laganes, qui sont trèshautes, ne diffèrent de celles des Lobophores, qui sont très-plates, que par la courbure de la charpente postérieure et par le développement plus considérable des lames vertieales, dont elles sont hérissées en dessus et en dessous; ensorte que celles qui nous paraissent les plus épaisses se trouvent réduites à des plaques très-minces, lorqu'on leur enlève ces lamelles, qui borlent leurs faees supérieure et inférieure. Mais comme ces variations se maintiennent dans des limites constantes, elles nons offrent d'excellens caractères génériques.

Chaque màchoire est eomposée de deux parties que M. Deslloulins appelle osselets. Ils sont si intimement unis qu'il est difficile d'apercevoir la suture. Cependant je me suis convaincu par l'examen des mâchoires de l'Arachoüles Placenta que les deux osselets sont articulés par une sorte de charnière, l'osselet gauche étant pourvu d'une petite carène qui s'emboile dans un sillon correspondant de l'osselet droit.

Les mâchoires antérieures sont plus petites que les postérieures, et enire celles-ci c'est toujours la mâchoire impaire qui est la plus grande. Pendant la vie de l'animal, les cinq mìchoires sont réunies par des fibres musculaires transversales qui, en se contractant et se dilatant successivement, délerminent des mouvemens de va et vient, qui rapproclient les pointes des den ts et opèrent ainsi la mastication. Dans les exemplaires desséchẻs, ces fibres musculaires ont ordinairement disparu, à bien plus forte raison ne doit-on pas s'altendre à les voir conservées dans les espèces fossiles; aussi les màchoires sont-elles rarement adhérentes entr'elles. Au reste les rapports de position de l'appareil masticatoire avec les autres parties de l'animal ne varient pas dans tout l'ordre des Echinites; chaque rayon de la rosette correspond à une aire ambulacraire, tandis que les cinq màchoires eorrespondent aux aires interambulacraires. La fig. 6, de Pl. 3, donnera une juste idée de cette disposition.

Il est rare de trouver les dents adliérentes aux mâchoires, surtout lorsque l'on a à faire í des exemplaires desséchés; eependant j’ai pu les observer daus la plupart des genres. Ce sont de 
petites lames placẻes vertiealement dans le sillon médian de la face supérieure des màchioires, et ordimairement émaillées dans toute leur longueur, exceptẻ dans les Laganes, où elles ne le sont qu’ả leur extrémité, comme dans les vrais Clypéastres. Lorsque les mìehoires sont plates, (dans les Lobophores, les Mellites), les dents sont à peu près horizontales; elles sont au contraire arquées lorsque celles-ei sont très-élevées (dans les Rotules et les Laganes, etc.).

\section{De I'intestin.}

Il paraît que la forme générale de l'intestin ne varie pas d'une manière sensible dans les différens groupes de la famille des Clypéastroïdes. M. Charles DesMoulins en décrivant et figurant cet organe dans le Clypeaster Rangiamus DeslI. nons a en même temps fait connaitre toutes les particularités essentielles du canal intestinal des Seutelles ("). En sortant de l'appareil masticatoire, le canal intestinal va se fixer dans un ereux de la rosette apiciale interue, au sonmet du planeher supérieur, entre les pores génitaux; de là il se dirige sur l'avant, en passant par dessus la màchoire antérieure droite; arrivé près du bord, il se détourne à gauclıe, longe le llanc gauche, retourne par le flane droit jusque dans la région antérieure et de lä, se repliant sur lui-même, revient de nonveau en arrière et va abontir à l'orifice anal qui est sitıé a la face inférienre de la région postérieure; il passe par conséquent denx fois sur le eoté droit et nne fois senlement sur le còté gauche. Je me suis assuré par l'examen attentif de l'intérienr du test daus plusieurs espèees, entre antres dans une Lagane conservée dans l'esprit de vin et dans un exemplaire très-bien conservé du Mellita pentapora, que lintestin est garni dans tout son trajet d'appendices on de processus latéranx qui vont se loger dans les cellules de la masse calcaire; ensorte que ces eellules, sur la nature desquelles M. DesMoulins conservait des doutes, sont bien réellement des poches de l'intestin. Cette disposition ressort d'une manière évidente de la fig. 29 de Tab. 22, qui représente la moitié de l'intérieur dı Laganum Bonani vu par la face inférieure. Dans cette espèce et dans tontes les Laganes eu général, ces eellules latérales sont moins nombreuses que dans d'autres genres tels que les Mellites, les Encopes et les vraies Scutelles; mais l'on voit très-distinctement la manière dont elles communiquent avec le eanal principal. Il m’a élé impossible, faute d'exemplaires assez bien conservés, de distinguer exactement les différentes parties du eanal intestiual; eependant je pense que la

\footnotetext{
- Charles DesMloulins. Premier mémoire sur les Echinides, avec planches; p. 64. pl. 2.
} 
portion étroite du tube, qui s’étend de l'appareil masticatoirc jusqu'au bord de la cavité intestinale, correspond à l'ésophagc; la partie qui s'élend sur le flanc gauchc, et qui est la plus renflée, me paraît êtrc l'estomac; enfin la partic qui occupe le flanc droil et qui se replie sur elle même me paraît corrcspondrc à lintestin grểe. La partic que j’envisaggc comme correspondant à l'estomac est largement plissée, au moins dans les Laganes (Tab. 22, fig. 28 $n$ ), tandis quc les proccssus latéraux paraissent être lisses. Ellc est de plus ordinaircment vide dans les excmplaires desséchés; les deux anses du còté droit, au contrairc, sont constamment rcmplies de débris de substances organiques réduits à l'élat d'une pâte fortcment triturée, dans laquelle on distingue cependant encore des fragmens de petits coraux cl de menus débris d'autres animaux testacés.

\section{De l'appareil génital.}

Lcs organes génitaux n’avaient jusqu'ici été observés que dans la famille des Cidaridcs, où ils acquièrcnt ordinairement un développement extraordinaire. M. DesMoulins lui-même n'cn fait aucune mention dans sa description d'ailleurs très-complète du Clypeaster Rangiamus. Je devais par conséquent envisager comme une bonne fortune la posscssion d'un exemplaire du Lagamun Bonani conservé dans l’esprit de vin, que j’ai dù à la générosité de M. Valenciennes. Afin d’en tirer le meilleur parti possible, je priai mon ami, M. le professeur Valentin, de vouloir bien en faire l'anatomic. Voici ce que nous avons observé à l'égard des organes génitaux : lorsqu'on enlève le plancher supérieur du tcst, on trouve une membrane d’apparence réticuléc et diversement raniliée, qui recouvre tout lintestin. Comme cette membranc communiquait par des tubes allongés avec les pores génitaux situés au sommet du test, nous ne pouvions doutcr que ces tubes ne fussent ou des oviductes ou des canaux spcrmatiques. Nalheureusement la membrane rétieuléc n’était pas assez bien conscrvée pour qu’il nous fùt possible de reconnaître si c'était un organe målc ou femelle, car il est probable quc, de même que dans les vrais Echinus, les ovaircs et les testicules sont très-ressemblans, même daus les individus vivans. Les tubes (oviductes ou canaux spermatiques) sont au nombre de cinq, et la membrane elle-mème, quoique continuc, nous parut également divisée en cinq partics, cnsorte que le nombre cinq sc répète également dans les organes reproducteurs, au moins dans le gcurc Lagane. La fig. $11 x$ de Tal. 22 montre la manière dont ces organes sont élendus sur lintestin el la disposition de trois canaux conducteurs, passant par dessus le milieu des mâchoires pour regagner les pores 
génitaux. J'ai infiniment regretté de n'avoir pu me procurer un exemplaire frais d'un genre u'ayant que quatre trous oviducaux au lieu de cinq, afin de m'assurer si cette absence du cinquième pore correspond ou non à l'absence du cinquiène ovaire ou du cinquième testicule.

\section{Du mode d'accroissement des Scutelles.}

Il est fort difficile de se rendre compte de la manière dont s'opère l'accroissement dans les Scutelles. A-t-il lieu par l'addition de nouvelles plaques, ou bien les plaques primitives ne fontelles que s'agrandir sur leurs bords, ou bien ces deux modes d'accroissement ont-ils lieu simultanément? Il existe a cet égard des opinions très-différentes entre les naturalistes. 'Tous, il est vrai, reconnaissent que les plaques principales, d'abord petites dans le jeune àge, s'étalent en s'élargissant sur leurs bords ; il suffit d'ailleurs d'examiner attentivement la structure des plaques dans un individu un peu détérioré, pour voir qu'elles se composent de lames déposées successivement de l'intérieur à l'extérieur; ce qui fait qu'elles paraissent souvent renllées au milieu.

On est loin de s'entendre aussi bien sur la question de savoir si de nouvelles plaques s'ajoutent aux anciennes, comme c'est le cas des Cidarides. En tous cas, si une pareille addition a lieu , je ne pense pas que ce puisse être, comme dans ces derniers, autour de la rosette apiciale, car ici toutes les parties du test sont trop intinement liées à l'organisation entière de l'animal pour que l'on puisse admettre une pareille adjonction.

Mais est-il vrai que de nouvelles plaques perforées naissent entre le bout de l'ambulacre et les anciennes plaques ambulacraires, comme le prétend M. Ch. Des.loulins (“). Je ne le pense pas, par la raison qu'ayant eu l'occasion d'étudier comparativement, dans différentes espèces, des séries d'exemplaires de tous les âges, entr'autres du Rotula Rumphii et de l'Encope Stockesii, je me suis assuré que les plus petits (parmi lesquels il y en a qui n'ont pas même la moitiè du diamètre des plus grands), ont cependant le même nombre de plaques que les plus grands. Je me suis égalenent convaincu, par l'ẻtude de l'intérieur du test dans ces séries, que M. DesMoulins s'est trompé en supposant que lintervalle entre les piliers du bord finit par se remplir avec l'àge; car il n'y a pas jusqu'aux digitations des Rotules, dont l'intérieur ne soit le même dans les jeunes et dans les vieux exemplaires. Il n'en est pas de même des entailles qui, ainsi que nous le verrons en traitant des Rotules, augmentent et se modifient considérablement avec l’àge.

(*) Ch. Des.loulins, Etudes sur les Echinides, p. 137. 


\section{Inpports des Scutelles avec les antres Clypéastroides.}

Un groupe aussi nombreux que eelui des Seutelles doit néeessairement avoir des points de contaet avee plusieurs autres genres de la famille. C'est dans l'appréeiation juste de ees affinités que consiste le prineipal mérite du naturaliste qui, selon que les ressemblanees l'emportent sur les dissemblanees, devra rapproeher ou éloigner tel groupe de tel autre.

Les Seutelles tiennent d'une part aux Galérites par les Eehinoeyames, et d'autre part aux vrais Cly péastres par les Laganes (*) ; mais eette ressemblanee n'est pas une raison pour confondre ees divers genres dans un même groupe avee les Seutelles. Je eonviens qu'en eomparant eertaines espèes d'Eehinocyames avec les Fibulaires, on ait pu ètre tenté de les assoeier géuériquement, comme l'ont fait presque tous les auteurs. Mais iei eneore on s'est laissé induire en erreur par une ressemblanee extérieure; ear en étudiant comparativement l'intérieur du test de ees animanx, jai recommu que les uns (les Eehinocyames) sont eonstruits sur le même plan que les Seutelles, landis qu'il n’en est pas de mème des Fibulaires, qui n'ont ni cloisons, ni cellules, ni piliers.

Les vrais Clypéastres soṇt sans contredit eeux qui ont le plus d'analogie avee les Seutelles, malgré que leur forme élevée leur donne souvent une apparenee tout à fait différente. Les Laganes et surtout les Eehinoeyames rappellent, par leurs bords renllés et par leurs ambulaeres souvent légèrement saillans, le type des vrais Clypéastres. De plus, la position de l'intestin est absolument la même dans les deux groupes, ainsi que l’a déjả démontrẻ M. Des.loulins; mais à côté de ees ressemblances nous trouvons des différences très-notables dans la strueture de l'intérieur du test et notamment de l'appareil mastieatoire. Et d'abord l'intérieur des Seutelles n'est point hérissé de ees aiguilles vertieales, qui frappent si fort dans les vrais Clypéastres. Les dents ne sont point non plus vertieales, mais horizontales, et il n'existe point de rotules servant à l'artieulation des mâehoires, comme dans les Clypéastres. La bouche enfin, qui est toujours pentagonale et très-eoneave dans ees derniers, est à fleur de test dans les Seutelles. Les Eehinoeyames et les Laganes du type du Lagamum Bonani ont bien aussi la bouehe pentago-

(“) Les Clypeus n’ont des Scutelles que la forme aplatie discoïde du test; mais la position particulière de l'anus dans uu profond sillon de la face supérieure et la forme concave de la bouche les rapprochent davantage des Nucléolites. Aussi je ne sache pas qu'aucun auteur les ait jamais associés au groupe des Scutelles, ou les ait même placés dans leur roisinage. 
nale; mais il y a cette différence, c'est que les angles du pentagone correspondent aux ambulacres, tandis que dans les Clypéastres, ils correspondent aux aires interambulacraires.

J'aurais désiré pouvoir étudier comprarativement l'intérieur du test et notamment les parties molles dans plusieurs genres de la famille des Clypèastroïdes; mais l'extrêne rareté des espèces rend cette tảche trés-difficile, sinon impossible.

\section{Distributiou géologinue des Sentelles.}

Les prenieres traces des Scutelles apparaissent dans la partie supërieure de la formation crétacie, qui contient plusieurs espèces d'Echinocyames, et même une espèce de véritable Scutelle, le $S c$. Rogersi Mort., qu'on trouve dans la craie de New-Jersey. Les terrains de la formation jurassique n'en ont offert jusqu'ici aucune trace, non plus que les ètages inferieurs de la formation crétacèe, tels que le néocomien et le grès vert. En revanche, les terrains tertiaires en renferment un nombre assez considérable, notamment le calcaire grossier des environs de Paris et les faluns de la Touraine.

En comparant les espèces fossiles avec les espéces vivantes, on remarque entre elles des diffẻrences assez notables. Les espèces vivantes sont en gènèral plus accidentées dans leur forme que les especes fossiles : elles sont marquées de lunules, de vacuoles et d'entailles plus ou moins variées. C'est ainsi que les genres Rotula, Mellita et Encope, qui ont le test plus accidenté, ne comptent que des espéces vivantes (a l'exception du genre Runa, qui est a la limite entre les types a bords entiers et les formes entaillées, et qui renferme deux espèces fossiles des terrains les plus récens). Les vraies Scutelles, dont le test ne prẻsente aucune solution de continuité dans son pourtour, sont toutes fossiles. Les genres Echinarachnius, Echinocyamus et Lagauum, dont le bord est également entier, semblent rattacher plus particuliẻrement la faune fossile à la faune vivante, car ils existent à la fois daus les terrains tertiaires et dans l'èpoque actuelle; le genre Echinocyame a mêne des représentans dans la formation crétacẻe, ainsi que nous l'avons dit plus liaut. Il en est de ce genre comme de certains autres types de la famille des Cidarides, qui se maintiennent à travers plusieurs formations, tandis que d'autres sont remplacés d'une formation a l'autre par des types nouveaux. C'est ainsi que dans la famille des Cidarides, le genre des vrais Cidaris, même dans les limites auxquelles je l'ai restreint dans ma Description des Echinodermes fossiles de la Suisse (*), a des représentans dans la formation juras-

(*) Description des Echinodermes fossiles de la Suisse, $2^{e}$ Partie, dans les Nouv. Mémoires de la Soc. Hel. des Sc. nat. Tom. IV, p. 5 \% 
sique, dans la formation erétaeée, dans les terrains tertiaires et dans l'époque aetuelle, tandis que les Salénies, par exemple, sont limitées à la formation crétaeée, les Acrosalénies et les Henicidaris, à la formation jurassique $\left(^{*}\right)$.

Les genres Lobophore et Amphiope forment en quelque sorte le passage entre les vraies Scutelles, d'une part, les Encopes et les Mellites, de l'autre. Le premier ne eontient que des espèces vivantes. Le second (Ampliope) ne compte encore que deux espèces, qui toutes deux sont fossiles.

Il est également digne de remarque que les plus grandes espèees soient celles de l'époque actuelle. Je ne sache pas que l'on ait signalé nulle part une espèee de vraie Seutelle, dont la taille approchât de eelle de l'Encope Valenciennesi. Cette supériorité des espèees vivantes n'est pas seulement propre au groupe des Scutelles. On remarque une progression semblable dans plusieurs autres groupes de l'ordre des Echinites, dont les espèces paraissent être d'autant plus volumineuses, qu'elles sont d'une origine plus récente; c'est tout le contraire de ee qui a lieu dans d'autres classes du règne animal, et notamment dans l'embranelıement des vertébrés et dans celui des mollusques, qui affectent en général des dimensions moins considérables dans l'époque actuelle que dans les époques plus anciennes. Nous aurons oeeasion de revenir sur cette question, en traitant des autres groupes et en particulier des vrais Spatangus et des vrais Eehinus.

Les Seutelles vivantes habitent pour la plupart les régions tropicales. Elles paraissent surtout être fréquentes dans les parages de l'Océan pacifique. Les mers du nord n'en contiennent que quelques espèces, entre autres des Echinaraelınius, tels que l'E. parma et l'E. atlantieus, qui vivent sur les côtes du Canada. Les mers d'Europe et la Méditerannée n'ont fourni jusqu’ici que quelques petits Echinocyames.

(*) Je cite ces exemples afn de prouver aux naturalistcs qu'en restreignant les limites des genres, je ne me suis poiat laissé guider par des considérations systématiques, et que loin de subordonner mes déterminations à l'habitation ou au gisement, comme on me l'a reproché, j'ai toujours pris pour base de mes déterminations les caractères zoologiques et anatomiques. Si en procédant de cette manière, je suis parvenu á démontrer que, tout en indiquant une liaison incontestable entr'elles, les diverses époques n'en présentent pas moins toutes un nombre plus ou moiss considérable de types particuliers, qui en constituent la pliysionomie générale, j'aurai obtenu, par l'étude des Echiuodermes, un résultat qui ne fera que corroborer ceux auxquels m'avaient déjà conduit mes Recherches sur les poissons fossiles. 


\section{CIAPITRE I.}

DU GENRE ROTULA Ílein (Ag.).

Le genre liotula, ainsi que nous l'avons dit plus haut, remonte a Klein, qui y rangeait les deux espèees ci-dessous décrites. Il ne fut pas maintenu par Leske, qui confondit les Rotules arec les Laganes sous le nom d'Echinodiscus. Linné ne mentionne pas même les noms de Klein et de Leske, mais se contente de plaeer les Rotules dans son genre Echinus. Arant Klein, Breynius avait déjả décrit et figuré les deux espèces de ce genre, mais sans leur donner de nom spécifique. Lamarck et DesIloulins placent les Rotules en tête de leur genre Scutelle, mais sans les séparer génériquement des autres types.

Il suffit d'aroir vu une Rotule pour en saisir le earactère générique, et lorsque l'on considère la manière précise dont Klein détermine son genre Rotula, on comprend à peine que ses successeurs aient pu le confondre de nouveau avec des espèces apparteuant à des types entièrement diffẻrens tels que les Laganes, les Encopes, les Lohophores, les Echinarachnius, etc. En réintégrant les Rotules dans leurs droits, je ne crois done pas encourir le reproche de nultiplier trop) les genres, attendu que celui-ci au moins avait déja été eireonscrit de la mème manière par le eélèbre naturaliste de Dantzig.

Les Rotules sont des oursins très plats, de forme eireulaire, nettement caraetérisés par la présenee de digitations très prononcées au bord postérieur ou anal, mais dont le nombre, la forme et les dimeusions varient dans des limites assez étendues, suivant les espèces et même suivant les individus. Ayant eu l'oceasion de comparer des séries nombreuses d'exenplaires des

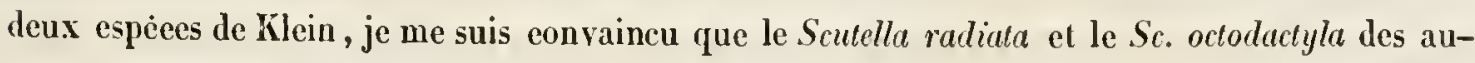
teurs ne sont que des variétés d’àge, l'un du $R$. Rumphii et l'autre du $\boldsymbol{R}$. Augnsti, et quil n'existe réellement que ces deux espèees dans les grands musćes d'Europe. La bouche est petite, circulaire et placée au ecntre de la faee inférieure. L'anus, tantôt circulairc, tantòt ovoïde, est plus rapproché de la bouehe que du bord postérieur. L'étoile ambulacraire est de moyenne 
grandeur, et les zones porifères des pétales, au lieu de se former à leur extrémité, ont au contraire une tendance à diverger. Ordinairement les pores se prolongent, d'une manière irrégulière, jusque près du bord. A la face inférieure, les ambulacres sont représentés par cinq sillons eriblés d'une multitude de petits pores invisibles à l'œil nu, mais fort distincts à la loupe. Ces sillons ne se ramifient pas d'une manière aussi variée que dans les Encopes et les Mellites. Chaque sillon se divise, à une petite distance de la bouche, en deux branches qui se subdivisent a leur tour en deux rameaux, ensorte qu'il y en a un pour chaque digitation. Cette disposition des sillons, jointe à l'uniformité des tubercules, est cause que la face inférieure des Rotules est u1oins accidentée que celle de la plupart des autres genres.

La rosette apiciale présente une structure toute particulière : les trous oviducaux, au nombre de quatre, sont excessivement rapprochés; mais au lieu d'ètre placés ả l'extrémité des rayons dı corps madréporiforme, ils sont logés dans les sinus intermédiaires; ce sont, en revanche, les Irous ocellaires qui occupent le sommet des rayons. Il suffira de comparer la fig. 7 de tab. 2 avec la fig. 7 de tab. 9 pour se rendre compte de cette différence. Le corps madréporiforme luimême est très petit relativement à la grandeur du test; examiné à la loupe, il présente la structure spongieuse ordinaire à toutes les Scutelles.

L'intérieur du test n'est pas moins remarquable que sa surface. Il n'existe point de cloison solide entre la cavité buccale et la cavité intestinale, et, comme les entailles correspondent aux aires interambulacraires, tandis que les aires ambulacraires sont moins découpées, il y a tout lieu de eroire que l'intestin se déploie dans les anses de ces dernières et envoie des processus dans la masse cellulaire qui remplit l'intérieur des digitations et le bord intérieur du côté antérieur ( Tab. 4, fig. 2). La face interne du plancher supérieur est à peu près lisse; car il n’y a que les rayons de la rosette apiciale qui fassent une légère saillie; le plancher inférieur est hérissé intérieurement de petites crêtes irrégulières qui rappellent à certains égards la structure celluleuse des Encopes et des Lohophores. L'appareil masticatoire est petit ; les màchoires sont garnies de lames calcaires sur leurs deux faces ; mais celles de la face inférieure sont beaucoup plus hautes que celles de la face supérieure, quoique elles ne débordent pas la lame osseuse, comme c'est par exemple le cas des Mellites et des Encopes. Le sillon de la face supérieure des mâchoires, dans lequel s'articulent les dents, est très profond. Je n'ai pas vu les dents elles-mêmes; mais à en juger par les mâchoires, elles doivent être minces et tranchantes comme dans toutes les Scutelles. Les auricules sont larges, mais peu saillantes; elles ont an milieu une petite fosette qui correspond à une petite carène de la face inférieure des màchoires. 


\section{Rotela livapmin kilein.}

Tall. I.

Srx. Rotula Rumphii Kilein. Nat. Disp. Echinodermatum Ed. Leshe, p. 26, $\$ 91$, Tah. 22, fig. E. F.

Placenta Rotula sp. 2. Kílein. Gall. $\$ 91$, 1. 96, Tab. 12, fiğ. C.

Echinodiscus, dimidla perifcria incisionibus acqualibus fore praedita Breyn. Dissert. phys. de Polythal. Schediasma, etc., p. 64, Tab. 7, fig. 3 et 4 .

Echinotrochus deccm dentatus Vain Phelsmm, p. 33.

Echinus solaris (de Zonnestraal de Pannekoek) d'Aquet. in Rhumph. p. 37 (nota), Tab. 14, fig..1.

Echinus orbiculus var, $a$ et $b$. L. Gm. p. 3192.

Oursin denté Bosc (Deterv. Tom. 21, p. 281).

Oursin solaire (Rotula) Davila, Cat. Tom, I, p. 425, N॰959.

Oursin disque D'Arwenv. Zoomorph. Tab. 7, fiğ.D.

Echinus planus, singularis, etc. Seba. Thes. Tom. III, p. 35. Tab.15, fig. 15, 16.

Tertia Echinodisci spccies minuscula Seba. Thes. ibid. p. 35. Tab. 15, fiğ 19 et 20 .

Echinodiscus dcntatus Leskie apud K1. p. 212, Tab. 22. figg. E, F.

Var. minor Leske ibid, 1. 212, Tab. 49, fiğ. 6 et 7.

Scutclla dcrtata Blainv. Dict. sc. t. 48, p. 226. - Zooph. p. 201. - Agass. Prod. Ech. p. 138. -

E. Desl. Enc. T. 2, p. 675, నৃo 1. - Encycl. méth. Pl. 151, fiğ. 1-1 - Laun. Hist. nat. 3e Ed. Tom. 3, p. 277, $\boldsymbol{N}^{\circ} 1$ - DesMoul. Tabl. syn. p. 220, $\boldsymbol{N}^{\circ} 1$.

Scutella scmisol DeBl. Dict. sc. nat. Tom. 48, p. 226 - Deslloul. Tabl. syn. p. $220 . \mathbf{N}^{0} 2$.

Scutclla radiata DeB1. Zooph. p. 201. - Agass. Prodr. Ech. p. 188. - Lamarcli p. 278, No $1 a^{\circ}$ Boccon. Observ. p. 273. - Favan. Zoomor. Tab. 74, fig. C. - Gualtieri, Test. 110, fig, II. - Valent. MIus. T. 3, p. 177, fig. 2.

Nous royons par cette longue liste de synonymes que l'espèce dont il est ici question a fixi nombre de fois l'attention des naturalistes. Nous la trouvons figurée pour la première fois dans Breynius sous le nou d'Echinodiscus, par lequel cet auteur désignait toutes les Scutelles. Klein la décrivil sous le nom de Rotula Rumphii, la dédiant au célèbre Rumph. Leske et Lanarck qui n’admirent pas le genre Rotula, la rangèrent, le premier, dans son genre Echinodiscus, le second, dans son genre Scutella. II. de Blainville en fit le type de sa division des Demi-soleils. En rẻintégrant le genre Rotula daus les mèmes limites que Ḱlein l'avait établi, il était naturel que jadmisse aussi ses nous spécifiques de préférence à ceux de ses successeurs; et c'est pourquoi 
cette espece figure ici sous le nom de Rotula Rumphii, au lieu de s'appeler Scutella dentata ou Sculella radiala.

Avant d'avoir à ma disposition une séric complète d'individus de tous les àges, dont les variations les plus importantes sont représentées sur la Pl. 1, je partagcais l'opinion de Blainville qui envisage les formes que l'on a distinguées depuis sous les noms de $S c$. dentala et $S c$. radiata, commc deux cspèces distinctes; je les ai même citées commc tclles dans mon Prodromc; et, en effet, l'exenplaire de fig. 1 ( $S$ c. radiata des auteurs) parait au premicr abord fort différent de ccux de fig. 5 et 8 (Sc. dentala des autcurs); le nombre des digitations y est surtout bien moins considérable. Mais si l'on poursuit ce caractère dans unc série d'excmplaires, on trouve qu’il n’a absolument rien de constant. C'est ainsi que l'exemplaire de fig. 5, quoique plus petit que cclui de lig. $\$$, a trcize digitations, tandis que ce dernier n'en a que onze, et néanmoins il ne viendra à l’idée de personne de fairc de ces excmplaires deux espèces différentes. Ce qui prouve en outre quäil n'cxiste aucune règle fixc dans la distribution de ces digitations, c'est qu'clles ne sont pas réparties d'une maniẻre uniforme sur les deux côtés d'un même individu: témoin encorc l'exemplaire de lig. 5, dans lequel l'ambulacre antérieur gauche est séparé en deux digitations, tandis que l'ambubulacre antérieur droit n'en a qu’une. Dans l’cxemplaire de fig. 3, les digitations ne sëtcudent pas aux ambulacres antérieurs; aussi n'y en a-t-il quc dix en tout; dans la figg. 1 enfin il n’y a que l'une des sérics des aires interambulacraires postéricures qui se détache du reste du test; ce qui fait que nous n'avons ici que luail digitations. La longueur des digitations varie également dans des limites assez notables; clles sont plus développées dans les individus adultes que dans les jeuncs, et celles du milieu sont plus longues que celles des hords. Il est assez difficile, dans l'état actuel de nos connaissances, de dire si ces différences résultent du mode d'accroissement ou si elles ne sont qu'un cffet de résorption. Je serais tenté d'admettre cette dernière cxplication de prélérence a l'autre, par la raison que dans les individus les plus digités, tels que les excmplaires de fig. 5 et 8 , les digitations diminucnt de longueur à mesure qu'elles approchent du bord antérieur; et commc les dernières n'cxistent pas dans les jeuncs individus, on est naturellement conduit à supposer qu'elles sont les plus récentes. En tout cas, l'accroisscment ne se fait pas par l'addition de nouvelles plaques, attendu que lcur nombre est a peu près le nềme dans tous les individus, quils soient grands ou petits. Dans le $R$. Augusti, les entailles sont bicn plus inégales; celles qui corrcspondent aux aires intcrambulacraires sont notabement plus grandes que celles des ambulacres, et c'est cn quoi cette espèce se distingue essen- 
liellentent de notre R. Rumphii, quoique plusieurs exemplatires de celui-ci présentent aussi des traces de celte irrégularité, par exemple l'exemplaire de fig. 5.

La forme générale du R. Rumpliii est à peu près cireulaire en supposant l’intervalle entre les digitations rempli; dans la plupart des individus, le diamètre lougitudiıal est un peu plus graud que le diamètre transversal. Le sonmet est seusiblement renflé et dècline d'une manière graduce rers les bords, ainsi que le montrent les fig. 7 et 10, qui représentent le profil de deux exeruplaires rus par la face postérieure. L'étoile ambulacraire est assez grande. Les pétales sont de noyenne largeur, de forme allongée et toujours plus ou moins renflés; les zones porifires sont sensiblement plus étroites que l'espace intermédiaire. Tous les pétales se prolongeut jusqu’au delá de la moitié du rayon qui va du sonmet à la périphẻric, mais sans s’arrondir à leur extrémité, comme c'est le cas de la plupart des autres geures. Passé celte limite, les pores sout encore visibles, mais ils ne montrent plus cette continuité quiils ont dans les pétales et ne sont plus réunis par un sillon. La fig. 13, qui représente l'ambulacre antérieur de fig. 8 grossi, donnera une idée exacte de cette structure. Le sommet du disque est oceupé par la rosette apiciale qui est représentée grossie dans la fig. 12, avec les quatre trous oviducaux qui sont trèsrapprochés, et les cinq trous ocellaires, qui ne sont pas visibles à l'xil nu. Vue à la loupe, cette rosette présente une structure finement spongieuse. La lig. 1't représente l'aire interambulacraire postéricure vue par la face supéricure, afiu de donner une idée exacte de la disposition et de la granteur relative des plaques.

La face inferieure présente au premier coup d'œil une apparence uniforme et treillissée, qui provient de ce que les sutures des plaques sont toujours trés marquées, surtout dans les individus adultes (royez fig. 6 et 9 ); à côté de ces sutures, l'on apergoit les sillons ambulacraires qui sont en général plus grèles et souvent a peine visibles à l'ail nu. Ces sillons représentent ici les ambulacres, et malgré leur petitesse, ils sont garnis, dans toute leur longueur, de pores microscopiques. Ils rayonnent de la bouche rers la périphéric, se divisant d'abord en deux branches, lesquelles se subdivisent chacune en deux rameaux qui gagnent le bord sans se ranifier ultérieurement; claque digitation est ainsi accompagnée d'un rameau ambulacraire. Quant aus tubercules qui garnissent la face inféricure, ils sont à peu près aussi uniformes que ceux de la face supérieure. On n’y retroure point celte variété que nous rencontrerons dans les différentes espéces d'Encopes et de Mellites. - Lourerture buccale est à peu près ceutrale, elle est petite el circulaire. La fig. 11 nous la représente sous un grossissement de 1\%a diamètre, qui permet de reconnaitre la structure intiune des sillons ambulacraires, et à l'extrémité de 
chaque sillon, sur le pourtour de la bouche, les trous un peu plus grands qui etaient sans doute destinés à loger les branchies buceales. L'anus est placé à peu près à moitié chemin entre la bouche et l'extrémité des digitations; il est plus petit que la bouehe et de forme circulaire. La fig. 16, qui représente le plancher inférieur du test vu par sa face interne, ne montre autre chose que les cinq a uricules implantées dans les aires interambulacraires et destinées à fixer les màchoires. En général lïntérieur du test est beaueoup plus accidenté dans les espaces interambulacraires que dans les ambulacres; il y a mème de petits piliers qui s'avancent vers le centre et qui se retrouvent également à la face supéricure et à la face inférieure. Au deli de ces piliers, la cavité intérieure ne prẻsente qu'un rẻseau de cellules plus ou moins réguliẻres qui s’étendent jusqu'à l'extrémité des digitations. La fiğ. 17 reprèsente l’appareil masticatoire grossi, vu par sa face inféricure, les cinq mâchoires étant réunies. La fịg. IS est une dent isolée, légérement grossie, vue par la face inférieure et montrant la structure, lamelleuse de ses bords. La fig. 19 est la mème màchoire, vue par sa face supérieure, avee le sillon dans lequel ètait fixée la dent. La fig. 20 enfin représente cette même màchoire, vue de profil, afin de montrer son épaisseur considérable et la juxta-position des lames calcaires dont ses bords sont garnis. La fig. 17 représente les contours de l'appareil masticatoire, de grandeur naturelle.

Parmi tous les exemplaires que jai eu l'occasion d'examiner, je n'en ai retroure aucun qui eǹt conservé ses soies. La couleur du test est en général d’un vert foncé; les jeunes individus cependant se font remarquer par des teintes ordinairement plus claires (voy. fig. 1, 2, 3, i); il est probable que les soies avaient la même couleur que l’épiderme. Tous les exemplaires que je connais de cette espèce proviennent de la côte occidentale d'Afrique et particulièrement du Sénégal. Quelques auteurs citent comme origine les cótes d'Antérique, mais je crois cette citation erronnée. Les originaus de mes figures mont été communiqués par M. Nichelin.

\section{Rotera Augusti Klein.}

Tab. 2. fig. 1-10. et tab. i. a fig. 1-6.

Srx. Roula Augusti Klein. Edt. Leske, p. 26. $\$ 90$, Tab. 22, fig. A, B, C, D.

Echinodiscus dimidia perifcria incqualibus incisionibus, etc. Breyn. p. 64, Tab. 7. fig. 5 et 6.

Placcnta rotula sp. 1 Klein Gall. p. 94, Tab. 12, fig. A. B.

Echinodiscus decies digilatus Leslie apud KI. p. 209. Tab. 22, fig. A. B.

Echinodiscus oclies digitants Leshe ibid. p. 211, Tab. 22, fiğ. C, D. 
Outrsin à dix doiggts Bose, Déterv. T. 24, p. 281.'

Fechinodiscus Gualt. Test. Tab. 110, fig. II.

Echinus octoulactilos I. Gm. p. 3191 .

Echinus altcrplanus Seba Ther. III, Tab. 15, fig. 17, 18.

Echinotrochus octodigitatus (Agtringeterige Egelschyv) van Phels. p. 33. Gen. 3, sp. 6.

scuella dccadactyla deBl. Dict. Sc. nat. T. 48, p. 227. - Zooph p.. 201. - DesMoul. 'Tahl. syu. p. 222.2. $\mathrm{N}^{\circ} 3$.

Scutclla digitata Lam. Tom. 3. p. 278, No2. - E. Desl. Enc. 'Tom. 2, p. 675, No2. - Encycl. métl. Pl. 150, fig. 3-6. - Agass. Prod. Ech. p. 188.

Scuclla octodactyla de Bl. Dict. Sc. nat. Tom. 48., p 227. - Looph. 201. - Lamarck. Tom. 3, p. 279. - Agass. Prod. Ech. p, 188.

Javila, Catal. Tom. I. p. 425, No 960.

Encycl. (Dict. des Sc.) Tal. 59, fig. 7.

Faranne, Tal-58, fig. C 2 et 6 í.

Cette espèce est, comme la précédente, assez généralement connue des naturalistes, qui en ont également fait deux espèces, sans doute parce qu'ils n'ont pas eu l'occasion de l'étudier aux différens âges. Je serais probablement tombé dans la même erreur, si je n’avais eu le bonheur de trouver dans la collection de mon ami, M. Ch. Stokes, deux exemplaires de moyenne taille (Talı. 2, figures 1 et 5) qui forment éridenment le passage entre les grands exemplaires connus sous le nom de $S c$. decadactyla ou digitata (fig. 1) et les pelits semblables à celni de Tab. 4 a, fig. 1, que $\mathrm{II}$. de Blainville a désignés sous le nom de $S$. octodactyla. Ne possédant pas moimème $u n$ individu d'aussi petite taille, j’ai reproduit (Tah. ' $a$, fig. 1) la figure de Breynius, qui m’a paru être la plus caractéristique de toutes celles qui ont été publiées. Il suffira de conparer cette figure aux figures $1,2,4$ et 5 de Tab. 2 pour acquérir la certitude que ces trois individus appartiennent bien réellement à la mème espèce et que la profondenr des entailles dans les grands individus n'est qu'un effet de la croissance.

La forme générale de cette espèce est à peu près circulaire; cependant le dianètre transversal est un peu plus long que le diamètre longitudinal. C'est en outre une espéce très plate, le sommet surtout est bien moins renflè que dans le R. Rumphii. Mais le caractère essentiel de l'espéce réside dans les entailles et les vacuoles du test : le bord postérieur est entaillé sur tout son pourtour, comme le R. Rumphï, mais avec cette différence que les entailles sont beauconp plus inégales et que celles des aires interambulacraires sont toujours beaucoup plus profondes que celles des aires ambulacraires. Cette différence se reproduit dans les individus de tous les ìges, 
"t nous royous que dans le jeune exemplaire de Tab. 4 a fig. 1 , oủ les entailles des aires amInlacraires ne sont encore que très légèrement marquées, celles des aires interambulacraires sont dẹja très profoudes, ensorte que le bord postéricur parail ici compose de deux festons portant chacun quatre courtes diggitations, ce qui porte le nombre de ces dernières à lıuit: de là le nom de $S$. octodactyla que lui ont donné les auteurs. Dans l'exemplaire de fig. 5 (Tal.2), nous eu comptons déja dix el dans celui de fig. 4 douze; dans l'exemplaire de fig. 1 les varuoles des aires ambulacraires paires antérieures sont restées fermées; mais cette circonstance n'est point un caractẻre coustant, comme on peut s'en assurer en comparant l'exemplaire de fig. a do elles sont ourertes. Nous en concluons que la forme et la grandeur des entailles et des lunules ne peuvent point être envisagées coume des caractères spécifiques, nais qu'elles n’indiquent que des variétés d’àge. Une autre particularité de cette espèce, qui ne se rencontre point daus la précédente, c’est la présence de vacuoles un peu moins allongées que les entailles des aires interambulacraires postéricures et toujours fermées, dans les aires interambulacraires paires antérieures. Les pétales des ambulacres sont allongés et de largeur mojenne; ils ne sont point fermés à leur extrémité, et leurs pores, non réunis par un sillon, se prolongent par paires isolées, à peu près jusqu'au bord de la circouférence. La roselte apiciale est limitée à un très petit espace, aussi les pores oviducaux sont-ils très rapprochés; ils sont logés dans les sinus que forme le corps madréporiforme au sommet des aires interambulacraires. Les trous ocellaires, au nombre de cinq, sont silués à l'extrémité des rayons de l'appareil oviducal el par conséquent plus distans les uns des autres. La fig. 7, qui représente cet appareil grossi, donnera une idée de la dispositiou de ces divers orgaues. -Lorsqu'ou examine la surface du test a l'ocil uII, on n'y voil qu'uue fine granulation très lomogène; mais lorsqu'on vient à examiuer celte granulation sous un fort grossissement, on la trouve composée de tubercules spinifères crénelés, mamelonıés et perforés, entourés d’une multitude de tubercules miliaires très-petits, mais également mamelonnés, ainsique les représente la fig. 9, qui est prise à la face supérieure. Je n’ai jamais vu d'exemplaires avec ses soies.

La face inférieure présente à peu prés la mème structure que nous arons décrite dans le $R$. Rumphii. Les sillons ambulacraires sont étroits et se divisent en quatre branches, qui se prolongent jusqu’à l'extrémité des digitations, saus détacher de rameaux latéraux. La rosette buccale qui entoure la bouche, est des plus distinctes; elle est composce de dix plaquues cunéiformes ; relles qui correspondent aux aires interambulacraires sont sensiblement plus étroites que celles qui correspondent aux aires ambulacraires. La bouche elle-mème est petite et circulaire. 
en l'examinant a la loupe, on observe sur son pourtour, a l'origine des sillons, phusieurs ouvertures distinctes (ordinairement trois), (qui correspondent anx tubes branchiferes et sont probablement destinées à donner passage anx branchies buccales. La fig. 10 représente celte structure de louverture luccale sous un grossissement de deux fois le dianètre. L'anus est plus lapproché de la bouche que du bord; il est snbcirculaire, ordinairement un peu allongé daus te sens du diametre transversal.

L’intérieur du test est lisse; il ny a que que le bord et lextrémilé des digitations qui soient celluleux, ainsi quon le voit par la fig. 2 de Tah. 4 a. La lig. 3 de la mème plancle montre une portion de la faee interne du plancher inférieur, qui est plus inégal que le plancher supérieur; autour de l'ouverture bueeale qui est au milieu, se voient les cing aurienles, qui sont simples, assez largeses, mais peu élevées. Les fig. 4 et 5 nontrent l'appareil mastieatoire, en grandeur naturelle, dans l'une (lig. 1) vu par en bas, dans l'autre (fig. 5) vu par en haut. Il diflére is peine de eelui du R. Rumphii; cependant les lames calcaires qui garnissent les màchoires sont proportionnellement moins léveloppées que dans cette dernière espèce. Les mâchoires postérieures, et notamment la mìchoire impaire, sont sensiblement plus grandes que les màchoires antérieures. Les dents elles-mèmes ne sont pas eonservées; mais, á en juger par la direction drs sillons destinẻs à les loger, il est probable quelles étaient lëgèrement recourbées de haut en las. Les fig. 6 et $6 a$ présentent le profil de la màchoire postérieure vu par devant et de còté.

L'habital de eetle espéce m'est inconnu. 


\section{CHAPITRE II.}

DU GENRE RUNA Agass.

Le caractire saillant de ce petit genre consiste dans la forme et les proportions des aires interambulacraires, qui sont sensiblement plus itroites que les aires ambulacraires et sẻparées de ces dernières par des sillons plus ou moins profunds. Les pétales ambulacraires, au lieu de se fermer, s’évasent au contraire à leur extrémité. Il parait aussi qu’il n'existe point de sillons transverses entre les rangées des zones porifères. L'ouverture buceale, de forme circulaire ou ellipsoïde, est placée au centre de la face inférieure. L’anus, plus petit que la bouche, est situé entre l'ouverture buccale et le bord postérieur.

Je ne connais jusqüici que deux espèces de ce genre; le Runa Comptoni, décril ci-dessous, et le Runa decemfissa (Scutella decemfissa Des.I.), mdiqué par H. Charles DesMoulins, dans ses tableaux synonymiques des Echinides, et qui se trouve en la possession de M. Jouannet. L'une et l'autre sont de très-petite taille, et proviennent des terrains terliaires.

En plaçant ce petil genre après les Rotules, je n’ai eu pour me guider que la forme exlirieure, car ne possédant que deux exemplaires du R. Comptoni, il ma été impossible d’éludier lintérieur du test. Il se pourrait done, qu'en réalité, les Runes fussent plus voisines des Laganes et des Echinocyames que des Rotules. En attendant de plus amples informis, il m'a semble que par les entailles de leur bord, elles élablissaient en quelque sorle un passage entre les genres à bords cutiers et ceux qui ont les bords entaillés.

\section{i. Resi Conptoni Ag.}

Tab. II, fig 11-19.

Cette petite espece est de forme subcirculaire on plutòt ovoïde, plus longue que large et médiocrement renflie; la hauteur, qui égale à peu près les deux tiers de la longueur, présente 
une déclivité trés-uniforme du sommet vers les bords, qui sont trés-épais. Les aires interanbulacraires sont très-étroites; elles n'ont que la moitié de la largeur des aires ambulacraires, comme on le voit surtout bien a la face inférieure, oủ la séparation des aires est très-distincte. Les zones porifères des ambulacres ne sont visibles à la face supéricure que jusqu’a mi-bord, oủ elles disparaissent en divergeant. Les entailles qui séparent les aires ambulacraires des aire. interambulacraires sont profondes; elles sütendent au dela du tiers de la distance entre le bord et le sommet. La bouche, de forme elliptique, est située dans une dépression au centre de la face inlérieure. L’anus, sensiblement plus petit que la bouche, est circulaire et plus rapproche In hord postérieur que de l'ouverture buccale. Je n'ai pu reconnaître la disposition des tubercules, la surface du test étant trop altérée. La rosette apiciale contient quatre pores génitaux. Les pores ocellaires, placés au sonimet des pétales, sont excessivement petits.

J’ai représenté de grandeur naturelle (fig. 11-13 et 14-15) les deux seuls exemplaires que je possèle, et dont l’un (fig. 14), paraît être un jeune. Les fig. 17-19 représentent l'indivilu de fig. 11 grossi, afin de faire voir les détails du test. L’apparence écailleuse de la fice inférieure (fig. 1S) provient de ce que les plaques du test sont rongies près des bords articulaires, ce qui les fait paraître saillantes au milieu.

Cette espece a été découverte dans le terrain tertiaire des environs de Palerme, par M. le marquis de Northampton, président de la Société royale de Londres, auquel je me suis fail un plaisir de la dédier.

\section{RTNA DECEMFISSA Ag.}

Srv. Scutella decemfissa DesMoul. Tabl. syn. p. 232.

Je ne connais cette espèce que par un croquis que je dois à l'obligeance de M. Deslloulins, et prar lequel jai pu me convaincre qu'elle est réellement différente du $\boldsymbol{R}$. Comptoni. Quoique trẻs-petite, puisqu'elle a moins diune ligne de long, elle est cependant proportionnellement plus allongée que l'espéce ci-dessus; l'anus est plus rapproché de la bouche, et le pourtour du test est bien plus flexueux.

Cette espece a été découverte par M. Jouannet dans le terrain tertiaire de Terre Nigre, près de Bordeaux. MI. Clı. Des.Inulins a promis d'en donner une deseription détaillée. 


\section{CHAPITRE III.}

DU GENRE MELLITA Klein $\left(A_{\mathfrak{G}}\right)\left({ }^{*}\right)$.

Ce genre tient en quelque sorte le milieu entre les Rotules et les Encopes. Tandis que la disposition des vacuoles le rapproche de ces derniers, sa forme aplatie et l'alsence d'un trou génital dans l'aire interambulacraire impaire semblent au contraire le rattacher aux Rotules. Vais à côté de ces affinitẻs, les Mellites présentent plusieurs caractères qui leur sont propres et qui justifient pleinement la coupe générique que Klein déjà avait établie sous le nom de Mellita, et que je propose de rẻintégrer, en en défalquant les espèces à deux entailles que cet auteur confondait avec les véritables Mellites et dont j’ai fait mon genre Lobophore.

Le genre Mellita, ainsi circonserit, comprend de grandes espèces très plates et de forme subcirculaire, les diamètres longitudinal et transversal étant à peu prẻs égaux; quelques espèces, tels que le $M$. pentapora et le $M$. testudinata sont même plus larges que longues, comme c'est aussi le cas de plusieurs espèces de véritables Scutelles. Les lunules sont tantòt au nombre de ‘inq, tantôt au nombre de six, suivant qu'il y en a une dans l'aire ambulacraire impaire ou non. Les ambulacres pairs en sont toujours pourrus, ainsi que l'aire interambulacraire impaire; la lunule de cette dernière est même pour lordinaire la plus grande. Cette variation dans le nombre et la forme des vacuoles constitue des caractères spécifiques dont il faut tenir compte dans l'ẻtude de chaque espèce. En général, les lunules des Mellites sont allongées, grêles et presque toujours fermées, tandis que celles des Encopes sont rondes, larges el souvent onvertes str les bords. Létoile ambulacraire est de moyenne grandeur; les pétales sont arrondis à leur extrémitẻ. La rosette apiciale présente une structure poreuse et finement granulaire. Les pores oviducaux, au nombre de quatre, s'ouvrent á l'extrémité des rayons du corps madréporiforme, au sommet des aires interambulacraires. Les cinq trous ocellaires placés au sommet des ambulacres, sont ordinairement trop petits pour pouvoir êire aperçus a l'ail nu. La bouche 
est légèrement subcentrale; elle est de forme circulaire, mais les tubes des branchies qui font saillie sur son pourtour lui donnent ordinairentent une apparence ondulée. L'anus est de forme ovale ou pyriforme, et d'autant plus rapprochie de la bouche que la lunule de l'aire interambularraire impaire est plus longue; en général l’espace qui sépare l'ouverture buccale de l'ouverture anale n'excede pas la longueur de cette dernière.

La face inféricure est aussi accidentéc que la face supérieure est uniforme. Les sillons ambulacraires se ramifient de toute manière dans leur trajet du centre à la périphérie; les tubercules affectent également une disposition très variéc: ils sont ordinairement trẻs développés sur le milieu, tandis qu’ils sout beaucoup plus serrés et presque microscopiques le long des sillons. Cette disposition des tubercules se réfléchit nécessairement dans l'arrangement des piquans, ensorte que les aires interamlulacraires sont garnies de soies beaucoup plus développées que les aires ambulacraires. Il existe en outre une différence profonde, quant à la forme, entre les soies de la face inférieure et celles de la face supérieure. Ces dernières sont courtes el clavellées; celles de la face inféricure au contraire sont grẻles et subulées. Une troisième espèce de soies, de forme aplatic, entoure les lunules à la face supérieure ; ce sont les plus grosses.

La cavité intérieure présente des particularités fort remarquables : du plancher inférieur naissent, dans les aires interambulacraires, des piliers plus ou noins développés, qui semblent destinés à supporter le planclier supérieur. Leur forme n’a rien de régulier ; il y en a ordinairement deux dans claque aire, mais sourent aussi ils sont soudés entre eux de maniẻre à n'en former qu'un seul. Une membrane est étendue autour de ces piliers et sépare ainsi la cavitẻ luccale de la cavité intestinale. Quoique les exemplaires dont je me suis servi pour étudier les organes intérieurs ne fussent pas entièrement frais, j'ai cependant pu y reconnaitre la forme de lintestin et le poursuivre dans son trajet depuis la bouche jusqu'à lanus. En sorlant de l'appareil masticatoire, l'intestin va s'altacher à la rosette apiciale interne, passe par dessus la màchoire antérieure droite et de là se courbe à gauche; d'abord très grẻle, il se dilate peu à peu et acquiert sa plus grande largeur vers le milieu de son trajet. Après avoir parcouru le flane gauclie et envoyé des processus dans toutes les cavités cellulaires, il arrive au bord postérieur: ici les cloisons de la lunule de l'aire interambulacraire impaire lui barrant le passage, il sinfléchit en dedans, passe par dessus l'ouverture anale en traversant un canal formé par les piliers de l'aire interambulacraire impaire, qui sont adossés contre les cloisons de la lunule, et de là se dirige sur le còté droit, remonte jusqu'à l'aire interambulacraire antérieure droite, où il se replic sur lui-mème pour regagner de noureau le bord postérieur et renir aboutir à l'ouverture 
anale (Voy. pour les détails la fig. 6 de Tab. 3, qui représente l'intérieur du Mellita quinquefora, vu d'en haut).

L’appareil masticatoire est composé de cinq mâchoires à clıarpente trẻs grèle, mais garnies de lames nombreuses et très allongées, surtout dans les mâchoires postérieures. Les dents sont de petites lames aplaties, émaillées et fixées verticalement dans le sillon de la face supérieure des màchoires; comme ces dernières ne sont pas très hautes, les dents ne sont que légèrement inclinées de haut en bas. Clıaque màchoire s'appuie sur une des cinq auricules qui entourent l'ouverture buccale.

Je connais jusqu’ici cinq espèces de Hellites, dont les unes habitent les côtes occidentales d'Afrique, les autres les côtes orientales du centre de l'Amérique. Celles qui ont conservẻ leurs teintes sont toutes vertes.

\section{Miellita Quiveuefori Ag. *}

Tal.. 3.

Srx. Scutella quinquefora Lam. 3e Ed. Tom. 3. p.280. - E. Desl. Enc. Tom. 2, p. 676, No 5. - DeBl.

Dict. Sc. nat. T. 48, p. 223. - DesMoul. Tabl. syn. p. 224, No\% Seutella pentapora DeBI. Zooph. p. 220. - Agass. Prod. p. 188.

Cette espèce figure généralement dans les collections d'Europe sous le nom de Scutella quinquefora que lui a donné Lamarck. Ayant un jour eu l'occasion de comparer une sẻrie assez nombreuse d'exemplaires qui m'avaient été envoyés de Porto Rico, je m'aperçs qu'on avait confondu plusieurs espèces sous ce nom. Les exemplaires provenant de la Vera-Crux différaient évidemment de ceux de Porto Rico, et comme c'est l'espèce de la Vera-Crux qui se trouve figurée dans Leslie, je lui conservai le nom de Mellita testudinata que lui avait donné Klein, en la distinguant du Mellita quinquefora, qui est l'espèce de Lanarck.

Les fig. 1 et 2 représentent le Mellita quinquefora avec ses teintes naturelles, lorsque les soies sont enlevées. La fig. 3 le montre avec ses soies par la face supérieure. La fig. 5 est une esquisse d'un jeune individu vu par la face inférieure. Un coup d'œil jeté sur ces diverses figures suffit pour en faire ressortir l'un des caractères les plus importans, la largeur extraordinaire du test comparće à sa longueur. Dans l'exemplaire de fig. 3, l'un des plus beaux et des plus

(“) Lorsque je fis exécuter les planches ci-jointes, je n’avais pas encore distingué le genre Mellita des Encopes: c'est pourquoi cette espéce y figure sous le nom d'Encope pentapora, au lieu de Mellita quinquefort. 
grands que je connaisse, le diamètre transversal est de $\%$; plus long que le diametre longitudinal, et l'on remarque que la région postérieure est toujours plus litrge que la région antérieure; au reste, la forme du test est assez généralement subcirculaire. Le côté antérieur est tantòt arrondi, tantôt tronqué. Il en est de même du côté postérieur; en sorte que le plus ou le moins de régularité dans le pourtour du test ne peut point être invoqué comme un caractère spécifique. L'exemplaire de fig. 6 a même une forte échancrure au bord postérieur dans le prolongement de la lunule de l'aire interambulacraire impaire; mais il est probable que cette échancrure n'est qu'accidentelle, peut-être même le résultat d’une brisure qui se sera cicatrisée et recouverte de soies avec le temps. La fig. 4 représente le profil de cette espèce qui, comme on le voit, est très plate; le plus fort renflement correspond à la région postérieure. Les lunules sont au nombre de cinq, ainsi que l'indique le nom spécifique. Il y en a une dans le prolongement de chaque ambulacre et une dans l'aire interambulacraire impaire ; l'ambulacre impair en est dépourvu; toutes ces lunules sont étroites et très-allongées; celle de l'aire interambulacraire est la plus grande. Les pétales ambulacraires sont larges et s’étendent jusqu’au dela de mi-bord; elles montrent un léger renflement au milieu. Les deux pétales pairs postérieurs sont ordinairement un peu plus grands que les antérieurs, plus ou moins tronqués à leur extrémité et légèrement fléchis en dedans, sans doute par l'effet de la lunule de l'aire interambulacraire impaire qui les refoule latéralement. L'espace occupé par les petits sillons, ou la zone porifère proprement dite, est plus large que l'espace intermédiaire. La fig. 9 représente une partie d'un ambulacre sous un très fort grossissement, oủ l'on voit que même l'espace entre les sillons est garni de petits tubercules très rapprochés et disposés par rangées transversales. La face supérieure du test présente une granulation très homogène qui correspond à l'unifornité des soies. Il n'y a que les bords des lunules qui soient garnis de tubercules plus gros; aussi portent-ils des soies beaucoup plus développées, qui souvent ferment presque entièrement les lunules. La rosette apiciale est petite et d'une structure spongieuse. Les quatre pores génitaux sont placés à l'extrémité des rayons de cet organe spongieux, au sommet des aires interambulacraires. Les trous ocellaires, placés au sommet des aires ambulacraires, sont à peine visibles à l'œil 11u. La face inférieure, ainsi que nous l'avons dit à l'article du genre, n’a rien de l'uniformité de la face supérieure; les aires interambulacraires y sont garnies de tubercules beaucoup plus nombreux que les aires ambulacraires; aussi portent-ils des piquans sensihlement plus grands. Cette différence dans la structure de la face inférieure se réfléchit même dans les teintes de l'animal, qui sont toujours plus claires sur les aires interambulacraires que sur les aires ambulacraires, alors 
nème que les soies sont enlevées, voy. figg. 2. La figg. 10 représente une portion grossie d'une aire interambulacraire de la face inférieure; les tubercules y sont entourés d'une granulation excessivement fine que l'on n'aperçoit qu'à l'aide d'une forte loupe. Les sillons qui correspondent aux ambulacres, sont criblés de petits pores dans toute leur étendue, jusqu’à l'extrémité des rameaux latéraux les plus menus. Ces sillons, très marqués dans cette espèce, se ramifient d'une manière fort irrégulière, ensorte que la fréquence des loranches latérales ne yeut pas être envisagée comme un caractère spécifique: elle varie d'un individı à l'autre, et souvent même les sillons d'un seul ef même individu peurent présenter des variations très notables, comme c'est par exemple le 'as de l'exemplaire figuré : les sillons des ambulacres postérieurs sont bien plus ramifiés que ceux des ambulacres antérieurs et, qui plus est, ils empiètent même sur l'aire interambulacraire impaire, qu'ils sillonnent dans tous les sens (fig. 2). La bouche est subcentrale, plus rapprochée du bord antérieur que du bord postérieur; elle est de forme circulaire et entourée, dans les exemplaires bien conservés, d'un cercle de soies qui la masquent plus ou moins. Son apparence ondulée provient uniquement des saillies que font sur son pourtour les tubes des branchies buccales, qui occupent la partie antérieure des sillons ambulacraires. Ces tubes sont plus longs dans les sillons des ambulacres postérieurs que dans ceux des ambulacres antérieurs, par la raison que dans ces derniers les deux branches du sillon ne se réunissent que dans le voisinage dı ponrlour de la bouche. L’anus est de forme oroüde et très rapproché de la bouche, il est ordinairement fermé par un tissu de plaques calcaires de forme irrégulière.

J'ai pu étudier, dans l'exemplaire de fig. 3, les trois sortes de niquans qui caractérisent les Mellites: ceux de la face supérieure sont en général petits, mais d'une forme particuliere; on dirait de petites massues très renflées a leur extrémité; la fig. 11 a en représente un sous un Irès faible grossissement. Ceux de la face inférieure sont les plus longs, cylindriques et subulés: aulin les soies qui orcupent le bord des lunules, forment la troisiẻme espèce; ce sont des piquans moins longs que les précédens, mais sensiblement plus massifs; les fig. 1 ' $l$ el $c$ les monIrent par leur face aplatie, qui présente d'un côté une espèce de dépression en forme de cuillère allongẻe. La fig. $d$ représente le mème piquant vu de profil par sa face tranchante. Toutes ces soies paraissent soumises dans leur disposition à des lois constantes. Cenx de la face supérieure sont généralement inclinés vers la périphéric avec une tendance plus ou moins marquée à se courber latéralement, disposition qui n'est pas visible à l'oeil nu a cause de la petitesse des soies. mais quon aperçoit fort bien au toucher. Les soies des lunules sont génẻralement dirigées obliquement des hords vers le milieu, ce qui fait que sourent elles masquent à peu prés compléte- 
ment ces dernieres. A la face inféricure, les soies des aires interambulacraires postérieures paires sont dirigúes en dedans, tandis que celles des aires anterieures le sont en dehors. Comme la mème disposition se reproduit à peu prés dans toutes les especes dont jai ohservé les soies, je renvoie à la figr. 11 de pl. 't a qui représente la face inférieure du Mellita hexapora aves ses soies.

La disposition des organes intëricur's est d'un trẻs grand intérêt : la fig. 6 de Tab. 3 représente lintcirieur du test, vu d’en haut, le plancher supérieur étant enlevé. On y reconnait trés distinctement la lorme et la direction de lintestin, qui, en quittant le sommet de la rosette apiciale interne, passe par dessus la màchoire antérieure droite, de la se déploie, sous forme l'estomac, sur le flane gauche, passe ensuite sur le flanc droit, remonte vers le bord autérieur et revient de nouveau en arrière; en sorte qüil passe deux fois sur le còté droit el une fois sur le còté gauche. Toute la masse du test est en outre remplie de cellules, que j’ai trourées tapissées d'une membrane brunâtre, absolument semblable à l'intestin, en sorte que je ne dou te nullement qu'elles ne soient destinées à receroir des appendices du canal intestinal. L'appareil nasticatoire occupe le centre de la cavité intérieure; il est séparé de la cavité intestinale proprement dite par les piliers qui sélèvent du plancher inférieur dansles aires interambulacraires. La fiğ. 8 représente lappareil masticatoire isolé, vu par sa face inférieure. On remarque que les deux rayons postérieurs de la rosette sont sensiblement plus Iongs que les antérieurs. Cette différence tient uniquement à ce que les lames inférieures sont beaucoup plus longues dans la màchoire postérieure que dans les autres, ainsi qüil est facile de s'en convaincre en étudiant attentivement les mâchoires isolées. Les dents, dont l'extrémité seule est émaillée, sont fixées par leur tranche dans le silton des mâchoires. La fig. T représente la partie centrale du plancher inférieur, aprẻs en avoir enlevẻ la rosette masticatoire. On y distingue la position et la forme des auricules destinées á supporter l'appareil masticatoire; elles sont larges et présentent une légère échancrure au nilieu. La houche, qui est au centre, est entourée de soies rayonnantes. Enfin l'on apercoit aussi dans cette mème figure les piliers calcaires, qui sont situés, ainsi que les auricules, dans les aires interambulacraires. Jai dejja fait remarquer plus haut que ces piliers varient considérablement de forme et de grosseur suivant les individus.

Je dois à l'obligeance de mon parent, M. Auguste Mayor, de New-York, une séric nombreuse d"individus de cette espèce, recueillis par lui à Porto-Rico. Tous sont d'une helle teinte rerte. 
II. Mellita testedinata Kil.

Tab. $4 a$, fig. $7-9$.

Sya. Mcllita tcstudinata Klein, Ed. Leske, pag. 25, Tab. 21, fig. C. D. - Ejusd. Maxillæ, 1. 36, Tab. 33, fig. $r$ et $s .-$ Klein Gall. $\$ 82$, p. 92, Tab. 11, fig. C.

Echinodiseus quinquies perforatus Leslie apud Klein, p. 197, sp. 51.

Eelinus orbieulus var. ๆ Lin. Syst. nat. $12^{e}$ édit. p. 1105.

Echinus pentaforus Lin. Gm. p. 3189.

Echinoglycus quinque canalibus pervius van Phels. Brief over ZeeEgelen, p. 35.

Pain d'épice de la Vera-Crux Davila. Catal. T. 1, p. 423.

Echinus laganoïdes orbicularis Seba, Thes. Tom. 3. Tab. 15, fig. 9 et 10.

Scutclla quinqucfora Encycl. mèth. T. 149, fig. 3 et 4.

Echinodisclis Gualt. Test. Tab. 110, fiğ. E.

Muller Dclic. nat. I. p. 93. Tab. D. I, fig. 16.

L'espèce dont il est ici question a déjả été dẻcrite et figurée par Ḱlein, et comme les figures que cet auteur en donne se trourent reproduites dans l'Eneyelopédie méthodique, el que la figure de Seba semble être la mêne, j’ai rapporté au M. testudinata tous les synonynes des aulteurs anciens, en ne citant au $M$. quinquefora que ceux des auteurs qui ont décrit des exenplaires du Muséum de Paris ou du moins les ont eus sous les yeux.

Le principal caractère qui distingue le $\boldsymbol{M}$. Lestudinata du $\boldsymbol{M}$. quinquefora consiste eu ce que le plus grand diamètre transversal, au lieu de correspondre à la région postẻrieure, correspond au contraire à la région antérieure. Cette diffërence, bien qu'essentielle et eonstante, ne frappe pas au premier abord, surtout lorqu'on n'a pas l'habitude d'orienter les individus en les étudiant. Sous tous les autres rapports le $\boldsymbol{M}$. testudinata présente à peu près les mèmes particularilés de structure que nous avons signalées dans le $\boldsymbol{H}$. quinquefora (voyez la deseription ei-dessis). La fig. 10 représente les tubercules de la face supérieure sous un fort grossissement, afiı de faire voir leur forme et la manière dont ils sont entourés de plus petites verrues. Les soies présentent la même structure et la même disposition que dans le $M$. quinquefora. J'ai figuré au microscope (fig. 7 a) l'un des piquans qui bordent les lunules à la face supérieure, afin de faire voir que malgré son apparence lisse, il est cependant hérissé de nombreuses aspérités, conme les piquans de tous les Echiuides en gẻnẻral. Le dessin le représente par la face aplatie. 
Klein a domé une figure assez imparfaite de l'une des màchoires. Je n'ai pas eu l'occasion d'observer moi-mêmel'appareil masticatoire dans son ensemble; mais je ne pense pas qu'il puisse ¿tre bien différent de celui du $M$. quinquefora, qui se trouve figuré sur la pl. 3, fig. 6 et 8 .

Tous les exemplaires de cette espece que j’ai pu examiner jusqüici proviennent de la VeraCrux, d’où élait anssi originaire l'exenplaire de Klein. Je les ai tous trouvés d'une teinte brunàtre; mais comme les soies des lunules sont encore vertes dans l'exemplaire figuré, il est rraisemblable qu'i l'élat vivant ces animaux sont verts comme le M. pentapora. Les exemplaires figurés font partie du Muséum de Paris et mont été communiqués par M. Valenciennes.

\section{Mellita hex.ipori Ag.}

Tal. IV, fig. 4-7, et Tal. IV a, fig. 11 et 12.

Six. Echinus hexaporus L. Gm., p. 3189. - Farann. pl. 58, fig. Ci3.

Scutella hexapora DeBl. Zooph. p. 200. - Agass. Prodrome Echin. p. 188.

Scuella serforis Iam. T. 3, p. 279, No 4. - E. Desl. Enc. T. 2, p. 676, No 4. - Encycl. méth. pl. 149, fig. 1 et $2 .-$ DesMoul. Tabl. syn. p. 224, $N^{0} 6$.

Echinotrochus perforatus (Doorgeboorde Eggelschyr) Van Phels. p. 33, N०2.

Echinodiscus sexies perforatus Leslie apud KI., p. 199, Tab. 50, fig. 3, 4.

Eelionanthus Seba Thes. Tab. 15, fig. 7, S.

Oursin de mer étoilé Kilein Gall. Suppl. au Cab. de Réaumur, p. 230, 231. Tab. 24, fig. A, B, et 1, 2. Pain d'épice de la Barbade ù six fentes. Davil. Catal. I. p. 423, No9.55.

Müller Deliciae nat. I, p. 93, Tab. D, 1, fig. 17.

Encycl. (Dict. des sc.) Tab. 59, fig. 6.

Knorr, Delic. Tab. D, I, fig. 17.

C'est évidemment à tort que Lamarck envisage le Mellita hexapora et le Mellita quinquefora comme de simples variétés d'une seule et même espèce. Non seulement le M. hexapora a constamment six lunules, mais sa forme est aussi complètement différente. Le diamètre longitudinal et le diamètre transversal sont à peu près égaux; le còté postérieur est tronqué ou subtronqué; le côté antérieur au contraire est légèrentent rostré. Les lunules sont en général étroiles et trèsallongées; celle de l'aire interambulacraire impaire est la moins développée; elle est mème trẻspetite et presque rudimentaire dans les jeunes individus (voy. fig. 7). Le test est très-aplati (fig. 5). La rosette ambulacraire est petite proportionellement aux dimensions du test (roy. 
fig. 4); les pétales n’atteignent pas même la moitié de la distance entre le sommet et la périphérie; les zones porifères ont à peu près la nêtme largeur que l'espace intermédiaire. Les pores génitaux sont distans; les pores ocellaires sout trop petits pour être aperçus à l'oil nu. Les plaques dout se compose le test sont toutes reuflées an milieu, quoique d'une manière moins frappaute daus les vieux individus que dans les jeunes : ceux-ci ont au centre des plaques uue petite aspéritè plus ou moins saillante, qui cependant n'est poiut un tubercule (fig. 7 ). L'iutérieur ne laisse apercevoir aucune trace de l'articulation des plaques: on n'y remarque qu'une surface rugueuse, cellulaire, en forme de lames saillantes, (voy. la fig. 6, qui représente le plancher supérieur vu par sa face interne). Les quatre pores génitaux s'y ouvrent à l'extrénité des rayons osseux qui s'avancent dans les aires interambulacraires. Les ambulacres montrent la structure intime et l'articulation des plaques des pétales. Au sommet de ceux-ci se voient les trous ocellaires qui sont au nombre de cinq. Eufin l'on remarque aussi des traces de l’intestin autour de l'extrémité des pétales ambulacraires.

La fig. 11 de Pl. 4 a montre la disposition des soies à la face inférieure, telle qu'elle se présente dans toutes les espèces de ce genre. Celles des aires interambulacraires paires postérieures sont couchées de dehors en dedans; celles des aires interambulacraires paires antérieures, au contraire, de dedans en dehors; de telle manière qu'en promenant le doigt de l'aire interambulacraire postérieure gauche à l'aire interambulacraire autérieure droite, et de mème de l'aire interambulacraire postérieure droite à l'aire interambulacraire antérieure gauche, on Irouve les soies inclinées dans la même direction, à l'exception de celles qui entourent immédiatemeut la bouche, et dont la dispositiou est circulaire. Les soies de l'aire interambulacraire iuppaire sont inclinées latéralement vers la lunule.

J'ai figuré des soies isolées des différentes parties du test sous un très-fort grossissemeut, afin de douner une idée exacte de leur forme et de leur structure. Celles de fig. $11 a, b$, sont tirées de la face supérieure; elles se font remarquer par leur forme clavellée. Les soies de la face inféricure sout plus cylindriques, celles de fig. $12 d, e$, sont prises sur les aires ambulacraires; celles des fig. $a, b$ sont des aires iuterambulacraires, et celle de fig. $c$ du bord de la bouche. On le voit, il n'y a que la forme qui varie; la structure intime est la même dans toutes ; même le piquant de fig. 7 a, qui appartient au $M$. teshudinata, ne présente sous ce rapport aucune différence.

Il y a tout lieu de croire que les auteurs ont confondu plusieurs espèces sous le nom de M. (Scutella) hexapora; surtout si l'on considère les habitats très-diflérens qu'ils lui assignent. 
Leske dit que l'exemplaire du Musée de Réaumur fut rapporté de l'île Barbade par Itughes. Muller la cite a la fois dans l'Océan indien et dans les mers septentrionales; Davila la dit originaire de la còte de Coromandel et de la Vera-Crux. Or il n'est pas vraisemblable que la même espèce se rencontre dans des contrées et des climats aussi diflérens. Parmi les nombreux exemplaires que jai eu l'occasion d'examiner, il ne s'en trouve aucun dont l'origine me soit connue. Je dois a l'obligeance de M. Gray la communication de l'exemplaire muni de ses soies, représente Tab. 'a a, fig. 11. Sa couleur est d'un beau vert olive. D'autres exemplaires m'ont ité coufiés par M. Michelin et par MI. le docteur Mayor, de Genève.

\section{Mel.Lit. similis Ag.}

Tal. IV, fig. 1-3.

11 est probable que cette espèce a été confondue jusqu'ici avec le $\boldsymbol{M}$. hexapora dont elle est effectivement trẻs-voisine. Sa forme est subcirculaire, le côté postérieur est plus ou moins tronqué; le côté antérieur, au contraire, a une légère tendance à se rostrer. Le diamètre longitudinal est plus grand que le diamètre transversal. L'espèce est en mème temps moins plate que les préeedentes et notamment que le $M$. hexapora, et l'on remarque que la plus grande ipaisseur, au lieu de correspondre au sommet, est à la région antérieure (voy. Tab. 4, fig. 3). Les lunules sont au nombre de six, mais elles sont bien moins allongẻes et plus irrégulières que dans le M. hexapora. Enfin, quoique l'espèce soit plus petite, l’étoile ambulacraire est en gènéral plus grande que dans eette dernière. La face inférieure se fait remarquer par des sillons et des ondulations très-prononcés, surtout au bord des lınules; ce qui lui donne une apparenre très-accidentée, que n'a point le $\boldsymbol{M}$. hexapora.

Je ne connais que deux exemplaires de cette espece; tous deux sont dépourvus de leurs soies; mais comme ils sont décolorés, je me suis contenté de représenter en noir l'exemplaire qui a servi d’original á mes figures. Il provient de Porto-Rico, d'oủ il m’a été envoyé par M. A. Mayor: le second fait partie de la collection de M. Micheliu. 


\section{Melliti lobita $\mathrm{Ag}$.}

Tal. 4a, fig 13, et Tab. 16, 1-7.

Quoique voisine du Mellita hexapora, cette espèce présente cependant une physionomie toute particulière, qui rẻsulte essentiellement de ce que les lunules des ambulacres postérieurs sont ouvertes. Ce caractère, quoique frappant, ne serait cependant pas suffisant pour constituer une espèce à part, si toutes les lunules n'étaient en mème temps sensiblement plus larges que dans les autres espèces du genre. La lunule de l'aire interambulacraire impaire est la moins longue et la plus étroite de toutes. La forme irrégulière du test n’est sans doute qu'accidentelle; cependant il est probable que, même dans les individus réguliers, le diamètre longitudinal esı plus grand que le diamètre transversal. Les pétales des ambulacres sont larges et arrondis à leur extrémité. Les zones porifères l'emportent de beaucoup en largeur sur les espaces intermédiaires. Les trous de la rosette apiciale sont très-distincts, et, par une particularité digne de remarque, les cinq pores ocellaires sont aussi grands que les pores génitaux; ceux-ci sont au nombre de quatre, comme dans toutes les espèces du genre.

La face inférieure ne présente rien de particulier dans sa structure; les sillons ambulacraires y sont très-fins et peu marqués, comme dans le M. hexapora, et l'on ne remarque autour des lunules aucune trace de ces ondulations prononcées qui sont un caractère essentiel du M. similis.

L'intérieur est conformé de la même maniëre que l'intérieur du M. quinquefora. L'appareil masticatoire est composé de màchoires de moyenne grandeur, hérissées de fines lames calcaires en haut et en bas. La fig. 4 de Tab. $16^{*}$ représente cet appareil ru par la face inférieure, les cinq mâchoires étant réunies et montrant, sur la ligne médiane, la pecite carẻne qui s'engrène dans l'échancrure des auricules. La fig 7 représente les cinq mâchoires disjointes, vues par la face supérieure, avec le sillon médian, dans lequel étaient fixées les dents. Les fig. 5 et 6 montrent le profil de l'une des mâchoires, de côté (fig. 6), et par derrière (fig. 5).

Je ne connais de cette espèce que le seul exemplaire qui est ici figuré. ll fail partie de la collection du Muséum de Paris et m’a été communiqué par M. Valenciennes. Son origine est inconnue.

(") C'est par erreur que les mâchoires de cette espèce ont été ajontées aux figures du $S_{c}$, truncata, au lieu d'être figurécs sur la Tab. $4 a$. 


\section{CHAPITRE IY.}

\section{DU GENRE LNCOPE.}

Les Encopes sont en général des espèces de grande dimension, qui, pour la plupart, se font remarquer par leur forme élégante et par les belles proportions de toutes les parties de leur test. Toutes ont une échancrure ou une lunule dans le prolongement des pétales ambulacraires et une ouverture dans l'aire interambulacraire impaire. La forme et les dimensions de ces lunules varient plus ou moins dans les diffẻrentes espèces, et l'on remarque même des différences assez notables dans les individus d'une seule et mème espèce, suivant leur àge. Les échancrures ambulacraires, ordinairement très ourertes dans les jeunes, ont une tendance à se fermer dans les rieux. La bouche est centrale ou subcentrale, sa forme est circulaire; mais comme les tubes destinés à loger les branchies buccales font saillie sur son pourtour, il en résulte que celui-ci prend, dans la plupart des espèces, une apparence ondulée. Dans les individus qui ont conservé leurs soies, la bouche est plus ou moins masquée par les piquans qui naissent et s'entrecroisent sur ses bords. L'anus est très rapproché de la bouche et placé sur le bord interne de la lunule de l'aire interambulacraire impaire. Les pétales ambulacraires sont en général très déreloppés et arrondis à leur extrẻmité. Lorsque la lunule interambulacraire est très grande, les pétales postérieurs qui sont toujours les plus longs, sont ordinairement un peu refoulés latéralement; de lả leur forme souvent arquée. Les soies varient suivant leur position ; celles de la face supérieure sont courtes et clavellées, celles de la face inférieure sont grêles et cylindriques.

Mais tous ces caractères sont plus ou moins communs aux Mellites. Voici maintenant à quels signes particuliers nous distinguerons le type des Encopes : Les lunules et les entailles sont toujours élargies, plus ou moins arrondies et souvent très ouvertes, tandis que dans les Mellites elles sont allongẻes, trẻs grêles et généralement fermées. De plus, il y a cinq pores génitaux, tandis que les Mellites n'en ont que quatre. Enfin la couleur des Encopes est généralement 
rouge, violette ou brune; celle des Mellites est au contraire verte ou olivàtre. A ces caractères extérieurs correspondent des différences plus profondes dans la structure de l'intérieur du test. Ces diflěrenees consistent essentiellement dans la présence d'une cloison eelluleuse continue qui sépare la cavité buccale de la eavité in testinale el qui remplace parconséquent les piliers ealcaires qui se trouvent dans les Mellites. Pour donner une idée exacte de eelte disposition, j’ai représenté sur la Pl. 19 a , fig. 7 , lintérieur de l'E. micropora, après eu avoir enlevé le plancher inférieur. La cavité buccale, qui est au centre, prísente un pourtour pentagonal, dont les anses correspondent aux aires ambulacraires; e'est daus ces anses que se logent les rayons de l'appareil masticatoire. En sortant de la cavité buccale, l'ésophage passe par dessus un col de la cloison médiane $(x)$ eorrespondant à l'aire ambulacraire impaire, s’étale sur le flanc gauche $(a)$, traverse, au dessous de l'anus, un eanal étroil qui se trouve à l'origine de la lunule de l'aire interambulacraire impaire, passe sur le flane droil, oủ il remonte jusqu’à l'aire interambulacraire antérieure gauche $(b)$; là il se replie sur lui-même et rétrograde vers l'anus en suivant un eanal hordé d'une part par la cloison de l'ouverture buccale et, de l'autre, par une cloison particutière $(c)$. Arrivé de nouveau au bord de la lunule postérieure, après avoir décrit plusieurs contours très prononcés, il s'enfonce daus le test el vient aboutir à l'anus (d) qui est percé obliquement de dehors en dedans. L'intestin passe par eonséquent, eomme dans toutes les Scutelles, deux fois sur le llanc droit et une fois sur le flane gauche; il est très large sur ce dernier. Enfin ee qui earactérise d'une manière toute spéciale les Encopes, e'est que la eloison intermédiaire entre les deux parties terminales de l'intestin, au lieu d’ètre membraneuse, conme dans les autres genres, est au contraire ealcaire el celluleuse, comme la cloison qui entoure la cavité buccale. L'E. Stokesi fait seule exception à eette règle (voyez la description de ectte espece). Il existe en outre une séparation ou une sorte de plancher horizontal entre la cavité buccale et le plancher supérieur (o) ; e’est dans celte dernière cavité que sont contenus les organes ambulacraires intérieurs; la face inférieure du pétale postérieur gauche se montre à travers une lacune de ce plancher (s). La masse entière du test est beauconp plus celluleuse que dans aueun autre genre. L'appareil mastieatoire se compose de màchoires très fortes, mais d'ailleurs très semblables dans leur structure à celles des Mellites.

Le nombre des espèces connues se monte à onze. Toutes sont de l'époque actuelle. Mallıureusement il y en a plusieurs dont je n’ai pu connaitre l'origine, les ayant trouvées pour la plupart sans éliquettes dans les collections. 
I. Excope mingivita Agass.

Tab. 10.

Siv. Scutella enarginata Lam. T. 3, p. 279, N03. - E. Desl. Enc. T, 2, p. 675, N0 3. - Encycl. métl. pl. 150, f. 1, 2. - DeBl. Dict. sc. mat. T. 48, p. 224 . - DeBl. Zooph. p. 201. - Agass. Prodr. Echiu. p. 188. - DesMoul. Tabl. syn. p. 222, N ${ }^{0} 5$.

Echinodiscus emarginalus Leske, $\mathrm{N}^{0} 53, \mathrm{p} .200, \mathrm{pl} .50 ;$ f. 5,6 .

Echimus emarginatus L. Gm. p. 3189.

Grand Oursin de mer éloilé. Kil. Gall. suppl. du Cab. de Réaumur; p. 231, 232, pl. 2h, f. A. et pl. 26, f. B.

Echinoglyeus frondosus. Van Plielsum, p. 31 .

Quoique trẻs rare dans les collections, cette espèce est cependant connue depuis long-temps des naturalistes. Sa forme est subcirculaire en avant et plus ou moins tronquée en arrière. Le diamètre transversal et le diamètre longitudinal ont sensiblement les mèmes dimensions. L'épaisseur' égale à peu près le sixième de la longueur (fig. 3). La surface entière du test, lorsqu'elle est dépourvue de ses soies, présente une granulation très liomogène, surtout à la face supérieure. La face inférieure est plus variée; les tubercules y atteignent leur plus grand développement sur les aires interambulacraires, tandis qu'ils sont d'une finesse extrême sur les aires ambulacraires. La fig. 6 représente quelques tubercules spinifères des aires interambulacraires sous un grossissement de $1 \frac{1}{2}$ fois le diamètre et entourés de tubercules miliaires qui occupent l'espace compris entre les aréoles des plus grands.

J'ai indiqué, dans les fig. 1, 2 et 3 , les ouvertures du test par des lettres, ayant trait au plan de position de l'animal. La lunule de l'aire interambulacraire impaire $(p)$ est proportionnellement petite; ses bords ne sont point renflés; les cinq ouvertures des aires ambulacraires ne sont pas non plus très développées; celles des ambulacres postérieurs ( $p d$ et $p s$ ) sont labituellement lermées près du bord et plus grandes que celles des ambulacres antérieurs $(a, l d$ et $l s)$; mais comme il règne une trẻs grande variété dans la forme et la grandeur de ces ouvertures, on ne saurait guẻre les envisager comme des caractères spécifiques. C'est ainsi que dans l'exemplaire figuré, la lunule de l'ambulacre antérieur droit $(l d)$ est fermée, tandis que celle du côté gauche $(l s)$ est ouverte. Dans d'autres, les deux ourertures du côté droit sont seules ouvertes, 
dans d'autres encore toutes sont fermées. Il en est de même de la lunule de l'ambulacre antérieur impair $(a)$ : elle est trẻs ouverte dans l'exemplaire figuré, tandis que dans la plupart des autres exenplaires que jai sous les yeux, elle est fermée; e'est toujours la plus petite des ouvertures. L'étoile ambulacraire est très élégante. Les pétales postérieurs sont les plus longs et en même temps les plus étroits ; les antérieurs pairs sont courts, larges et trẻs arrondis à leur extrémité. Le pétale antérieur impair enfin tient généralement le milieu entre les autres. L'espace conipris entre les zones poriféres est sensiblement plus large que ces zones elles-mêmes dans les ambulacres antérieurs; dans les ambulacres postérieurs, en revanclie, eette différence est moins sensible; les zones porifères et l'espace intermédiaire sont à peu près d'égale largeur. La figure 4 représente la moitié du pétale antérieur grossi afun de faire voir la forme des sillons transverses et la manière dont ils sont séparés par une rangée de tubercules. Les pores ambulacraires se laissent encore poursuivre au deli de la rosette ambulacraire. L'on remarque sur chacune des plaques du test formant le prolongement des pétales, une paire de pores situce tantôt an milieu, tantôt au bord de la plaque; mais ils sont souvent tellement petits, qu'on a de la peine à les reconnaitre à l'œil nu. La rosette apiciale présente une étoile pentagonale dont les rayons s'arancent dans les aires interambulacraires, oủ ils se terminent par les pores génitaux qui sont au nombre de cinq, comme dans toutes les espèces du genre. Les trons ocellaires placés au sommet des ambulacres, sont beaucoup plus petits que les trous oviducaux, mais cependant Irès distincts, mêne à l'ail nu. La surface de l'appareil oviducal ne présente point une struclure tuberculeuse comme le reste du test, et lorsqu'on l'exanine a la loupe, on la trouve composée d'un tissu spongieux, à la surface duquel viennent aboutir une quantité de petits tubes. La lace inférieure est trẻs ẻlégamment accidentée par suite de la variélé des tubercules et de la ramification des sillons (fig. 2). La houche qui est un peu rejelée en avant, est petic proporlionuellement à la grandeur du test. On remarque sur son pourtour les vinq petits tubes destinés à loger les branchies buccales et dont les extrémités, en forme de bourrelets, fout saillie sur le pourtour de la bouche (royez la fig. 5 qui représente la bouche grossie). L'anus, de forme sub'muique, осcupe à peu près le milieu de l'espace entre le hord interne de la hunle interambulacraire et louverture buccale. Les sillous ambulacraires se ramifient d'une manière très variée, el. lorsquiou vient ì les exanniner à la loupe, on trouve que nou seulement les rigoles principales, uicis même les plus petits cauaux lateraux, sont parsemés de pores microscopiques. II en résulte que les tubes auxquels ces trous donnent passage, doirent nécessairement être plus nombreux à la face inférieure qu’a la face supérieure. 
Las figures ci-jointes sont dessinces d'après l'exemplaire original de Lamarck, le seul qui existe dans la collection de Paris; je n'en connaissais pas d'autres, lorsque mon ami Mr. Stolies. de Londres, eut l'obligeance de m’en commmniquer toute nne série, qui una servi à com-pléter la description de celte espèce. Plısieurs de ces exemplaires ont conservé une partie de lenrs soies. Elles sont petites et en apparence lisses. Mais lorsquon vient à les examiner à la loupe, on trouve qu'elles sont toutes striées et hérissées d’épines: celles de la face supérieure sont clavellées; celles de la face inférieure sont cylindriques et subulées, a peu près comme celles de l'Encope tetrapora (voyez Pl. 10 a). Les teintes de la surface du test sont d'un brun-jaunàtre: mais cette couleur passe au lilas sur les bords des lunules et du pourtour.

L'habitat de cette espèce n’est pas exactement comn ; elle paraît provenir des Philippines.

\section{Excope tetrapora Ag.}

Tab. $10 a$, fig. 1-3.

Echinus tetraporus Gm. p. 3190.

Scutella tetrapora DeBl. Zooph. p. 200. - Agass. Prod. Ech. p. 188.

Scutella quadrifora Lam. Tom. III, p. 280. - E. Desl. Enc. Tom. 2, p. 676, No 6. - Encycl. méll. PI. 148, fig. 1, 2. - DeBl. Dict. Sc. nat. T. 48, p. 224. - DesMoul. Tabl. syn. p. 224.

Echinodiscus quater perforautus Leske p. 204. Sp. 56.

Echinoglycus oblique ineisus (Schyf geschenrde Ligel kock met buisen) van Pliels. p. 34, No 5.

Echinanthus spec. 3. Seba Thes. Tom. III, Tal. 15, fig. 5, 6.

Quoique le Scutella (Encope) tetrapora se trouve mentionné dans tous les ouvages qui traitent des Oursius, il n'est cependant connu que par la figure qu'en a donnée Sćba et qui a été copiée par plusieurs auteurs. J'ai vainement cherché dans les collections et les musées d'Europe une especce qui portât ce nom. N'en trouvant pas, j'ai cru devoir envisager comme telle celle de mes especes qui se rapproche le plus de la figure ci-dessus mentionnée, sans que je puisse garantir d'une manière certaine son identité spécifique. C'est une question que l'on ne pourra décider que lorsqu'on aura retrouvé l'original de l'auteur hollandais. En attendant, voici les caractères de l'espèce que j'envisage comme l'Encope trelapora: la forme est ì peu pris circulaire; la plus grande largeur est en arrière du sommet. L'exemplaire figuré est même un peu plus larğe qư long̨. Le pourtour du test présente de légères échancrures dans le prolongement des ambu- 
lacres. Les lunules des ambulacres postérieurs sont ouvertes et d'égale largeur dans toute leur étendue. Les lunules des ambulacres antérieurs et latéraux sont petites, de forme ovoïde et complètement fermées. L'ẻpaisseur est assez considérable, et la surface supérieure présente une déclivité uniforme, mais très-brusque, sur le pourtour du test (fim. 3 ). La bouclie est centrale et circulaire. L'anus est petit, de forme ovoïde et plus rapproché de la bouche que du bord postérieur (fig. 2). Les sillons se ramifient considérablement dans toutes les directions. Les pétales sont larges, et malgré les soies qui recouvrent toute la surface du test, l'on remarque que l'espace intermédiaire entre les zones porifères est très-large.

L'exemplaire figuré a conservé sa couleur, qui est d'un rouge-brun très-foncé. Les soies sont très abondantes et diversement conformées suivant la place qu'elles occupent sur le test. Celles de la face supéricure sont en forme de massues (fig. $1 a, b$ ); celles de la face inférieure sont rylindracées et beaucoup plus longues que celles de la face supérieure, surtout dans les aires interambulacraires (fig. $d, c$ ). Examinées au microscope, toutes sont garnies de plis longitudinaux, finement dentelés.

L'exemplaire figuré, le seul que je possède, m’a été communiqué par mon ami MI. Stockes ; il provient des îles de Gallopagos. M. Ch. DesMoulins cite comme origine de son exemplaire la rôte occidentale d'Afrique, d'oủ il a été rapporté par M. Rang. Reste à savoir si c'est le même Iype. J'ai lieu de croire que non, car M. DesMoulins trouve la figure de Seba, plus ronde que son exemplaire.

\section{Excoñe micropora Agass.}

Tab. $10 a$, fig. i-S et Tab. $19 a$, fig. 7 .

Très-voisine à bien des égards de l' $E$. emarginata, cette espèce n'en diffère que par quelques caractères en apparence peu importans, mais qui n’en sont pas moins des caractères spécifiques, attendu qu'on les retrouve invariablement dans tous les individus. Ces caractères sont : $1^{\circ}$ la petitesse de la lumule de l'aire interambulacraire impaire, que rappelle le nom de micropora; $2^{\circ}$ la largeur considérable des pétales ambulacraires, qui s’arrondissent fortement à leur extrémité, sans cependant se fermer complètenent. L'espace compris entre les zones poriféres de chaque pétale est notamment plus large que ces zones elles-mêmes, surtont dans les pétales anlérieurs; $3^{\circ}$ la forme de la rosette apiciale, qui est moins grande que dans 
l'E. cmarginata. Les pores génitaux sont aussi en général plus rapprochés, quoique placés à l'extrémité des rayons du corps madréporifornte. Ce dernier est d'un aspect spongieux comme diuns toutes les especes d'Encopes (fig. 6). Les trous ocellaires sont excessivement petits, mais cependant visibles mème à l'oil nu. L'épiderme, finement granulaire, présente, sous un fort grossissement, les deux sortes de tubercules qu'on retrouve dans presque toutes les Scutelles, les tubercules spiniféres, qui sont distinctement perforés et mamelonnés, et les tubercules miliaires qui entourent ces derniers et sont très-nombreux (voy. fig. 8). Dans les zones porifères des pélales ambulacraires, les tubercules spinifëres forment des séries trausversales très-rëguliẻres, séparées par les sillons transverses (voyez fig. 7). La face inférieure ne présente rien de particulier : c'est la nême disposition des sillons et des tubercules que nous avons décrite dans l'espèce précédente. L'ouverture buccale est petite et circulaire. L'anus est pyriforme et allongè dans le sens du diamètre longitudinal. Quant à la forme générale, elle est à peu près circulaire. Le diamètre longitudinal et le dianètre transversal sont sensiblement égaux. Le bord postérieur est un peu plus tronqué dans les vieux exemplaires que dans les jeunes. La fig. 5 représente le profil; la plus grande épaisseur est vers le bord antérieur.

La fig. I de Tab. 19 a représente la cavité intérieure, telle que nous l'avons décrite à l'arcle du genre (voy. pag. 46). La différence spécifique de cette espèce d'avec l' $E$. emarginata est encore confirméc par le trajet du canal intestinal, dont les contours sont bien plus nombreux, notanment sur le flanc droit.

Je possẻde plusieurs exemplaires de cette espèce, qui m’ont été donnés par M. Stokes ; mais il n'en est aucun dont l'origine me soit connue. Leur teinte paraît être, à l'état vivant, d'un brun foncé, à en juger d'après quelques traces qui en sont conservées.

\section{Excope penspectiva Val.}

Tab. 10 b, fig. 1-5.

Celte espece a la plus grande ressemblance avec l'E. micropora. Sa forme (fig. 1), son profil (fig. 2), la disposition de ses Iunules, sa rosette apiciale (fig. 5), sont à peu près identiques; et cepeudant je la crois différente, par plusieurs raisons : et d'abord la lunule de l'aire interambulacraire impaire, au lieu d'être petite et allongée, est très grande, élargie et ovoïde; son pourtour est marqué de tubercules beancoup plus développés que ceux du reste du test; ce qui fait 
supposer qu'elle était bordée de soies correspondantes. En second lieu, les pẻtales ambulacraires sont moins larges que dans l'espèce précédente, surtout les postérieurs, qui sont en outre légèrement flexteux par l'effet de la lunule qui empiète en quelque sorte sur leur domaine. Enfin les zones porifères égalent à peu près en largeur l'espace intermédiaire; à I'origine des pétales elles sont même plus larges. Les pétales antérieurs sont sensiblement plus courts et plus arrondis que les postérieurs. Les sillons de la face inférieure se ramifient considérablement. Les aires ambulacraires auxquelles ils correspondent sont revêtues de tubercules tellement fins qu’ils domnent a la surface un air velouté. Les aires interambulacraires sont garnies de Iubercules plus développés. La bouche est flexueuse ou légẻrement pentagonale, par suite des saillies que font sur son pourtour les tubes des branchies buceales (voyez fig. 3). La fig. 4 représente la forme et la disposition des tubercules de la face supérieure sous un très fort grossissement. Je ne eonnais de eette espèce que l'exemplaire figuré qui m'a été communiqué par M. Valenciennes, sous le nom ci-dessus, mais sans indication d'origine. Sa couleur est tout à fait ternie. C'est par erreur que cette espèee est indiquée sur ma planehe comme établie par moi; ćest M. Valenciennes qui le premier l'a distinguée.

\section{Excope cyclopora Ag.}

Tab. 10 b, fig. (;-?.

Il n’est guère possible de eonfondre cette espèce avee les précédentes. La tendance de ses lunules, et en particulier de la lunule de l'aire interambulacraire impaire, à s'arrondir, lui donnent une plysionomie toute particulière. Elle est en outre remarquable par sa forme trẻs élargie ; e'est jusqu’ici la seule Encope eonnue dont le diamẻtre transversal soit plus eonsidérable que le diamėtre longitudinal. Son épaisseur est moyenne; mais la partie la plus renflée ne correspond pas exactement au sommet apicial (fig. T). Le côté antérieur est moins largge que le eòté postérieur. Celui-ei présente une échancrure assez prononcée dans le prolongement de la lunule de l'aire interambulaeraire. Les lunules des ambulacres postérieurs sont ouvertes, au moins dans l'exeme plaire figuré. Les pétales ambulacraires sont droits, réguliers et trẻs uniformes; les antérieurs sont a peine plus petits que les postérieurs; les zones porifères sont aussi larges et même plus larges que l'espace intermédiaire. La rosette apiciale est légèrentent saillante; les cinq pores génitaux y sont fort distincts et placés à l'extrémité des rayons du corps madrẻporiforme. Les 
pores ocellaires sont également distincts, mème à l'wil nu. Le corps madréporiforme lui-méner est composé d'ume agglomeration de fubes capillaires très serrís (fig. 8). Eufun une deruière particularité de celte espèce consiste dans l'absence de tubercules miliaires distincts; on ne remarque que des tubercules spinifères, qui, exanimés sous un fort grossissement, présentent la forme et la disposition indiquees dans la fig. $\mathbf{9}$.

La face inférieure est très accidentíe, les sillons y sont plus ramifiés que daus aucune autre rspece; mais les rameaux latéraux sont courts et larges, à l'exception des derniers qui s'ütendent autour des lunules. La houche est de moyenne grandeur. Lianus, de forme pyriforme, r'st placé au hord interne de la lunule de l'aire interambulacraire. L'exemplaire figuré, le seul que je connaisse, m’a été communiqué par M. Michelin; son origine est inconnue. Ses teintes sont entièrement fanées.

\section{Excope oblosga Ag.}

Tah. 9.

Cette espère est plus allongée qu'aucune autre Encope; elle formerait un ovale régulier, si le còté postéricur n’était légèrement tronqué. La hauteur est proportionnée aux autres dimensions; mais le point le plus élevé, au lieu d'ètre en avant ou an centre, est reporté sur l'arrière et le sonmet apicial est mème un peu déprimé (fig. 2). Les lunules ambulacraires, ainsi que la lumule de l'aire interambulacraire, sont très-grandes, surtout cette dernière, ef ont les bords considérablement renflés; toutes sont contiguës à l'extrémité des pélales dont elles sont en quelque sorte le prolongement. Les ambulacres eux-mêmes ne diffèrent, ni dans leur forme, ni dans leurs dimensions, de ceux de l'E. emarginata. La fig. 4 représente la moitié du pétale antérieur gauche sous un grossissement de deux fois le diamètre, afin de montrer la structure intime de cette partie du test. On roit par rette figure que les zones porifères sont garnies de petits tubercules entre les sillons transversaux absolument comme le reste de la surface. Les pores internes sont ronds, tandis que les externes paraissent sensiblement allongés. La rosetle apiciale se fait remarquer par la saillie extraordinaire de ses rayons; le rayon postérieur est tronqué, et par là mème sensiblement plus petit que les autres (fig. 7). Les pores génitaux sont placés à lintérieur des rayons. Les pores ocellaires occupent le sommet des ambulacres dans les angles rentrans du corps madréporiforme. 
Les sillons de la face inférieure sont de largeur moyenne, mais leurs ramifications sont moins marquées que dans l'autre espèce, quoique on y distingue toujours les pores ambulacraires, lorsqu'on vient à les examiner à la loupe. La bouelıe ne présente rien de partieulier; elle esı comme d'ordinaire subcentrale en avant, et laisse apereevoir l'extrémité des dents. La fig. 5 représeute le pourtour de la bouche grossi, montrant un nombre extraordinaire de pores microseopiques, plus eimq trous un peu plus grands, placés à l'extrémité des petits tubes qui, sans doute, contenaient les branchies buecales. L'anus est très rapproché de la bouche, ce qui s'explique par la grandeur de la lumule de l'aire interambulaeraire. J'ai dù la communieation de cette curieuse espèee à mon ami, II. le professeur Pictet. Son origine n'est malleureusement pas connue. Le seul exemplaire que j’en aie vu est celui que j’ai figuré; il est déposé au Musẻe de Genève.

\section{Excope valexciexsesil Ag.}

\section{Tab. 7 et 8.}

C̈est la plus grande espèee de la fanille des Scutelles et l'un des plus grands Oursins connus. Bien quil en existe des exemplaires dans plusieurs collections, je ne les trouve décrits ni figurés nulle part ; e'est à l'obligeance de mon ami, M. Valenciennes, que je dois la communication de l'exemplaire figuré qui fait partie du Muséum d'Histoire naturelle de Paris; aussi me suis-je fait III plaisir de lui dédier cette belle espèce.

La forme èlégante de l'E. Valenciennesii est due aux belles proportions de toutes les parties du test. Les entailles ambulaeraires, ainsi que la lunule de l'aire interambulacraire, sont en rapport avee les dimensions du test ; cependant il existe des différences assez marquées dans leurs dimensions et dans leur forme : les entailles des ambulaeres postérieurs sont plus grandes que celles des ambulaeres antérieurs; la plus petite est celle qui eorrespond à l'ambulaere antérieur (a). Ces cinq entailles, lont j’ai indiqué par des lettres la position relativement au plan de l'animal, ont à peu près la même forme et sont toutes contiguës à l'extrémitẻ des ambulacres. Quoique aucune d'elles ne soit fermée, on remarque cependant qu'elles ont unc tendance à se rétrécir sur le pourtour du test : par conséquent je ne pense pas que l'on puisse envisager eomme un caractère spécifique le eas où l'une ou l'autre de ces entailles serait fermée. La lunule de l'aire interambulacraire est grande et de forme allongée; ses bords sont irrégulièrement ondulés et forment un renflement assez. 
marqué au dessus de la surface du test, comme cela se voit surtout bien dans la fig. 2 de la planche 7 qui représente le profil vu par derrière. Le contour du test est à peu près circulaire: cependant le diamètre longitudinal est un peu plus grand que le dianètre transversal. La hauteur est plus considérable que dans d'autres espèces; clle égale le sixième de la longueur et diminue d'une manière graduée vers les borls, de manière que la face supérieure est très régulièrement hombée (royez la fig. 2 de Tab. 8 qui représente le profil réduit vu par le côté). Les pétales autérieurs et latéraux sont plus larges, plus courts et plus arrondis que les postérieurs ; aussi l'espace compris entre les zones poriféres est-il dans ces derniers plus étroil que les zones ellesmêmes; enfin, comme la lunule de l'ambulacre impaire est très grande, il en résulte que les ambulacres postérieurs sont refoulés latéralement et prẻsentent une courbe assez marquéc. Les contours de la rosette apiciale ne sont pas très-précis; en revanche, les pores n'en sont que plus distincts; les trous ocellaires sont très visibles et tout aussi développés que les pores gé̉uitaux. Examiné à la loupe, le corps madréporiforme présente la mêne apparence spongicuse que nous avons signalée dans les espéces précédentes; mais ce quil y a de particulier, c'est quil s'étend plus en avant dans les aires interambulacraires; car les pores génitaux, quoique très dislants du centre, s'ouvrent cependant encore dans cette surface spongieuse. La face supérieure est garnie de tubercules spinifères trẻs lomogènes surgissant chacun du milieu d'une petite dépression et entourés des tubercules miliaires qui ne s'apercoivent qu'à l'aide d'un fort grossissement. La fig. 3 de Tab. 7 représente quelques-uns de ces tubercules grossis; la figure i, une portion de la zone porifère d'un pétale, prise à son extrémité et montrant les intervalles des sillons garnis de tubercules, de même que le reste de la surface.

La face inférieure (Tab. 8) présente la mème variété des tubercules que nous avons déja signalée dans l' $E$. emarginata; ceux des aires interambulacraires étant toujours plus gros que ceux des aires ambulacraires. Mais ce qui mérite surtout d'ètre remarqué, c'est la profondeur et la largeur des sillons et la manière dont ils se ramifient dans toutes les directions; les moindres rameaux montrent encore jusqu'à leur extrémité des pores très visibles à la loupe. Liouverture buccale est circulaire, plus rapprochée du bord antérieur que du bord postérieur. L'anus est à l’origine de la lunule interambulacraire et séparée de l'ouverture buccale par un espace qui correspond au neuviẻme de la longueur; il est deforme ovale comme dans toutes les Encopes.

L'appareil masticatoire présente la structure ordinaire à cet organe dans toutes les Encopes ; mais il est digne de remarque que malgré les dimensions plus grandes de notre espéce, ses machoires soient moins développées que celles de l'E. cmarginata. Comme à l'ordinaire, la uâ- 
choire postérienre impaire est plus déreloppée que les mâchoires paires; ses ailes surtout sont plus allongées. La fig. 3 de Tab. 8 représente les cinq ntichoires disjointes, vues d'en haut et monIrant d'une manière fort distincte la juxta-position de leurs lames perpendiculaires ; les carènes saillantes qui se voient sur la ligne médiane sont les dents qui sont fixées dans un sillon eorrespondant à la soudure des deux osselets ou demi-mâchoires. La fig 4 représente les mêmes màchoires vues par la face inférieure avec le renflement médian qui correspond à l'échancrure du sommet des auricules. La fig. 5 représente la màchoire impaire vue de profil.

Les soies ne sont pas conservées dans l'exentlaire figuré ; mais je les ai retrouvées sur des exemplaires de la collection de M. Stokes ef du Musée britannique; elles sont cylindriques avec un fort renflement annulaire au dessus de la surface articulaire; leur grandeur est en rapport avee la grosseur des tubercules; aussi, à la face inférieure, celles des aires interambulacraires sont-elles beaucoup plus développées que celles des aires ambulacraires; celles de la face supérieure sont très petites et en forme de massue. Celte espèce provient de la Martinique.

\section{Excope subclausa Ag. (")}

Talı. 5.

On ne saurait méconnaitre la grande ressemblance qui existe entre cette Encope et l'E. Valenciennesï que nous venons de décrire. La seule différence qui frappe au premier coup d'œil rest que les entailles postérieures sont fermées: or, en posant en fait qu'en général les entailles ont une tendance à se referner avec l'àge, il n’est guère possible d’identifier ces deux espèces, attendu que l'E. V'alenciennesii, malgré ses plus grandes dimensions a eependant toutes les entailles ambulacraires largement ourertes. Mais, d'un autre côté, nous avons vu aussi qu'il existe de nombreuses exceptions à celte rẻgle et que la forme des entailles peut varier considérablement daus une même espèce. Je ne puis done affirmer d'une manière positive que l'E. subclausa soit réellement une espèce distincte, quoique j’y aie remarqué quelques autres

(") Dans l'origine de mon travail sur les Scutelles je pris cette espéce pour le Scutella tetrapora des auteurs, et je la fis figurer, dès 1839, sur la planche citée, sous le nom d'Encope tetrapora. Mais ayant eu plus tard occasion d'examiner l'exemplaire figuré, Tab. 10 , fig. 1-3, je lui ai trouvé plus de rapports avec la figure de Seba que tous les autenrs citent comme Scutella tetrapora, qu'avec l'espèce que je désigne maintenant ici sous le nom d'Encope subclausa; ensorte que le nom de Ficope tetrapora, qui se trouve an bas de la Pl. 5, devra ètre changé en celui de Encope sutclausa, qui a trait à la formc des entailles. 
particularites que je vais indipuer : et d'abord la lunule de l'ambulacre impair est proportionuellenent plus étroite que dans leE. Valenciemnesii; les sillons de la face inférieure sont moins profouds et moins larges, les rameanx secondiaires surtout sont moins apparens; enfin les bords du rest sont plus tranchans et s'anincissent d'une manière noins graduée. Sous tous les autres rapports, notre espéce ne diffère en rien de l'E. Valencienmesii. Sa forme générale est sensihement lit mème. Les ouvertures buccale el anate ne montrent aueune différence, non plus que la rosette apiciale qui se fait remarquer par ses pores génitaux et ocellaires trés-dislincts. Enfin les ambulacres out la mème forme; les soies qui reeouvrent le test empéchent d'en apercevoir les délails.

Cette espèce m’a été communiquée par M. le professeur Pictet; l'exemplaire figuré provient du Brésil el se trouve an Musée de Geneve.

\section{Excope grispis $\mathbf{A}$.}

Tab. 6.

Cette espèce est eonstruite sur le même plan que le $E$. Valenciemesi, et quiconque ne verrait qu'une figure de la face inférieure ou de la face supéricure, ne pourrait guère s'empêcher de la prendre pour un jeune de cette espece, altendu que le principal caractère qui l'en distingue, consiste dans l'épaisseur du bord, qui est plus considérable que dans ancune autre espèce du genre (royez les fig. 3, 4, 5 et 6 qui en représentent le profil). L'étoile ambulacraire présente les mèmes proportions que dans les espèces précédentes. Les pétales postérieurs sont sensiblement plus longs que les antérieurs et légèrement fléchis de dehors en dedans. Les entailles du pourtour sont peu profondes et largement ouvertes ; celles qui correspondent aux ambulacres postérieurs sont plus grandes que eelles qui correspondent aux antérieurs et notamment a l'ambulaere impair. La lunule de l'aire interambulaeraire impaire est large et de forme ovale, ses bords sont très renflés et forment une espèce de crête ì la face supéricure. La face inférieure, représentée dans la fig. 2 , nous offre les mêmes délails de structure que nous avons reconnus dans les espices précédentes.

Les fig. \& et 5 montrent l'intérieur du test ru de profil, l'exemplaire étant coupé par le milieu, dans le sens longitudinal. La cavité buccale occupe le centre ; elle esl sẻparée de la cavité iutestinale par une cloison eellulense qui u'est interrompue que sur le devant pour donner passage 
à l'intestin; une cloison lorizontale sépare également l'appareil ambulacraire des cavités buccale et intestinale. J'ai indiqué par des lettres les différentes cavités telles qu'elles se présentent dans les profils ci-dessus : $\iota$ est la cavité buccale; $o$ et $p$, sont des oreillettes; $a$, l'anus; $n$, la cavité occupée par la première anse de l'intestin; $b$, louverture que traverse le canal intestinal en passant du côté gauche au côté droit; $e, c, l, i, g h, d$, trous conduisant sous les ambulacres dans les cavités occupées par les tubes ambulacraires lorsqu’ils sont rentrẻs ; $m$ et $q$ deux de ces cavités ouvertes longitudinalement $(m)$, et en travers $(q) ; k$ et $\int$ ouvertures conduisant dans la cavité des aires interambulacraires. La fig. 6 est une section transversale du còté droit, $s$ est l'ouverture par laquelle le canal intestinal sort de la cavité buccale pour s'engager dans les réseaux calcaires de la périphérie du test; $q$ est le canal qui renferme l'anse externe et $\ell$ celui qui renferme l'anse interne du côté droit du canal intestinal.

J'ai représenté trois mâchoires par leurs différentes faces, afin de donner une idée exacte de leur forme. Les fig. 7,8 et 9 les montrent de profil, les fig. $7^{\prime} 8^{\prime} 9^{\prime}$ par la face inférieure el les fig. $7^{\prime \prime} 8^{\prime \prime} 9^{\prime \prime}$ par la face supérieure. Les dents proprement dites ont disparu. Elles étaient fixées dans le sillon qui est à la face supérieure et qui correspond à la suture des deux osselets de la mâchoire.

Cette espèce m’a été communiquèe par M. Michelin; elle provient probablement des Antilles.

\section{Excope machelisi Ag.}

Tab. $6 a$, fig. 9 et 10.

C'est une espèce très-massive, sensiblement plus longue que large, à bords épais ; mais ce qui la distingue d'une manière toute particuliẻre, c'est que le maximum de hauteur, au lieu d'être au sommet apicial, est considérablement rejeté en arrière, ensorte que le côté postérieur présente une dẻclivité très-considérable, tandis que le côtẻ antérieur est très gradué, ainsi que le montre la fig. 10, qui représente le profil. Le bord postérieur est tronqué et même légèrement échancré au milieu de l'aire interambulacraire impaire. La rosette anbulacraire est grande; les pétales sont arrondis à leur extrémité, les postérieurs sont plus élancés que les antérieurs, et les zones porifères sensiblement plus larges que l'espace intermédiaire. Les entailles des aires ambulacraires sont très-ouvertes, de moyenne largeur et très-uniformes; cependant les postérieures sont un peu plus profondes que les antérieures: les unes et les autres ne 
montrent aucune tendance à se refermer au bord. La lunule de l'aire interambulacraire postérieure est petite et étroite; ses bords sont légérement renflés à la face supérieure. La rosette apieiale est un pentagone régulier dont les einq angles sont oceupés par les pores génitaux. La face inférieure est entièrement plane; ses sillons sont peu frofonds, mais diversement ramifiés. La bouche est centrale; son pourtour onduleux rẻsulte de la saillie des tubes branchiaux.

C'est encore it II. Nichelin que je dois cette belle espèce; son origine n'est malheureusement pas connıe. Je l'ai dédiée ì l'ïufatigalle paléontologiste qui me l'a communiquée.

\section{ExCORE STOKESU Ag.}

Tab. 6 a, fig. 1-8.

On rencontre souvent, sur la limite des genres, des espèces qui, par la combinaison de leurs caractères, semblent se soustraire à la détermination zoologique. L'E. Stokesii est dans ce cas : sa plyssionomie est toul at fait celle des Encopes; mais si l'on vient à ourrir lintérieur, on est tout étonné d'y trouver la structure des Nellites. Au lieu de la cloison calcaire, qui sépare la cavité buccale de la cavité intestinale, et qui s’étend en outre sur le flanc droit, entre les replis de l'intestin grềle, nous n’avons ici que des piliers ealcaires qui sẻlèvent des aires interambulacraires, absolument comme ceux que nous avons décrits dans le $\boldsymbol{M}$. pentapora (Tal. 3 , fig. 6 el 7 ). J'ai voulu m’assurer si ce caractère particulier existait dans tous les exemplaires, et je l'ai retrouvé le mệme dans les adultes conme dans les jeunes, ensorte qu'il ne peut y avoir de doute sur sa valeur réelle. Si d'un autre côté nous considérons que l'E. Stoliesii a tous les caractères extérieurs des Encopes, la forme générale, la grandeur de l'étoile ambulacraire, la forme arrondie et souvent ouverte des lunules, et enfin les cinq pores génitaux, ensorte que pour qui ne connaitrait pas la structure intérieure, il ne pourrait y avoir aucun doute sur le genre auquel il faut rapporter cette espèce; si, dis-je, l'on tient compte de toutes ces circonstances, on devra convenir quïl est à peu près impossible, dans l'ẻtat actuel de nos eonnaissances sur l'anatomie de ces animaux, de prononcer un jugement définitif; aussi n'ai-je pas la prétention de décider la question dés maintenant. Il est un seul caractère extérieur qui, quoique secondaire, semble cependant trahir une plus grande affinité avec les Mellites, céest la couleur, qui est verte, comme dans les Mellites; tandis que nous avons ru que toutes les Encopes, dont les teintes sont conservées, sont brunes, violettes ou lilas. 
Considéré en lui-même et comme espece, l'E. Stokesii se fait remarquer par sa forme circulaire dans les jeunes individus, et plus ou moins tronquée en arriere dans les adultes. Le diamètre transversal et le diamètre longitudinal sont à peu près égaux. Le point culminant correspond au sommet apicial et la face supérieure présente une déclivité uniforme vers les bords (royez fig. 3). Les pétales ambulacraires sont larges et arrondis à leur extrẻmité, mais n'atteignent pas le bord des entailles. La lunule de l'aire interambulacraire impaire est de forme ovoïde et très rapprochée du bord. La bouche est au centre de la face inférieure, entourée d'une rosette luccale décagonale (fig. 2). Lorsque les soies sont conservées, comme c'est le cas de la plupart des exemplaires que je possède, l'ouverture buccale est masquée par des soies trẻs roides qui naissent sur son pourtour. L'anus est pyriforme, situé à moitié chemin entre la bouche et le bord postérieur. Les sillons de la face inférieure sont très marqués, même dans les exemplaires revêtus de leurs soies; ils se bifurquent une ou plusieurs fois avant d'atteindre le bord.

J'ai représenté des exemplaires de différens âges, afin de faire mieux ressortir les modificalions que subissent ces animaux en grandissant. J'ai pu m'assurer en comparant une vingtaine d'exemplaires de taille différente, que, dans cette espèce au moins, les entailles des aires amlsulacraires, au lieu de s'élargir avec l'àge, tendent au contraire à se refermer sur le bord. En effet, elles sont très ouvertes dans le petit exemplaire de fig. 1 ; dans les exemplaires de fig. 2,5 et 8, elles montrent déjà une tendance très prononcée à se fermer; enfın, dans l'exemplaire de lig. 6, les entailles antérieures sont complètement fermées, et les postérieures ne sont que très peu ouvertes sur le bord.

Les soies varient de forme suivant leur position; celles de fig. 4, prises à la face supérieure, se font remarquer par leur forme essentiellement clavellée. Celles de fig. 7 sont de la face infèrieure; elles se distinguent par leur forme cylindrique et subulée. La fig. $e^{\prime}$ représente une partie du piquant $7 e$ sous un grossissement double, montrant la forme et la disposition des fines dentelures dont sont liérissées les stries longitudinales. Tous ces piquans ont la face articulaire très distincte et séparée par un anneau ou renflement circulaire très marqué.

La fig. 8 montre la cavité intérieure avec les piliers calcaires que nous avons signalés plus lıaut; autour de ces pilicrs, s’étend le canal intestinal, qui est ici représentẻ à l'état desséché, ce qui le fait paraitre si étroit. Je me suis assurè par l'examen de la cavité d'autres exemplaires que la partie qui occupe le flanc gauche est sensiblement plus large que dans la fig. $\mathbf{S}$.

L'appareil masticatoire est loin d'être massif; la clıarpente des mâchoires surtout est très mince 
ct les lames verticales très délicates. La face inférienre présente une petite carène qui siddapte dans un sillon du sommet des auricules. Ces dernières sont petites et rapprochées.

Cetle espèce parait être commune sur les côtes oceidentales de l'Amérique tropicale. Je dois at l'obligeance de mon ami, M. Stokes, la communication d'une série considérable d'exemplaires provenant des iles Gallopagos. Leur couleur est d'un vert cendré, un peu plus foncé dans les vieux individus que dans les jeunes. Les naturalistes de la Bonite, MINI. Eydoux et Souleyet en ont déposé au Mluséum d'histoire naturelle de Parris plusieurs exemplaires, provenant de Guayaquil t teintés de lilas, mais dépourvus de leurs soies. 


\section{CIIAPITRE V.}

\section{DU GENRE LOBOPIIORA Agass.}

Ce genre se distingue par plusieurs caractères de première valeur tant extérieurs qüintérieurs. Il comprend en général des espèces très aplaties, ayant le bord antérieur arrondi, tandis que le bord postérieur est tronqué et entamé par deux entailles ou lunules plus ou moins profondes, correspondant aux aires ambulacraires postérieures. La présence de ces deux entailles, sans être un caractère essentiel, suffit cependant, dans l'élat actuel de nos comnaissances, pour distinguer les Lobophores de tous les autres genres de Scutelles. L’éloile ambulacraire est petite proportionnellement aux dimensions du test, et les pétales alteignent rarement la moitié du rayon entre le bord et le sommet. La rosette apiciale montre la mème structure spongieuse qui est propre à toutes les Scutelles. Les pores génitaux au nombre de quatre souvrent à l'extrémité des rayous de cette rosette; les pores ocellaires sont ordinairement très distincts. Lat face infërieure est complètement plane. Les sillons ambulacraires sont moins prononcés, et surtout moins ramifiés que dans les genres précédens, mais également criblés de pores microscopiques. La bouche est centrale; l'anus est circulaire et plus ou moins rapproché du bord postérieur, sans cependant ètre marginal.

La cavité intérieure se fait remarquer par l'absence d'une cloison etde piliers entre l'appareil masticaloire et le canal intestinal. En revanche il existe tout autour de lintestin un réseau de cellules calcaires très-développées, qui occupe plus de la moitié de la cavité du. lest et qui paraît destiné à loger des appendices du canal intestinal. L’intestin lui même est très grêle; sou Irajet est le mème que dans les genres précédens, c’est-à-dire qu’il passe une fois sur le côté gauche et deux fois sur le côté droit. La seule particularité qui distingue, sous ce rapport, les Lobophores, c’est qu'arant de rétrograder vers l'anus, lintestin se replie sur le côté, dans une anse assez profonde, correspondant à l'aire interambulacraire antérieure droite (voy. Tab. 13 fig. 6). 
Lappareil masticatoire présente une structure tout-ä-fait particulière. Les mìchoires sont excessivenent plates, par la raison que les lames verticales dont elles sont hérissées à la face supérieure el à la face infërieure, sont trẻs peu développées. Mais ee qui en constitue le caractère le plus remarquable, c'est que les auricules destinées à maintenir les mâchoires dans leur position, ne forment point un enclos autour de ces dernières, comme c'est le cas des Mellites, des Encopes et surtout des Laganes, mais s'articulent au contraire dans une fosselte qui est au milieu de la face inférieure des mâchoires, à peu près de la même manière que cela a lien dans les vrais Clypéastres. Cette fossette qui est représentée dans la fig. 5 de Tab, 14, dansla fig. 7 de Tab. 12, et daus la fig. f. de Tab. 13, a été désignée par M. DesHoulins, chez les Clypéastres, sous le nom de fossette naviculaire. Les dents elles-mêmes sont des lames émaillées fort minces, inıplantées de champ dans le sillon de la face supérieure des machoires, dont elles noccupent pas toute la longueur.

Les soies sont plus uniformes que dans les genres précédens; cependant il existe encore unc différence entre celles de la face inférieure el celles de la face supérieure : ces dernières sont légèrement renflées à leur extrémilé; celles de la face inféricure au contraire sont grèles el cylindriques. Je n’ai vu jusqu’ici qu'une seule espèce qui ait conservé sa couleur, e’est le L. bifissa , qui est dune belle teinte violelle.

Les espèces connues jusqu'à ce jour sont au nombre de quatre; toutes appartiennent à l'époque actuelle. Mallıeureusement il règne quelque confusion dans la synonymie, par suite de la mauraise habitude des auteurs, de citer des synonymes sans consulter les ouvrages, et de copier leurs figures sur des figures plus anciennes, au lieu de prendre pour types des exemplaires originaux. 


\section{Lobophom biroki Agass.}

Tal. 12.

Srr. Sculella bifora Lam. T'om. 3, p. 281, No 7. - Mgass. Prodr. Ech. p. 188.

Echinus biforis I. Gm. p. 3188 (pro parte).

Echinoglycus irregularis (Onreģelmatige Egelloels) Van Phels. p. 33, No 15, (pro parte).

Eclinodiscus Kinorr Delic. nat. T. 1.p. 92, Tab. D 1 fig. 1. - (pro parte).

Scutella bilincarifora Desiloul. Tabl. syn. p. 226, N०11.

Liespèce que je désigne sous ce nom, ne se trouvant figurée dans aucun auteur, je n’aurais pas songé à lui conserver, de préférence à la suivante qui est plus anciennement connue, le nom si généralement recu maintenant de $S$. bifora, si je n’avais acquis, au Musée de Paris, la certitude que Lamarck l'envisageait comme le type de son Scutella bifora, nom sous lequel il confondait cependant comme de simples variélés plusieurs espèces très distinctes.

La forme du L. bifora est irrégulière; le côté antérieur est arrondi et sensiblement plus étroit que le côté postérieur, qui est tronqué et présente une légère échancrure dans le prolongement de louverture anale. La plus grande épaisseur n'est pas exartement au centre, mais en avant de la rosette apiciale (fig. 3). Les lunules sont très obliques, allongées et plus rütrécies au milieu qu’à leur extrémitć. La rosette ambulacraire est très inégale, les pétales postérieurs élant sensiblement plus longs que les antérieurs ; ces derniers sont en outre comme atrophiés, et, au lieu d'être arrondis à leur extrémití, ils paraissent tronqués. On est assez naturellement porté a attribuer cetie circonstance à l'empiélement des vacuoles; cependant il faut remarquer que les pétales antérieurs qui n'ont point de vacuoles dans leur prolongement, ne sont pas non plus parfaitement arrondis. La fig. 6 représente une portion d'une zone porifère sous un grossissement de plusieurs diamètres, pour montrer que même les espaces intermèdiaires entre les sillons transverses sont garnis de petits tubercules comme le reste de la surface. La fig. 5 représente la face interne d'un pétale ambulacraire sous un grossissement moins fort. On y voit d'abord les deux rangées régulières de pores, et de plus, dans l'espace intermédiaire, entre les deux zones poriféres, deux autres rangées moins régulières, dont l'usage m’est demeuré inconnu jusqu ici.

La face inférieure est d'un aspect beaucoup plus varié que dans les autres espeeces, el d'abord les sillons ambulacraires sont plus larges et plus distiucts, sans cependant etre plus ramifiés: 
chaque sillon n'a qu'un seul rameau principal qui se dirige sur l'aire interambulacraire. De plus, les aires interambulacraires se distinguent des aires ambulacraires par une granulation toute différente, composée de tubercules spinifères très serrés, mais qui ne sont point entourés de tuberrules miliaires (royez fig. 11). Dans les aires ambulacraires, au contraire, les tubercules spinifëres sont plus petits et naissent du milieu d'une dépression entourèe de tubercules miliaires très apparens, à peu près comne cela se voit dans la fig. 10, qui représente une portion de la face supéricure grossie. Enfin les sillons ambulacraires sont accompagnés, dans toute leur longueur, d'une bande d'apparence lisse et veloutée, mais qui, lorsqu'on l'examine à la loupe, se montre également composée de tubercules excessivement fins et nombreux. Cette diversité dans la forme et les dimensions des tubercules implique sans doute des différences analogues dans la structure des soies; il n’en est donc que plus à regretter que celles-ci ne soient pas conservées.

L'ouverture buccale est à peu près centrale, très petite et de forme lobée par suite des saillies que font sur son pourtour les tubes des loranchies buccales. La fig. 4 représente cette partie du test sous un grossissement de $1 \%$ diamètre, afin d'en faire voir la structure intime; la rosette buccale est composée de cinq grandes plaques lobées correspondant aux aires interambulacraires et de cinq autres plaques excessivement grêles correspondant aux sillons des aires ambulacraires; les sillons montrent les pores microscopiques qui sont ici moins nombreux que dans les genres précédens. L'anus est très petit et de forme circulaire; il est situé en face d'une échancrure du bord postéricur.

L’intérieur est remarquable par la structure compacte de la masse cellulaire qui remplit surtout les bords et qui, lorsqu'on l'exanine de profil, ressemble à une forêt de piliers osseux. Les màchoires sont excessivement minces, ainsi qu'on le voit par la fig. 9, qui reprẻsente le profil d'une màchoire isolée. J'ai indiqué par les lettres $a, l, p$ la position antérieure, latérale et postèrieure des màchoires dans les figures 7 et 8 . L'une (fig. 8) représente l'appareil masticatoire vu par sa face supérieure, les mâclioires étant réunies; on distingue trẻs bien au milieu de chaque màchoire un petit sillon dans lequel étaient fixées les dents, qui ont disparu. Dans la fig. 7 , qui représente l'appareil masticatoire par sa face inférieure, les màchoires sont disjointes et l'on remarque sur chacune d'elle une petite dépression qui est la fossette naviculaire. Les auricules qui correspondent à ces fossettes sont très petites.

M. DesMoulins ayant eu l'obligeance de madresser un croquis de son Scutella bilinearifora, u’a mis à mème d'affirmer avec certitude que son espèce est hien la forme dont Lamarck faisait le type de son $S c$. bifora. Les exemplaires que j’ai eu occasion d'examiner m'ont été commu- 
niqués par M. Valeneiennes et par M. Chavannes, mais sans indieation d'origine. L'un de ees exemplaires a la faee inférieure teintée de brun-olivâtre terni. M. Des.loulins rapporte que le sien provient des eòtes de la Cafrerie.

II. Lobophom truxcita Ag.

Tab. 11, fig. 11-16.

Sis. Scutella bifora var. 2. Lam. T. 3, p. 281. - E. Desl. Enc. T. 2, p. 676. - DeBl. Dict. sc. nat. T. 48, p. 223. - DesMoul. Tabl. syn. p. 226. - Encycl. méth. Tab. 147, fiğ. 7 ct 8.

Scutella biforis DeBl. Zooplı. p. 200.

Echinus biforis L. Gm. p. $318 \mathrm{~s}$.

Mcllita lacvis Klein Edt. Leske p. 25, Tab. 21, fig. A, B. - Klein Gall, $₫ 81$, p. 90, Pl. 11, figg. B.

Echinodiscus bipcrforatus Leske apud Iil. p. 196.

Echinodiscus MIull. Dcl. natur. I, p. 92, Tab. D I. fig. 15,

Pain d'épicc à dcux fentes Davila Catal. T. 1, p. 423, Nº55.

Cette espèee paraît avoir été la plus anciennement eonnue des auteurs. Klein déjả en a domné une figure sous le nom de Mellita lavis; plus tard Leske ehangea ee nom en eelui d'Echinodiscus biperforatus en eomprenant dans la niême espèee le L. bifora que nous venons de déerire. Lamarek, au lieu de séparer ees deux espèces, les envisage eomme deux variétés et leur en adjoint même une troisième, qui est mon Ampliope bioculata. Deslloulins le premier a fait de ees divers types trois espèees distinetes qu’il désigne sous les noms de Scutella bitincarifora (mon L. bifora), de Sc. bioculata (mon Amphiope bioculala) et de $S c$. bifora (l'espèee dont il est iei question). Nayant pas eru devoir eonserver le nom spéeifique de Klein, qui eomprend deux espèees distinctes, on me demandera pourquoi je n'ai pas maintenu eelui de DesMoulins. J'ai déjà répondu à eette objeetion dans la deseription de l'espéee préeédente, en rappelant que éest eette dernière que Lamarek envisageait eomme le type de son Scutella bifora. Foree done me fut de donner à l'espéee qui nous oeeupe un nouveau nom : je l'appelle truncata à eause de la forme tronquée de son bord postérieur qui est à peu près droit.

Quoique eette espèee soit très voisine de la préeédente, on l'en distinguera eependant très facilement à la forme toute diffẻrente de ses lunules, qui, au lieu d'ètre grêles et allongées eomme dans le $L$. bifora, sont sensiblement plus eourtes et plus élargies. De plus, la rosette ambula- 
craire présente une structure toute différente; les pétales ue sont point atrophiés en delors, mais s'arrondissent au contraire il leur extrémité et sont séparés des lunules par un espace assez. considérable. Enfu les zones porifires sont moins larges, et les sillons transverses intermédiaires ne sétendent pas d'une rangée à l'autre, comme dans le L. bifora, mais sont an conraire très limités (voyez la fig. 15 de Tal. 11 qui représente une portion de l'ambulacre grossi). La face inférieure ne montre aucune particularité remarquable, si ce n’est que les sillons ambulacraires se ramifient un peu plus que dans le $L$. bifora; la bande lisse qui borde les sillons est en revanclıe moins prononcéc. La rosette apiciale est représentée grossie dans la fig. 14; on y reconnait très-distinctement la position des pores génitaux, au sommet des aires interambulacraires et celle des pores ocellaires, au sommet des ambulacres. La fig. 13 représente le profil du test, qui est très régulier. Les mâchoires offrent la même structure que celles du $L$. bifora. mais elles sont proportionnellement un peu plus petites.

L'origine de cette espéce m'est inconnue. L'exemplaire figuré fait partic du Musée de Paris.

\section{Lobophona bifissa Ag.}

Tal. 13, fig. 2-6 et Tab. 14, fig. 1 et 2 .

Sir. Scutclla bifissa Lam. Tom. 3, p. 281, No S. - E. Desl. Euc. Tom. 2, p. 676,No 8. - DeBl. Dicl. sc. nat. T. 48, p. 224, - DesMoul. var. A. Tahl. syn. p. 226, No 12. - Encycl.métl. Tab. 152, fig. 1 et 2.

Scutclla inaurita (pro parte) DeBl. Zooph, p. 200. - Agass. Prod. Ech. p. 188.

Eclinus inauritus var. a. L. Gm. p. 3199.

Echinoglycus inauritus (Ongeoorde Stomphart) van Phels. p. 34, Nº 2.

Echinodiscus inauritus Leske apud Jỉein, p. 202.

Echinus planus (Groote Pannekoek) liumph. p. 37, Tab. 14, fig. F.

Placcnta lagantm majus Rumphii Krlein Gall. $\$ 85$, p. 92.

Oursin doublc-cntaille Bosc Deter. T. 24, p. 281.

Echinanthus Seba Thes. Tab. 15, fig. 1 et 2.

La détermination de cette espèce m’a présenté les plus grandes difficultés à cause des renseignemens contradictoires des auteurs. Van Phelsum et plus tard Leslie distinguaient déjà deux especes dans le type des Lobophores a deux entailles ouvertes, l'une ayant le bord postérieur tronqué (inauritus), l'autre l'ayant pourvu de prolongemens saillans (auritus). Leske rapporte 
a la première les fig. 3 et 4 de Tab. 15 de l'ouvrage de Séba, ainsi que la figure de Rumph (Tab. 14 F.), mais en faisant remarquer qu'il trouve à peine les diffèrences suffisantes. Lamarcli et DesMoulins ne les envisagent que comme des variẻtés d'une seule et même espèce, qu'ils désignent sous le nom de Scutella bifissa.

L'espèce que je décris ici sous le nom spécifique de Lamarck correspond à sa variélé $a$ et à la fig. 3 de la Pl. 15 de l'ouvrage de Séba. Il est vrai que le lobe postérieur intermédiaire entre les deux entailles est un peu moins saillant; mais en revanche, son bord est tronqué et plus ou moins flexueux; or comme ce caractère est précisément celui que van Plelsum indique comme le plus significatif, j’ai rapporté à cette espèce tous les synonymes qui ont trait à la figure ci-dessus mentionnée de Séba, et à celle de la Pl. 152 de l'Encyclopédie méthodique qui n’en est qu'une copie rẻduite.

Par sa forme générale, le $L$. bifissa ressemble parfaitement à une houe; le côté antérieur est arrondi et sensiblement plus étroit que le côté postérieur, surtout dans les vieux individus. C'est l'espèce la plus aplatie de tout le genre, et peut-être de tout le groupe des Scutelles. Dans es vieux exemplaires, tels que celui de Tab. 13, fig. 2 , l'épaisseur égale à peu près le onzième de la longueur. Les entailles situées dans le prolongement des aires ambulacraires postérieures sont de largeur moyenne à leur origine, mais s’ülargissent sensiblement vers la périphérie. La rosette ambulacraire est petite proportionnellement à la grandeur du test; les pétales postérieurs sont, comme dans tous les Lobophores, plus courts que les antérieurs. Leur longueur est égale à celle des entailles, et l'espace intermédiaire a à peu près les mêmes dimensions. La rosette apiciale est petite; les pores génitaux, au nombre de quatre, sont à l'extrémité de ses rayons; les pores ocellaires sont à peine visibles. L'articulation des plaques est très distincte particulièrement dans les jeunes exenplaires (Tab. 14, fig. 1 et 2); les soies sont très petites, surtout à la face supérieure. L'exemplaire de Tab. 13, fig. 2, en est revêtu dans une moitié, tandis que l'autre moitié montre l'apparence granulaire des tubercules. Les soies de la face inférieure sont plus développées, notanment dans les aires interambulacraires; au lieu d'être renflées à leur extrémité, elles sont grêles et cylindriques dans toute leur largeur.

La face inférieure est plus uniforme que dans les deux espèces précédentes; les sillons ambulacraires y sont moins prononcés, mais plus ramifiés, au moins dans les vieux exemplaires. Les tubercules, quoique d'apparence uniforme, sont cependant différens suivant leur position; ils sont bien plus développés dans les aires interambulacraires que dans les aires ambulacraires, et_cette diffërence se traduit mêne dans les soies. L'ouverture buccale est au centre de la face 
inférieure; son pourtour est circulaire. La rosette qui l'entoure est fort distincte et composie cu apparence de cinq plaques rhomboüdales ; nais lorsqu'on l'examine de près, on y reconnail encore cinq autres plaques très-itroites, correspondant aux sillons ambulacraires, ensorte qu'il y en a réellement dix, conme daus toutes les Scutelles. L'anus est placé à la lauteur de lorigine des entailles, c’est-à-dire un peu plus prìs lu bord postérieur que de l'ouverture buccale; il est très petit et de forme circulaire. La couleur est d'un violet très vif dans les jeunes exemplaires ; dans les vieux, elle semble passer au rouge brun. On remarque qu'à la face infërieure, les soies sont plus virement coloríes dans les aires interambulacraires que dans les aires ambulacraires.

L'intérieur est en grande partie occupé par les réseaux cellulaires; il ne reste par conséquent que tris peu de place pour l'appareil masticatoire et pour l'intestin ; aussi ce dernier est-il riduit à un boyau très étroit; la fig. 6 de Tab. 13 représente son trajet sur le côté droit : après ètre rémonté jusqu'à la liauteur de l'aire interambulacraire antérieure droite, il entre dans une anse profonde où il se replie sur lui-même pour rètrograder vers l'ouverture anale. Cette anse est fortement infléchie à droite, tandis que dans l'espèce suivante elle est moins courbée. Les fig. \$ et 5 de Tab. 13 représentent l'appareil masticatoire d’un individu de même taille que celui de Tab. 1. 4, fig. 1; il est vu par sa face inférieure, dans la fig. 4, et par sa face supérieure dans la fig. 5 . Dans cette dernière, on voil les dents en place. La fig. 3 représente le plancher inférieur vu par sa face interne, l'appareil masticatoire étant enlevé; on y reconnait les cinq anricules sur lesquelles s'articulent les mâchoires.

L'exemplaire de Tab. 14, fig. 1 et 2 , m’a été confié par $\mathbf{M}$. Valenciennes; il provient de la Mer-rouge, doù il a été rapporté au Musíum de Paris par M. Roux. L'exemplaire de Tab. 13, fig. 2, m’a été conmuniqué par M. Pictel, de Genève; son origine n'est pas connue. Dans le grand ourrage sur l'Egypte, Savigny a donnẻ une figure de cette espèce parfaitement conforme ì l'exemplaire que j’ai représenté Tab. 14, et provenant également de la Mer-Ronge. 


\section{Lobophora Aurita Ag.}

Tal. 13, fig. 1 et Tab. 1't, fig. 3-7.

Sin. Scutclla aurita DeBl. Zooph. p. 200; - Agass. Prod. Ech. p. 188.

Scutella bifissa var. 2. Lam. Tom. 3, p. 282. - Encycl. métı. PI. 151, fig. 5, 6. - DesMoul. rar. C, Tabl. syn. p. 228.

Echinoglycus antius (Geoorde Stromphart) Van Phels. p. 34.

Echinus auritus L. Gm. p. 3189.

Echinodiscus auritus Leske apud KRlein, p. 202.

Echinanthus maximus Seba Thes. 3. Tab. 15, fig. 1, 2.

Favanne Tab. 58, fiğ. C, 1.

Ce n'est pas sans quelque hésitation que je rapporte cette espece au Scutella aurita des auteurs. L'exemplaire figuré, le seul que je connaisse, n’a pas le bord postérieur intact, ensorte que je ne puis affirmer avec une pleine certitude qu’il était réellement pourvu de prolongemens auriculés. Une circonstance cependant me fait supposer que ces prolongemens existaient : c'est l'épaisseur du test qui est ébréché et plus considérable en cet endroit (l'angle des entailles) qu'ailleurs. En tous cas cet exemplaire apparlient à une espèce différente de la précédente, ainsi que nous allons le voir. Et d'abord son pourtour n'est pas le mème; le côté antérieur surtout est plus large et bien moins uniformement arrondi ; les pétales ambulacraires sont plus étendus et les entailles, au lieu de s’élargir vers la périphérie, ont au contraire une tendance à se rétrécir ; elles sont en outre proportionnellement plus longues, ce qui fait que l'espace qui les sépare de l'extrémité des pétales est d'autant plus restreint. Enfin l'anus est placé sensiblement en arriẻre de lorigine des entailles et par conséquent plus rapproché du bord postérieur.

La fig. 3 de Tab. 14 représente la fice supérieure qui montre distinctement l'articulation des plaques du test; la forme des pétales ambulacraires el l'arrangement des pores génitaux, qui sont au nombre de quatre et très apparens. Les cinq pores ocellaires, situés au sommet des pétales, sont à peine perceptibles à l'oeil nu. La face inférieure n'offre aucun caractère particulier à cette espèce, si ce n'est que la différence entre les tubercules des aires interambulacraires et reux des aires ambulacraires est plus frappante que dans le L. bifissa. Les sillons y sont peu marqués. 
La fig. 1 de Tab. 13 représente la cavitè in térieure, le plancler inférieur étant enlevé; les pétales ambulacraires s'y dessinent aussi nettement qu’a la face externe; on voit les pores génitaux s'ouvrir dans quatre carènes osseuses saillantes, qui s’étendent dans les aires interambularraires ; la carène correspondant à l'aire interambulacraire impaire ne diffẻre des autres, qu'en ce qu'elle est dépourvue du pore génital. $\Lambda$ côté de l'ambulacre antérieur impair se voit le sinus dans lequel l'intestin se recourbe sur lui-mème pour regagner l'anus. Les fig. 5 et 6 de Tab. 1' reprẻsentent l'appareil masticatoire, vu en dessous (fig. 5), et en-dessus (fig. 6); les lettres a. l. p. indiquent, comme dans le $L$. bifora, la position relative des màchoires. Dans la fig. 5 , 011 dislingue fort bien, à la surface de chaque mâchoire, les fossettes naviculaires; elles correspondent aux cinq auricules qu'on voit surgir des aires interambulacraires dans la fig. 4 , qui représente: le plancher inférieur du test vu par sa face interne. Les màchoires sont très grandes, mais peu ¿paisses; la fig. 7 en montre une de profil avec la dent fixée verticalement à sa surface.

L'exemplaire figuré a été adressé au Musée de Neuchittel par M. Guebhard, consul de Prusse à Alexandrie. Il provient de la Mer rouge. 


\section{CIIAPITRE VI.}

\section{DU GENRE AMPIIOPE Ağ.}

Les espèces que je range daus ce genre ont les plus grands rapports avec les Lobophores; rependant j'ai cru devoir les en séparer à cause de la forme de leurs lunules qui est arrondie, au lieu d'ètre allongée comme dans les Lobophores. Cette forme particulière détermine un arrangement tout différent des plaques des aires ambulacraires postérieures qui, au lieu de former des rangées régulières de chaque côté de la lunule, sont disposées en cercle autour d'elle. (Comparez les fig. 1 et 6 de la pl. 11 avec la fig. 11 de la même planche.) A part cela, les Loboplıres sont des Oursins très réguliers, fort aplatis, à pourtour généralement sulbcirculaire. Les pétales ambulacraires, larges et courts, s'arrondissent à leur extrémité, mais dépassent rarement la mi-bord. Les pores génitaux sont au nombre de quatre el placés au sommet des rayons du corps madréporiforme; les trous ocellaires occupent leur place lıabituelle à l'origine des pétales. La face inférieure est plane. Les sillons qui indiquent les ambulacres se divisent à une petite distance de la bouche en deux branches qui détachent dans leur trajet vers la périphérie un nombre plus ou moins considérable de rameaux latéraux. La bouche est centrale; son pourtour circulaire est reudu flexueux par les saillies des cinq tubes branchiaux. La rosette buccale est en apparence pentagonale; mais examinée de prẻs, on y reconnaît dix plaques comme dans les Lobophores. L’anus est à la face inféricure et très rapproché du bord postérieur, il est petit et circulaire.

Je ne connais encore que deux espèces de ce genre; toutes deux sont fossiles, des terrain. tertiaires. 


\section{AMPHOpe moculata Ag.}

Tal. 11 , fig. $1-5$.

Sry. Scutclla bioculata DesMoul. Tabl. syu. p. 232, No 23.

Sc. bifora Lam. var. c, Tom. 3, p. 282. - E. Desl. Encycl. Tom. 2, p. 676, No 7. - Encycl. méth. Tab. 147, fig. 5-6. - Desmar. dans Al. Brong. Théor. des terr. Tabl. No 5, p. 12. Dict. sc. nat. T. 54 .

Amphiope bioculata Ag. Catal. syst. Ectyp. Mus. Neoc. p. 6.

Cette espèce est de forme à peu prẻs circulaire et médiocrement aplatie. Son pourtour ne présente aucune échancrure, mais bien de légères rentrées en face deș ambulacres pairs. Le diamètre longitudinal égale à peu près le diamètre transversal. Le côté postérieur est tronqué. Les lunnles sont à peu prẻs circulaires; elles occupent l'espace intermédiaire entre le bord et l'extrémité des pétales postérieurs et autour d’elles, les plaques du test sont disposées en cercle (fig. 1). Les pétales ambulacraires sont courts, mais larges et arrondis a leur extrémité. La fig. 4 représente la rosette apiciale avec l'extrémité des ambularres sons un faible grossissement. On y distingne les quatre trous oviducaux au sommet des angles du corps madréporiforme, qui correspondent aux aires interambulacraires paires ; laire interambulacraire impaire en est dépourvue. Les sillons de la face inférieure donnent lieu à de nombreuses ramifications, dans lesquelles on distingue, à l'aide d'une forte loupe, des rangées de pores microscopiques. Près de la bouche, là où ils sont encore indivis, ces sillons sont plus profonds et présentent de légères carènes qui sont sans doute les tubes dans lesquels étaient logées les branchies bnccales. La fig. 5 qui représente la rosette buccale donnera une idée assez claire de cette disposition des tubes branchifères antonr de la bouche. L'anus est infra-marginal, mais il ne dètermine ancune échancrure dans le bord postérieur.

L'Amphiope bioculata provient du terrain tertiaire de France. M. Desmoulins cite comme localité Bordeaux, et Sure près Bolléne, département de Vaucluse. Les exemplaires que jai sous les yeux mont été commnniqués, l'un par M. Deslıyes, et l'autre par M. Miclıelin; ils proviennent de la Touraine. 


\section{Anitiope perspicillata Ag.}

Tab. 11, fig. 6-10.

Sin. Catal. syst. Ectyp. Mus. Neoc.p. 6.

Cette espèce est l'une des plus plates de la famille des Scutelles. Elle n'a pas plus d'une ligne l'épaisseur, tandis que sa longueur et sa largeur sont de près de deux pouces. Le eôté antérieur est sensiblement plus étroit que le côté postérieur ; ce dernier, au lieu d'être tronqué comme dans l'A. bioculata, est au contraire arrondi et mème légèrement rostré; les deux sinus qui correspondent aux ambulacres pairs postérieurs sont très marquẻs. Les lunules ont une forme subcirculaire et sont de mème grandeur que dans l'espèce préédente. On remarque aussi autour d'elles la même disposition des plaques en cerele. Les ambulacres sont plus petits et surtout moins larges que ceux de l'A. bioculata; leur extrémité est aussi moins arrondic. La fig. 9 représente l'appareil ovidueal avec le sommet des ambulacres. A la faee inférieure, on distingue fort bien les sillons ambulacraires, et à l'origine de ces derniers, près de la bouelıe, les tubes branehifères avec leur ouverture, telles que les montre la fig. 10, qui représente la rosette buccale. L'anus, sensiblement éloigné du bord, est à peu près au quart de la distance entre eelui-ei et la bouche.

L'exemplaire figurẻ m’a été communiqué par M. Michelin; il provient du terrain terliaire de Rennes. 


\section{CHAPITRE VII.}

DU GENRE SCUTELAA Lam. (Ag).

Après avoir défalqué du genre des Scutelles tel que l'a caractérisé Lamarck, d’une part toutes les especes pourvues d'entailles, de lunules, de digitations, etc., dont nous arons fait les genres Rotula, Runa, Mellita, Encope, Lobopliora et Ampliope ; et d'autre part, les espèces ayant l'anus marginal, tels que les Echinarachuius, les Arachnoides, les Scutellines, ainsi que les espèces plus voisines des vrais Clypéastres, tels que les Layamum, les Echinocyamus et les Moulivia, il ne reste plus comme vraies Scutelles, que les espèces à bords entiers, qui ont les ambulacres conrergens et l'anus à la face inférieure.

Les Scutelles ainsi limitées sont des oursins de grande taille, ordinairement tris aplatis et présentant une déclivité très graduće du sommet vers le bord. La plupart des espèces sont plus larges que longues; leur pourtour est généralenent ondulé et le còté antérieur pour l'ordinaire sensiblement plus étroit que le côté postérieur. Le point culminant du test coïncide avec la rosette apiciale. Les pétales ambulacraires sont plus ou moins développés suivant les espéces; leur longueur et leur largeur relatives constituent les principaux caractères spécifiques des espèces. La rosette apiciale présente ordinairement un pentagone assez régulier. Il n'y a que quatre pores génitaux; les trous ocellaires, moins distincts que ces derniers, sont cependant reconnaissables dans tous les exemplaires bien conservés. Le corps madréporiforme se montre composé d'une agglomération de tubes capillaires comme dans les genres précédens. La face inférieure est moins uniforme que la face supérieure; les sillons surtout s'y ramifient considérablement. La bouchc est centrale, entourée d'une rosette buccale ordinairement très grande et composée de dix plaques cunéiformes dont les plus grandes correspondent aux aires ambulacraires; elle serait de plus circulaire, n'étaient les tubes branchiaux dont l'extrẻmité fait saillie sur son pourtour. L'anus est petit, plus ou moins rapproché du bord postérieur ; mais jamais il n'est entièrement marginal. 
L'intérieur des Scutelles rappelle ả beaucoup d'égards la cavité intérieure des Lobophores; il n’y a ni piliers, ni cloison calcaire destinés à séparer l'intestin des organes masticatoires; mais la cavité libre du milieu est très petite; en revanche les bords ne présentent qu'un labyrinthe de piliers calcaires, entre lesquels étaient sans doute logẻs, pendant la vie de l'animal, des appendices du canal intestinal. L’appareil masticatoire est en général très solide; les màchoires sont fortes, hérissẻes de lames calcaires très hautes, implantées sur une charpente massive.

Je ne connais que des espèces fossiles de ce genre. A l'exception d'une seule, le $S_{c}$. Rogersi, qui est de la craie, elles appartiennent toutes aux diffẻrens étages de la formation tertiaire, depuis le calcaire grossier des environs de Paris jusqu'aux Faluns de la Touraine.

\section{Scutella subrotunda Lam.}

Tab. 17.

Srv. Scutlla subrotunda Lam. Tom. III, p. 2S4, No 14. - DeFr. Dict. sc. nat. T. 48, p." 230. DeBl. Zooph. p. 201.- DesMonl. Tabl. syn. p. 232...- Brom Lethaea p. 138. — Ag. Cat. syst. Ectyp. Mus. Neoc. p. 6.

Rien n’était plus facile que de déterminer cette espèce lorsqu'elle était la seule Scutelle connne ayant l'anus inframarginal, le bord entier et les cinq ambulacres resserrés à leur extrémité. Mais depuis que lion a reconnu dans les nombreux exemplaires confondus sous le nom de $S$. subrotumela, des variations constantes, les caractères diagnostiques indiquẻs par Lamarck (") sont devenus insuffisans comme caractères spécifiques et ne peuvent plus s’appliquer qu'au genre. Il importe par conséquent maintenant, pour distinguer le $S$. subrotunda de ses congénères, d'entrer dans l'examen détaillé de son test et d'avoir égard à toutes les particularités de sa structure.

L'espèce à laquelle je conserve le nom de $S c$. subrotumda est celle que Lamarck désignait ainsi et dont M. Valenciennes n'a fait voir au Muséum de Paris des exemplaires portant encore l'étiquette écrite de la main de Lamarck. Elle est de forme subcirculaire, légérement ondulée sur son pourtour, par suite des sinuosités qui correspondent au milieu des aires ambulacraires; le còté postérieur est tronqué el séparé du reste du test :par les deux sinus des aires ambulacraires paires postérieures; le diamètre transversal est un peu plus grand que le diamètre longitudinal.

(*) Scntella orbicularis, dorso conrexiuscula; ambulacris quinis subovatis, apice coarctatis; ano infra marginem. 
La hauteur du test égale à peine le sixième de la longueur et le septième de la largeur; les bords sont minces sans être aussi tranchans que dans le $S_{c}$. Iruncata. La surfice entière du test est revêtue d'une granulation lıomogène, composée de tubercules spinifëres surgissant du milieu d'une aire hexagonale entourie d'une quantité de tubercules miliaires. La fig. 11 représente quelques tubercules de la face infërieure sous un grossissement de plusieurs diamètres. Ceux de la face supérieure sont moins gros; d'oủ je conclus que les soies devaient être plus déreloppéés ả la fice inférieure qu’ì la fice supérieure. La disposition des plaques se reconnaît souvent à travers cette granulation, surtout dans les exemplaires dont la surface est un peu usée. On peut voir par mes figures que les plaques sont proportionnellement bien moins larges à la face supépérieure qu’à la face inférieure; autour de la rosette buccale qui est formíe de pièces prismatiques disposées en rayons, elles affectent mêne souvent une forme allongée plus ou moins irrégulière.

L'ẻtoile ambulacraire est très régulière et ne fait nullement saillie au-dessus du test. Par suite de la convergence des zones porifẻres, les pétales s'arrondissent ả leur extrémité, mais sans se fermer complètement; les postérieurs sont à peine de quelques lignes plus longs que les antérieurs. L'espace intermédiaire entre les deux zones porifères est un peu moins large que ces zones elles-mèmes; les pores des rangíes externes sont allongés, tandis que ceux des rangées internes sont petits et ronds; les sillons qui les unissent sont dirigés obliquement de dedans en dehors. La rosette apiciale représente un pentagone régulier; les pores génitaux, au nombre de quatre, sont fort distincts et placés à l'extrémité des angles du pentagone; les Irous ocellaires, beaucoup plus petits, sont à l'origine des pétales, dans le sinus du pentagone apicial (fig. 6). La face inférieure est plane; les sillons ambulacraires y sont assez profonds, mais irríguliẻrement ramifiés. La bouche est centrale, petite et ondulée. La rosette buccale est grande et très reconnaissable dans cette espèce; il n’est pas une sulure que l'on ne distingue parfaitement (fig. 2). L'anus est inframarginal, petit et très rapprochẻ de l'échancrure du bord postérieur qui est trẻs prononcée dans cette espèce.

L’intérieur du test présente sur ses bords un labyrinthe très compliqué de piliers, de cellules et de canaux (fig. 4.5), ensorte que la cavité centrale est très restreinte; et si l'on considère que l'appareil dentaire (fig. 7 ) en occupait une honne partie, il laut convenir qu'il ne restait que peu de place pour les parties molles de l'animal. La fig. 4 montre dans son bord gauche, et la fig. j dans son bord droit, le canal qui traverse l'extrémité postérieure de l'intestin. Le test lui-même est d'une épaisseur médiocre; prẻs de la bouche il est même très mince. 
L'appareil masticatoire est admirablement conservé dans l'exemplaire figuré. La fig. 7 le montre d'en haut, les cinq mâchoires étant réunies. Dans la figg. 8, le même organe est vu d'en bas, les cinq mâchoires étant séparées. De même que dans les genres précédens, les màchoires antérieures $(a$ a $)$ sont plus petites et plus symétriques que les latérales $(l . l$ l.), dont lune des branches est sensiblement plus longue que l'autre. La mâchoire impaire est la plus développée de toutes $(p)$; la fig. 10 représente cette dernière de profil montrant son épaisseur qui est assez considérable; la fig. 9 la représente en face, pour faire voir sa forme ondulée et la hauteur des lames calcaires dont elle est hérissée.

Cette espèce paraît être particulière au terrain tertiaire de Bordeaux. Au moins je n'en connais pas d'exemplaires provenant d'une autre localité; l'exemplaire figuré fait partie de la belle collection de M. Deshayes. L'espèce figurée par M. de Grateloup (Tab. 1, fig. 3) a la plus grande ressemblance avec le $\mathbf{S}$. subrotunda, au point qu'il serait difficile de l'en distinguer, si l'auteur ne disait expressément que l'anus est sensiblement rapproché du centre; ce qui me fait supposer que c'est le Sc. propinqua.

\section{Scutella truxcata Val.}

Tab. 16, fig. 1, 2, 3, 8, 9, 10 et Tab. 19, fig. 3-6.

Srr. Scutella truncata Val. Explic. des Planches de l'Encycl. méth. Tabl. 146, fiğ. 45.

Scutella integra Del3l. Dict. sc. nat. T. 48, p. 225. - Zooph. p. 201 - Ağ. Prod. p. 188.

Scutella latissima DesMoul. Tabl, syn. p. 228 (pro parte).

Cette espèce se fait remarquer par sa forme renflée et par son bord très- aminci. L étoile ambulacraire est grande; les ambulacres sont larges, très-arrondis à leur extrẻmité, par suite de la convergence des zones porifẻres. Le pourtour du test, à l'exception des deux sinus correspondant aux ambulacres postérieurs, ne présente que de très-légères ondulations. La bouche est centrale. Son pourtour sinueux se montre criblé d'une immense quantité de petits pores dans les aires ambulacraires (fig. 10). Les sillons de la face inférieure sont peu profonds; chaque sillon se divise, à l'extrémité du petit tube branchial, en deux branches, qui détachent un ou deux rameaux latéraux. La rosette buccale montre la mème disposition que dans le $S c$. subrounda ; les plaques dont elle se compose sont au nombre de dix; il y en a par conséquent une par aire. L'anus est placé au prenier quart de la distance entre le bord et le centre. Le bord pos- 
lirieur ne présente point eette échanerure profonde qui caractérise le Se. subrotunda; l'on n'y remarque qu'une lëgère ondulation. La surface entière du test est revêtue de tubercules très serrés qui s'ëtendent même entre les sillons ondulés des zones porifêres (fig 8 ). En les examinant sous un fort grossissement, on y reconnaît des tubereules spinifères très distincts, entourés de tubercules miliaires exeessivement petits (fig 9).

L'appareil masticatoire (Tab. 19 fig. 3) * ne diffère pas sensiblement de celui du Sc. subrotunda; il est digne de remarque que les lames vertieales se soient aussi bien eonservées dans un espèee fossile (fig. 5, 6). La fig. 3 représente eet appareil vu en dessous, montrant les einq màchoires réunies et au milieu de chaeune d'elles une petite earène suivie d'un petit creux (la fossette naviculaire) destiné à l’engrènement des auricules. Dans la fig. 4. les mâchoires sont disjointes et l'on voit sur la ligne mẻdiane le sillon dans lequel étaient fixées les dents.

J'ai sous les yeux plusieurs exemplaires de eette espèce. Celui qui est ici figuré est originaire le l'Anjou et fait partie de la colleetion de M. Deshayes. Le Muséun de Paris en possède de non moins parfaits provenant des faluns de la Touraine. M. Ch. Des Moulins rapporte à tort la planclie eitée de l'Encyl. méthod. à son Sc. latissima, qui est un vrai Clypeaster.

\section{Scutella propingei Ag.}

Tab. 16, fig. 11-16.

Par sa forme générale, eette espèce se rapproche sensiblement des Sc. truncala et subrotunda, mais elle en diffère d'un autre côté par plusieurs caractères que nous allons indiquer. El d'abord létoile ambulacraire est proportionnellement beaueoup plus petite (fig. 11). Les pétales ambulacraires sont ronds à leur extrémité, et de plus l'espace eompris entre les zones porifères est sensiblement plus large que les zones elles-mèmes. Le diamètre transversal du test est plus grand que le diametre longitudinal. Le bord est entier et n'offre d'autres sinus que ceux qui eorrespondent aux ambulacres pairs postérieurs. Le bord anal lui-mème ne présente qu'une très légère rentrée bien différente de l'échancrure profonde qui caractérise le $S c$. subrotunda. L'anus est encore plus éloigné du bord que dans le Se. truncata; il est au tiers de la distance entre le lord et la houche.

(") Le lithographe a figuré par erreur l'appareil masticatoire du Mellita lobata, au lieu de celui du Sc. truncata, sur la Pl. 16, ce qui m’a obligé de reporter sur la PI. 19 le véritable appareil masticatoire du $S c$. truncata. 
La bouche est de moyenne grandeur; la rosette buccale qui l'entoure est petite et les dix plarpues dont elle se compose ne paraissent pas être aussi allongées que dans les espèces précédentes.

La surface entière du test est revêtue d'une granulation en apparence très lomogène, qui occupe mème les espaces intermédiaires entre les sillons transverses des pétales (fig. 15), mais qui, 'xaminée sous un fort grossissement, présente des tubercules spiniféres distinctement mamelomiés et entourés d'une quantité de tubercules miliaires (fig 16). La fig. 14 représente la rosette apiciale grossie, laissaut apercevoir les tubes capillaires dont elle est criblée.

Cette espèce se trouve dans les faluns de la Touraine; l'exemplaire figuré provient de SaintGeorges en Anjou, et m’a été communiqué par M. le Dr. Mayor de Genẻve.

\section{Scutella Brovgniarti Ag.}

Tal. 15, fig. 1-3.

Cette espèce est de moyenne taille, très aplatie et à bords trẻs minces. Le diamètre transversal n'excède que de quelques lignes le diamètre longitudinal. La liauteur égale à peine le sixième de la longueur. Le pourtour du test est légèrement sinueux, mais les deux sinus postérieurs sont très marqués, de façon que le côté postérieur paraît sensiblement rostré. Les pétales ambulacraires sont de moyenne grandeur et presque fermés à leur extrémité. L'espace compris entre les zones porifères est plus large que les zones elles-mèmes. A la face inférieure, les sillons sont peu profonds et peu ramifiés ; la bouche est petite; l'anus est très rapproché du bord, sans cependant être marginal.

Vue d'en haut, cette espece a la plus grande analogie avec le $S c$. propinqua; mais elle en diffire cependant par sa forme plus aplatie et par la position de l'anus qui est plus marginal.

Je ne connais qu'un exemplaire de cette espèce. Il provient du terrain tertiaire de Grignon, oủ je l'ai trouvé moi-même. 


\section{Scutela Faujasil DeFr.}

Tab. 15, fig. '. -6.

Srx. Sc. Fuujasii DeFr. Dict. sc. nat. T. 48, p. 230. - DeBl. Zooph. p. 201. - DesMoul. Tabl. syn. p. $214, N^{\circ} 27$.

Lin caractère essentiel de cette espece, et qui frappe an premier coup d'œil, c'est l'épaisseur du bord comparé ì la hauteur peu considérable du test. Les sinus postérieurs sont très prononcés, ensorte que le bord anal forme une sorte de rostre très marquẻ et plus étroit que dans les espèces précédentes. Les pétales ambulacraires sont de forme elliptique, arrondis à leur extrémité. Les sillons de la face infèrieure sont très profonds et très sinueux. L'anus est placé à peu près au tiers de la distance entre le bord et le centre, à peu près comme dans le $S c$. truncata. Le test est très épais, comme j’ai pu en juger par quelques brisures du bord et par la cavité buccale. Son apparence est aussi en géuéral plus massive que celle de la plupart des autres espèces.

Je ne connais que très peu d'exemplaires de cette espèce; celui qui est ici figuré provient du terrain tertiaire du département de la Sarthe, et m’a été communiqué par M. EudesDeslonchamps. Le Sc. Faujasii de M. de Grateloup (Mém. sur les Oursins foss. Tab. I , fig. 2) est le $S c$. truncata de M. Valenciennes, tandis que sa variété $b$ (Pl. 1, fig. 3) est probablement le $S_{c}$. propinqua. $\mathrm{Ag}$.

\section{Scutelda strutula M. de SR.}

Tab. 18, fig. 1-5.

Syn. Scullla stricuula M. de Sr. Géogr. p. 156. - DesMoul. Tabl. sỹn. p. 234.

Scutclla subrotunda Grat. Tabl. 1, fig. 1 .

II. IIarcel de Serres est le premier qqui ait distingué cette 'spéce; elle est en effet fort différente de toutes ses conginères par sa forme subconique (fig. 3), par son pourtour fortement ondulé et par une échancrure étroite et très profonde au bord postérieur. Les pétales ambulacraires sont très arrondis à leur extrémité et plus petits que daus aucune autre espèce, car ils 
alteignent rarement la mi-bord. Les zones porifires sont un peu phus larges que l'espace intermédiaire. La fig. 5 représente l'extrémité d'un pétale sous un faible grossissement montrant li forme des pores qui sont allongés dans la rangée externe, petits et circulaires dans la rangée interne. Enfin, les sillons qui réunissent les deux rangées, au lieu d'être obliques ou ondulés, sout transverses jusqu'it l'extrémité des pétales. La fig. 4 montre la disposition des tubercules sous le mème grossissement que la fig. 5. La face infẻrieure est plane. La bouche est entourée d'une rosette décagonale fort élégante. Les sillons sont peu profonds et peu ramifiés. L'anus est sulomarginal el presque contigu a l'échancrure du bord postèrieur. M. de Grateloup, qui l'a rapportée à tort au Se. subrotunda, la cite dans les falıns jaunes et sur la couche superficielle des dépôts de St Paul, près de Das, au Mainot, à Mandillot, en faisant remarquer qu'elle ne se rencontre jamais dans les falums bleus.

Cette espece se trouve dans le terrain tertiaire de l'Europe méridionale. L'exemplaire figuré u’a élé communiqué par M. Brongniart.

\section{Scutelli provects Ag.}

Tab. 18, fig. 6-10.

Au premier abord, celte espèce a la mème plysionomie que le $S c$ striatula figuré sur la même planche. Mais il suffit d'entrevoir les détails du test pour se convaincre qu'elle en diffère complètement. L'un de ses caractires les phus saillans consiste dans la forme très rostrée de son bord postérieur; son pourtour est très ondulé; son épaisseur est moyenne; mais au lieu d'être subconique, elle est arrondie et légèrenent déprimée au sommet (fig. 8). L'étoile ambulacraire est de moyenne grandeur; les pétales sont très arrondis à leur extrémité; ils dépassent rarement la mi-bord. Les zones porifëres, d'aloord très étroites à leur origine, s’élargissent considérable ment vers leur extrémité, oủ elles sont sensiblement plus larges que l'espace intermédiaire. La lig. 10 représente l'extrémité d'un pétale grossi, ou l'on voil que les sillons qui unissent les deux rangées de pores, au lieu d'être transverses comme dans l'espèce précédente, sont au contraire obliques. La face inférieure laisse apercevoir quelques traces de la rosetle buccale entourant la bouche. Les tubes brimchiaux y sont un peu plus distincts. Les sillons paraissent ètre peu 
marqués et peu ranifiés. L'anus est situé au tiers de la distance entre le bord postérieur et la houclie, el par conséquent bien moins marginal que dans le $S_{c}$. striatula.

Je connais plusieurs exemplaires de cette espece, dont je dois la communiration a l'obligeance de MI. Valenciennes et de M. DeFrance; ils provienment des environs de Saumur.

\section{SCLTELII PIILExSis ig.}

Tab. 19, lig. 8-10.

Celte espéce est la plus commune dans les collections, ou elle figure ordinairement sous le nom de $S_{c}$. subrotunda. Elle est en effet très voisine de cette dernière; sa lorme est subcirculaire fortement diargie en arrière, de manière que te diamètre transversal est sensiblement plus grant que le diamétre longitudinal. Son épaisseur est peu considérable (fig. 10); ses bords son!t amincis, sạns ètre aussi tranchans que dans le $S c$. truncata. Les pétales ambulacraires sont de mogenne grandeur, très arrondis a leur extrémité; et les zones poriféres sont plus larges que l'espace intermédiaire. La boncle est petite et centrale. L'anus est infra-marginal, mais l'on ne remarque point, au bord postérieur, cette échancrure caractéristique da Sc. subrolunda. Le pourtour du test est légèrement ondulé, et les sinus des ambulacres postérieurs eux-mèmes sont peu prononcés.

Comme tous les exemplaires que j’ai rus de cette espece proviennent du terrain tertiaire supérieur de St Paul-Trois-Chàteaux près de Dax, je lui ai donné le nom de $S_{c}$. paulensis, ıui rappelle son origine. Les originaux de mes figures mont élé communiqués par M. Ie docteur Mayor de Geneve.

\section{Scutella stellati Ag.}

Tal. 19, fig. 1, 2.

L'épaisseur extraordinaire du test constitue le caractère essentiel de cette espèce. Quoique je ne la connaisse que par l'exemplaire assez défectuenx représenté Il. 19, fig.1 et 2 , jene crains cependant pas d'être taxé de témérité pour l'avoir distinguée de toutes les autres Scutelles. Le còté dorsal en particulier se fait remarquer par son excessive épaisseur, qui, comme on le roit 
par le profil de fig. 2 , est égale à la moitié de la hauteur. Les bords s'amincissent brusquement. Les ambulacres sont très-larges, surtout vers leur extrémité, oủ ils s'arrondissent à-peu-près romplètement. Les sillons de la face inférieure sont peu profonds, quoique larges.

L'original de mes figures fait partie de la belle collection de II. Deshayes el provient des filuns de la Touraine.

\section{Scutella subtetiagona Grat.}

Tab. 19, fig. 7 .

Sry. Scutclla subtetragona Grat. Mém. sur les Ours. foss. p. 87, Tab. 1, figg. 4. - DesMoul. Tabl. syn. p. 234.

Cette espèce, découverte par M. Grateloup dans les faluns jaunes des environs de Dax, ne m'est comnue que par la description et la figure que ce naturaliste en a données dans son Mimoire sur les Oursins fossiles des environs de Dax, et que je reproduis dans la planche ci-dessus. Il suffit de jeter un coup d'oeil sur cette figure pour saisir le caractère distinctif de cette espèce, qui consiste dans son extrème largeur, qui est d'un tiers à peu près plus considérable que la longueur. Le pourtour du test est très onduleux, presque quadrilatère, par suite des échancrures très profondes correspondant aux ambulacres pairs. Le bord postérieur est aussi marqué l'une légère entaille. Les pétales ambulacraires sont petits, étroits et lancéolés.

M. DesMloulins rapporte que l'exemplaire de M. Grateloup est le seul qui soit connu jusqu ä présent. L'anus n'y est pas visible.

\section{Scutelda Suithina $A g$.}

Tab. $19 a$, fig. 5 et $6,$.

Cette espèce est jusqu'ici la seule qui ait été signalée dans les terrains molassiques. Quoique l'exemplaire que je possède soit très-imparfait, j’ai cependant cru devoir le figurer, parce que jai tout lieu de croire qu'il constitue une espèce à part, très-voisine du Sc. subrotunda et qui étant entière, paraît avoir eu des dimensions assez considérables, ainsi qu'on peut en juger par la figure ci jointe, qui représente un exemplaire dont le bord antérieur est en grande partie enlevé. 
In caractère cependant la distingue de l'espèce précitée, c'est la largeur proportionnellement plus grande des pétales ambulacraires, qui, quoique arroudis à leur extrémité, ne se ferment cependant pas entièrement. Je n’ai pas pu réussir a dégager la face inférieure ensorte que la position de l'anus mest demeurée inconnue. Le profil (figg. 6) fait voir que c'est une espèce Irès aplatic.

L'original m'a été communiqué par M. Smith de Jordan-IIill; il provient de la molasse des environs de Lisbonne. C'est jusqu'ici le seul exemplaire connu.

\section{Scutelita rogeisi Mort.}

Tab. 19 a, fig. $1-4$.

Sry. Scutclla Rogersi Morton, Synops. des foss. de la Craie des Etats-Unis. - DesMoulins. Tabl. syn. p. 236.

Lagana Rogersi Ag. Catal. syst. Ectypt. MIus. Neoc. p. 6.

Cette espèce, décrite et figurẻe par Morton, dans son ouvrage sur la Craie des Etats-Unis, paraît ètre particulière à la Craie d'Amérique. Au moiıs je ne sache pas que personne l'ait signalée jusqu'à présent daus les terrains crétacés de l'Europe. Elle n'est pas moins remarquable par ses caractères zoologiques que par son gisement, car elle participe des caractères de plusieurs genres à la fois. Elle tient aux Echinarachnius par sa forme circulaire et par la disposition de ses sillons; aux Laganes par son bord renflé, et aux vraies Scutelles par la forme de ses ambulacres, qui sont arrondis à leur extrémité et par la position de son ouverture anale. Suivant que l'on accordera une valeur prépondérante à l'un de ces caractères, on la rangera dans l'uı ou l'autre de ces genres; mais sa place définitive ne pourra lui être assignée que lorsqu'on aura appris à connaître la structure de la cavité intérieure. Peut-être devra-t-on alors en faire le type d'un nouveau genre. En attendant, il m’a paru que c'était du genre des vraies Scutelles qu'elle se rapprochait le plus ; et, en effet, si l'on fait alsstraction de sa forme circulaire et de la présence de cinq pores génitaux au lieu de quatre, elle a tous les caractères essentiels de ces derniers: la forme arrondie des pétales ambulacraires, la position de l'anus, qui est au milieu de l'espace intermédiaire entre la bouche et le bord postérieur, les sillons de la face inférieure, quí sont ramifiés comme dans les vraies Scutelles, et la prẻsence de tubes branchiaux autour de l'ouverture buccale. 
En tout cas, ces earaetères sont plus que suffisans pour la distinction spécifique de l'espéce. Voici conment on peut la earactériser : c'est une Scutelle de forme circulaire, d'épaissenr moyenne, a bord trés renflé, el montrant de plus, entre ce dernier et le sommet, une dépression eirculaire assez marquée conme daus les Laganes du type du L. Bonami (*). Les pétales seétendent un peu au dela de mi-lord; ils sont très arrondis a leur extrémité sans eependant se fermer eomplètement. Les zones porifires sont sensiblement plus larges que l'espace intermédiaire. La rosette apiciale est petite; on y reconnait distinetement cing pores génitamx plaeés à l'extrémité des rayons du corps madréporiforme. Il y a également cinq pores ocellaires trés pelits. La bouche est centrale, de forme circulaire, entourée de cinq tubes branchiaux tris distinets. L'anus, plus petit que la bouche, est égalentent eireulaire et occupe le milieu de l'espace entre cette dernière et le bord posterrieur. Les sillons ambulacraires de la face inférieure se ramifient it plusieurs reprises dans leur trajet. Le test est épais comme dans les vraies Sculelles; sa surface entière est revêlue de tubereules d'apparence tris lomogine, semblables à ecux des Sculelles; re qui me fait présumer que les soies étaient de même nature.

L'exemplaire qui a servi de yype a celle description, fail partie de la collection du Musée de Lausanne, et m’a élé eommuniqué par M. le professeur Clavannes; il provient de la craie d'Mlabama, dans l'Amérique septentrionale.

\section{OBSERVATIONS ADDITIONNELLES SUR LES SCUTELLES.}

M. Charles DesMoulins mentionne dans ses Tableaux symomymiques deux espéces fossiles du terrain tertiaire de Blaye qui me sont incomnues, le Scutella marginalis DesIIoulins, dont il dit exister deux variélés, et le Scutella polygona Des Moulins. Il est possible que ce soient de vraies Scutelles, et dans ce cas elles font peut-être double emploi avec l'une ou l'autre des espèces décriles ci-dessus; ou bien ce sont des Laganes analogues aux Lag. reflexum $\Lambda_{g}$. et Lag. termissimum Ag. figurées sur la Pl. 26. Je ne comnais pas davantage le Scutella gibbercula de Marcel de Serres qui provient du terrain tertiaire de Cadenet, département de Vaucluse, et dont M. Destloulins dit avoir vu un exemplaire dans la collection de M. Requien. Espérons que

(*) Cette particularité m’avait engagé préccedemment à ranger le $S_{c}$. Rogersi dnus le genre Laganum. Catal. syst. Ectyp. Mus. Neoc p. 6. 
M. Deslloulins ne tardera pas à en pullier la description et yuil complètera ainsi celle étude monographique des Scutelles.

Quant aux deseriptions et aux figures des auteurs anciens, qu'on cite généralement dans la synonymie du Scutella subrotunda, elles ne mont pas paru assez précises pour pouvoir ètre rapporties avec certitude à cette espece plutot qu’ì telle ou telle autre qui en est roisine, les figures ne représentant pour l'ordinaire que la face supérieure, et les lescriptions ne portant pas sur les dètails de structure qui constituent les différences spécifiques. L'espèce figurée par Scilla sous le nom de Echimus Mclifensis (") se rapproche beaucoup, il est vai, de notre Sc. subrotunda; cependant sa forme plus arrondie et son gisement dans les terrains tertiaires de Malte, me font supposer que éest une espèce particulière. Il en est de mème de celle que Leslie décrit sous le nom d'Echinodiscus subrotundus et lont il donne une figure empruntée à l'ourage de il. Andreae ("*); comme cette figure est faite d’après un exemplaire provenant de l'ile de . Malte, il est probable qu'elle représente la même espèce. La figure de Parkinson ("**) est plus préeise; uais comme l'auteur n’indique pas la position de l'anus, il est impossible de dire avec certitude si ćest au $S_{c}$. subrolunda ou au $S$. propinqua, ou au $S c$. paulensis yu’il faut la rapporter. C'est peut-être de cette dernière qu'elle se rapproche le plus; l'auteur la dit originaire d'Italie. Il serait tout aussi hazardé de vouloir rapporter au Sc. sulorotunda, plutôt qu'à telle ou telle autre espéce, l'Echimus subrotundus de Linné, ainsi que la figure de Valentin ("..*).

(") Scilla de Corp. marinis, Tab. 8, fig. 1-3.

(") Andreae, Bricfe aus der Schweiz nach Ifannover geschrieben, in dem Jahre 1703. Zurich und Winterthur, 1776. Tab. 5, fig. f, ${ }^{\circ}$.

(**) Parkinson, Organic Remains, etc. Tab. 3, fig. 2.

("**) Valentin, Musei Museorum, 1714. Tab. 3, fig. 7 b. 


\section{CHAPITRE VIII.}

DU GENRE ECHINARACINIUS v. Phels.

Le genre Echinarachnius remonte dans l'origine à van Plielsum auquel l'emprunta Leske, qui le substitua au genre Arachnoïdes de Klein. Mais K̉lein ne cite qu'une espèce dans son genre Araclmoïles, l'A. placenta qui est le grand Echinodiscus de Breynius; et ce n'est que tout récemment que M. Gray, en réintégrant le genre Echinarachnius, a groupé autour de cette première espece d'autres espèces qui en sont plus ou moins distinctes. Ayant reconnu des différences génériques très marquées entre l'E. placenta et les espèces du type de l'E. parma, j’ai dù conserver à cette première le nom primitif d'Arachoüdes que lui avait donné Kílein et réduire le genre Echinarachius a celles du type de l'E. parma.

Circonserit daus ces limites, le genre Echinarachnius sé- rapproche sensiblement des vraies Scutelles, dont il diffère cependant par sa forme plus circulaire, par ses pétales ambulacraires plus ouverts, et surtout par la position marginale de l'ouverture anale. Sans accorder a ce dernier caraclère une valeur aussi grande que l'ont fait la plupart des auteurs, je crois cependant qu'il doit être pris en considération dans la délimitation des genres, surtout lorsqu'il coüncide avec d'autres caractères constans et qu’il contribue ainsi à donner á toute une série d'espèces une plyssionomie particulière.

Les espèces connues jusqu'ici sont au nombre de quatre, dont trois vivantes et une fossile. Ce sont en général des Oursins à test massif, de forme circulaire et à bords étroits. L'étoile ambulacraire est distincte; les pétales sont très-larges et s'étendent au delà de nui-bord, mais ne se ferment pas à leur extrémilé. La rosette apiciale se distingue à peine du reste du test; il n'y a que quatre pores génitaux; les trous ocellaires sont au nombre de cinq. $\Lambda$ la face inférieure, les ambulacres sont indiqués par des sillons très distincts, qui s'étendent jusqu’à la périphérie, en détachant ordinairement deux rameaux latéraux. La bouche est centrale, circulaire et de moyenne grandeur. La rosette buccale est décagonale conme dans les vraies Scutelles. La surface du test 
est revitue d'une grannlation trés uniforme, composée de tubereules spinifères autour desquels se gronpent une quantile de tubercules miliaires. Il n'y a que peu de différence à cet égard entro la fice supérieure et la face inférieurre, si ce n’est que, sar cette dernière, les tubercules spinilëres sont un pen plus développés et espacés qu à la face supérieure. Cette différence se traduit dans les soies; celles de la face supérieure sont courtes, très serrẻes et renflées à leur extrémité; celles de la face inférieure son! plus longues, cylindriques et effilées; les unes et les autres sont distinctement striées lorsquion les examine au microscope. Les espéces dont j’ai pu observer la coukeur sont, ou d'un violet foncé tirant sur le brun, comme l'E. parma, ou d'une teinte roselilas, comme l'E. allanticus.

La cavité intérieure offre a peu près la mème structure que celle des vraies Scutelles; il n'y a ni cloison ni piliers calcaires entre l'appareil masticatoire et lintestin; en revanche, le hord présente un labyrinthe très compliqué de canaux circulant entre de nombreux piliers calcaires. Lappareil masticatoire se compose de mâchoires trẻs hautes; aussi les dents sont-elles dirigées a peu près verlicalement de haut en bas. Les auricules, contre lesquelles sont appuyées les máchoires, ont une petite échancrure très distincte au milieu. Je n’ai pas vu les dents proprement dites, ensorte que je ne puis dire si elles sont émaillées dans toute leur longueur on senlement à leur extrémité.

\section{Echisirucusics purus Gray.}

Tab. 20, fig. 7-18.

Six. Echinarachnius parma Gray. Attempt on Ech. p. 6. - Ag. Prodr. p. 188.

Echinodiscus parma IeBI. Zooph. p. 199.

Scutclla parma Lam. p. 284, No 13.-E. Del. T. 2, p. 67\%. No 13.-DeBl. Dict. sc. nat. T. 18, p. 226.

C'est une espèze de forme subcirculaire pllus ou moins rostrée en arrière, notamment dans les vieux exemplaires el d'unc épaisseur moyenne, présentant une déclivité uniforme vers le bord, qui est fort épais. Le sommet correspond à la rosette apiciale. Les pétales ambulacraires, ouverts el même légèrement évasés à leur extrémité, s’étendent au delà de mi-bord; les zones poriféres n'ont pas même la moitié de la largecur de l'espace intermédiaire; au delí de leur extrémité, l'on voit encore les pores ambulacraires se prolonger par paires isolées jusqu'au pourtour du lest. La face inféricure est à pen près aussi uniforme que la face supéricure; les sillons 
y sont trẻs marqués; thaque sillon détache deux branches principales près du pourtour du test el plusieurs autres petits rameaux moins marqués, et qui, par cette raison, ne sont pas visibles sur les exemplaires munis de leurs soies (fig. 13).

La surface du test est revètue d'une granulation excessivement serrée, surtout à la face superieure. La fig. 1' représente une portion de l'extrémité de l'un des pétales ambulacraires, sous un grossissement de 1 1/2 diamètre, montrant lit disposition des tubercules spinifères et la manière dont ils sont entourés par les tubercules miliaires; on y voit également les pores ambulacraires devenir de moins en moins réguliers à l'extrémité des pétales, à mesure que la distance qui les sépare est plus considérable. Les tubercules de la face inférieure sont moins nombreux et plus développés. A ces différences correspondent des différences analogues dans la forme et la disposition des soies: celles de la face supéricure sont courtes et très serrèes; leur extrémité est plutôt tronquée que renflée (fig. $7 a b c c$ ). Celles de la face inférieure sont subulées, cylindriques et considérablement phus longues que celles de la face supérieure (fig. 8 a $b$, et fig. $13 a b c$. Examinées au microscope, les unes et les autres se montrent carénées et hérissèes de fines dentelures sur les carènes; la face articulaire seule est lisse.

L’appareil masticatoire est composé de mâchoires trẻs fortes, hérissées de lames fort élevées; aussi chaque mâchoire prise isolément est-elle d'une très grande épaisseur, comme on le voit par la fig. 17 qui en représente le profil. La lig. 15 est une màchoire vue par la face inférieure, montrant au milieu la petite carène qui s'adapte sur l'auricule. La fig. 16 montre la mème mâchoire vue par sa face supérieure, l’on y remarque le sillon médian dans lequel était fixé la dent. La fig. 18 enfin représente encore la même mìchoire par sa face postérieure. Par une inadvertance du dessinateur, elle se trouve iei sens dessus dessous, ensorte que les ares montans de la charpente, au lieu d'ètre dirigés en haut, le sont en bas.

J'ai représenté plusicurs variétés d’àge de cette espèce dans la planclıe ci-jointe. La fig. 9 est un jeune individu entièrement circulaire, sur lequel on distingue parfaitement l'articulation des plaques du test, sans doute parce que l'épiderme n'a pas encore atteint toute son épaisseur. Fig. 10 est un individu un peu plus àgé, dans lequel le rostre du bord postérieur est déjả sensiblement marqué. Les fig. 7 et 8 montrent un individu de moyenne taille, revêtu de ses soies. Enfin les fig. 12 et 13 représentent deux individus adultes, l'nn (fig. 13), arec ses soies, vu par la face inférieure, l’autre dèpourvu de soies (fig. 12) ef trẻs distinctement rostré.

L'Echinarachnius parma habite les côtes du Canada, oủ il n'est pas rare. Une partie des originaux de mes figures ont élé rapportés de ce pays par M. Lyell, frère du célèbre géologue anglais. 
II. Ecuxumcasus Rrmpun Ag.

Tal. 20 , fig. $1-6$.

Siv. Echinarachnius Rumphii Ağ. Prodr. p. 188.

Echinodiscus Rumphii DeBl. Zooph. p. 199.

Scutella Rumphii DeBI. Dict. sc. nat. T. 18, p. 226.

Echinus planus Rumpl. Tabl. $14 \mathrm{G}$.

II. de Blainville le premier a distingué cette espèce de la précédente, sous le nom d'Ĺchinodiscus Rumphii. Plus tard cette différence a èté contestée; cependant comme elle habite la còte d'Amboine d’ou elle a élé rapportée par Rumph, tandis que l'autre provient du Canada, on est en quelque sorte en droil d'en conclure à priori qu'elles sont spéciliquement dictinctes. Je ne connais point l'origine de l'exemplaire que je figure ici sous le nom d'E. Rumphii, et ce n'est qu'en m'appnyant sur la description de M. de Blainville avec laquelle il s'accorde en tous points que je l'ai distingué de l'espèce canadienne. Il m’a paru qu'elle en différait par la forme plus arquèe de ses ambulacres, par la position plus supère de l'ouverture anale, et en ce que le loord posterieur, au lieu d'ètre arrondi ou lègẻrement rostré, est plus ou moins tronqqué. Sous tous les autres rapports les deux espèces sont parfaitement identiques. La bouche est centrale, entourée d'une rosette buccale décagonale. Les sillons ambulacraires sont fort distincts et criblés d'une multitude de petits pores; on remarque également sur le pourtour de la bouche les ouvertures des tubes branchiaux (voy, fig. 4, l'ouverture buceale grossie). La fig. 5 représente la rosette apiciale également grossie avec ses quatre pores génitaux situés au sommet des aires interambulacraires, à l'extrémité des angles du corps madréporiforme, qui présente une surface finement granulaire, au milieu de laquelle on distingue de petits tubes très menus. La fig. 6 enfin montre la disposition des tubercules sous un très fort grossissement. On voit que les tubercules spinifères sont très développés et distinctement mamelonnés el perforés. C'est à tort que sur la Tab. 20 les fig. 7 et 8 sont attribuées à cette espèce; elles appartiennent à l'Ech. Parma.

L'original de mes figures fait partie de la collection du Muse de Neuchatel. M. de Blainville en cite deux exemplaires dans la collection du prince d'Eslingen. 


\section{Echivaracinies athanticus Gray.}

Tah. 21 , fig. 32-34.

Cette espèce a été établie par M. J. E. Gray d'après une série d'exemplaires déposés au Musée britamnique. Elle a le test proportionnellement moins massif que les autres. La liauteur égale à peine le sixième de la largeur. Sa forme est à peu près circulaire; cependant le diamètre transversal l'enporte sur le diamètre longitudinal : le bord postérieur présente un léger sinus au milieu de l'aire interambulacraire impaire. Un second earactère consiste dans la forme des pétales ambulacraires, qui, au lieu d'être très ouverts, comme dans les espèces précédentes, ont au contraire une tendance très prononcée à s'arrondir à leur extrémité sans cependant se fermer entièrement. Les zones porifères des pétales sont sensiblement plus étroites que l'espace intermediaire. La rosette apiciale montre quatre pores génitaux et cinq pores ocellaires; les uns et les autres sont à peine visibles à l'œil nu. L'ouverture buccale est au centre de la face inférieure; elle est circulaire et entourée d'une roselte composée de dix plaques cunéiformes, dont celles qui correspondent aux aires interambulacraires sont plus grandes que celles des aires ambulacraires. Les sillons ambulacraires sont peu marqués, aussi n'en apercoit-on aucune trace lorsque le test est recouvert de ses soies; ils ne se bifurquent que deux fois dans lenr trajet du centre i la circouférence. L'anus est entièrement marginal et situé dans l'échancrure du bord postérieur.

Ne possédant qu'un individu de cette espéce, que je dois à l'olligeanee de M. Gray, je l'ai représentẻ de moitié avec ses soies, afin de donner une idée d'autant plus exacte de sa structure. Il en existe plusieurs exemplaires an Museum britannique, qui sont tous d'une belle teinte rosée lirant au lilas et qui proviennent tous des côtes de Terre-Neuve. 


\section{Ecminaracunit's mosts Ag.}

Tal. 21, lig. 29-31.

Srx. Scutclla incisa Defr. Dict. sc, nat. T'. 48, p. 231. - DesMonl. 'Tabl. syn. p. 234. No 32.

C̈est jusqu ici li seule espece d'Echinaradonius fossile connue : quoique petite, elle est roisine a bien des égards de l'E. parma. Sa forme est circulaire, son épaisseur égale à peu près un cinquiène de sa longueur; son bord est renflé (fig. 30). L'ouverture buccale, située au centre de là face inférieure, est pelite el circulaire. Mais ce qui la distingue de toutes ses congénères, c'est la position de l'ouverture anale qui est très petite et tournée vers la face inférieure (fiz. 31), audessous de l'échancrure du hord postérieur. Les pétales ambulacraires sont trés ouverts à leur extrémilé, et de même que dans toutes les especes de ce genre, les zones porifëres sont moins liurges que les espaces intermidiaires.

Cetle espèce a élé décrile sous le nom de Scutella incisa par M. Defrance qui l'a recueillie dans le calcaire grossier de IIauteville. L'exemplaire figuré qui m’a élé conmuniqué par Mr. DesHayes et dont jai complélé le dessin d’après un exemplaire du Huséum de Paris, provient de la mème localité. J'en ai vu d'autres exemplaires dans la collection de M. DeFrance; en sorle qu ïl ne peut rester aucun doute sur lidentite de ce fossile avee le synonyme que je lui rapjurite. 


\section{CIIAPITRE IX.}

DU GENRE AR ACHNOIDES Klein.

Klein, en élablissant son genre Arachoüdes, n’y rangea qu'une seule espèce, qui avail deji ílé figurée anterieurement par Breynius, sous le nom d'Echinodiscus el que Linné appela phus tard Echimus placenta. Comme celte espèce est encore aujourdhui la seule connue de ce genre, il suffira le la décrire pour signaler en même temps ses caractères génériques.

\section{Alenchioides placerta $\mathrm{Ag}$.}

Tab. 21 , fig. 3j-42.

Srx. Arachnoüdes Klein, ed. Leske, p. 26, $\$ 94$, Tabl. 20, fig. A, B. - Iilein Gall, p. 98, Talı. 11, fig. A. Scuella placenta Lam., p. 283 - E. Desl., Encycl. T. 2, p. 67\%. - DeBt. Dict. sc. nat. T. 48, 1. 225. - Encycl. méth. Tabl. 143, fiģ. 11 et 12. - DesMoul. Tabl. syn. p. 22S, No 15.

Echinarachnius placenta Gray Attempton Ecl. p. 6. - Flem. Brit. An. p. 479.- Ag. Prod. p. 188.Forbes llistory of British starfishes. p. 178.

Echiaodiscus placenta DeBl. Zooph. p. 199.

Eclimus placenta Limn. 12e edit. p. 1105. - Bosc Déter. T. 24, p. 281.

Echinodiscus maximus etc., Breyn. Sched. p. 64, Tabl. 7, fiğ.7, 8.

Echiaarachnius Leske, ap. Klein, p. 218, Tab. 20, fiğ. A, B.

Echinarachaius (Egelspinneweb) van Phels. p. 38.

Arachaö̈les Davila, Cat. Tom. 1, p. 424, No 958.

Gualt. Test. Tal. 110, fiợ. G.

Scuella porpiı Expl. Enc. métl. Tab. 152, figg. 3 et 4. - A\%. Prod. p. 18s. (Très-jeune exemplaire).

On reconnait au premier abord cette espèce à sa forme lenticulaire, à ses bords trés amincis, à son profil subconique et à son anus supra-marginal. J'ai long-tenus partagé l'opinion des 
naturalistes qui l'envisagent comme congénẻre des vais Lehinarachnius que nous venons de décrire dans le chapitre précédent. Mais une étude plus approfondie des détails de son organisation m'a appris que les différences qui les distinģuent sont trop profondes pour que lon puisse se refuser it y voir deux types independans. En effet, si l’A. placente lient aux Echinarachnius par sa forme circulaire, par ses pélales ouverts et mème très évasés í leur extrémité, el par la position de l'ouverture anale, qui est presque marginale, il s’en éloigne par d'autres caractères peut-itre bien plus importans: et d'abord les sillons de la face inférieure ne sont pas de même nature, ils ne se ramifient point dans leur trajet du bord à la circonfërence, et, malgré toute la peine que je me suis donnée, je n’ai pu y découvrir la moindre trace de pores microsenpiques; c'ast une bande lisse et déprimée qui se continue également sur la face supérieure jusqu ì la rosette apiciale. En second lieu, la structure dı test est très différente : aı lieu d'ètre massif, comme dans la plupart des Echinarachunius, il est au contraire très mince et revètu d'une granulation toute particuliere, remarquable surtout par l'arrangement variable des tubercules. Sur les aires ambulacraires, les tubercules spinifẻres forment des séries régulières obliques, séparées par de petiles lignes en apparence continues (fig. 39), mais qui, examinées sous un phus fort grossissement (fig. 39 a), se montrent composées de tubercules miliaires conformés de la mème manière que les tubercules spinifères, c’est-à-dire mamelonnés et perforés, quoique d'une pelitesse extrème. Cette disposition des tuhercules est la même à la face inférieure, quoique moins: apparente à l'ceil nu. Les tubercules des aires interambulacraires sont loin de présenter celte régularité; ils sont répartis sans ordre apparent à la surface du test, et les tubercules sont entourés de tubercules miliaires comme dans les genres précédens. Cependant l'on remarque que ces derniers (les tubercules miliaires) sont proportionnellement moins nombreux (fig. 37 a).

Un troisiẻme caractẻre qui distingue cette espèce des Echinarachnius, c'est la présence de cinq pores génitaux, tandis qu’il n'y en a que quatre dans ces derniers. Ces pores oceupent leur place habituelle au sommet des aires interambulacraires. Les pores ocellaires au nombre de cinq et á peu près aussi grands que les pores génilaux, sont placés au summet des pétales ambulacraires et forment avee ces derniers un cercle régulier autour dı corps madréporiforme, qui est composé, comme ì l'ordinaire, d’une agglomération de petils tubes capilTaires invisibles à l'œil nu, mais très distincts à la loupe (fig. 41).

Les ambulacres ont une forme trẻs particuliẻre; ils ressemblent i des triangles allongés at étranglés sur le milieu des flancs; et comme ils s’évasent considèrahlement, de manière à affectrer à peu près les contours des aires interambulacraires dius d'autres geures, il est arrive quin 
les a confondus avec ces dernieres, el prélendu que l'anus souvail daus un ambulacre. (Toyez la fig. 39 qui représente un pétale grossi). Les zones poriféres ne se maintiennent comme zones contiuues que jusqu'à la moitié de la largeur du test; passé cette limite, les pores n'existent plus 'jue par paires isolées que l'on poursuit jusqu'à la circonférence. Les sillons Iransverses qui unissent les deux rangées de pores d'une même zone sont très marqués. Les pores eux-mêmes sont ronds el très uniformes.

La structure de l'intéricur justifie aussi sous plusieurs rapports la distinction que nous avons étahlie entre ce genre et les Echinarachnius. A part les rẻseaux ou piliers calcaires qui occupent les bords, on ne renarque à la face interne du test d'autres aspérilés que les auricules; mais celles-ci sont d'une forme trés particulière, car elles se terminent par deux petits hourrelets séparés par une échancrure très profonde. L’appareil masticatoire est aussi grềle que celui des Echinarachnius est massif: les màchoires représentent un compas très ouvert (fig. $42 a, b$ ); leur cliarpente est très mince, hérissée de fines lames calcaires, sur les bords; (voyez les fig. 42 c et $d$ 'fui représentent le profil d'une màchoire vue par derrière et de côté). Il existe en outre, à la face supéricure des màchoires, une crête assez saillante qui sülère de chaque còté du sillon dentifère (fig. $42 b, c, d$ ). La face inférieure (fig. 12 a) n'est hérissée que de très petites lames calcaires bien moins élevées que celles de la face sıpérieure.

C'est à ma connaissance la seule espèce oủ l'articulation des deux demi-nàchoires sur la ligne médiane soit distincte. Elles se lésarticulent même très facilement, et il est alors facile de se convaincre que la demi-mâchoire droite est pourvue d’une petite carène longitudinale articulée dans un sillon correspondint de la demi-màchoire gauche.

La bouche est centrale et circulaire, entourée d'une rosette buccale peu distincte, mais qui parait composéc de dix plaques, dont celles qui correspondent aux aires ambulacraires sont les plus étroites (fig. 36). J'ai représenté (figg. 40) le pourtour de la bouche sous un grossissentent de $1 \frac{1}{2}$ diamètre, pour faire voir que les sillons qui viennent ici aboutir à la bouche sont réellement dépourvus de pores nicroscopiques. Dans l'exemplaire qui a servi de nodèle ả la fig. 40 , l'on voit quelques soies des bords des aires interambulaeraires converger vers le centre de l'ouverture buccale, à peu près comme dans les $\Lambda$ stéries. Une autre particularité, éest que dans l'enceinte de la rosetle buccale, on ne remarque aucune différenre entre les tubercules des aires imbulacraires et ceux des aires interambulacraires; ils ne reprennent leur disposition respective yu'en dehors de cette rosette. L'anus, comme nous l'avons dit plus haut, est supra-marginal, circulaire et parait pereé d'arrière en avant. 
Les soies sont très fines, mais il ne parait pas qu'elles diffèrent beaucoup dans leur structure de celles des autres genres. Exanninées au microscope, elles se montrent hẻrissées de carènes fortement dentelées; celles de la face supérieure sont clarellées; celles de la face inférieure plus ou moins cylindriques. M. Forbes en a donné une figure grossie dans son Ilistoire des Echinodermes anglais, par. 181 .

Le Scutella Porpita des auteurs est bien certainement un jeune de l'Araclenoiles Placenta; je m’en suis assuré par la comparaison que jai faite des exemplaires du Husée de Paris. Il miest dés lors démontré que l'espèce fossile que M. Cl. DesMloulins a signalie dans ses Tableaux synongmiques sous le nom de Cassidulus Porpita et que je neconnais pas, ne saurait avoir pour synonymes les citations relatives au Scutella Porpita des auteurs que 11. Des.loulins lui rapporte; car il m'est impossible de penser que M. DesMoulins ait pu prendre un jeune Arachnoides Placenta pour une espece du genre Cassidulus.

C'est par erreur que l'on a cru cette espèce originaire de l'Océan austral; elle habite en réalité les mers du Nord. M. Forbes au moins assure que l'exemplaire quill a décrit et figuré daus son ouvrage a été recueilli par II. le professeur Jameson a l'île Toulah, l'une des îles Shetland; mais c'est à tort qu'il la confond avec l'espèce du Canada de la collection de M. Lyell, qui est l'Echinarachius parma, ainsi que nous l'avons dit plus haut en traitant de celle espece.

Les orıginaux de mes figures miont été communiqués par MM. Valenciennes et J. E. Gray. 


\section{CIIAPITRE $\mathrm{X}$.}

\section{DU GENRE SCUTELLINA (Ag).}

Au premier abord les espèces de ce genre ne semblent pas différer beancoup des Echinarachnius, dont elles parlagent les caractẻres les plus frappans, tels que la forme circulairc ou subcirculaire, l'anus marginal ou submarginal et les pétales ambulacraires disjoints; aussi les avais-je rangées parmi les Echinarachnius avant que je n'eusse étudiẻ leur structure intérieure. Pour justifier l'établissement de ce nouveau genre, je vais indiquer les caractères particuliers que m'a présentés la cavité intérieure. Lorsque l'on vient ả ouvrir une Scutelline, on est tout étonné d'y rencontrer, au lieu des réseaux calcaires qui forment un labyrinthe continu sur le pourtour intérieur du test des Echinarachnius et de la plupart des autres genres, une série de lames ou cloisons verticales rayonnant du centre vers la périphérie et séparant les aires ambulacraires des aires interambulacraires. Aux abords de la bouche, ces cloisons ne s'élèvent pas jusqu'au plancher supérieur en sorte qu'il est probable que l'intestin passait par dessus pour s'étendre successivement dans les anses des aires interambulacraires entre les cloisons. L'appareil Inasticatoire présente aussi une structure diffẻrente de celui des Echinarachnius. Les màchoires, au lieu d'être courtes et hautes comme dans ces dernières, sont au contraire très basses et fort allongées (Tab. 21, fig. $14 a b c$ ). Leur charpente est horizontale et les lames qui hérissent leurs bords sont à peine sensibles. A ces particularitẻs de structure intérieure se joignent des caraelẻres extérieurs non moins importans, quoique peu apparens; et d'abord il n'existe point de sillons visibles à la face inférieure, ou bien s’ils existent, ils ne sont jamais ramifiés comme ceux des Echinarachnius; de plus, les pores des zones porifẻres des pétales ne sont point rẻunis par des sillons transverses. Si l'on tient compte de tous ces caractères, on trouvera que les Scutellines sont bien plus voisines des Echinocyames que des Echinarachnius ou de tout autre genre. Elles ne diffèrent mème des preniers que par un seul caractère essentiel, la position 
marginale de l'anus, auquel il faut ajouter la forme circulaire ou subcirculaire du test, tandis que la forme des Echinocyames est généralement sulpentagonale ou pyriforme.

Les Scutellines sont des Oursins de petite taille et tris aplatis. On nien connaît jusqu'ici que des fossiles qui proviennent toutes des terrains tertiaires. Souvent la surface du test présente une apparence fínestrée, une sorte de mosaïque rỉgulière résultant de ce que le milieu des plaques est corrodé, tandis que les bords sont entiers ; ensorte que chaque plaque fait l'effet d'un carrean entouré d'un cadre.

\section{Sceteldisi sumelaria Ag.}

Tab. 21, fig. 8-14.

Sr.. Scuiclla nummularia. Defr. Dict. sc. nat. T. 48, p. 231. - DeBI. Zooph. p. 202. - Jaun. Tom. III, p. 28\%, N॰20-Ag. Prodr. p. 188. - DesMoul. Tabl. syn. p. 236, Nº 34.

Echinarachnius nummularis Ag. Cat. syst. Ectyp. Mus. Neoc. p. 6.

Je prends cette espece pour type du genre Scutellina, parcequ'elle est assez frẻ(puente dans les collections de fossiles tertiaires. On la reconnaît facilement à sa forme parfaitement circulaire, sauf une petite échancrure au bord postérieur dans laquelle s'ouvre l'anus. C'est une espéce très plate à bord assez renflé. Les pétales ambulacraires sont grands, arrondis en forme de lobe, mais cependant ouverts à leur extrémité; ils sẻtendent au delả de mi-bord. Les zones poriféres sont bien moins larges que l'espace intermédiaire, et leurs pores ne sont pas réunis par des sillons transverses, ou siil y en a, ils sont à peine risibles. La rosette apiciale se présente sous la forme d'un petit bouton légérement saillant; en l'examinant à la loupe, on y reconnait fort bien les quatre pores génitaux; quantaux pores ocellaires, je n'ai pas pu les découvrir, mais je ne doute pas qu’ils n'existent, les ayant aperçus dans d'autres espèces. La bouche est circulaire. La face inférieure est complètement plane; ce n'est que dans lez exemplaires parfaitement conservés que l'on remarque quelques traces des sillons, qui sont droits et non ramifiés comme dans toutes les especes de ce genre. L'anus est entièrement marginal, ensorte quon ne le voit ni de la face supérieure ni de la face inférieure ; il est en outre très petit et correspond, ainsi que je l'ai dit plus liaut, à l'échancrure du bord postérieur.

Les fig. 11,12 et 13 représentent un exemplaire trés extraordinaire, en ce qu'il n’a que quatre ambulacres; jai cru dans l'origine qu'il constituait une espèce à part, mais ayant ren- 
contré đlepuis plusieurs anomalies semblables dans d'autres genres, j'envisage ce cas comme une monstruosité par défaut; et comme cet exemplaire a du reste tous les caractẻres du $S$ c. mummularis et qu'il provient de la même localité et du mème terrain, je ne crois pas être téméraire en lassociant ì cette espèce; sa forme subquadrangulaire provient sans doute de la même cause. La fig. 14 représente une màchoire de cette espèce vue par ses différentes faces; fig. a la moutre de grandeur naturelle; la fig. $b$ montre la face supérieure sous un grossissement de deux diamètres, en sorte que l'on y remarque très bien le sillon médian dans lequel était fixée la dent; la fig. $c$ inoutre la face inférieure sous le même grossissement; la fig. $d$ est vue par la face antérieure ; et la fig. e de profil. On voit par cette figure que ce qui caractérise surtout ces màchoires, c'est leur forme allongée, comparativement à leur faible hauteur.

Cette espẻce est fréquente dans le terrain tertiaire de Grignon. Elle se trouve également, suivant M. DesMoulins, à Blaye (département de la Gironde).

\section{Obseination.}

Les anomalies dont cette espèce nous offre un exemple ne sont pas très rares dans les Echinodermes.

Dans un travail inédit sur l'analogie qui existe entre les parties solides des Oursins et celles des Astéries, travail que jai présenté, il y a plusieurs années, à la société des sciences naturelles de Neuchâtel, jai cherché à démontrer que chaque rayon d'Astérie correspond à une aire ambulacraire d'Oursin, plus les deux demi-aires interambulacraires adjacentes, de telle sorte que les grosses plaques qui bordent les rayons de certaines Astéries correspondraient aux plaques interambulacraires des Oursins. Cetle analogie se trouve pleinement confirmée par les anomalies que j'ai observées dans les Oursins; car dans les déviations du nombre typique des aires, c'est toujours une aire ambulacraire et les deux demi-aires interambulacraires adjacentes qui manquent, comme c'est le cas du Scutellina mummularis, mentionné ci-dessus et comme je l'ai encore observé dans un Discoidea cylindrica de la collection de M. Michelin et dans un Cidaris coronata du Musée de Carlsruhe ; ou bien il y a une aire ambulacraire surnuméraire, accompagnée de deux deni-aires interambulacraires, interposées entre l'aire ambulacraire impaire et l'aire anıbulacraire paire antérieure de droite ou de gauche. J'ai vu une anomalie de ce genre dans une 
Galérite du Muséum de Paris: M. H. de Neyer en a figuré et décrit un autre eas "). La découverte qu'a faite M. E. Forbes des yeux des Oursins confirme également cette analogie entre les Oursins et les Astéries. On savait par M. Ehrenberg qu'ils se trouvent dans la plaque terminale des rayons: des que jappris qüils avaient été observés dans les Oursins, je supposai qu’ils devaient se tronver au sommet des aires ambulacraires, et c'est en effet dans le trou des plaques que l'on a appelées jusqu’ici interoviducales et que j’appelle plaques ocellaires, quils sont logés et où je les ai vus dans plusieurs espèces. Les anomalies observées chez les Crinoides contribueront sans doute aussi à faciliter les comparaisons entre ces animaux et les autres Echinoderunes.

\section{Scutelixa lexticulais Ag.}

Tab. 21, fig. 20-23.

Six. Scuclla lcnticularis Defr. Dict. sc, nat, Tom. is, p. 230. - Lam. Tom. 111, p. 282, N9. - E.

Desl. Enc. Tom. 2, p. 67\% - DeBl. Zooph. p. 202. - DesMoul. Tabl. syn. p. 23-4, No33. Echinarachnius lenticularis Gray. Att. on Ech. p. 6. - Ag. Prodr.j. 188.

De même que la pricédente, cette espece a été décrite en premier lieu par M. DeFrance, sous le nom de Scutella lenticularis. Son pourtour est elliptique; sa face superricure n'est pas également déclive; les flanes sont au contraire fléchis en dos d'àne, ce qui lui donne une apparence gibbeuse toute particulière; en même temps la face inférieure est légèrentent concave; les sillons ambulacraires sont droits et se présentent sous la forme de rigoles déprimées. L'anus est marginal ou plutòt légèrement infra-marginal, car il n'est pas visible d'en haut, nais lien en partic d'en bas. Les pétales ambulacraires s’étendent jusquà mi-bord, mais ne se ferment point à leur extrémité. Les tubercules ne sont pas visibles à l'œil uu , mais lorsqu on les examine à la loupe, on les trouve disposis de la mème manière que dans les autres genres: les tubercules spiniféres sont entourés de tubercules beancoup plus petits, mais ayant la mème forme et la même structure. La fig. 20 a représente le sommet apicial sous un faible grossissement, afin de faire voir la disposition des pores génitaux qui sont au nombre de quatre. La fig. 23 unontre les dix cloisons rayonnantes dont nous avons parlé à l'article du genre; elles divisent 
le test en dix triangles à peu prẻs réguliers. Autour de la bouche se voient les cing auricules qui sont fort larges et contre lesquels s'appuyaient les mîchoires. Ces dernières ne me sont pas connues daus cette espèce; je doute cependant qu' elles diffèrent beaucoup de celles du $S c$. mummularis.

Il existe de nombreux exemplaires de cette espèce dans les diverses collections de fossiles tertiaires que jai examinées; la plupart proviennent du calcaire grossier de Grignon. M. DesMonlins la cite également dans le terrain tertiaire de Blaye (département de la Gironde) et d'Antibes (département du Var).

III. Scetellixi phacejtula Mer.

Tah. 21, fig. 1-7.

Srx. Cassidulus placcntula Mérian, Mus. de Bâle.

Celte espéce est l'une des plus petites de toute la famille. Je n'ai jamais rencontré d'Oursin plus petit que celui de fig. 1 qui a à peine une demi-ligne de diamètre. Sa forme est circulaire ou plutòt subovale et très aplatie. L'anus est supra-marginal; la face inférieure est légèrement concave; la bouche qui est située au centre, est circulaire. Quant anx détails de la structure du lest, ils ne peuvent guère être apercus autrement qu'à la loupe; aussi ai-je ajouté aux figures de grandeur naturelle les fig. 6 et 7 , qui représentent lindividu sous un grossissement de $1 \%$ diamètre. On voit par ces figures que la surface du test est revêlue d'une granulation très homogène. Mais ce qui constitue un caractère saillant de l'espèce, c’est la forme des pétales anlublacraires qui sont très étroits, en sorte que les zones porifères sont aussi larges que l'espace intermédiaire.

Cette espèce provient du terrain tertiaire de Chaumont. J'en ai rencontré plusieurs exemplaires au Musée de Bàle; c'est à l'obligeance de mon ami M. Mérian que je dois la commur:cation des originaux de mes figures. 


\section{SClteldisi siperi Ig.}

Tab. 21, fig. 15-19.

La position supère de l'anus dans cette espèce pourrait faire naitre des doutes sur ses rapports génériques, si elle ne rappclait par les détails de sa structure le type rẻel des Scutellines, et si nous n’avions comme intermédiaires entr'elles et les espèces à anus complètement marginal, le $S_{c .}$ placentula qui, comme nous venons de le voir, a égalementl'anus supère, mais plus rapprodhé du bord. Son pourtour est pyriforme, le côté antérieur est beaucoup plus étroit que le còté postérieur. La face supérieure présente une sorte de dẻelivité bilatérale comme dans le Sc. lenticularis et par la mème raison la face inférieure est concave. La houche située au centre de la face infërieure est circulaire et proportionnellement plus grande que dans les autres espèces. Les pétales ambulacraires sont de moyenne grandeur, mais ne se ferment pas á leur extrémité. Les zones porifères y sont très étroites et dépourvues de siltons transverses. Au reste la position supère de l'anus à laquelle il est fait allusion dans le nom spécifique, suffirait à elle seule pour dislinguer cette espèce de toutes ses congénères.

C'est peut-ètre le Cassichlus Hayesiamus de M. Desiloulins, qui ne m'est conuu que par la simple citation de cet auteur pag. 276 de ses Tabl. synonymiques.

Elle provient du calcaire grossier de Grignon. Je n'en connais encore qu'un seul exemplaire qui a été déposé au Musée de Neuchàtel par M. Auguste de Montmollin.

\section{Scctellisi obovati Ag.}

Tab. 21, fig. 24-23.

Le caractère principal de cette espèce réside dans sa forme ovoïde. Je l'avais d'abord envisagée comme une simple variété du $S_{c}$. mummularia, mais la constance de sa forme mia lait clianger d'opinion et je crois qu'elle constitue réellement une espèce particulière; elle est d'ailleurs beaucoup plus petite que cette dernière. L'anus est complètement marginal. La bouche est grande et centrale. Les pétales ambulacraires sont trẻs ouverts ả leur extrémité; mais les zones porifères n'en sont que plus étroits, et l'on ne remarque aucune trace de sillons transverses entre 
leurs pores. La rosette apiciale est remarquable en ce que les pores génitaux sont fort distans; il y en a quatre comme dans toutes les Scutellines.

Cette espèce est fréquente dans le terrain tertiaire de Grignon, oủ on la tronve avec le $S c$. mummalaria. Il se pourrait que ce fùt le Scutella elliptica de M. DesMoulins, cité dans les Tabl. synon. pag. 236, mais qui n'est encore décrit et figuré nulle part, lien que M. DesMoulins le dise commun dans le terrain tertiaire de Paris. S’il en était ainsi, il faudrait changer le nom de Scutellina olovata en celui de Scutellina elliptica Desiloul. 


\title{
CHAPITRE XI.
}

\author{
DU GENRE LAGANUM Klein.
}

Au premier coup d'œil, les Laganes ont plus de ressemblance avec les vrais Clypéasires et notamment avec les espèces plates telles que les Clypeaster placunarius, C. latissimus, C. scutiformis, etc., qu'arec les Scutelles. Leur forme pentagonale ou sulppentagonale contraste surtout arec la forme arrondie de ces dernières; cependant cette différence est plus apparente que réelle, car il suffit d'avoir observé l'organisation intérieure de res animaur pour se convaincre qu'ils sont construits sur le mème plan, et, chose singulière, ćest le genre Rotula, relıi qui a le moins de ressemblance extérieure avec les Laganes, qui s’en rapproche le plus par sa structure intérieure.

Le genre Laganum a eu le même sort que beaucoup d'autres genres de l'ordre des Echinites ; ćest-it-dire qu’il a été circonscrit de la manière la plus variée. Klein qui l'ẻtablit, y rangeait des espèces trẻs diverses, préoccupé qu’il était de l’ilée que le caractère essentiel des Echinites consiste dans la position de l’anus; c'est ce qui fait quil rangea dans son genre Laganum de véritables Scutelles. Leslie ne tint pas plus compte de ce genre que des autres et confondit les Laganes de Ǩlein dans son genre Echinodiscus. Lamarck et Des Noulins en firent des Scutelles. Ce fut .I. DeBlainville qui réunit de nouveau les Laganes en un geure particulier; mais au lieu de lui conserver le nom de Laganum de Ḱlein, il l'appela Lagana.

Je range dans le genre Laganum les espèces de forme subpentagonale ou ovoïde ayant le bord postérieur tronqué ou subtronqué, et le borl antérieur tantôt arrondi, tantôt plus ou moins anguleux. Le diamètre longitudinal l'emporte ordinairement de beaucoup sur le diamètre transversal. Quoique la lıauteur ne soit pas très considérable, le bord est généralement renfté; en revanche, la face supérieure n'en est que plus plate, et dans plusieurs espèces dont le sommet est à peine plus élevé que les bords, il règne une dépression sensible sur tout l'espace compris entre le sommet et les bords.

La rosette ambulacraire est grande; les pétales se ferment plus ou moins à leur extrémité; 
je ne connais aucune espèce dans laquelle ils ne dépassent la moitiẻ du rayon entre le sommet et le bord. La bouclie est centrale, circulaire et proportionnellement plus grande que dans les genres précédens. L'anus, tantòt circulaire, tantôt allongé, oscille entre le bord postérieur et l'ouverture buccale, sans être jamais complètement marginal. Les sillons ambulacraires ne se bifurquent pas dans leur trajet et sont rarement visibles au delà de mi-bord, bien qu'ils soient criblés de pores microscopiques. Les aires interambulacraires sont bien moins larges que les aires ambulacraires, surtout à la face inférieure oủ elles sont réduites, dans la plupart des espèces, à une bande très étroite que l'on poursuit du centre à la circonférence. La surface du test présente une granulation très homogẻne qui diffẻre complètement de celle que nous avons observée dans les genres précédens, en ce que les tubercules spinifères y sont bien moins serrés et bien moins nombreux, tandis que les tubercules miliaires y sont excessivement abondans. Ceux de la face inférieure ne diffèrent guère en général de ceux de la face supérieure, si ce n’est par leurs dimensions plus considérahles. Il n'existe non plus aucune différence sensible entre ceux des aires ambulacraires et ceux des aires interambulacraires. La même uniformité se reproduit dans les soies. Cependant celles de la faee inférieure sont en général un peu plus longues et un peu plus grèles que celles de la face supérieure.

Ainsi que je l'ai fait remarquer ci-dessus, c’est dans la cavité intérieure que jai puisé les caractères les plus importans pour la classification de ce genre. C'est surtout en étudiant la structure de l'appareil masticatoire que j’ai été conduit à ranger les Laganes dans le groupe des Scutelles, au lieu de les envisager comme un groupe à part. En effet, quoique les mîchoires des Laganes se distinguent par leur apparence massive, elles sont cependant couformées de la mème manière que celles des genres précédens ; c'est-à-dire que les dents sont articulées dans un sillon de la face supérieure des màcloires, et si parfois elles paraissent très inclinées et presque verticales, ce n'est que par l'effet du développement excessif des lamelles inférieures; ce qüil importe de constater, e'est qu'elles ne sont jamais fixées dans un sillon vertical de l'extrémité des mâchoires, comme cela a lieu dans les vrais Clypéastres; mais un caractère qui leur est conmun arec ces derniers, c’est que l'extrémité des dents est seule émaillée.

Il n'existe aucune trace de cloisons ni de piliers entre l'appareil masticatoire et le canal intestinal; ces deux organes ne sont séparés que par une membrane. En général, l'intérieur du test est moins celluleux que dans les genres précédens; il n'y a guère que les bords de la cavité qui présentent un labyrinthe de piliers calcaires; doủ je conclus que les appendices du canal intestinal sont moins nombreux que dans les espéces qui ont la cavité intérieure très cellulaire. Le 


\section{$-107-$}

trajet du canal intestinal est le mème que dans les autres Scutelles, ainsi qu'on peut le voir par la for. 5 de Tab. 25, qui représente la cavilé intérieure du Lagamum rostralum vue par dessous. L'intestin sort de la cavité centrale, en passant par dessus lat máchoire antérieure droite ; de lả il se déploie, sous forme d'estontac, sur le flane gauche, passe sur le flanc droit, oủ il remonte jusqu’à la hauteur de la màcloire antérieure droite et rétrograde de nouveau vers l'anus, en contournant une cloison tendineuse très solide.

La structure et la position relatives des différens organes intérieurs sont indiquées par des lettres concordantes dans les fig. 25,27 et 28 de Tab. $22: n$ est l’intestin qui est également plissé sur le flanc droit et sur le flanc ganche ; $r$ (fig. 27) représente l'oesophage qui est plus étroit et marqué de plis plus serrés; s. $s$ (fig. 28) sont les appendices de l'intestin en communication avec ce dernier ; $x . x$ (fig. 25 et 27) sont les ovaires étendus sur l’intestin; $l$ (fig. 28) est, suivant M. Valentin, une partie des branchies inférieures; $t$ (fig. 25 et 27) est l'extrémité des rayons de l'appareil masticatoire. La fig. 29 eufin représente l'un des sucoirs des sillons inférieurs de la mème espèce sous un grossissement de 102 diamètres.

Il est un point de l'organisation des Laganes qui offre de graves difficultés, c'est la variẻté qui règne dans le nombre des pores génitaux, une partie des espèces en ayant invariablement cinq, tandis que d'autres n'en ont que quatre. J'ai vainement cherché à rattacher ce fait à quelque autre caractère constant de l'organisation; mais n'ayant reconnu dans la structure de l'appareil génital à l’intérieur aucune diffërence entre les espèces qui ont quatre pores et celles qui en ont cinq, j’ai dù renoncer provisoirement à les diviser. Plus tard, les naturalistes reviendront sans doute sur ces diffërences, et peut-être sépareront-ils les espèces du type du Lagamum Peronï (qui ont généralement quatre pores très distans) de celles du type du L. Bonani (qui en ont cinq très rapprochés), en faisant en outre du $L$. rostratum le type d'un genre a part distinct de celui du $L$. Bonani, etc., par ses quatre pores génitaux et par sa forme rétrécie en arrière. En attendant des renseignemens plus complets, que l'anatomic comparée de ces divers animaux ne manquera pas de nous fournir avec le temps, je me contenterai de réunir ces divers types sous la rubrique du genre Laganum, qui comptera ainsi 14 espèces, dont 12 vivantes et 2 fossiles. 


\section{Lug.snum boxani Klein.}

Tab. 23, fig. 8-12, et Tab. 22, fig. 25-29;

Sry. Laganum Bonani Klein, p. 25, $\$ 84$, Tab. 22, frg, $a, b$.

Laganum minus Bonani Klein, p. 25, $\$ 84$, Tab. 22, fig. $c$.

Lagana minor Gray Att. on Ech. p. 6.

Cljpcaslcr laganum Lam. T. 1II, p. 291, No5. - E. Desl. Encycl. T. 2, p. $199, \mathbf{N}^{\circ} 5$.

Scutella laganum DelB. Dict. sc. nat. T. 48, p. 228. - DesMloul. Tabl. syn. p. 230.

Lagana laganum DeBl. Zooph. p. 196.

Echinodiscus laganum Leske ap. Klein, p. 204, Tab. 22, fig. c.

Echinus laganum L. Gm. p. 3190.

Echinus planus (Zeereal) Kumpl. p. 36, 37, Tab. 14, figg. E.

Echinodiscus Gualt. Tab. 110, fig. $c$.

Seloa Thes. Tab. 15, fig. 25, 26.

Le nom de Lag. Bonani a été donné ả celte espèce par K̉lein, et comme c'est le plus ancien, jai cru devoir le conserver dans son intégrité de préfërence aux noms des auteurs postérieurs. La forme de cette espèce est pentagonale ; le bord postérieur est tronqué et quelquefois même légèrement rentrant ; le bord antéricur est saillant. Le dianıètre longitudinal l'emporte sur le diamètre transversal. La plus grande largeur est ordinairement en avant du sommet el correspond à une ligne lirée de l'extrémité de l'un des ambulacres antérieurs pairs á l'extrémité de l'autre. L'épaisseur n'est pas considérable; mais le bord est très renflé; aussi le sommet s'éléve-t-il à peine au dessus de ce dernier (fig. 10); il y a de plus entre le sommet et le bord une dépression très sensible. Léloile ambulacraire est très grande ; les pétales, de forme lancéolée, se prolongent au delà de mibord saus se fermer complètement, quoiqu’ils se rétrécissent considérablement à leur extrémité. La rosette apiciale n’occupe qu'un très petit espace au sommet des ambulacres; les pores génitaux, à peine visibles à l'neil nu, sont au nombre decinq et très rapprochés. Les trous ocellaires sont encore plus petits et difficiles ì découvrir, même à la loupe. A la face inférieure, les sillons anbulacraires sont trẻs prononcés; ils s'étendent jusqu’au delà de mi-bord, mais sans se ranifier ( fig. 9); exaninés à la loupe, ils se montrent criblés de pores microscopiques, surtout prẻs de l'ouverture buccale. On remarque en outre au milieu des aires interambulacraires (fig. 9), mais seulement dans les jeunes individus, une sorte de bande très peu marquée, qui résulte de 
ce que les tubercules sont ici moins serrés que sur le reste de la surface. La bouche est distinctement subpentagonale. Dans aucun exemplaire je n’ai pu aperceroir la rosette buccale, mais je suppose qu'elle n'en existe pas moins. L'anus est au nilieu de l'espace entre le borl postérieur et l'ouverture buccale; son pourtour est distinctement ovale; seulement le bord tourné vers la bouche est légèrement déprimé, comme si l'ouverture anale avait élé percée obliquement d'avant en arriẻre. Les tubercules sont nombreux et serrés; ceux de la face inférieure présentent la même disposition que ceux de la face supérienre, mais ils sont un peu plus développés.

Les soies sont en apparence très lomogènes, et les individus qui en sont revêtus (figg. 12) se font remarquer par leur uniformité ; à peine distingue-t-on, à la face supérieure, les ambulacres et parfois quelques petites taclıes noires sur les aires interambulacraires. Mlais dès que l'on vient à examiner les soies des diverses parties du test au moyen d'une forte loupe ou au microscope, on y reconnaît les mêmes différences tranchées que nous avons signalées dans la plupart des „zenres précédens. Celles de la face supérieure sont grèles, petites et se terminent en un bourrelet ì leur extrémité (Tab. $22 \mathrm{fig} .27$ a.b.); celles de la face inférieure sont plus longues et subulées (fig. $2 S$ c. d.); vues sous un fort grossissemient, elles laissent apercevoir distinctement Jes carẻnes dentelées, dont elles sont hẻrissées dans toute leur longueur (fig. c); enfin, il y a encore les soies du pourtour de la bouche : ce sont les plus grandes; mais elles sont moins régulières et surtont moins droites que les précédentes (fig. 28 a b). Toutes ces soies ont à leur base une facette articulaire lisse, surmontée d'un anneau saillant et crénelé.

J'ai représenté Tab. 22, fiğ. 26, une mâchoire du L. Bonani vue par ses diverses faces ; la figg. a montre sa face inférieure et la manière dont les lames calcaires latérales sé rẻunissent en faisceaux; la fig. $b$ représente la face supérieure avec le sillon médian daus lequel était logée la dent; la fig c. montre le profil et les proportions relatives des lames feuilletées et de la charpente ou plaque massive; la fig. $d$ enfin est la dent vue par derrière, montrant les deux ares montans de la charpente et la manière dont les lames feuilletées y adhẻrent; on voil par cette ligure que les lames inférieures sont bien plus longues, et plus fortes que les supérieures.

Les fig. 25,27 et 28 de Tab. 22 représentent les détails anatomiques que nous avous décrits a l'article du genre et dans les généralities.

Cette espèce est fréquente dans les collections où elle figure ordinairement sous le nom de Clypéastre ou Scutelle beignet, (Clypeaster ou Scutella Lagamum) sans doute à cause de sa forme très aplatic. Il en existe de noubreux exemplaires conservés daus l'esprit de vin, au Muséum 
de Paris: la plupart ont été rapportés de l'Océan austral par MM. Quoy et Gaimard; il y en a plusieurs de la Nonvelle Guinée; les originaux de mes figures proviennent de Vanicoro.

C'est évidemment à tort que Leske confond cette espèce avec le $S$ c. orbicularis, qui en est fort distinct. En revanche, la petite variété ou le Laganum Bonani minus de Klein ne me parait pas en différer spécifiquement.

\section{Laganum depressum Less.}

Tal. 23, fig. 1-7.

Cette espèce est voisine à plusieurs égards de la précédente, entre autres par sa forme subpelltagonale et par la dépression qui règne autour dı sommet; mais d'un autre côté elle est bien plus aplatic, et le eôté antérieur est proportionnellement trẻs large, tandis que le côté postérieur est sensiblement rétréci. Le pourtour du test est en outre plus anguleux, notamment dans les vieux exemplaires. Mais ee qui la distingue surtout du L. Bonani, e'est la forme de l'anus, qui, au lieu d'être longitudinal, est au contraire allongé transversalement, ainsi que le montre la fig. 6, qui représente cet organe sous un faible grossissement; l'anus est en outre sensiblement plus rapproché du bord postérieur. Les pétales ambulacraires sont larges, mais se rétrécissent fortement ì leur extrémité, sans cependant se fermer complètement; les sillons qui unissent les rangées de pores sont très marqués. La rosette apiciale est petite et les pores génitaux à peine visibles. Les tubereules spinifïres ne sont pas aussi serrés que dans la plupart des autres espèces, notamment à la face inférieure; aussi les soies n'y sont-elles pas très fournies; en revanche, les tubereules miliaires et les petites soies qui en dépendent sont très abondans. La bouche est petite et centrale; la fig. 7 la montre grossie, afin de faire voir la forme et la disposition des tubercules et des tubes branchiaux qui rayonnent autour de son pourlour. Les sillons ambulacraires ne sont pas visibles jusqu'au bord. La rosette ambulacraire faiblement indiquée dans l'exemplaire de fig. 2 , se compose de dix plaques; celles qui corres.pondent aux aires ambulacraires sont sensiblement plus larges que celles des aires interambulacraires. L'articulation des plaques est en général beaucoup plus distincte que dans le $L$. Bonani, par la raison que lépiderme est bien moins épais; aussi est-ce une espèce plus élégante. Les fig. 4 et 5 représentent un très grand exemplaire revîtu de ses soies. La fiğ. 3 est un exemplaire plus petit garni de ses soies sur la moitié de sa surface et montrant sur l'autre la structure des 


\section{$-111-$}

diverses parties du test. Fig. 1 et 2 représentent un individu de moyenne taille, proportionnellement un peu plus large que les autres.

La carité intérieure ne diffère en rien de celle du L. Bonani, si ce n'est qu'elle est moins élevée; l’appareil masticatoire est très puissant et maintenu en place par des auricules tris hautes, contre lesquelles sont adossées les mìchoires. Les dents, très arquées, ne sont émaillées qu’i leur extrémite.

Cette espèce provient de l'ile Bourou, d'oủ elle a élé rapportée par MII. Lesson et Garnot, 'qui l'ont déposie au Muséum d'histoire naturelle de Paris, sous le nom de Lagana depressa.

\section{Ligaxum elupticey Ag.}

Tab. 23, fig. 13-15.

La forme elliptique de cette espèce rappelle les Laganes à quatre pores génitaux du type du Lag. orbiculare; mais sa structure intime la rapproche du Lag. Bonami; elle a comme celle-ci le bord très renflé et une dépression trẻs marquée entre le bord et le sommet; a ussi ce dernier ne lait-il qu'une très légère saillie au-dessus du bord (fig. 15.) Les pétales ambulacraires s’arrondissent presque complètement à leur extrémité. Les zones porifères, quoique plus étroites que l'espace intermédiaire qu'elles circonscrivent, vont cependant en s'élargissant du sommet vers la periphérie. Les pores génitanx sont au nombre de cing et très petits, comme dans les espèces prẻcédentes. Les pores ocellaires ne sont pas visibles. La face inféricure est légèrement concave; l'ouverture buccale est située à peu près au centre; sa forme pentagonale est à peine sensible. Les sillons ambulacraires qui l'entourent, ne sont visibles que jusqu'à une assez faible distance. En revanche, les bandes des aires interambulacraires se poursuivent jusqu'au bord. Louverture anale est allongée transversalement, comme dans le $L$. depressum, et plus rapprochée du bord postéricur que de l'ouverture buccale. Les tubercules qui garnissent la surface du lest, sont de même nature à la face inférieure; et à la face supéricure les tubercules spinifères naissent d'une dépression très marquée, surtout à la face infẻrieure, ce qui lui donne une apparence très rugueuse.

J'ai réussi à extraire une mâchoire de l'exemplaire figuré ; elle présente à peu prés la móme structure que les mâchoires du Lag. Bonani, figurées Tab. 22 , fiğ. 26.

Cette espèce m’a ćté communiquée par II. Stockes; son origine est inconnue. 


\section{Laganum decagonum Less.}

Tab. 23, fig. 16-20.

Cette espèee n'est eonnue que par un seul exemplaire rapporté de lîle Waigiou par MM. Lesson et Garnot. Elle est remarquable par sa forme très aplatie et subeonique au sommet et par son pourtour à peu près cireulaire, ensorte qu'on la prendrait facilement pour un Araelınoïde, si elle n’avait d’ailleurs tous les autres earactères des Laganes du type du Lag. Bonani. Les pétales ambulacraires en particulier sont conformés de la même manière que dans cette dernière espèce. Ils sont étroits, lancéolés et ne se prolongent guère au delả de mi-bord; leurs zones porifères sont très rétrécies et n’égalent pas même la moitiẻ de l'espace intermédiaire. Le bort du test est légèrement renflé sur son pourtour, mais d'une manière plus sensible en avant que latéralement (fig. 18). La roselte apieiale laisse apercevoir à la loupe quelques traces assez distinetes de sutures qui ne permeltent pas de douter que les pores gẻnitaux et ocellaires ne s'ouvrent dans des plaques particulières. Le corps madréporiforme est garni de tubereules comme le reste de la surface; les pores génitaux, au nombre de cinq, sont trẻs distincts, les pores ocellaires en revanche ne sont pas visibles (fig. 20). La bouclıe est au centre de la face inférieure, oủ elle se montre entourée de cinq petits sillons qui, vus sous un fort grossissement, apparaissent bordés d'une infinité de pores microscopiques (fig. 19). L'articulation des plaques y est fort distincte, et l'on voit par la fig. 17 que les aires interambulacraires sont proportionnellement plus étroites qu'à la face supérieure, car elles n'ont pas même la moitié de la largeur des aires ambulacraires. L’anus, sensiblement rapproché du bord postérieur, est petit, de forme circulaire, et semble percé de delıors en dedans. Le test est revêtu d'une granulation très homogène, mais remarquable en ce que les tubercules spinifëres sont moins nombreux que dans les espèces ci-dessus et entourés d'un nombre considérable de tubercules miliaires, ainsi qu'on peut le voir par la fig. $16 a$, qui représente une portion de la face supérieure sous un fort grossissement.

L'original montre des vestiges d'une belle couleur rouge, qui s'est surtout conservée vive sur - les artieulations de la face supérieure. 


\section{Liganem texoissinu $\mathrm{Ag}$.}

Tab. 26, fig. 4-6.

Syn. Lagana tenuissima Ag. Cat. Ectyp.Mus. Neoc. p. 6.

Le nom de cette espèce en indique le principal caractére, qui consiste dans son extrême aplatissement (fig. 5). Les bords cependant sont lègèrement renflés, surtout en arant, ensorte que l'espace intermédiaire entre le pourtour et le sommet forme une zone sensiblement déprimée. La forme gẻnérale du test est ovoïde; le côté postẻrieur est tronqué. Les pétales ambulacraires s"étendent jusque près du bord, sans se fermer à leur extrémité. Les zones porifères ègalent en largeur à peu près la moitié de l'espace intermédiaire. La rosette apiciale n'est pas assez. bien conservée pour laisser aperceroir exactement le nombre des pores génitaux; mais jai tout lieu de croire qu’il y a en cinq comme dans les espèces précédentes. L'articulation des plaques est assez distincte, et j’ai pu m’assurer que, comme dans toutes les Laganes, les aires interambulacraires sont plus étroites que les aires ambulacraires, notamment à la face infẻrieure. La bouche est centrale et circulaire. L'anus a la même forme, mais il est plus petit et situé près du bord postérieur.

Cetle espèce provient du terrain tertiaire de Blaye. L'original de mes figures m'a été communiquẻ par M. Michelin.

\section{Lagaym Reflexum $d$ g.}

Tab. 26, fig. 1-3.

Cette espèce diffère du Lagamum tenuissimum par son épaisseur plus considérable et par le renflement extraordinaire de ses bords et particulièrement du bord antérieur (fig. 2); la face supérieure est par conséquent marquée d'une large dépression qui règne tout autour du sommet. Le pourtour du test est ovoïde, le côté postérieur est tronqué, le còté antérieur est plus étroit que le côte postérieur. Les pétales ambulacraires sont trés allongés; ils atteignent presque le 


\section{$-114-$}

bord du test el sont très ouverts a leur extrémité. La bontehe est circulaire el centrale. L'anns est petit et rapproché du bord postérieur.

L'exemplaire figuré est le seul que je connaisse de cette espéce; comme le précédent, il provient des terrains tertiaires de Blaye, et m’a été communiqué par M. Valenciennes.

Mes Lagamum tenuissimum et reflexum correspondent probablement aux Scutella marginatis et polygona de M. Ch. DesMoulins, qui proviennent également de Blaye; mais comme ces dernières ne sont ni dérrites ni figurées, je n’ai pas pu m’en assurer. S̈il en était ainsi, je serais le premier à regretter d'avoir multiplie inutilement les synonymes.

\section{Lagaviy Toxganesse Quoy el Gaim.}

\section{Tah. 26, fig. $7-19$.}

Cetle espèce tient en quelque sorte le milieu entre les espèces du type du Lag. Bonani et celles du Lag. Lesueuri décrites ci-dessous. Elle a les grandes dimensions el la forme anguleuse de ce dernier, tandis que son profil ondulé, résultat d'une dépression plus ou moins marquée entre le sommet et le bord (fig. 9) et la prẻsence de cinq pores génitaux très petits, la rapprochent du Lag. Bonami. Les fig. 8 et 10 représentent deux variétés de cette espèce, l'une allongée et woïde (fig. 10), lautre large, anguleuse et courte (fig. 8). La fig. 7 est un jeune individu revêtu de ses soies. Les pétales ambulacraires sont lancéolés et en général peu réguliers; leurs zones porifères, bien moins larges que l'espace intermédliaire, ne se rejoignent point à leur extrémité. Le pétale antérieur est en général plus grèle que les autres. La surface du test est revètue d’une granulation très-lomogène, qui, examinée sous un fort grossissement, se montre composée de gros tubercules spinifères déprimés sur leur pourtour, distinctement mamelonmés et perforés ả leur sommet et entourés d'une quantité de tubercules miliaires (fig. 13.) La rosette iuberculeuse apiciale présente la mème apparence, et lon y reconnait de plus quelques traces de sutures. Les pores génitaux sont petits et au nombre de cinq. Les pores ocellaires ne sont pas visibles à la surface (fig, 12). L'arrangement des plaques est toujours distinet lorsque les soies sont enlevées, et l'on reconnait dans leur disposition les mèmes rapports que nous avons déjả signalés dans les antres espèces, c’est-à-dire qu’ả la face supérieure les plaques des aires interambulacraires sont bien moins larges, quoique plus hautes, que celles des aires ambulacraires (fig. 8). A la face inférieure, elles sont encore moins développées; aussi les aires 
interaubulacraires y sont-elles rẻduites à cinq bandes trés-étroites qui rayonnent du centre a la périphérie (fig. 7.) La bonche est centrale el cireulaire, entourée de cinq sillons ambulacraires visibles jusquu it mi-bord. Dans les exemplaires revêlus de leurs soies, louverture buccale est fermée par des piquans d'une espece particulière, implantés sur tout son pourtour el convergeant vers le eentre (fig. T). L'anus est grand et cireulaire, silué à-peu-près à moitié chemin de la bonehe au bord.

La cavité intérieure ne présente ancune aspérité, si ee n’est sur les bords, oú l'on remarque des piliers et des réseaux calcaires, comme dans toutes les especes du genre. La fig. 10 montre li face interne du planclıer supérieur, on l'on distingue fort bien larticulation des plaques des pétales, et, au centre, les cinq pores génitaux s'ouvrant dans de petites carènes. L'aire interambulacraire impaire est marquée d'un large sillon eorrespondant à l'ouverture anale. La fig. 11 montre la face interne du plancher inférieur enlevé à la fig. 10; on y remarque louverture buccale, entourée des cinq aurieules qui s’élèvent en forme de gros piliers arqués, destinés á maintenir en place l'appareil masticatoire. Ce dernier est construit sur le même plan que celui des Laganes en général; e’est-à-dire qu'il se compose de mâchoires très-haules et garnies, tant à leur face supérieure qu’à leur face inférieure, de nombrenses lames calcaires, conme on le voil par les fig. 17 et 18, qui représentent une mâchoire isolée, de profil (fig. 18) et par derrière (fig. 17). La fig. 16 est la mème mâchoire, vue par sa face supérieure avee le sillon destiné à receroir la dent. Les fig. 14 et 15 enfin montrent l'appareil masticatoire tel qu'il se prẻsente lorsque les cinq mâchoires (dont la position se trouve indiquée par des lettres) sont réunies. La fig. 1't représente la face inférieure, la fig. 15 la face supérieure avee le cercle formé par la juxtaposition des ares montans de la eharpente massive de ehaque mâehoire.

Les soies qui revêtent la surface du test, quoiquo d'apparence uniforme, se montrent cependant très variées dans leur forme lorsqu'on vient à les examiner an mieroscope. J'ai figuré (fig. 19), sous le même grossissement, des soies empruntées aux différentes parties du test, afin de donner nne idée de leurs proportions : $a$ est un piquant de la face supéricure ; $b$ est le piquant d'un tubercule spinifére de la face inférieure; $c$ est le piquant d'un tubercnle miliaire; $d$ enfin est l'une des soies qui entourent le pourtour de la bouche. Comme à l'ordinaire, ces dernières sont plus développées, mais aussi plus irrégulières que les autres soies de la face inférieure. II est digne de remarque que celles de la face supérieure (fig. 19a) ne sont point clavellées à leur extrémité. 
Cette espèce a élé rapportée de Tonga par MII. Quoy et Gaimard, qui l'ont déposée au Muséum de Paris, sous le nom de Lagana tonganensis. C'est à tort qu'elle est inscrite sous mon nom, sur la planclie.

\section{Lagaven Lescedn Val.}

Tab. 24, fig. 3-6.

C'est la plus grande espèce du genre; elle atteint jusqu'à 5 1/2 pouces de longueur sur 5 pouces de large. La hauteur est peu consilérable, elle n'atteint pas mème 1 pouce dans les plus grands exemplaires. Le bord n'est point renflé comme dans les espèces du type du Lag. Bonami, et par la mème raison il n'existe point de dépression entre ce dernier et le sommet. Le pourtour du test est polygonal, et l'on remarque une espèce de troncature en face de claque ambulacre; ensorte que si l'on voulait préciser rigoureusement les contours du test, on trouverait quil est décagonal. Ces troncatures ambulacraires sont toujours plus petites que la partie qui correspond aux aires interambulacraires. Au rebours des espèces précédentes, le côté antérieur est sensiblement plus large que le côté postérieur. Les pétales ambulacraires se font remarquer par leur itroitesse, comparée à la grandeur du test ; ils sont tout d'une venue, et, au lieu de s'arrondir, ils sont comme tronqués à leur extrémité. L'espace intermédiaire entre les zones porifères est plus large que ces zones elles-mêmes. Les pores oviducaux sont très apparens, mais au nombre de quatre seulement, situés à l'extrémité des rayons du corps madréporiforme, qui affecte la forme d’une étoile à cinq rayons très prononcés et échancrés à leur extrémité (voyez dans la lig. 6 , la rosette apiciale grossie). Il nła élé impossible d'apercevoir les trous ocellaires; cependant je ne doute pas qu’ils n'existent dans les sinus du corps madréporiforme, au sommet des ambulacres. La face inférieure est complètement plane. L'ouverture buccale est centrale et circulaire; sur son pourtour se voient les tubes branchiaux qui ont à leur extrémité plusieurs ouvertures plus ou moins distinctes (voyez fig. 5 , qui représente la houche grossie). La rosette buccale n'est pas bien distincte; quant aux sillons anbulacraires, ils sont très marqués prẻs du centre et criblés d'une quantité de pores microscopiques, mais ils disparaissent vers le bord. Les aires interambulacraires sont excessivement étroites a la face inférieure, où elles se présentent sous la forme de bandes indistinctement limitées ; c'est dans une de ces bandes que s'ouvre l'anus, qui est très rapproché du bord. Sa forme est circulaire, mais il semble percé obliquement de dehors 
en dedans. Une granulation très uniforme recourre toute la surface du test. Les tubercules spiuifëres, un peu plus gros à la face inférieure qu’ì la face supérieure, naissent du milieu d’une dépression très prononcée, et l'espace intermédiaire est garui d'une quautité de tubercules miliaires. Les soies, mème celles qui s'articulent aux tubercules spiniféres, sont très grrêles; mais examinées a la loupe, elles se montrent distinctement carénées (fig. $3 b$ ), et si l'on vient à les observer sous III plus fort grossissenient, on trouve que ces carènes sont hérissées de petites dentelures trẻs acérées (fig. $3 c$ ).

La cavité intérieure n'a ni cloisons ni piliers, et le réseau đle cellules n'existe que sur les bords, où il est cependant plus varié que dans le Lag. Bonani. La rosette apiciale interne affecte la forme d'une étoile composée de cinq rayons, qui s'étendent dans les aires interambulacraires et a l'extrèmité desquelles s'ouvrent les pores génitaux. La carène qui cotrespond à l'aire interamluulacraire ne diffère des autres qu'en ce qu'elle est un peu plus forte el qu'elle n’a point de pore génital; au reste sa forme et sa structure sont les mêmes.

Cette espèce a été rapportée par Péron et Lesueur de leur voyage aux terres australes et par II. Plée de la Guadeloupe. Je n’en connais pas d’autres exemplaires que ceux du Muséun de Paris. C'est M. Valenciennes qui le premier a reconnu les caractĕres spécifiques qui la distingueut du Lagamum tonganense.

Aiusi que je l'ai dit plus haut, lorsqu'ou aura une connaissance plus approfondie de ses rapports anatomiques, cette espèce devra probablement former le type d'un genre à part, auquel se rapporteront également les Lagamom clongatum et rostratum et peut-être aussi le L. comganense.

\section{Lagiven eloggaten Ag.}

Tal. 24, fig. 1, 2.

Cette espèce a absolument la mème pliysionomie que le $L$. Lesueuri, dont elle ne différe que par un seul caractère essentiel, la position de l'anus, qui, au lieu de correspondre au cólé le plus étroit, est au contraire au côté le plus élargi, ou, en d'autres termes, le côté postérieur, qui, dans l'espèce précédente, est très étroit, est ici élargi. A part cela, on retrouve en elle tous les caractères principaux du L. Lesucuri; sa forme est subdécagonale, quoique un peu moins anguleuse. La hauteur égale ì peu près $1 / 6$ de la longueur. Les pétales sont allongés, mais a vec une tendance assez prononcée à se fermer à leur extrémité. La rosette apiciale est com- 
posée de cinq rayous trẻs dégagés et échancrés à leur extrẻmité, près de laquelle sourrent les pores génitaux. Les tubercules qui garnissent la surface du test sont conformés de la même manière à la face supéricure et à la face inféricure; ils occupent également les espaces intermẻdiaires entre les sillons transverses des zones porifëres, oủ ils sont disposés par rangées régulières (fig. 1 a).

La face inférieure est entièrement plane. Les aires interambulacraires y sont indiquées par des zones très étroites, qu’on poursuit jusqu'à la périphérie; les sillons ambulacraires ne s’étendent guère au delà de mi-bord. La bouche est circulaire et centrale : sur son pourtour s'apercoirent les ouvertures des petits tubes branchiaux (fig. 2). L'anus est à peu près aussi grand que la bouclı et également eireulaire.

Je ne connais encore qu'un seul exemplaire de cette espèce que m’a eommuniquẻ M. Stolies ; son origine n'est mallıcureusement pas connuc.

\section{Lighisur rostritula Ag.}

Tab. 25.

Cette espèce appartient au type du L. Lesueuri; elle est très allongéc et ovale. Le côté postérieur est moins large que le côté antéricur. Le pourtour du test u’a point eette forme anguleuse qui caractérise l'espèce ci-dessus mentionnée, bien que l'on remarque encore de légères troncalures dans le prolongement des aires ambulacraires, surtout des postérieures. Mais un caractère particulier de cette espèce consiste dans la déclivité uniforme de la face supérieure (voyez le profil en fig. 3). Le lıorl est épais sans ètre renflé. Les pétales ambulacraires, étroits et lancéolés, ne se ferment point à leur extrémité. L'espace intermédiaire entre les zones porifères a le double de la largeur de ces zones elles-mêmes. La rosette apiciale est assez large et lorsqu'on l'examine de près, l’on y reconnaît la mème structure spongieuse qui caractérise la plupart des Scutelles. Les pores génitaux, au nombre de quatre, sont très apparens; l'un d'eux, celui de l'aire interambulacraire postérieure droite, est mème double dans un de mes exemplaires. Je n'ai pu reconnaître que des traces incertaines des trous ocellaires qui paraissent eachés sous l'épiderme (royez fig. 4, qui représente la roselte apieiale et deux pélales grossis).

La face inférieure est eomplètement plane. L'ouverture buccale est centrale et circulaire; elle est entourée diun cercle de petites soies très roides et distinctement striées dans le sens de leur 
longueur. Les sillons ambulacraires sont très marqués et, comme d'ordinaire, ils contiennent une quantité de petits pores. Les aires interambulacraires forment une bande étroite et assez distinctement limitée; elles affectent même une teinte plus vive que le reste du test dans les exemplaires qui ont conservè leur couleur. L'anus est très rapproché du bord; son pourtour est garni de petites soies, qui naissent dans la dépression même de l'ouverture anale el qui, par leurs dimensions, sont intermédiaires entre celles des tubercules spinifères et celles des tubercules miliaires. C'est la seule espèce qui m'ait présenté une disposition pareille des soies autour de l'anus. La surface entière du test présente une granulation très uniforme, mais remarquable en ce que les tubercules spinifères sont bien moins serrés que dans la plupart des autres Laganes. On ne remarque à cet égard aucune différence sensible entre la face supérieure et la face inférieure.

L’intéricur, que j’ai représenté dans la fig. 5, le plancher inférieur étant enleré, m’a fourni de précienx indices sur plusieurs points obscurs de l'organisation des Scutelles : j’y ai trouvé, outre la position relative des principaux organes que nous avons décrits à l'article du genre (p. 106), les pétales ambulacraires garnis intérieurement d'une espèce de tissu spongieux qui parait avoir été mou durant la vie de l'animal et que je crois être les véritables branchies, car elles sont composées de feuillets qui viennent aboutir à la rangée exterue des pores, absolument comme dans les vrais Echinus. Ces branchies ne seétendent pas au delà de l'extrémité des pétales; ensorte quil y a tout lieu de prèsumer quils constituent un organe différent de celui dont dépendent les sucoirs de la face inférieure. L'appareil masticatoire est remarquable par son apparence massive. Les màchoires sont très hautes par suite du développenent extraordinaire des lames feuilletées à la face inféricure. La charpente elle-mème, et particulièrement ses arcs montans sont très forts, et, rus d'en lıaut, ils forment à la face supérieure de l'appareil masticatoire un cercle très massif, lorsque les cinq uảchoires sont rẻunies (fig. T). Les figg. 8,9 et 10 représentent une màchoire isolée de grandeur naturelle, vue d'en lıaut en fig. 9, de profil en fig. 10, el par derrière en fig. 8; ces deux dernières figures donnent une idée de la hauteur extraordinaire des mâchoires et de la disposition des feuillets calcaires. Les dents sont fixées de champ dans le sillon de la face supérieure des mìchoires; mais comme celles-ci sont trés laautes, il en rẻsulte qu'au lieu d'ètre horizontales, comme dans les espèces à màchoires plates, les dents doivent ètre obliques et très arquées pour atteindre l'ouverture buccale; de plus elles ne sont émaillées qu'ả leur extrẻmité, de mème que dans les vrais Clypéastres. L'appareil masticatoire est maintenu en place par cinq fortes auricules, qui, au lieu de servir de pivot aux mâchoires, comme c'est le cas des Lobophores, forment au contraire de puissans contre-forts qui 
les empêchent de dévier. Ces auricules sont toujours placées sur les aires interambulacraires, comme on le voit par la fig. 6 qui représente la face interne du plancher inférieur avec la bouche au milieu.

La couleur de cette espèce est d'une teinte brunâtre tirant sur le violet. Elle provient de la Nouvelle-Zélande; j’en ai dù des exemplaires à M. DesIfayes et à M. Michelin.

\section{Lagavum orbiculare Ag.}

Tab. 22, fig. 16-20.

Srx. Echinodiscus orbicularis Leske p. 208, Tab. 45, fig. 6,7.

Fchinodiscus circinatus etc. Breyn. Sclied, p. 64, Tab. 7, fig. 1, 2. - Gualt. Tah. 110, fig. B.

Laganum Schynoetii Klein, p. 25.

Echinus planus (Zeeschelling) Rumph. p. 3\%.

Echinus orbiculus L. Syst. nat. XII, p. 1105, $N^{\circ} 17, d$.

Echinus orbicularis L. Gm. p. 3191.

Boccon Obs. p. 269, fig. 2, 3.

Encycl. méth. Tabl. 147, fig. 1, 2.

J'envisage cette espèce comme le type de la division des Laganes à quatre pores génitaux. C’est sans donte la même qui se tronve dëjả figurée dans Breynius et dans Leslie el qui de là a passé dans tous les ouvrages qui traitent des Fchinodermes. Sa forme est subcirculaire; le côté postérieur est légèrement rostrẻ. Elle est en outre très-aplatic ; le bord est renflé et sẻparé du sommet par une large dépression (fig. 18.) Les pétales s'étendent jusqu'au delà de mi-bord ; ils sont de moyenne largeur et se terminent en pointe effilée; les sillons des zones porifères prennent une direction de plus en plus oblique vers l'extrẻmitẻ des pétales. La surface entière est revêtue de tubercules spinifères très-distincts, fort espacés, qui s'étendent également sur les aires interambulacraires, sur les aires ambulacraires et sur la rosette apiciale. Les quatre pores génitaux sont situés au sommet des aires interambulacraires, qui sont ici bien moins larges que les aires ambulacraires (fig. 19). Lorsqu'on examine les tubercules sous un fort grossissenent, on les trouve distinctement mamelonnés, perforés et entourẻs d'une multitude de tubercules miliaires qui paraissent être conformés de la même manière (fig. 16 a). L'anus est circulaire, situé au tiers de l'espace entre le bord et la bouche; il a l'air d'ètre percé obliquenent d'arrière en avant. Je 
n'ai point pu observer la bouche faute d'exemplaires entiers; mais il est prohable que sa forme est la mème que dans les espèces suivantes, si toutefois il est permis d'en juger par l'analogic des parties avoisinantes. La fig. 20 représente la rosette apiciale vue par la face interne sous le mène grossissement que fig. 19 ; on y distingue fort bien les quatre rangées de piaques qui composent les pétales ambulacraires et, au centre, une dépression très-marquée, bordée d'un bourrelet ridé auquel était fixé l'cesophage. Les bords du test montrent, à l'intérieur, des piliers calcaires et une espèce de labyrintlıe ou de réseau dans lequel se logent sans doute les appendices de lintestin, comme cela a lieu dans le $L$. Bonani.

L'exemplaire figuré appartient au Musée de Neuchàtel; son origine m’est inconnte.

Je ne rapporte point à celte espèce le Scutella orbicularis de Lamarck, qui est le Lagana orbicularis de M. de Blainville, parce que l'exemplaire du Muséum de Paris, qui a servi à ces descriptions, est une espèce très différente de l'Echinodiscus orbicularis de Lesle dont il sagit ici; je décris ci-dessous l'espice de Lamarck sous le nom de Laganum Peronii.

\section{XI1. Lagiven margivale Ag.}

Tals. 22, fig. $11-15$.

Celte espèce est très-roisine du Lag. orbiculare; il se pourrait même qu'elle n'én füt qu'une variété. Cependant voici pourquoi je penche à croire qu'elle en diffère spécifiquement. Quoique aussi plate et peut-être mème plus plate que cette dernière, son bord est proportionnellement plus renflé. La dépression qui occupe l'espace entre le sommet et le bord est plus prononcée. Les pétales ambulacraires sont plus larges et plus en relief; enfin les pores génitaux sont plus grands (comparez les fig. 14 et 19). Quant à la forme générale, elle est oroüde comme celle du Lag. orbiculare. La face inféricure est plane ou à-peu-près. L'anus est petit et cireulaire. Je n’ai pas pu observer la bouche; au lieu de cela jai représenté ( fig. 15) la face interne de la rosette apiciale qui montre absolument la même disposition que celle du Lag. orbiculare, excepté que les pétales ambulacraires sont un peu plus larges à leur sommet. La surface du test est revètue des mèmes tubercules spinifẻres et miliaires qui caractérisent toutes les Laganes et dont la fig. 11 a représente la structure et l'arrangement sous un très-fort grossissement. Outre ces tubercules, le bord renllé du test présente une quantité de petites vésicules vitrées, dont il ma été inpossible de reconnaitre la nature : elles sont aussi nombreuses que les tubercules spi- 
niféres el à-peu-près de la mème taille, lorsqu'on les examine à la loupe. La fig. 11 les montre mêlées aux tubercules miliaires.

Je ne connais qu’un seul exemplaire de cette espèce, qui m’a été communiqué par M. Michelin ; son origine m'est inconnue.

\section{Xili. Laganem gtellatum Ag.}

Tal. 22, fig. 7-10.

La forme de cette espèce est largement ovoüde; sa liauteur est plus considérable que celle des deux espèces précédentes; en revanche la dépression intermédiaire entre le sommet et le bord est à peine sensible (fig. 9.) Le bord est épais. Les pétales ambulacraires sont larges, lancéolés; et ce qui constitue un caractère particulier de cette espèce, ils ne convergent point vers le sommet, ensorte que les pores génitaux situés an sommet des aires interambulacraires sont nécessairement très-distans ( fig. T). Les zones porifères sont étroites, et les sillons transverses qui unissent les pores des deux rangées, à peine visibles. La face inférieure est légèrement déprimée; on y recomnaît les traces de cinq bandes ou sillons ambulacraires dirigés vers la bouche, ‘ui est au centre de la dépression. L’anus est plus petit que l'ouverture buccale et de forme sulycirculaire. Les tubercules spinifèrés sont conformés comme dans les autres espèces, mais les tubercules miliaires qui les entourent sont moins nombreux (fig. Ta). Etant parvenu ì extraire quelques mâchoires de l'un de mes exemplaires, j’ai pu m'assurer que l'appareil masticatoire est construil, dans cette espèce de la même manière que dans les espèces du type du Lagamum Bonani. Les màchoires sont trés-lautes et garnies d'abondantes lames calcaires, comme on peut le voir par les fig. $10 \mathrm{c}$ et $d$, qui représentent le profil d'une màchoire, vue latéralement en $c$, et par derlière en $d$. La figg. 10 a représente la face inférieure, et la fig. 10 la face supérieure de l'appareil masticatoire, les cinq màchoires étant réunies. Je n'ai pas vu les dents; mais l'on peut juger par la liauteur des mâchoires et par la forme des sillons destinés à les loger, qu elles sont trèsarquées.

Je dois à l'obligeance de mon ami M. Stokes plusieurs exemplaires de cette espèce, provenant de la Nouvelle-Galles du Sud. 
XIV. L.hG.hum peronit $\Lambda_{g}$.

Tab. 22, lig. 21-2\%.

Six. Scutlla orbicularis Lam. Tom. III, p. 282, No 10. - E. Desl. Enc. T. 2, p. 67\%, N 10. - DeB1. Dict. sc. nat. T. 48, p. 228. - DesMonl. Tab]. syn. p. 232.

Lagana orbicularis DeB1. Zooph. p. 196.

Echinodiscus orbicularis DeBI. Zooph. P. 199.

C'est à tort que Lamarck, DeBlainville et DesMoulins rapportent cette espèce au Lagamum orbiculare. Il suffit de comparer les fig. 16 et 21 de Pl. 22, qui représentent ces deux espèces par la face supérieure, pour se convaincre de leur grande diffërence spécifique. Le Lagamum Peronii est beaucoup plus élevé (fig. 23), à peine ondulè cntre le sommet et le bord, et son pourtour, au lieu d'ètre circulaire, est subpentagonal. Les pétales ambulacraires s’ètendent jusque près du bord, et sont plutòt arrondis qu'effilés a leur extrémité. Les zones porifëres sont étroitcs et les sillons transverses fort obliques. Enfin un dernier caractère du Lag. Peromii, qui, à lui seul, suffirait pour faire distinguer cette espèce de toutes ses congénères, c’est l'éloignement considérable des pores génitaux, qui sont à peu près aussi distans du sommet que du bord. La surface entière du test est revêtue d'une granulation homogène composẻe de tubercules spinifëres entourés d'une quantité prodigieuse de tuhercules miliaires (fig. $21 a$ ). Les bords du test se listinguent en outre par une quantité de vésicules vitrées comme celles que nous avons signalées dans le Lag. marginale. La face inférieure est médiocrement déprimée; la bouche, située au centre de cette dernière, est sulpentagonale, el lorsqu'on l'examine à la loupe (fig. 2\%), on trouve que les sillons ambulacraires qui régnent autour de son pourtour, quoique très peu marqués, sont cependant criblés d'une quantité de petits pores. On remarque en outre, sur le pourtour immédiat de la bouche, à l'extrèmité de claque sillon, deux pores un peu plus marqués, qui sont sans doute les ouvertures des tubes branchiaux. L'anus est petit, circulaire, et situé au tiers de la distance, entre le bord postérieur et la bouche.

J'ai appelé celle espéce du nom de l'illustre naturaliste voyageur qui l'a rapportée des mers australes. Mes figures sont faites d'après l'exemplaire même de Péron, qui est déposé au Muséum de Paris, et qui m’a été communiqué par M. Valenciennes. 


\section{REMARQUES ADDITIONNELLES SUR LES LAGANES, LES SCUTELLINES ET LES ECHINARACHNIUS.}

Liindécision qui a régné chez la plupart des auteurs à l'égard des limites à assigner au genre Lagamum y a fait rapporter des espèces qui doivent en ètre exclues maintenant que ses caractères sont mieux déterminés.

C'est ainsi que le Lagana ou Scutella ocalis des auteurs, qui est aussi le Scutclla reticulata DeBl. el dont l'Encyclopédie méthodique renferme une figure Pl. 144, fig. 5 et 6, doit être reliré du genre Lagamm pour prendre place dans le genre des vrais Clypcaster.

Mon Lagana profunda, (Catal. syst. Ectypor. Mus. Neoc. p. 6, fossile des Alpes suisses, est également un vrai Clypeaster.

Plus loil, nous aurons occasion de faire remarquer encore que plusieurs espèces rapportées aux geures Lagamum et Fibularia doivent maintenant prendre place parmi les Echinocyamus; telles sont le Lagana occitana et les Fibularia altavilensis, obtusa, sicula, pyriformis, elc.

Le Lagamum Scillœ de Kilein est une véritable Scutelle qui se trouve mentionnée p. S7.

Quant au Laganum Rumplia de Klein, M. DesMoulins le rapporte à son Scutella bifissa qui est mon Lobophora bifissa; mais jignore ce que peut être son Laganum Plotii.

Plusieurs espèces que jai rapportées au genre Echinarachius dans mon Prodrome et dans non catalogue des moules d'Echinodermes, doivent aussi être éloignées de ce genre maintenant qnil est autrement circonscrit; telles sont les Echinarachnius mummularis et lcnticularis qui rentrent dans le genre Scutellina, l'Echinarachius Parma qui est redevenu avec Klein le type du genre Arachoörles, et les Echinarachius placunarius et latissimus (rapportés par N. de Blainville ì son genre Echinodiscus), qui sont de vrais Clypcaster. Il en est de même du Scutlla clypeastriformis DeBl. qui est rederenu plus tard le Clypeaster scutiformis de Lamarck. Pour le dire en passant, je ferai remarquer que le Chypaster placunarius Lamarch est en même temps le Scutclla cimbigena Lamarck; je m’en suis assuré au Muséum de Paris par l’inspection des exemplaires originaux de Lamarck. Enfin M. le professeur Brom assure que les Scutclla giblosa et pyramidalis de Risso sont également de vrais Clypeaster. 


\section{CHAPITRE XII.}

DU GENRE ECHINOCT 1 MUS v. Phels.

Ce genre, quoique très ancien, est cependant celui dont l'étude m'a offert les plus grandes difficultés. Van Phelsum qui l'établit y rangeait quatorze espèces, auxquelles il assignait comme principal caractère, suirant Leske, d'avoir l'anus à la face inférieure et rapproché de la bouche. Lamarck circonscrivil cegenre à peu prẻs de la même manière ("); mais au lieu de lui conserver le nom primitif d'Echinocyamus, il le changea en celui de Fibularia. Dans ce genre ainsi délimilé sont compris deux types très différens, ainsi que nous allons le voir. Goldfuss, dans son grand ouvrage sur les pétrifications d'Allemagne, leur en a même associé un troisiẻme, en les confondant arec les Echinonées. M. de Blainville a de nouveau rẻintégrẻ le geure Echinocyamus, en prenant pour type l'Echinocyamus pusilhus décrit ci-dessous; mais d'un autre còté il confond les Fibulaires el plusieurs espèces de vraies Echinocyames dans un mème genre avec les Echinonées et les Galérites, ce qui est une grave erreur.

Cette confusion, que je n'ai pu éviter entiẻrement dans mon Prodrome, faute de matériaux suffisans, tient à deux causes principales, qui sont, en premier lieu, la rareté de ces animaux, que les collecteurs ont sans doute dédaignés à cause de leur petitesse el de leur peu d'apparence, et en second lieu, la rareté plus grande encore de l'ouvrage de van Phelsum. A défaut de l'original, j’ai élé obligé de me contenter de l'extrait qu'en donne Leske dans son édition de Klein, et quoique les descriptions des espéces y soient peu précises, j’ai cependant pu y reconnaitre les deux types mentionnés ci-dessus, sayoir : des especes globuleuses, ou des Fibulaires, et des espèces aplaties, ou de vrais Echinocyames. Les premières paraissent être les plus nombreuses dans louvrage de ran Phelsum.

(") Corpus subglobosum, oboratum aut orbiculare, margine uullo pel roundalo; spinis minimis. Ambulacra quinque, bresia, angusta, circumscripta. Os inferum, centrale; ano ori vicino wel mediano intra os et marginem. 
Jai déja insisté dans l'introduction (pag. 20) sur les différences profondes qui distinguent ces deux genres en apparence si voisins. Tandis que la cavité intérieure des Fibulaires est complètement unie et ne présente d'autres aspérités que les cinq auricules lestinées à supporter les màchoires, les Echinocyames ont l'intérieur du test garni de cloisons calcaires, qui rayonnent du centre à la périphérie et divisent ainsi la cavité en dix sections correspondant aux aires ambulacraires et interambulacraires; c'est absolument la mème structure que nous avons reconnue dans les Scutellines. Cette structure particulière implique nécessairement une disposition des organes intérieurs, et notamment du canal intestinal, fort différente de ce qu'elle doit être dans les Filuulaires. Quant aux Echinonées, que Goldfuss confond avec ces dernières, M. DesMoulins a déjà fait remarquer que celte association d’espèces si différentes doit être rejetẻe d'emblée. Dans mon Prodrome je les avais également déjả séparées.

Circonscrit dans les limites que nous lui assignons ici, le genre Echinocyame tient donc d'une f art aux Scutellines, par la structure cloisonnée de l'intérieur du test, et d'autre part aux Fibulaires par son apparence extérieure, par la forme de ses pétales ambulacraires et par la position de l'anus, qui est plus ou moins rapproché de la bouche. D'un autre côté, les mêmes caractères qui le rapprochent de l'un de ces genres, l’ẻloignent de l’autre ; il diffëre par conséquent des Scutellines par la position de l'anus ì la face inférieure, et des Fibulaires par la strueture cloisonnée de sa cavité intérieure. Conme ce dernier caractère est lié à l'organisation intimc de ces animaux, les différences doivent ètre plus profondes entre les Echinocyames et les Fibulaires qu’entre les Lchinoryames et les Scutellines. En conséquence, jai non seulement séparé les Fibulaires comme genre, mais je crois encore qu’elles doivent être complètement éloignées du groupe des Scutelles et reportées dans un autre groupe; car jenvisage quelles sont bien plus roisines du type des Galérites et surtout des Echinonées que du groupe des Scutelles.

Un caractère important des Echinocyames consiste dans leur forme ovale et renflée sur les hords. Les pétales ne sont pas limités d'une manière bien distincte, et, sous ce rapport, ce genre forme en quelque sorte le passage entre les Clypéastroïdes à ambulacres bornés et ccux à ambulacres continus. Les zones porifẻres sont très rapproclı́es, mais les pores ne sont pas réunis par des sillons transverses, ou, si ces sillons existent, ils sont si petits, qu'ils cessent en quelque sorte d'être un caractère important. Il n'y a que l'E. occilamus dans lequel ils soient très distincts. La surface entière du test est recouverte de tubercules spinifères ordinairement très développés relativement à la taille de ces oursins et entourés de tubercules miliaires; cette même gramulation s'étend atussi sur la rosette apiciale, ensorte qu'il serait assez difficile de la reconnaitre 
si elle nétait ordinairement un peu plus saillante que le reste du test. La's pores génitaux sout an nombre de quatre et ordinairement très petits. Les pores ocellaires sont généralenent imperceptibles. Les soies sont assez déreloppées sur toute la surface du test; celles de la face inférieure sont comme d'ordinaire eylindriques et plus longues que celles de la face supérieure, qui sont tronquèes et légèrement renflées à leur extrémité.

Lappareil masticatoire se compose de michoires très lıates, à peu près comme celles des Laganes, ensorte que les dents, pour atteindre l'ouverture buccale, devaient nécessairenent ètre très-arquées.

Les espèces que je décris ici sont au nombre de onze: deux sont de l’èpoque actuelle, sept proviennent des terrains tertiaires, et deux, l'Echinocyamus alpinus et l'Echinoc. occitamus, de l’ëpoque crétacée: cette dernière, qui est la plus grande de tout le genre, deviendra peut-ètre un jour le type d'un genre à part; car elle diffìre notablement des autres espèces (voyez cidessous la description de l'espèce).

La synonymie des espèces de ce genre est très-difficile à établir. Il m'a été impossible de retrouver dans les collections les originanx des descriptions de la plupart des auteurs; méne ceux des espèces de Lamarek et de Blainville ne se trouvent pas au Musée de Paris, et la briévetéde leurs descriptions ue permet pas de déterminations rigoureuses : aussi, sur les onze espèces ci-dessous décrites, il n'y en a quine seule que jaie cru pouvoir rapporter aux synonymes de van Pliclsum et de Leske. Il m’a paru préférahle de passer sous silence toutes les citations douteuses et de m’en tenir à la description des espèces que je possède noi-mème. J'ajouterai sous forme d'appendice, a la fin de ce chapitre, les indieations les plus importantes que jai rérueillies dans les divers ourrages qui traitent de ces petits animaux. 


\section{Echivocranus pusillus Flem.}

Tab. 2T, fig. 1-8.

Srx. Echinocyamus pusillus Flen. Brit. anim. p. 481. - Ed. Forbes Hist. of br. Srarfish. p. 175.

Spatangzts pusillus Muller Zool. dan. p. 18, Tab. 91, fiø.. 5, 6.

Echinus minutus L. Gm. p. 319 4.

Echinocyamus minutus DeBl. Zooplı. p. 195.

Cette espèce semble rattacher d'une manière directe, par sa forme renflée, les Fibulaires aux Echinocyames. Il importait par conséquent d'étudier avant tout l’intérieur, pour s'assurer si ve passage existe réellement, et, dans le cas contraire, pour savoir auquel des deux genres il fallait la rapporter. Or il suffit de jeter un coup d'ocil sur les fig. 6 et 7 , qui représentent l'intérieur, pour se convaincre que c’est bien réellement un Echinocyame, car il n'y a que les espèces de ce genre qui aient des cloisons semblables; les Fibulaires, comme nous venons de le dire à l'arlicle du genre, n’ont d’autres aspérités à l'intérieur que les auricules.

L'E. pusillus est une petite espèce de forme ovoüde ou pyriforme, très-haute comparativemen! à son volume (fig. 3). La face supérieure est uniformément bombée, et le point le plus saillant correspond à la rosette apiciale. La face inférieure est légèrement concave; la bouche, de forme circulaire, en occupe le centre. L'anus, situé à moitié clıemin entre l'ourerture buccale et le bord postérieur, est très-petit (fig. 4). Afin de donner une idée plus exacte de la structure de ce petit oursin, j’ai ajouté aux figures de grandeur naturelle, les fignres $\mathbf{2}, \mathbf{5}, \mathbf{7}$ et 8 qui sont vues sous un grossissement de deux diamètres. Une particularité de cette espèce consiste dans la grosseur proportionnellement très-considérable des tubercules spinifères (fig. 2 et 5). Les pétales ambulacraires sout à peine sensilıles, même sous ce grossissement; cependant l'on remarque qu'ils affectent une forme plus ou moins arquée, mais sans s'arrondir ì leur extrémité. J'ai cru remarquer aussi que les pores des zônes porifères n’étaient pas réunis par des sillons transverses. La fig. 8 représente un exemplaire garni de ses soies; voes à l'oil nu, ces soies paraissent être trèsuniformes sur toute la surface; mais en les examinant au microscope, on trouve entre elles des différences de forme très-notables : celles de la face inférieure (fig. 8 a) sont cylindriques, subulées et beaucoup plus longues que celles de la face supérieure (fig. $8 b$ ), qui n’ont guère que la moitié de la longueur des précédentes, et sont renflèes á leur extrémité; mais les unes et les 
autres présentent la même structure, éest-ii-dire qu'elles sont marquées de carènes longitudinales hérissées de fines épiues. La figg. 7 est un grossissement de fig. 6, d’après un exemplaire un peu plus grand que celui de fig. 1: on y recommaît distinctement les dix carènes qui rayounent du centre à la périphéric et séparent les aires ambulacraíres des aires interambulacraires. Les auricules aussi y sont très-distinctes : elles correspondent aux aires interambulaeraires, qui sont ici, comme dans les Laganes, sensiblement plus étroites que les aires ambulacraires. Depuis l'impression des planches ci-jointes, j’ai eu l'oceasiou d'ohserver aussi l'appareil masticatoire; il est composé de cínq màchoires très-hautes, ì-pen-près comme celles de l'Echinocyamus pyriformis représenté dans les fig. 2\%. de la même planche. Uue conséquence naturelle de celle hauteur cousidẻrahle des mâchoires, c'est que les dents sont trés-arquées.

Celte espèce est fréqueute sur les côtes d'Angleterre. Les originaux de mes figures nóoni été communiqués par M. Ed. Forhes; ils proviennent des cìtes de l'île de Man et de la laie d'Edimbourg. 11. Fleming mieu a communiqué un exemplaire provenant des iles Slıetlant. On la dit tris-répandue en Europe; mais il importerait de revoir ces indications, des exemplaires en main, afin de ne pas confondre sous une mème dénomination des individus qui pourraient appartenir à des espices distinctes.

\section{Ecmiocrames stffolciexcis Ag.}

Tal. 27, fig. 9-13.

Sir. Fibularia suffolciencis Ag. Prodt. p. 18S. - DesMoul. Tabl. syn. p. 241.

Voisine à bien des égards de l'E. pusillus, cette petite espèce en diffère cependant par sa forme plus déprimée et plus élargie (fig. 11) qui la rend à peu près circulaire, tandis que l'E. pusillıs est bien plus oroïde. Quant aux détails de la structure du test, ibs sont sensiblement les mèmes dans les deux espèces, ainsi que le montrent les dessins grossis de fig. 10 et 13 comparés à ceux de fig. 2 et 5 . Les pétales ambulacraires sont peu distincts, mais l'on remarque cependant quils ne s'arrondissent point à leur extrémité. La bouche est beancoup plus grande que l'anus et situće au centre de la face inférieure, qui est légèrement déprimée. Les lubercules qui revétent la surface du test sont très développés, sans cependant être aussi gros que ceux de l'E. pusillus, 
Cette espèce a élé trouvée dans le Crag rouge d'Angleterre à Sutton dans le Suffulli. J'en ai vu de nombreux exemplaires dans la collection de M. Wood, qui possède en outre plusieurs autres espèces encore inédites de ce genre, provenant ẻgalement du Crag. L'exemplaire figuré ní a été communiqué par M. Woodward fils; il est d'une teinte brun foncé, comme beancoup de lossiles de cette localité. Cette couleur est due aux parties ferrugineuses que contient ce terrain.

\section{Echinocyanus axgcloses Leske.}

Tab. 27, fig. 14-18.

Syo. Echinocyamus angulosus Leske ap. K1. p. 215.

Fibularia angulosa DeBl. Dict. sc. nat. T. 16, p. 512. ... E. Desl. Enc. 'T. 2, p. 390. - DesMoul. TalJl. syn. p. 236. - Lam. T. 3, p. 301.

La forme de cette espéce est tantòt subpentagonale, tantôt plus ou moins ovale ; le côté anlérieur est un peu moins large que le còté postérieur, qui est en outre tronqué ou subtronqué en arrière; la liauteur est moyenne; la face supérieure est médiocrement bombẻe; les bords sont épais. La face inférieure est ordinairement un peu déprimée, et c'est an centre de cette dépression qu'est située l'ouverture buccale. Les pétales ambulacraires ne montrent aucune tendance à s'arrondir à leur extrémité ; c'est à peine s’ils sont un peu arqués à leur origine, près de la rosette apiciale. Les aires interambulacraires, dont on distingue fort bien les sutures à la lace inféricure (fig. 16), sont très étroiles, car elles n'ont guẻre que le quart de la largeur des aires ambulacraires. Les fig. 17 et 18 représentent lintérieur de cette espéce avec ses cloisons divergentes, qui ne permettent pas de douter que ce ne soit un Echinocyame. La fig. 17 montre la face interne du plancher supérieur, la fig. 18 la face interne du plancher inférieur avec les ciny auricules qui entourent l'ouverture buccale.

Cette espéce lıabite les côtes d'lrlande. J'ai recueilli l'exemplaire figuré avec plusieurs autres petites coquilles marines dans l'intérieur d'un Murex de la baie de Belfast. Je la rapporte i l'Echinocyamus angulosus de Leske, parce qu'elle m'a paru correspondre le mieux il la descriplion qu'en donne cet auteur. Les naturalistes qui possedent l'ouvrage de van Phelsum déciderout si mon espèce est réellement identique avec celle de l'auteur hollandais. 


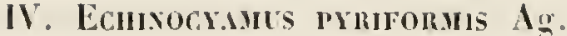

Tah. 27, fig. 19-2?.

Srs. Fibularia pyriformis Ag. Catal. syst. Ectyp. Mus. Neoc. p. 6.

Quoique fossile, cette espèce ressemble si fort a l'E. angulosus, quil m’a été impossible dans lorigine de l'en distinguer spécifiquement. Il est vrai que sa forme est en général moins anguleuse et plus pyriforme, et que dans la plupart des exemplaires, le côté antérieur n’a guère que la moitié de la largeur du côté postérieur ; mais celte différence ne pouvait à elle seule constituer à mes yeux un caractère spécifique, attendu que javais reconnu des passages incontestables entre ces direrses formes. Ce ne fut qu'après aroir examiné l'intérieur de ces deux espèces que je reconnus quielles élaient ríellement distinctes; la principale différence consiste dans l'épaisseur du test qui est assez considérable dans l' $E$. pyriformis, tandis que le test de l' $E$. angulosus est d'une ténuité extrême.

La surface prẻsente une granulation très homogène, et quoique l'espèce soit plus grande que l'E. musillus, les tubercules spinifères sont cependant sensiblement plus petits. Les pétales ambulacraires, d'abord très distincts près de la rosette apiciale, se perdent insensiblement vers le bord, el l'ou ne remarque en eux aucune tendance à sefermer. Les pores oviducaus, au nomlore de quatre, sont petits et rapprochés. Les pores ocellaires ne sont pas visibles, sans doute a cause de leur extrème petitesse. La fig. 2 ł représente l'appareil masticatoire sous ses différentes faces, en a par la face inférieure, en $b$ par la face supérieure, les cinq mâchoires étant réunies. La mâchoire postérieure se fait remarquer par son excessive largeur, qui est à peu près double de celle des autres màchoires. Les autres figures représentent le profil de rette même mìchoire, vu de côté en $d$, par derrière en $c$, et par devant en $c$.

Celle espèce est très fréquente dans le terrain tertiaire de Grignon. Je pense que c'est le Scutella inflata de M. DeFrance; mais je n'oserais l'affirmer, n'ayant pas ru d'exemplaire original de cette espèce. S'il en est ainsi, le nom d'Echinocyamus pyriformis devra être remplací par celui dEchinocyumus inflatus. 


\section{Echinocrants altavillexsis Ag.}

Tab. 27, fig. 25-28.

Srr. Scutella altavillensis DeFr. Dict. sc. nat. T. 48, p. 231. - DeB1. Zooph. p. 202. - Ag. Prod. p. 188. - Desilonl. Tabl. syn. p. 234. - Lam. T. 3, p. 286.

Fibularia altavillensis Cat. syst. Ect. Mus. Neoc. p. 6.

La forme de cette espèce est en général subcirculaire; le côté postérieur est tronqué, le côté antérieur tantòt arrondi, tantòt rostrẻ. La face supérieure est aplatie et légèrement inclinée d'avant en arrière, ensorte que la plus grande hauteur est au bord antérieur (fig. 27). Les pétales aṇbulacraires sont quelque peu renflés près de la rosette apiciale et arqués à leur origine ; mais ils ne se ferment pas à leur extrémité (fig. 26). Les pores génitaux, au nombre de quatre, sont situés au sommet des aires interambulacraires, dans une petite dépression, du milieu de laquelle le corps madréporiforme s'élève sous la forme d'un petit bouton légèrement saillant. La bouche est circulaire et située dans une petite dépression au centre de la face inférieure. L'anus est excessivement petit (fig. 28).

Cette espèce se trouve dans le terrain tertiaire de Hauteville, oủ elle a été recueillie par M. DeFrance, qui l’a décrite sous le nom de Scutella altavillensis.

\section{Echivocyanus obruses Ag.}

Tab. 27, fig. 29-32.

S.s. Fibularia obtusa Ag, Cat. syst. Ect. Mus. Neoc. p. 6.

Au premier abord, cette espèce ne paraît différer de l'E. altavillensis que par sa forme plus allongẻe et plus ovoïde. Cependant il est un autre caractère qui lui est particulier, et qui, ả mon avis, est plus important que la forme générale; c'est que les pétales ambulacraires, au lieu d'ètre arqués, sont droits dans toute leur longueur, et disparaissent près du bord sans se courber ni en dehors, ni en dedans; ce caractire ressort d'une manière trés distincte de la comparaison 
de fig. 30 aree la fig. grossie de l'espèce précédente (fig. 26). La face inférieure est légèrement concave, la boucle est circulaire, ainsi que l'anus, qui est situé à moitié clımin entre l'ouverture buceale et le hord postérieur. La face supérieure présente la même déclivitẻ uniforme que nous avons signalée dans l'espèce précédente, ensorte que le point eulminant est au bord antérieur (lig. 31). Les pétales sont aussi légèrement saillans.

Il est probable que eette espèce a été confondue plus d'une fois avec l'E. allavillensis qui se trouve aree elle dans les mêmes localités. Loriginal de mes figures provient du terrain tertiaire de Hauteville; il ma été communiquué par Mr. Michelin.

VI. Ecingocranus sicules $\mathbf{A g}$.

Tab. 27, fig. 33-36.

Srx. Fibularia sicula Ag. Cat. syst. Ect. Mus. Neoc. p. 6.

Il se pourrait que cette espèce ne fùt qu'une variété de l'E. pyriformis décrit ci-dessus. Cependant, comme je sais par expérience combien il est facile de se tromper dans l'identification des espéees et surtout des espéces tertiaires, j’ai eru devoir séparer provisoirement l'espèce sicilienne tertiaire, dont il est ici question, de celle des terrains de Grignon, par la raison qu'au lieu d'ètre pyriforme, elle est ovoïde, légèrement rostrẻe en avant, tronquée en arrière, et que la différence de largeur entre le eòté antérieur et le côtẻ postérieur n’est pas aussi grande que dans l'espèce précitée. Quant aux pétales ambulaeraires, ils sont execssivement gréles. Les zones porifères ne montrent aucune traee de sillons transverses, ni aucune tendance à converger à leur extrémité.

Cette espèce provient du terrain tertiaire de Sicile. L'original de ma figure m'a été communiqué par M. Deshayes. 
VIII. Echrochands axwosir Mer.

Tal). 2T, fig. 3T-40.

Srx. Fibularia Annonii Merian Catal. mansc. du Musée de Bâle.

Knotr II, 2, p. 180, Tab. E, II, fig. 8.

Cette espèce a déjả été décrite et figurée par linorr, et j’ai mème lieu de croire que l'original de cet auteur est le mème que celni qui a servi à mes figures. Elle se distingue de toutes ses congénères par sa forme circulaire, qui semble la rattacher plus directement aux Scutellines; mais elle n'en est pas moins un véritable Echinocyamus, attendu que l'anus est à la face inférieure. Un autre caractère qui lui est propre et qui ne se trouve pas suffisamment indiqué dans la fig. 38 , c'est que les pétales ambulacraires sont plus saillans que dans aucune autre espéce de ce genre; de plus ils sont très larges, distinctement arrondis et ont une tendance très marquée à s'arquer à leur extrémité sans toutefois se fermer. On remarque aussi entre les zones poriferes des traces distinctes de sillons transverses. La roselte apiciale montre quatre pores génilaux très distincts. Les pores ocellaires ne sont pas visibles. Le point le plus éleré est an centre de la face supérieure qui présente par conséquent une déclivitẻ uniforme dans toutes les directions. La bouche est centrale, petite el circulaire. L'anus, encore plus petit, est situé entre le bord postérieur et l'ouverture buccale.

Celte espèce provient du terrain pisoolitique de Vérone. Tous les exemplaires que j’en ai vus et qui m’ont été communiqués par M. Mérian, sont d'une teinture rougeâtre, comme tous les fossiles de ce terrain ferrugineux; ils sont déposés au Musée de Bàle et faisaient jadis partie de la collection d'Annone que Knorr a illustrée.

\section{Echivocranus alpives Ag.}

Tab. 27, fig. 41-43.

Srn. Fibularia alpina Ag. Descr. des Ech. foss. de la Suisse, $1^{\mathrm{re}}$ part. p. 74, Tab. 12, fig. 1-3.

Cette espèce, que j’ai décrite et figurée dans ma Description des Echinodermes fossiles de la Suisse sous le nom de Fibularia alpina, se fait remarquer par sa forme réguliérement ovale et par 
la position de l'ourerture anale, qui est très rapprochée du hord postérieur. La face supérieure est très bonbée; la face infërienre est lëgërement concave; l'ouverture buccale qui en occupe le centre, est circulaire. Hais ce qui rend surtout cette espèce intéressante, c’est son gisement. Je n'en connais que deux exemplaires qui font partie du Musẻe de Berne; ils ont été recueillis

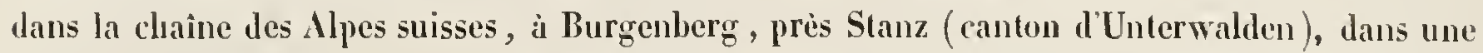
sorte de conglomérat fossilifère noir appartenant au terrain crétacé et contenant une quantité de fossiles triturés, entre autres une grande nummulite.

\section{Echixocrinus imbiguts Ag.}

Tab. 27, fig. 14-47.

Sis. Scutlla ambigua Expl. de la PJ. 153, de l’Encycl. méth. fig. 1.

Le caractère saillant de cette espèce, dont l'Encyclopédie méthodique a donné une bonne figure, est facile à saisir : il consiste dans l'épaisseur extraordinaire du bord (fig. 46); en l'evanche, la face supérieure est complètement plate. Les pétales ambulacraires sont distinctement arqués, mais ne se ferment point à leur extrémité. La fig. 4j représente l'origine des pétales sous un grossissement de plusieurs diamètres. On roit par celle figure que les zones porifères sont d’une étroitesse extrème comparées à l'espace intermẻdiaire; ce caractère, joint à l'absence de sillons transverses, sert à distinguer notre espèce de l'E. occitamu décrit ci-dessous. La face inférieure présente une dépression centrale assez marquée dans laquelle est située la houche. L'anus est au milieu de l'espace entre celte dernière et le bord postérieur.

M. Mérian m’a communiqué de fort bons exemplaires de cette espèce, provenant d'Alençon. Le Yusée de Pariš en possède également plusieurs exemplaires trẻs-bien conservés.

J'ai tout lieu de croire que celte espèce est synonyme du Scutella hispana de M. Deliance, lont je n’ai cependant pas pu constater lidentité, faute d'exemplaires originaux. 


\section{Echirocrands occitares Ag.}

Tal. 27, fig. 48-58.

Srx. Scutella orcitana DeFr. Dict. sc. nat. Tom. 48, p. 231.-Deß1. Zooph. p. 202.-Ag. Prodr. p. 188. Lagana occilana Ag. Cat. syst. Ectyp. Mus. Neoc. p. 6.

Il est très facile de prendre le change sur cette espèce et de la confondre avec les Laganes du type du Lag. Bonani, à cause de son bord renflé et de ses longs pétales ambulacraires qui atteignent presque le pourtour du test. Je suis moi-mème tombé dans cette erreur, et ce n'est quiapris avoir ouvert un exemplaire que je me suis assuré qu'elle appartient bien réellement au genre Eclinocyame; car les lames rayonnantes qui séparent les aires ambulacraires des aires interambulacraires sont aussi distinctes qu'il est possible de l'ètre. Mais ces lames présentent une prarticularité de structure qui ne se retrouve point dans les autres espèces : au lieu d'ùtre unies, elles sont hérissẻes de limes latérales ou de processus nombreux qui se présentent comme des épines adhérentes aux cloisons (fig. 53). Ces épines ne se voient pas au plancher supérieur (fig. 52), car les cloisons ne l'atteignent que sur ses bords. Les auricules entourent le pourtour de la bouche, mais elles sont proportionnellement bien moins larges que dans les petites espèces que nous arons décrites plus laaut, tels que les $E$. pusillus, angulosus et pyriformis.

La forme générale de l'E. occitamus est subcirculaire, légèrement tronquée en arrière, comme le montrent les fig. 48 et 49 qui représentent deux individus de différens àges. La face supérieure est à peu près plate ; aussi le bord est-il très-épais (fig. 50). Les pétales ambulacraires se font remarquer par leur longueur extraordinaire; ils alteignent à peu près le bord du test, mais sans se fermer à leur extrémité; cette dernière particularité est très importante, car elle est le principal caractère qui distingue extérieurement cette espèce des Laganes. En second lien, les pores des zones porifères sont réunis par des sillons Iransverses obliques très distincts; or nous avons vu par les descriptions qui précédent que ces sillons ne se rencontrent point dans les autres espèces d'Echinocyames, ou du moins n’y sont que très rudimentaires. Les pores génitaux sont au nombre de quatre, comme à l'ordinaire; les pores ocellaires sont rarement reconnaissables. La face inférieure est légèrement déprimée; la bonche, de forme sulpentagonale, en occupe le centre. L'anus est circulaire et situé au milieu de l'espace entre le bord postérieur et l'ouverture buccale. Les aires interambulacraires sont beaucoup plus étroites que les aires ambulacraires, 
notamment à la face infërieure, ou elles sont ordinairement indiquées par einq bandes qui rayonnent dı centre a la périphérie et daus l’une desquelles s'ourre l’anus (fig. 51). La surface entière dn test est revêtue de tubercules tries muiformes sur toutes les faces.

L'appareil masticatoire est remarquable par sa hauteur extraordinaire (voyez les fig. 56 , 57 et 58, qui représentent les différentes taces de l'une des màchoires, vue de profil en fig. 57, par derrieire en fig. 58 par devant en fig. 56). Cette hauteur est le résultat du développement extraordinaire que prennent les lames calcaires qui entourent la cliarpente de la michoire. La fig. 5̌ représente l'appareil masticatoire vu d'en bas, les cing màchoires étant réunies; la fig. 5.5 le représente vit d'en hant.

Cette espèce paraît ètre fréq̨uente dans la craie supéricure. Les originaux de mes figures m’ont été communiqués par M. Aleide d’Orbigny, qui les a recueillis á Royan, département de la Gironde.

\section{REMARQUES ADDITIONNELLES SUR LES ECHINOCYAMES.}

Il ne peut y aroir de doute sur les affinités génériques des espèces figurées et décrites par Goldfuss comme appartenant au genre Echinoneus.

L'Echinoucus scutatus Munst. (Goldf. Tal). 12, fig. 11), du grès marin tertiaire de Bünde, est un vrai Echinocyame très voisin de mes Echinocyamus altavillcusis et obtusus. Cependant, comme jen'en possède pas d'exemplaire authentique, je u’ai pas cru devoir me prononcer sur les rapports de ces especes. Jignore quels motifs ont pu engager MI. Des》loulins à réunir comme synonymes les Echinocyamus scutatus, ambiguus et occitanus.

L'Echinoncus placenta de Goldfuss (Tah. 42, fig. 12), du calcaire crétacé de la montagne de St-Pierre de Maestricht, est un vrai Echinocyame très voisin de mon Echinocyamus pyriformis; il parait n'en différer que par sa forme plus angulense.

L'Echinoncus ovatus Münst. (Goldf. Tab. 42, fig. 10) des marnes sableuses tertiaires d'Astrupp, près d'Osnabrücli, et de Wilhelmslıölıe, près de Cassel, est également un vrai Echinocyame, roisin de mon Echinocyamus suffolcicusis, mais constitnant évidenument une espèce particulıère que je n’ai pas encore vue en uature.

L'Echinoneus sulglobosus Goldf. (Tab. 42, fig. 9) est une véritable Filunlaire.

Le Fibularia Francii de DesIloulins, du terrain tertiaire de Paris, ancquel il donne pour synonyme le Scutclla inflata DeFr., est très vraisemblablement mon Echinocyamus pyriformis. 


\section{$-153-$}

J'ignore ce que peurent ètre les Fibularia australis, affuis, et subcaudala de M. DesMoulins.

Le Scutella fibularis Lam., auquel M. Dujardin a donné pour synonyme, dans la seconde édition des Animaux sans vertebres, les Echinoneus ovalus Munst. et Scutella hispana DeFr., est très probablement un véritable Echinocyame; il serait fort possible qu'il fìt double emploi avec l'une ou l'autre des espèces que j'ai décrites. Mais il sera difficile de s'en assurer, les originaux de Lamarck ne s’étant pas retrouvés dans les collections de Paris.

Les nombreuses espéces rapportées par van Phelsum à son genre Echinocyamus paraissent appartenir en grande partic au genre Fibularia; tels sont au moins ses Echinocyamus mucleus, latlyyrus el cramiolaris.

Quant au Fibularia tarentina Lam., espéce vivante de la Méditerranée, je pense que c'est un vèritable Echinocyame, quoique je n'aie pu m'en assurer par des exemplaires authentiques. Il en est de même du Fibularia trigona Lam. et du Fibularia inaequalis de MI. de Blainville. Le Fibularia ovulum de Lamarck est très probablement synonyme de l'Echinocyamus pusillus.

L'Echinocyamus indéterminé, mentionné dans mon tableau de la distribution géographique des espèces, comme habitant la Méditerranée, est une trẻs petite espèce, voisine de l'Echinocyamus pusillus. M. Desor en avait recueilli, il y a quelques années, plusieurs exemplaires dans l'intérieur d'un Spatangue provenant des côtes de Sicile; malheureusement ces exemplaires ont été égarés, ensorte que je n’ai pu en domner la description. 


\section{CHAPITRE XIII.}

\section{DU GENRE MOULINIA Ag.}

Ce petit genre constitue un type tout-à-fait particulier et fort différent de tous les genres dont nous arons trailé jusqu’à préseut, mais qui cependant parait se rapprocher sous plusieurs rapports des Echinocyames et des Scutelles. Je l'ai dédié à M. Clı. DesMoulins, dont les travaux sur les Echinodermes ont si puissamment contribué à l'avancement de nos connaissances sur cette classe des Rayonnés. Je n’en connais encore qu’une seule espèce,qui est le

\section{Mochisia cassidulivi Ag.}

Tab. 22, fig. 1-6.

Srr. Scutella cassidulina DesIloul. Tabl. syn. p. 232.

Le caractère qui frappe le plus dans cet Oursin, c'est la présence de sillons profonds entre les différentes rangées de plaques, ensorte que le test se trouve divisé extérieurement en vingt sections très marquées; ce qui fait que le bord est fortement ondulé. Les sutures transversales sont également indiquées par de petits sillons, qui cependant sont moins profonds que les sutnres des rayons. Ces sutures ou dépressions ne sanraient être le résnltat d'une altération, car dans ce cas les tubercules et l’épiderme auraient disparu; or, loin de là, tous deux sont parfaitement conservés; les tubercnles surtout sont trẻs saillans et fort distincts. Les pétales ambulacraires divergent fortement à leur extrémité ; les pores ne sont pas réunis par des sillons transverses; ils ne s'ouvrent pas non plus dans des plaques particulières, comme c'est le cas de la plupart des antres genres; mais ils sont percés dans les plaques mèmes de l'aire anbulacraire, absolument comme les plaqnes des Galérites, avec cette différence quils sont limités 
à la face supérieure. On pourrait dès lors se demander si cette espèce appartient bien réellement au groupe des Scutelles et s'il ne vaudrait pas mieux la reporter avec les Fibulaires dans le groupe des Galérites. Il est incontestable que l'affinité est grande entre ces deux genres, et si je me suis décidé à l'associer au groupe des Scutelles, e'est eu égard à sa forme très aplatie, qui rappelle tout particuliẻrement les Scutellines. La bouche est centrale et circulaire. L'anus, situé à la moitié de la distance entre le bord et la bouche, est également circulaire et de grandeur moyenne. Je n'ai pas eu l'oceasion d'observer la structure de l'intérieur du test, ni l'appareil masticatoire.

L'espèce dont il est ici question, est de forme subcirculaire, un peu plus longue que large, très plate, à bords minces, ondulés et arrondis. Les fig. 1, 2 et 3 la représentent de grandeur naturelle par les faces supérieure, inférieure el de profil. Afin de faire mieux ressortir les détails du test, j’ai représentẻ ces mêmez figures sous un grossissement de deux diamètres dans les lig. 4,5 et 6.

La fig. 4 a montre une portion de la surface sous un grossissement plus consilérable encore, afin de donner une idée de la disposition des tubercules spinifères, qui sont distinctement mamelonnés, perforés et entourés d'un cercle de tubercules miliaires qui paraissent être conformés de la même manière. Mais un caractère particulier qui ne se retrouve dans aucun autre ģenre du groupe des Scutelles, pas même dans les Echinocyames, c'est qu'au lieu d'être entourés d'une iréole lisse, les tubercules s'élèvent immédiatement de la surface du test, ce qui les fait paraitre si saillans. Je n’ai pas pu observer la rosette apiciale; mais je ne donte nullement qu'elle ne présente encore quelque caractère particulier qui permette d'établir d'une manière plus complète les affinités naturelles de ce genre.

Je ne connais cette espèce que par un seul exemplaire, que je dois à l'obligeance de $\mathrm{M}$. DesMoulins. Il provient des còtes de la Martinique, oủ celte espèce a èté découverte par MI. Rang. 


\section{TABLEAU DE LA DISTRIBUTION GÉOLOGIQUE ET GÉOGRAPHIQUE DES ESPĖGES DU} GROUPE DES SGUTELLES.

\section{1). Espèces de l'éporue crétacée.}

Scutella Rogersi, Mort . C Craie blanche, . Amérique septentrionale.

Echinocyamus alpinus, Ag., . Craie alpine,. . Stanz, canton d'Unterwalden.

" occitanus, Ag., Craie supérieure - Royan (départ. de la Gironde).

\section{2). Espèces de l'époque tertiaire.}

Scutella Brongniarti Ag., . Calcaire grossier, Grignon.

* Smithiana Ag., . . Molasse . . Lisbonne.

" subrotunda Lam., . Terrain tertiaire,. Bordeaux.

" Faujasii DeFr., . ” . . Département de la Sarthe.

" producta Ag., . . n . . . Saumur.

* truncata Val., . Faluns . . Anjou, Touraine.

" propinqua $\mathrm{Ag}_{\mathrm{g}}$, . . ” . . . Touraine.

" striatula M. de Ser., " . . . St. Paul, près Dax.

" paulensis Ag., . . „ . . . St. Paul, près Dax.

" stellata Ag., . . . n . . . Touraine.

" subtetragona Grat., . " . . . Dax.

Echinocyamus pyriformis Ag., Calcaire grossicr, Grignon,

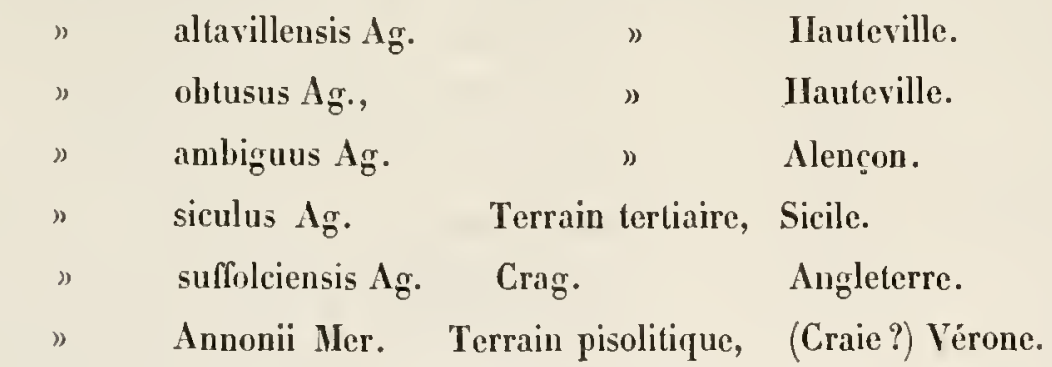

Scutellina nummularia $\mathrm{Ag}$., Calcaire grossier, Grignon.

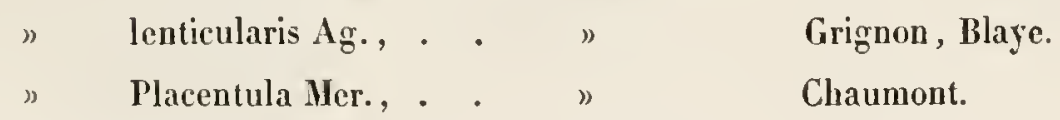


Scutellina supera Ag. - . . Calcaire grossier, Grignon.

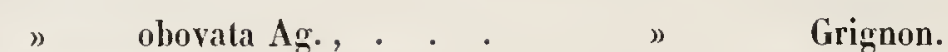

Echinarachnius incisus $A g .$, . „ Iauteville.

Laganum tenuissimum Ag., . . ” Blaye.

" reflexum $\mathrm{Ag}$. , . . " Blaye.

Amphiope lioculata Ag., . . . Faluns, . . Touraine, Bordeaux.

" perspicillata $\mathrm{Ag.}$, . . ” $\quad$ Rennes.

Runa decemfissa Ag. . . . . . Terrain tertiaire, Bordeaux.

"Comptoni Ag. . . . . » $\quad$ Palerme.

\section{3). Espèces vivantes.}

a). Des mers boréales, de la mer du nord et de TOcéan allantique, jusquau $45^{\circ}$.

Echinarachnins Parma Gr., . . . . Canada.

» atlanticus Gr. , . . . Terre-Neuve.

Arachnoïdes Placenta Ag., . . . Foulah (Iles de Shetland).

Echinocyamus pusillus Flem., . . . Mers d'Irlande et côtes d'Ecosse.

» angulosus Leslie, . . . Côte d'Irlande.

b) De la Méditerrane.

Echinocyamus (espèce indéterminëe.)

c) Mer des Antilles, golfe du Mexique, ềtes du Brèsit et côtes oceidentales d'Afrique.

Rotula Rumpliii Kl., . . . . . . Sćnégal.

Mellita quinquefora Ag. . . . . . Porto-Rico.

" testudinata Kíl., , . . . . . Vera-Cruz.

" hexapora $\mathrm{Ag.} \mathrm{,} \mathrm{.} \mathrm{.} \mathrm{.} \mathrm{.} \mathrm{.} \mathrm{Antilles?} \mathrm{(DesMoulins).}$

" similis $\mathrm{Ag}$. . . . . . . Porto-Ricco.

Encope Valenciennesii Ağ. . . . . . La Martinique.

" subclausa $\Lambda_{g}$. . . . . . . . Côtes du Brésil.

" grandis $\Lambda$ g., . . . . . . La Martinique.

Laganum Lesueurii Val. . . . . . . Guadeloupe.

Moulinia cassidulina Ag. . . . . . . La Martinique. 
d) Ocean indien, mer rouge, golfe persique et golfe du Bengale.

Encope emarginata $\mathrm{Ag}$. , . . Ile de Bourbon ou Philippines?

Lobophora bifora $\mathrm{Ag}$., . Còtes de la Cafrerie?

» bifissa $\Lambda \mathrm{g}$. , . . Mer rouge.

" aurita $A g ., \quad$. Mer Rouge.

e) Iles de la Sonde, Australic et Polynésic.

Laganum Bonani Kl. . . . Nouvelle-Guinée. Vanicoro.

" depressum Less. . Ile de Bourou.

" decagonum Less. . Ile de Waigiou.

» tonganense Q. etG.,. Ile de Tonga.

") stellatum $\Lambda$ g., . . Nouvelle-Galles du Sud.

" rostratum Ag. . . Nouvelle Zélande.

" Peronii Ag. . . . Mers australes.

f) Côtes occidentales de l'Amerrique tropicale et iles Gallopagos..

Encope tetrapora Ag. . . . Ues de Gallopagos (Còte occidentale d'Afrique, DesMoulins).

" Stokesii Ag. , . . . Guayaquil et îles de Gallopagos.

g) Espèces d'origine encore inconmue.

Rotula Augusti Kl.

Mellita lobata Ag.

Encope micropora $\mathrm{Ag}$.

" perspectiva VaJ.

) cyclopora $\mathrm{Ag}$.

" oblonga Ag.

"Michelini $\mathrm{Ag}$.

Lobophora truncata Ag.

Echinarachnius Rumphii Ag., (Amboine?)

Laganum ellipticum $\boldsymbol{\Lambda}$.

") elongatum $\mathrm{\Lambda g}$.

" orbiculare $\mathrm{Ag}$.

" marginale $\mathbf{A g}$. 


\section{$-141-$}

Il résulte de ces tableaux que dès leur première apparition, les Scntelles ont habitẻ le noureau aussi bien que l'ancien monde, mais qu’elles ont élé beaucoup plus nombreuses en Europe durant l'ẻpoque tertiaire que maintenant. Quant anx espèces vivantes, qui diffẻrent toutes spécifqquement, et même pour la plupart génériquement des espèces fossiles, il est curieux que les Echinarachnius, les Arachnö̈des et les Echinocyamus, qui se rapprochent le plus des fossiles, habitent seulement les mers du Nord, tandis que les Mcllites et les Moulinies caractérisent les mers des Antilles et le golfe du Mexique, les Rotulcs les côtes occidentales d'Afrique, et les Lobophores l'Océan indien. Les Encopes et les Laganes sont répandues dans toutes les mers tropicales, les Encopes surtont sur les còtes orientales et occidentales d'Amérique, et les Laganes dans le grand Océau.

Le nombre total des Scutelles qui me sont connues maintenant est de 73, dont 33 fossiles el $\mathbf{4 0}$ vivantes. 


\section{CONSPECTUS GENERUM ET SPECIERUM SCUTELLARUM.}

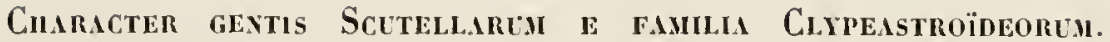

Testa depressa, circularis vel ovata. Os centrale, rotundatum vel subangulatum. Anus inferus vel marginalis. Ambulacra petaloïdea.

I. Genus ROTULA Kilein. Discus orbicularis , margine posteriore digitatus; petala ambulacrorum magna, elongata, aperta. Quatuor foramina genitalia in sulcis corporis madreporiformis sita. Os medium, anus inferus; sulci ambulacrales inferiores dichotomi, vix ramosi.

1. Rotula Rumphii Ḱlein (Tab. 1). Disco convexiusculo, petalis angustis, elongatis, apertis ; digitis numerosis, cylindricis.

2. Rotula Augusti Ílein (Tab. 2, fig. 1-10 et Tab. 4, fig. 1-6). Disco depresso; petalis latioribus, arcuatis, apertis; digitis dichotomis depressis.

II. Genus RUNA Agass. Testa ovata; area interambulacrales angustae, incisuris marginalibus sejuncta; petala angusta, divergentia.

1. Runa Comptoni (Tab. 2, fig. 11-19) Agass. Testa lata, ovata; ore medio, magno, elliptico; ano parvo, margini posteriori propinquiore.

2. Runa decemfisa Agass. Testa elongata, margine flexuoso, ano ori propinquiore.

III. Genus MELLITA K̉lein. Discus suborbieularis; petala lata, arcuala, subclausa. Foramina genitalia quatuor in angulis corporis madreporiformis. Lunula elongate in areis ambulacralibus et in area interambulacrali posteriori. Os parvum, medium, sinuosum. Anus pyriformis ori proximus. Sulci ambulacrales inferiores ramosissimi.

1. Mellita quinquefora (Tab. 3) Agass. Disco suborbiculari postice latissimo, lunulis quinque; petalis latis, areuatis, subclausis. Ore sinuoso; ano magno pyriformi ; sulcis ambulacralibus inferioribus latis, ramosissimis.

2. Mellita testudinata Klein (Tab. 4 a , fig. T-9). Disco suborbiculari, antice latissimo; lunulis quinque; petalis latis, sulsclausis.

3. Mellita hexapora Agass. (Tab. 4, fig. 4-7, Tal. 4 a, fig. 11-12). Disco suborbiculari valde depresso; lunulis sex, angustis; lunula area posterioris imparis angustissima; petalis parvis, clausis ; basi subrequali. 


\section{$-146-$}

4) Mellita similis Agass. (Tab. 4, fig. 1-3). Diseo suborbieulari vel subquinquangulari, lunulis sex; basi undulata; sulcis ambulacralibus valde ramosis.

5. Mellita lobata Agass. (Tab. 4 a, fig. 13, et Tal. 16, fig. 4-7). Diseo suborhiculari, lunulis sex; lunulis ambulacralibus posticis apertis; petalis brevibus, ovatis, sulsclausis; poris genitalibus ocellaribusque vere distinetis.

IV. Genus ENCOPE Agass. Discus magnus orbicularis, vel ovatus. Aperture vel lunule sex. Petala magna, clausa vel subelausa. Pori genitales quinque, in angulis corporis madreporiformis. Os eentrale, sinuosum. Anus elongatus, ori proximus. Sulei ambulacrales inferiores ramosissimi.

1. Encope emarginata Agass. (Tah. 10). Disco suborbiculari, postiee truneato; petalis ambulacralibus magnis, latis, subelausis ; lunulis ambulacralibus clausis vel subclausis ; lunula arex interambulacralis elongata.

2. Encope tetrapora Agass. (Tab. 10 a, fig. 1-3). Diseo orbieulari ; lunulis ambulaeralibus postieis angustis, apertis; petalis latis, ovatis, subclausis.

3. Encope micropora Agass. (Tab. 10 a, fig. 4-8, Tab. 19 a, fig. 7). Disco orbiculari; lunulis ambulacralibus clausis; lunula postiea minima; petalis latissimis, ovatis, subelausis.

4. Encope perspectiva Val. (Tab. 10 b, fig 1-5). Disco orhiculari; lunulis ambulaeralibus clausis, ovatis; lunula postica maxima, ovata; petalis anticis breviorilus, ovatis.

5. Encope cyclopora Agass. (Tab. 10 b, fig. 6-9). Disco subeirculari, postice latissimo ; lunulis ambulacralibus posticis apertis, antieis ovatis, clausis ; lunula postica magna sulcirculari; petalis elongatis; angulis corporis madreporiformis prominentibus; basi plana; sulcis ambulaeralilus ramosissimis.

6. Encope oblonga Agass. (Tab. 9). Disco elliptieo ; lunulis ovatis, clausis, margine superiori incrassatis; lunula postica maxima ; petalis postieis elongatis, antieis brevioribus, latis ; angulis corporis madreporiformis prominentibus.

7. Encope Valenciennesii Agass. (Tab. 7 et 8). Diseo maximo convexiuseulo; sinulus ambulacralibus latis, apertis ; lunula postica elongata, margine superiore inerassata; petalis posticis elongatis, leviter incurvis, anticis latis, ovatis.

8. Encope subclausa Agass. (Tab. 5). Disco subovato; aperturis antice subelausis; lunula postica elongata, margine superiori leviter inerassata.

10. Encope Michelini Agass. (Tab. 6 a, fig. 9-10). Disco subovato, postice truncato, ill parte posteriore altiore; sinubus ambulaeralihus apertis ; lunula postiea parva, angusta. 
9) Encope grandis $\Lambda$ gass. (Tab. 6). Disco suborato, postice cmarginato margine crassissimo; simubus anbulacralilus latis, apertis; lumula postica clliptica, magna.

11. Encope Stokesii Agass. (Tab. 6 a, fig. 1-8). Disco orlhiculari convexiusculo ; sinubus in prima atate apertis, in adultis subclausis; petalis subovatis latis. Differt ab aliis specielus paricte intestinum sejungente nullo.

V. Genus LOBOPHORA'Igass. Discus suborbicularis, dualous incisuris vel lunulis in margine posteriore. Petala breviora, convergentia. Foramina genitalia quatuor, in angulis corporis madreporiformis. Os medium, simuosum. Anus parvus, margini propinquior quam ori. Sulci ambulacrales inferiorcs ramosi.

1. Lobophora bifora Agass. (Tab. 12). Disco sinuoso, postice valde dilatato, lunulis angustis clongatis; petalis latis, brevibus, truncatis.

2. Lobophora truncata Agass. (Tab. 11, fig. 11-16). Disco sinuoso postice truncato; lunulis elongatis; petalis brevibus, ovatis, clausis.

3. Lobophora bifissa Agass. (Tab. 13, fig. 2-6 et Tab. 14, fig. 12). Disco depressissimo, valde dilatato; incisuris posticis duabus; petalis latis, ovatis, clausis.

4. Lobophora aurila $\Lambda$ gass. (Tab. 13, fig. 1 et Tab. 14, fig. 3-7). Disco sinuoso, incisuris angustis, elongatis. Petalis subovatis, clausis.

VI. Genus AMPHIOPE Agass. Discus valde depressus; lunulis duabus rotundatis, posticis; petala ambulacralia lata, subovata, clausa, foramina genitalia quatuor. Os parvun ; anus margini postico propinquus.

1. Amphiope bioculata Agass. (Tab. 11, fig. 1-5). Disco suborliculari, postice truncato; lunulis subcircularibus ; petalis latis, ovatis, subclausis. Ano margini proximo; sulcis ambulacralibus ramosissimis.

2. Amphiope perspicillata Agass. (Tab. 11, fig. 6-10). Disco valde depresso, postice sub)rostrato; lunulis subcircularibus; petalis subovatis, acutis.

VII. Genus Scutella Lam. (Ag). Discus orbicularis, margine integro. Petala ambulacralia subovata, subclausa. Foramina genitalia quatuor. Sulci ambulacrales inferiores ramosi. Os medium sinuosum. Anus margini postico proximus.

1. Scutella subrotunda Lam. (Tab. 17). Disco suborbiculari, valde dilatato, margine postico subrostrato, truncato, in medio inciso; petalis elongatis, subclausis ; sulcis ambulacralibus inferioribus ramosissimis; ano infra margincm. 
2. Seutella truncata Val. (Tab. 16, fig. 1, 2, 3, 8, 9). Disco inflato; margine tenuissimo postice subrostrato, truncato; petalis latis, ovatis, clausis; ano a margine remoto.

3. Scutella propinqua Agass. (Tab. 16, fig. 11-16). Disco convexiusculo, postice truncato, rostrato; petalis ovatis; ano a margine valde remoto.

4. Seutella Brongniarti Agass. (Tab. 15, fig. 1-3). Disco subcirculari; margine postico lato, truncato, subrostrato; petalis latis, ovatis, clausis; ano margini postico propinquiore.

5. Scutella Fanjasii DeFr. (Tab. 15, fig. 4-6). Disco dilatato; margine crassissimo, pos_ tice angusto, rostrato, truncato; petalis latis; ano a margine remoto.

6. Sentella striatula M. de Sr. (Tab. 18, fig. 1-5). Disco tenui, subconico, postice rostrato, inciso; petalis parvis, ovatis; ano infra incisionem marginalem posticam.

7. Seutella produeta Agass. (Tab. 1S, fig. 6-10). Disco convexiusculo, postice valde rosIrato; petalis ovatis; ano a margine remoto.

8. Seutella paulensis Agass. (Tab. 19, fig. 8-10). Disco convexiusculo, valde dilatato, postice truncato, non inciso; petalis elongatis', subclausis; ano infra marginem.

9. Seutella stellata Agass. (Tab. 19, fig. 1-2). Disco convexiusculo; petalis magnis, latis, ovatis ; testa crassissima.

10. Sentella subtetragona Grat. (Tab. 19, fig. 7). Disco valde simuoso, subquinquangulato, postice truncato, inciso; petalis parvis.

11. Seutella Smithima Agass. (Tab. 19 a, fig. 5). Disco tenui, dilatato ; petalis latis, ovatis, clausis.

12. Scutella Rogersi Mort. (Tab. 19 a, fig. 1-4). Disco orbiculari, superne undato, margine crassissimo; petalis ovatis, non clausis; ano inter os et marginem medio.

VIII. Genus ECHINARACHNIUS v. Phels. Discus orhicularis, convexiusculus, margine integro; Petala lata, aperta. Foramina genitalia quatuor. Basis plana. Anus marginalis. Os circulare, medium. Sulci ambulacrales inferiores trifurcati.

1. Eehinaraehmius parma Gray (Tab. 20, fig. 7-18). Disco orbiculari, margine crasso, postice subtruncato; petalis latis, valde apertis; ano marginali.

2. Echinaraehmius Rumphii Agass. (Tab. 20, fig. 1-6). Disco subovali, margine crasso ; ano subntarginali; petalis latis, valde apertis.

3. Echimarachrius atlentieus Gray (Talb. 21, fig. 32-34). Disco circulari, margine tenui; petalis subovatis, convergentibus, non clausis; ano marginali. 
4. Echinarachnius incisus $\Lambda$ gass. (Tab. 21, fig. 29-31). Disco circulari; testa subconica; ano sub margine; petalis subovatis, valde apertis.

IX. Genus ARACINOIDES Kilein. Discus circularis. Anus supra marginem. Petala valde aperta. Foramina genitalia quinque. Basis plana. Os rotundatum. Sulci ambulacrales inferiores simplices, recti.

Arachnoüdes Placenta $\Lambda$ gass. (Tab. 21 , fig. 35- 12. Testa subconica, margine tenuissimo; areis anbulacralibus multo majoribus quam area interambulacrales, tuberculis per series obliquas dispositis; ano supra marginem.

X. Genus SCUTELIINA $\Lambda$ g. Discus orloicularis vel ovatus; intus parietibus radiantibus proditus. Anus marginalis vel supramarginalis. Petala aperta, poris non conjunctis. Os rolundatum.

1. Scutellina mummularia Ag. (Tab. 21, fig. 8-14). Disco orbiculari, valde depresso; basi plana; petalis apertis, leviter convergentibus; ano marginali.

2. Scutellina lenticularis $\Lambda$ g. (Tab. 21, fig. 20-23). Disco ovato, convexiusculo; loasi concava ; ano marginali.

3. Scutellina placentula Mer. (Tab. 21, fig. 1-7). Disco ovato, minimo, depresso; ano supramarginali.

4. Scutellina supera Ag. (Tab. 21, fig. 15-19). Disco ovato, convexiusculo, antice angustiore, ano supra marginem; basi concava ; ore magno, rotundato.

5. Scutcllina obovata Ag. (Tal). 21, fig. 2'-28). Disco ovato, depresso ; ano marginali.

XI. Genus LAGANUM Klein. Discus elongatus, subcircularis vel angulosus, margine tumido vel inflato. Basis plana. Os rotundatum. Anus infra marginem. Petala elongata, lanceolata. Foramina genitalia qualuor vel quinque.

1. Lagamm Bonami lilein (Tab. 23, fig. 8-12 et Tab. 22, fig. 25-29). Disco subquinquangulato, depresso, margine valde inflato ; petalis elongatis, lanceolatis, subclausis ; foraminibus genitalibus quinque; ano longitudinali, inter os et marginem medio; suleis ambulacralibus inferioribus ad dimidiam peripherian productis.

2. Lagamum depressum Less. (Tab. 23, fig. 1-7). Disco subdecagonali, postice truncato, antice dilatato, margine inflato; petalis elongatis, lanceolatis, subclausis ; foraminibus genitalibus quinque; ano transverso, margini postico propinquiore.

3. Laganum ellipticum Ag. (Tab. 23, fig, 13-15). Disco ovato, depresso, margine tumido; 
petalis elongatis, subclausis; foraminibus genitalibus quinque; ano transverso, margini postico propinquiore.

4. Laganum decagonum Less. (Tal. 23, fig. 16-20). Disco convexiusculo, subcirculari, sulsangulato; testa tenuissima, margine leviter inflato; petalis angustis, subclausis; foraminibus genitalibus quinque; ano margini postico proximo.

5. Lagamum temuissimum Ag. (Tab. 26, fig. 4-6). Disco ovato, postice truncato; testa tenuissima, margine antice inflato; petalis elongatis, postice apertis; ano postico.

6. Laganum reflexum Ag. (Tab. 26, fig, 1-3). Disco ovato, postice truncato, margine anlico reflexo maxime tumido; petalis longis, apertis ; ano postico.

7. Lagamun tonganense Quoy et Gaim. (Tab. 26, fig. 7-19). Disco convexiusculo, subovato vel subangulato, postice truncato, margine tumido; petalis elongatis, apertis, irregularibus; foraminibus genitalibus quinque; ano magno inter os et marginem posticum medio.

8. Lagamm Lesueuri Val. (Tab. 2', fig. 3-6). Disco convexiusculo, decagonali, antice dilatato ; petalis elongatis, apertis ; foraminibus genitalibus guatuor ; ano magno, margini postico propinquiore.

9. Laganem elongatum Ag. Ag. (Tab. 2r, fig. 1-2). Disco ovato, subangulato; antice rostrato, truncato; petalis convexiusculis ; foraminilsus genitalibus quatuor ; ano magno, margini postico propinquiore.

10. Lagamum rostratum $\mathrm{Ag}$. (Tab. 25). Disco convexiusculo, ovato, postice rostrato, margine crasso, non inflato; petalis elongatis, apertis; foraminilus genitalibus quatuor; ano margini postico proximo.

11. Laganum orbiculare Ag. (Tab. 22, fig, 16-20). Disco orbiculari, postice subrostrato, margine inflato; petalis lanceolatis, acutis, clausis; foraminibus genitalibus quatuor; ano postico.

12. Laganum marginale $\mathrm{Ag}$. (Tal). 22, fig. 11-15). Disco orato, tenuissimo, convexiusculo, margine inflato; petalis lanceolatis acutis; foraminibus genitalibus quatuor.

13. Lagamum stellatum Ag. (Tab. 22, fig. 7-10). Disco convexo, ovato ; petalis acutis ; foraminibus genitalibus quatuor, distantibus.

14. Laganum Peronii Ag. (Tab. 22, fig. 21-24). Disco alto, subcirculari, postice truncato; petalis ovatis; foraminibus genitalibus quatuor, maxime distantibus.

XII. Genus ECHINOCYAVUS v. Phel. Discus ovatus, depressus, intus parietibus 
radiantibus praditus. Petala aperta, recta vel ovata. Foramina genitalia quatuor. Basis plana vel concava. Os rotundatum, centrale. Anus infra marginem.

1. Echinocyamus pusillms Flem. (Tab. 27, fig. 1-S). Disco ovato, inflato, tuberculis maxinis ; ano inter os et marginem posticum medio.

2. Echinocyamms snffolciensis Ig. (Tal). 27, fig. 9-13). Disco ovato, depresso ; tulserculis luagnis.

3. Echinocyamus angulosus Leske (Tab. 27, fig. 14-18). Disco ovato, subinflato ; petalis angustis, apertis; testa tenui.

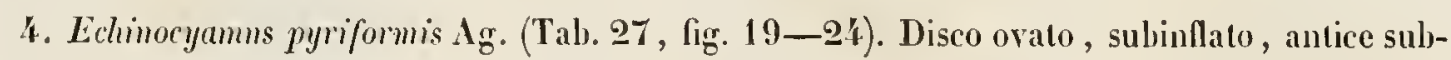
acuto, postice dilatato; petalis angustis, apertis ; testa crassiore.

5. Echinocyamus altavillensis $\Lambda_{\mathrm{g}}$. (Tab. 27, fig. 25-28). Disco circulari, depresso; petalis ovatis, apertis.

6. Echinocyamus obusus $\Lambda$ g. (Tab. 27, fig. 29-32). Disco ovato, depresso; petalis rectis, aperlis.

7. Echinocyamns siculns $\mathrm{\Lambda g}$. (Tab. 27, fig. 33-36). Disco ovato, subinflato, antice subacuto, postice dilatalo; petalis apertis, rectis.

8. Echinocyamus Ammomii Mer. (Tab. 27, fig. 37-40). Disco orbiculari; petalis ovatis, convexiusculis, apertis.

9. Echinocyamus alpims $\Lambda$ g. (Tab. 27, lig. 41-13). Disco ovali, inflato; ano margini postico propinquiore.

10. Echinocyammes ambiguts Ag. (Tab. 27, fig. 4\%-47). Disco ovato, depresso, margine crassissimo; petalis ovatis vel subovatis, apertis.

11. Echinocyamms occitamus $\mathrm{Ag}$. (Tab. 27, fig. 48-58). Disco depresso, subcirculari, postice truncato, margine crasso; petalis magnis, apertis, sulcis transversis conjunctis; ano inter os et marginem posticum medio.

XIII. Genus MOULINIA Ag. Discus ovatus, depressus, extus sulcis radiantilus inter areas preditus. Anus inferus, inter os et marginem medius. Petala ambulacralia aperta, sulcis transversis non conjunctis.

Moulinia cassichlina $\mathrm{Ag}$. (Tab. 22, fig. 1-6). Disco ovato, convexiusculo, sulcis radiantibus profundis; margine undato; tulherculis prominentibus. 


\section{ER R A A.}

Page 6, ligue 12, ou il est à la région postérieure, ajoutez: ou antérieure.

" " "15, les Echinodiscus, liscz: les Echinocyames.

" 7 , " 5, le nombre normal des plaques, lisez: le nombre normal des séries.

" $\mathrm{s}, \quad$ "19, des ambulacraires, lisez: des ambulacres.

"9, "30, les Echinodiscus, lisez : les Scutellines.

" 13, " 25 , des Echinodiscus, lisca : des Scutellines.

"22, "21, cffecez: les mers d'Europe.

"24, "24, se former, lisez: se fermer.

" $2 \pi$, " 31 , circulaire, lisez: subcirculaite.

" 37 , " 10, postérieure, lisez: antérieure.

$" 38, \quad$ "25, les fig. $14 l$, lisez : les fig. $11 l$.

" 97: " 15, l'île Toulalı, lisez : l'île Foulah.

"100, " 3 et 24 et p. $102,1.4$, nummularis, lisez: nummularia.

"111, "24, à la face inférieure; et à la face supérieure les unberculés, lisez: ì la face supérieure et à la face inférieure; les tubercules.

"124, " 20, l’Echinarachnius Parma : lise : l’Echinarachnius Placenta.

"139, "5, Scutelles, lıse: : Scutellines. 

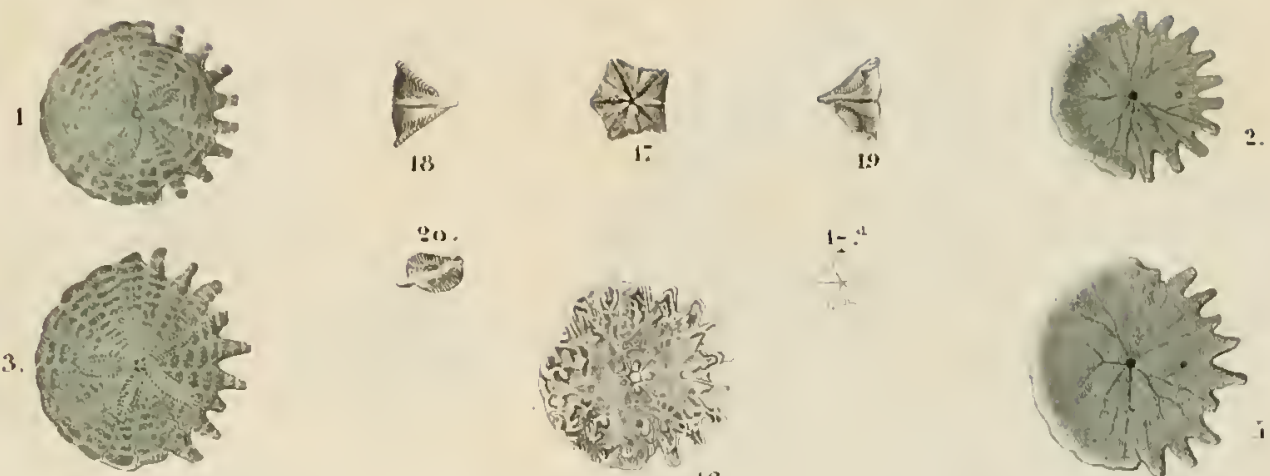

90.
(r)
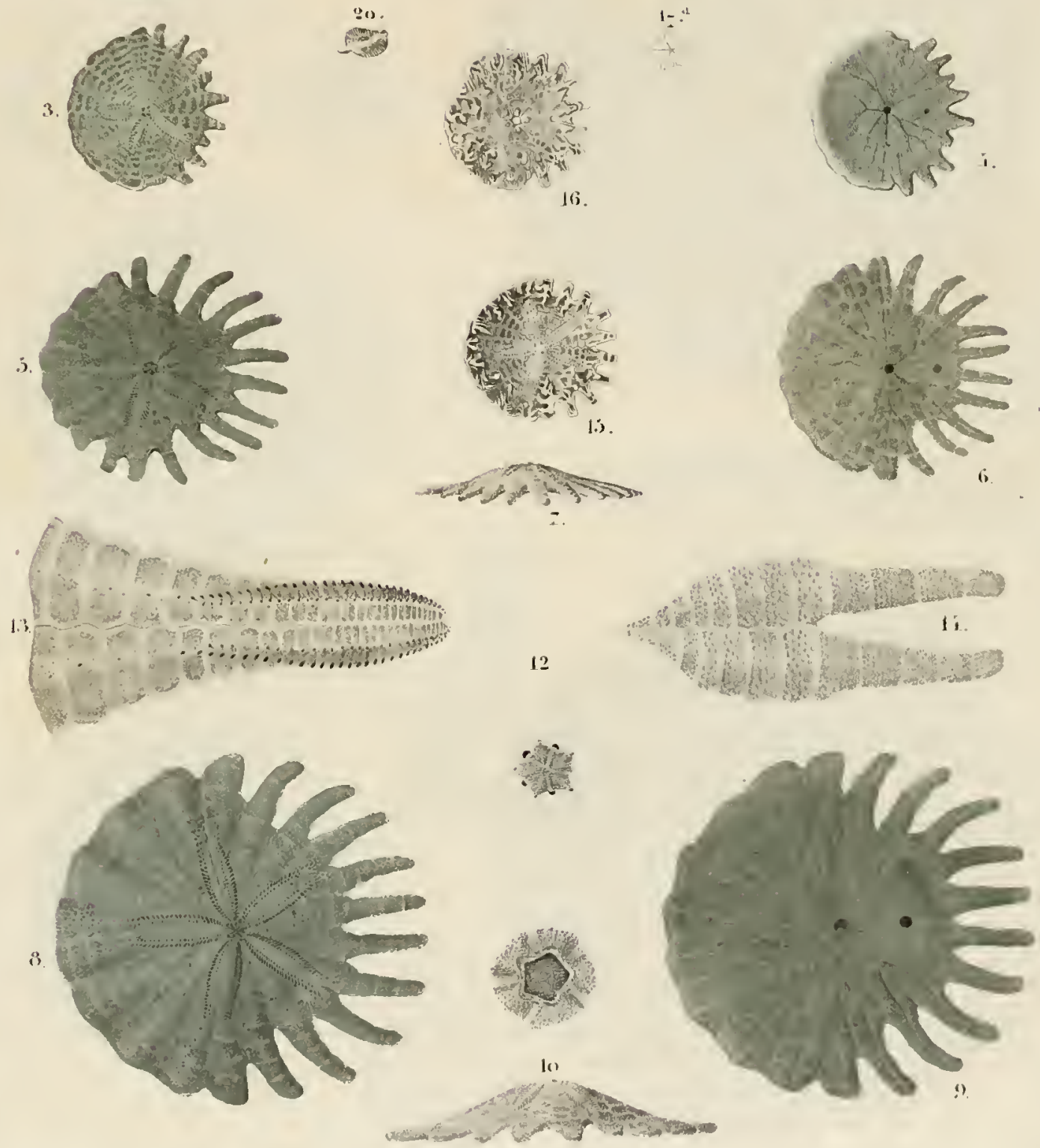

Srutelles.

Tab:

11. 13.12 की
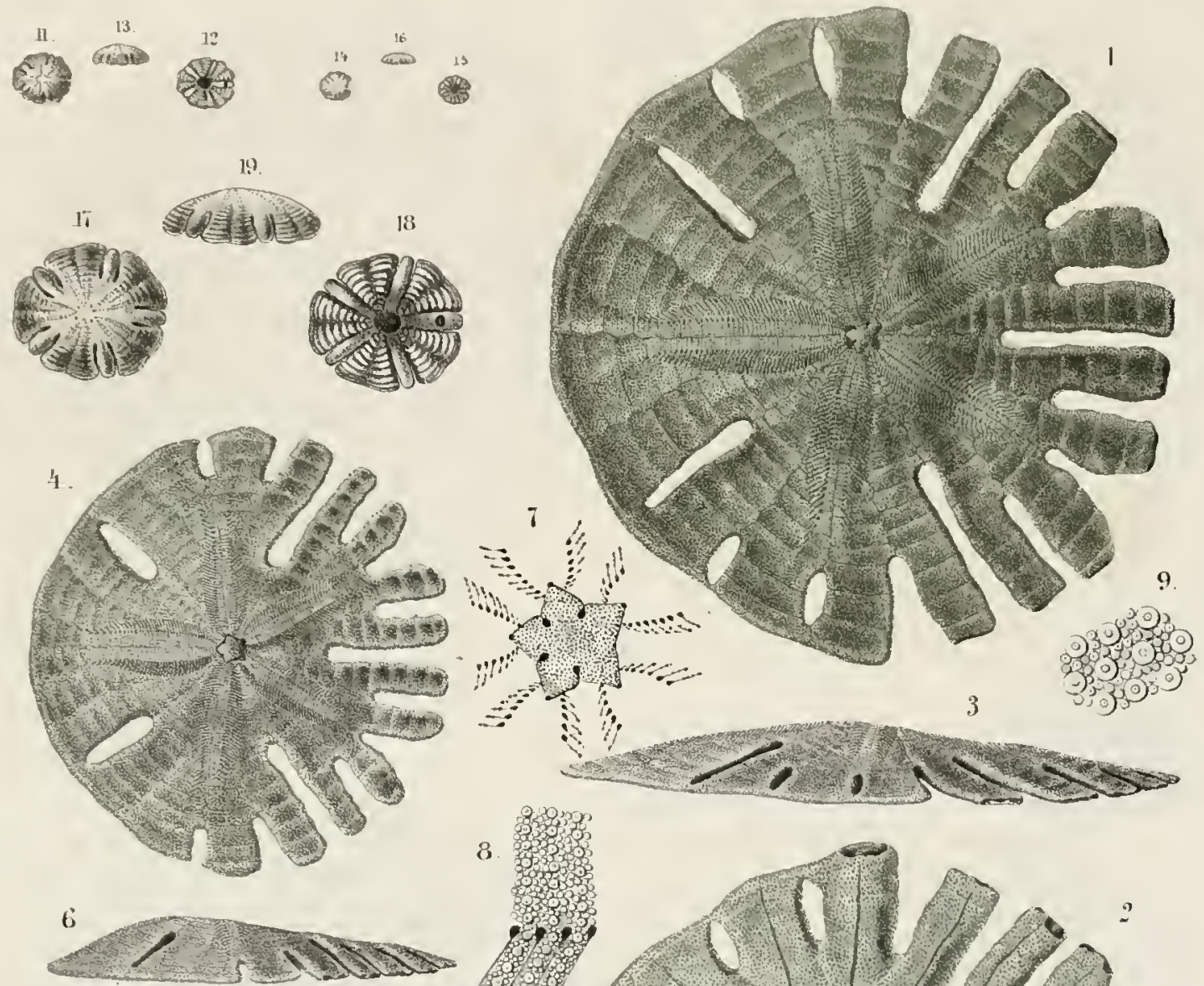

8.
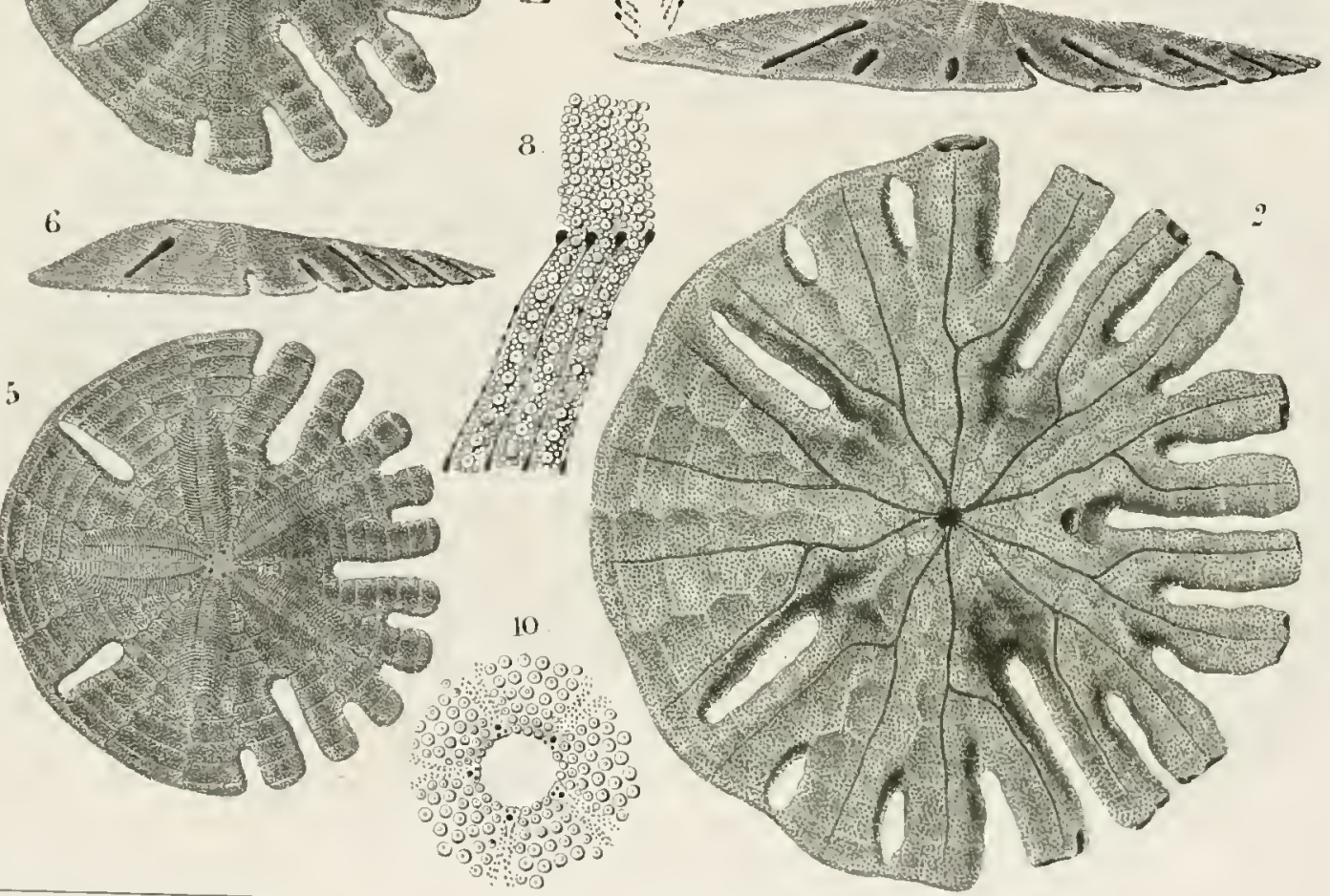

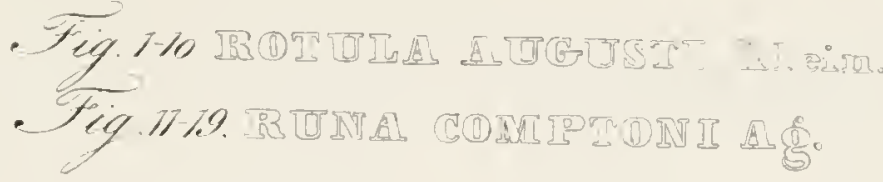





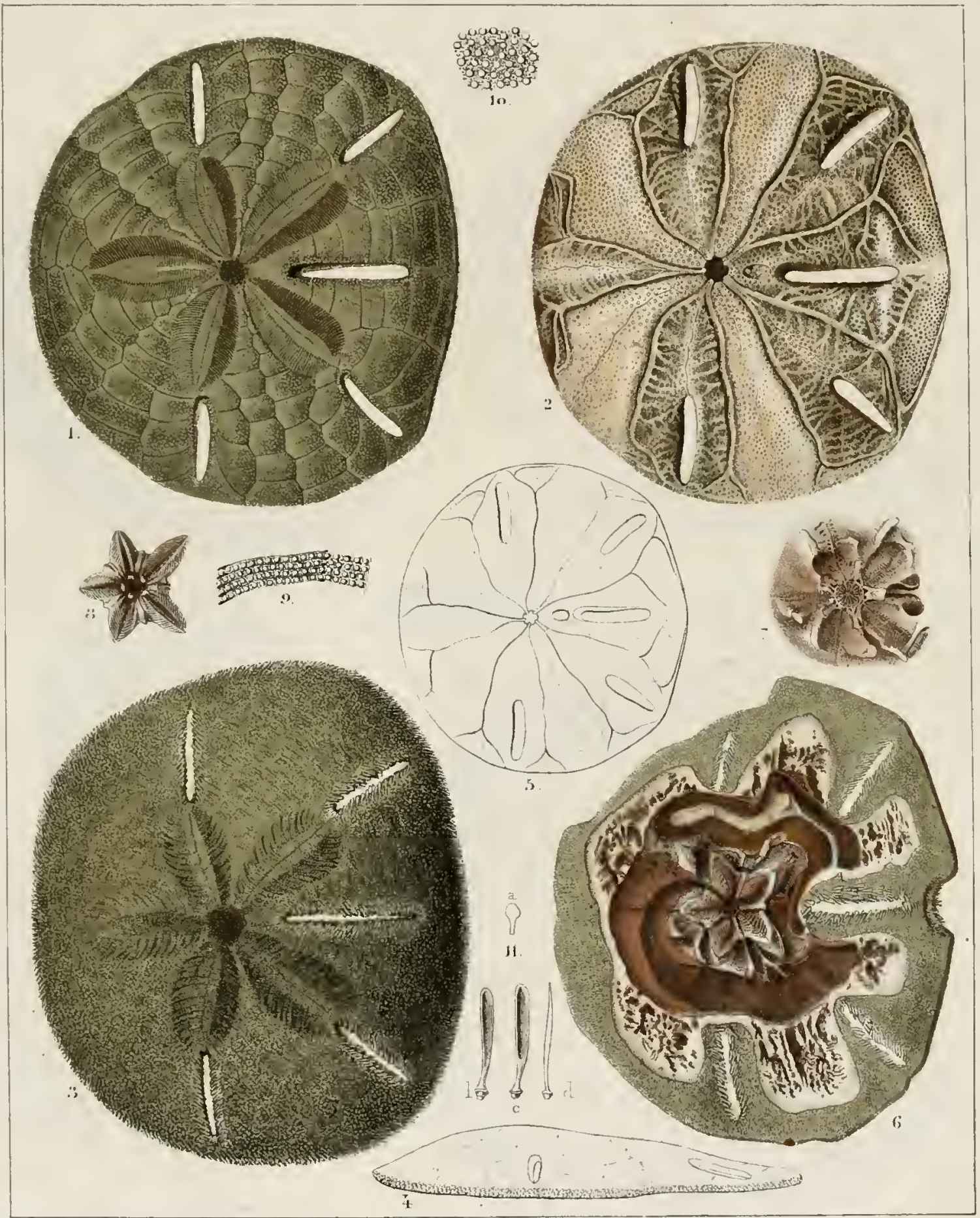





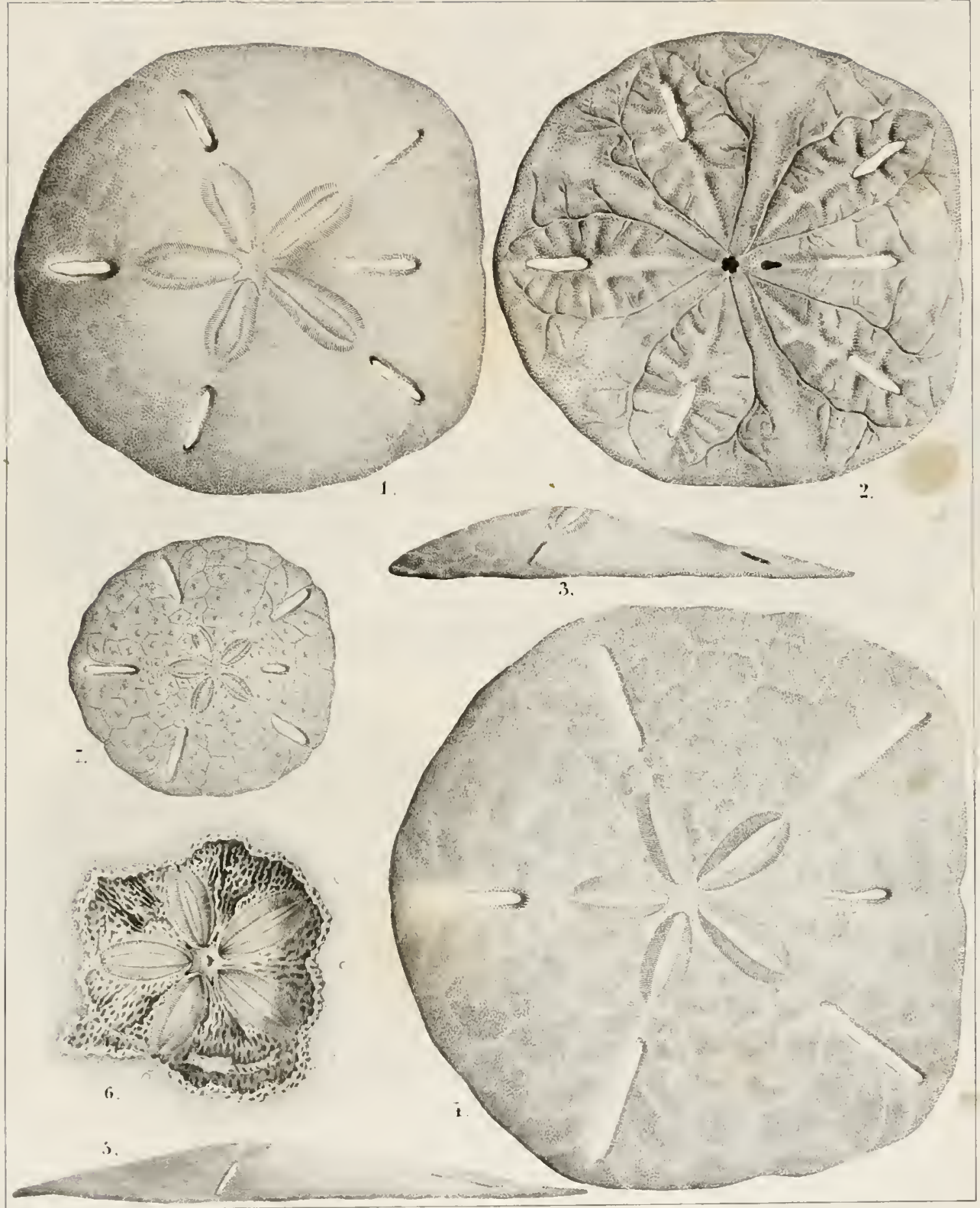

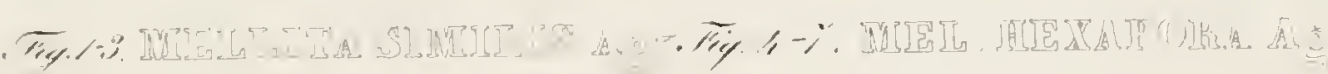



Soutelles

Tit 1 ?

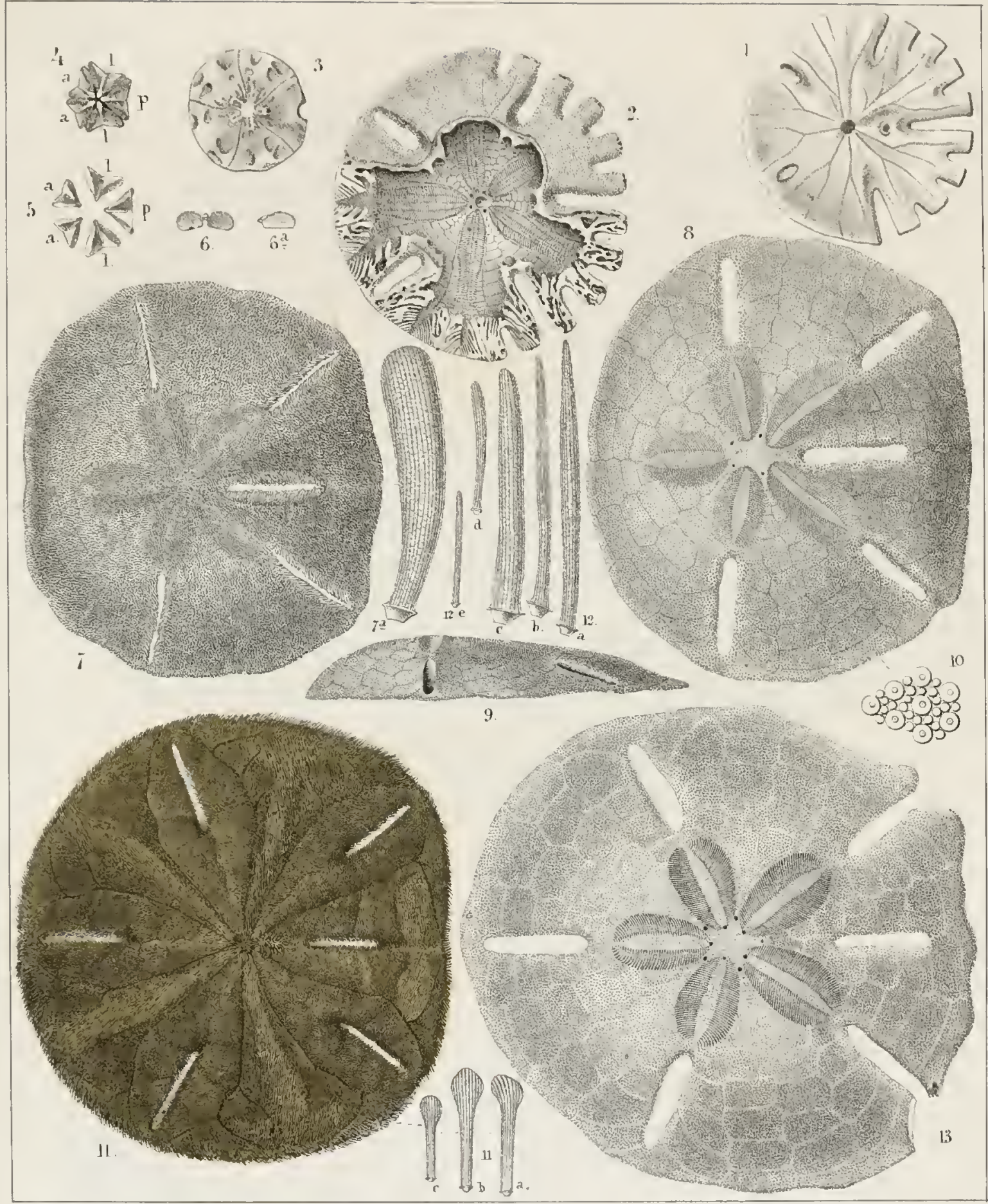

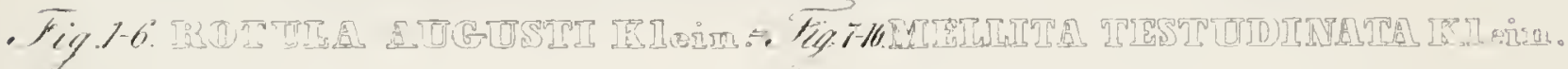

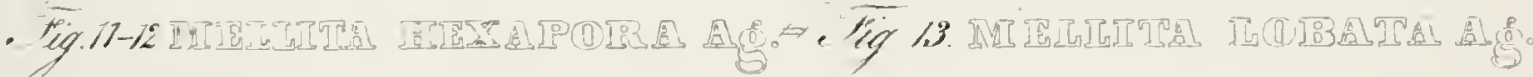



Souldell,

Tal, .)

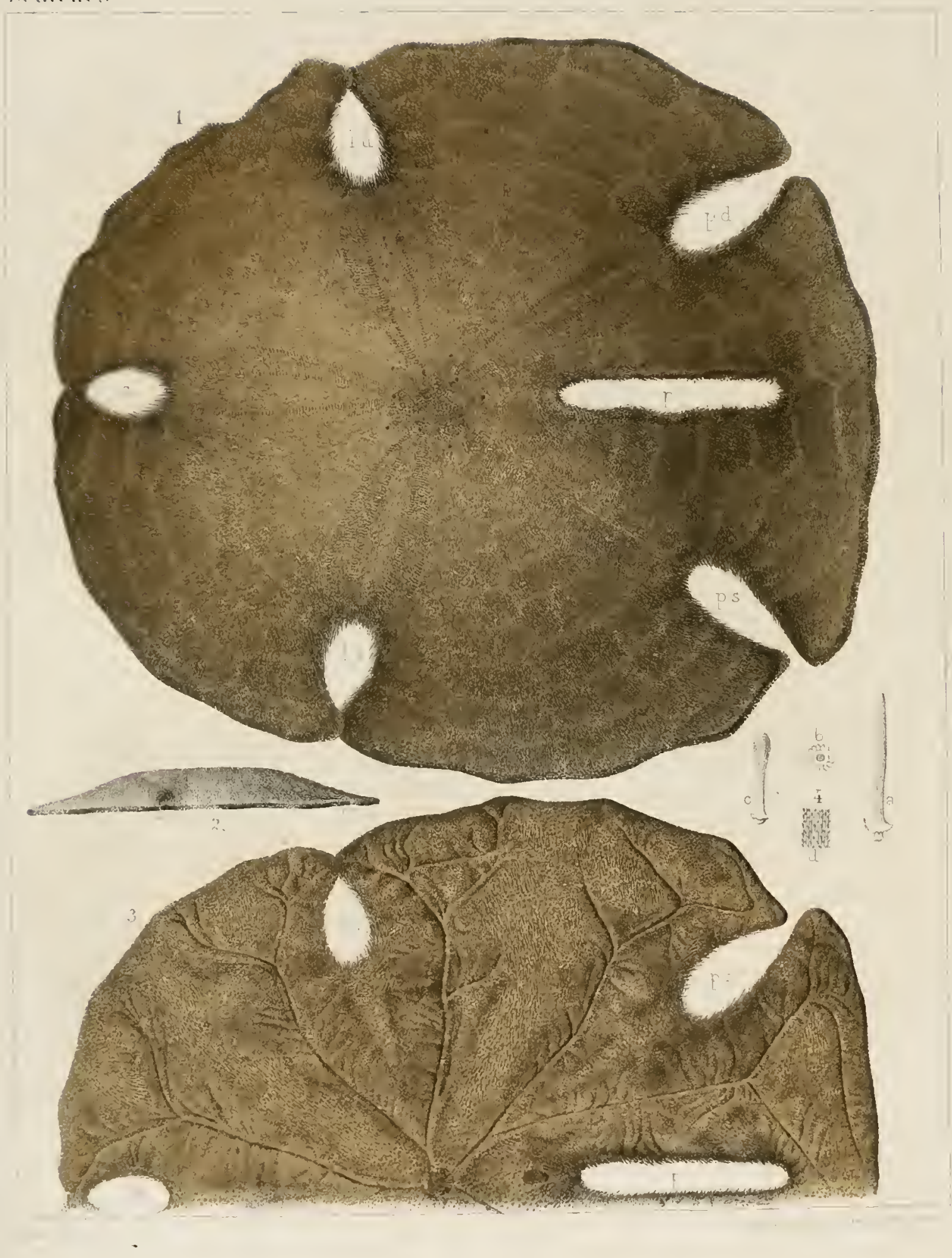





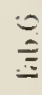
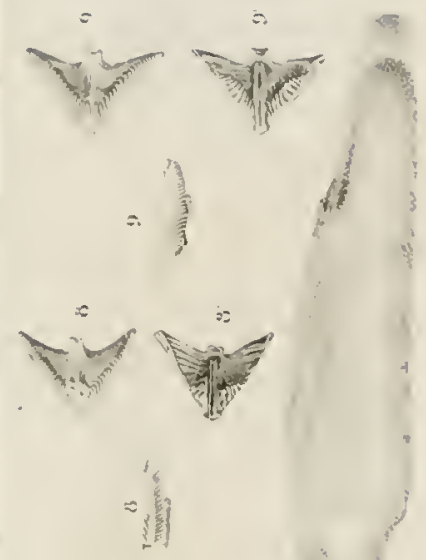

17

-1)
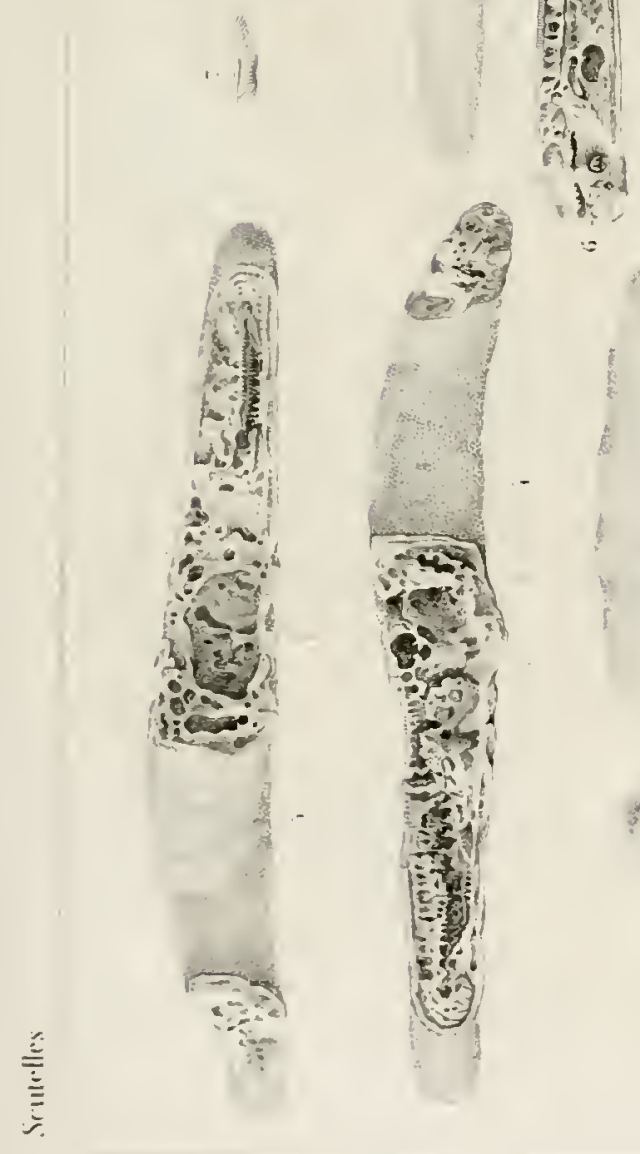

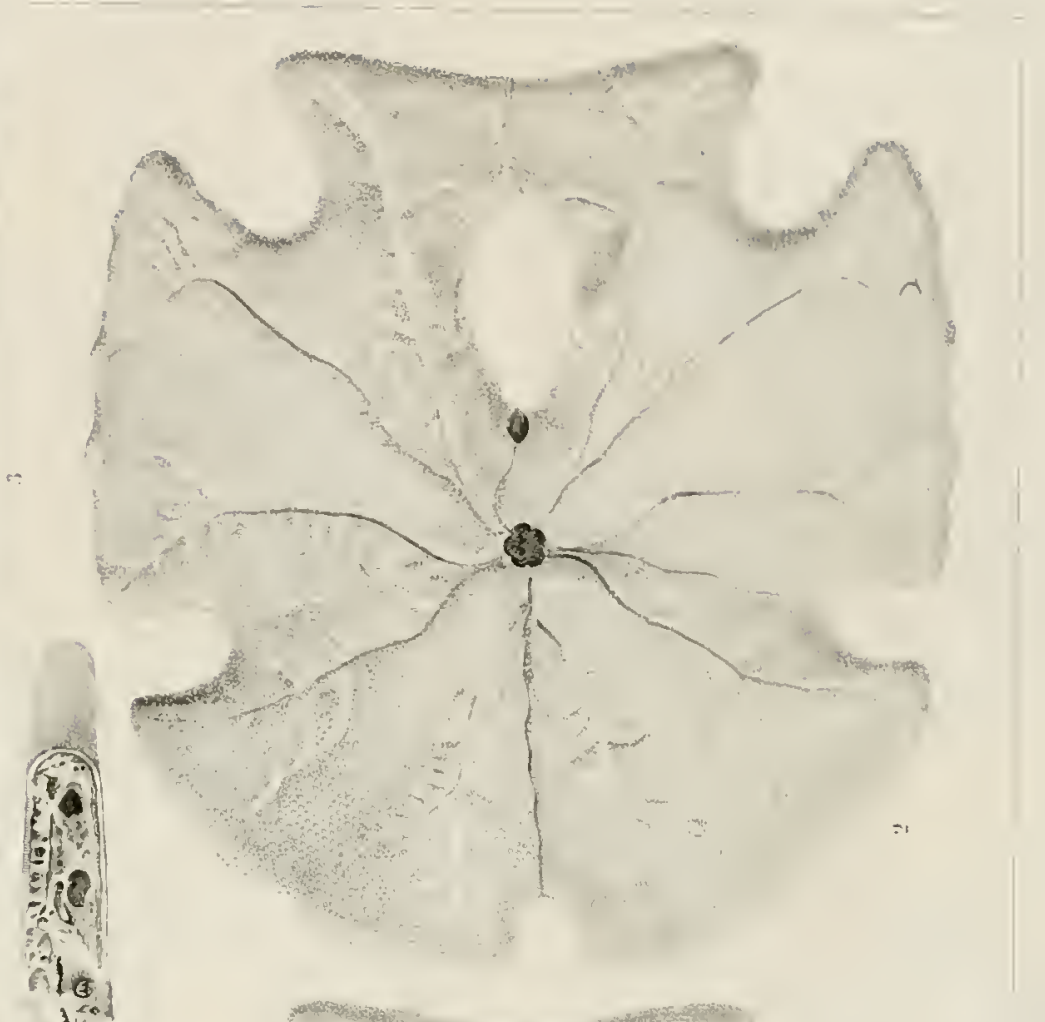



Souldelles

Tab $6 a$

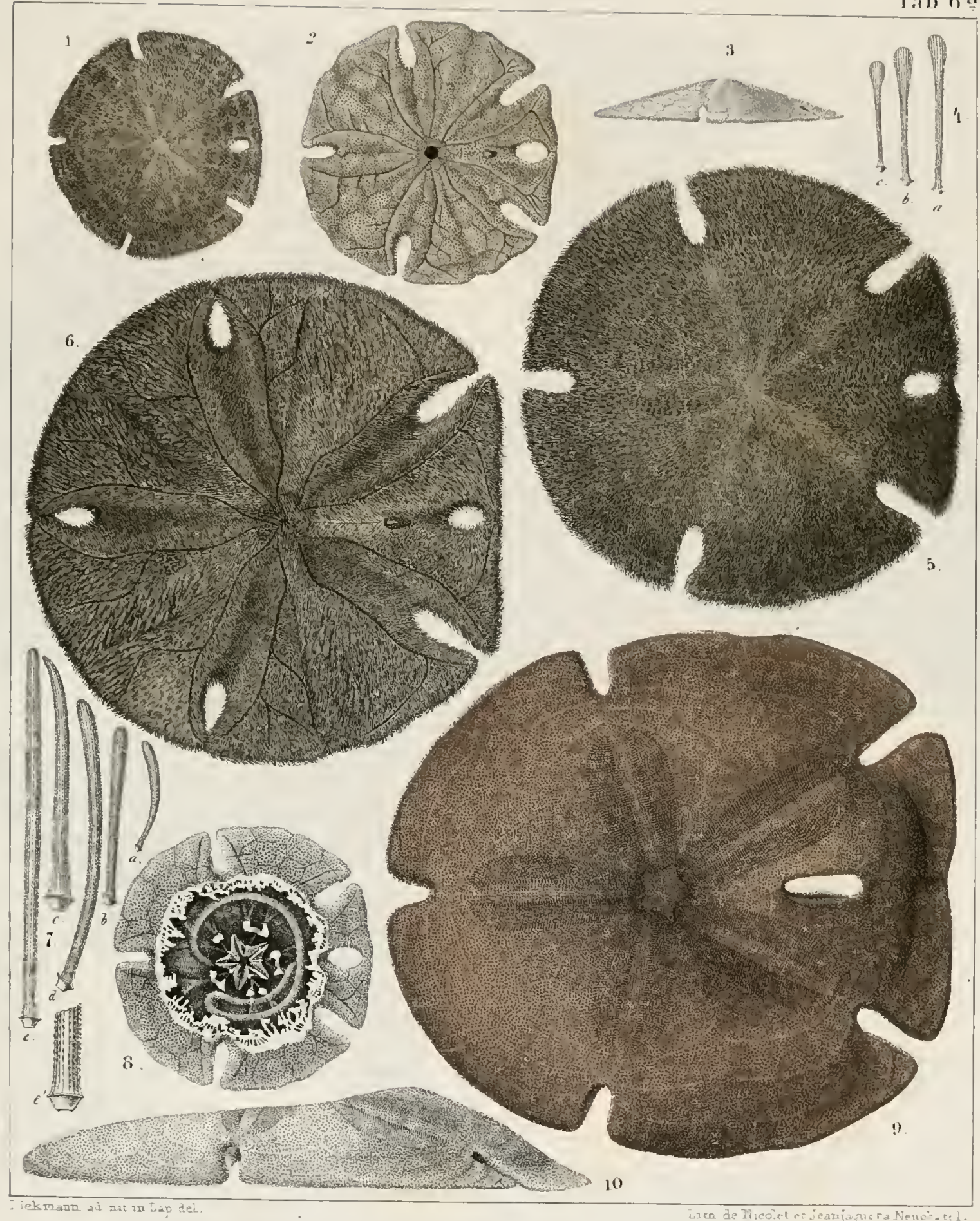

- Fig.t-8 adr ore 



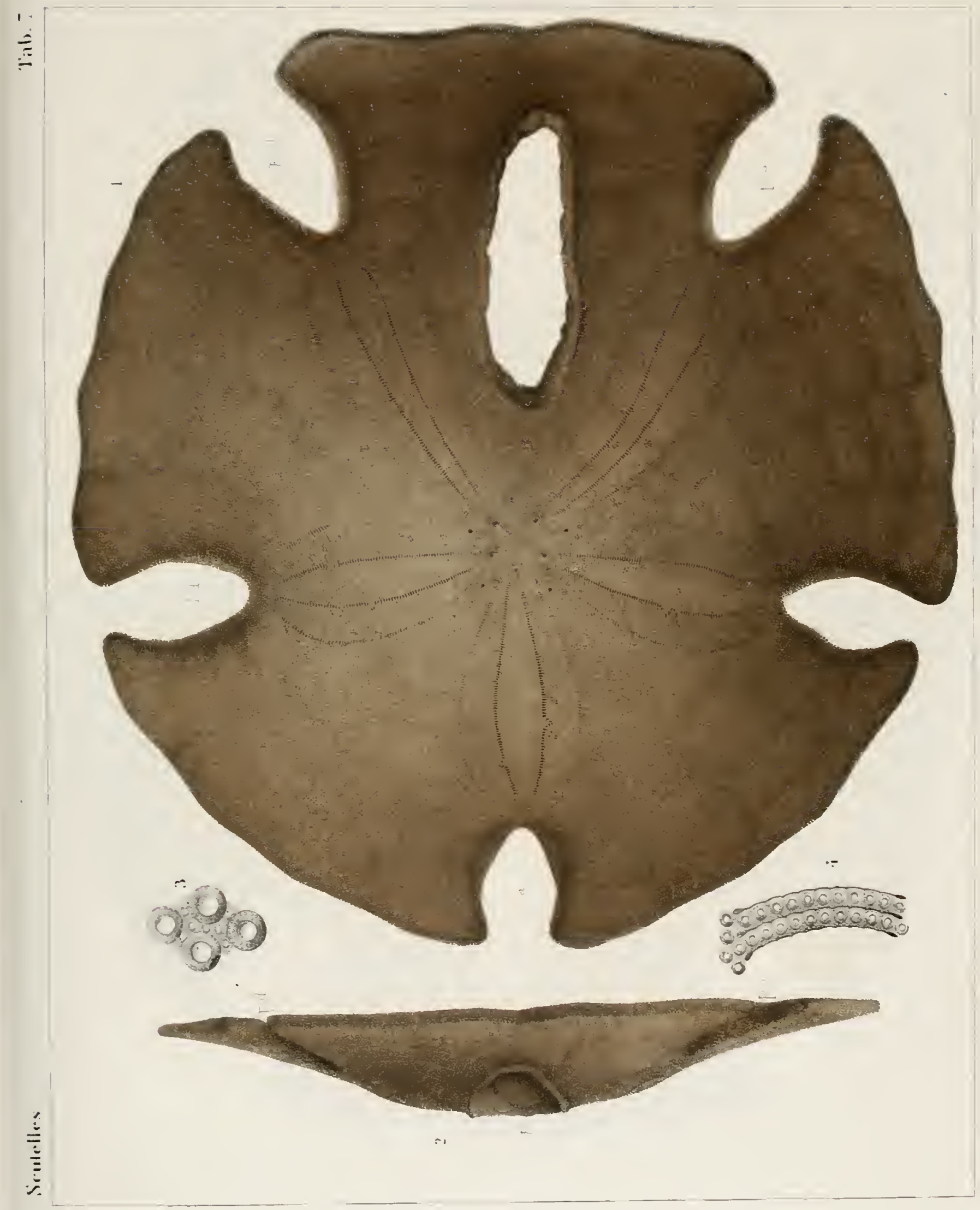





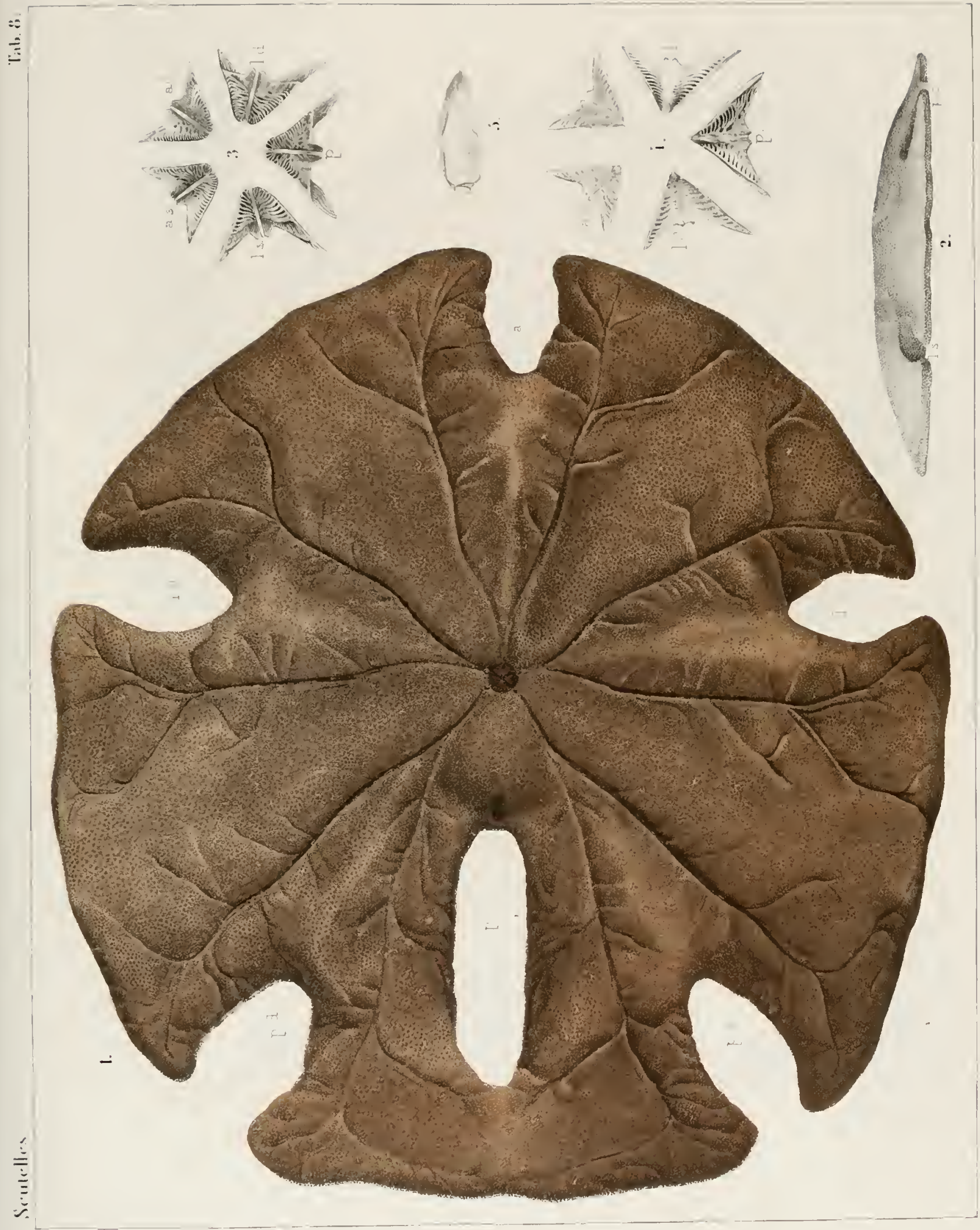



soutollos

Tial, :

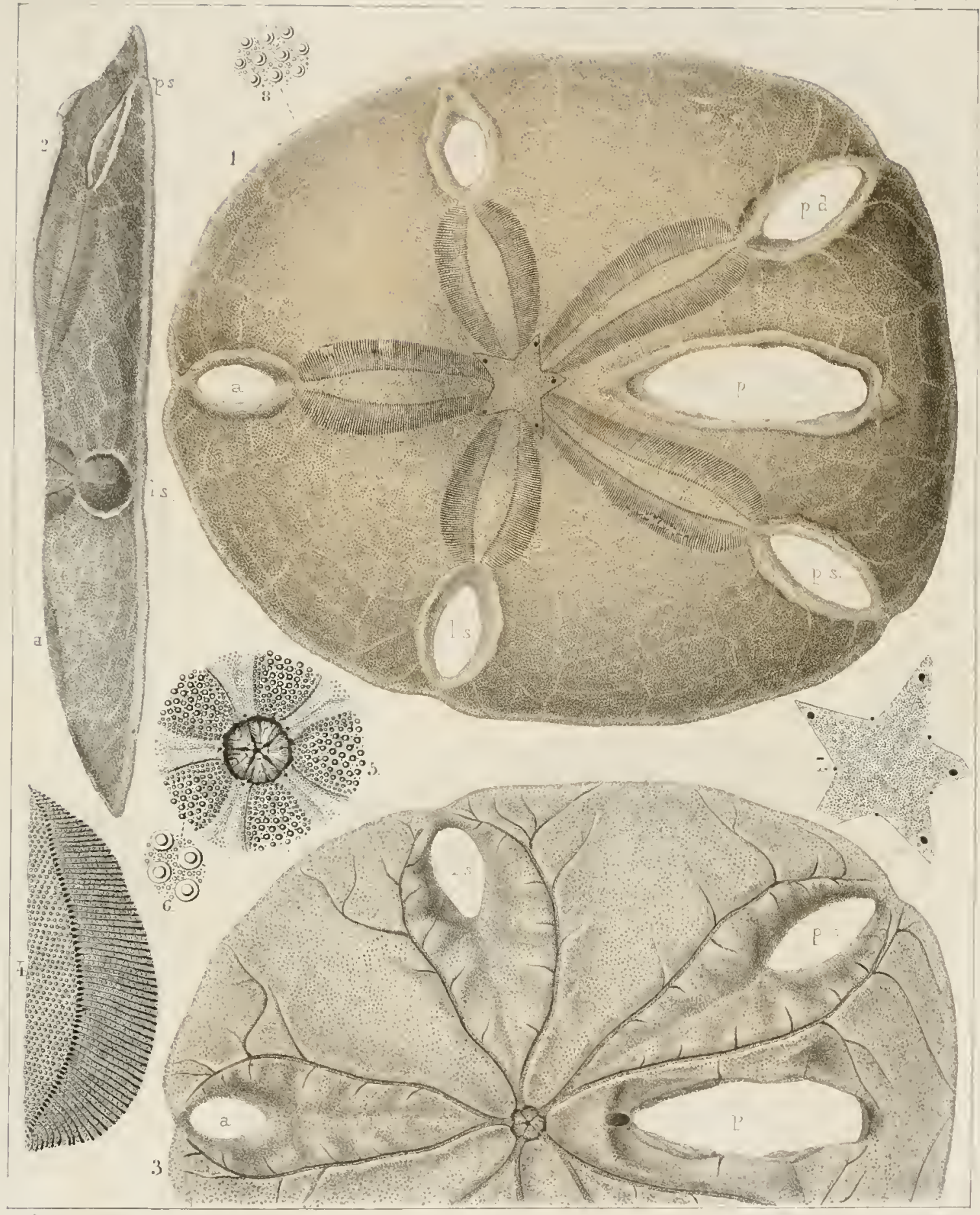



sindelles

Till. I0

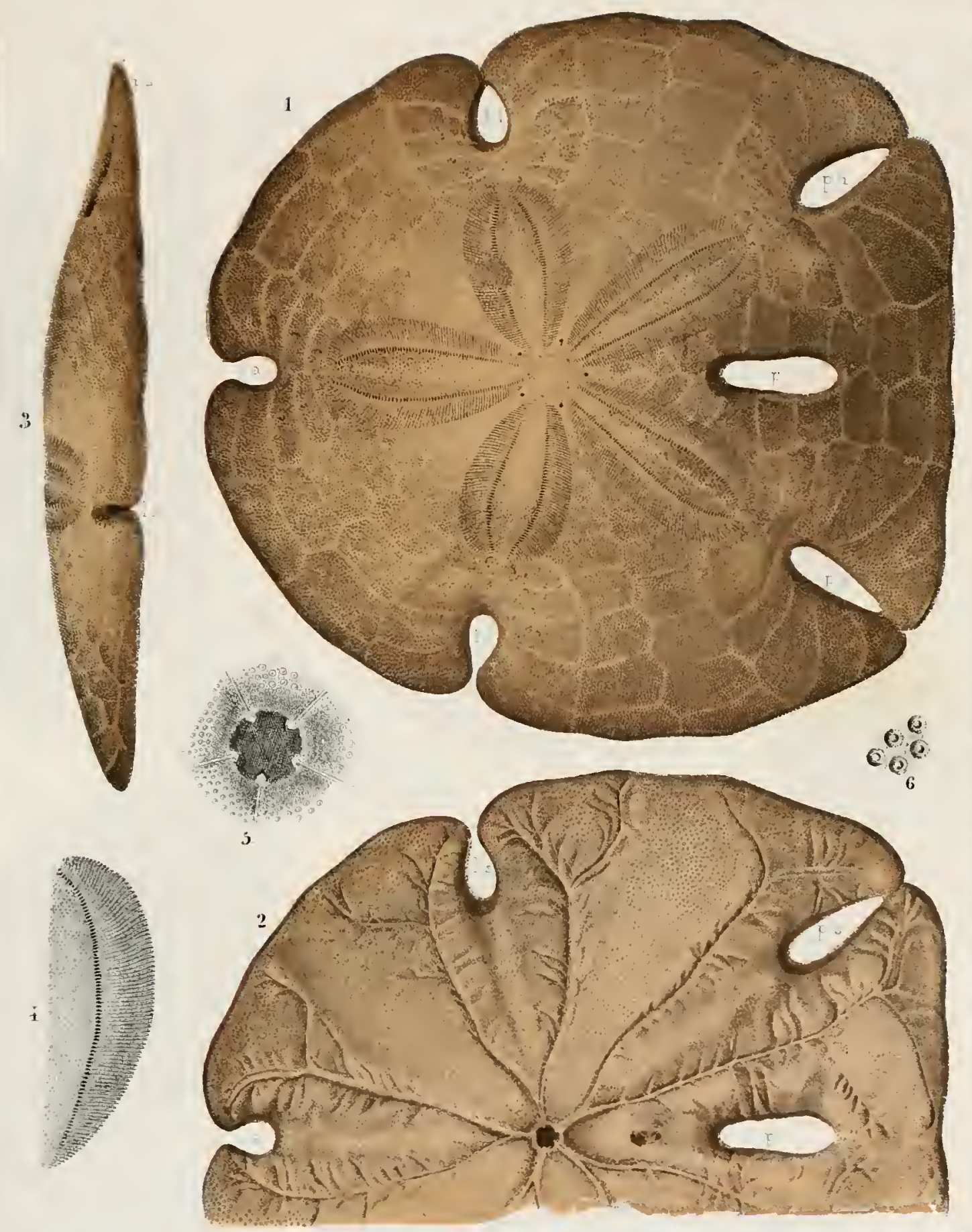





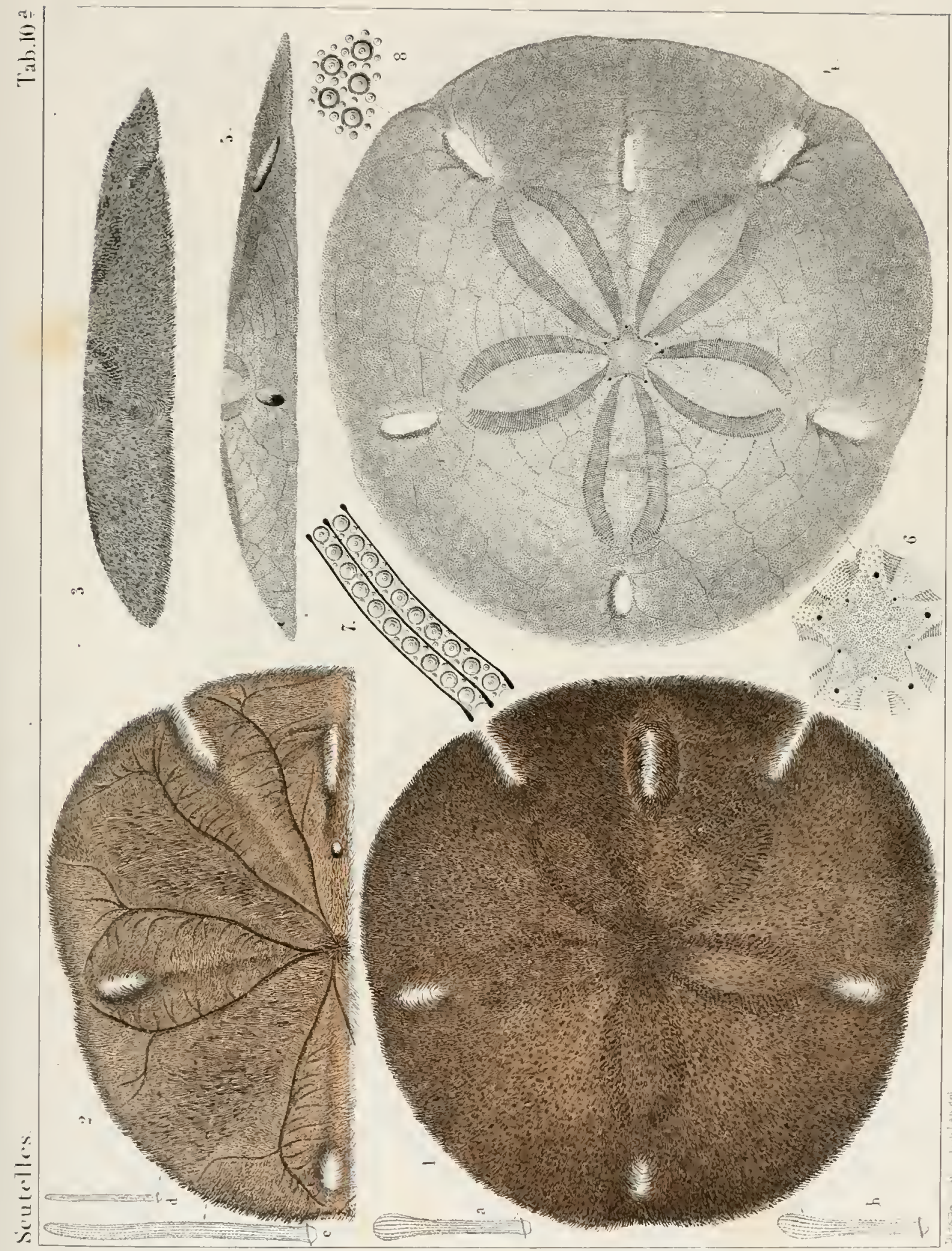

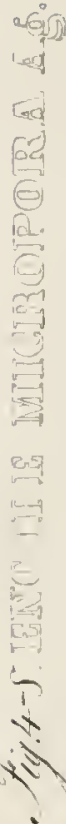

1 



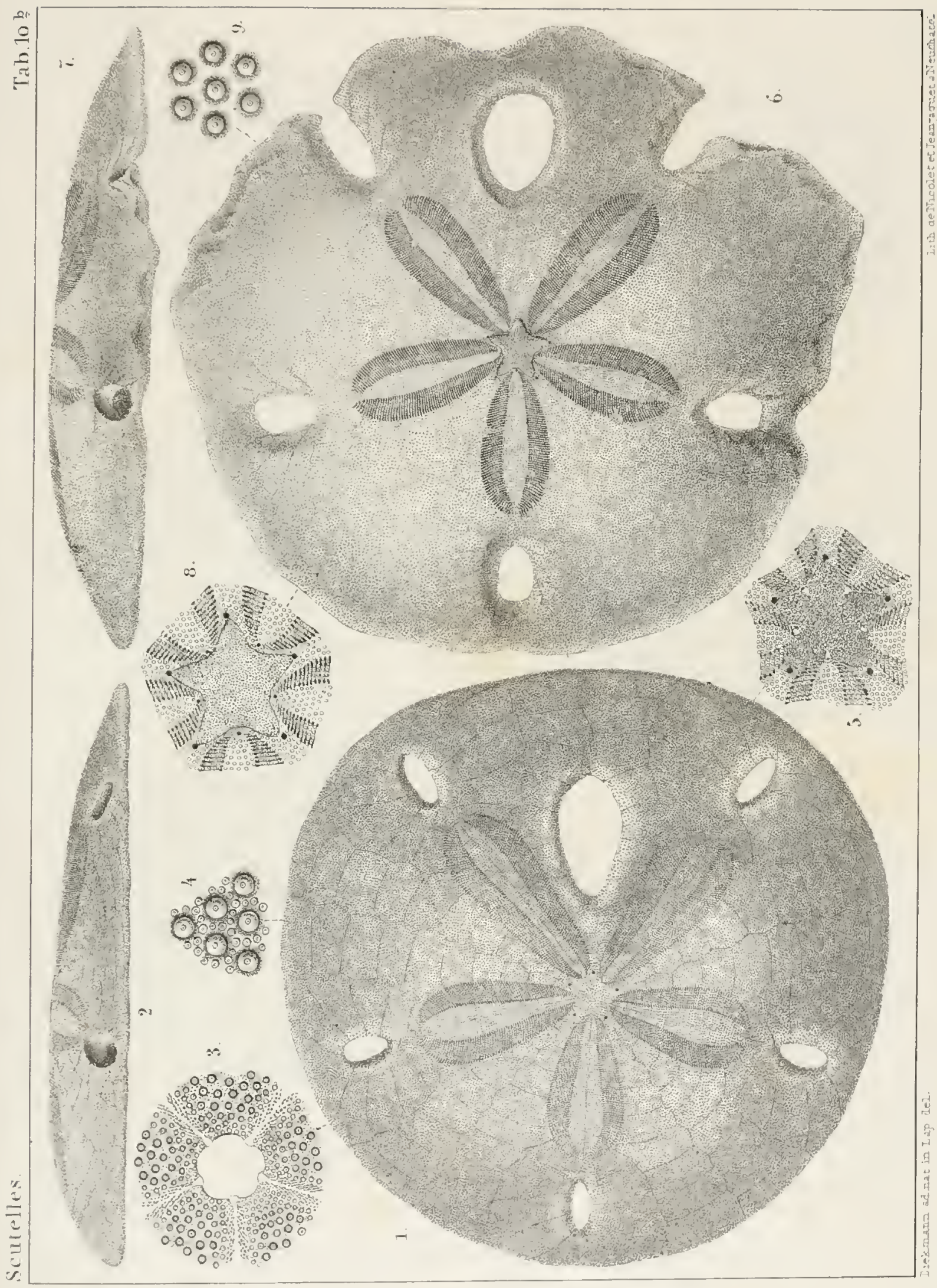

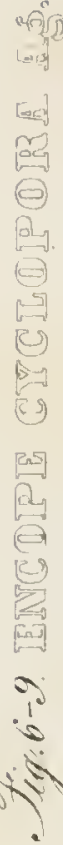

$\checkmark$

ध्रा

Ed]

6

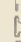

है

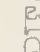

2.

a

A.

록

ह

रa

) 



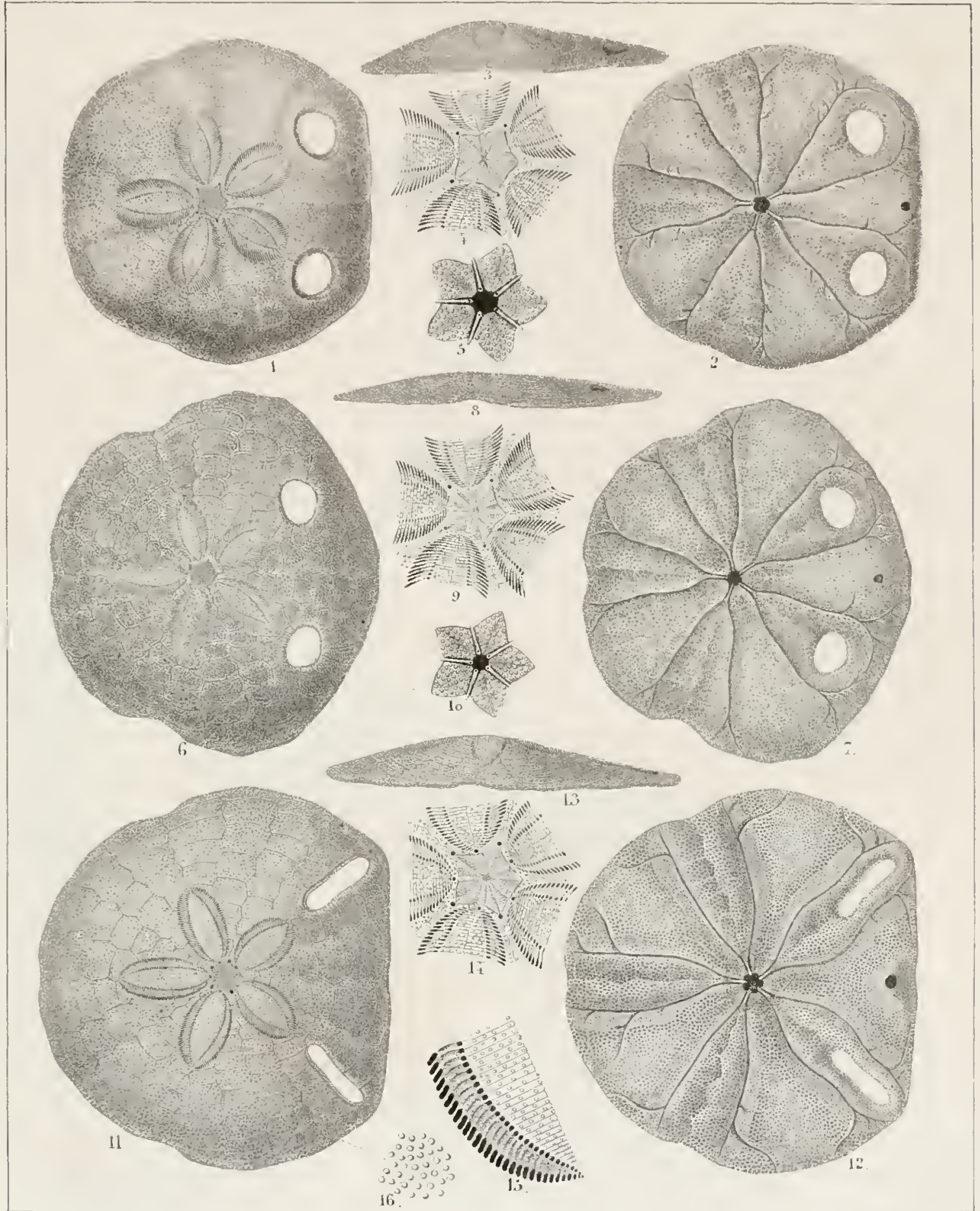

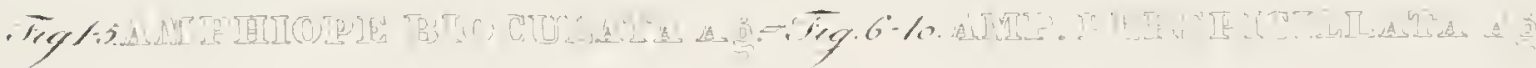
Tig. $/ 1-10$ 



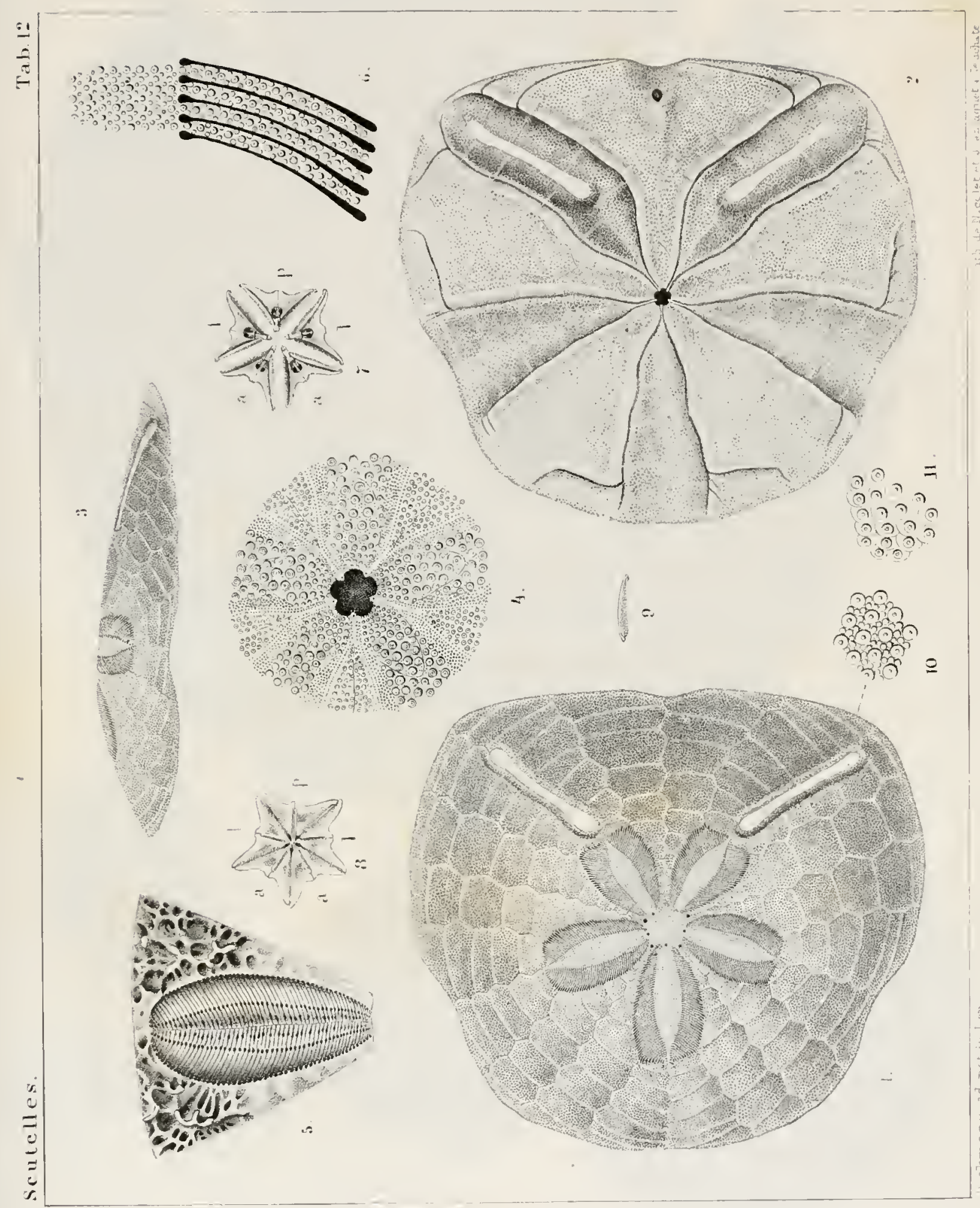





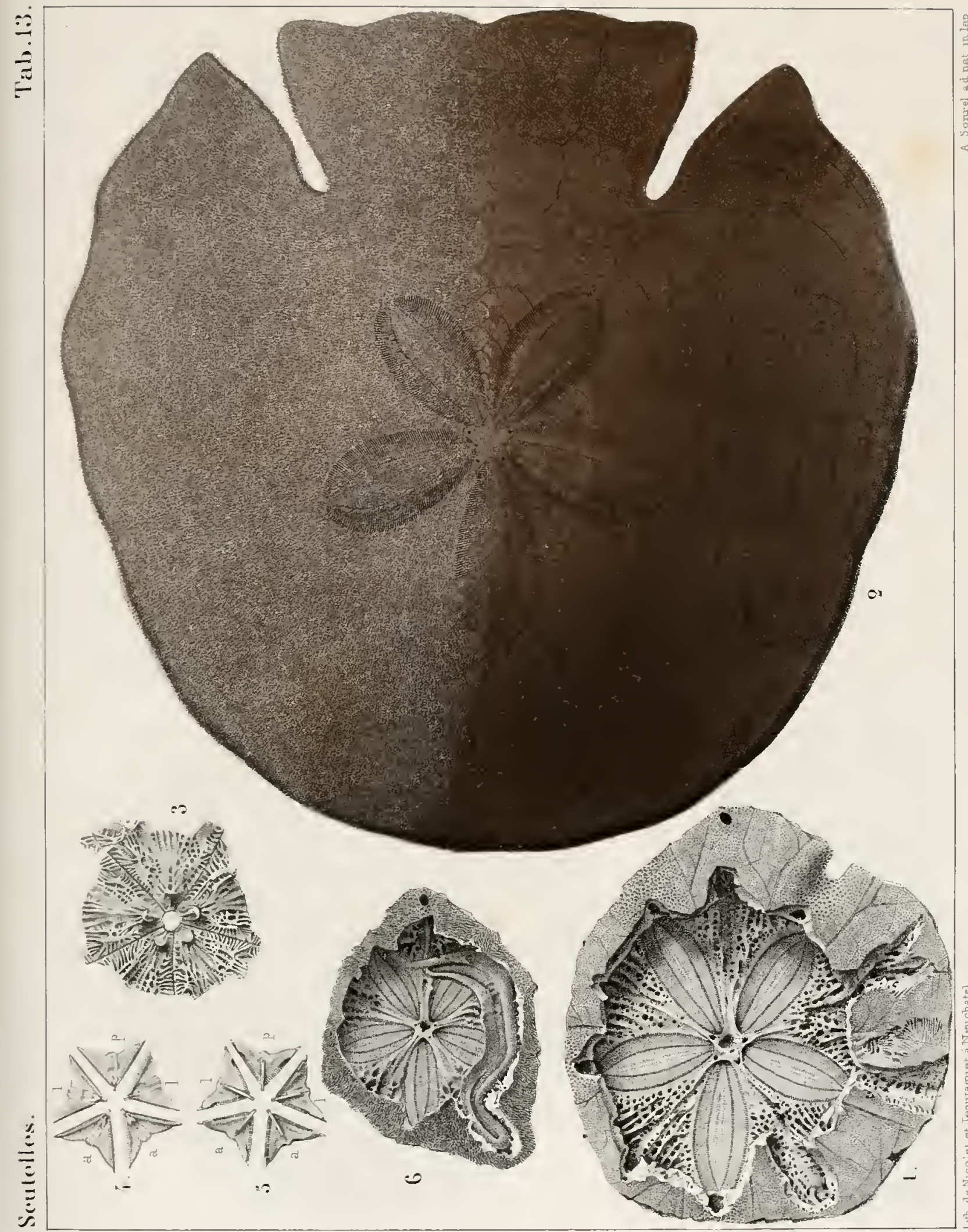

की 



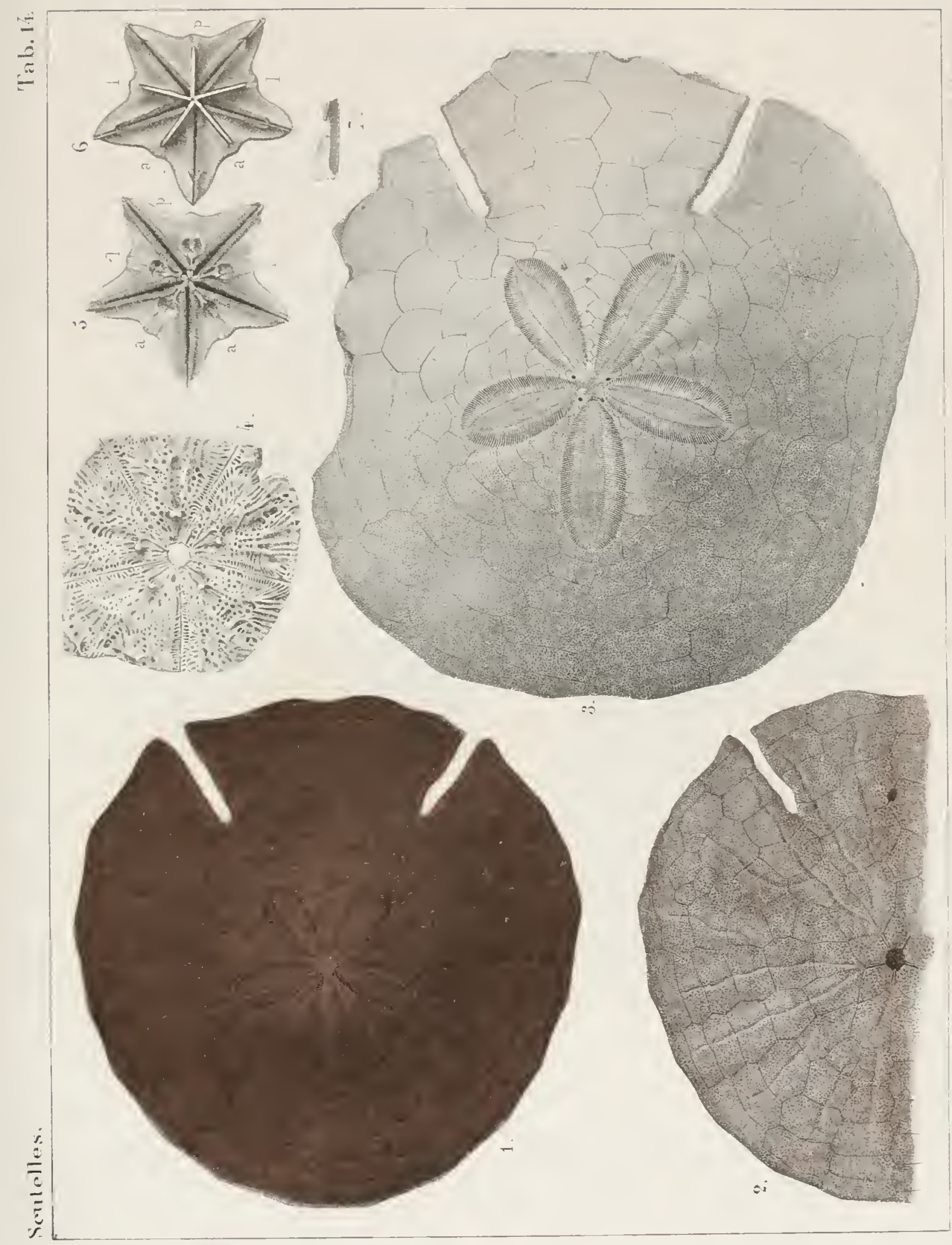





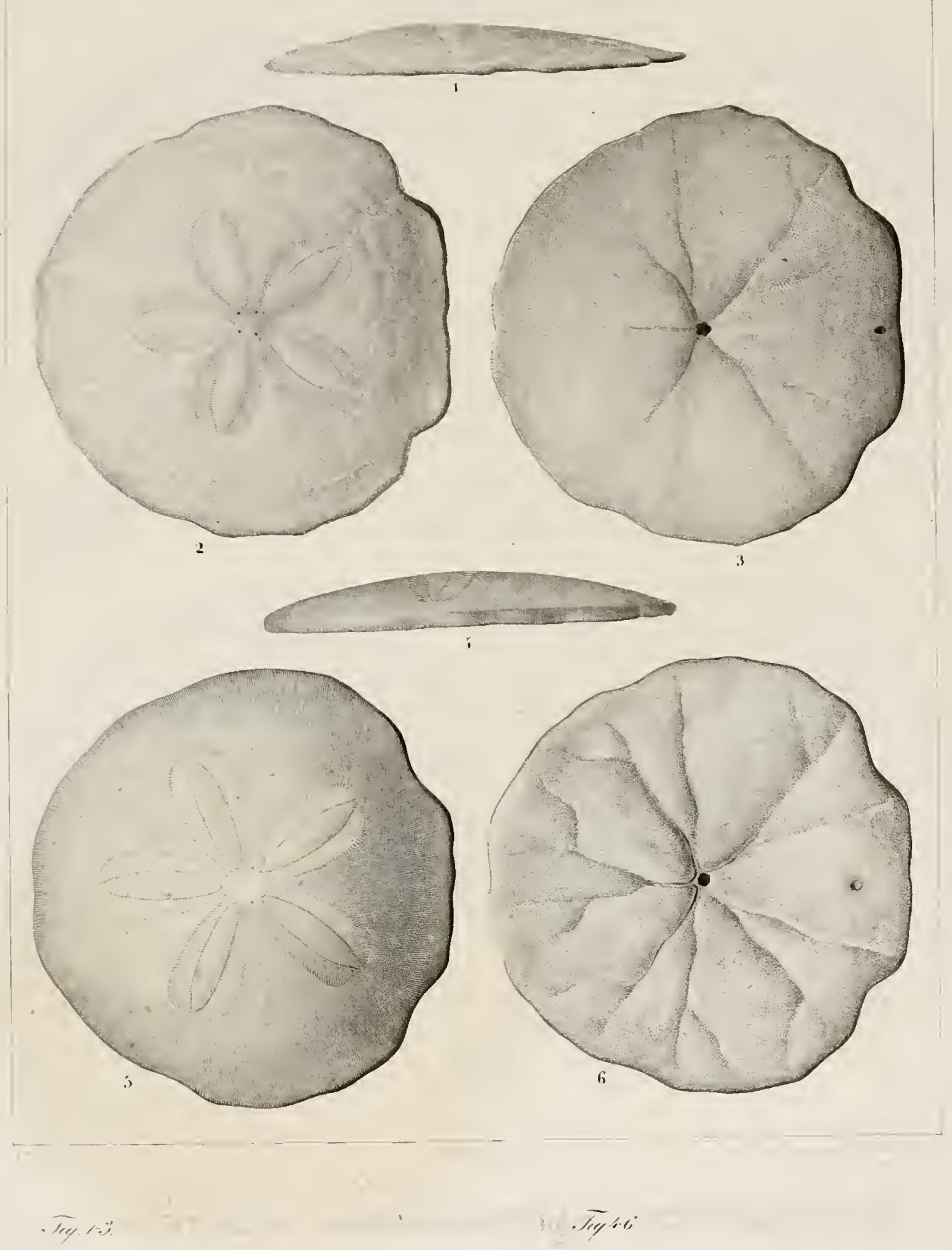





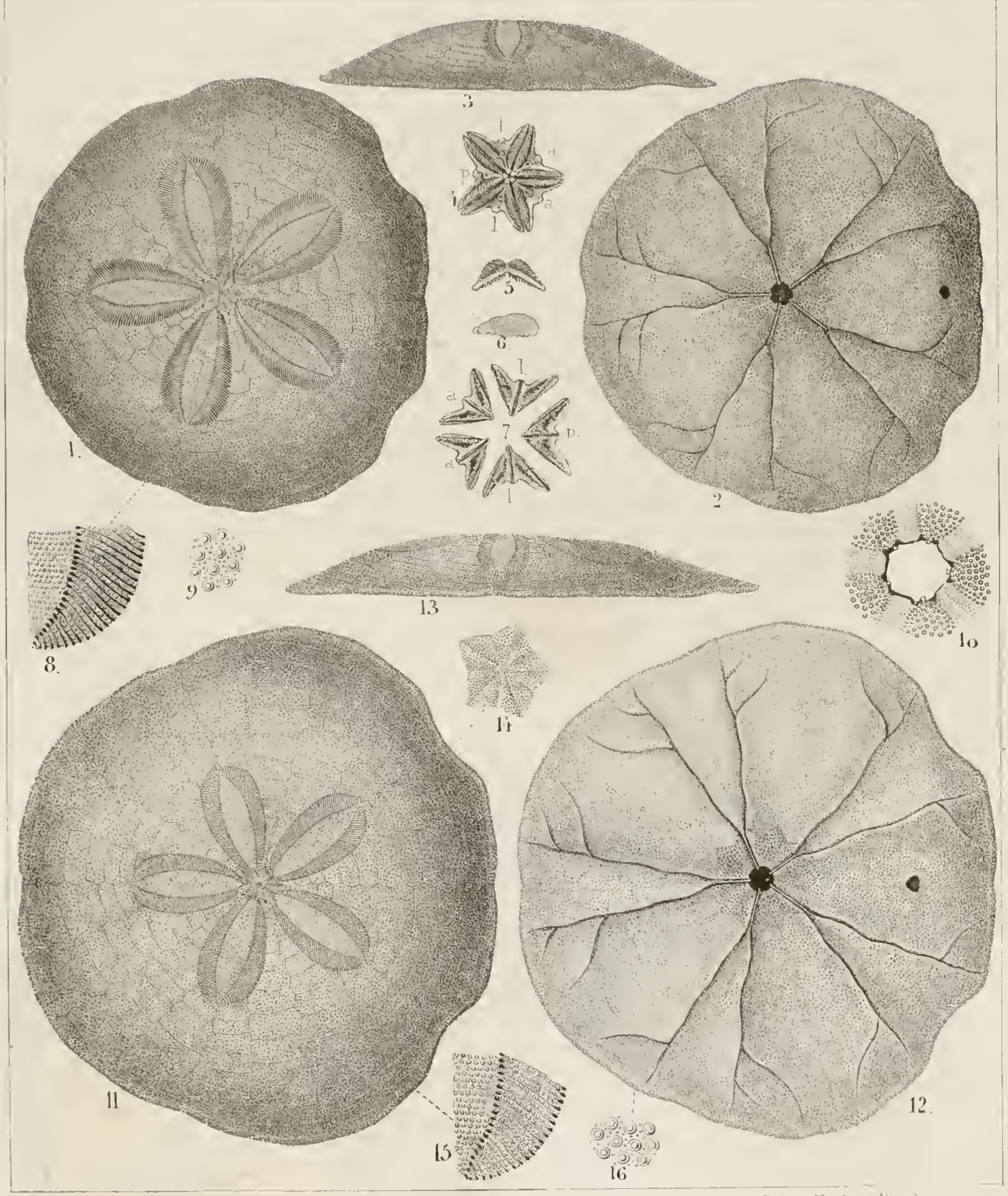

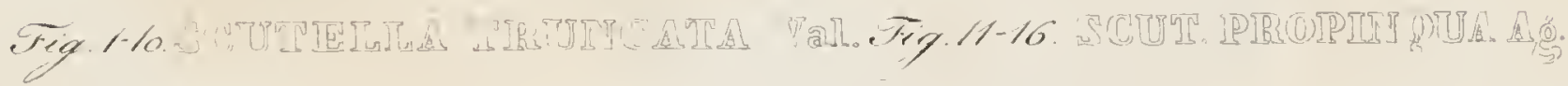





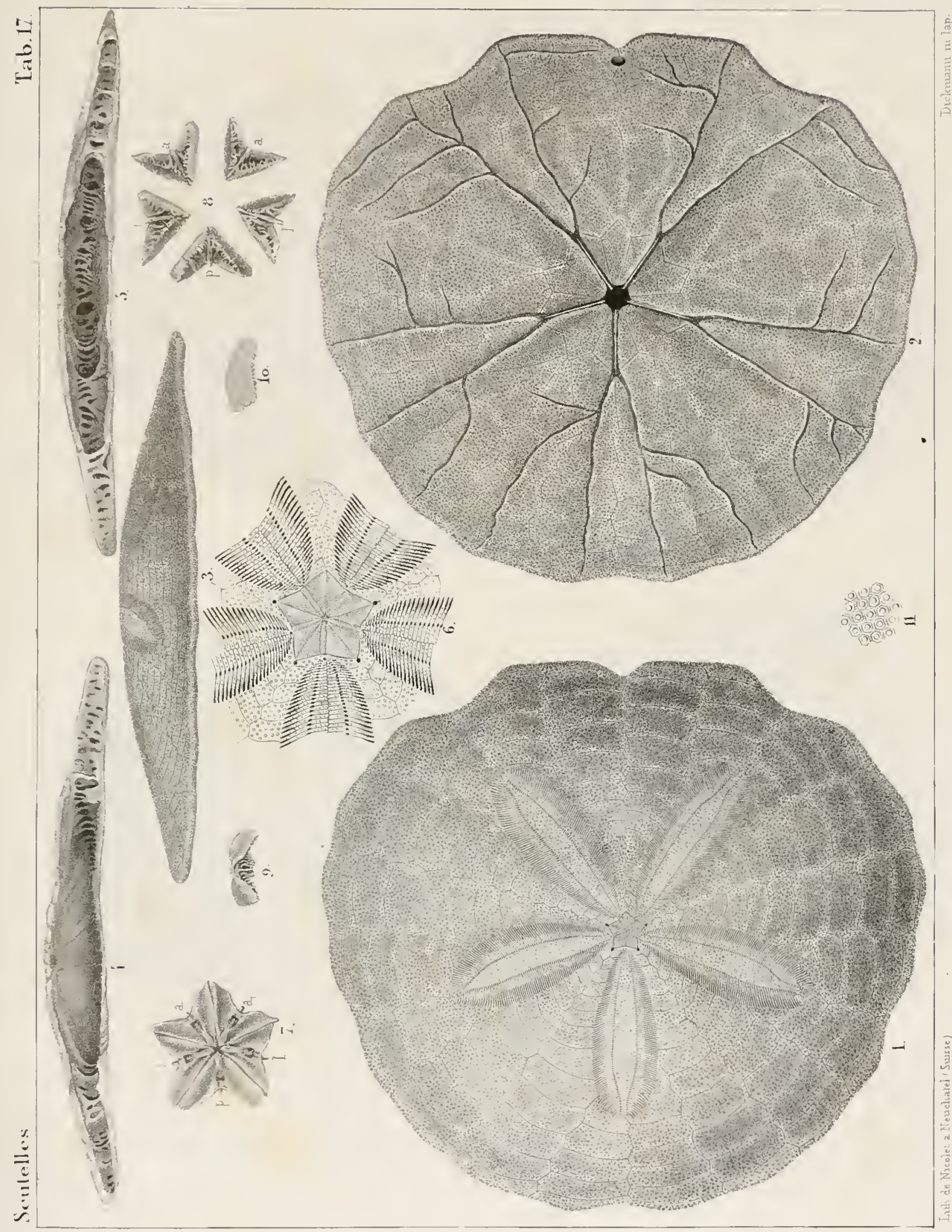



Sieutelles

Tab. 18.

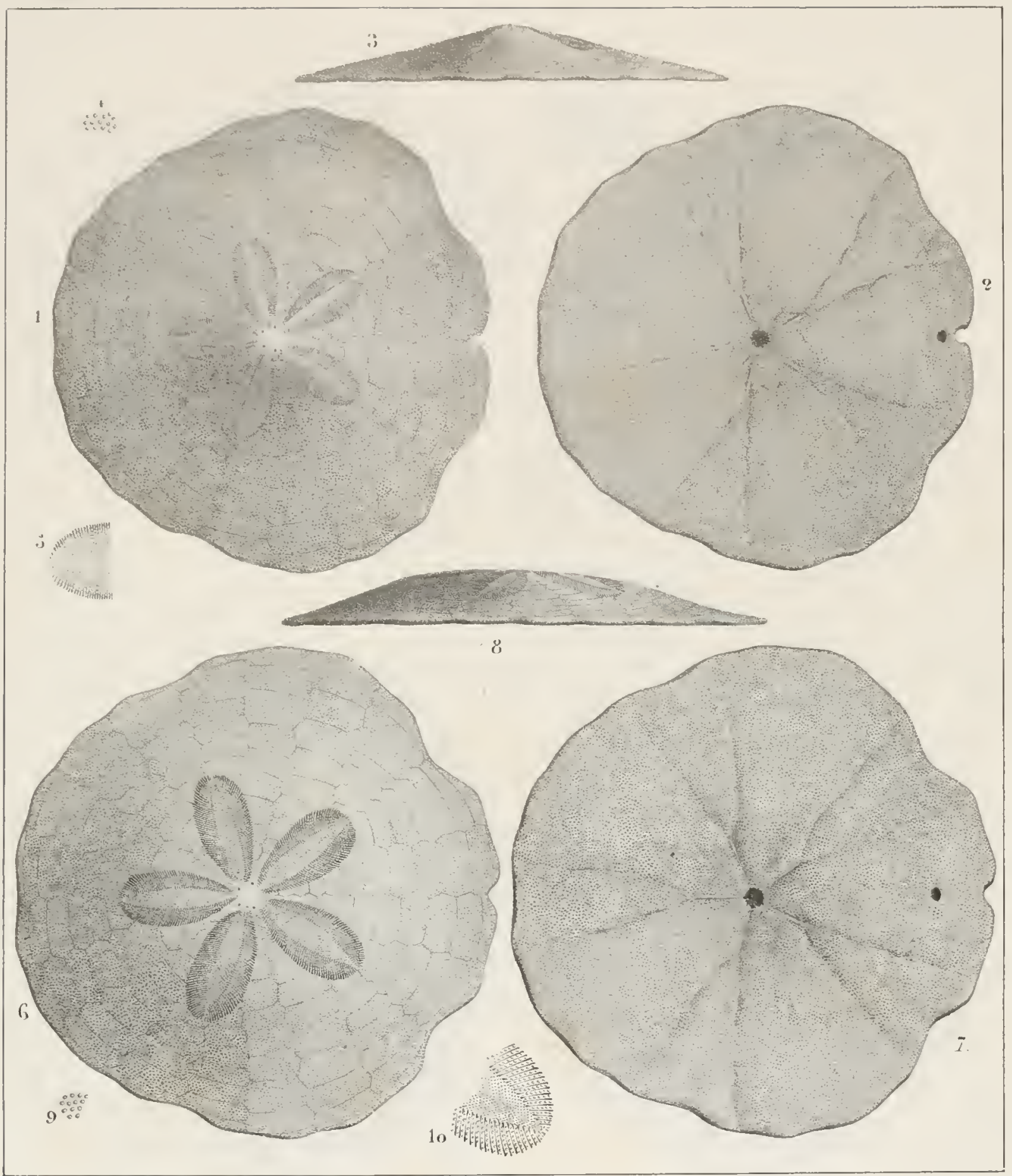

dellicolet Neuchatel

A Sonvel ad nat me lap

: Fiy $/$, SED 



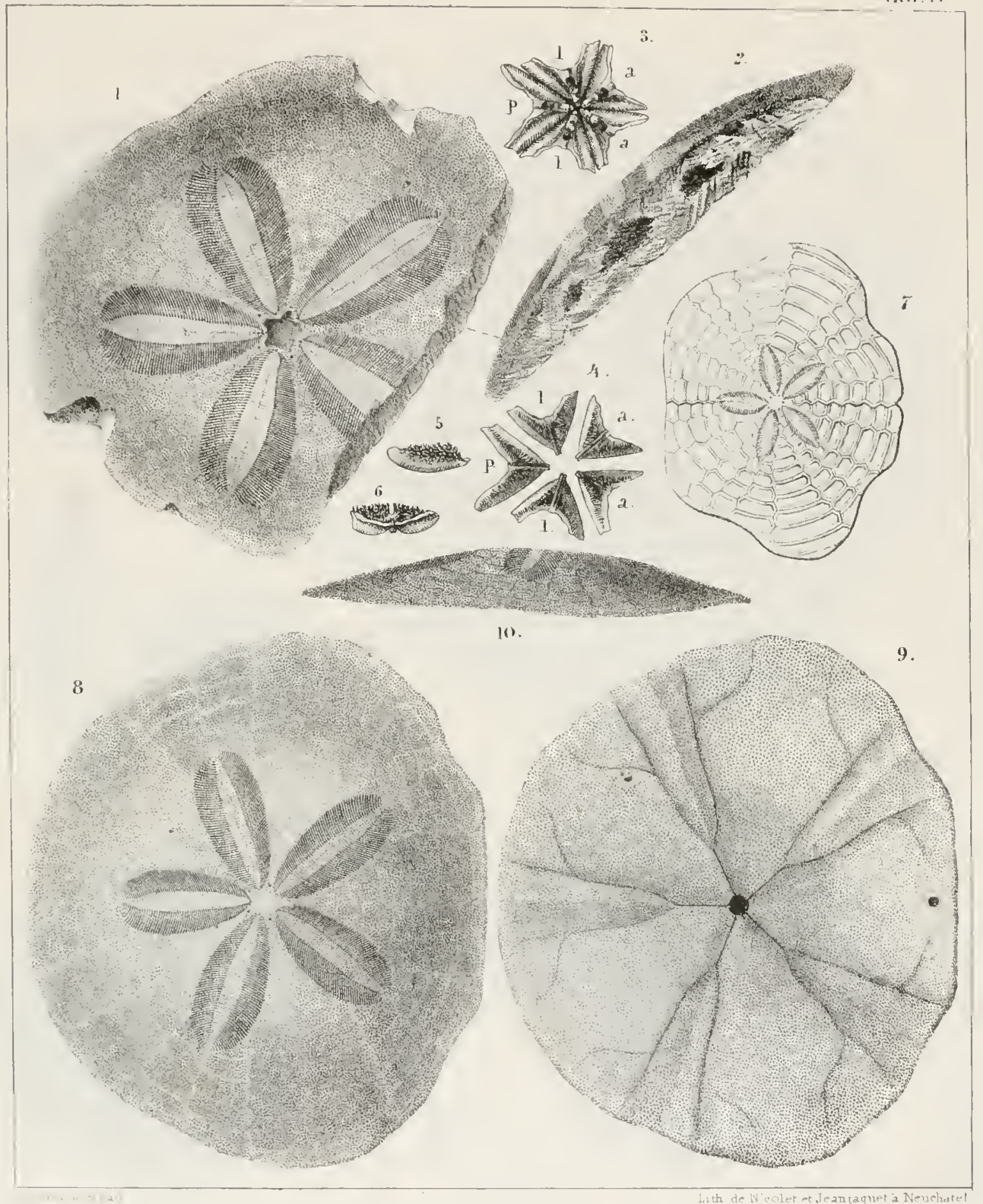

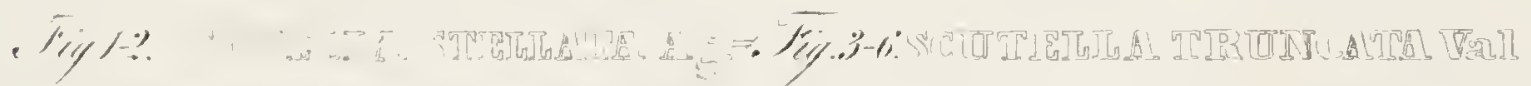

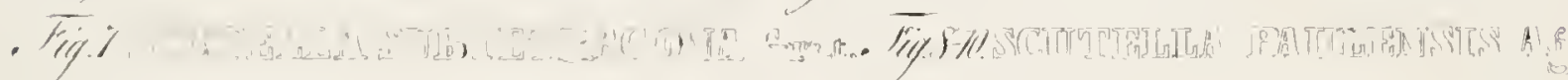





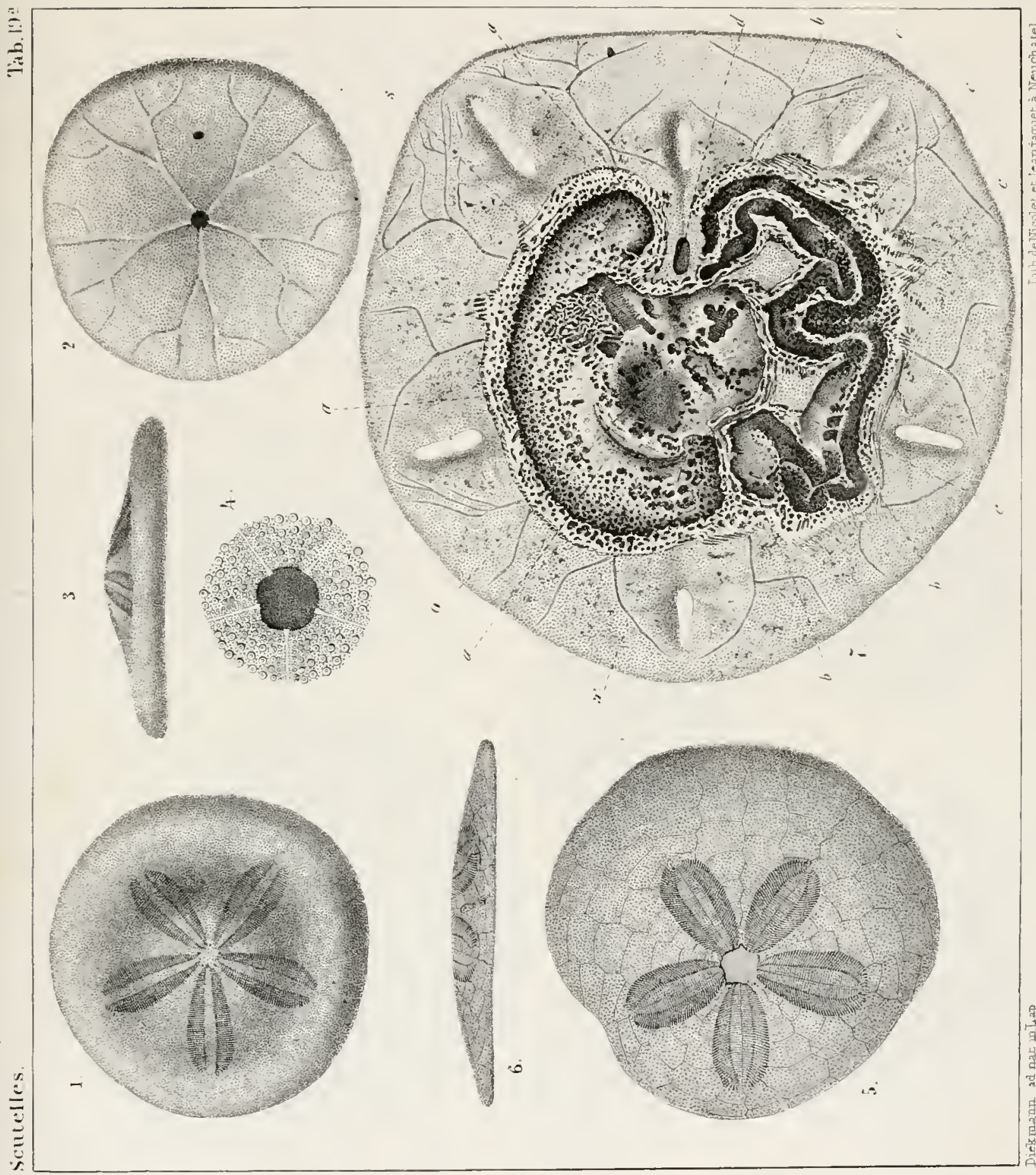





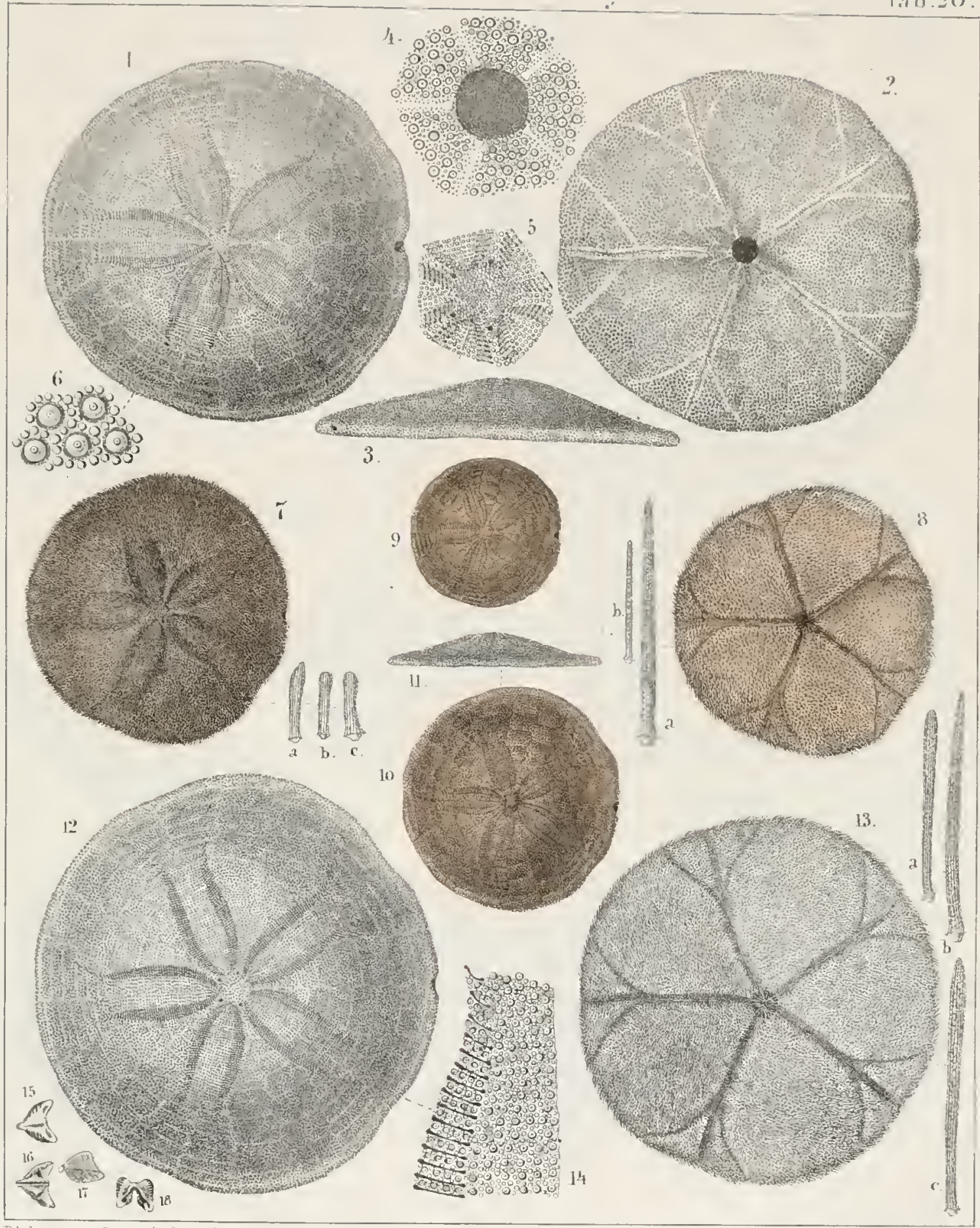

Diekmasn ad nat in l.ap.del.

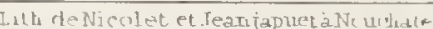

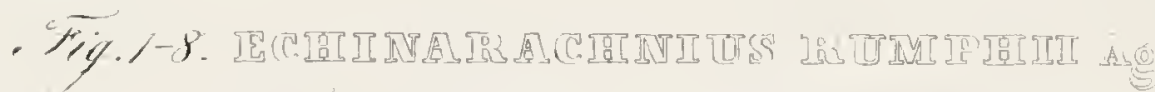

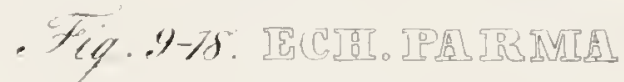





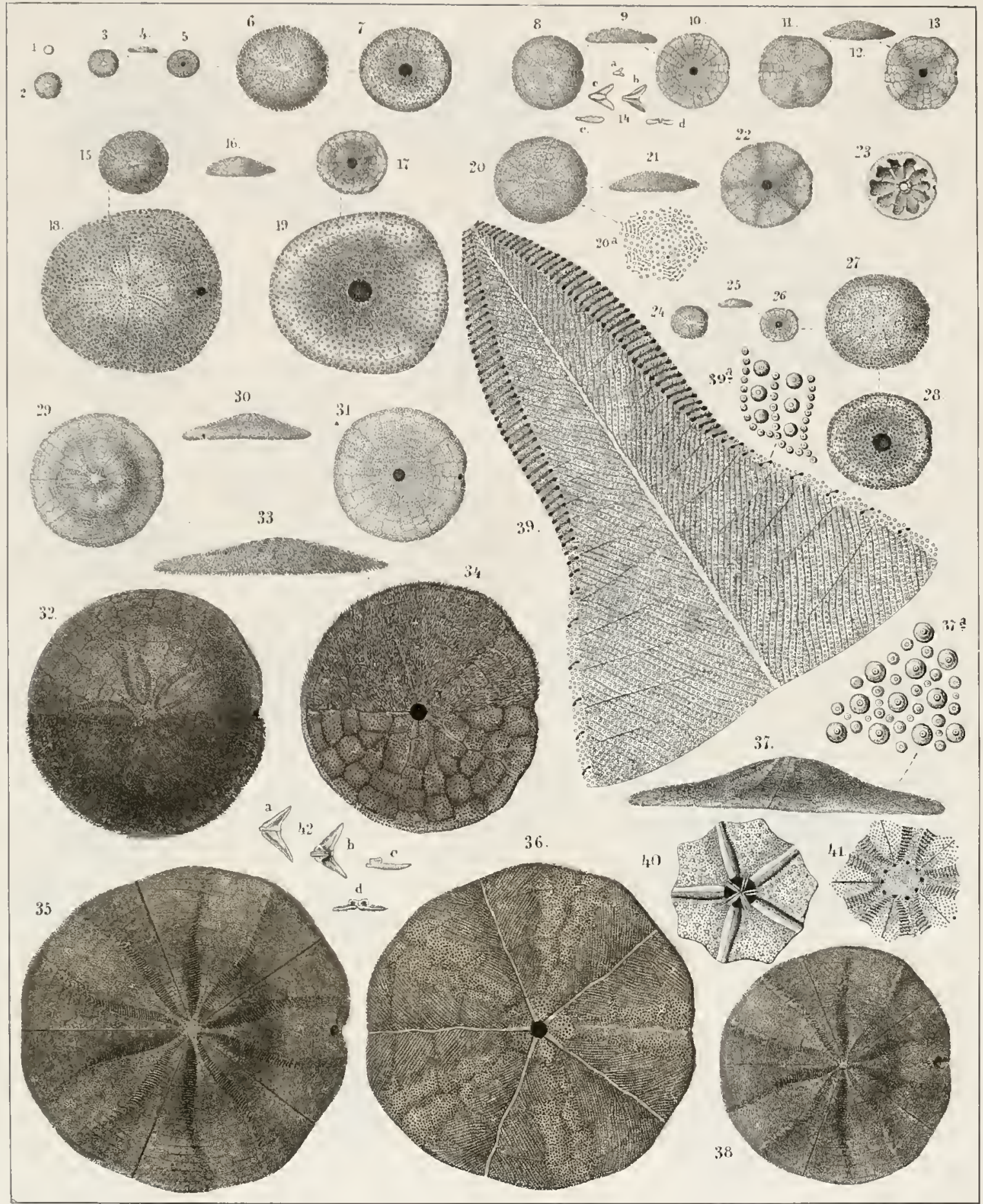

Fiy.

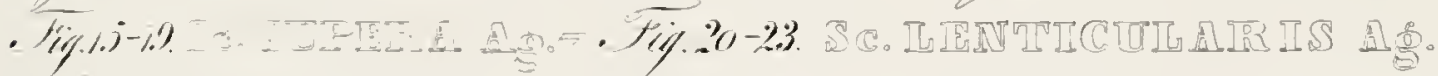

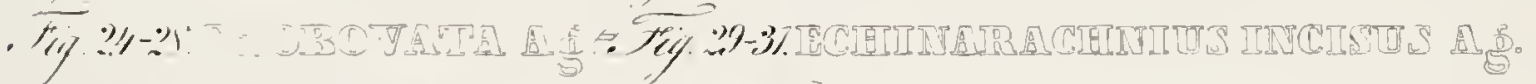

- "1\%.\%:\% 



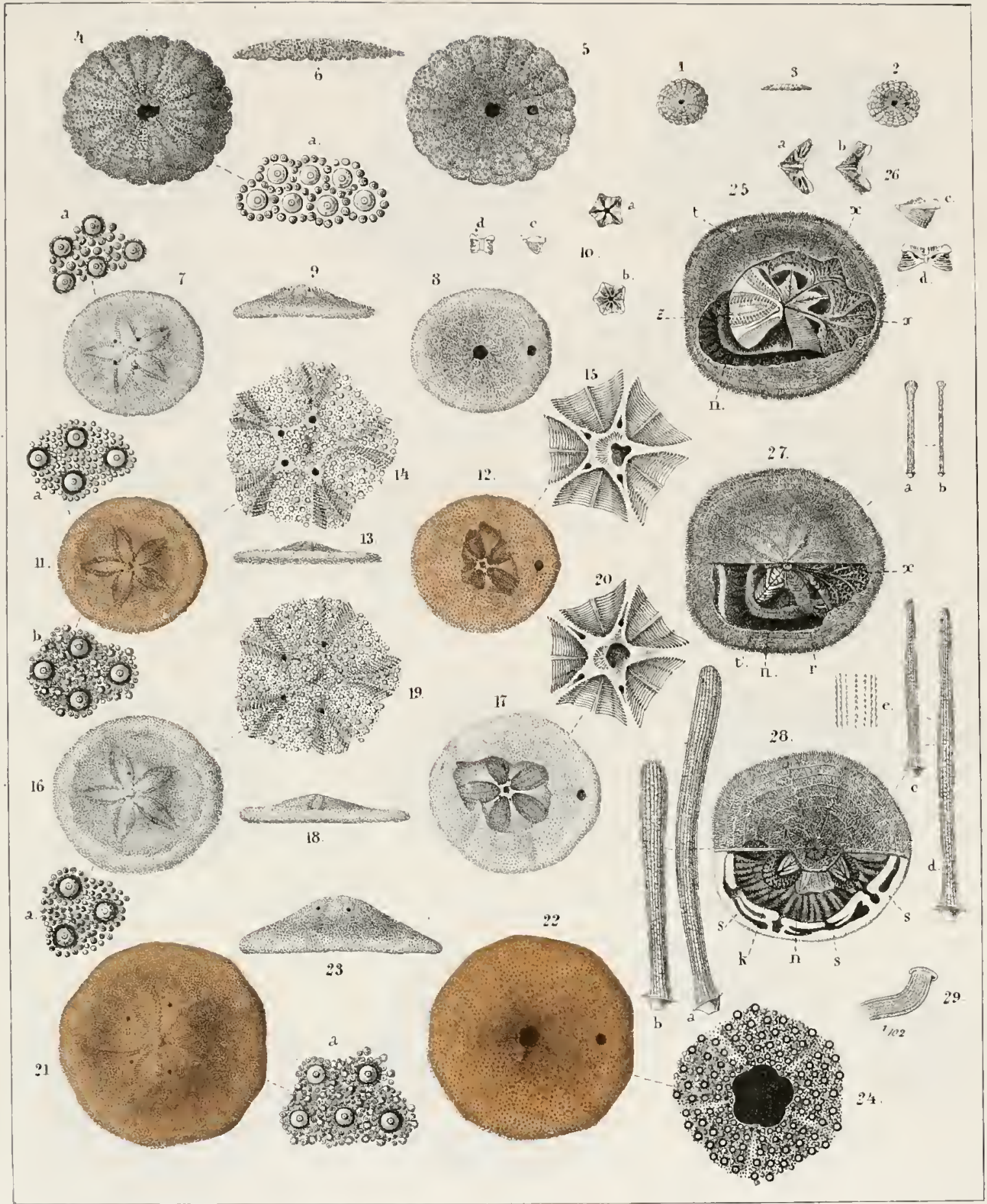

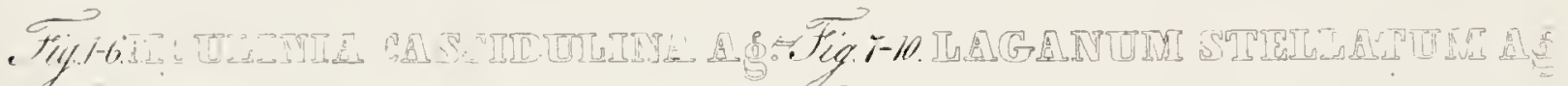

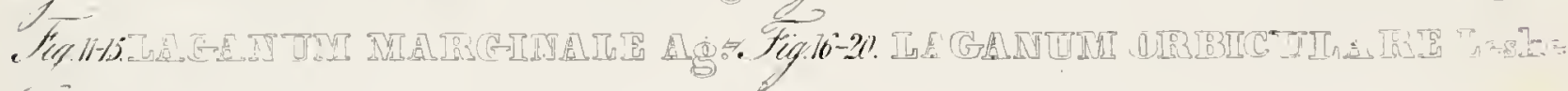

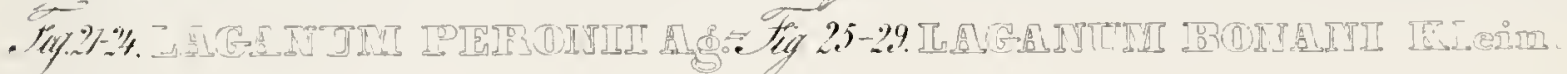





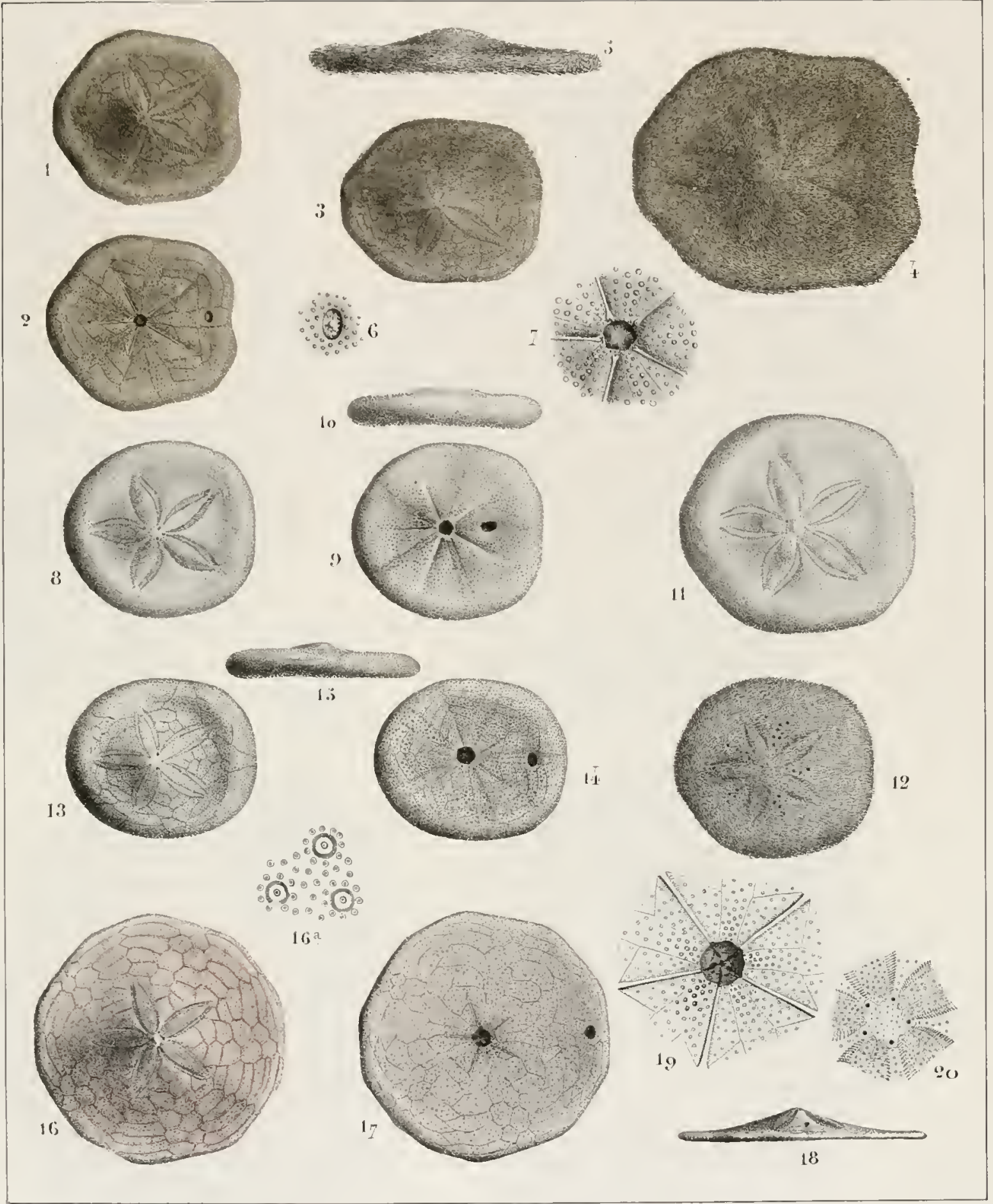

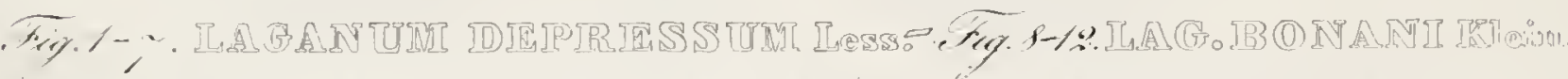

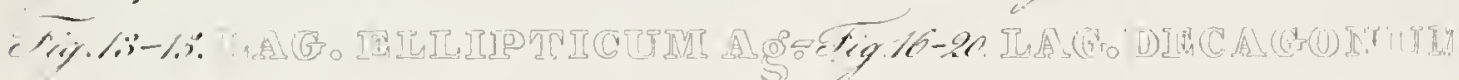





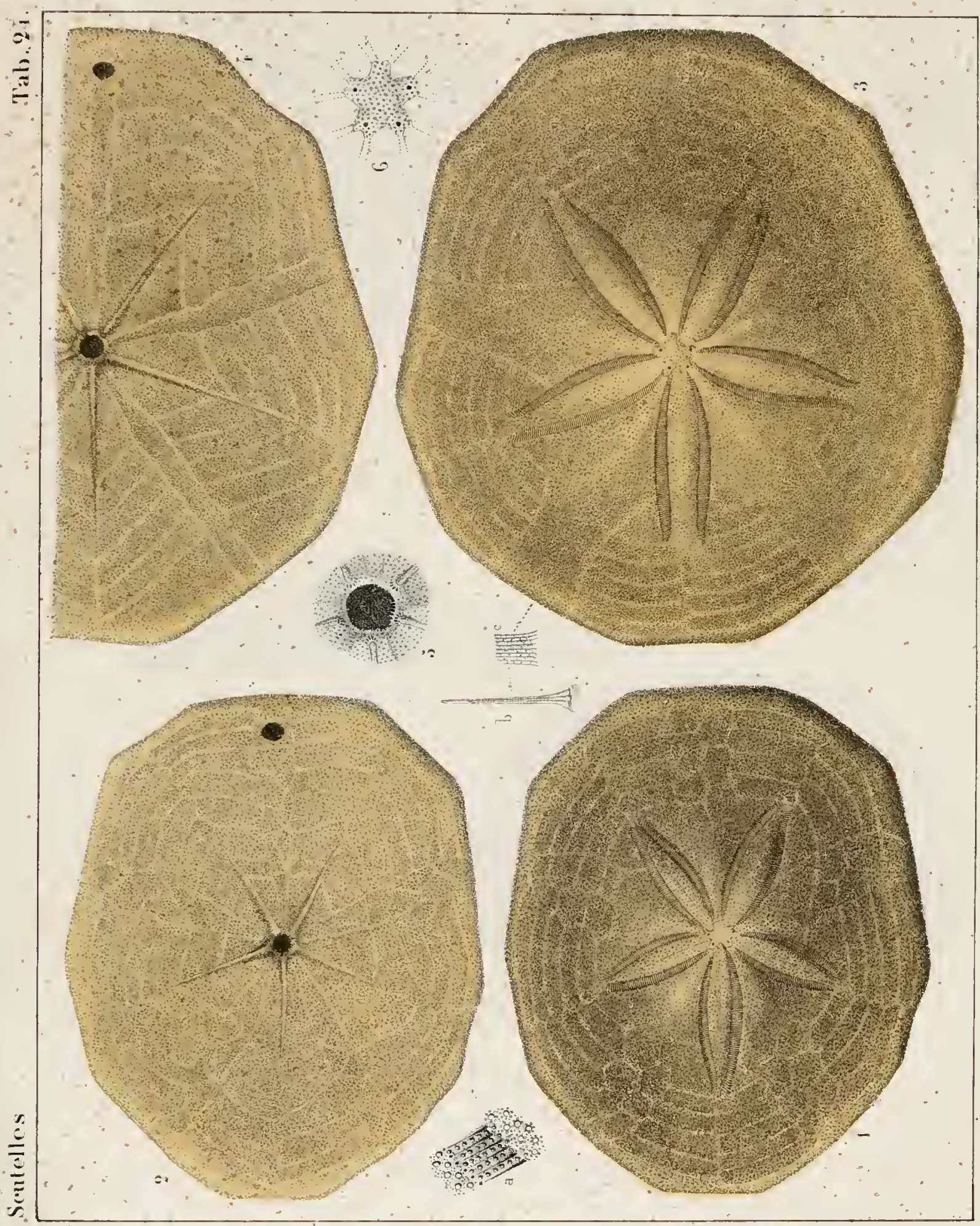





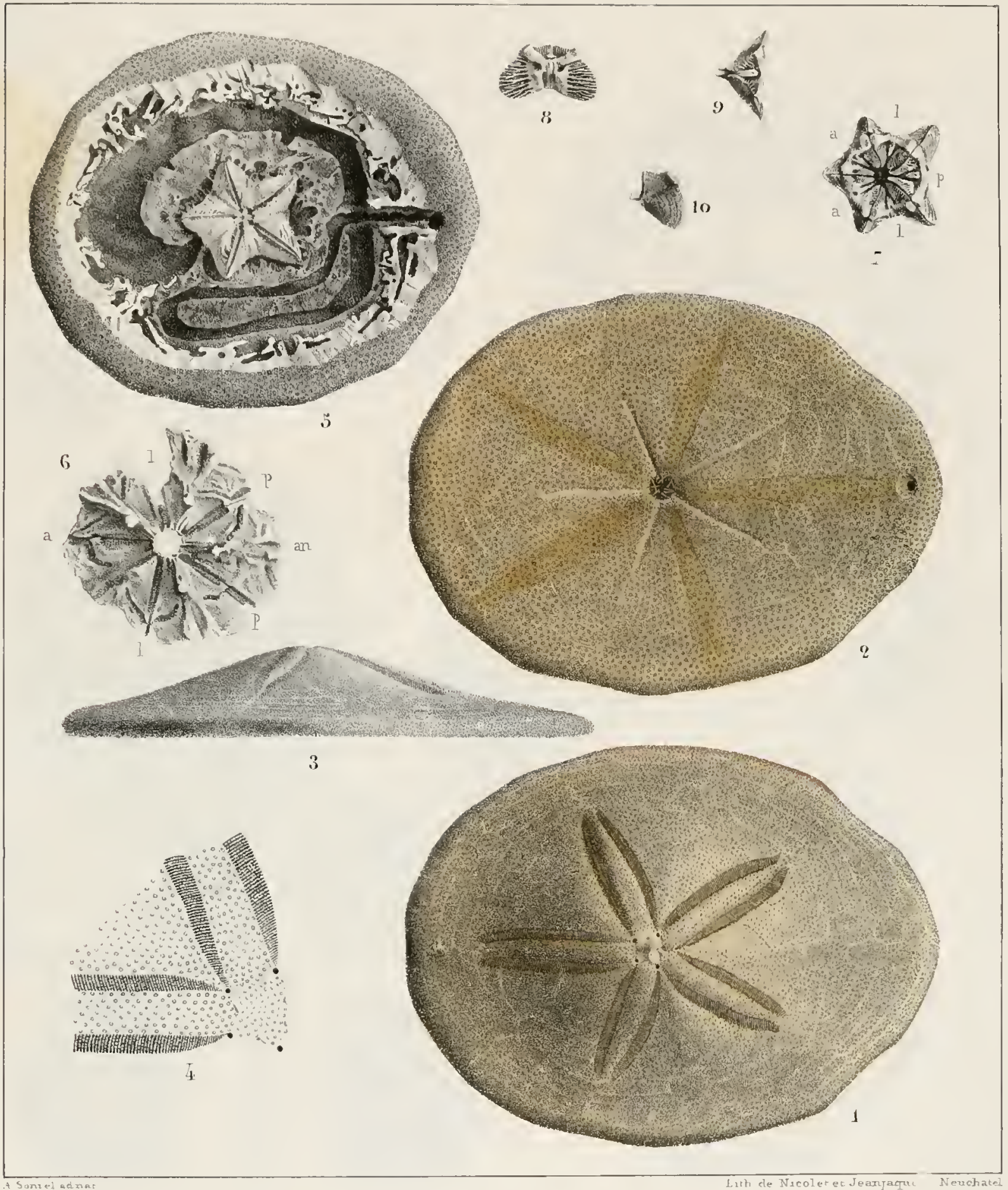

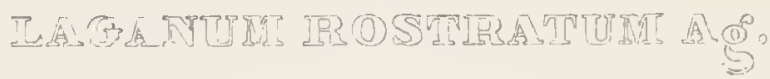






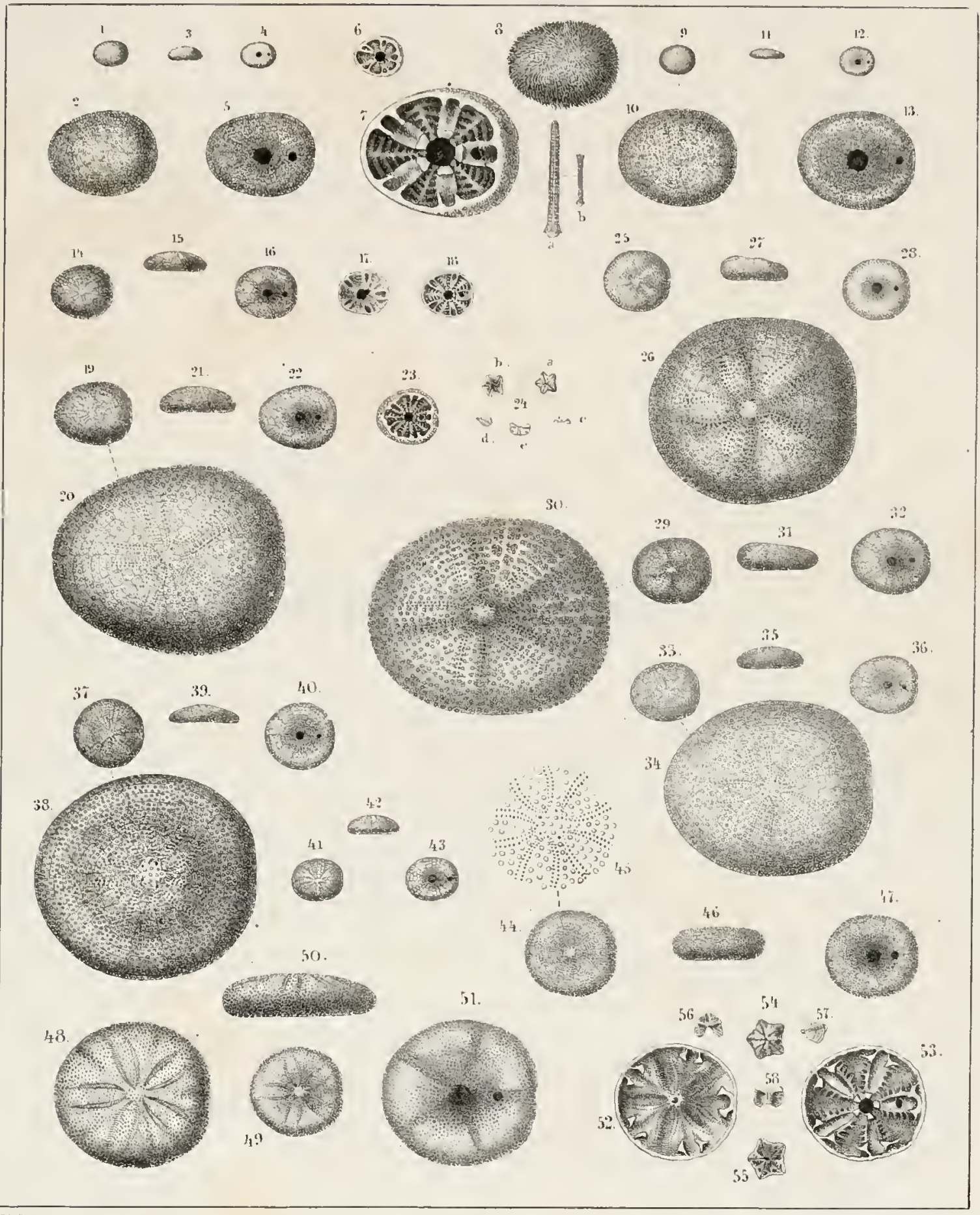

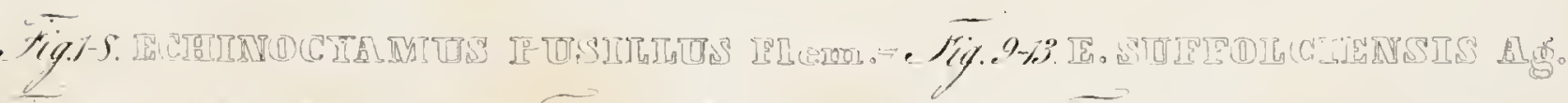

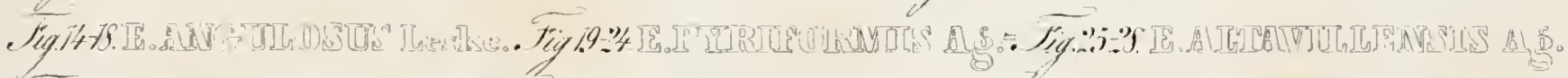

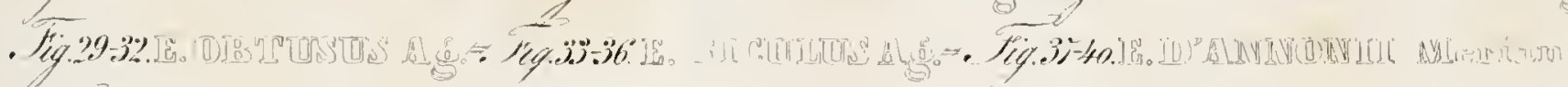

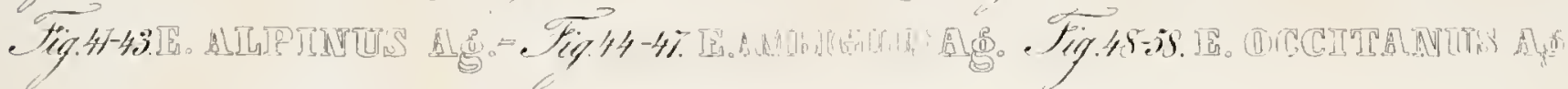





\section{MONOGRAPHIES}

\section{DP:GTINODRRMIRS.}




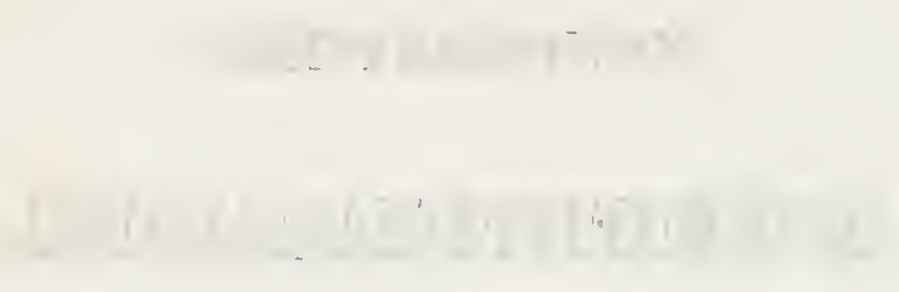




\section{ÉCHINITES.}

FAIILLLE DES GLIPEASTROIDES.

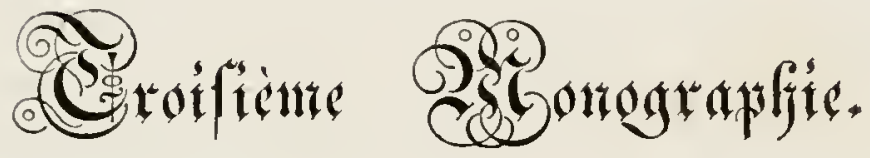

\section{DES GALÉRITES.}

BD。DESDB。

1842. 


\section{PRÉ ICE.}

En livrant ce travail au public, j'éprouve le besoin d'en dire cn peu de mots l'histoirc. Lié d'amitié depuis plusicurs annécs avec MI. Agassiz, j'eus le bonheur de prendre part à quelques-uncs de ses nombreuses rccherches scicntifiques. L'étude des Echinodermes en particulier eut pour moi un grand attrait. M. Agassiz, désirant activer la publication de son ouvragc sur cette classe d'animaux, me proposa d'élaborer et de rédiger une livraison de ses Monographies, et, non content de me communiquer les matériaux dont il disposait, il consentit à revoir toutcs mes épreuves, afun d'en partager en quelque sorte avec moi la responsabilité.

Cette livraison se compose de deux Monographies comprenant, la première, le groupe des Galérites, et la scconde, le groupe des Dysastres. J'ai choisi ces deux types de la famille des Clypéastroïdes, de préférence à tous les autres, parce qu'il m'a paru qu'ils étaient de tous les Echinites ceux dont la synonymie avait lc plus grand besoin d'ètre revue, et que bon nombre d'espèces qui passent pour des fossiles caractéristiques de certaines formations, se trouveut citćcs sans critique dans unc foule de terrains. Aussi me suis-jc particulièrement appliqué à mettre en lumière lcs caractères distinctifs des espèces les plus communes, en les décrivant comparativement aux autres espèces qui s'en rapprochent le plus; persuadé que c'est le mcilleur moyen de préciser la limite des espèces et de leur assurcr une valeur réelle dans la grande question du mode de succssion et de liaison génétiques des animaux à la surface de la tcric. 
A l'exemple de M. Agassiz, j’ai réuni dans ce travail les espèces vivantes et les fossiles des groupes dont je m'occupe; les premières sont cependant peu nombreuses et se boruent au scul genre des Echinonées; les fossiles sont sans exception des animaux des ćpoques jurassique et crétacće.

Souvent les différences spécifiques sont peu apparentes; mais c'est là le propre des Echinites, que leur test, par là même qu'il est intimement lié à l'organisation de l'animal, offre jusque dans ses plus menus détails, une précision et une constance qu'on chercherait en vain dans le test des antres animaux testifères. Dans beaucoup de cas, et surtout lorsqu'il s'agit de petites espèces, il est presque indispensable, si l'on veut arriver à des déterminations rigoureuses, d'avoir recours à des grossissemens artificiels. C'est ce qui m'a engagé à donner des figures grossies de la plupart des espèces; et comme les grossissemens employés sont toujours les mêmes, je me suis contenté de dire, dans la description, que tels grossissemens sont à la lonpe et tels autres au microscope. Ceux à la loupe sont d'un diamètre et demi; ceux au microscope de 19 diamètres.

Il est vrai que lorsque les différences spécifiques reposent uniquement ou essentiellement sur des détails qui exigent une si grande attention, il faut avoir à faire à des exemplaires bien conservés, pour pouvoir se prononcer avec une entière certitude. Quand ces détails manquent, on doit user de beaucoup de circonspection dans la détermination spécifique: aussi n’ai-je pas cherché à cacher mes doutes lorsqu'il m'cn est resté; je me suis alors borné à décrire des formes, une réservant de vérifier mes observations sur des individus plus parfaits qui ne manqueront pas de surgir tôt on tard.

Un fait important se trouve néanmoins confirmé d'une manière positive par l'ćtude des Lehinites, qui font le sujet de ces monographies : c'est qu'il u'existe pas diespèce idlentique dans des fornations diverses: il y a plus; cette loi s'étend aussi aux différens étages d'une seule et mème formation; et je crois pouvoir affurmer que les espèces de l'oolite inférieure sont constannuent différentes de celles du Jura supérieur et moyen, et de même que les espèces du néoconien n'ont rien de commun avec celles de la craie supérienue. Peut-citre s'écoulcra-t-il encorc beaucoup de temps avant que les paléontologistes, qui s'occupent des différentes classes dı règue animal, arrivent au même résultat. Pour ma part, j’insiste d'autant plus sur ces conclusions, qu'mn 
paléontologiste éminent, M. Brom, a émis récemment (Jahıbuch fïr Mineralogie, 1842) une opinion diamétralement opposée. Je ne saurais décider jusqu'it quel point les exemples qu'il tire des Mollusques à l'appui de ses allégués, sont londés; j'ai rérifié ceux qu'il emprunte à la elasse des Echinodermes, et je les ai trouvés erronés.

Afin de simplificr autant que possible les descriptions, j'en ai élagué tons les caractères communs à la totalité des espèces pour les répartir dans les descriptions génériques qui figurent en tète de chaque chapitre et qui contiennent, outre l'exposé des caractères dı genre, le résumé de leurs rapports géologiques et de lenrs conditions d'association dans les différens terrains. L'introduction eontient le tableau des groupes et l'étude des principaux organes et de leurs fonctions en tant qu'ils sont comnus.

A la fin de chacune de ces deux monographies se trouvent en ontre un tableau de la répartition géologique et géographique des genres et des espèces, et un résumé des caractères diagnostiques, génériques et spécifiques.

Si, présentées de cette manière, mes recherehes peuvent ètre de quelque utilité aux géologues et aux zoologistes, e'est pour mon célèbre ami que j’en revendiqnerai l'honncur; car si e'est avec son appui, e'est aussi dans son esprit que ces pages ont été élaborées. Fort de cette conscience, je n'ai pas hésité à signaIer les crreurs que j’ai rencontrécs sur mon chemin, et je dois dire que toutes les corrcetions que j'ai apportées dans l'étude de ces animaux, ont étć approuvées par H. Agassiz, mème celles qui concernent ses propres travaux.

Les planches qui accompagnent ces Monographies ont été cxécutées dans l'Institut lithographique de M. Nicolet à Neuchitel, et sont dues sans exception an crayon habile de M. Diekmaun, qui les a lithographiées d'après uature.

Je termine en adressant des remerciemens sincères à tous ceux qui ont bien voulu me confier des matériaux et des renscignemens pour ee travail. Je m'estime heureux d'avoir à inscrire ici les noms de MM. Brongniart, DeLinc, Studer, Mérian, DuBois de Montpéreux, Coulon, le Marquis de Northampton, le Comte de Münster, le Comte de Mandelslohe, Alcide d'Orbigny, Hardouin Michelin, Paul DeslIayes, Eudes DesLongehamps, Ibbetson, Latrobe, Alphonse Favre-Bertrand et le Doct. Mayor, de Genève.

Les principaux ouvrages que j'ai consultés pour ce travail et dont les titres fignrent en abrégé dans la synonymie, sont: 
Klein. Naturalis dispositio Echinodermatum. Edt. Lcske, in-4º 1778.

Goldfuss. Petrefakten, etc. Le grand ouvrage sur les Pétrifications de l'Allemagne.

Charles DesMoulins. Etudes sur les Echinites de Bordeaux, 1833-1837.

Agassız. Prodrome d'une Monographie des Radiaires, dans les Mémoires de la Soc. des Sc. nat. de Neuchàtel, vol. I, 1835.

" Description des Echinodermes fossiles de la Suisse, $1^{\mathrm{ro}}$ et $2^{\mathrm{c}}$ partie, in $-4^{\circ}, 1839-1840$.

" Catalogus systematieus Ectyporum Echinodermatum fossilium Musei Neocomensis, in- $4^{\circ}, 1840$.

Brons. Lethæa geognostica 1840.

Lamarck. Histoire naturelle des animaux sans vcrtèbres, $2^{\text {me }}$ édition, 1840 .

Il serait trop long de donner ici le titre de tous les ouvrages de géologie, de zoologie et dc palćontologie qui contiennent quelques figures ou descriptions de Galérites et dont il est fait mention à l'occasion de quelques espèces seulement. M. Agassiz se propose d'ailleurs de publicr dans une des procliaincs livraisons qui servira d'introduction générale à eet ouvrage, un résumé de toute la littérature concernant cette classe d'animaux. 


\section{IITRODICTIOI.}

Le groupe des Galérites qui fait le sujet de cetle monographie, appartient à la fanille des $C$ lypéaströ̈des, c'est-à-dire à cette division des Echinites dont le caractẻre distinctif est d'avoir la bouche centrale et l'anus excentrique. Mais comme les Oursins qui participent à ce caractère sont fort nombreux, on a cherché, afin d'en faciliter l'étude, à les grouper suivant leurs affinités les plus naturelles, et il n’a pas été difficile de distinguer dans les Clypéastroïdes, ainsi que dans les Cidarides, plusieurs ensembles plus ou moins nettement circonscrits. C'est ainsi que II. Agassiz a rẻuni, dans son groupe des Scutelles, un certain nombre de genres qui, bien que fort dislincts, se lient cependant par plusieurs caractères communs. Le lien principal qui unit entre eux les genres du groupe des Galérites, consiste moins dans leur physionomie extérieure que dans la conformité de certains traits de leur organisation intinte, et notamment dans la forme des ambulacres, qui est beaucoup plus simple que clıez les autres Clypéastroïdes, en ce sens, qu'au lieu d'être pétalö̈des et hornées, les zones porifères s'étendent sans interruption du sommet ả la bouche. Cette particularité de structure m’a paru d'autant plus importante qu'elle correspond, selon toute apparence, à une différence d'organisation dans le système de la respiration de ces animaux. En effet, nous savons, par les recherches de MII. Tiedenann et Valentin, que les tubes ambulacraires, auxquels les pores des ambulacres donnent passage, ne sont pas seulement des organes locomoteurs, mais qu’ils communiquent aussi directement avec les lranchies internes, en servant d’intermédiaires à la respiration. Dès lors, quoi de plus naturel que d’en conclure que leur distribution a la surface du test implique une structure, ou au moins une disposition particulière des organes respiratoires à lintérieur? Sans doute ces donnẻes ne sont pas vérifiées par l'autopsie, car nous ne connaissons malheureusement encore l'anatonie d'aucun Oursin de la famille des Clypéastroïdes, et nous n'ayons, pour nous guider, que l'analogie que l'on doit sup- 
poser exister entre les Oursins de cette famille et les vrais Echinus. Cependant, il résulte des observations que M. Agassiz a pu faire sur quelques espèces du groupe des Scutelles, que dans ces animaux, dont les ambulacres sont pétaloïdes, les organes branchiaux ne sétendent que jusqu’à l'extrémité des pétales ambulacraires. Au delí de ces pétales, et surtout à la face inférieure, les pores donnent bien aussi passage à des tubes ou suçoirs très-délicats ; mais les feuillets spongieux et réticulés que ce savant envisage comme les branchies ne se retrouvent plus; d'oủ l'on est en quelque sorte conduit à en conclure que, dans les Clypéastroïdes à ambulacres bornés, les tubes ambulacraires servant à la respiration extérieure sont limités à la face supérieure et ne s'étendent point au delà des pétales. Rien de semblable n'existe dans les Galérites ou Clypéastroïdes à ambulacres simples. En revanche, l'analogie est complète entre ces derniers et les vrais Echinus. Or comme, dans ceux-ci, les tubes ambulacraires communiquent avec les branchies dans toute la longueur des zones porifëres, depuis le sommet jusqu'à la bouche, pourquoi n’en conclurions-nous pas qu'il en est de même dans les Clypéastroïdes à ambulacres simples ? Nous aurions, de cette maniere, dans la forme et la disposition des pores ambulacraires, l'expression d'une particularité essentielle de l'organisation des animaux, qui respireraient d'une manière uniforme par tous les pores de leur test, tandis que les Clypéaströ̈des à ambulacres bornés, tels que les vrais Clypéastres, les Scutelles, les Echinolampes, Ies Nucléolites, etc., affecteraient, à leur face supérieure, dans les limites de leurs pétales, un mode de respiration particulier.

Ces caractères paraîtront peut-être un peu spécieux; peut-être aussi encourront-ils le doute des anatomistes, qui ont I'labitude de vérifier, le scalpel à la main, les caractères sur lesquels on prétend établir les divisions du régne animal. Nais si l'on se rappelle que la plupart des genres que je fais entrer dans ce groupe sont composés uniquement d'espèces fossiles, à l'exception du seul genre Echinonée, dont il n'existe, à ma connaissance, aucun exemplaire conservé à l'esprit de rin', dans les collections d'Europe, on comprendra limportance que jaattache à ce caractère en apparence si secondaire.

J'eusse sans doute été heureux si j’avais pu trouver dans la structure de l'appareil masticatoire des caractères qui vinssent à l'appui de la division que je propose; nais je dois commencer par déclarer que jignore complètement la structure de cet appareil si important pour la classification, et je ne sache pas non plus qu'il en ait jamais été donné la moindre description. Tout ce que l'on sait à cet égard, c'est que cet appareil existe. M. Stokes possède un exemplaire d'un Galcrites albogalerus dans lequel on aperçoit les extrémités des mâchoires faisant saillie sur le pourtour de l'ouverture buccale (Tab. XIII, fig. 7). Quand mème on ne posséderait pas cette 
preuve directe de leur existence, on pourrait encore linférer de certains autres caractères, tels que la présence de certains petits bourrelets sur le pourtour intérieur de l'ouverture luccale, bourrelets qui élaient évidemment destinés à servir d'appui aux mìchoires.

Les autres parties du test présentent des différences fort notables qui constituent les différens genres du groupe, et que nous allons successivement passer en revue.

L'oucerture buccule du test est généralement anguleuse et, lans le principe, décagonale, alors mème qu'elle paraît eirculaire. Les Echinonées seuls font exception. Ce caractère sert à distingruer ce groupe de la plupart des autres Clypéastroïdes, qui ont en général la bouche allongée transversalement et simplement pentagonale, comme, par exemple, les vrais Clypéastres, les Clypeus et les Nucléolites. Quelques genres, tels que les Pygaster et les Discoïdées, ont en outre le pourtour de l'ouverture buccale garni d'entailles à l'endroit des sutures des aires ambulacraires arec les aires interambulacraires, et rappellent, sous ce rapport, les Cilarides.

L'amus, toujours grand, et en général elliptique ou pyriforme, oscille entre la bouche et le sommet; il est inframarginal dans les Discoïdées et les Echinonées, marginal dans les Galérites, supramarginal dans les Pyrines, et trẻs-rapproché du sommet dans les Pygaster, les Nucleopygus et les Hyboclypus. J'ai pu m’assurer, par un exemplaire d'une Echinonée et par une espéce de Discoülée, qu’il est recouvert de plaques calcaires de limensions variables, qui s’écartaient pour domner passage aux excrénens, comme cela s'opère dans les Echinus. Ces plaquettes anales sont mème revêtues de petits tuhercules; te qui fait supposer qu'elles étaient velues comme le reste du test.

L'appareil génital, invariablement situé au sommet du test, est en général composé de cinq plaques génitales, entre lesquelles sont insérées les plaques ocellaires. La grandeur relative de ces plaques varie suivant les genres. La plaque génitale impaire est surtout sounise à des variations notables; tantot elle l'emporte sur les plaques paires, comme dans les Discoïlćes; d'autres fois elle est plus petite et atrophiée ; enfin elle est constamment imperforée. Les cinq plaques gẻnitales et les cinq plaques ocellaires forment entre elles un anneau distinct autour d'un bouton d'apparence spongieuse, qui est le corps madréporiforme. Ces détails de structure, quoique très-importans, puisqü̈ls sont liés aux organes les plus importans de l'animal, noffrent cependant que de faibles ressources à la détermination des espéces et mème des genres, par la raison qưeétant extrêmement délicats, ils sont rarement assez lien conservés dans les espéces fossiles pour pouvoir être étudiés exactement.

L'extérieur du test présente une variété très-grande de détails; on y distingue, comme dans 
tous les Echinites, deux sortes de tubercules, les uns plus gros, connus sous le nom de tubercules principaux, et d'autres, plus petits, appelés tubercules miliaires. Ces derniers sont excessivement nombreux, et parfois si fins, quil est impossible de les reconnaître autrement qu’à la loupe. Les tubercules principaux sont tantôt disposés par séries verticales, et tantôt répartis sans ordre a la surface du test. Ceux de la face inférieure sont constamment plus développés que ceux de la face supérieure, qui diminuent de grosseur à mesure qu'ils approchent du sommel. Quant à leur structure, ils sont en général mamelonés, et leur mamelon, séparé de la base par un étranglement, est généralement perforé à son sommet et crénelé à son pourtour. Le seul genre des Echinonées fait encore ici exception; non seulement la base du mamelon n'est pas crénelée, mais le sommet est aussi imperforé.

Les piquans qui s'articulaient sur ces tubercules ne nous sont encore connus dans aucun genre fossile; nous n’en avons une idée que par les piquans des Echinonées que jai eu le bonheur d'examiner sur un exemplaire de l' $E$. conformis. Ils sont excessivement petits, ayant à peine une ligne de long. Mais, examinés sous un grossissement considérable, ils se montrent pourvus de carènes très-distinctes, à-peu-près comme les piquans des Scutelles, et présentent, en outre, des divisions transversales assez marquées (Tab. VI, fig. 21). Suivant que les tubercules principaux sont plus ou moins nombreux, ces animaux devaient paraitre plus ou moins velus, et l'on peut admettre qu'en général ils étaient ras, à 'l'exception, peut-être, des Pygaster et de certaines Discoïdées, dont les tubercules plus développés portaient sans doute des piquans un peu plus longs.

Les plaques coronales qui composent le squelette du test ne présentent rien de particulier; celles des aires interambulacraires sont beaucoup plus grandes que celles des aires ambulacraires; elles atteignent leur plus grande longueur au milieu de la circonférence. Leur lauteur est à-peu-près uniforme dans toute la série, ce qui prouve, qu'arrivés à une certaine taille, elles s'accroissent uniquement en longueur. Les plaques des aires ambulacraires sont beaucoup plus petites; il y en a souvent quatre, et mème cinq pour une plaque interambulacraire. Leur forme est plus ou moins régulière, suivant les genres. Les pores ambulacraires s'ouvrent, en général, sur leur bord externe; rarement au milieu des plaques. Lorsque les plaques sont irrégulières, on roit une partie des pores s'ouvrir dans de petits écussons particuliers intercalés entre les plaques primordiales, comme c'est, par exemple, le cas des Galérites. Les pores sont disposés par paires obliques formant, par leur superposition, des lignes trẻs-régulières qui s'étendent du sommet jusqu'à la bouclıe. Quelquefois, cependant, cette uniformité est interrompue à la face inférieure, oủ l'on aperçoit plusieurs rangées obliques composées de trois ou quatre paires. 
Les moules interieurs sont fort nombreux dans certains terrains, et comme ils montrent d'une manière fort distincte l'articulation des plaques, on peut, toutes les fois qu'ils ne sont pas déformés, reconnaître le geure et mème souvent l'espèce à laquelle ils appartiennent. Il est d'autant plus important d'avoir égard à ces moules, que certaines espèces ne se rencontrent guère que sous cette forme. Une particularité sur laquelle je crois devoir insister dès maintenant, c'est que les ouvertures buccale et anale paraissent ordinairement plus grandes qu’à la surface du test. C'est une conséquence de la forme du pourtour de ces ouvertures à la face interne du test, dont il faut savoir tenir compte dans la détermination spécifique.

Si nous résumons tous ces caractères, nous trouverons qu’en définitive le groupe des Galérites présente des affinités assez nombreuses avec certains genres de la famille des Cidarides, entre autres avec les vrais Echinus et les Diadèmes. Les Discoïdées et les Pygaster sont particulièrement propres à faire naître l'idée d'un pareil rapprochement. En effet, la forme et la pliysionomic générales sont les mêmes; l'ouverture buccale présente les mêmes entailles; l’appareil génital est construit sur le mème plan; les tubercules sont mamelonés et crénelés de la même manière, et nous savons que, dans les Discoïdées et les Pygaster, ils sont disposés en séries verticales régulières. Ces analogies sont, d'un autre côté, balancées par la différence de position de l'anus, qui n’est jamais complètement apicial dans les Galérites. Mais tout en reconnaissant l’importance de cette position de l'ouverture anale qui, par cela mème qu'elle est invariablentent liée à l'appareil génital, dans toute la famille des Cidarides, semble impliquer un plan d'organisation important pour la classification de ces animaux, je crois cependant qu'on lui a accordé une valeur trop prépondérante. Les oscillations considérables de cet organe, dansles genres qui composent le groupe des Galérites, pourraient au besoin venir à l'appui de celte opinion. Cependant, la question de l'affinité eutre le groupe des Galérites et des Cidaris ne pourra être complètement résolue que lorsque l'on connaitra exactement la structure de l'appareil masticatoire dans les Galérites. Si par lasard l'on venail à démontrer que les mâchoires sont combinc̉es entre elles de manière à former un organe compliqué, tel que la lanterne d'Aristote dans les Cidarides, je pense qu'il ne faudrait pas hésiter ả proclamer le rapprochement dont il est ici question ; tout comme l'affinité entre les vrais Clypéastres et les Galérites n'en deviendrait que plus intime, si l'on trouvait que l'appareil masticatoire est composé de grosses mìchoires juxta-posées comme celles des vrais Clypéastres et des Scutelles.

Les anomalies paraissent être plus fréquentes dans ce groupe que dans aucun autre de la famille des Clypéastroïdes. Les auteurs les ont en général envisagées comme autant d'espèces dis- 


\section{$-6-$}

tinctes : aussi voyons-nous les Gal. sexfasciatus et Gal. quadrifasciatus figurer parmi les espèces les plus connues, quoique l'un et l'autre ne soient que des monstruosités du Dise. cylindrica. C'est d'ordinaire une aire ambulacraire, accompagnée de deux demi-aires interambulacraires, qui manque ou qui est surnuméraire. Dans la monstruosité par défaut, que j’ai représentée dans la Tab. VIII, fig. 8-11, c'est l'aire ambulacraire antérieure qui manque. Dans le Gal. sexfasciatıs de Lamarck, cette même aire ambulacraire est double. Cette particularité, comme l'a déjả démontrẻ II. Agassiz (seconde monographie contenant les Scutelles p. 100), correspond parfaitement au plan de structure de tous les Echinodermes, chacun de leurs cinq segmens étant composé d'une aire ambulacraire et de deux demi-aires interambulacraires. Cependant, à côté de ces anomalies, qu'on pourrait jusqu’à un certain point appeler régulières, il en en existe d'autres plus profondes. J'ai représenté dans la Tab. XIII, fig. 4, 5 et 6, un individu du Gal. vulgaris, qui n’a que trois ambulacres à la face supérieure; mais si l'on vient à l'examiner attentivement, on trouve, sur le bord de la face inférieure, entre deux rangées de plaques interambulacraires, une aire interambulacraire rudimentaire sans trace d'ambulacre. Cette structure très-parliculière m’a paru assez importante pour que jaie cru devoir en donner une figure grossie (Tab. XIII, fig. 5 b).

La distribution géologique du groupe des Galérites présente un vif intérêt par les caractères particuliers de ses représentans aux différentes époques. Sa première apparition remonte à la formation jurassique. Nous trouvons dans l'oolite infẻrieure des Discoïdées el des Hyboclypes. L'étage du lias, si riche en fossiles, ne nous en a jusqu'à présent fourni aucune espèce. L'étage oxfordien, y compris le terrain it chailles ou corallien inférieur, contient encore des Discoïdées, mais d'autres espéces ; il en est de même du portlandien. Les vrais Galérites sont complètement étrangers à cette formation; et si nous comparons les Discoïdées jurassiques avec celles de la craie, nous verrons qu'elles appartiennent à un type fort différent de celui des Discoïdées crélacées, et dont j'ai fait une division a part, sous le nom de IIolectypus. Dans la formation crétacée, nous voyons d'abord prédominer les vraies Discoïdées, qui sont surtout propres aux étages inférieurs de cette formation, et, plus tard, apparaissent, dans les dépôts supérieurs de cette formation, les vrais Galérites, les Caratomes, les Nucleopygus, etc. En revanche, il n'existe plus aucune trace ni des Hyhoclypes, ni des Holectypes ou Discoïdées à moule intact. Les terrains de l'époque tertiaire ne nous ont encore offert aucune trace de ce groupe, et, dans l'ëpoque actuelle, nous ne le trouvons représenté que par les Echinonẻes, qui napparaissent plus que comme un écho lointain et altéré de ce type, tel qu'il existait dans les époques antérieures.

Ces rapports de distribution géologgique et géographique sont indiqués en détail dans le tableau qui fait suite à la description des espèces. 


\section{CIIAPITRE I.}

\section{DU GENRE GALERITES LAH.}

Autrefois les espèces de ce genre élaient connues sous le nom de Comulus, que leur avait donné Klein et qui fisi adopté par Leske et par les auteurs anglais. Lamarck le remplaça par celui de Galerites, en réunissant sous cette dénomination á-peu-près tous les Clypéastroïdes à ambulacres simples, à, l'exception des Echinonées. Peu-ä-peu, cependant, le besoin de nouvelles coupes se fit sentir. M. Gray commença par rëintégrer le genre Discoüdea dans ses anciens droits. M. DesMoulins, a s in tour, défalqua des Galérites son genre Pyrina, et M. Agassiz établit en outre, à leurs dépens (i) ses genres Pygaster, Caralomus, Nucleopygus et Globator. Il y eut moyen, dès lors, de limiter le genre des vrais Galérites d'une manière rigoureuse. Voici comment M. Agassiz le caractérise dans son Conspectus gen. et spec. Echinod. foss., annexé à ses Descriptions des Echinodermes fossiles de la Suisse : Ambinus subovalis, postice angustior; os subquinquangulare, longiudinale, facies inferior plana, anus posticus marginalis, ambulacra simplicia, poris simplicibus, ad peripheriem divergentibus. Cette diagnose résume d'une manière assez complète la physionomie de ces animaux. La forme renflée, parfois turritée, plus ou moins pentagonale et généralement rẻtrẻcie en arrière; l'anus elliptique, le plus souvent marginal et quelquefois supra-marginal;

(1) Par suite de cette nouvelle délimitation, une granłle partie des Galérites de Lamarck devra être reportée dans d'autres genres : son Galeriles cylindricus qui est synonyme du Gal. Iaukinsii et son Gal. rolularis (Subuculus) sont de vérifables Discoidces; les Gal. depressus, Gal. hemispharicus, appartienuent à la division des Holectypes ou Discoïdées jurassiques. - Les Gal. conoileus, Semi-globus, Patella, excenlvicus et scutiformis, sont des Clypéastroïdes a ambulacres pétaloïdes; les deux premiers rentrent dans le genre Conoclypeus de $\mathbf{H}$. Agassiz; le G. Palella dans le genre Clypens. Le Gal. excentricus (qui n'est pas le Gal. excentricus de Grateloup) parait étre un moule intérieur d'une espéce d'Echinolampe; le Gal. sculiformis est un Echinolampe. - Le Gal. umbrella est un Pygaster. - Le Gal. sulcalo-radialus Gldf. esl uu Caratome. - Le Gal. fissuralus n'est vrai-

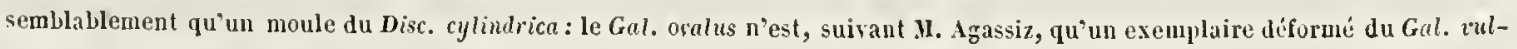
guris. - Enfin le Gal. speciosus Gluf. est une Discoïdée jurassique. 
l'ouverture buccale anguleuse, allongée dans le sens du diamètre antéro-postérieur et située au milieu de la face inférieure qui est généralement plane; les ambulacres simples, à pores non réunis, tels sont en effet les caractères qui distinguent les Galérites proprement dites; mais, au nombre de ces caractères, il y en a qui sont communs à tout le groupe, par exemple, les ambulacres simples, et d'autres qui sont partagés par quelques genres seulement, telle que la forme de l'ouverture buccale, qui est la même dans les Galérites, les Pyrines, les Nucleopygus, les Globator et les Caratomus. Je crois devoir insister d'une manière toute particulière sur la forme anguleuse de l'ouverture buccale, par la raison que M. DesMoulins prétend, à tort, que les Galèrites, ainsi que les Pyrines, ont la bouche circulaire. Une pareille divergence d'opinion, relativement à l'une des parties capitales du test, aura lieu d'étonner tous ceux qui, n'étant pas familiarisés avec l'étude des Oursins fossiles, ignorent combien sont rares les individus parfaitement intacts. Il peut arriver que l'on parcoure toute une collection sans rencöntrer un seul exemplaire dont l'ouverture buccale ne laisse rien à désirer. Le plus souvent, cette ouverture paraît en effet circulaire ou ovale, parce que les bords en sont ébrêchés; mais si on·l'examine attentivement dans un exemplaire non endommagé, on ne manquera pas d'y reconnâtre dix angles obtus correspondlant aux sutures des aires ambulacraires avec les aires inter'mbulacraires, absolument comme dans les Discoïdées et les Cidarides.

L'articulation des plaques est ordinairement distincte dans les vrais Galérites. Les plaques des aires interambulacraires sont allongées dans le sens lorizontal et, sur le milieu du test, leur longueur égale et dépasse même le double de leur hauteur; mais il u'en est pas de même près de l’appareil génital, où les proportions sont inverses, en ce sens que la hauteur des plaques l'emporte sur leur longueur, et qu'à mesure que l'aire se rétrécit, les plaques se raccourcissent, sans perdre beaucoup de leur hauteur.

Les aires ambulacraires offrent une structure très-particulière. Non seulement leurs plaques sont très-étroites, puisqu'il y en a toujours au moins six pour une plaque de l'aire interambulacraire, mais elles sont en outre très-irrégulières et souvent cunciformes. On pourrait être tenté d'en distinguer deux catégories, des primordiales, qui s’étendent d'une suture à l'autre, et des intercalécs, qui semblent s'ùlre insinuées entre ces dernières. Les pores s'ouvrent en général alternativemement dans les uns et dans les autres. Cette disposition, qui est la même dans loute l'étendue des ambulacres, se voit à peine à l'xil nu: mais on s'en fera une idée exacte en examimant attentivement les figures grossies de Tab. II, lig. 7 et 8 , qui sont empruntées au test d'un $G$. vulgaris. 
La surface du test des vrais Galérites est en général peu accidentée. Les tubercules principaux y sont peu développés et plus clair-semés que daus aucun des autres genres du groupe; et, comme a chaque tubercule correspondait naturellement un piquant, il en résulte que ces animaux, étant bien moins épineux que la plupart des autres Clypéastroüdes, devaient présenter , a létat vivant, une pliysionomie toute particulière. Dans les espèces les plus tuberculeuses, il n'y a guère plus de dix-huit à vingt tubercules principaux sur une plaque interambulacraire du milieu du test; ils se maintiennent dans les mêmes proportions relativement à la grandeur des plaques, jusqu'au sommet du test, sans affecter aucune symétrie réelle dans leurị distribution. Cependant, conme les plaques se rétrécissent considérablement prés de l'appareil génital, il en résulte que les dernières n'ont quelquefois qu'un ou deux tubercules. Il n'en est pas de même à lia face inférieure : ici les plaques se rétrécissent aussi vers l'ouverture buccale ; mais les tubercules ne diminuent pas dans la même proportion, et comme ils sont en même temps plus gros que sur les flancs, il en résulte que la face inférieure a une apparence beaucoup plus tubercìieuse que le reste de la surface. Les aires ambulacraires, quoique beaucoup plus étroites que les aires interambulacraires, ne sont pas pour cela moins tuberculeuses; mais conme leurs plaques sont très-petites, elles ne peuvent guère porter qu'un, et tout au plus deux tubercules principhux. Examinés sous un grossissenent de plusieurs diamètres, les tubercules se montrent distinctement memelonnés ; leur mamelon est perforé et entouré d'une collerette de plis ou de crénelures très-distinctes. Suivant les espèces et même suivant les régions du test, le mamelon est plus ou moins gros. On remarque qu’il est en général plus développé dans les tubercules de la face inférieure qne dans ceux de la face supérieure (comparez à cet effet Tal. I, fig. 9 et 11 , Tab. III, fig. $8 c$, et Tab. IV, fig. 6 b). Les tubercules principaux, quoique eux-mèmes très-petits, sont entourés d'une immense quantité de tubercules miliaires, à peine visibles à l'œil nu, mais qui, examinés au microscope, offrent la mème structure que les tubercules principaux.

L'appareil génital, fort difficile à reconnaître dans la plupart des exemplaires, présente une structure très-particulière, qui est commune aux Globator, aux Caratomes et probablement aussi aux Pyrines. Les plaques génitales forment, avec les plaques ocellaires, un anneạu irrégulier et anguleux, entourant un bourrelet d'apparence spongieuse, qui occupe le sommet du test. Les quatre plaques génitales paires sont ì-peu-près d'égale grandeur et percées chacune d'un trou ordinairement peu apparent. La plaque impaire seule n'a point de pore; elle est aussi beaucoup plus petite que les autres. Les plaques ocellaires sont également percées; mais leurs trous sont si petits qu'il est fort difficile de les apercevoir. 
La face interne dı test nous est connue par les moules, qui en sont l'image parfaite. On y reconnaît ordinairement l'impression des zones porifères et même l'empreinte des sutures des plaques; mais on n'y découvre aucune trace de ces entailles, qui sont si remarquables dans les moules des Discoïdées crétacées. Les petits creux du pourtour de la bouche ont également laissé des traces de leur présence, et se reproduisent ici sous la forme de petits bourrelets. Quant à l'appareil masticatoire proprement dit, je n'en ai trouvé aucune trace sur aucun des moules que jai eu l'occasion d'examiner.

Le genre des vrais Galérites, ainsi limité, compte onze espèces, toutes de la formation crétacée : les plus grandes espèces sont de l'étage supérieur ou de la craie blanche; quelques-unes seulement se trouvent dans la craie marneuse; mais on n'en a point encore signalé dans l'étage néocomien. Il paraitrait donc que ce type remarquable n'existait pas encore pendant l'égóque jurassique, et qu’il a disparu à la fin de l'époque crélacée ; car on n’en trouve aucune trace ni dans les dépôts tertiaires, ni dans l'époque actuelle. 


\section{Galentes Albo-galeitus Lam.}

Tab. 1 , fig. $4-11$ et Tah. 13 , fig. 7.

Sxx. Galerites Albongalerus Lan. III. p. 306.- E. Desl. Enc. T. 2.p. 431.- Defr. Dict. sc. nat. T. 1S. p. S6. — Encycl. méth. Talb. 152, ligg. 5, 6.- Al. Brongnn. dans Curier Os. foss. $4^{\mathrm{me}}$ Ed. Pl. L. fig. 12 . A et B. - Phill. Geol. of Yorksh. p. 119. - Gldf. Petref. p. 12\%. Tilb. 40 , fig. 19. - Gratel. Ours. foss. p. 5\%. (excl. icon.) - Desilonl. Tabl. syn. p. 24S. - Stockes Geol. Trans. T. II, p. 406. Tab. 43, fig. 14, 15. - Passy Seine inf. p. 338. - Kloeden Verst. Bündenb. p. 246. - De la Bèche. Geol. Trans. II, p. 111.- d'Arch. Soc. Géol. II. p. 179. - Eichw. Zool. spec. 1. p. 229. - Lill dins Leonlı. et Br. Jalırb. 1836, p. 235. - Ag. Cattil. syst. Ectyp. Suppl.—Cuvier. Règr. An. Ed. ill. Zoph. Pl. 14, fig. 4.

Conthus Albo-galerus Klein. p. 19, §.51. Tib. 13, fig. A. B.- Klein. Gall. §. 51, p. 72. Tab. \%, fig. B. C. - Leske apud Klein, p. 162. Tab. 13, lig. A. B. - Fleming Brit. An. P. 4S1. - Taylor Gcol. Trrans. I. p. 33\% - Beck Min. Zeitschr. 1S28, p. 581. - Mantell Geol. of Sussex (var. acuta), fig. 16 et 19.

Eehinus Albo-galerus Lin. G. p. 3181.

Eehinoneus Albo-galerus DeBl. Zooph. p. 194.

Diseoüdea Albo-galera Ag. Prod. p. 1S6.- Bronn Leth. p. 614. Tilb. 29, Lig. 18 a, b.

- Oursin eonique Bosc. Déterv. p. 2S1. T. 24.

P'uthinson 0rg. Rem. T. 3. Tab. 2, fig. 10, 11.

Brernius Echin. p. 5\%. Talı. 2, fig. 1, 2.

Lang Lap. lig. p. 125. Tab. 36, fig. 1.

Jac. a Melle Ech. Wagrr. p. 7, fig. 6.

Morton N. H. North. p. $235, \mathrm{sp} .1$.

Lister Lap. 1urh. 1. 219, Tit. $1 \mathrm{~s}$.

Luid Lith. Brit. p. $4 \%$ N 958.

Bonrguet Pítref. p. 7\%. Tab. 53, fiģ. 361. (Echinite conoide uppelé Echinometrites).

Davila Catal. 3, p. 179. № 220 (Bouton nomemé le bonnet blane).

Van Phelsmm p. 31. N ${ }^{0}$ 15. (Egelsteen tienband rondtop).

C'est une espèce très-anciennement connue et fort répandue dans la craie blanche. Breyuius déjả en a donné une bonne figure, sous le nom d'Echinoconus. Klein la décrivit et la figura à son tour sous le nom de Comulus Albo-galerus, qui rappelle cerlains bonnets blancs que portaient les prêtres de Jupiter. Lang et Bourguet en donnèrent aussi des figures, moins parfaites il est vrai, mais cependant très-reconnaissables, le premier sous le non d'Echinometrites et le second sous celui d'Echimite conoüde. Lamarck en fit le type du genre Galerites, et éest sous ce nom qu'elle a été r'eproduite dés-lors dans tous les ouvrages de géologie et de paléontologie. 
La forme régulièrement conique de cette espèce en coustitue le principal caractėre ; sa base est très-élargie, parfois presque circulaire; néanmoins l'on y reconnait toujours les traces du pourtour pentagonal qui est commun à la plupart des Galérites (fig. 6). L'anus est infra-marginal, et son bord renflé détermine une sorte de troncature du côté postérieur, lorsqu'on examine l'Oursin de profil (fig. 5). La face inférieure est complètement plane; ses bords sont arrondis, mais cependant bien moins renflés que dans toutes les autres espèces. L'ouverture buccale, qui occupe le centre de la face inférieure, laisse apercevoir, dans certains exemplaires très-bien conservés, des traces distinctes de sa forme décagonale. Les aires ambulacraires sont proportionnellement étroites; elles portent ordinairement quatre rangées de tubercules principaux, qui se réduisent à deux près du sommet. A la face inférieure, ces mêmes aires se rétrécissent également, mais les tubercules y gagnent en grosseur et sont surtout plus serrés et entourés de tubercules miliaires plus nombreux q'à la face supéricure. Les ambulacres ou zones porifères s'élargissent considérablement à la face inférieure et présentent, près de la bouclre, des rangées obliques composées de trois paires de pores, ainsi que le montre la fig. 8, qui représente une aire ambulacraire de la face inférieure. Les plaques des aires interambulacraires ont, sur le milieu du test, une longueur double de leur hauteur et comptent ici environ une douzaine de tubercules (fig. 10). Près du sommet, au coutraire, elles sont aussi hautes que longues et n'ont guère que quatre ou cinq tubercules. Examinés ati microscope, tous ces tubercules paraissent distinctement mamelonnés, perforés au sommet et entourés de crénelures à la base du mamelon. La fig. 9 représente quelques tubercules ainsi grossis pris sur le milieu du test, et la fig. 11 quelques tubercules de la face inférieure sous un grossissement un peu moins fort. En comparant ces deux figures, on aura une idée du rapport qui existe ì cet égard entre les tubercules des flancs et ceux de la face inférieure.

L'appareil génital est composé de la même manière que celui du G. vulgaris, c'est-à-dire, que les quatre plaques génitales paires, qui sont à beaucoup près les plus grandes, sont seules percées de pores très-apparens, tandis que la plaque impaire est petite et dépourvue de pores. Les plaques ocellaires sont petites et n'ont qu'un trou très-fin qu' on ne distingue qu'à l'aide d'un trèsfort grossissement.

On trouve cette espèce à-peu-près partout dans la craie blanche, mais elle parait être surtout fréquente en Angleterre. L'exemplaire figuré, l'un des plus beaux que je connaisse, appartient à II. De Luc. Les individus de cette taille sont très-rares; la plupart n’ont guère que la moitié ou les deux tiers de ces dimensions.

La fig. 7 de Tab. 13 représente l'appareil masticatoire faisant saillie sur le pourtour de l'ou- 
verture buccale, d’après le mêmc cxemplaire que M. Stockes a figuré dans les Transactions de la Société géologique de Londres. Je ne peusc pas que ces saillies soient les dents proprement dites; car dans ce cas, il devrait y en avoir, selon toutes les analogies, cinq. Or comme j'cn compte dix sur le dessin qu'en a fait exécuter M. Agassiz, j’en conclus que ce sont plutôt les cxtrémités des màchoires; car il est probable que claque màchoire sc compose, comme dans les Clypéastres et les Scutelles, de deux osselets réunis sur la ligne médiane. (Voy, seconde Livr. Monographic des Scutclles par M. Agassiz.)

\section{Galerites Pyranidais DesMoul.}

Tab. 1, fig. 1-3.

Srx. Galerites pyramidalis DesMoul. Tabl. syn. p. 24S. - Lam. III. p. 312. - Ag. Catal. syst. Ectyp.. p. 6.

Le G. pyramidalis se trouve mentionné comme espèce dans les tablcaux synonymiques de DcsMoulins, d'où il a passé dans la seconde édition de Lamarck. Mais comme cet auteur n'en donne aucune description et que la plupart des synonymes qu'il énumère ne sont autre chose que le $G$. abbreviata décrit ci-dessous, il était difficile de savoir ce qu’il fallait entendre dorénarant par G. pyramidalis. Cependant le nom était consacré et pour ne pas embrouiller davautage la synonymie, M. Agassiz jugea convenable de le conserver à une espèce particulière, voisine de l'espèce ci-dessus, à laquelle il paraît très-approprié.

Cettc espèce ne m'est encore connue qu’à l'état de moule (fig. 1, 2 et 3 ). Je ne puis donc indiqucr que la forme ct la position des principaux organcs. Sa forme générale est celle d'unc poire ; de lả son nom spécifique : c'est, avec le G. conica, le seul Oursin de la famille des Clypéastroïdes dont la hauteur égale le diamètre longitudinal. Ce caractère est tcllement saillant qu'au premier coup d'œil, ct lorsqu'on n’a pas soin de mesurer cxactement les dimcnsions, l'Oursin paraît bcancoup plus haut que long: sa base est étroite, comme dans le $G$. vulgaris; ses bords sont arrondis, son sommet est pointu et précédé d'un étranglement assez prononcé, qui déterminc son aspect pyriforme. Les aires ambulacraires sont légèrement saillantes et très-étroites. Les aires intcrambulacraircs laissent apercevoir distinctement les sutures des plaques coronales. L'anus est marginal. L'ouverture buccale est centrale ct se montre cntouréc de dix petits bourrclets allongés, correspondant à de pctits creux qui règnent tout autour du pourtour intcrne de la bouche et qui étaicnt sans doute destinés à maintenir l'apparcil masticatoire en place. 
Je n'en connais eneore qu'un exemplaire; c'est le même que M. Agassiz a reproduit dans ses collections de moules en plàtre. L'original est un moule ealeédonieux qui fait partie de la belle colleetion de M. Michelin. Son origine ne m'est pas eonnue; mais il est hors de doute que e'est un fossile crétacé.

\section{Galerites vulgaris Lam.}

Tab. 2, fig. 1-10 et Tab. 13 , fig. 4-6.

sw. Galerites vulgaris Lam. III. p. 307. (non Gldf.) - E. Desl. Enc. T. 2, p. 431. - DeBl. Zooph. p. 203. — Gratel. Ours. foss. p. 56. № 8. A Ag. Prodr. p. 186. - Desiloul. Tabl. sỵn. p. 250. № 4. (var. a.) Ag. Catal. syst. Ectyp. p. 6.

Echinites vulgaris (pro parte). Leske apul Klein p. 165.

Conulus gedanensis (pro parte). Klein p. 20 \$. 52. Tab. 14, fig. $e, f$.

Galerites oratus Lam. III. p. 310.- E. Desl. Enc. T. 2, p. 433.

Jacolb a Melle. Ech. Wiggr. Tab. 1 , fig. 3.

Le $G$. vulgaris semble avoir été longtemps une sorte d'incerte sedis dans lequel on rangeait, sans critique, cette quantité de moules siliceux de Galérites qui sont si fréquens dans la craie. J'ai vainement cherché, dans les auteurs, une figure qui représentât cet Oursin avec son test. Tout le monde s'en rapporte aux figures de Ḱlein. Or, quoique ces figures soient assez défectueuses, on peut cependant y reconnaitre des moules de différentes espèces. La plupart représentent évide mment le G. abbreviata, que l'on distingue aisément à sa forme conique et circulaire. D'autres indiquent des moules d'une espère plus élevée, subpentagonale et voisine à plusieurs égards du $G$. Albo-galerus. Ce sont eeux que Lamarck paraît avoir eus en vue, lorsqu'il distingua son G. vulgaris de son G. abbreviata. Comme le test de cette espèce n'est encore décrit el figuré nulle part , je vais essayer d'en indiquer les principaux traits ainsi que ses rapports avec les noules. Le caractère le plus saillant du $G$. vulgaris consiste dans sa forme ramassée. Sa hauteur est au diamètre de la base comme 4 a 5 , et, sous ce rapport, il tient en quelque sorte le milieu entre les $G . p y-$ ramidalis, conica et Albo-galerus, d'une part, et les G. abbreviata, angulosa, lavis, Castanea, ete., de l'autre. La face inférieure est subcirculaire et parfois subpentagonale, surtout dans les moules. La louelıe paraît, au premier abord, cireulaire; mais si l'on vient à l'examiner de près, on trouve qu'elle est anguleuse, comme dans toutes les autres espèces. L'anus est grand et de forme elliptique. Sa position est, à vrai dire, infra-marginale; mais comme les bords du test sont fortement arrondis, il en résulte qu'on le voit en entier de profil et en dessous (voy. fig. 3 et 4 ). La 
carẻne sur-anale, sans être trẻs-forte, est cependant très-distincte, surtout dans les moules (fig. 6). La structure du test offre une grande variété de détails; mais pour bien en saisir les rapports, il faut les examiner à la loupe; c'est dans ce but que j'ai joint à mes figures de grandeur naturelle les figures 7 et 8 représentant, l'une le sommet du test avec l'appareil génital, et l'autre une partie d'une aire ambulacraire et d'une aire interambulacraire vues sous le mème grossissement. Les tubercules principaux sont répartis sur toute la surface du test, mais ne forment pas de séries régulières. Ils sont plus serrés que dans le G. Albo-galerus, car on en compte de seize à vingt sur une plaque interambulacraire du milieu du test (fig. 8), tandis qu’il n'y en a guère qu'une douzaine sur les plaques interambulacraires de cette dernière espèce. Les plaques des aires ambulacraires sont beaucoup plus petites et de plus irrégulières (fig. 8); on en distingue de deux sortes, les plaques primordiales ou celles qui s’étendent sur toute la largeur d'une demi-aire, et les petites plaques intercalées qui sont limilées aux bords; les pores ambulacraires s'ouvrent indifféremment dans les unes et dans les autres.

Pour donner une idée aussi parfaite que possible de l'appareil gẻnital, je l'ai représenté isolé dans la fig. 9. Les quatre plaques génitales paires sont celles qui frappent le plus, autant par leur forme et leur grandeur que parce qu'elles sont les seules perforées. La plaque génitale impaire est imperforée et de moitié plus petite. Ces cinq plaques forment un anneau qui entoure le corps madréporiforme; elles sont mème si intimement unies à ce dernier, qu'on n'aperçoit aucune trace des sutures qui les sẻparent; elles semblent faire corps avec lui. Les plaques ocellaires sont très-petites et bilobées à leur bord externe, de manière que le sommet de l'aire interambulacraire vient s'insinuer dans l'échancrure qui sépare les deux lobes, comme cela se voit dans le dessin grossi de fig. 7. Les plaques ocellaires sont également percées d'un petit trou, qui, quoique d'une exiguité extrême, est cependant visible à l'aide d'une bonne loupe; c'est par inadvertance qu’ils ont été omis dans les figures ci-jointes (fig. 7 et 9).

Le moule, comme on le pense bien, ne montre aucune trace de ces ornemens qui caractérisent le test ; mais sa forme est en général la neême. On y reconnait toutes les divisions principales du test, et mème l'empreinte des sutures qui unissaient les plaques entre elles. Les aires ambulacraires présentent même un relief plus marqué qu’à la surface du test. L'ouverture anale y parait aussi plus grande; mais c'est là un caractère propre à la plupart des moules.

Si nous groupons autour du $G$. vulgaris les diverses espèces suivant leur affinité, nous trouverons que les plus voisines sont le $G$. angulosa, le $G$. subrotunda, le $G$. Albo-galerus et le $G$. conica. Le premier cependant est plus anguleux et moins élevé, le second est plus hémisplıérique 
et a l'ouverture anale plus haute. Le G. Albo-galerus est plus conique ; ses bords sont moins renflés, et sa face inférieure est plus plate. Quant au $G$. conica, il ne paraît en différer que par sa forme plus élevée et plus comprimée vers le sommet. Le $G$. vulgaris est ainsi en quelque sorte l'espèce typique du genre; elle est comme un centre auquel les autres espèces viennent se rattacher, les unes, par tel caractère, les autres, par tel autre.

Cette espèce se trouve à-peu-près partout dans la craie blanche, et peut être comptée parmi les fossiles caractéristiques de cette formation. L'original des fig. 1, 2, 3 et 4 fait partie de la collection du Musée de Berne, et m’a été communiqué par M. Studer. Le moule représenté dans les fig. 5 et 6 provient de l'ìle de Wight, et a été déposé au Musée de Neuchâtel par M. Ibbetson. C'est le plus grand que j’aie rencontré jusqu'ici; il est simplement pyriteux, tandis que le plus grand nombre, et notamment ceux du nord de l'Allemagne, sont calcédonieux et semi-transparens. Je rapporte à cette espèce le monstre de Tab. XIII, fig. 4-6, dont il a été question dans l'introduction à l'article des anomalies. Il se pourrait cependant que sa forme renflée ne füt qu'une conséquence de son test déformé, et dans ce cas, on devrait l'envisager comme un $G$. Albogalerus, car c'est de cette espèce qu'il se rapproche le plus par la disposition de ses tubercules interambulacraires, qui sont moins nombreux et plus gros que ceux dı G. vulgaris.

Il ne faut pas confondre cette espèce avec le G. vulgaris de Goldfuss, qui n'est autre close que le $G$. abbreviata Lam., décrit ci-dessous. Quant aux autres synonymes, je n'ai rapporté que ceux dont l'identité m'a paru incontestable. Les citations des auteurs anciens, que l'on place ordinairement en tète de cette espece, se rapportent toutes plutôt au G. abbreviuta qu'au $G$. vulgaris.-Le $G$. ovatus Lam. n'est pas une espèce particulière; M. Agassiz, qui a eu l'occasion d'examiner l'original de Lamarck au Muséum de Paris, m’a assuré que ce n'est autre clıose qu'un très-grand $G$. vulgaris comprimé.

\section{Galerites conica $\mathrm{Ag}$.}

Tab. 1, fig. 12-19.

SYx. Galerites conica Ag. Catal. syst. Eetyp. Suppl.

Conulus Albo-galerus Mant. Geol Sussex. Tab. 17, fig. S a 20.

Cette espèce se rattache de très-près au $G$. vulgaris décrit ci-dessus, mais par d'autres caractères que le $G$. subrohunda. En envisageant le $G$. vulgaris conme type ou comme centre du 
genre, et en groupant autour de lui tontes les autres espèces dans l'ordre de lenr affinité, le G. conica, dont il est ici question, devrait être placé d'un côté, et le G. subrotunda de l'autre.

Le G. conica participe, en effet, de tous les caractères principaux du G. vulgaris. Sa plysionomie générale est à-peu-près la mème. La position de la bouche et de l'anus en particulier ne présente aucune différence sensible; il en est de même de l’appareil génital et de la disposition des tubercules : les plaques interambulacraires du milieu des flancs comptent une vingtaine de tubercules principaux (fig. 16), entourés d'un nombre bien plus considérable de tubercules miliaires. Les uns et les autres sont surmontés d'un petit mamelon qui, dans les tubercules principaux au moins, est perforé et crénelé à sa base (fig. 15). Un seul trait constitue en définitive le caractère distinctif de notre espèce relativement au $G$. vulgaris; c'est sa forme très-élevée et comprimée latéralement qui lui donne en quelque sorte l'apparence d’une mitre (*). Sa hauteur égale et parfois excède même sa longueur.

On a aussi confondu parfois notre $G$. conica avec le $G$. Albo-galerus, quoique ce dernier se distingue d'une manière très-nette par sa forme conique. M. Dujardin a déjà appelé l'attention sur cette différence, en faisant remarqquer, dans ses annotations à la deuxième édition de l'Histoire naturelle des Animaux sans vcrtebres, tom. III, p. 306, que le fossile fignre par Mantell conme G. Albo-galerus doit constituer une espèce distincte, caractérisée par sa forme en ellipsoïde a sa hase. Ce fossile, que Mantell prend à tort pour le G. Albo-galerus, n'est autre que notre G. conica.

Les moules intérieurs reproduisent en général d'une manière très-fidèle la forme et les proportions du test, ensorte que l'on n'ẻprouve aucune difficulté á les délerminer lorsque, comme c'est ici le cas, le principal caractère de l'espèce consiste dans sa forme. J'ai représenté, dans les fig. 17-19, un moule dont on ne saurait mettre en doute lidentité spécifique; il a alssolument la même forme que l'exemplaire revêtu du test, et est en outre un peu plus comprimé. Sa substance est siliceuse.

Cette espèce provient de la craie blanche d'Angleterre, oú elle ne parait cependant pas être bien fréquente. L'origrinal des figures 12 à 14 est un magnifique exemplaire de la collection de

(') En réfléchissant à la grande ressemblance de ces deux fossiles, du G. conica et du G. vulgaris, qui ne diffèrent en réalité que par la forme du test, je n'ai pu me soustraire à la tentation de les rapprocher d'une maniére qquelconque, et songeant que, dans les animaus inférieurs, les fenelles se distinguent ordinairement des uâles par leur forme renflée et plus trapue, il m’a semblé que notre G.conica pourrait bien être le mảle du G. vulgaris. Toutefois, ce n'est là qu'une simple lỵpothèse, dénuée jusqu'ici de tout fondement. 
II. De Luc. Le noule figuré a élé déposé au Musée de Neuchâtel par M. Ibbetson, qui l’a recueilli dans l'ìle de Wight.

\section{Galerites subrotund $\mathbf{A g}$.}

Tab. 2, fig. 11-14.

Cette espèce est très-voisine du G. vulgaris, et c'est à dessein que je l'ai représenté sur la même planclıe, afin qu'en les comparant on fùt à mème de saisir les diflérences qui les distinguent, différences qui portent essentiellement sur la forme du test. En effet, le G. subrotunda est i-peuprès hémisphérique. Quelquefois, il est vrai, on trouve aussi des exemplaires du G. vulgaris, dont le sommet est très-arrondi ; mais jamais la carène postéricure ou stur-anale n'est aussi obtuse que dans notre espèce. Un second caractère qui lui est particulier consiste dans la position de l'ouverture anale, qui est complètement supra-marginale et se voit en entier lorsque l'Oursiu repose sur sa face inférieure. Ces caractères ont paru suffisans à M. $\Lambda$ gassiz pour justifier l'établissement de cette espèce qui, sous tous les autres rapports, est parfaitement semblable au G. vulgaris.

Je n'ai vu, jusqu’ici, qu'un seul exemplaire de cette espèce; c'est le même que M. Agassiz a fait mouler pour sa collection de moules d'Echinodermes fossiles. Il provient de la craie blanche de l'île de Wight, et fait partie de la collection du Musée de Neuchàtel.

Le Conulus subrotundus de Mantell (Geol. of Sussex Tab. 17, fig. 15) est un moule très-imparfait, qui, tel qu'il est représentẻ, ne pernet aucune détermination rigoureuse. C'est plutôt une Discoïlée qu'un Galérite.

\section{Ginentres Guonums Des.}

Tal. 4, fig. $1-4$.

Cette espèce est à-pen-près globuleuse, et éest en cela que consiste son principal caractère spécifique. Aussi forme-t-elle un contraste frappant arec les espèces pointues, telles que le $G$. $A l$ bo-galerus et le G. pyramidalis, et de même avec les espèces anguleuses, comme le $G$. angulosa, le G. Castanea, etc. Mais, d'un autre còté, elle se ratlache au G. subrotunda, dont elle est même très-voisine, car elle n'en diffère que par le rétrécissentent plus considérable de la face inférieure, qui détermine précisément sa forme globuleuse. La carène postérieure est très-peu accusée. L'a- 
nus, de forme elliptique, est entierement supra-marginal nuis comme le bord de la face inferieure est très-arrondi, il en résulte qu'il est égalenent visible en dessous (lig. 1 1). La structure du test noffre rien de particulier, comme on peut le voir par les figures grossies. La fig. 2 a represente une aire ambulacraire montrant la disposition des plaques, des tubercules et des pores dans cette partie du test. La fig. 26 représente quelques plaques de l'aire ambulacraire sous le mème grossissement, pour montrer la disposition des tubercules principaux et la manière dont ils sont entourẻs par les tubercules miliaires. On n'en conpte guère qu'une dizaine par plaque.

L'appareil génital est admirablement conservé dans l'exemplaire figuré. Jaai cru y reconnaîtce une structure un peu différente de celle que j’ai décrite dans le G. vulguris. Ét d'abord, la diflè-rence entre les plaques génitales et ocellaires est moins sensible, et les pores des plaques ocellaires sont heaucoup plus apparens que ceux des plaques génitales, qui sont à peine sensibles, mème sous un fort grossissement. Enfin, le trait le plus remarquable consiste en ee que la plaque gínitale impaire parait manquer completement.

Je ne connais qu'un seul exemplaire de cette espece ; il provient de la craie blanche d'Angleterre, et lait partie de la collection de M. De Luc, qui a bien voulu le confier à MI. Agassiz. 


\section{Galemtes abbreviata Lam.}

Tab. 3, fig. 9-17.

SYx. Galerites abbreviatus Lam. III. p. 307.-E. Desl. Ene. Tom. 2, p. 431.- DeBl. Zooph. p. 204.-Ag. Prodr. p. 185. - DesHoul. Tabl. Syn. p. 252.- Ag. Catal. Eetyp. Suppl.

Galerites vulgaris Gldf. Petref. p. 12S. Tilb. 40, fig. 20.- Bromn. Leth. p. 616. Tal. 29, fig. 17 a b. De la Bèche. Geol. Trans. 1826, II, p. 111. - Passy. Sein. inf. p. 338. - Kloed. Vert. Brandenb. p. 246.

Conulus vulgaris Mant. Geol. Trans. III, P. 205. - Id. Geol. S. E. Engl. p. 373.- Parek. Org. Rem. T. 3. Tab. 2, fig. 3. - Beck Min. Zeitsehr. 1828, p. 581.

Echinus vulgaris Lin. G. p. 3182.

Galerites truncata Defr. Diet. se. nat. T. 1S , P. S7. - E. Desl. Ene. T. 2, p. 434.

Globulus Wagricus Klein. p. 20 , fig. C. D. E. F.J.K.

Globulus uodus Klein. p. 20. Tab. 1/1, fig. $g, i$.

Globulus Bulla Klein. p. 20. Tilb. 14, fig. $i, k$

Echinites vulgaris (varietates) Lesk. P. 166.

Conulus Globulus Kl. gall. §52, p. 72.

Oursin vulgaire Bose. Déterv. T. 24, p. 280. Tab. G. fig. 3, 4. T. 28, p. 153.

Fivanne Pl. 6\%, fig. 1. 2.

Waleh Del. nat. T. 2, p. 1\%6. Tilb. E. 1, fig. 1. 2.

Van Phelsum p. 31. (Silverknoop, Holletop, Topmuts, Traphand, Plattetop.)

Olearius Mus. Gottorp. Tab. 21, fig. 5,6 .

Besler Gazoph. eontin. Tab. 19. (Scolopendrites).

Morton N. H. Nortl. p. 235, sp. 2, Tab. 10, fig. 11.

Lister Lap. turb. P. 219. Tit. et figg. 1S.

Luid Lith. p. 16. N. 941. 930.

Rumph Amboin. Tab. I, fig̛. 6, 7, 8. 9.

Mereatus Metil. p. 246. (Brontia et Chelontis).

Mylins Memoral. Sax. p. 45-47, fig. 2, 4, 5, 9, 10.

Volkman siles. sulbt. p. 179. Tals. 30 , fiģ. 6, E.

Hellwing Lill. p. 71. Tab. 8 , fig. 13.

Bytemeister Tal). 23, fig. $2 \% 0$.

Baier Oryet. Nor. Tab. 3, fig. 31-34.

Schreber Lithog. Halensis. p. $103 a$.

Gesner De Petref. p. 24.

Wilch Delic. nat. II, p. 177. Tilb. E. $4 a$, fig. 2.- Ib. Suppl. IX $d$, fig. 2 , 1. 217.

Davila Catal. p.1S0. N. 220. (La Bulle, le petit Globe).

Waller' Syst. miner. p. $50 \%$.

Semblable au G. vulgaris, cette espèce n'ẻtait connue jusqu'ici qu'à l'état de moule, et le plus souvent les deux espéees ont été confondues par les auteurs. Van Plrelsum et lílein les avaient, 
il est vrai, distinguées; mais leurs successeurs ne tinrent aucun compte de ces diffërenciations qui, au reste, ne sont pas toujours basées sur de bons caractères. Ainsi que je l'ai dit en décrivant le $G$. vulgaris, la plupart des figures de Ḱlein, de même que les citations de presque tous les auteurs anciens, m’ont paru devoir être rapportées à cette espèce, de préférence au G. vulgaris; d'autres ne paraissent pas susceptibles de dèterminations.

Suivant Lamarck, le principal caractère du $G$. abbreviatus consiste dans sa forme conique, raccourcie et circulaire, qui suffit en effet pour le faire reconnaitre entre toutes les espèces du genre. La hauteur est au diamètre transversal comme 2 à 3 , dans les exemplaires adultes; elle est plus considérable dans les jeunes exemplaires (fig. 12 à 14). Grâce à l'obligeance de II. De Luc, qui a bien voulu confier à MI. Agassiz un exemplaire garni de son test (fig. 9-11), le seul qui existe, à ma connaissance, je suis à même de compléter aujourd'hui l'étude de cette intéressante espèce, si généralement répandue dans les collections.

Le test est épais, comme dans la plupart des Galérites. La face inférieure est à-peu-près plane. L'ouverture anale est infra-marginale et circulaire, son diamètre est moins considérable à la surface du test que dans les moules; mais cette particularité n'est pas seulement propre à notre espèce; elle se retrouve également dans le G. vulgaris el dans d'autres espèces, et s'explique par le renflement du test qui règne ordinairement autour de cette ouverture. L'ouverture buccale montre des traces distinctes de sa forme décagonale. Mallıcureusement le test de l'exemplaire liguré n’est pas assez bien conservé pour que jaie pu y reconnaître la forme et la disposition des tubercules. Les pores y sont disposés par paires obliques plus ćloignées les unes des autres que dans les autres espèces. Je n’ai pu distinguer, d'une manière précise, l'articulation des plaques des aires ambulacraires; mais je suis porté a croire que les pores s'ouvrent tous dans des plaques primordiales, et qu’il n’y a point de ces plaques intercalées, comme dans la plupart des espéces précédentes. Sur les moules, la place des pores est indiquée par de petites impressions très-profondes, formant une série non interrompue de chaque côté d'une carène médiane qui correspond au milieu de l'aire ambulacraire.

Le grand exemplaire de fig. 9-11, et le moule de fig. 15-17 proviennent tous deux des sables détritiques de Stada dans l'Allemagne septentrionale, et font partie de la belle collection de II. De Luc.

Goldfuss a figuré cette espèce sous le nom de $G$. vulgaris. Le fossile quill décrit conıme étant le G. abbreviatus pourrait bien n'ètre qu'une variété un peu plus conique de la mème espèce. 


\section{Gilentes orbigiyisi Ag.}

Tal. 3, fig. 5-8.

Six. Galerites Orbignyanus Ag. Catal. syst. Ectyp. p. 7.

Cette espèce est circulaire, comme le Gr. abbreviala; mais, au lieu d'être conique, elle est arrondie et presque hémisphérique (fig. 6 et 8). Un autre caractẻre qui la distingue d'une manière non moins précise, c'est la position de l'anus, qui est marginal et par conséquent visible d'en bas et de profil (fig. 7 et 8 ), tandis que, dans le $G$. abbreviala, l'anus n'est visible qu'en dessous (fig. 11, 14 et 17). La face inférieure est lëgèrement concave, à bords très-renflés. Les dètails du test sont très-bien conservés dans l'exemplaire figuré, mais ils ne présentent rien de particulier dans leur structure. La fig. $6 b$ montre une aire ambulacraire vue à la loupe, offrant la disposition des tubercules et des pores ambulacraires. La fig. 6 a représente quelques plaques d'une aire interambulacraire : les tubercules principanx ne sont pas bien nombreux, puisqu'il n’y en a guère que douze sur une plaque. En revanche, les tubercules miliaires y sont très-abondans. La fig. $\$ c$ enfin montre plusieurs tubercules principaux, vus au microscope, avec les tIIbercules miliaires qui les entourent et qui sont très-nombreux.

Je ne connais cette espèce que par un seul exemplaire appartenant à M. D'Orbigny, et prorenant de la Touraine. C'est, selon toute apparence, un fossile crétacé.

\section{Gilemires ivgelosa Des.}

Tab. 4 , fig. 5-7.

C'est encore le contour du test qui constitue le principal caractère de cette espèce, dans la'quelle la forme pentagonale semble être arrivée a son plus grand développement. Conme d'ordinaire, ce sont les ambulacres qui correspondent aux parties saillantes et anguleuses. La longueur l'emporte de beaucoup sur la hauteur ct sur la largeụr; le côté antérieur est presque deux fois aussi large que le còté postérieur. L’anus est entièrement marginal et parât être moins elliptique que dans la plupart des autres espèces. J'ai représenté, dans la fig. $6 b$, quelques tubereules inlerambulacraires du bord inférieur vus au microscope, et montrant leur structure intime et la manière dont ils sont entourés par les tubercules miliaires. En général, les tubercules augmentent 
de grosseur à la face inférieure, et comme la séparation des plaques y est plus distincte, on remarque, dans leur répartition, une certaine régularité linéaire qui n'existe point sur les flanes. Les pores aubulacraires s'y groupent aussi d'une manière toute particulière, ensorte que trois paires de pores correspondent á uı petit sillon oblique, ainsi que cela se voit dans la fig. 7 a, qui représente une aire ambulacraire de la face inférieure, vue à la loupe. L'exemplaire figuré est le seul que je connaisse; il provient de la craie blanche d'Angleterre, et a été communiqué à II. Agassiz par MI. le marquis de Northampton.

\section{Gilenites Cistives Ag.}

Tab. 4, fig. 12-16.

Srx. Calerites Castanea Ag. Descr. des Ech. foss. de la Suisse 1re part. 1. 7\%. Tial. 12, fig. 7,9.- I1. Catal. syst. Ectyp. p. 7.

Catopygus Castanca Ağ. Prodr. m e. Mém. de la Soc. l'Hist. nat. de Neuchâtel Tom. I, p. 1 Sä.

Nucleolites Castanea AI. Brong. dians Cuvier Rech. sur les 0ssem. foss. $4^{\text {me }}$ Edit. Pl. Q. figg. 14. - Defr. Dict. sc. nat. T. 33̈, p. 214.- DeBl. Zooph. p. 1 ss.

Pyrina Castanea Deshioul. Tabl. syut. p. 205S. No 3.

Galerites rothomagensis Ag. Catal. syst. Ectyp. p. 7.

La comaissance de cette espèce est due ì M. Alex. Brongniart, qui la figura sous le nom de Vucleolites Castamea, dans les Ossemens fossiles de Cuvier. NI. Agassiz la rangea d'abord dans son genre Catopygus, mais en la décrivant avec plus de détails, dans ses Descriptions des Echinodermes fossiles de la Suisse, il lui assigna sa véritable place dans le genre des Galérites. Tout en reconnaissant la grande ressemblance de cette espèce alpine avec un fossile analogue de la craie marueuse de Rouen, ce naturaliste ne crut cependant pas devoir les identifier, et il donna à ce dernier le nom de G. rhothomagensis. Ayant repris plus tard la comparaison de ces deux fossiles sur des exemplaires plus parfaits, que je dois surtout à lobligeance de M. le docteur Nayor, de Genève, je crois m'ètre assuré que l'espèce de Rouen, qui est représentée dans les fig. 12 et 13 , est identique avec celle de la craie des Alpes, ou du moins n’en est qu'une variété. Cette identilé n’a d'ailleurs rien qui doive étonner, car on en connait plusieurs exemples; et parmi les Echinodermes, je citerai en particulier le Holaster suborbicularis, qui est très-fréquent dans les deux localitis.

Le G. Castanea est une espèce sulpentagonale, plus longue que large, et plus large que haute. Sa plus grande largeur est à la partie antérieure, entre les deux ambulacres antérieurs pairs. Le 
côté postérieur est sensiblement rétréci, sans cependant l'être autant que dans le G. angulosa. La carène postérieure est à peine sensible. L'ouverture anale est grande, elliptique et marginale. Le test est mince, comme on peut le voir par les brisures que j’ai eu soin d'indiquer dans l'exemplaire figuré. Je n'ai pu observer les détails du test que dans la variété de Rouen, et je me suis assuré que les tubercules y sont plus nombreux que dans toutes les autres espèces du geure; car les aires ambulacraires ont sur le milieu du test an moins six rangées de tubercules (fig. $13 b$ ), et les plaques des aires interambulacraires comptent jusqu'à vingt-cinq tubercules principaux (lig. $12 a$ ).

Les exemplaires alpins se trouvent au Reposoir, à la Montagne des Fis et au Sacconnet, où ils sont assez fréquens. La variété de Rouen ne paraît pas être bien rare. J'en dois deux exemplaires à l'obligeance de M. Studer.

\section{Galenites levis Ag.}

Tah. 4, fig. 8-11.

Srn. Galerites loevis Ag. Catal. syst. Ectyp. p. \%.

Cette espèce se fait remarquer par quelques caractères qui, pour n'être pas très-apparens, n'en sont pas moins précis : le plus saillant consiste dans la forme et la grandeur de l'ouverture anale, qui est supra-marginale, et s'élève jusqu'à la moitié de la hauteur du test (fig. 9 et 10 ). La forme générale est indistiuctement pentagonale, élargie en avant, plus ou moins rétrécie en arrière. La hauteur n’a guère plus de la moitié de la longueur. La carène postérieure ou suranale est très-peu apparente. La face inférieure est à-pen-près plane, à bord arrondi ; les tubercules sont moins nombreux que dans le G. Castanea, particulièrement cenx des aires ambulacraires, qui ne forment guère que quatre rangées principales. Les tubercules des aires interambulacraires sont fort irréguliers; on n'en compte que dix ou douze sur une plaqne, tandis que nous avons vu qu'ils étaient bien plus nombreux daus le G. Castanea de Rouen.

Je ne connais encore qu'un exemplaire de cette espèce; il fait partie de la collection de M. Desllayes, et est saus doute originaire des terrains crétacés de France. 


\section{CHAPITRE II.}

\section{DU GENRE PYRINA Deshoul.}

M. DesMoulins a réuni sous ce nom plusieurs espèces fossiles de la craie quil caractérise de la manière suivante : "forme générale régulière, circulaire ou ovale, plus ou moin s bombée en des" sus ; surface inférieure plate, ou légèrement pulvinée, ou légèrement concave; sommet médian; " quatre pores génitaux; aires interambulacraires doubles ou triples des aires ambulacraires ; am" bulacres complets, droits, plans, bordés de chaque côté d'une seule paire de pores fort rappro" cliés, unis ou non par un sillon; houche symétrique, centrale, ronde, peu ou point enfoncée; anus " supra-marginal, ou entre le bord et le sommet, ovale ou arrondi, quelquefois énorme." (") Cette diagnose est évidemment trop vague; aussi ne doit-on pas s'étonner de voir figurer parmi les Pyrines de Deslloulins, des espèces qui diffërent dans des points essentiels de leur organisation. Des sept espèces que l'auteur énumère dans ses Tableaux synomymiques, trois seulement sont connues par des descriptions et des figures: ce sont les Pyrina Castanea, Rotula et depressa, (Nucleolites Castanea, Rotula et depressa de M. Alex. Brongniart) (“*). Or, le P. Rotula est une véritable Discoïdée; l'espèce appelée Castanea est, comme nous l'avons vu plus haut, une véritable Galérite; et comme M. Deslloulins convient lui-mème que le genre Pyrina ne diffère des Galérites que par son anus supère, il n’y aurait que l'espèce figurée par Brongniart sous le nom de Nucleolites depressa qui pùt rester dans le genre Pyrina. Néanmoins, je crois avec M. Agassiz que, restreint à ses limites les plus précises, ce genre représente une coupe naturelle du groupe des Galérites. Il suffit en effet de supprimer de la diagnose de MI. DesIIoulins " la forme circulaire et les ambulacres unis par un sillon", pour en élininer a la fois les Discoïdées et les Catopygus, et avoir ainsi

(*) Des.loulins Etudes sur les Echinites. Prodr. p. 26.

$\left(^{* *}\right)$ Les quatre autres espéces ne me sont connues que par les citations purement nominales de II. Des.loulins. Il parait cependaut, d’après le sỵnonyme de Leske, que le Pyrina dubia est une véritable Galérite; le Pyrina petrocoriensis. que l'auteur dit differer lece dernier par la position plus supire de lanus, pourrait bien être une espece de Glubator. Le P. cassidularis ( Echinoneus casidularin DeBl.) parait ctte un Catopggs. Le $P$. echinonea moel complitement inconnu. 
l'expression de la véritable physionomie du genre Pyrina tel que 11. Agassiz l'a circonscrit dans ses Characteres diagnostici annexés i son Catalogue systématique des moules d'Echinodermes fossiles lu Musée de Neuchàtel. Les Pyrines ainsi délinnitées sont des Oursins allongés, ovoïdes, reullés, a tubercules irréguliers, ayant la bouclıe centrale et l’anus situé á la face postérieure. Voisins à la fois des Galérites et des Globator, ils diflèrent des uns et des autres par leur forme réguliẻrement ovale, les Galérites étant coniques et subpentagonaux et les Globator circulaires. Ce même caractère les èloigne aussi des Nucleopygus. En revanche, ils se rapprochent beaucoup, par leur apparence extérieure, des Catopygus qui sont également de forme ovale et ont l'anus supra-marginal, mais qui présentent, en même temps, cette différence capitale, d'avoir des ambulacres pétaloïdes. Quant à la bouche des Pyrines, au lieu d'être ronde el symétrique, comme le dit M. DesMoulins, elle est au contraire anguleuse comme dans les Galérites et, de plus, allongée dans le sens du diamètre longitudinal; mais il faut avoir a sa disposition des exemplaires parfaitement conservès pour s'en assurer. Je n'ai pas pu étudier l'appareil génital d’une manière détaillée; mais tout ce que jen ai vu me fait présumer qu’il est construit sur le même plan que celui des vrais Galérites.

Les espèces ici décrites sont le $P$. Ovuhum $\mathrm{Ag}$., le $P$. ovata Ag., le $P$. depressa DesM., et le $P$. pygá Des. qui figure, dans le Catalogue syst. des moules de M. Agrassiz, sous le nom de Galerites pygra. Les trois premières sont de la craie moyenne et supérieure, la dernière est propre au terrain néocomien.

\section{Prisici Orulum Ag.}

Tal. 5, fig. 35-37.

Srx. Pyrina Ovulum Agg. Catal. syst. Ectyp. p. \%.

La plysionomie de cette espece me paraît renfermer l'expression la plus parfaite de ce petit groupe de Galérites ovoïdes, dont on a fait, à tort ou à raison, le genre Pyrina. Aussi large devant que derrière, elle forme un ovale régulier. Le côté postérieur est marqué d'un sillon trèsblargi au dessous de l'ouverture anale, et paraît par conséquent tronqué lorsqu'on l'examine d'en bas ( fig. 37), tandis qu'il l'est moins v'u d'en haut (fig. 35). L'anus lui-mème est elliptique et situé au borl supérieur de la face postérieure, de manière qu'on l'aperçoit aussi bien d'en haut qu'en face. L'ouverture buccale laisse apercevoir des traces distinctes de sa forme anguleuse, et si elle parait ici oblique (fig. 37), ce n'est sans doute qu'accidentellement. Les tubercules sont 
plus serrés que dans aucune espece de Galérite; examinés au microscope, ils présentent l'aspect de fig. $37 c$; c'est-à-dire que les gros tubercules sont distincte ment mamelonnés; le mamelon luimème est perforé au sommet et entouré d’une collerette de plis très-apparens à sa loase. Des tubercules miliaires en très-grand nombre occupent l'espace entre les tubercules principaux. Les aires ambulacraires comptent, sur le milieu du test, six rangées de tubercules qui se réduisent à quatre près du sommet (fig. $35 a$ ). I Les pores sont superposés d'une manière assez régulière, au moins à la face supérieure (fig. $35 a$ ), tandis qu’à la face inférieure, ils forment de petites lignes obliques composées de plusieurs paires superposées, ainsi que le montre la fig. $37 b$, qui représente une aire ambulacraire prise à la face inférieure.

Je ne connais de cette espèce que l'exemplaire figuré qui a été communiqué à M. Agassiz par M. Desllayes; il provient des terrains crétacés de France.

\section{Primi ovati Ag.}

Tab. ๖, fig. 32-34.

SY. Pyrina ovata Ag. Catal. syst. Ectry. p. \%.

Entre cette espèce et la précédente, la différence n'est pas grande, et il se pourrait fort bien qu elles ne fussent que des variétés d’une seule et même espèce. La forme du $P$. ovata, comme celle du $P$. Oxulum, représente un ovale régulier. Le côté antérieur et le côté postérienr sont d'égale largeur. La face supérieure est aplatie; la face inférieure est légẻrement pulvinèe. L'ouverture buccale, de forme anguleuse, en occupele centre. La seule différence que j’aie remarquée, c'est que l'anus s'èlève un peu moins haut et que le sillon sous-anal est moins accusé. Les tubercules aussi sont un peu moins serrés.

Plusieurs exemplaires de cette espéce ont été comuniquès à M. Agassiz par M. d’Orbigny, qui les a recueillis dans la craie infẻrieure de Saintes, près de la Charente. 


\section{Pyrixa depressi DesMoul.}

Srv. Pyrina depressa DesMoul. Tabl. syn. p. 258.

Nucleolites depressa Al. Brong. dans Cuvier Ossen. foss. $4^{\text {me }}$ Ed. Tab. 2, figg. 17.

Galerites Castanea Af. Catil. syst. Ectyp. P. \%. No 66 tant seulement.

L'ẻtat de conservation, généralement très-imparfait de cette espèce, et la figure assez incomplète qu'en a donnée M. Alex. Brongniart dans ses Ossemens fossiles, ont occasionné quelques erreurs qu’il importe de rectifier avant de passer à la description de ses caractères spécifiques. Un Oursin de forme oblonge et ovoïde, provenant de la montagne des Fis et fort semblable à celui qui nous occupe ici, avait été communiqué à M. Agassiz; ce savant reconnut que les ambulacres étaient pétaloïdes, et rangea par conséquent l'espèce dans son genre Catopygus. Comme elle avait la mène forme que le Nueleolites depressus de Brongniart et qu'elle provenait de la même localité, 11. Agassiz crut devoir identifier ces deux Oursins; et c'est ce qui nous explique pourquoi le Nueleolites depressus Brong. figure dans la Deseription des Eehinodermes fossiles de la Suisse comme syunyme du Catopygus depressus. Cependant, M. le Dr Mayor, de Genève, recueillit plıs tard, dans la même localité, plusieurs exemplaires également ovoïdes, mais dont les ambulacres simples indiquaient qu'ils n'appartenaient point au genre Catopygus : ce sont ces exemplaires que je désigne ici sous le nom de Pyrina depressa; et comme ils ressemblent davantage à la figure de Brongniart que l'espèce à ambulacres pétaloïdes (Catopygus depressus $\mathrm{Ag}_{\mathrm{g}}$ ), je crois devoir rapporter, de préférence à l'espèce qui nous occupe ici, le synonyme de Brongniart, quoique la figure originale ne donne pas d'une manière précise la structure des ambulacres. Il importera done de bien distinguer à l'avenir le Pyrina depressa du Catopygus depressus, qui, quoifue tris-semblable par sa forme, fait cependant partic d'un autre groupe. Dans son Catalogue systématique des moules d'Eehinodermes fossiles, M. Agassiz fit de cette espèce un Galerites Castanea, l'envisageant, à tort, comme un jeune de cette espèce. On ne saurait disconvenir en effet que le $P$. depressa ne ressemble beaucoup aux Galérites; car en dépit de sa forme ovale et allongèe, on y reconnait encore, d'une manière distincte, les rudimens de celte forme pentagonale qui caractérise la plupart des Galérites. L’anus, quoique situé à la face postérieure, est moins élevé que dans les autres espèces, ensorte que l'on peut dire, sans être témẻraire, que le Pyrina depressa forme le passage des Pyrines aux vrais Galérites. Le test n'est pas assez bien conservé pour que I'on puisse en apercevoir les détails; mais l'on voit par les brisures qu’il est extrèmement mince. 
Les aires ambulacraires sont proportionnellement très-étroites, elles n’ügalent guère en largeur que le tiers des aires interambulacraires. La face inférieure est bombẻe sans ètre pulvinée. L'ouverture buccale, qui en occupe le centre, est distinctement pentagonale dans l'exemplaire figuré. L'anus est très-grand et de forme elliptique, mais pointu.

Je ne connais encore que quelques exemplaires de celte espéce, qui proviennent du terrain crétacé de la montagne des Fis et du Reposoir. Des circonstances indépendantes de ma volontí mont empèché d'en donner des figures. Il sera cependant facile, à l'aide de cette description, de la distinguer de ses congénẻres, si l'on se rappelle qu'elle est sensiblement plus renflée en avant qu'en arrière, et que l'anus est moins liaut.

\section{Prrisa prgea Des.}

Tab. 5, fig. 27-31.

Srr. Galeritcs pygra Aß̈. Descr. des Ech. foss. de la Suisse 1re partie p. 78. Tab. 12, fig. 3-6. - Catal. syst. Ectyp. p. $\%$

Quoique assez fréquentè dans le calcaire jaune de l'ẻtage néocomien, cette espèce est cependant rarement bien conservée. L'exemplaire représenté dans mes figures 27-30 est le seul qui m'ait offert toutes les parties du test intactes. Sa forme ovoïde et la position de l'anus au bord postérieur mont engagé à le transporter du genre Galérite, dans lequel l'avait rangé II. Igassiz, dans le genre Pyrina, dont il a toute la physionomie. Il n'existe en effet aucune différence de largeur entre le còté antérieur et le còté postérieur. La face supérieure est plus ou moins aplatie, tandis que la face inférieure est fortement pulvinée. Ce n'est qu'accidentellement qne l'ouverture buccale, qui en occupe le centre, parait ici oblique (fig. 30); il est probable qu'à l’état normal, elle est anguleuse comme dans les autres espèces de ce genre. Les tubercules sont fort nombreux; on en compte jusqu'à six rangées sur le milieu des aires ambulacraires; mais leur nombre diminue considérablement près du sommet. La fig. 31 a représente quelques tubercules diune aire interambulacraire, montrant leur structure intime et la manière dont ils sont entourés par les tubercules miliaires; il faut que les crénelures de la hase des mamelons, qui sont si distinctes dans les tubercules du $P$. Ouulum (fig. $37 c$ ), soient ici très-fines, car je n’ai pu les apercevoir, mème au microscope. La fig. 28 représente un exemplaire de grande taille, du même terrain, des environs de Neuchàtel, mais moins renflé et plus large que l'autre, et qui pourrait bien ètre une variété de l'espèce. 


\section{CHAPITRE III.}

DU GENRE GLOBATOR AG.

Ce genre a été établi par M. Agassiz dans ses Characteres diagnostici, ete., annexés au catalogue des moules d'Echinodermes fossiles du Musée de Neuchâtel. En réalité, il ne diffẻre des Galérites et des Pyrines que par sa forme. Aussi pourrait-on être tenté, par cette raison, de mettre sa validité en doute. Cependant, si l'on se rappelle qu'un trait fondamental des Galérites consiste dans leur forme plus ou moins pentagonale, et que, quelque circulaires qu’ils puissent paraître, ils sont cependant tous plus étroits du còté postérieur que du côtẻ antérieur, el que, chez tous, l'anus est surmonté d'une carène plus ou moins saillante, on comprendra qu'une espèce presque globuleuse, aussi large en arrière qu'en avant, et sans aucune trace de carène sur-anale, ait pu paraître à M. Agassiz digne de devenir le type d'un genre particulier, tout comme d'autres naturalistes ont séparé les Echinomètres des Echinus, uniquement à cause de leur forme allongée. La position de l'anus au milieu de la face postérieure ne peut pas être envisagée conıne un caractère générique, attendu qu'elle est la mème dans certains Galérites, entrautres dans le Galerites Globulus.

Ce genre ne compte encore qu'une seule espèce, le Globator Nucleus.

\section{Globatok Necleus Ag.}

$$
\text { Tal). 3, fig. 1-4. }
$$

Srx. Globator Nucleus Agg. Catal. syst. Eetyp. p. $\%$

La forme circulaire et globuleuse de cette espèce, jusqu'ici la seule de son genre, ressort d'une manière assez évidente des figures ci-jointes, pour que je puisse me dispenser d'insister sur ce caractère. Cette forme est due essentiellement à l'étroitesse de la face inférieure, qui s'efface presque complètement. L'ouverture buccale, qui en occupe le centre, est anguleuse et, de 
plus, elle m’a paru être allongée dans le sens du diamétre longitudinal. Sous ce rapport, le Glohator dont il est ici question, semble se rapprocher plus des Pyrines que des Galérites. Peutètre trouvera-t-on un jour que cette forme correspond à quelques particularités de l'appareil masticatoire. L'anus est elliptique et situé au milieu de la face postérieure.

L'appareil génital, qui se trouve très-bien conservé dans l'exemplaire figuré, présente les mêmes dimensions et est conformé i-peu-près de la mème manière que celui du Gulerites Globulus. Les quatre plaques génitales paires sont percées d'un trou assez apparent. La plaque impaire manque completement. Les plaques ocellaires, au nombre de cinq, sont aussi grandes que les plaques génitales; mais leurs pores sont d'une petitesse extrène et se voient à peine à la loupe (fig. 1 a). Quant aux détails du test, les tubercules principaux sont très-nombreux, distinctement mamelonnés, perforís au sommet et crénelés à la base du mamelon. Chaque tubercule naît d'une zone circulaire lisse, qui est surtout distincte et profonde à la face inféricure. Les aires ambulacraires ont quatre rangées de tubercules, mais elles ne sont pas très-régulières. Je n’ai pas pu m'assurer si les plaques dont elles se composent sont toutes de même forme, ou s’il y en a de primordiales et d’intercalées, comme dans les vrais Galérites. Les pores sont disposẻs par paires obliques.

Je ne connais qu'un exemplaire de cette espèce, le même que M. Agassiz a fait mouler pour sa collection de moules. Il fait partie de la collection de M. DesHayes. Son origine n'est pas connue, mais je ne doute nullement que ce ne soit un fossile crétacé. 


\section{CHAPITRE IV.}

DU GENRE NUCLEOPYGUS AGaSS.

Ce genre, institué comme le précėdent, par M. Agassiz, dans son Catalogue systématique des moules d'Echinodermes fossiles, comprend quelques espèces qui ont la physionomie générale des Nucléolites, mais qui en diffèrent en ce que les ambulacres, au lieu d'être pétaloïdes, sont simples et vont en divergeant du sommet vers le bord. Or s'il est vrai que la forme et la disposition extérieure des pores correspond à des particularités d'organisation daus le système respiratoire, la place que l'on assignera aux espèces dont il est ici question devra être subordonnée à la valeur 'que l'on accorde aux modifications du système respiratoire. Si l'on attache une grande importance à ces organes, on devra placer les Nucleopygus dans le voisinage des Galérites, comme nous le faisons ici; si au contraire il résultait d'observations ultérieures que la forme et la disposition des pores ambulacraires n'implique point une structure particulière de l'appareil respiratoire, on devrait les rapprocler des Nucléolites, avec lesquels ils ont extérieurement la plus grande ressemblance.

Il résulte de tout ceci que les Nucleopygus tiennent, jusqu’à un certain point, le milieu entre les Galérites et les Nucléolites; ce sont de petits Oursins déprimés, à Lubercules irrégulièrement répartis, ayant l'ouverture buccale au centre de la face infërieure, tandis que l'ouverture anale est à la face supérieure, très-près du sommet, et s'ouvre même dans une espéce de sillon, comme c'est le cas des Nucléolites. Mais, d'un autre côté, les ambulacres sont simples, c'est-í-dire que les pores ambulacraires ne sont pas réunis à la face supérieure par de petits plis transverses, mais sont au contraire rangés par paires obliques superposées comme dans les Galérites.

Je ne connais encore que deux espèces de ce genre, qui toutes deux appartiennent it la formation crétacée. 


\section{Nucleopyges mixon Ag.}

Tab. 5, fig. 20-22.

Srx. Nucleopygus minor Ağ. Catal. ş̣st. Ectyp. p. \%.

Cette petite espéce a au plus haut degré la physionomie des vraies Nucléolites. Comme ces dernières, elle est arrondie et rétrécie en avant, tronquée et élargie en arrière. Le côté antérieur est sensiblement plus renflé que le còté postérieur, qui paraît même fortement déclive, lorsquion l'examine de profil (fig. 21). L'ouverture buccale est sitnée à-peu-près au centre de la face inférieure, dans un grand creux de forme anguleuse. L'anus s'ouvre au fond d'un large sillon, tout près du somnet (fig. 20). Cet ensemble de caractères est bien de nature à faire supposer une vraie Nucléolite; d'autant plus que les ambulacres sont tellement petits, qu'on a de la peine à les apercevoir, mème à la loupe. Mais si on les soumet à un examen rigoureux, on ne tarde pas ì s'apercevoir que les pores ambulacraires se continuent d'une manière uniforme depuis le sommet jusque prẻs de la bouche, sans être unis par un sillon transversal (voyez le dessin grossi de fig. 21 a, qui reprèsente la partie supérieure d'une aire ambulacraire). Dès-lors, d'après les considérations que j’ai présentées à l'article du geure, on ne doit pas hésiter à ranger cette petite espéce parmi les Nucleopygus. Les tubercules sont très-serrés, comme on peut le voir par la fig. 216 , qui représente une portion d'une aire interambulacraire vue à la loupe; et de plus, les mamelons de ces tubercules ne sont pas perforés à leur sommet, ni plissés à leur base.

Je ne connais de cette espèce que l'exemplaire figuré qui fait partie de la magnifique collection de M. DesIlayes. C'est, selon toute apparence, un fossile crètacé.

\section{Nucleopyges nisists Ag.}

Tal. 5, fig. 23-26.

SW. Nucleopygus incisus Agr. Catal. syst. Eetyp. p. \%

Cette espèce est une de celles dont le classement présente les plus grandes difficultés; elle est fort différente de la précédente, et rien en elle ne rappelle le type des Nucléolites; sa physionomie générale la rapproche au contraire des Pyrines, dont elle a la forme ovoüde et les ambulacres; mais elle a en même temps le côté postérieur déclive (fig. 2ít) et l'anus, sans ètre logé au 
fond d'un sillon, est cependant très-rapproché dı sommet ( fig. 23). Cette dernière considération a sans doute engagé M. Agassiz à ranger notre espèce dans son genre Nucleopygus, dans lequel je l'ai laissée, ne voulant pas laire d'une espèce qui n'est encore connue que par un seul excmplaire, le type d'un nouveau genre. Peut-ĉtre l’incorporera-t-on par la suite au genre Pyrina, lorsqu'on aura recomnu que la position de l'anus ne doit pas constituer à elle seule un caractèr c géuérique. Le côté antérieur et le côté postérieur sont de mème largeur et également arrondis ; la face inféricure est pulvinée, et l'ouverture buccale, qui en occupe le centre, est anguleuse. L'anus est très-grand et pyrifornı. Les tubercules sont nombrcux et disposés de la mêne manière que dans les Pyrimes. Je n'ai pas pu distinguer les détails de l'appareil génital, non plus que la forme des plaques des aires ambulacraires; tout ce que j’ai vu, c'est que les pores sont simples et non réunis par un sillon.

L'original appartient au Muscee de Neuchâtel. Son origine ne m'est pas connue d'une manière certaine, nais je suis porté a croire que c'est un fossile néocomien. 


\section{CHAPITRE V.}

\section{DU GENRE CARATOMUS Ag.}

Ce genre ne comprend en général que de petites espèces, voisines à plusieurs égards des vrais Galérites, mais présentant cependant un ensemble de caractères qui leur donne une physionomie particulière. Et d’abord, la forme èlevée et subpentagonale des Galérites est ici remplacée par une forme déprimée, ovale ou circulaire. Le còté antérieur ne l'emporte plus en largeur sur le côté postérieur, et si l'on remarque, à cet égard, quelque différence entre le devant et le derrière, c'est plutòt le côté postérieur qui est le plus large. On ne saurait pas davantage confondre les Caratomes avec les Pyrines, à cause de leur forme toute différente, et parce que l'anus est invariablement situé à la face inférieure et surmonté dinne espèce de carẻne, qui, dans quelques espèces, devient un rostre trés-proéminent. L'ouverture buccale est centrale et en apparence circulaire; mais lorsqu'on l'exanine avec soin dans un exemplaire bien conservé, on ne manque pas d'y reconnaitre la forme décagonale qui est commune ả presque tout le groupe. Les tubercules sont très-fins, et irrégulièrement répartis à la surface du test. L'appareil génital est composé de quatre plaques génitales paires et de cinq plaques ocellaires très-petites; mais il est rare que l'on puisse les distinguer.

L'appareil masticatoire nous est complètement inconnu; mais nous avons une preuve de son existence dans les petits creux qui entourent la face interne de la bouche et qui se traduisent, dans les moules, sous la forme de petits bourrelets très-saillans (Tab. V, fig. 19). Comme nous l'avons dit, en traitant des vrais Galérites, il est probable que ces petits creux servaient à fixer d'une manière quelconque les màchoires.

Les espèces connues jusqu'à ce jour se montent à cinq et proviennent toutes des étages supérieurs de la formation crẻtacée. 


\section{Caratomus Avellana Ag.}

Tab. 5, fig. 11-13.

Srv. Caratomus Avellana Ag. Catal. syst. Ectyp. p. 7.

Catopygus Avellana DuB. Voy. au Caucase. Tab. I, figg. 19-21.

Cette espèce, figurée pour la première fois sous le nom de Catopygus Avellana, par II. DuBois de Montpéreux, réunit à un lıaut point tous les caractères que j’ai énumérés ci-dessus comme distinctifs des Caratomes, et e'est pour eette raison que je l'envisage comme le type de ce genre. Sa forme est ovale et déprimée; sa plus grande largeur est en arrière du sommet; mais, à partir de ee point, le test se rétrécit brusquement pour former un rostre qui est assez sensible. L'anus est inframarginal et situé à l'extrémité du rostre. La face inférieure n'est pas parfaitement plane; ses bords sont très-arrondis. L'ouverture buccale est petile; mais ce n'est sans doute que par suite d'une pression qu'elle paraît irrégulière dans l'exemplaire figuré. Les tubereules, que leur petitesse rend imperceptibles à l'oil nu, sont peu nombreux; on n'en compte guère que huit à dix dans une plaque de l'aire interambulacraire. Le test, sans être bien épais, est eependant loin d'être mince. J'ai été assez heureux pour découvrir dans un exemplaire appartenant à M. DuBois de Montpéreux, la disposition des plaques dans les aires ambulacraires. Elles sont enchevêtrées de manière à former un ziğ-zag très-prononcé sur la ligne médiane. Toutes les plaques sont égales, et l'on ne remarque point, comme dans les Galérites, de ees plaquettes intercalées dans lesquelles s'ourrent une partie des pores ambulaeraires. Les pores sont au reste très-petits, comme on peut le voir par le dessin grossi de fig. 11 a, qui représente un ambulacre de la face supérieure. La fig. $12 b$ représente la disposition de l'appareil génital sous le même grossissement. Les plaques génilales paires sont grandes, pentagonales et perforées à leur sommet. La plaque impaire paraît manquer complètement. Les plaques ocellaires sont tellement petites qu’il m’a été impossible de m’assurer si elles sont perforées; cependant l'analogie nous oblige en quelque sorte à le supposer.

Ce fossile est particulier à la craie, et il n'est pas sans intẻrêt d’avoir rencontré le même fossile dans la eraie de Crimée, où l'a découvert M. DuBois de Montpéreux, et dans les terrains erétacés de France, où il a élé recueilli par M. DesIIayes. 


\section{Caratonus Faba Ag.}

Tab. 5, fig. 8-10.

Sw. Caratomus Faba Ag. Catal. syst. Ectyp. p. \%.

Cette espèce ne se distingue du $C$. Avellana que par sa forme plus allongée et plus régulièrement ovale. Le côté postérieur ne l'emporte point en largeur sur le côté antérieur. Le rostre postérieur paraît aussi moins accusé. Malgré ces particularités, la pliysionomie des deux espèces èst ì-peu-près la même, et l'on pourrait encore conserver des doutes sur leur différence spécifique, si les caractères que je viens d’assigner à notre espèce n’étaient empruntés qu'à un seul exemplaire; mais ayant vu toute une série d'individus affecter constamment ces mêmes particularités, je pense que $\mathrm{M}$. Agassiz a eu raison de faire de ce fossile une espèce distincte du $C$. Avellana.

L'exemplaire figuré fait partie de la collection de M. Michelin, qui l'a conmuniqué à M. Agassiz, sans indication d'origine. J'en ai vu d'autres non moins bien conservés, provenant de l'tle d'Aix, à l'emhouchure de la Clıarente, où ils ont été recueillis par M. Alcide d'Orbigny.

\section{Caratonus henispherices Des.}

$$
\text { Tab. 5, fig. 14-15. }
$$

Le nom de cette espèce en indique le caractère saillant qui consiste dans sa forme régulièrement hémisphérique. Le rostre postérieur n'est plus indiqué que par un faible renflement audessus de l'anus, à-peu-près comme dans les Galérites. L'anus lui-même est complètement marginal. La face inférieure est plane. L'ouverture buccale, qui en occupe le centre, parait, au premier abord, circulaire; mais lorsqu'on l'examine attentivement, dans des exemplaires bien conservés, on y reconnaît la forme décagonale qui parait être commune à toutes les espèces. Les tubercules sont un peu plus serrẻs que dans les espèces précédentes, et il paraît quill en est de mème des pores ambulacraires. L'appareil génital offre la même disposition des plaques que nous avons décrite à l'occasion du $C$. Avellana. Le moule intérieur, dont j’ai représenté nn exemplaire très-bien conservé (fig. 17, 18 et 19) a la mème physionomie que les individus revêtus de leur test, bien qu'il soit beaucoup plus grand qu'aucun de ceux que je connais. On remarque, sur le pourtour de l'ouverture buccale, les cinq paires de petits bourrelets dont j’ai parlé à l'article du genre; ils correspondent aux aires ambulacraires, et sont plus développés que dans la plupart des moules de vrais Galérites. 
Cette espèce paraît être assez fréquente dans la craie blanche d'Angleterre. M. le Marquis de Northampton a eu l'obligeance d'en communiquer toute une série à M. Agassiz.

Le Galerites sulcato-radiatus de Goldfuss (Petref. Tab. XL, fig. 4), est une espèce très-voisine de celle-ci, mais moins renflèe.

\section{Caratones ormicelanis Ag.}

Tab. 5, fig. 5-7.

Srv. Caratomus orbicularis Ag. Catal. syst. Ectyp. p. \%

Un caractère assez frappant de cette espèce, consiste dans l'absence i-peu-près complète du rostre postérieur que nous avons signalé comme caractéristique pour le genre des Caratomes, alssence qui pourrait peut-être faire naître quelque doute sur sa position générique, si l'ensemble de ses autres caractères et sa pliysionomie toute semblable à celle des espèces non douteuses ne nous disaient que ce n'en est pas moins un véritable Caratome. Sa forme est parfaitement circulaire et mềne lıémisphérique. Sa face inférieure est plutôt renflée que plate. L'ouverture buccale, qui en occupe le centre, est petite. L'anus est marginal, de manière qu’il se voit également de profil et d'en bas. Les tubercules sont clair-semés et proportionnellement moins petits que dans le C. Avellana. L’appareil génital semble présenter la mème structure que dans celle dernière espéce.

L'exemplaire figuré provient de la craie de Villers, et m’á été communiqué par M. Studer. J'en ai vu d'autres dans la collection de M. Michelin. Tous sont très-petits et ont à peine uı demi-pouce de diamètre.

\section{Cinatonus rostritus Ag.}

Tab. 5, fig. 1-4.

Srx. Caratomus rostratus Agg. Catal. syst. Eetyp. p.\%

Cette espèce frappe au premier coup d'œil par son rostre très-pointu, qui lui donne une apparence pyriforme. Elle est en outre très-déprimée. L'anus, situé a l'extrémité du rostre, est complètement infra-marginal. La bouclıe est ouverte au centre de la face inférieure, qui est légèrement concave. Les tubercules de la surface sont clair-semés et assez gros proportionnellement à la taille de l'Oursin. A l'aide de ces caractères, qui sont tous très-précis, on ne court 
aucun risque de confondre cette espèce avec aucune de ses congènères. Eu revanche, les caraclères génériques n’en sont que plus difficiles à démontrer, par la raison que les ambulacres sont fort peu distincts; ce n'est qu'après avoir exposé un exemplaire à l'action de l'acide, que II. Agassiz est parvenu à découvrir la disposition des pores ambulacraires. Une fois qn il eut reconnu, au moyen de ce procédé, que les pores ne sont point réunis à la surface supérieure par des sillons transverses, ou en d'autres termes, que les ambulacres ne sont point pétaloïdes, la position générique de cette espèce ne pouvait plus supporter aucun doute, ef ce fut dans son genre Caratomus qu'il devait la placer. Les fig. 1, 3 et 4 représentent ce petit Oursin en grandeur naturelle. La fig. 2 est un dessin grossi a la loupe, montrant la disposition des tubercules qui s'aperçoivent à peine autrement. La fig. $2 a$, enfin, représente une portion d'une aire interambulacraire prise à la face supérieure; malgré ce grossissement, les pores sont à peine reconnaissables; cependant l'on peut voir quils sont disposés par paires obliques qui sont assez distantes les unes des autres.

Les originaux de mes figures m’ont été communiqués par M. DesHayes et proviennent, selon toute apparence, de la craie blanche de France. 


\section{CHAPITRE VI.}

\section{DU GenRe eGhinoneus van Phel.}

Ce genre, institué d'abord par van Phelsum, sous le nom hollandais d'Egelschuitjc, et admis par Leske et plus tard par Lamarck sous le nom d'Echinoneus, comprend certaines espèces vivantes caractérisées par leur forme ovoïde et par leur anus infère et rapproché de l'ouverture buccale. "On " les distingue des Fibulaires, dit Lamarck, par leurs ambulacres complets qui rayonnent du sonn met à la base, et des Galérites, parce qu'elles ont l'anus voisin de la bouche. „ Cette première distinction ne fut pas admise par Goldfuss, qui confondit les Filublaires et les Echinonẻes en un seul genre, sous prétexte qu'il existe, parmi les Fibulaires, des espèees à ambulaeres non convergens. Il est vrai que le Fibularia subglobosa, qu'il cite comme exemple, n’a point les zones porifères arquèes à leurs extrémités; mais ces zones n'en sont pas moins limitées à la face supérieure, ou, si elles se poursuivent à la face inférieure, c'est sous une autre forme. Mais en supposant mème que la différence ne fùt pas réelle, sous le rapport des ambulacres, il n’en faudrait pas moins séparer les Echinonées des Fibulaires, à cause de la forme de leur bouche. Toutes les Echinonées connues jusqu’à ce jour ont la bouche oblique. Lorsqu'on voit pour la première fois une Echinonée, on est naturellement porté à attribuer cette particularité à un acrident queleonque, d'autant plus que l'une des deux espèces de Leske porte le nom d'E. cyclostomus (à bouehe ronde). Mais lorsque on a eu l'occasion d'étudier de nombreux exemplaires appartetenant à des espèces différentes, et qu'on les trouve tous affectés de cette singulière forme buecale, on est bien forcé d'y voir un caractère générique. Mais alors, comment se fait-il que tous les auteurs parlent d'une espèce à bouche ronde? J'ai cherché en vain cette singulière espèce; bien plus, les exemplaires d'E. cyclostomus du Musèe de Paris, d'après lesquels Lamarck a fait ses descriptions, ont tous la bouche oblique. En conséquence, je suis porté à croire que ce caractère de la bouche ronde a été emprunté à quelque dessin d'un auteur ancien, soit de Breynius, soit de Séba, et que de là il aura passé dans la méthode, sans qu'on ait songé depuis à le vérifier. S'il en était autrement, 
une pareille exception serait suffisante pour reporter l'E. cyclostomus dans un autre genre. C'est ceque M. DesMoulins a fort bien senti; anssi le range-t-il dans le genre des Galérites, sous le nom de Galerites echinonea, en faisant cependant renarquer qu'il n’en a pas vu d'exemplaire. Les mèmes raisons éloignent les Echinonées des Pyrines, qui en diffẻrent en outre en ce qu'elles ont l'anus al la face postérieure.

Les rapports de cette forme particulière de l'ouverture huccale avec l'appareil masticatoire me sont demeurés inconnus; non seulement je n’ai trouré cet appareil dans aucune des espèces que II. Agassiz a bien voulu me confier pour ce travail; mais je me suis encore assuré qu'il n'existe pas la moindre trace d'auricules sur le pourtour interne de l'ouverture buccale; ensorte que, loin de pouvoir donner à cet égard des explications satisfaisantes, j'en suis encore à me demander šil existe réellement un appareil masticatoire cliez les Echinonées. L'analogie pourrait mème en faire douter, puisqu'on ne connaît aucun genre de la famille des Clypéastroïdes dont l'appareil masticatoire ne soit appuyé sur des auricules.

Un autre caractire, moins apparent, mais qui n'en mẻrite pas moins d'ùtre constaté, c'est que les tubercules des Echinonées ne sont ni perforés, ni ornés d'une collerette de plis à leur base, comme c'est le cas de tous les autres genres de ce groupe. Ce caractere, bien qu'en apparence peu important, mérite cependant d'ùtre pris en considération, à cause de sa constance dans d'autres groupes de l'orlre des Echinites; il constitue, entre autres, l'une des différences qui distinguent les vrais Cidaris des vrais Echinus.

L'appareil génital est, en apparence, simple, puisqu’il se compose de quatre pores génitaux formant un carré régulier et correspondant au sommet des quatre aires interambulacraires paires. Je n’ai pu apercevoir, dans aucune des espèces ci-dessous décrites, la moindre trace de sutures indiquant les contours des plaques; cependant je ne doute pas que ces plaques n'existent, car elles sont un caractėre fondamental de toutes les familles; et si on ne les apercoit pas, ćest probablement parce que les sutures sont trop intimes. Elles ne se voient pas davantage a la face interne. Les trous ocellaires, situés au sommet des aires ambulacraires, sont tellement petits, qu'on les remarque á peine à la loupe. Ils sont un peu plus apparens ì la face interie.

Il est un dernier caractère qui mérite particulièrement de fixer notre attention. Lorsquon examine à l'aide d'une forte loupe une espèce quelconque d'Echinonée, on distingue, entre les tubercules principaux et miliaires, qui sont mamelonıés et opaques, un nombre considérable de lubercules transparens, souvent aussi gros que les tubercules principaux, mais qui échappent facilement à la vue, à cause de leur transparence. Ces tubercules, que j’appelle tubercules vitrès, 
ne sont pas mamelonnés, et par conséquent ne portent pas de piquans. J'ai longtemps hésitẻ à leur accorder une valeur organique; car, comme on ne les'retrouve que dans des espèces vivantes, je soupconnais quils pourraient n'être autre chose que des glolsules ou vessies mucilagineuses. Ces doutes ne pouvaient être résolus que par l'observation microscopique. Je m’adressai à cet effet à M. Valentin, qui, ayant examiné un fragment de test de l' $E$. conformis, trouva les réseaux calcaires formés de la même manière que ceux de l'Echinus (voyez Monogr. d'Ecl. viv. et fossiles, qe liv.), mais avec cette différence, que les mailles, au lieu d'être vides, étaient remplies d'une substance transparente, qui, près de la surface, recouvrait mème les piliers de mavière à ne présenter qu'une couche lımogène. C'est sans doute cette substance émaillée qui forme les tubercules vitrés. Ces tubercules sont plus ou moins nombreux et de dimensions variables, suivant les espèces. En général, ils sont plus nombreux que les tubercules principaux, au moins à la face supérieure, tandis qu’à la face inférieure, ils sont constamnent plus petits et plus rares. Ces variations ne laissent pas que d'être d'un grand secours pour la détermination des espèces; et c'est dans ce but que j’ai ajouté, à chacune des espèces représentées, une ou plusieurs figures grossies au microscope.

Les Echinonées ne sont connues que dans l'époque actuelle, dans laquelle elles sont, jusqu'à présent, les seuls représentans du groupe des Galérites ou Clypéaströ̈des à ambulacres simples. Ce sont aussi les seuls dont nous connaissions les piquans; encore ne les ai-je vus que sur un seul exemplaire de l'Echin. conformis (Tab. 6', fig. 18-21). Ce sont de très-petites arêtes , comme on peut l'inférer de la petitesse des tubercules; mais leur structure n'en est pas moins intéressante ; non-seulement ils sont distinctement carénés ; mais on remarque aussi, clıez eux, une sorte de division transversale par anneaux, division qui ne se retrouve dans aucun autre genre. Les piquans des tubercules miliaires sont tellement petits qu'on les distingue à peine à la loupe.

Quant aux espèces, elles se ressemblent si fort dans leur forme et leur physionomie, qu'il faut souvent avoir recours à la loupe ou au microscope pour reconnaitre les différences. 


\section{Ecninoseus cyciostonus Leske.}

Tal. 6, fig. 13-15.

Srx. Echinoneus cyclostomus Leske ap. Klein. p. 173, Til). 3\%, fig. 3, 4. - Lam. III, P. 304. - Encycl. métlod. Tal. 153 , tiy. 19 , 20. - E. Desl. Ene. T. 2, p. 296. - DeBl. Dict. sc. nat. T. 14, p. 196. Ag. Prodr. (Mém. Neneh. p. 187).

Echinus cyclostomus L. Gm. p. 3183.

Galerites echinonea DesMoul. Talbl. sỵ. p. 246.

Oursin cyclostome Bose. Déterv. T. 24, p. 280.

Sela Mus. 1II, Tab. 15, figs. 33-3s.

Breynius Sched. p. 5\%, Tal. 2 , fig. 5-6.

Bocene obs. nat. p. 219.

Rumph Amb. p. 6, Tab. 14, fig. D.

Müller Del. p. 90 , Tilb. D. I , fig. 11.

Vim Phelsum p. 32, sp. 1 (Rondmond).

Baier Oryet. Tals. 3 , fig. 35.

Il est assez difficile, en examinant les figures de Breynius et de Leslie, que Lamarck rapporte à l'E. cyclostomus, d'arriver à une détermination rigoureuse de l'espèce qu’il a voulu décrire. Et d'abord, la figure de Leske est trop imparfaite pour pouvoir servir de guide. Il y a plus, elle est même fautive, puisque l'anus y est placé à la face supérieure; et si la description de l'auteur ne disait positivement "amus oblongus, ori vicimus, " on devrait mème supposer qu'elle représente un Oursin d'un autre genre. Les figures de Breynius et de Sẻba sont meilleures, mais je doute qu'elles soient parfaitement correctes, par la raison que l'anus, au lieu d'ètre grand et elliptique, est trèspetit et de forme circulaire. Lamarck, dans la diagnose qu'il donne de cette espèce, me semble ¿galement s'être laissé induire en erreur; car il dit qu’elle a la bouche ronde et cinq pores génitaux, lui assignant ainsi deux caractères qui ne se retrouvent dans aucune des espèces d'Echinonées que j’ai eu l'occasion d'examiner; toutes, au contraire, ont la bouche transversalement oblique el quatre pores génitaux.

En présence de ces indications eontradietoires, on comprend que ce n'est que d'une manière très-dubitative que je puis rapporter les synonymes ci-dessus à telle espéce plutôt qu’à telle autre. Si, malgré cela, je me suis décidé à le faire, c'est que, sentant le besoin de fixer d'une manière plus rigoureuse les limites des especes, et ne voulant pas remplacer par des noms nouveaux des noms déjà consacrés dans la science, jai cru devoir conserver le nom d'E. cyclostomus a celle qui, par sa forme générale, se rapproche le plus des figures mentionnées ci-dessus. 
L'espèce qui figure ici sous le nom d'E. cyclostomus se distingue par sa forme large et ovoïde, de mème qu'elle est aussi proportionnellement la plus déprimée. Entre le côté antérieur et le côté postérieur, il n'y a qu'une très-petite différence de largeur. La face inférieure est sensiblement coneave; mais, je le répète, la bouche n'est nullement ronde, mais oblique, comme dans toutes les autres espèces (fig. 15). L’anus, qui en est très-rapprochẻ, est grand et elliptique. Le test est exeessivement mince, a tel point, quill en est presque transparent. L'artieulation des plaques y est indiquée par des lignes un peu plus ternes.

L’appareil génital ne présente rien de partieulier dans sa structure; les quatre pores génitaux sont très-visibles; mais il n'existe aucune trace d'un cinquième pore. Les pores ocellaires, au nombre de cinq, sont très-distinets à la face interne. Examinés à la loupe, les tubercules des aires interambulacraires présentent l'apparence de fig. $13 a$, et si l'on vient à examiner quelques uns de ces tubercules au microseope, ils présentent l'aspect de fig. $13 \mathrm{~b}$; c'est-à-dire que les tubercules principaux sont distinetement mamelonés et s’èlèvent sur une base conique assez roide, tandis que les tubereules vitrés, qui les entourent, sont beaucoup plus nombreux et n'ont que la moitié de la taille des précédens. A la face inférieure, la différenee entre les tubereules principaux et vitrés est encore plus grande ( fig. $15 \mathrm{c}$ ). Les tubercules miliaires se distinguent des tubereules vitrés par leur apparenee plus terne et en ee qu'ils sont mamelonés comme les tubercules principaux.

M. $\Lambda$ gassiz possède plusieurs exemplaires de cette espèce provenant des îles de Lord Hood et d'autres qui lui ont été communiqués par M. Mielıelin sans indication d'origine. De ce nombre est l'exemplaire figuré. 


\title{
II. LCunoneus minor Leske.
}

\author{
Tab. 6, fig. 16.
}

Syx. Echinoneus minor Leshe ap. Klein. p. 1\%, Til. 49, fig. \$-9.

Echinoneus semilunaris var. 2. Limn. Ill, 1. 304. - E. Desl. T. 2, p. 290. - Ag. Prodr. (Mém. Nench. T. 1, p. 187). - Desloul. Tilbl. syu. p. 340. - Lamour. Dict. sc. nat. T. 6, p. 38. - DeBl. Zooph. p. 193.

Echinus oralis Mus. Tessin. P. 114, Tab. 6, figg. 2.

Sela Mus. III, Tab. 10. figg. 7 a. $b$.

Van Phelsum p. 32, sp. 2 (Spcletmond).

D'Arģ genville, Tab. $5 \%$, fig. B 6 et B. $\%$.

Lamarck admet, dans l'espèce qu'il signale sous le nom d'E. semilunaris, deux variètès, et il rapporte à la seconde l'espèce que Leske dèsigne sous le nom d'E. minor. Or, comme les figures de Leske ressemblent beaucoup, par leur forme générale, à une espèce recueillie par M. Latrobe à la Trinité et envoyée à M. Agassiz, je n’ai pas hésité à l’identifier. Le caractère essentiel de cette espece consiste dans sa forme très-allongèe et arrondie au sommet, ce qui la fait paraître presque cylindrique. Le còtẻ postẻrieur n'est pas beaucoup plus large que le côté antẻrieur. L'anus est très-rapproché de la bouche; sa forme est plus ou moins cunėiforme.

J'avais envisagé, dans l'origine, cette espèce comme une variété de l'E. conformis, et c'est ce qui m’avait engagé à n'en donner qu'une seule figure; mais ayant reconnu plus tard qu'elle en diffërait par sa structure microscopique, j’ai dù la décrire comme espéce à part. La fig. $16 a$, comparée à la fig. $19 a$, montre au premier coup d'œil cette différence. Les tubercules vitrés sont ici beaucoup plus petits que dans l'E. conformis. En revanche, les tubercules miliaires sont plus gros et atteignent à peu près les dimensions des tubercules vitrés.

Quant à la première variétė de l'E. semilunaris de Lamarck, à laquelle cet auteur rapporte la figure de Sẻba, Tom. III, Tab. 15, fig. 37, je n'ai pas encore rencontrẻ jusqu’ici une espèce qui pùt lui ètre rapportẻe avec quelque certitude. 


\title{
III. Ecmivonecs gibbosus Lam.
}

\author{
Tab. 6, fig. 4-6.
}

Sry. Echinoneus gibbosus Lam. III, p. 305. - E. Desl Enc. T. 2, p. 296. - DeBl. Dict. sc. nat. T. 14, p. 196. - Ag. Prodr. (llém. Neuch. p. 157).-DesMloul. Tabl. sỵn. p. 340.

On distingue assez facilement cette espèce à sa forme bossue, qui contraste d'une manière assez tranchée avec la forme régulière et ovoïde de la plupart des autres espèces. Lamarck, qui lui donna, pour cette raison, le nom de gibbosus, la dit plus grosse que les autres espèces connues; mais comme il n'en indique pas les dimensions et qu'il ne cite point de figures, je ne pense pas que cette indication doive servir de guide dans la détermination spécifique. L'exemplaire dont je donne ici plusieurs figures vues par les diverses faces, serait, dans ce cas, un jeune; car non seulement il n'est pas plus grand que les autres espèces, mais il figure mème parmi les plus petits. Les zones porifères sont situées dans des sillons étroits et profonds, qui font que les aires ambulacraires se détachent très-bien des aires interambulacraires. La fig. $5 b$ représente la partie supérieure d'une aire interambulacraire, vue à la loupe, et montrant la disposition des pores et des tubercules. La structure microscopique varie considérablement, suivant les régions du test. A la face supérieure, les tubercules principaux ne sont pas beaucoup plus gros que les tubercules vitrés. Ces derniers, quoique nombreux, le sont cependant proportionnellement moins que dans l'E. cruciatus (fig. $1 b$ ). Des tubercules miliaires sont dispersés çà et là, sans ordre apparent, dans les interstices des tubercules principaux et vitrés (fig. 4 a). La fig. $6 c$ représente quelques tubercules principaux de la face inférieure, entourés de quelques tubercules miliaires. Les tubercules vitrés ont ici à-peu-près complètement disparu.

J'ignore quelle est l'origine de cette espèce. Lamarck indique, mais d'une manière dubitative, les mers d'Amérique.

\section{Ecmivosers chuchitus Ag.}

$$
\text { Tab. 6, fig. 1-3. }
$$

Au milieu de l'uniformité générale qui rend les déterminations spécifiques si difficiles, cette espèce se distingue par plusieurs caractères faciles à saisir : elle est régulièrement ovoüde ; sa face supérieure est très-aplatie; mais son caractère essentiel réside dans ses tubercules. Les tubercules 
principaux sout petits et proportionnellement peu nombreux (fig. 1 a), surtout si on les compare aux tubercules ritrés. $\Lambda$ la fice supérieure, ces derniers sont trois fois aussi nombreux et, pour le moins, aussi gros que les tubercules principaux; mais pour se faire une juste idée de ces rapports, il est presque indispensable d'examiner le test au microscope. La fig. $1 b$ représente une portion d'une aire interambulacraire vue de cette manière. Les rapports numériques des tubercules sont tout autres à la surface inférieure, oủ les tubercules principaux acquièrent une prépondérance marquée sur les tubercules vitrés, qui ne sont guère plus gros que les tubercules miliaires (voy. fig. $3 c$ ). Les ouvertures buccale et anale ne présentent rien de particulier, nou plus que l'appareil génital.

L'habitat de cette espèce m'est inconnu. Je n'en connais encore qu'un seul exemplaire, qui fait partie du Musée de Neuchàtel.

\section{Echivoneus elegars Des.}

Tab. 6, fig. 7-9.

Cette espèce est très-voisine de l'E. cyclostomus, et il se pourrait même qu'elle n'en fùt qu'une variété. Toutefois, j’ai cru remarquer en elle eertaines particularités qui, quelle que soit la valeur qu'on leur accorde, méritent cependant d'être mentionnées. Et d'abord, elle est plus allongée et proportionnellement moins déprimée. La différence de largeur entre le côté antérieur et le côté postérieur est plus notable. Enfin, le test est aussi plus épais. Passant de là à l'étude des détails, nous trouvons que les tubercules sout en général très-nombreux, comme le montrent les fig. $7 a$ et $8 c$, qui représentent, la première, une aire interambulacraire, et la seconde, une aire ambulacraire de la face supérieure, vues à la loupe. Cette dernière figure indique en outre, d'une manière très-distincte, la disposition des pores, qui sont ici rangẻs par paires superposées et légèrement obliques. A la face infẻrieure, ees mêmes pores sont bien moins apparens et très-obliques (fig. $9 d$ ). Les détails microscopiques, tels que les représentent les fig. $7 b$ et $9 e$, ne différent pas d'une manière sensible de ceux de l' $E$. cyclostomus, comme on peut le voir en comparant ces figures avec les fig. $13 b$ et $\mathbf{1 5 c}$, qui représentent les mêmes parties dans l'E. cyclostomus.

M. Agassiz possède plusieurs exemplaires de cette espèce, qui proviennent de l'île de PortoRicco, où ils ont été recueillis par M. Auguste Mayor. 


\section{Echinoveus serintis Des.}

Tab. 6, fig. 10-12.

Jai appelé cette espèce serialis, parce qu'elle est jusqu'ici la seule dont les tubercules soient disposés par séries rëguliẻres; et ce caractėre, qui est surtout frappant dans les aires ambulacraires (fig. $11 c$ ), suffirait pour justifier l'établissement d'une nouvelle espèce. C'est un Oursin d'assez grande taille, ayant la face supérieure trẻs-déprimée et presque plate. Le côté antérieur est sensiblement plus étroit que le côté postérieur. Le test est épais. L'anus, très-rapproché de la bouche, est grand, et surtout remarquable par sa largeur (fig. 12). Enfin, la disposition sériale des tubercules, qui sont très-apparens, donnent au test une élégance toute particuliẻre, que n’ont pas les autres Echinonées. La régularité et la grosseur des tubercules principaux semblent en quelque sorte rachetées aux dépens des tubercules" vitrés, qui sont proportiounellement plus petits que dans aucune autre espèce, comme le montre la fig. $10 \mathrm{~b}$, qui représente une partie d'une aire interambulacraire vue au microscope. A la face inférieure, chaque tubercule nait du milieu d'une surface distiuctement hexagonale (fig. $12 d$ ). Les tubercules vitrés sont ici très-peu nombreux et limités, en quelque sorte, aux angles de l'hexagoue.

Je ne connais cette espèce que par un seul exemplaire qui a été communiqué à M. Agassiz par M. Michelin. Sa couleur est un fond brun tirant au violet, sur lequel les tubercules, d'apparence nacrée, se détachent d’une manière très-gracieuse. Son lıabitat n'est pas connı.

\section{Echinonecs conforuis Des.}

Tab. 6, fig. 17-21.

Cette espèce présente de grandes affinités avec plusieurs de ses congénẻres. Elle est très-renflée, à-peu-près conme l'E. minor; cependant le côté antérieur et le côté postérieur sont plu uniformes (fig. 18). La bouche est large, oblique et très-rapprochée de l'anus, qui est lui-même très-grand (fig. 20). L'exemplaire figuré est, sous ce rapport, d'autant plus précieux, que nou seulement les contours des orifices sont intacts, mais que les plaques anales y sont encore conservées, et permettent par conséquent une étude détaillée de leurs parties. La fig. $20 b$ les représente dans leur position naturelle, vue à la loupe. Un cercle de plaques assez semblables par leur forme, quoique de grandeur variable, et qui sont probablement immohiles pendant la vie, garnissent 
le pourtour immédiat de l'ouverture. Au milieu de ce premier cercle, on remarque d'autres plaques, de forme diffèrente, entourant un bouton en forme de panache, qui, probablement, se déplaçait pour donner passage aux excrémens. Toutes ces plaques sont garnies de tubercules portant de petits piquans.

Les détails du test (fig. 19 a) rappellent ceux de l'E. elegans : les tubercules principaux sont plus gros que les tubercules vitrés, et les intersticcs de ces derniers sont parsemés d'une quantití de tubercules miliaires.

Cette espèce est jusqu'ici la seule sur laquelle jaie retrouvé les piquans adhérens au test. J'ai ainsi pu massurer qu’il n'y a que les tubercules principaux et les tubercules miliaires qui portent des piquans. Les tubercules vitrés n'en ont point. Ces piquans sont trop petits pour que l'on puisse cn saisir la structure à l'œil nu; la loupe même ne suffit pas, et il faut avoir recours au microscope. Les fig. 18 et 20 montrent quelques parties du test garnies de ces soies. La fig. 21 représente deux piquans vus au microscope. On y distingue fort bien la tête ou la partie condyloïde, qui est entièrement lisse. La collerette, qui sépare la tête de l'aiguille, est saillante, mais très-étroite. L'aiguille elle-même est pourvue de carènes longitudinales très-fines, mais saillantes; on y remarque, en outre, une quantité d'anneaux transverses, qu'on serait tenté de prendre pour des anncaux d'accroissement.

La fig. 17 représente un grand exemplaire de forme un peu différente, mais cependant trèsrenflé; peut-être appartient-il à une autre espèce; toutefois sa structure nicroscopique (fig. 17a) ne m’a pas paru motiver une séparation spécifique.

L'origine des deux exemplaires micst inconnue. 


\section{CHAPITRE VII.}

\section{DU GENRE DISCOIDEA GRAY}

Le genre Discoidea peut passer pour le plus difficile de tout le groupe des Galérites, à cause de la graude uniformité de ses espèces, et plus encore à cause de ses rapports intimes avec les Galérites. Etabli dans l'origine par Klein, sous le nom de Discoïdes, il a eu le sort de beancoup d'autres, éest-it-dire que les naturalistes plus récens n'en ont tenu aucun compte. Linné ne le mentionne pas même. Leske, Lamarck, Goldfuss et DesMoulins le confondent dans les Galérites. Ce n'est que dans ces derniers temps que Gray l'a de nouveau réintégré dans ses droits; mais il n’y range encore qu'une seule espèce, le Discoidea rolularis qui n'est autre, d'après sa propre citation, que le Discoides subucuhus de Kklein. Tout récemment, M. Agassiz en a décrit et figuré un certain nombre d'espèces nouvelles dans ses Descr. dEch. foss. de la Suisse, en les accompagnant d'une description générique (") qu’il résume de la manière suivante : "Ce sont des Oursins de forme " circulaire, ayant l'ouverture buccale placée au centre de la face inférieure et ornée de dix créne" lures. L'ouverture anale est grande, ovale, ordinairement submarginale, rarenent marginale. " Les ambulacres sont composés de deux rangěes de petits pores ronds et très-rapprochés. Les tu" hercules, disposés par séries régulières, sont perforés et mamelonués, et l'espace intermédiaire " entre les séries principales est recouvert d'une fune granulation souvent imperceptible a l'ceil nu.

"L'appareil oviducal est au sommet du disque; il est formé d'un hourrelet central, entouré de n cinq plaques ovariales et de cinq plaques interovariales ".

Je n’aurai que jeu de chose à ajouter à cette description du genre Discoidea. Je dirai seulement que l'étude d'un grand nombre d'espèces, tant jurassiques que crétacées, m’a fait dècouvir cer-

(*) A celle occasion, и. Agassiz aurait dủ préférer le non de Discö̈des, qui est le nom original de klein, à celui de Discoidea, ¡jue lui a substitué Gray, sans direse, raisons. Ç'eñt été un hommage rendu à la mémoire de l'un des naturalistes qui ont le Plus contribué à faire comaitre les Echinodermes. Maintenant que le nom de Discoidea est consacré par l'usage, ce serail pousun trop loin le désir des réformes nominales, si j'essayais encore de proposer cette substitution. 
taines combinaisons de caractères qui semblent rapprocher plus particulièrement telles especes, en même temps qu'elles les éloignent de telles autres. Les moules intérieurs sont, sous ce rapport, d'une très-grande importance. Lorsqu'on vient à examiner certains moules, on est étonné de voir leur pourtour entamé par des entailles très-larges et très-profondes (Tab.VII, fig. 21 et 22, Tab. VIII, lig. 12 et 13). Il en est de ces entailles à-peu-près comme des lobes des cloisons dans les Ammouites : elles ne se voient pas à la surface, mais elles n’en fournissent pas moins des caractères importans à la déternination zoologique; car en les étudiant de près, on trouve qu'elles sont occasionnées par des processus du test qui s'élèvent du plancher inférieur de ce dernier, a-peu-près comme les piliers et les cloisons verticales de plusieurs genres du groupe des Scutelles $\left({ }^{1}\right)$. Cette particularité n’a point échappé à l'attention de Lamarck, qui, ayant reucontré un moule ainsi crénelé daus sa circonférence, en fit le type d'une espèce à part, sous le nom de Galerites fissuratus. Goldfuss, au contraire, altrilue cette forme à un remplissage incomplet du test, et ne voit dans le Gal. fissuratus qu'un exemplaire imparfait du Gal. abbreviata. N'ayant pas vu l'exémplaire original de Lamarck, je ne puis dire à quelle espece il appartient; mais on ne saurait douter que ce ne soit une Discoïlée, probablement le $D$. cylindrica, à en juger d'après un croquis qu'en possède II. Agassiz.

Ces entailles n'existent pas dans toutes les especes que M. Agassiz range dans sou genre Discoïdée. En étudiant, sous ce rapport, les différentes espèces dont j’avais des moules à ma disposition, j’ai reconnu que les espèces qui en sont pourvues, présentent aussi à l'extérieur une certaine plrysionomie particulière qui permet de la distinguer facilement. Ainsi les espéces ì moule entaillé sont en général plus hautes et plus hémisphériques que les autres; elles ont la fice inférieure plane, la bouche et l'anus plus petits, les tubercules très-fins, et se distinguent en général par leur grande affinité avec les Galérites. Les espèces dont le moule est entier sont au contraire plus ou moins dépriniées; elles ont la face inférieure concave, l'anus très-grand et pyriforme, les tubercules plus développés, notamment ì la face iuférieure, et leur extérieur rappelle davantage le type des Echinus. Cette distinction mérite d'autant plus d'ètre prise en considération, qu'elle correspond, d’une manière assez exacte, à la répartition géologique des espèces, en ce sens, que toutes les especees du Jura, autant qu'clles sont connues jusqu'à ce jour, ont le moule intact, tandis que celles de la formation crélacée, à l'exception du seul Discoidea macropyga du

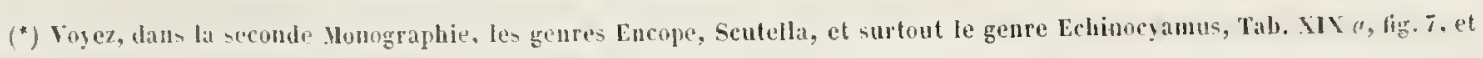
Tab. XYIII Gg. $6,7,95,82,55$. 
Néocomien, ont toutes le moule entaillé. D'autres naturalistes n'auraient pas hésité à faire de ces deux types deux genres distincts; cependant, comme je ne connais pas encore assez l’importance de ces entailles, j’ai préféré, pour éviter de trop fréquentes mutations, les décrire ici sous le nom de Discoïdées, en les rangeant en deux seetions : l'une comprenant les espèces à moule entaillé ou les vraies Discoïdées ayant pour type le $D$. Subuculus, et l'autre, celles à moule iutaet ou les Holectypes $\left({ }^{1}\right)$, ayant pour type le D. depressa.

Quant à l'appareil génital, je n’ai pu étudier sa structure d'une manière rigoureuse que dans les Discoïdées jurassiques ou Holectypes. Il se compose de cinq plaques génitales et de cinq plaques ocellaires, entourant une plaque d'apparence spongieuse, qui est le corps madréporilorme. Les plaques génitales sont pentagonales et ont leur angle le plus saillant tourné en dehors; les plaques ocellaires sont plus petites, et c'est leur còté le plus large qui est en dehors. Les unes et les autres sont perforées, à l'exception de la plaque génitale impaire qui est en même temps la plus grande ( Tab. $\mathbf{X}$, fig. 4 a et fig. 7 a).

Je ne possède aucun indice de l'appareil masticatoire; mais la conformité qui existe, dans la strueture de l'ouverture buccale, entre les Diseö̈dées et d'autres genres de la famille des Clypéastroïdes que nous savons pourvus de luâchoires (les Clypéastres, les Seutelles et même les Galérites), ne nous permet pas de douter que cet appareil n'existe aussi bien dans ce genre que dans les autres.

Les tubercules prineipaux forment des séries régulières qu'on poursuit depuis la bouche jusqu’à l'appareil génital. Ces séries sont surtout frappantes dans les IIolectypes on Discoïlées jurassiques; et cette particularité contribue essentiellement à leur donner eette grande ressemblance extérieure avee les Cidarides. Dans les Discoïdées proprement dites, les tubereules sont beaucoup plus petits, et souvent on éprouve quelques difficultés á reconnaitre au premier coupd'ail leur alignement; cependant leur disposition sériale ne saurait être contestée; car mème dans les espèces les plus uniformes, on reconnait toujours au moins deux séries régulières dans ehaque aire interambulacraire, alors mème que les autres ne sont pas assujettis ì un parallélisnte complet. Pour qu'il n'existe aucun doute à cet égard, j’ai donné des figures grossies du test, toutes les fois que mes exemplaires me l'ont permis. Il arrive cependant quà la faee inférieure, les tubercules d'une mème plaque se resserrent et forment des séries transversales très-apparentes qui empèchent

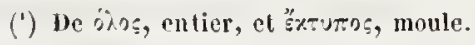


parfois de reconnaitre les séries verticales; mais ceci n'a lieu que près de la circonférence; plus loiı le parallélisme reparaît toujours.

Les tubercules miliaires sont en gẻnéral microscopiques, et l'on n'est ordinaírement guère tenté d'en faire un sujet d'étude. J'ai eependant reeonnu que leur disposition prẻsente des eombinaisons très-variées qui peuvent, dans certains cas, être très-utiles à la détermination spéeifique. Ils sont non-seulement plus ou moins abondans, mais leur disposition est aussi fort différente suivant les espèees. Parfois ils sont dispersés sans ordre apparent autour des tubercules prineipaux ( Tab. VII, fig. $13 a$, fig. $18 a$, Tab. VIII, fig. 15a); d'antres fois ils forment des séries horizontales régulières, et plus ou moins serrées (Tab. IX, fig. $11 a$, fig. $14 a$, fig. $18 b$ ). Ces différences ne eoïncident pas, eomme on pourrait le penser, à la division que je propose de faire entre les Diseoïdées proprement dites el les Holectypes, car on en trouve des deux sortes dans l'une et dans l'autre de ees divisions; mais en eomparant ees différentes figures entre elles, on comprendra quelle peut ètre limportanee de ces tubereules pour l'étude eomparative de eertaines espèces. La strueture des tubereules n'est pas sans importance. Les tubereules prineipaux sont mamelonnés dans les rraies Discoïdées eomne dans les IIoleetypes; la plupart ont en outre leur mamelon perforẻ au sommet et entouré d’une eollerette de plis à sa base (Talo. VII, fig. 1ł $e$, Tab. VIII, fig. $15 \mathrm{~b}$, fig. 9, fig. $13 e$ ). Cependant quelques petites espèees de vraies Diseoïdées, entre autres le $D$. Subuculus et le $D$. minor font exception à la règle, en ee que leur mamelon n’est ni perforé ní plissé à sa base (Tab. VII, fig. ł e et fig. $5 e$ ). Les tuberenles míliaires ont, selon toute apparenee, la mème structure que les tubereules prineipaux; j’ai pu m’assurer qu’ils sont au moins mamelonnés.

J'ai dit plus haut que les Discoïdées jurassiques ou Holectypes se trahissent à l'ceil exereé par une physionomie partieulière, ensorte qu'il n'est pas néeessaire d'avoir toujours reeours au moule pour déeider de la division à laquelle une espèee appartient. Les Diseoïdées jurassiques rappellent les Pygastres et mème les Cidarides; les vraies Discoïdées, au contraire, se rapproehent davantage des vraies Galérites. La ressemblance entre ees deux types est mème parfois trèsgrande, et l'on conçoit qu'en plaẹant eòte à eòte un exemplaire du Discoidea cylindrica et un Galerites abbreviala, les auteurs aient trouvé naturel de les elasser dans le mème genre. Et cependant il existe des différenees profondes entre ees deux Oursins.

Le nombre des espèces se monte à vingt, dont dix vraies Discoïdées et dix IIoleetypes on Discoïdées jurassiques. Les premières se trouvent réparties dans la formation crétaeée, depuis le grès vert jusqu’à la craie blanehe. Les autres sont des fossiles jurassiques, à lexception du seul Dis- 
coidea (Holectypus) macropyga qui appartient à la formation crétacée. Les plus anciennes se trouvent dans l'Oolite-inférieure.

\section{A. Discoidées proprement dites.}

IIufix. Tuhcrcules peu apparens; facc inférieure planc; anus moins grand que dans lcs Holcctypus ou Discoülées jurassiques. Moulc marqué d'cntailles sur son pourtour (*).

\section{Discoidea Stbeccles Bronn.}

Tab. 7, fig. 5-7.

Srx. Discoidca Subuculus Bronn. Leth. p. 615. Tab. 29, fig. 19. - Ag. Culal. syst. Eclyp. elc., p. 7.

Discoidca rotularis Gray Att. p. \%. - Ag. Prodr. p. 186.

Galerites rotularis Lam. III, p. 309. - E. Desl. Enc. T. 2, p. 433. - Defr. Dict. sc. nat. T. 18 , p. $\$ 6$.

-Encycl. mésh. Pl. 153, figg. 14-1\% - Al. Brongin. dans Cuvier 0ss. foss. $4^{\mathrm{e}}$ édit. Tall. 2 , fig. 13.

Discoides Suhuculus Klein p. 20-21, Tab. 14, fig. 7 . m. n. o. - Klein gall. $\$ 5 \%, ~$ 1. \%6, pl. 8, fig. D. E.

Tiylor in Geol. Trans. vol. 1, p. 3\%8.

Echinites Subuculus Leske ap. Klein p. $1 \% 1$.

Echinus Subuculus var. a et $b$. L. Gm. p. 3183.

Galerites Subuculus Glelf. Petrf. p. 129, Tul). 41, fig. 2, a. b.c.-Desmoul. Tabl. ș̣n. p. 254.-Pass! Seine-Inf. p. 335. - Fitton in Geol. Trans. vol. 4, p. 128, 332.- Kloeden Versl ein. Btandenl. p. $21 \%$. Parkinson 0r\% Rem. T. 3, p. 2]. Tals. 2, fiģ. \%.

Van l'hels. p. 37. Rosetop Egelmuts et Krecft oogic E. Naapjc.

Gesner Petrif. p. 35, n 6. "Echinitcs discoideus depressus".

Davila Catal. 111, p. 180. "Echinite cn forme de disque".

Lang Lap. fig. P. 126. Tab. 36.

Bourgnet Périf. p. \%7. Tab. 53 , fig. 359, 360.

plott. Oxforlsh. Tab. $\mathbf{8}$, fig. 9.

Mart. Lister Lap. tur'b. fig. 2

Ciest cette espèce que Kilein a prise pour type de son genre Discoüdes, en lui donnant le nonı spécifique de Subuculus, qui signifie bouton. Ce nom s'est maintenu dans les auteurs jusqu'à Lamarck qui, trouvant sans doute les figures et la description de Klein trop peu précises, appela l'espèce dont il est ici question Galerites rotularis, en lui rapportant comme synonyme le Discoüdes

(*) Elimimation faite des especes jurassiques, on pourrait eucore admettre deux sous-types dans cette division des vraies Discoides, représentés, l'un par le $D$. Subuculus et l'antre par le $D$. cylindrica. Les uns sont de jelits oursins coniques tréslants a bords renflés; les autres sont grands, liémisplériyues à base plus plane. 


\section{$-\mathbf{3} 3-$}

Subuculus, de Klein. Goldfuss, en la figurant avec la précision qui lui est habituelle, lui rendit de nouveau son ancien nom de Subuculus; Gray, en rétablissant le genre Discoüdes sous le nom de Discoidea, ne songea pas à rẻintégrer aussi l'espiee, qu’il cite, ainsi que MI. Agassiz (dans son Prodrome), sous le nom de Discoidea rotularis. C'est dans la Lethaca de Bronn que je retrouve pour la première fois le nom de Discoidea Subuculus, sous lequel cetle espèee se trouve ici décrite, et que je crois être a la fois le plus légitime et le plus convenable. Quant aux synonymes des auteurs antérieurs i Klein, tels que Lang, Gesner, Plott, van Plelsum, ete., n'ayant pu les consulter tous moi-même, je les ai en partie rapportés sur l'autorité de Kílein et de Leske.

C'est sans contredit l'une des plus élégantes espéces du genre; aussi, en examinant allentivemu ent la richesse de ses détails, on ne sétonne pas qu'elle ait élé remarquée entre toutes ses congénères. Sa forme est conique et, sous ce rapport, elle contraste d'une manière assez frappante arec les autres espèces dont nous aurons à nous occuper dans ce chapitre. Sa hauteur est au diamètre de sa hase, comme 3 à 4 . Sa face inférieure est pulvinée, et l'ouverture buccale, situèe dans une cavité assez profonde, présente ce pourtour déeagonal, qui est un caractère de toutes les Discö̈dées. L’anus est infra-marginal et largement elliptique (fig. T). Quant aux détails du test, il est impossible de les saisir tous à l'oil nu; mais en s'aidant de la loupe, on voil que les tubercules principaux, quoique très-petits, forment des rangées très-élégantes sur tout le pourtour du test. Au bord de la circonférence, ces rangées se montent à dix, dans les aires interambulacraires (fig. $5 b$ ), et à quatre seulement dans les aires ambulacraires (fig. $5 a$ ); mais celles des aires interambulacraires disparaissent trẻs-promptement à la face supérieure qui n'en compte plus que deux bien avant d'atteindre le sommet. Les tubereules des aires ambulacraires sont de moiliẻ plus petits que ecux des aires interambulacraires, et se distinguent à peine des tubercules miliaires. Une plaque isolie d'une aire interambulacraire, vue au microscope, se présente sous la forme de fig. 5 , et l'on peut s'assurer que, même les tubereules miliaires dont le test est si abondamment fourni, sont distinetement mamelonnés; mais ni les tubercules principaux ni les tubercules miliaires ne paraissent ètre perforés au sommet, et garnis d'une collerette de plis à leur base. La division des plaques est indiquée dans eette espèce d'une manière très-distincte, par de petits sillons transverses, qui correspondent aux sulures horizontales. L'on remarque en outre, sur chaque aire interambulaeraire, deux earènes qui s'ètendent de la bouche au sommet et déterminent celte variété de relief qui fail du $D$. Subuculus un Oursin si élégant.

L'appareil génital n'offre rien de particulier dans sa strueture. On y reconnaît les cinq plaques génitales et les einq plaques ocellaires, entourant le corps madréporiforme. Toutes, à l'excep- 


\section{$-56-$}

tion de la plaque génitale impaire, sont perforées. Les plaques ocellaires sont d'une petitesse extrème.

C'est une espèce particulière, à ce qu'il parait, à la craie marneuse. Elle se trouve également en France, en Angleterre et en Allemagne. L'original de mes figures fait partie de la collection de M. DesHayes. D’autres, qui m’ont été communiqués par M. Alex. Brongniart proviennent de Longleat.

\section{Discoldea minima $\Lambda$ g.}

Tab. 7, fig. 1-4.

Srs. Niscoidea minima Ag. Catal. syst. Ectyp. p. 7.

C'est jusqu'ici la plus petite espèce du groupe des Galérítes. Sa plyssionomie rappelle à tous égards celle du $D$. Subuculus, et lorsqu'on l'examine à la loupe, on y reconnaît, à la face supérieure, les mêmes rangées de tubercules et de pores (fig. 4). Sa forme générale est cependant un peu moins conique; la face inférieure paraît aussi être moins concave et ses hords moins renflés ; mais l'anus présente les mêmes rapports de dimension et de position, c'est-à-dire qu’il s'étend un peu au-delà de la moitié de l'espace entre le bord et la botuche. Un hazard heureux a rendu M. Michelin possesseur d'un exemplaire dans lequel les plaques anales sont parfaitement conservées. J'ai représenté, dans la fig. $3 a$, cet organe tel qu'il se voit sous un grossissement de deux diamètres : les plaques, distinctement juxtaposées et séparées par des sutures très-apparentes, sont de grandeur inégale; on en remarque de nombreuses petiles du côté voisin de l'ouverture buccale, et trois grandes du côté externe; celle qui est au milieu porte un tubercule assez gros ; les autres sont parsenées de très-petites granules. La fig. $3 b$ représente une section de la face inférieure, comprenant une aire ambulacraire et une aire interambulacraire, avec l'une des entailles du pourtour de la bouche. Les fig. $4 a$ et $\$ b$ représentent ces mêmes parties à la face supérieure, savoir, fig. $4 a$ une aire ambulacraire, et fig. $4 b$ une aire interambulacraire. Les tubercules principaux sont moins nombreux, mais plus gros poportionnellement à la taille de l'Oursì que ceux du D. Subuculus.. De plus, les tubercules miliaires forment des séries horizontales obliques comme le montre la fig. 4 $c$, qui représente une plaque isolée d'une aire interambulacraire vue au microscope, tandis que les tubercules miliaires du $D$. Subuculus, sont répartis uniformément autour des tulercules principaux. 
Celte espèce ne mi est encore connue que par un seul exemplaire qui provient, selon toute apparence, de la craie marneuse de France.

\section{Disconei piscu Mer.}

Il existe au Musée de Bàle une série de petites Discö̈lées que M. Mérian a inserites dans le catalogue des Collections sous le nou de D. Pisum. Extérieurement, ces petits Oursins ne diffèrent en rien du $D$. mimima; aussi les avais-je identifiés avee cette dernière espèce, lorsque rencontrant dans le nombre un exemplaire mieux conservé que les autres, je vis, en l'examinant il la loupe et au microscope, que les tubercules miliaires, au lieu d'ètre rangés par séries horizontales, sont répartis uniformėment à Ja surface du test, comme ceux du D. Subuculus (Tab. T, fig. c), et que les tubercules principaux sont distinctement perforis au sommet, particularité que je n'ai pas remarquée dans les deux espèces précédentes. Mais, je le répète, ces caractères ne sont appréciables que sur des exeuplaires parfaitement conservis. Lorsquil u'en est pas ainsi, il faut renoncer à l'espoir de distinguer le D. Pisum du D. minima.

L'origine de cette espèce ne m'est pas connue. Cependant je ne doute pas que ce ne soit un fossile crétacé, et la présence de paillettes de nica dans l'intérieur de quelques-uns fait présumer qu’ils appartiennent a la Glauconie.

\section{Disconea tumma Des.}

Tab: 13 , fig. 1-3.

Srs. Galerites turrita Des. (sur la plinche).

Cette espéce vient d'être découverte par MI. Gressly, dans le grès vert de la Perte-du-Rhòne. Elie a la forme conique du $D$. Subuculus, et, quoique proportionnellement plus haute, elle ne lui en ressemble pas moins par l'ensemble de sa physionomie. Mais les détails de son test présentent certaines différences très-inıportantes, quoique peu sensibles au premier abord. En effet, en examinant cette espèce à la loupe, on reconnaît, dans les aires interambulícraires, au moins douze séries de tubercules, tous semblables, sauf que les uns s'élèvent plus haut que les autres : or, comme nous l'avons vu plus haut, il n'en est pas de même dans les aires interambulacraires du D. Subuculus, oủ les rangées qui correspondent aux deux carẻnes verticales des aires interambulacraires sont seules bien apparentes. Il suffira de compareś à cet égard notre fig. $2 b$, qui repré- 
sente une aire interambulacraire vue i la loupe, avec la fig. $5 b$ de Tab. 7 , qui représente la mème parlie du lest sous le mème grossissement. Enfin, et ceci mérite surtout d'ètre remarqué, les lubercules principaux sout distinctement perforés, cequi n'est pas le ras des tubercules du $\boldsymbol{D}$. Subuculus. Le test lui-même est assez épais, et, comme il est brisé sur l'un de ses bords, j’ai pu m’assurer de la présence des entailles marginales, qui sont ici proportionnellentent aussi marquées que dans les autres espèces. J'en ai reconnu deux dans chaque aire interambulacraire. Je n’ai pas rẻussi à légager l'ouverture buceale, el ne puis par conséquent indiquer les détails de son pourtour. L'anus est pyriforme et occupe a-peu-près la moitié de l'espace entre le bord et l'ouverture buccale.

Je n'en connais encore que le seul exemplaire qui est ici liguré.

\section{Discemen crimnitica Ag.}

Tal. 8 , fig. 8-16.

Sw. Diseoidea eylindrica Ag. Deser. des Echinod. fossiles de la Suisse, $1^{\text {cr }}$ part. p. 92, Tab. 6, fig. 13-15. - Catal. syst. Ectyp. etc., p.\%

Gulerites eylindrieus Lam. III, p. 311 (excl. syn.) - E. Desl. Enc. T. 2, p. 433.

Conulus Hawkinsii Mantell Trans. Soc. geol. Lond. T. 3, p. 201.

Galerites Ifawkinsii Des.loul. Tabl. syn. p. 255.

Galerites eanaliculatus Gldf. p. 125. Tab. 41, fig. 1.

Galerites quadrifaseiata Val. Expl. de la pl. 153 de l'Enc. méth. fig. 10, 11. - DeBl. Zooph. p. 203. Eehinus quadrifasciatus L. Gm. p. 3193.

Eehinites quater-faseiatus Leske p 1\%0. Tabl. 4\%, fig. 3, 4, 5.

Van Phelsum p. 30, 31. (Tierbandige cirkelronde Egelsteen.)

Gehler Diss, de char. foss. extern. p. 13.

Walch. Knorr. Delic. nat. Suppl. p. 215 et 233. Talb. 9 $g$, fig. 7, 5, 9, et Til, 9 $d$, fig. 3.

Galerites sexfusciatus Lam. III, p. 308. - E. Desl. Ene. T. 2, P. 432. - Eneycl. méth. Tab. 15:3, fig. 12, 13. - Defr. Dict. sc. nat. T. 1S, p. 86.-DeBl. Zoopli. P. 201.

Eehinus sexies fasciatus L. Gm. p. 3183.

Eehinites sexies faseiatus Leske p. 1\%0, Tab. 50, fig. 1-2.

Gehler Diss. de char. foss. extern. p. 13.

Walch. Knor' Delic. nat. Sulpl. Tab. $9 g$, lig. 4, $5,6$.

Viul Pliclsum p. 31 (Zesband).

Ce fossile, l'un des plus beaux de la craie, a élé décrit et figuré sous divers noms génériques et specifiques par les auteurs. Lanarck l'appelle Galerites cylindricus; Mantell, dans sa Géologie de Sussex, le nomme Comulus Ilaukinsii, et Goldfuss le décrit sous le nom de Galerites canaliculata. 
M. Agassiz, en le reportant dans le genre Discoiden, lui a conservé le nom spécifique de cylindrica, qui est le plus ancien, el qu’il ne fitut pas confondre, comme l'a fait $\mathbf{I}$. Desmonlins, avec le Clypeaster subcylindricus de Mïnster dans l'ouvage de Goldfuss, qui est un Pygorhynchus du terraiu tertiaire, éest-à-dire, un Clypiastroüle à ambulacres pétaloïdes.

C’est une espèce circulaire, à sommet rígulièrement bombè, et comme sa lauteur dépasse, dans les grands exemplaires, la moitiè de sa longueur et qu'elle en égale même les deux tiers, il rn résulte que, vue de profil, elle présente une apparence quelque peu cylindrique (fig. 12 et 15), qui lui a valu son nom spécifique. La face inférieure est ì-peu-prés plane, sauf quelques ondulalions qui se rattachent à la structure intérieure. Sa bouclıe a une apparence circulaire; mais en l'examinant de près, on reconnaît qu'elle est, en réalite, décagonale. L'anus est, proportionnellenent à la taille de l'Oursin, beancoup' plus petit que dans aucune autre espèce: sa longueur égale la septième partie de la base; sa position est intermédiaire entre la bouclıe et le bord. Les tubercules sont très-petits et d'une uniformité remarquable. Ceus des aires interambulacraires, quoique nombreux, ne forment que deux séries régulières qui s’étendent de la base au sommet, et correspondent à une espèce de carène qui vient aboutir aux entailles du pourtour; les autres sont disseminées sur les plaques sans ordre apparent. On en compte environ six ou sept sur une plaque du milieu du test (voy. figg.15a). Ceux de la face infërieure sout plus déreloppès et disposés en séries liorizontales (fig. 16); mais en s'éloignant du bord, ces rangées sont moins fournies, et, sur le pourtour de l'ouverture buccale, il n'y a plus guère qu'un tubercule par plaque, ainsi que le montre la fig. 17, qui represente l'origine d’une aire interambulacraire vue á la loupe. Examinés au microscope, ces tubercules présentent une structure très-délicate; ils sont perforés, mamelonnes et garnis dune collerette de crénelures a leur base ; les tuhercules miliaires qui les entourent sont fort nombreux (fig. 15 b). Dans les aires ambulacraires, les tubercules principaux ne forment guẻre que deux rangèes. Les plaques de ces aires sont très-étroites ì la face supérieure , mais cependant régulières, et dans chaque plaque s'ouve une paire de pores disposés obliquement (fig. 14a). A la face inférieure, ces mêmes plaques augmentent considérablement de hauteur; elles sont mème, près de la houche, plus hautes que longues; aussi portent-elles chacune un tủercule, et sont percées de trois ou quatre paires de pores bordés extérieurement par une série régulière de tubercules miliaires. Il suffit de comparer la fig. 16 a à la fig. 14 a pour se faire une idèe de la valeur de ces détails.

L’appareil génital est très-petit et d’apparence spongieuse; les plaques génitales, au nombre de cinq, sont ì-peu-près d’égale grandeur; les quatre plaques paires sont perforèes près de leur 
sommel; la plaque impaire m’a paru dépourvue de pore génital. Les plaques ocellaires sont d'une petitesse extrême, et se reconnaissent à peine à la loupe.

Le moule intérieur n’est pas moins intéressant à éludier que le test lui-même. Les articulations des plaques et même les empreintes des pores y sont ordinairement visibles (fig. 12). Mais ce sont surtout les sillons de la face inférieure qui méritent une attention particuliẻre; il y en a deux principaux sur chaque aire interambulacraire, qui s’étendent du bord de la circonférence jusqu'au pourtour de la bouche. C'est même ici quils atteignent leur plus grande longueur; en revanche, ils sont plus profonds près du pourtour du test, oủ ils s'enfoncent de plusieurs lignes dans lintérieur du moule (fig. 12). Il existe en outre, entre ces sillons principaux, de chaque còté de la suture médiane des aires interambulacraires, trois petites rainures marginales qui sont également visibles d'en has et de profil. Ces rainures affectent une forme un peu différente dans l'aire interambulacraire impaire, où elles sont plus profondes; de plus, il n'y en a que quatre au lieu de six.

L'ouverture buccale, par là même qu'elle est plus grande dans le moule qu'à la surface du test, laisse apercevoir plus distinctement sa structure décagonale, qui empiète plus sur les aires iıterambulacraìres que sur les aires ambulacraires. On y remarque aussi, en face de chaque aire ambulacraire, deux petits bourrelets saillants produits évidemment par de petits creux de la face interne du test, qui sans doute servaient an mécanisme de l’appareil masticatoire.

Il existe plusieurs monstruosités de cette espece, les unes n'ayant que quatre, les autres six ambulacres, monstruosités dont on a fait des espèces à part, sous les noms de Galerites quadrifasciata et $G$. sexfasciata. Nos figures 8,9 et 10 représentent un exemplaire très-hien conservé de re soi-disant $G$. quadrifasciata. Quant au $G$. sexfasciata des auteurs, c'est avec doute que je le rapporte comme synonyme à cette espèce. Cependant, jai cru remarquer dans la figure de Leske quelques entailles sur le bord du moule; ce qui pronverait que c’est au moins une Discoïlée, et non une vraie Galérite.

On rencontre le D. cylindrica à-peu-près partout dans la craie marneuse, en Angleterre, en France, en Allemagne, etc. Le bel exemplaire de fig. 14-16 a été communiqué à M. Agassiz par II. le marquis de Northampton; le moule de fig. 12 et 13 provient de la craie alpine de la montaggne des Fis, et fait partie de la collection du Musée de Neuchâtel. L'exemplaire de fig. 810 appartient a M. DesIIayes; celui de figg. 11 est nne variété moins élevée provenant de la craic. En ce qui concerne le moule de fig. 12 et 13 , il ne sera peut-être pas sans intérêt de faire remarquer qu'il est clarbonné, à-pen-près comme tous les fossiles de la montagne des Fis ; 
et comme jusqu ici je n’ai rencontré des moules naturels de Discoïdées que dans ces terrains, je vois dans ce fait une nouvelle preuve en faveur de lopinion qui envisage ce terrain comme noirci et transtormé par la chaleur, d'autaut plus qüil suffit d'exposer des exempliares de la craic blanche à l'action du feu, pour en enlever le test avec la plus grande facilité.

\section{V1. Discoinea Rotula Ag.}

Tal. 7, fig. 15-16. (excl. fig. 12, 13, 1.)

Srx. Miscoidea Rotula Ag. Prolly. p. 18.j. - Descript. des Echinod. foss. de la Suisse, fre partic p. 90. Talb. 6, fig. 10-12. - Catal. Syst. Eetyp. Ech. p. 7.

Nucleolites Rotula A1. Brongogn. dans Caviel 0ss. foss. T. II, 2 e part. p. 336. Tab. 9, fig. 13.

Pyrina Rotula Desmoul. Tabl. syn. p. 25s, n. 1.

Alex. Brongniart a figuré, dans les Ossemens fossiles de Cuvier, sous le nom de Nucleolites Rotula, une espèce de Discoïdèe dont N. DesMloulins a fait, à tort, une Pyrine, et que M. Agassiz. a décrite et figurée plus tard sous le nom de Disc. Rotula, dans sa Description des Echinodermes fossiles de la Suisse. J'aurais pu me contenter de renvoyer les paléotolongistes í ces dcux ouvrages; mais ayant reçu récemment en eommunication plusieurs espèces fort semblahles, j’ai pense quil serait utile de les figurer toutes sur la mène planche, afin de mieux faire ressortir les caractères qui distinguent cliaque espèce.

Les fig. 15 et 16 représentent un moule de la montagne des Fis, qui me semble ètre le véritable Nucleolites Rotula de Brongniart. Un caractère particulier de ectte cspèce, caractère qui la distingue surtont du D. conica, e'est d'être parfaitement circulaire ct d'avoir l'ouverture anale située au milieu de l'espace entre le bord postérieur et l'ouverture huccale. Une seeonde particularité plus frappante, mais qui n'est visible que dans les moules, réside dans les entailles marginales, qui sont bien moins larges que dans le $D$. conica, comme on pourra s'en assurer en comparant les fig. 15 et 16 avee les fig. 20,21 et 22.

Lorsque je fis exécuter mes planclies, je ne eonnaissais encore le $D$. Rotula que par des moules; et si quelques exemplaires avaieut conservé des lambcaux du test, ces lambeaux étaient trop frustes pour quil fùt possible d'en étudier la structure intime; et comme j’avais rencontré, parmi des Oursins envoyés à MI. Agassiz par M. Alex. Brongniart, une espèce très-semblable par sa forme, javais cru pouvoir l'identificr avec le D. Rohula. Plus tard, M. Favre, de Genève, m'enroya, du Saxonnet, un exemplaire du $D$. Rotula avec son test parfaitement conservé. Je lo 
comparai a celui de Rouen, et je m’assurai que les tubercules du D. Rotula sont fort différens de reux du Discoïdea de Rouen, et qu'au lieu d'être répartis sans ordre apparent à la surface du test, ils forment des séries liorizontales très-continues, à-peu-près comme dans le D. macropyga (Tab. 7, fig. 9 b). En conséquence, je dus éloigner du Discoidea Rotula la Discoïdée de Rouen, pour en former une espèce à part sous le nom de $D$. Facrina.

\section{Discoldea Favriva Des.}

Tab. 7, fig. 12-14. (sous le nom de Discoidea Rotula.)

J'ai dit, en décrivant le $D$. Rotula, quelles étaient les raisons qui m’avaient d'abord fait rẻunir cette dernière espèce au $D$. Favrina dont il est iciquestion. Le D. Favrina que je dédie à II. Favre de Genẻve, parce que c'est à son zèle que je dois d'avoir pu complèter l'ètude du D. Rotula, est une espéce circulaire, à face inférieure plane, à sommet très-surbaissé. C'est du $D$. cylindrica qu’il se rapproche le plus par sa forme gènèrale; mais il m’a paru en différer par ses tubercules qui forment des rangées horizontales moins tranchées a la face infërieure, et par la position de l'anus qui est plus rapproclıé du bord. Il ne saurait être confondu avec le $D$. conica, á cause de la forme conique et tronquée de cette dernière, et des fortes entailles de son moule. Enfin, nous savons qu’il diffère du $D$. Rotula par la disposition de ses tubercules niliaires.

Loriginal de mes figures a été communiqué à M. Agassiz par M. Al. Brongniart qui le dit originaire de lionen, et les dẻbris de roclıe micacie, qui y sont adhérens, prouvent assez qu’il appartient au Grès vert ou à la Glauconie. M. Gressly vient de rapporter récemment de la Perte du Hhône une série d'exemplaires fort semblables, que j’ai tout lieu de croire identiques, quoique leur état de conservation ne m'ait pas permis d'en étudier tous les détails. Les moules sont marqués d'entailles profondes, quoique moins sensilles que celles du $D$. conica.

VIII. Discoldea covica Des.

Tal. 7, fig. 17-22.

Comparé aux autres espèces de cette catégorie, le $D$. conica peut paraitre conique, et c'est ce qui m’a engagé à lui donner le nom ci-dessus. Cette forme, jointe á la troncature du bord postérieur, constitue en effet le caractère le plus marquant qui puisse faire distinguer extérieurement notre espéce du D. Rotula. Les moules intérieurs sont beaucoup plus différenciés. Lenrs entailles 
interambulacraires sont beaucoup plus larges, et donnent a leur pourtour une apparence onduleuse des plus caractéristiques (fig. 20 el 21). Ces moules remarquables províennent de la Montagne des Fis; c'est sur la foi de leur forme conique el de la forme légérement tronquéc du bord postérieur que je les ai identifiés avec certains exemplaires d'autres localités qui ont conservé leur test. On ne pourra toutefois avoir une entière certitude il cet égard, que lorsqu'on aura trouvé à la Montague des Fis quelques exemplaires dont le test soil conservé, comme cela a lieu pour le D. Rotula. En aitendant, la grandeur de l'anus dans les moules ne saurait être une oljection contre lidentification que je propose ici, altendı qüil est reconnu que le pourtour de l'anus est ordiuairement plus grand dans les moules qu’à la surface du test. Les fig. 17, 18 et 19 représentent un exemplaire très-bien conservẻ, provenant des couches inférieures de la craie de France. La fig. 18 a représente une plaque grossie d'une aire interambulacraire; la fig. 19 b, une aire ambulacraire de la face inférieure, et la fig. $19 c$, une portion de l'aire interambulacraire prise également a la face inférieure et moutrant la disposition et la forme des tubercules quí, conme à l'ordinaire, sont ici beaucoup plus développés qu’à la face supérieure. Les plaques des aires interambulacraires sont proportionnellement plus hautes que celles du $D$. Farrina.

\section{Discoldea neconata Des.}

Tab. 8, fig. 1-3.

Au premicr abord, cette espéce a toute l'apparence d'une Discoïdée jurassique. Elle est dẻprimée; ses bords sont renflés; sa face inférieure est concave; l'anus, sans occuper tout l'espace entre le bord et l'ouverture buceale, est cependant plus grand que dans les autres espèces crétacées. Aussi l'avais-je rangé dans la section des Discoülées jurassiques, avant que je n’en connusse l'intérieur ; mais ayant exposé plus tard un exemplaire à l'action du feu, de manière ì en enlever le test, jai vu, à mon grand étonnement, que le moule présentait des entailles en tout semblables a celles des autres Discoïdées crétacées. C'était donc une véritable Discoïdée. Cette découverte me parut d'autant plus intéressante qu'elle est une nouvelle preuve de la délimitation de certains types, conformément à leur distribution géologique. Sous ce rapport, la présence d’une Discoïdée du type jurassique, dansla formation crétacéc, eùt été une exception à la rẻgle.

Les tubercules ne sont bien conservés qu à la face iuférieure dans les exemplaires que j’ai sous 
les yeux. Ils sont proportionnellement très-gros et répartis d'une manière fort ćlégante; ce qui lui a valu le nom de decorala.

II. Mérian de Bàle a communiqué à $\mathbf{H}$. Agassiz toute une série d'exemplaires de celle espéce provenant, d'après leur éliquette, du grès vert du Bas-Dauphiné.

\section{Disconea plana Ag.}

Tab. 9, fig. 1-3.

srx. Discoïdea plana Ag. Catal. syst. Ectyp. Ech. Mus. Neoc. p. \%

C'est l'espèce la plus plate de tout le genre; anssi est-il facile de la reconnaître à ce seul caractère; sa lıauteur n'égale pas meeme la moilié de son diamètre transversal. Par sa physionomie extérieure, elle tient à la fois des vraies Discoïdées et des Holectypes ou Discoïdées jurassiques ; et comme je n'ai pas pu voir l’intérieur, j’avoue qu'il me reste des doutes sur sa véritable position. Je l'avais d'abord rangée dans les IIolectypes; mais considérant plus tard que l'anus est plus petil que la bouche el qu'il n'occupe pas mêne la moiliẻ de l'espace entre le bord et l'ouverture buccale, je l'ai reportée dans les vraies Discoïdées. Sa place définitive ne pourra lui ètre assignée que lorsqu'on connaîtra l’intérieur. La face inférieure est sensiblement concave. L'ouverture buccale, qui en occupe le centre, parait circulaire; car les entailles de son pourtour sont trẻs-peu marquẻes. Les aires ambulacraires se maintiennent, relativement aux aires interanbulacraires, dans les proportions ordinaires. Les tubercules sont disposés par séries régulières; quoi'qu’ils ne soient pas très-bien conservés dans les exemplaires que je connais, j’en ai cependant compté six raugées dans les aires interambulacraires. Les aires ambulacraires n'ont que deux rangées de tubercules principaux. Les tubercules miliaires sont excessivement nombreux et disposés en séries transversales distinctes, comme dans les D. Mandelslohi et D. punctulata.

Je ne connais encore que deux exemplaires de celle espéce. Ils m’ont élé communiqués par 11. Michelin et proviennent des Vaches-noires, en Normandie. Sont-ils du grès vert ou du terrain jurassique? c'est ce qu'il m’a été impossible de savoir. 


\section{B. Holoctypes on Discoïdées jurassiques.}

Duag. Tubercules très-apparens; face inférieure concave; amus très-grand. Moule non entaillé sur son pourtour.

\section{Xi. Discoldea nepressa Ag.}

Tab. 10, fig. 4-12.

SYN. Discoidea depressa Agg. Prodr. p. 186. - Deser. des Eehinodermes foss. the la Suisse $1^{\text {re }}$ partie p. 88. Tilb. 6, fig. 7-9 et Tab. 13 bis, fig. \%-13. - Catal. syst. Eetyp. p. 7.

Galerites depressus Lam. III, p. 309. - Phill. Geolog. of Yorkshire Tab. 7, fig. 4. - E. Desl. Enc. T. 2, p. 432.- Encyel. méthod. Tal. 152, fig. 7-S. - Defr. Dict. se. nat. T. 18, p. S6.- Gldf. Petref. p. 129, Tilb. 41, fig. 3. - DeBl. Zooph.p. 204. - Leonh. et Br. Jahrb. 1834, p. 135. - DesMoul. Tabl. syn. p. 254.- Koeh et Dmk. Nord-deutseh. Dol. p. 40, Tab. 4, fig. 2 ; var. hemisph. Bronn Lethaea p. 280.

Echinus depressus Lin. Gn. p. 3182.

Echinites depressus Leske ap. Klein p. 161, Tab. 40 fig. 5-6.

Galerites radiatus Val. Encycl. méth. Tab. 163, fig. 1-2. (Expl. des Planehes).

Tab. 1\%, fig. 5.

Echinites orificiatus Schl. Petref. p. $31 \%$

Van Phels. p. 31 № 16. (Egelsteen tienband plattop).

Knorr Pelref. Vol. 2, Tab. E. II, figio. 6-7.

Bruekner Nerkwurdigk. der Landschaft Basel. Tab. 22, fig. G. H.

Kumdmann Rariora nat. etc. Tab. 5, fig. 12.

Jaeob a Melle de Eeh Wagr. Tab. 1, fig. 2.

Favanne Pl. 6\%, fig. 1-2.

J'envisage cette espèce comme le type des Holectypes ou Discoïdées jurassiques, car elle rẻsume au plus haut degré tous les caractères que nous avons assignés à cette sous-division. Sa forme est subconique, circulaire, généralement un peu rétrécie et tronquée en arrière. La face inférieure est légèrement concave. L'anus est pyriforme et très-grand, car il occupe à-peu-près tout l'espace entre le bord postérieur et l'ouverture buccale. Les tubercules principaux sont trèsapparens jusque près du sommet, comme le montre la fig. 12 qui est destinće à donner une idèe de leur distribution à la face supérieure. Cette figure contient un dessin grossi d'une aire interambulacraire et d'une aire ambulacraire empruntées à la fig. 6. On y remarque seize rangées principales de tubercules dans l'aire interambulacraire, et six dans l'aire ambulacraire. Dans les petits exemplaires, ces séries sont bien moins nombreuses et, comme elles augmentent proportionnellement à la taille des individus, nous sommes autorisés à en conclure que, dans les 
Holectypes, comme dans les vrais Echinus, les différentes rangées naissent successivement à mesure que les plaques coronales s'élargissent. Dans notre espẻce, c'est la quatriẻme rangée externe $\left({ }^{1}\right)$ qui doit être considérée comme la rangée primitive. Quant aux tubercules miliaires, ils sont excessivement nombreux; mais l'on ne remarque pas en eux cette disposition régulière si frappante dans les espèces suivantes. Les tubercules principaux de la face inférieure sont aussi toujours plus développés que dans les espèces du Jura moyen, telles que les $D$. Mandelshohi et punctulata. Je me suis assuré par un examen minutieux que l'intérieur ne présente aucune de ces carènes ou crêtes qui eussent pu déterminer des entailles dans le moule.

J'ai trouvé l'appareil génital assez parfait pour pouvoir en faire une étude détaillée, à l'aide le la loupe. La fig. 4 a représente cet appareil tel qu’il se voit sur l'exemplaire de fig. 4 : les plaques génitales sont de forme pentagonale et percées d'un trou trẻs-apparent, ả l'exception de la plaque impaire, qui, quoique plus grande que les autres, est cependant imperforée. Les plaques ocellaires, au nombre de cinq, sont insérées entre les plaques génitales et font cercle avec elles autour du corps madrẻporiforme, qui occupe le sommet réel du test. Toutes ces plaques sont garnies de petites verrues semblables aux tubercules miliaires. On remarque la même structure dans l'appareil génital du grand exemplaire de fig. 7 ; seulement les pores génitaux sont ici moins apparens; mais l'on aurait tort d'accorder à cette différence une valeur spécifique quelconque. Il serait plus naturel, a mon avis, d'y voir l'expression d'une différence sexuelle.

Cette espèce se rencontre dans toutes les collections jurassiques suisses, et pent être envisagée comme l'un des fossiles les plus caractéristiques de l'oolite inférieure. Ellle parait être également fréquente dans le calcaire ả polypiers de Normandie. M. Agassiz, dans sa Description des Echinodermes fossiles de la Suisse, a déjả appelé l’attention des paléontologistes sur cette ubiquité, mais sans cependant affirmer d'une manière positive leur identité. J'ai pris à tàche de soumettre de nouveau les exemplaires de ces différentes localités ả un examen comparatif, et je n'ai trouvé aucun caractẻre qui fùt de nature à justifier une distinction spécifique. La seule différence que j’ai remarquée, c'est que les exemplaires suisses sont en général plus petits que ceux de Normandie; mais les détails du test, ainsi que la forme générale, les ouvertures buccale et anale sont les mêmes dans les unes et dans les autres. J'ai représenté une série d'exemplaires de tous les âges.

$\left(^{*}\right)$ Nous appelons ici externes, les rangées les plus éloignées du centre de l'aire ambulacraire. Anatomiquement parlant, ces mémes rangées doivent ètre envisagees comme internes, puisque tout oursin se compose de cinq parties, comprenant, chacune, une aire anbulacraire et deux demi-aires interambulacraires. Voy. ces llonogr. $4^{e}$ livr. p. 3. 
Les fig. 10 et 11 représentent un jeune exemplaire recueilli par MI. Gressly dans les marnes à Ostrea acuminata (étage de l'Oolite inférieure) de Liesherg, dans le Jura hernois; les fig. 8 et 9, un exemplaire de moyenne taille de la mème localité; les fig. 4, 5, 6, un bel exemplaire du calcaire ì polypiers de Normandie, et la fig. 7, un autre trés-grand individu du même terrain.

Je niai aucun doute sur l'identité spécifique de la plıpart des synonymes mentionnés ci-dessus. La figure de Leslie en particulier me parait d'autant noins douteuse que l'oursin qu'elle reprísente provient de Muttenz, dans le canton de Bàle, d'une localité où ont été recueillis la plupart des exemplaires du Musée de Bàle.

\section{XiI. Discoloea Meriani Des.}

Tab. 10, fig. 1-3.

Cette espèce est très-yoisine, à bien des égards, du $D$. depressa, à tel point que l'on pourrait ètre tenté de l'envisager comme une variẻtẻ de cette derniëre. Cependant, lor'squ'on considère que sa forme est moins conique, que ses bords sont beaucoup plus renflés et que son anus est moins allongé et proportionnellement plus large (fig. 3), on ne peut guère se défendre de voir dans ces particularités un ensemble de caractères suffisans pour justifier l'élablissement d'une nouvelle espéce. Il est á regretter que les tubercules de la face supérieure ne soient pas assez bien conservés pour permettre une étude détaillée de leur structure et de leur disposition. Ceux de la face inférieure ne présentent aucun caractère qui ne soil aussi conmun au $D$. depressa.

L'original de mes figures, le seul exemplaire que je connaisse jusqu'ici, a élé communiqué a M. Agassiz par M. Mérian. Son origine n'est point indiquée d’une manière certaine dans le catalogue du Musée de Bàle; mais il me parait hor's de doute que c'est un fossile jurassique. En dédiant cette espèce à M. Mérian, je fais des vœux pour qu'elle contrihue á perpétuer, parmi les palćontologistes, le nom du célèbre gćologue dont les travaux et le zéle scientifiques ont si puissamment contribuć au développement des études géologiques en Suisse. 
XIII. Discoinea arevata Des.

Tab. 9, fig. 11-13.

En abordant cette espéce, je dois convenir qu'il est très-difficile, et souvent impossible de la distinguer de plusieurs de ses congénères, entre autres, des D. inflata, Mandelslohi et punchulata; car, comme ses caractères distinctifs résident essentiellement dans de menus détails du lest, il faut avoir à sa disposition des exemplaires bien conservés pour pouvoir se prononcer sur leur valeur spécifique. On peut a lors se convaincre que les tubercules sont d'une régularité remarquable, quoique très-nombreux, et que les tubercules miliaires forment des sẻries horizontales très-continues, (voy. la fig. $11 a$, qui représente une aire ambulacraire et une aire interambulacraire de la face supérieure, vues à la loupe). La face inférieure se fail remarquer par un autre caractère assez particulier, quoique peu apparent, et qui consiste dans la forme allongée qu'affectent certains tubercules miliaires sur le pourtour de l'ouverture buccale. Pour rendre ce caractẻre plus évident, j’ai représenté ces mêmes tubercules allongés avec quelques tubercules principaux, dans la fig. $13 c$, ou ils sont vus au microscope. La forme générale du test est la même que celle dı $D$. punctulata, el ne saurait fournir aucun caractẻre spécifique.

Celte espèce n'est encore connue que par un seul bon exemplaire, trouvé par M. Gressly dans l'oxfordien du canton de Soleure.

XIV. Discoinea Maxdelstom Des.

Tab. 9, fig. 14-16.

La forme de cette espèce est subconique. Sa face inférieure est à peine concave. L'ouverture anale, quoique taillée sur le plan ordinaire, est moins grande que dans la plupart des autres espèces jurassiques (fig. 16). Ses tubercules sont très-apparens à la face inférieure. Il n’y en a guẻre qu'un par plaque sur le pourtour immédiat de l'ouverture buccale; mais, près de la circonférence, ils augmentent considérablement en nombre, et l'on y compte douze séries de gros tubercules très-serrés (fig. 16 b). Ces séries se poursuivent encore à la face supérieure, où les tubercules diminuent cependant brusquement de grosseur (fig. 1' $\mathrm{k}$ a). Comme dans beaucoup d'espéces de cette taille, c'est la troisième rangée externe qui s’élève seule jusqu’à l'appareil génital. Les 
tubercules miliaires ne prẻsentent, au premier alord, aucune disposition régulière ; mais lorsqu'on vient à les examiner à la loupe, on reconnaît en cux une certaine disposition linéaire ; cependant les lignes sont moins régulières et plus nombreuses que dans le $D$. punctulata. La fig. $16 c$ représente quelques tubercules dessinés au microscope, afin de faire voir leur structure intime.

Je me fais un plaisir de dédier cette espèce à MI. le comte de Mandelslolı, qui l'ayant découverte dans le corallien inféricur (terrain à chailles) d'Urach, dans l'Albe wurtembergeoise, a eu l'obligeance de me le communiquer. M. Gressly l'a retrouvée depuis dans le terrain à chailles de Liebslerg, au canton de Soleure.

\section{Discoidea punctulata Des.}

$$
\text { Tal. 9, fig. 17-19. }
$$

Pour distinguer cette espèce, il faut avoir recours à la loupe, car son caractère spécifique essentiel réside dans les tubercules miliaires. Ces tubercules, à peine reconuaissables à l'oil nu, présentent à l'œil armé une disposition toute particuliẻre; ils sont bien moins abondans que ceux du $D$. Mandelslohi, et, de plus, ils forment des séries horizontales très-régulières, et d’autant plus distinctes qu'elles sont moins nombreuses. La figg. 18 , comparée à la fig. 14 a (qui représente la mème partie du test dans l'espèce précédente) suffira, je l'espère, pour faire ressortir cette différence mieux que ne le pourrait la description la mieux détaillée. Il va sans dire que, pour saisir cette différence, il importe d'avoir affaire à des exemplaires d'une conservation assez parfaite. Lorsque la surface du test est usée, il est d'autant plus difficile de distinguer cette espèce du D. Mandelslohi, que l'une et l'autre appartiennent au même terrain. Les tubercules priucipaux sont moins clair-semés; il y en a dix rangées dans une aire interambulacraire, et six dans une aire ambulacraire (fig. 17 a). La fig. $18 d$ représente l'un des tubercules principaux, et la fig. $18 c$ un tubercule miliaire, tous deux vus au microscope. L'un et l'autre sont mamelonés et perforés ; mais je n’ai pas remarqué que les tubercules miliaires fussent crénelés à leur lase. La forme générale du test ne présente rien de particulier. Par malheur, je ne possède aucun exeniplaire dont la face inférieure soit intacte. Le dessinateur, en la restaurant d'après ce qui en est conservẻ , a négligé, par mégarde, d'indiquer, dans la fig. 19, le contour de l'ouverture anale qui, au reste, ne diffère pas sensiblement de ce qu'elle est dans le D. Mandelslohi.

Cette espèce paraît ètre propre au terrain à clıailles. M. Gressly a trouvé les premiers exemplaires à Largue, dans le canton de Berne, dans une couche d'un calcaire jaune, qui forme, en 
Suisse, l'une des sous-divisions de ce terrain. M. le comte de Mandelslohe l'a également rccueillie dans les couches inférieures du corallien, à Dettingen, dans l'Albc wurtembergcoise. Enfin, II. Parandier en a recueilli dc fort bcaux exemplaires dans le terrain à chailles du Mont-de-Bregille, près Besançon.

\section{Discoidea coscava Ag.}

Tab. 9, fig. 4-6.

Syx. Discoïdea concava Ag. Catal. syst. Ectyp. p. 7.

C'est le plus élevé de tous les Holectypes ou Discoïdées jurassiques; sa forme est subconique, et sa hauteur égale les deux tiers de son diamėtre transversal. L'ouverture buccale cst située dans un crenx profond, et, commc la face inférieure n'cst pas très-large, il en résulte que ses bords prcnnent une apparence trẻs-pulvinée. L'anus cst moins grand que l'onverture buccale. Les tubcrcules principaux sont très-petits, mais ils n’en forment pas moins des séries trèsdistinctes; j’en ai compté dix dans les aires interambulacraires, et quatre dans les aires ambulacraires. Les tubercules miliaires, trẻs-abondans, ne sont pas disposés en séries horizontales.

Le scul exemplaire qui me soit connu de celte espèce a été communiqué à M. Agassiz par II. E. Deslongschanps, et provient de l'oolitc ferrugineuse de Bayeux en Normandie.

\section{Discoidea inflata Ag.}

Tab 9. fig. $7-10$.

Sir. Discoüdea infata Ag. Descr. des Ech. foss. de la Suisse, 1. S\%. Tal. 6, fig. 4-S. - Catal. Ectyp. p. 7.

Cette espéce, déja décrite et figurée par Agassiz, dans sa Descrip. des Echinod. foss.de la Suisse, se reconnaît aisément à son apparence renflée et rebondic qui lui a valu le nom de $D$. inflata. La face inférieure est légèrement concave; l'ouverture buccale, qui en occupe le centre, est de grandeur moyennc. L'ouverture anale, au contraire, est trẻs-grande et pyriforme; elle s'étend de l'ouverture bnccale jusqu'au pourtour du test (fig. 9). Le test est trés-mince, et les détails en sont ordinairement mal conservés, comme dans bcaucoup d'Oursins du portlandien. Les tubercules principaux sont petits et très-nombreux; il y en a douze rangécs dans les 


\section{$-71-$}

aires interambulacraires et quatre dans les aires ambulacraires, ainsi que le montre la fig. 10 , qui représente une aire interambulacraire et deux aires ambulacraires vues a la loupe. Les tulercules miliaires ne paraissent pas ètre rangés par séries horizontales.

Cette espèce est assez fréquente dans le portlandien. M. Gressly en a recueilli plusieurs exemplaires dans la vallée de la Birse, dans le facies quiil désigne sous le nom de facies de charriage. Le musée de Bàle en possède aussi une série d'exemplaires provenant du canton de Schlaflhouse.

\section{Discolvea nemispilerica Ag.}

$$
\text { Tab. 8, fig. } 4-7\left({ }^{*}\right) \text {. }
$$

Srx. Discoidea homispherica Ag. Cutal. syst. Ectyp. p. $\%$

Un caractère particulier, qui distingue cette espèce de toutes les autres Discoïdées jurassiques, c'est la position marginale de l'anus, qui, quoique très-grand, est placè de manière à être également visible d'en bas et de profil (voy. fig. 6 et 7). A cet ègard, elle forme en quelque sorte le passage entre les Discoïdées jurassiques et les Galérites; et l'on conçoit que, placée côte à côte avec certaines espèces circulaires de ce dernier genre, entre autres avec le Galerites abbreviata, on puisse la prendre pour une vraic Galérite. Cependant cette affinité est plus apparente que réelle; car en procédant à un examen minutieux, on trouve dans le $D$. hemisphorica tous les principaux caractères des Discoïdées jurassiques : et d'abord, les tubercules principaux, quoique trèspetits, sont disposés par séries assez régulières : j'en compte six dans les aires ambulacraires et au moins seize dans les aires interambulacraires. L'ouverture buccale est franchement décagonale et les augles s'enfoncent daus le test sous la forme d'entailles assez marquées.

Je connais plusicurs exemplaires de cette espèce; l'un a èté communiqué à MI. Agassiz par M. Eudes Deslongschamps et provient d'une couche particulière du calcaire à polypiers, connue en Normandie sous le nom de caillasse; l'autre fait partie de la collection de M. DesHayes.

(*) C'est par inadvertance que cette espèce jurassique se trouve ici figurée parmi les Discoïdées crétacées. La grandeur de lanus et la forme de la bouche la trahissent au premier coup-d'œil. 


\section{Discoidea speciosa Ag.}

Tab. 10, fig. 13-15.

Srv. Discoidea speciosa Ag. Prodr. p. 1S6. - Descr. des Ech. foss. de la Suisse, p. 93, Tulb. 6, fig. 16 Lam. III, p. 314 .

Galerites speciosa Münst. (in Goldf. Petref. p. 130, Tab. 41 fig. $5 a, b$ )

Nucleolites speciosus DesMoul. Tabl. syn. p. 360.

Cidaris angulosa? Leske p. 93. Tab. 42, fig. 1.

Il suffit dc jeter un coup d'œil sur les figures qui rcprésentcnt cette espéce pour se pénétrer de ses caractères distinctifs. C'est la plus grande espèce du genre. L'exemplaire figuré a près de trois pouces de long et à-peu-près autant de large, sur une hauteur d'un poucc ct un quart. La facc inférieure est légèrcment concave; mais son bord est mince, proportionnellement à sa taille. L'ouverture buccale ne se mainticnt pas dans les proportions lıabituelles aux Discoïdées, car elle égale à peine, en diamėtre, lc sixic̀me du diamėtre du test; tandis que, dans le $D$. depressa ct d'autres espèces, ellc en occupc le quart et mème parfois le tiers. Les entailles de son pourtour sont peu profondes, ou plutôt elles sont réduites à de simples angles obtus. L'anus est pyriforme, et, quoique grand, il n'occupe cependant pas la moitié de l'espace entre le bord postéricur et l'ouverture bnccale. Les tubercules principaux sont nombreux à la face inférieure, surtout près de la circonférence; ils sọt un peu moins serrés près de l'ouverturc buccale. Il est difficile d'y reconnaître une disposition par rangées rayonnantes; on dirait plutôt qu'ils forment des séries concentriques, comme les tuberculcs des Discoïdées de la craie. Le test ayant disparu de la facc supérieure dans l'cxemplairc figuré, cette face se trouve ici à l’état de moule, ce qui est cause qu'on n'y remarquc aucune trace des tubercules. En revanche, les articulations des plaques y sont indiquées d'une manièrc très-distincte, ainsi que les ambulacres. On est étonné de l’étroitesse des plaques dans les aires intcrambulacraires, comparées à leur longueur. Lcs plaques ambulacraires ont dù être très-petites, à en juğer par leur empreinte (fig. 14).

Entre cettc espèce et certains Pygaster de grande taille, la ressemblance extérieure est trèsfrappante; ct lorsque l'ouvcrturc anale manque, comme c'est le cas dans les exemplaires figurés par Leskc et par Goldfuss, il est difficile de se prononcer avec certitude sur le genre. Cependant, ce qui me fait croire que l'cxemplaire de Münster est bien une Discoïdée, c'est la grande inégalité des tubercules sur les deux faces, inégalité qui nc sc rctrouve pas au mème degré dans 
les Pygaster. L'exemplaire de Leske me paraît plus douteux; il se pourrait que ce füt le Pygaster temuis ou une espèee semblable, tont comme ce peut être une Diseö̈dée.

L'original de mes figures a étẻ trouvé par M. Gressly, dans le portlandien de la vallée de la Birse, près de Laufon. L'exemplaire de M. le comte de Münster provient de l'étage supérieur du calcaire jurassique de Ileidenheim en Wurtemberg.

\section{Discolnea machopyga Ag.}

$$
\text { Tab. 7, fig. 8-11. }
$$

Srx. Discoidea macropyga Ag̛̣. Foss. crét. du Jura Neuch. (Mém. de Neuch. T. 1, p. 137, Tab. 14, fiģ. 7. 8. 9. - Id. Catal. syst. Ectyp. p. 7. - DesHont. Tabl. syn. p. 256 - Lam. III , p. 314.

C'est une espèee du terrain néocomien, mais dont la pliysionomie générale rappelle tout-á-fait les IIolertypes ou Diseoïdées jurassiques : son test, quoique subconique, est trẻs-peu élevé; car il égale à peine la moitié de son diamètre ; son pourtour est circulaire; ses bords sont renflés; sa face inférienre est concave; sa bouche est décagonale et munie d'entailles très-distinetes; son anus est pyriforme et très-grand, puisqu'il occupe presque tout l'espaee entre le bord et le pourtour de la bouche. Enfin, pour n'avoir aueun doute sur l'analogic de cette espéee avee les Holectypes, j’ai enlevé le test d'un exemplaire intact, et j’ai trouvé le moule intérieur dépourvı d'entailles; ce qui m’a donné la certitude que, quoique d'origine crétacée, cette espèce n’a cependant rien de eommun avec les autres Diseö̈dées de eette formation, mais qu'elle rentre duement dans la catégorie des IIolectypes ou Discoïdées jurassiques. Sa ressemblance avec certaines espeeces et notamment avec les $D$. arenata Des., D. Mandelslohi Des. et D. punctulata Pes., est même telle, quill faut une grande habitude pour les distinguer au premier abord, surtout lorsque les détails du test ne sont pas parfaitement eonservés.

Cependant il existe des différenees eonstantes qu'il importe de signaler. Et d'abord, les tubercules principanx sont très-uniformes sur toute la surface du test, et contrastent, sous ce rapport, avee les tubercules des espèces ci-dessus, qui sont très-gros sur le pourtour du test, et très-petits près du sommet. Les tubereules miliaires sont disposés par séries horizontales coneentriques au sommet (fig. 9 b). Lorsque les tubercules ne sont pas conservés, on peut eneore distinguer le $D$. macropyga des autres Diseoïdées jurassiques, à son bord, qui est démesurẻment renflé. Sa taille est 
ordinairement d'un demi-pouce à trois quarts de pouce (fig. 8-10). La fig. 11 représente un exemplaire de très-grande dimension.

Cette espèce est assez fréquente dans le terrain néocomien, dans l'étage des marnes bleues aussi lien que dans le calcaire jaune susjacent. Les exemplaires figurés font partie du Musée de Neuchâtel et ont élé recueillis aux environs de cette ville. On la trouve également au Salève, près de Genève. 


\section{CIIAPITRE VIII.}

DU GENRE PYGASTER AG.

Ce geure, établi par M. Agassiz, aux dépens de l'ancien genre Nucleolites, compreud des espèces de forme circulaire, à tubercules sériaux, ayant l'ouverture buccale ceutrale et l'anus situé à la face supérieure, tout près du sommet. En les plaçant aujourd'lư côte à côte avec les vares Nuclíolites, on a tout lieu de s'étonner d’un pareil rapprochement. Je n’ignore pas que c’est par les Clypeus que l'on fut conduit à cette identification mal fondée; mai:; encore les Clypeus , quoique de grande taille, sont-ils des Oursins à ambulacres bornés et pétaloüles, à tubercules petits et irrẻguliers, ayant l'ouverture buccale subcentrale et allongée transversalement. Les Pygaster, au contraire, sont des Oursins à ambulacres simples, à tubercules sériaux et à ouverture buccale centrale el décagonale. Mème la forme de l'ouverture anale, que l'on a prise pour prétexte en les identifiaut avec les Nucléolites, est très-différente; car, tandis que cette ouverture est petite et située au fond d'un sillou daus les Nucléolites, elle est constamment trèsgrande et à fleur de test dans les Pygaster; ou bien, s'il existe quelque vestige d'un sillon au bord externe de l'anus, il est toujours très-évasé.

On pourrait, arec plus de raison, revendiquer une identité générique des Pygaster avec les Discoüdées; la forme du test, la disposition des tubercules et la forme de l'ouverture buccale sont, en effet, très-semblables dans les deux genres. Mais tous les auteurs étant d'accord pour attribuer une importance capitale à la position de l'auus, qui suppose nécessairement une différence notable dans la disposition de l’intestin, surtout lorsque cette position est aussi diamétralement opposée que dans ces deux genres (Discoüdées et Pygaster), je ne pense pas que l'on puisse se refuser à envisager le genre Pygaster, tel qu’il a été circonscrit par M. Agassiz, comme un type ả part, parfaitement caractérisé et facile à saisir au premier coup d'œil. Il est inutile de faire remarquer que les Nucleopygus, quoique ayant aussi l'anus supère, n'ont cependant rien de conmun avec les Pygaster, puisque ce sont de petits Oursins allongés, renflés, à tubercules irréguliers. 
Les tubercules sont en général plus développés que dans aucun genre de la famille des Clypéastroïdes, et l'on peut dire que, sous ce rapport, de mème que par leur ouverture buccale, profondément entaillée et toujours distinctement décagonale, les Pygaster sont le genre qui se rapproche le plus de la famille des Cidarides. Les tubercules principaux constituent des séries très-régulières et plus ou moins nombreuses, suivant les espèces et même suivant les variétés d’àge des individus. Les tubercules miliaires sont rẻpandus sur toute la surface du test, mais ne forment pas de ces séries horizontales distinctes, telles que nous les avons vues dans les Discoïdées jurassiques; ils sont aussi beaucoup plus nombreux à la face supérieure qu'à la face inférieure , où ils n'existent parfois qu'aux angles des espaces hexagonaux qui correspondent aux tubercules principaux (Tab. XI, fig. 7 b).

Je n’ai pu observer l'appareil génital que d'une manière très-imparfaite; mais il n’a paru être construit sur le même plan que celui des Discoïdées jurassiques, c'est-à-dire que les plaques génitales, au nombre de cinq, sont en général pentagonales et beaucoup plus grandes que les plaques ocellaires, qui s’insèrent entre ces dernières. Les unes et les autres sont, selon toute apparence, perforées.

L'appareil masticatoire est inconnu; mais j’ai pu m'assurer sur un exemplaire vide du $P y-$ gaster costellatus communiqué à M. Agassiz par M. Alex. Brongniart, qu'il existe sur le pourtour intérieur de la bouche, dix carẻnes fort saillantes qui rayonnent du centre à la périphérie. Ces carènes sont situées au bord externe des aires interambulacraires et doivent par conséquent déterminer, dans le moule intéricur, des entailles semblables á celles qui caractérisent les moules des vraies Discoïdées. Je ne connais pas encore de moule du genre Pygaster, mais je ne doute pas, d'après ceci, qu'ils ne soient plus ou moins sillonnés sur le pourtour de l'ouverture buccale.

Le nombre des espèces décrites et figurées dans cette monographie est de six, dont quatre jurassiques et deux crétacées. Les espèces jurassiques, telles que nous les connaissons jusqu’à présent, sont beaucoup plus développées que les crétacées. Dans ce nombre ne sont pas compris les Clypeus semisuleatus Phil., figuré dans l'ouvrage de Phillips, intitulé : Geology of Yorkshire, Tab. 3, fig. 17, et qui pourrait fort bien n'ètre autre chose qu'un jeune de notre $P$. Umbrella, ni le $\boldsymbol{P}$. Gresslyi. Le Nucleolites depressus Munst. est prohablement notre Pyg. eostellatus; il est probable que l'auteur aura fait restaurer l'anus, attribuant sans doute son irrégularité à quelque accident, comme je l'ai fait moi-même avant d'en avoir vu plusieurs exemplaires. Une autre espèce d'Espagne, à test très épais, a été communiquẻ à M. Agassiz par M. Alex. 
Brongniart, sans indication de gisement. Elle parait se rapprocher du $P$. Umbrella et du $P$. patelliformis, et la nature de la roche adlıérente rappelle plutòt le facies jurassique que la craie.

\section{Prgaster vabreila Ag.}

Tab. 12 , fig. $4-6$.

Sry. Pygaster Umbrella Ag. Descr. des Ech. foss. de la Suisse 1'e part. p. S3. Tab. 13. fig. 4-6. - Catal. syst. Ectyp. etc., p. \%

Galerites Umbrella Lam. III, p. 312.- E. Desl. Enc. T. II, p. 434.-Encycl. métl. Pl. 142 , figg. 7-8. Nucleotites Unbrella Defr. Dict. sc. nat. T. 18, p. 5\% - DesMonl. Tabl. syn. p. 354.

Echinoclypeus Umbrella Deßl. Zooph. p. 189.

Clypeus Plotii. Klein 1. 1\%, Tal. 12, fiơ. A. B.

Clypeus sinuatus Leske apud Klein p. 15\%. Til). 12. fir. A. B.

Placenta laganum sp. V, Plotii. Kleiu p. $25, \S$ SS.-Klein gall. $\S 40$, p. 64, Tab. 7, figg. A.

Luidii Lithopt. Britt. No 971 , p. 4 S.

Norton Nat. Hist. of Northamptonshire p. 233 sp. 1.

Clypeus semisulcatus Pliil? Geol. of Yorkshire, p. 127, Tab. 3, fig. 17.

Nucleolites semisulcatus DesMoul. Talll. syn. p. 362.

Pygaster semisulcatus Ag. Protr. p. 1 S5.

La grandeur de cette espèce la fait distinguer, au premier coup d'œil, entre toutes ses congénères. Sa forme est subpentagonale. Sa plus grande largeur correspond à une ligne tirée entre les deux extrémités des ambulacres antérieurs pairs. Les ambulacres postérieurs sont d'un tiers moins distans l'un de l'autre. Le bord postérieur est distinctement tronqué. La hauteur est à la longueur comme 2 à 5 (fig. 5 ); mais le maximum d'élévation ne correspond pas, au moins dans l'exemplaire que j’ai sous les yeux, au sommet organique; ce dernier est un peu en arrière. L'anus est grand, distinctement pyriforme ; il occupe plus de la moitié de l'espace entre le sommet et le bord supérieur. Au dela de son bord externe, le test présente une dépression assez marquée, que l'on a envisagée comme le représentant du sillon dans les Nucléolites. La face inférieure est légèrement concave. L'ouverture buccale, qui en occupe le centre, se fait remarquer par sa forme distinctement décagonale et par ses larges et profondes entailles. Son diamètre égale àpeu-près le cinquième du diamètre du test. Il est à regrelter que l'exemplaire figuré, quoique trèsparfait sous le rapport de la forme, n’ait conservé aucun détail de la surface du test. Depuis l'impression de ces planches, j’ai pu m'assurer, par un exemplaire trouvé récemment par M. Gressly, que les tubercules sont très-gros et disposés à-peu-près comme dans le $P$. patelliformis. Le test 
lui-mème est très-épais, à en juger par quelques lambeaux spathiques qui sont adhérens à mon exemplaire. On y voit aussi, d'une manière distincte, le rapport des aires ambulacraires avec les aires interambulacraires, ainsi que l'empreinte des plaques et des pores.

Les auteurs anciens rangeaient cette espéce dans le genre Clypeus; mais ce genre n'ayant pas été admis par les modernes, les uns, tels que Lamarck et E. Deslongchamps, l'ont reportíe dans le genre des Galérites, tandis que d’autres, tels que Defrance et DesMoulins, en font une Nucléolite, la rangeant ordinairement à côté du Clypeus (Nucleolites) Patella. Il suffira, pour counhattre ce rapprochement, de rappeler que cette dernière espéce a les ambulacres pétaloïdes et la houche pentagonale.

L'exemplaire qui a servi de base à cette description est le même qui se trouve déjả figuré et décrit dans la Deseription des Echinodermes fossiles de la Suisse, par M. Agassiz. Il provient du portlandien du Jura suisse, et a été trouvé par M. Gressly, dans la carrière de Greifel, dans la vallée de la Birse, canton de Berne. Comme nous l'avons dit à l'article du genre, il serait fort possible que le Clypeus semisulcatus Plil. de l'oolite coralline du Yorkshire fùt la mème espéce.

\section{Pygasten patellimomis Ag.}

Tab. 11, fig. $11-13$.

Srn. Pygaster patelliformis Agr. Deser. des Ech. foss. de la Suisse 1re palt. 1. S2. Tab. 13.- Catil. sýst. Ectyp. etc., p. \%

Quoique cette espèce ne soil encore connue que par un exemplaire assez défectucux, je la crois cependant très-fondée. Elle est renflée, subconique; sa forme est subcirculaire; son bord postérieur est moins tronqué que dans aucune autre espèce du genre; son lest a dù être trèsépais, surtout à la face supérieure, à en juger par quelques lambeaux qui y sont conservés, et si les détails de la surface ne sont pas entiers, on n'en recomnaitt pas moins, sur le moule, les divisions principales dı test; les sutures des plaques y ont laissé des empreintes distinctes, et les ambulacres sont sensiblement p'us saillans que le reste de la surface. L'anus est également trèsaccuse; il s'ouvrait, selon toute apparence, dans un large sillon aplati ; sa forme est pyriforne, c'est-à-dire qu'il est très-large en dehors et se termine en pointe du côté du sommet. La face inférieure est assez concave. L'ouverture buccale qui en occupe le centre n'est pas assez bien conservée dans l'exemplaire figuré, pour qu'il me soit possible d'en indiquer d'une manière rigou- 
reuse les proportions; mais il est cependant facile de s'assurer qu'elle noccupait pas plus du quart du diamètre du test; d'oủ il rúsulte qu'elle est proportionuellement plus petite que dans le P’ygaster laganö̈des. Les tubercules, à en juger d'après ce qui en est conservé à la face inférieure, sont de taille moyenne, relativement aux dimensions du test. Je n’ai pu observer leur structure intime; mais, d'après l’analogie, je ne doute pas qüils ne soient conformés comme dans d'autres espèces.

Le seul exenplaire qui me soit connu de cette espèce est le unême qui se trouve déjả figuré dans la Description des Echinodermes fossiles de la Suisse, par M. Agassiz. Il provient du portlandien de la vallée de la Birse, dans le Jura bernois.

\section{Pygaster lagavoides Ag.}

Tal. 11 , fig. 5-7.

Srx. Pygaster laganoïdes Ag. Deser. des Ech. foss. de la Suissc $1^{\text {re }}$ partie p. S1. Tab. 12, fig. 13-16. - Catal. șst. Ectrp. ete., p. $\%$

Cette espèce est proportionnellement très-aplatie. Sa hauteur égale à peine le tiers de sa longueur. Son diamètre longitudinal et son diamètre transversal sont à-peu-près égaux; la plus graude largeur correspond aux aires ambulacraires antérieures. L'ouverture buccale est trèsgrande, car elle occupe à-peu-près le tiers du diamètre du test; elle est en outre légèrement concave, et son pourtour présente des entailles fort distinctes. L'anus parait aussi avoir eu des dimensions considérables; cependant, comme il n'est pas entièrenent conservé dans l'exemplaire figuré, je ne saurais indiquer son pourtour d'une maniẻre rigoureuse. Les détails du test sont admirablement conservés, et permettent d'étudier d'une manière fort exacte les tubercules. La simple iuspection des fig. 5, 6 et 7 montre leur disposition sériale. J'en comple douze séries dans les aires interambulacraires, et quatre dans les aires ambulacraires. La difference de grosseur entre les tubercules de la face supérieure et ceux de la face inférieure est peu sensible ; mais la manière dont ils sont entourés par les tubercules miliaires n'a pas la moindre ressemblance. il suffira de comparer, à cet égard, les fig. 5 a et $7 b$, qui représentent, la première, une portion de la face supérieure, et l'autre, une portion de la face inférieure, vues à la loupe. Dans la première, les tubercules sont entourés d'une infunité de tubercules miliaires très-serrés (fig. 5 a), parmi lesquels il y en a de différentes grandeurs, entre autres, quelques-uns qui sont intermédiaires entre les tubercules principaux et les tubercules miliaires: dans la seconde, ils sont extrê- 
mement rares et ne se trouvent qu'aux angles des gros tubereules qui sont juxta-posés de manière à présenter des figures lıexagonales (fig. 7 b).

Je ne connais jusqu'ici qu'un exemplaire parfaitement earaetérisé de cette espéce; il provient du caleaire à polypiers de Ranville en Normandie, et a été eommuniqué à M. Agassiz par II. Eudes Deslongschamps. M. Agassiz, l'envisageant comme identique avec certains fragmens d'une espèce trouvée par M. Gressly dans le portlandien du Jura suisse, fit restaurer, d'après ce modẻle, les figures qu’il a publiées dans sa Description des Echinodermes fossiles de la Suisse. Après avoir comparé de nouveau ees différens exemplaires entre eux, j’avoue qu'il m’est resté des doutes sur l’identité admise par M. Agassiz. Les exemplaires du portlandien suisse mont paru être plus renflés et avoir les tubereules plus gros et plus serrés à la face supérieure; et comme ce sont précisément les plus petits exemplaires qui ont les plus gros tubercules, on ne peut guère attribuer cette différence à une variété d’àge; car, dans ce cas, ce serait l'inverse 'jui devrail avoir lieu. Je penehe par conséquent à envisager l'espèee suisse comme distincte de celle de Normandic. On pourrail l'appeler P. Gresslyi Des.

\section{Prgistelk tenuls Ag.}

Tab. 12, fig. $1-3$.

Srx. Pygaster tenuis Ag. Descr. des Ech. Coss. de la Suisse $1^{\text {re }}$ partie p. S3.

M. Agassiz mentionne cette espéce dans sa Descr. des Ech. foss. de la Suisse, comme étant voisine du Pyg. patelliformis; mais il n'en donna pas de figures, faute d'exemplaires assez bien conservés. Quoique les exemplaires dont je dispose soient loin d'être parfaits, ils m’ont cependant permis d'étudier les principaux caractères de l'espèce, et je me suis assuré qu’elle diffère à plusieurs égards de l'espéce ci-dessus. É d’abord, le test est beaucoup plus mince à la face supérieure et à la face inférieure; les tubercules sont aussi plus petits et plus nombreux; il y en a au moins vingt rangées dans les aires interambulacraires; les aires a mbulacraires n’en ont guère que six. A la face supérieure, les tubercules sont bien moins serrés qu'à la face inférieure; on peut même dire qu’ils y sont clair-senés. L'espace intermédiaire entre les tubercules principaux est occupé par une immense quantité de lubercules miliaires qui, vus à la loupe, présentent l'ispect de fig. 1 a. Je n'ai pu mettre à découvert le pourtour de la bouche el ne puis par conséquent indiquer ses dimensions relatives. L’anus est très-rapproché du sommet; il m’a paru être plus allongé que dans l'espéce précédente; mais ses contours ne sont pas non plus intaets. 
Les seuls exemplaires qui me sont eonnus de cette espece ont éte reeueillis par M. Gressly dans le terrain i ehailles du Jura suisse, au Fringeli, lans le canton de Soleure.

\section{Pyg.istell costellatus $\Lambda$ g.}

Tal. 11, fig. 1-4.

Six. Pygaster costellatus Ag. Cital. syst. Ectyp. etc., p. \%.

Nucleolites depressus Münst. (dans Gidf. Petref.p. 137 Til). 43 ligg. 1.).

Pygaster depressus Ag. Prodr. P. 18.

Collyrites depressus Des.loul. Talb. syn. [1.368.

C'est une espèee déprimée, à peu près circulaire, ayant ses bords trẻs-renflés et l'ouverture buecale située dans un creux profond, au centre de la face inférieure. Les aires ambulacraires, lígèrement saillantes à la face supérieure, ont en quelque sorte l'apparenee de cinq còtes rayonnées; de lả le nom spécifique de costcllatus. Les tubercules sont d'une finesse extrême, surtout à la face supérieure. Examinés à la loupe ou au mieroseope, ils se présentent sous la forme de petits cônes surgissant du milieu d'une zone eireulaire très-déprimée et entourée de tubercules miliaires très-nombreux et d'une petitesse extrême. Il y en a six rangées dans les aires ambulacraires et au moins quatorze ou seize dans les aires interambulacraires; à la face inférieure, ces tubercules sont un peu plus développés et forment des séries horizontales déterminées par les articulations des plaques. Le test est épais. Je n'ai vu l'appareil génital qu'en partie, dans un seul exemplaire; sa disposition ne présente rien de particulier. L'anus est supra-marginal, moins grand et plus éloigné du sommet que dans anenne autre espéee; au premier abord, je fus naturellement porté à attribuer le pourtour oblique et irrégulier de cette ouverture, telle qu' elle se voit dans les fig. 1 et 3 , à l'eflet de quelque pression; mais il n'en fut plus de même lorsque j’eus rencontré cette mème forme irrégulière dans plusieurs exemplaires. Je ne pus m’empêclier de l'envisager dẻslors comme un caractère particulier de cette espẻce, analogue à la bouche oblique des Echinonées. Les exemplaires que j’ai sous les yeux proviennent tous du grès vert de lîle d'Aix, à l'emlıouclure de la Charente. Ils ont été communiqués à M. Agassiz par M. Alcide d’Orligny, par M. Paul DesIlayes et par M. Al. Brongniart. C'est dans ce dernier exemplaire que j’ai observé les carènes intérieures lont il a été question à l'article du genre.

Ainsi que je l'ai dit ả l'article du genre, le Nucleolites depressus de Münster n'est probablement pas autre clıse que notre Pygaster costellatus restauré sans doute d'après un exemplaire imparfait; on devra par conséquent changer le nom de $P$. costellatus en celui de $P$. depressus, dés que l'on 
aura acquis une entière certitude à cet égard. Si cependant l'exemplaire de $\mathbf{M}$. le comte de Münster avait réellement l'anus régulier, on ne pourrait plus donter de sa valeur spécifique.

\section{Pygaster troveatus Ag.}

Tab. 11, fig. 8-10.

Srx. Pygester truncatus Ag. Catal. syst. Ect. p.\%.

Le nom de cette espèce en rappelle le caractère principal, qui consiste dans la troncature trésprononcée du bord postérieur (fig. 8), qui fait que le diamètre transversal est d'un quart ì peu prés plus considérable que le diamètre longitudinal. De plus, toute la partie postérieure du test et notamment les aires ambulacraires montrent une tendance très-prononcée à s'arquer "n arrière. Cette forme particulière ressort d'une manière frappante dans la fig. $10 \mathrm{~b}$, qui représente l'aire interambulacraire postérieure droite vue à la loupe. La face supérieure est à peu prẻs plane ; l'anus est très-grand ; il occupe presque tout l'espace entre le bord et le sommet. Les tubercules sont fort distincts et forment des séries régulières qui participent aussi à cette disposition arquéc des aires ambulacraires et interambulacraires dans la partie postérieure du test ( $f \mathrm{~g} .10 \mathrm{a}$ et $10 \mathrm{~b}$ ); jen ai compté quatre dans les aires ambulacraires et neuf dans les aires interambulacraires. Il est fort possible que des individus de plus grande taille en aient un plus grand nombre; mais ce que l'on ne saurait méconnaître, c'est que les tubercules sont ici plus serrés que dans aucune autre espèce du genre. La face inférieure n'est malheureusement pas conservée dans l'exemplaire figuré : tout ce que j’ai pu voir, c'est que l'ouverture buccale occupe une dépression assez sensible.

L'original de mes figures, le seul complet que je connaisse, a été communiqué à M. Agassiz par II. d'Orbigny. Il provient du grés vert de l'lle d'Aix, á l'embouchure de la Charente. 


\section{CHAPITRE IX.}

\section{DU GENRE IYBOCLYPUS AG.}

Ce genre est un de ceux dont le classement offre le plus de difficultés, car il réunit en lui les caractères de plusieurs groupes fort distinets. Il tient aux Galérites par ses ambulacres qui sont simples, et par la forme, la structure et la disposition de ses tubercules. Il se rapproche des Dysaster par sa bouche excentrique, par ses deux sommets ambulacraires, et par l'aspect particulier de sa face inférieure qui est fortement pulvinée; enfin, il rappelle les Nucléolites par sa forme rétrècie en avant, élargie en arrière, et par la position de son ants qui s'ouvre dans un sillon de la face supérieure. Eı présence d'un assemblage de caractères aussi lıétérogènes, il serait téméraire de vouloir fixer dès à présent la place définitive que ce singulier type devra occuper daus la méthode naturelle, d’autant plus que l'appareil nasticatoire nous est complètement incomu. A défaut de ce caractère important, jai cru devoir prendre pour guide la forme des ambulacres, d'après le principe que j’ai établi daus l’introduction; et comme c’est du groupe des Galérites que les Iyboclypes se rapprochent le plus sous ce rapport, je l'ai placé provisoirement í la fin de ce groupe. En tous cas, s'il existe un passage des Galérites aux Dysaster, c'est au moyen des Iyboclypes qüil s'opère; mais la question des affinités ne pourra être jugée d'une maniẻre définitive que lorsque l'on possédera des données plus complètes sur l'organisation intérieure de ces aninıax.

Ce n'est pas seulement dans la classe des Echinodermes que l'on rencontre de ces types complexes que la nature semble s’ètre réservés pour protester en quelque sorte contre tous nos systèmes. Les recherches de M. Agassiz sur les Poissons fossiles et celles des savans anglais sur la classe des Reptiles fossiles nous ont fait connaitre plusieurs de ces êtres bizarres auxquels ọ̣ peut ramener, par la pensẻe, comme il autant de souches génẻtiques, plusieurs types qui, dans les époques suivantes, nous paraissent profondément séparés. Qui ne se rappelle ici les Ichthyosaures, les Ptèrodactyles, les Megalichtys, les Ceplıalaspis, les Pterichılıys, etc.? 


\section{$-84-$}

Les Ilyboclypes, envisagés sous ce point de vue, sont des plus intéressans. Nous n'en connaissons encore que deux especes, le $I$. gibberulus, et le II. canaliculatus. Toutes deux proviennent de l'oolite inférieure.

\section{Hrboclypes gaberoles Ag.}

Tal. 13, fig. $12-14$.

Syn. Hyboclypus gibberubus Ag. Descript. des Echin. foss. de la Suisse, p. 75. Tab. 12, fig. 11-12. - Catal. syst. Ectyp. ete. p. 6.

Un caractère qui ne peut manquer de frapper dans celte espèce, c'est sa forme bossue el irrégulière (fig. 13): elle est rétrécie en avant, élargie et aplatie en arrière, et ondulée sur ses bords; une carène très-saillante, qui correspond à l'ambulacre impair el rend le còté antérieur beaucoup plus haut que le còté postérieur, s'élève à la surface du test et se prolonge jusqu'au bord antérieur, où elle se transforme en une échancrure très-marquée. A l'opposite, sur le còté postérieur, on remarque un sillon assez profond qui débouche près du sommet, et s'élend en arrière en s'évasant, absolument comme dans les vraies Nucléolites. L'ouverture anale proprement dite paraît ètre plus grande que dans ces derniers; je n’ai cependant pas pu en reconnaitre le pourtour d'une manière exacte. La face inférieure est fortement ondulée et rappelle la face inférieure de certains Dysaster, et particulierement du Dysaster ringens. Les ambulacres, qui sont très-marqués, occupent de larges sillons, tandis que les aires interambulacraires apparaissent sous la forme de coussinets reuflés (fig. 1\%). L'ouverture luccale, siluée dans une dépression au tiers antérieur de la face inférieure, est indistinctement pentagonale. Les ambulacres, sans former deux sonımets aussi distans que ceux des Disaster, sont cependant disjoints. A la face inférieure, les pores sont bien plus éloignés qu'à la face supérieure, particularilé qui ne se retrouve dans aucun genre du groupe des Galérites. Les tubercules sont excessivement pelits; ce qui n’empêche pas qu'en les examinant à la loupe, on n'y reconnaisse fort bien des tubercules principaux entourés d'une quantité de tubercules miliaires, ainsi que le montre la fig. $12 a$. Ces mêmes tubercules, examinés au microscope, se présentent sous la forme de fig. $12 b$, c'est-à-dire que les lubercules principaux, aussi bien que les tubercules miliaires, sont distinctement mamelonés ; les premiers ont en outre leur mamelon perforé et plissé à la base; ce que je n’ai pu apercevoir dans les derniers. 
Cette espece ne parait pas ètre trés-rare, il en existe de fort beaux éehantillons an Musée de Carlsruhe, au Musée de Bàle et dans la collection de M. Strolmeyer d’Obergössehen. Suivant les indications que m'a fournies M. Gressly, on la trouve dans une eouehe particulière de l'oolite inférienre, la marne à Ostrea acuminala, la même qui eontient aussi le Discoidea depressa et le Dystster analis; c'est au moins dans eette couehe que l'a reneontrie M. Strohmeyer.

\section{IIvoclyeds cavaliculatus Des.}

Tal. 4 des Dysaster, fig. 8 et 9.

5r.x. Nucleolites canaliculatus Wunst. (dians Gid. Petref., p. 140, Tab. 1/99, fig. S.)

Autant l'espèce précédente est aeeidentée, autant eelle-ci est régulière: elle est subeirculaire, uniformenent bombée et peu élevée; le côté antérieur, sans être aussi large que le eôté postérieur, est eependant proportionnellement bien moins rétréci que dans le II. gibberulus; la carène dorsale et le sillon antérieur manquent complètement; le sillon postérieur, dans lequel s'ouvre l'aIIIs, est large, profond et évasé vers le bord; les ambulaeres sont disjoints et les deux sommets lien plus distans que dans l'espèce préeédente; les ambulaeres postérieurs surtout s'élèvent moins laut. La face inférieure n’est pas conservée. On ne saurait plus désormais confondre eette espèce avee les vraies Nueléolites, puisque elle a les ambulaeres simples, tandis qu'un earactère essentiel des Nucléolites est d'avoir les ambulaeres pétaloïdes.

L'original de mes figures est le même que M. le comte de Münster a figuré dans l'ouvrage de Goldfuss. Elle provient de l'oolite inférieure du Staffelberg, près de Bamberg. 


\section{TABLEAU DE LA DISTRIBUTION GÉOLOGiQUB ET GEOGRAPHIQUE DES ESPÈCES DU GROUPE DES GALÉRITES.}

\section{Espèces de L'ÉPoQue JURAssiQue.}

i) Jura inférieur.

Diseoidea depressa Ag.

$$
\begin{aligned}
& \text { hemisphaeriea Ag. } \\
& \text { eoneava Ag. } \\
& \text { Meriani Des. }
\end{aligned}
$$

Hyboelypus gibberulus Ag.

" canalieulatus Des.

Pygaster laganoides Ag.

11) Jura moyen.

viseoiclea arenita Des.

" Mandelsloli Des.

" Pinctulata Des.

Pygaster tenuis Des.

c) Jura supérieur.

Discoidea inflata $\mathrm{Ag}$. speciosa $\mathrm{Ag}$.

Pygaster patelliformis A:

" Umbrella Ag.

" Gresslyi Des.

\author{
junarnes ì 0 . acuminata \\ \{aleaire à polypiers \\ ealeaire à polypiers \\ oolite ferrugineuse
}

marnes à 0 . aeuminata

oolite ferrugineuse

calcaire ì polypiers

terrain à ehailles

ferrain ì ehailles

feorallien

f terrain à chailles

feorallien

Ierrain ì elailles
Jura suisse.

Normandie.

Normandie.

Normandie.

Jura solemois.

Stallelberg, près de Batmberg. Normandie.

Jura soleurois.

Jura soleurois.

Albe wurtembergeoise, Jura soleurois, Besancon. Alle wintembergeoise. Jurn soleurois.

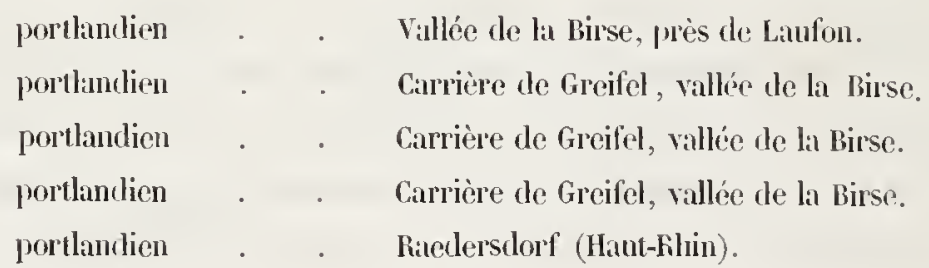

2. EsPÈces de L'ÉPOQUE CRÉt ACÉE.

i) Néocomien.

Diseoidea maeropyga Ag.

néocomien

Neuclitiel.

Pyrina pygaca Des.

néoeomien

Neuchilel.

Vucleopygus ineisus $\mathrm{Ag}$.

Neuellitel. 
1) Craie inféricure.

I iscoidlea Favrina Des.

Rotula Ay.

conica Des.

decorata Des.

suluuculus $A g$.

minima $\Lambda \mathscr{g}$

Pisum Mer.

turriti Des.

plana Ag.

Galerites Castanea $\mathrm{A} g$.

Pyrina ovulum Ag.

" depressa Desu.

" ovata $A g$.

Cauatomus Faba Agr.

Pygister costellatus $A g$.

truncatus $\Lambda \mathrm{g}$.

1) Craie supérieure.

Galerites Albogalerus Lam.

vulgaris Lam.

conica $\Lambda g$.

subjotunda Agr. .

grlolunlus Des.

angulosa Des.

pyramilalis Des.I.

orbignyana Ag. .

laevis $\mathrm{Ag}$.

ablo'eviata Lam.

Globator nucleus Af.

Nucleopygus minor $\mathrm{Ag}$.

Caratomus hemisplaticus Des.

rostratus $A_{\mathfrak{g}}$. .

Avellana $\Lambda: g$.

orbicularis Ag.
Glanconie

Glauconic

Glauconic

Glauconic

Glauconie

Glauconie?

Glanconie

Glauconie

?

Glatuconic

Glanconic?

Glauconie

Glauconie

Glanconic

Glauconie

Glanconie

craie blanche.

craie blanche

craie blanche

craic blanclıe

craie blanche

craie blanche

étage supérieur?

étage supérieur?

étage sipćrieur?

sables détritiques

étage supérieur?

étage supérieur?

craie blanche

craic blanclie

craie

craic
Rouen.

Montagne des Fis.

Saxomnet, Rouren.

Bas-Dauphinć.

France.

France.

Bas-Daupliné.

Perte-du-Rlıône.

Vaches-Noires.

Rionen.

France.

Montagne des Fis, Reposoir.

Saintes, Clıa'ente inf.

lle d'Aix. "

lle d'Aix.

Ile d'Aix

Angleter'e.

lle de Wight.

Angleterre.

lle de Wighlı.

Angleter're.

Angleterre.

France.

Touraine.

France.

Stada (Allemag. sept.)

France.

France.

Angleterire.

France.

Crimée, France.

Villers. 
3. ESPÈCES VIVANTES.

\begin{tabular}{|c|c|c|c|c|c|c|c|c|c|c|}
\hline Echinoneus & cyclostomus Les & & • & • & - & 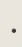 & ${ }^{\circ}$ & - & • & Iles de lord Hood. \\
\hline$"$ & minor Leske & . & • & • & & - & & • & $\cdot$ & Trinité. \\
\hline$"$ & gibhosus Lam. & . & & & & & - & $\cdot$ & $\cdot$ & Amérique? \\
\hline$"$ & cruciatus $\mathrm{Ag}$. & . & & 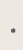 & & & & & ? & $?$ \\
\hline$"$ & degans Des. & . & . & . & v & ${ }^{\circ}$ & & & $\cdot$ & Porto-Ricco. \\
\hline$"$ & serialis Des. & . & & & $\cdot$ & • & & & $\bullet^{-}$ & ? \\
\hline$"$ & conformis Des. & . & . & . & . & . & . & . & ( & ? \\
\hline
\end{tabular}




\section{CONSPECTUS GENERUM ET SPECIERUM GALERITARUM.}

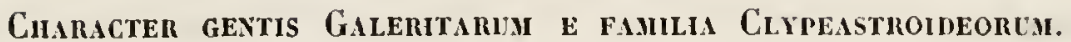

Testa inflata, raro depressa, orbicularis vel ovata vel subquinquangulata. Ambulacra simplicia, ad peripheriam divergentia. Os inferum centrale vel subcentrale. Anus intra os et verticem varie situs.

I. Genus GALERITES Lam. Testa inflata; ambitus suborbicularis vel subquinquangulatus, postice angustior; basis plana; os centrale, subdecagonale; anus marginalis vel inframarginalis; assulae genitales pares perforatae; assula impar imperforata, minor quam pares; tubercula non seriata, sed perforata et crenata.

1. Galerites Albo-galerus Lam. (Tab. 1, fig. 4-11, Tab. 13, fig. 7). G alta, conica, ambitu suborbiculari ; basi plana; ano marginali ; tuberculis magnis rarioribus.

2. Galerites pyramidalis DesMoul. (Tab. 1, fig 1-3). G. alta, pyriformis, ad verticem coarctata, ambitu subquinquangulato; basi plana; margine obtuso; ano inframarginali. Nucleus.

3. Galerites vulgaris Lam. (Tab. 2, fig. 1-10, et Tah. 13, fig. 4-6). G. valde inflata, postice angustata ; ambitu suborbiculari ; hasi plana ; margine obtuso; ano marginali ; tuberculis confertioribus.

4. Galerites conica Ag. (Tab. 1, fig. 12-19). G. altissima, ad verticem compressa, postice attenuata; ambitu subquinquangulato; ano marginali; basi plana; margine valde obtuso.

5. Galerites subrotunda Ag. (Tab. 2, fig. 11-14). G. inflata, superne hemisphaerica; ambitu orbiculari; ano marginali; hasi plana ; margine obtuso.

6. Galerites Globulus Des. (Tab. 4, fig. 1-4). G. valde inflata, subsphacrica, postice allenuata, subcarinata ; ambitu suborbiculari; hasi plana, angusta; margine valde obtuso ; ano supramarginali. Assula genitalis impar deest.

7. Galerites abbreviata Lam. (Tab. 3, fig. 9-17). G. conica, abbreviata; ambitn orbiculari; basi plana; ano inframarginali.

8. Galerites Orbignyana Ag. (Tab. 3, fig. 5-8). G. inflata, hemisphaerica; ambitu orbiculari ; basi subconcava; ano supramarginali. 
9. Galerites angulosa Des. (Tab. 4, fig. 5-7). G. inflata, elongata, postice valde angustata; ambitu suloquinquangulato; basi plana; ano marginali.

10. Galerites Castanea Ag. (Tab. 4, fig. 12-16). G. inflata, ovata; basi subconcava; margine tumido; ano magno, marginali ; testa tenui.

11. Galerites laevis $\mathrm{Ag}$. (Tal. 4, fig. 8-11). G. inflata, ovata; basi plana; margine tumido; ano supramarginali.

II. Genus PYRINA DesMoul. Testa tumida, elongata, ovata; ambitus ellipticus; basis plana vel subconcava; os subdecagonale; anus in facie postica; tubercula majora non seriata, perforata, crenata. Quatuor pori genitales.

1. Pyrina ovulum Ag. (Tab. 5, fig. 35-37). P. inflata, ovata, superne depressa; ambitu elliptico; lasi plana; margine valde tumido; ore elongato, obsolete decagono; facie postica late sulcata; ano elliptico, margini superiori proximo; tuberculis numerosis.

2. Pyrina ovata Ag. (Tab. 5, fig. 32-34). P. inflata, ovata, superne depressa, postice leriter sulcata; ambitu elliptico; basi plana; ano in medio faciei posticae.

3. Pyrina depressa DesMoul. P. inflata, superne convexiuscula ; ambitu ovato ; basi sulsconcava ; margine tumido; ano supramarginali.

4. Pyrina pygaa Des. (Tab. 5, fig. 27-31). P. ovata, inflata; basi subconcava; ano in medio faciei posticae.

1II. Genus GLOBATOR Ag. Testa orbicularis, subspliaerica; os subdecagonale; anus supramarginalis, altus. Quatuor pori genitales.

Globator Nucleus Ag. (Tab. 3, fig. 1-4). G. subsplaericus; hasi plana, angustata ; ore elongato, decagono; ano elliptico, in medio faciei posticae.

IV. Genus NUCLEOPYGUS Ag. Testa elongata, subdepressa; hasis subconcava; os obsolete decagonum; anus superus, in sulco areae interambulacralis imparis situs.

1. Nucleopygus minor Ag. (Tab. 5, fig. 20-22). N. antice rotundatus, postice depressus, truncatus, dilatatus; ore concavo; ano vertici proximo, in sulco lato.

2. Nucleopygus incisus Ag. (Tab. 5, fig. 23-26). N. subdepressus; ambitu ovato ; basi plana; ano elliptico, intra apicem et marginem posticum sito.

V. Genus CARATOMUS Ag. Testa inflata, vel subdepressa ; ambitus orbicularis vel ovaIus, postice rostratus; basis plana ; os angulosum ; anus inframarginalis. Quatuor pori genitales ; assula genitalis impar non perforata. 
1. Caralomus Avellena Ag. (Tab. 5, fig. 11-13). C. inflatus, dilatalus, postice rostratus; an1bitu ovato ; basi plana, ano inframarginali; testa crassa.

2. Caratomus Faba Ag. (Tab. 5, fig. 8-10). C. elongatus, convexiusculus, postice subcariuatus; ambitu ovato; ano iufranıarginali.

3. Caratomus hemispharicus Des. (Tab. 5, fig. 14-19). C. lıemisphlaricus, postice subcarinatus; loasi plana, pulviaata; ano inframarginali.

4. Curatomus orbicularis Ag. ( Talb. 5, fig. 5-7). C. valde inflatus, hemisplaericus; margine inflato; basi pulvinata; ano inframarginali.

5. Caratomus rostratus $\Lambda_{\mathrm{g}}$. (Tab. 5, fig. 1-4). C. depressus, valde rostratus; ambitu pyriformi; basi pulvinata; ano inframargiuali.

VI. Genus ECIINONEUS Van Plıels. Testa tumida, elongata, ovata ; ambitus ellipticus ; basis plana vel subconcava; os obliçuum, irregulare; anus inferus, ori vicinus, ellipticus; tubercula imperforata ; tubercula vitraea minora inter majora vulgaris indolis.

1. Echinoneus cyclostomus Leslie (Tab. 6, fig. 13-15) E. inflatus, ovatus, dilatatus, superne subdepressus; tuberculis vitreis parvis, numerosis; ore obliquo.

2. Echinoneus minor Leske (Tab. 6, fig. 16) E. inflatus, ovatus, cylindricus, superne convexiusculus; tuberculis vitreis paucis, parvis.

3. Eehinoneus gibbosus Lan. (Tab. 6, fig. 4-6) E. ovalus, inflatus, convexiusculus, gibbosus ; areis ambulacralibus distincte circumseriptis; tuberculis vitreis magnis, numerosis.

4. Eehinoneus crueiatus Ag. (Tab. 6, fig. 1-3) E. ovatus, inflatus, superne depressus ; tuberculis vitreis maximis, numerosissimis.

5. Echinoncus elegans Des. (Tab. 6, fig. 7-9) E. ovatus, inflatus, superne depressus; tuberculis vitreis multo minoribus quam vulgaria.

6. Echinoneus serialis Des. (Tab. 6, fig. 10-12). E. ovatus, inflatus, superne subdepressus, postice dilatatus; tuberculis magnis in area ambulacrali seriatis; tuberculis vitreis parvis.

7. Eehinoneus conformis Des. (Tab.6, fig. 17-21). E. ovatus, inflatus, superne convexiusculus; tuberculis vitreis mediocribus; aculeis parvis, striatis, transverse annulatis.

VII. Genus DISCOIDEA Gray. Testa subconica vel hemispharica; ambitus circularis ; basis plana vel concava; os centrale, decagonale, ad angulos incisum; anus pyriformis; tubercula seriata; pori genitales quatuor; pori ocularii quinque; assula genitalis inıpar non perforata. 
A) DISCOIDES PRopRIE SIC DIGTE. Tubercula minima; anus minor quam in flolectypis; nueleus incisus.

1. Discoidca Subuculus Bronn (Tab. 7, fig. 5-7). D. subeonica; basi concava, margine pulvinato; ano medioeri, elliptieo; tuberculis magnis plus minusve serialis, imperforatis; luberculis miliaribus irregulariter adspersis.

2. Discoidea minima Ag. (Tab. 7, fig. 1-4). D. minima subconica; basi plana; margine inflato; tubereulis miliaribus oblique seriatis.

3. Discoidea Pisum Mer. Testa minima, subconica; basi plana; Iuberculis miliaribus non seriatis; tuberculis magnis distinete perforatis.

4. Discoidea turrita Des. (Tab. 13, fig. 1-3), D. altissima, conica; tuberculis magnis valde seriatis, distinete perforatis; nucleo late inciso.

5. Discoidea cylindrica Ag. ( Tab. 8, fig. 8-16). D. inflata, bemisphæriea vel subeylindrica; ambilu orbiculari; hasi plana; ano elliptico, parvo; tubereulis parvis, indistincte seriatis ; nucleo in utraque area suleis magnis duobus et pluribus minoribus praedito.

6. Discvidea Rolula Ag. (Tab. T, fig. 15, 16). D. inflata, bemisphærica ; ambitu orbiculari; basi plana; margine inflato; ano parvo, elliptico; tubereulis miliaribus distincte seriatis.

7. Discoidea Facrina Des. (Tab. 7, fig. 12-14). D). inflata, hemispheriea; ambitu valde orbiculari ; basi plana; ano parvo, elliptieo; lubereulis miliaribus non seriatis.

8. Discoidea conica Des. (Tab. 7, fig. 17-22). D. inflata, subeoniea, postice truncata; basi plana ; ore subconcavo; ano elliptico; nuelei margine late et profunde ineiso ; tubereulis miliaribus non seriatis.

9. Discoidea decorata Des. (Tab. 8, fig. 1-3). D. subinflata; ambitu orbiculari; basi sulsconeava ; margine inflato; ano magno, pyriformi.

10. Discoidea plana Ag. (Tab. 9, fig. 1-3). D. depressa, subeoniea; ambitu ambieulari; basi coneava; ano pyriformi, infra-marginali; tubereulis miliaribus seriatis.

B). IOLECTYPI VEL Discoide E JURASSiC.E. Tubercula valde prominula ; testa subeoniea; basis coneava; anus maximus, pyriformis. Nucleus integer.

11. Discoidea depressa Ag. (Tab. 10, fig. 4-12). 11. alta subconica ; basi concava; oris margine late inciso; ano maximo; tuberculis miliaribus non seriatis.

12. Discoidea Meriami Des. (Tab. 10, fig. 1-3). D. inflata, superne rotundata, hemisphæriea ; Jasi subeoncava; margine inflato; ano latissimo. 
13. Discoidea arenata Des. (Tah. 9, fig. 11-13). D. inflata; hasi concava ; margine tumido; ore magno; ano maximo; tuherculis miliaribus seriatis, ad peripherian oris elongatis (fig. $13 \mathrm{c}$ ).

14. Discoidea Mandelslohi Des. (Tah. 9, fig. 1'1-16). D. inflata, subeonica; lasi subplana; tuberculis inferne valde prominulis; tuberculis miliaribus numerosis, seriatis.

15. Discoidca punctulata Des. (Tab. 9. fig. 17-19). D. inflata; basi subconcava; uargine tumido; tuberculis miliaribus paucis, distincte serialibus.

16. Discoidea concara Ag. (Tab. 9. fig. 4-6). D. alta, subconica; hasi concava; margine pulvinato.

17. Discoidea inflata Ag. (Tab. 9, fig. 7-10). D. inflata; basi subconcava; margine valde tumido ; ano maximo, pyriformi.

18. Discoidea hemispharica Ag. (Tab. 8, fig. 1-7) D. inflata, sulsconica; hasi concava; ano maximo, marginali.

19. Discoidea speciosa $\mathrm{Mg}$. (Tab. 10, fig. 13-15). D. depressa, subconica; basi subconcava ; ore parvo; ano ore majore, pyriformi.

20. Discoidea macropyga $\mathrm{Ag}$. ( Tab. 7, fig. 8-11). D. inflata; basi concava ; margine valde tumido ; ore magno, pyriformi; tuberculis miliaribus paucis, distincte seriatis.

VIII. Genus PYGASTER Ag. Testa depressa, vel subdepressa; ambitus orbicularis, vel subangulatus ; basis concava; os decagonum, ad angulos incisum; anus maximus, superus, in sulco lato situs; tubercula seriata ; pori genitales quatuor.

1. Pygaster Umbrella Ag. (Tah. 12, fig. 4-6). P. subeonicus, quinquangulatus, postice attenuatus; hasi subconcava; ore profunde ineiso ; ano maximo, pyriformi; tubereulis magnis; testa crassissima.

2. Pygaster patelliformis Ag. (Tab. 11, fig. 11-13). P. inflatus; ambitu orbiculari ; basi concava ; ano magno, pyriformi ; testa crassa ; tuberculis magnis.

3. Pygaster laganoides Ag. (Tab. 11, fig. 5-7). P. depressus, postice truncatus; ore magno, late inciso; ano in suleo lato, ad verticem porrecto; testa tenui.

4. Pygaster tenuis Ag. (Tab. 12, fig. 1-3). P. depressus, subconicus; ambitu subquinquangulato ; ano magno, pyriformi; testa tenui.

5. Pygaster costellatus Ag. (Tah. 11, fig. 1-4). P. depressus; margine inflato; ore parvo, impresso ; ano obliquo, supramarginali ; tuberculis parvis.

6. Pygaster truncatus Ag. (Tab. 11, fig. 8-10).P. depressus, postice attenuatus, valde truncatus; 
basi pulvinata; ore concavo; ano maximo, pyriformi; tuberculis seriatis, postice in seriebus arcuatis dispositis.

IX. Genus HYBOCLYPUS Ag. Testa angulata vel suborbicularis; os plus minusve excentricus; anus superne in sulco lato situs; ambulacra ad apicem non convergentia; tubercula non seriata, sed perforata.

1. Hyboclypus gibberulus Ag. (Tab. 13, lig. 11-14). H. subangulatus, antice attenuatus, emarginatus, postice truncatus, superne carinatus; ore excentrico, antico; sulco analilato, ad apicem angustato, profundo.

2. Iyboclypus canaliculatus Des. (Monogr. quart. Tab. 4, fig. 8, 9). II. suborbicularis, ovalus, antice attenuatus, postice dilatatus ; sulco anali profundo; anbulacris posticis in medio inter apicem et marginem posticum conjunctis. 


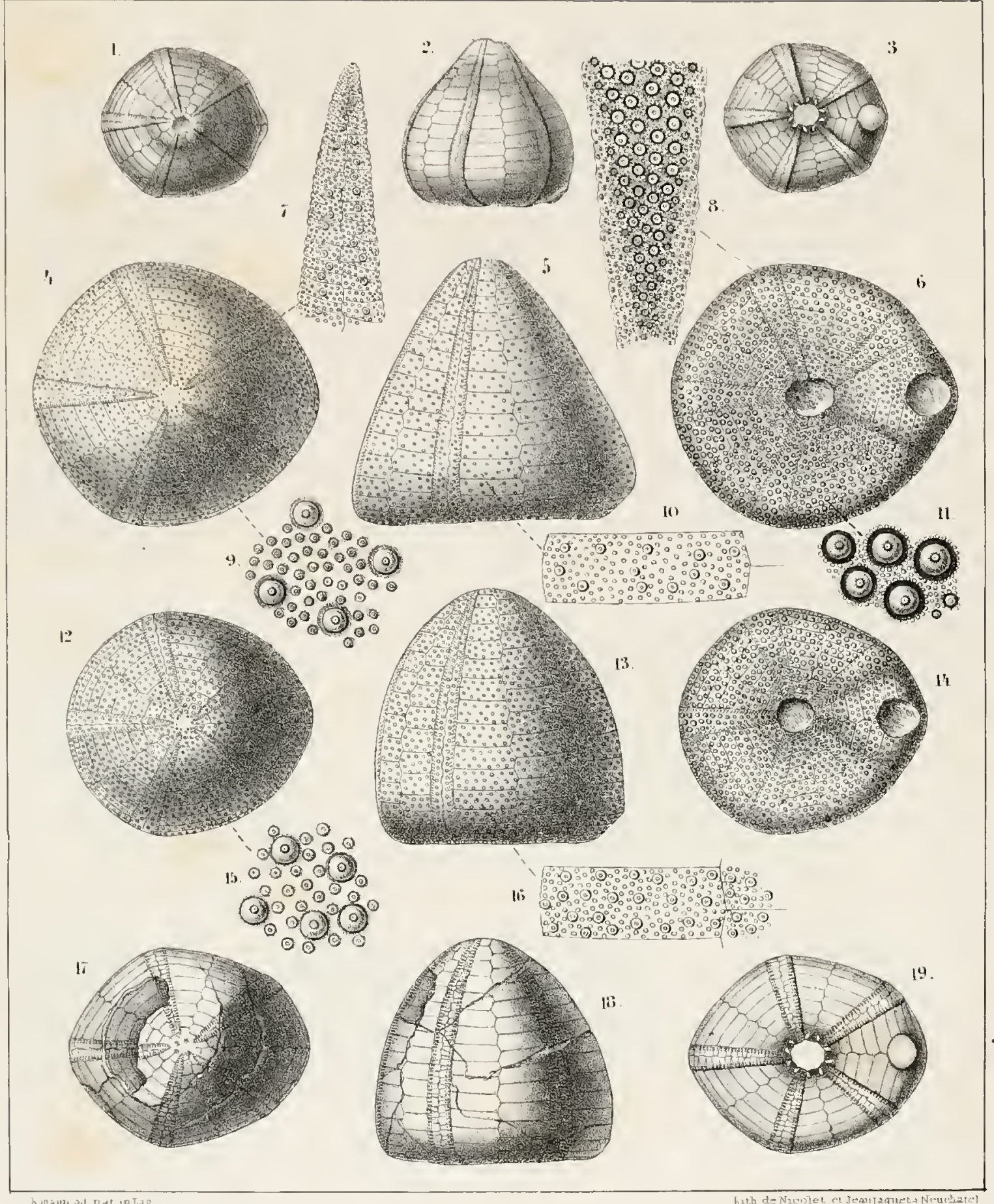

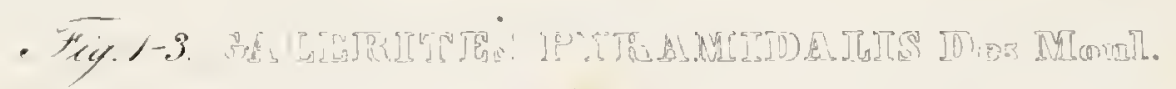

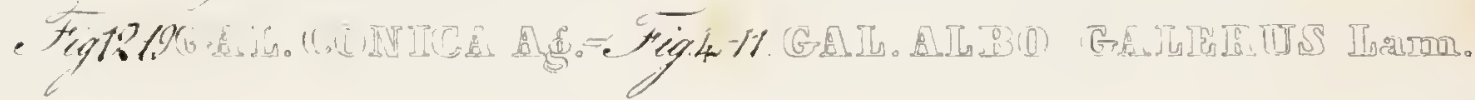





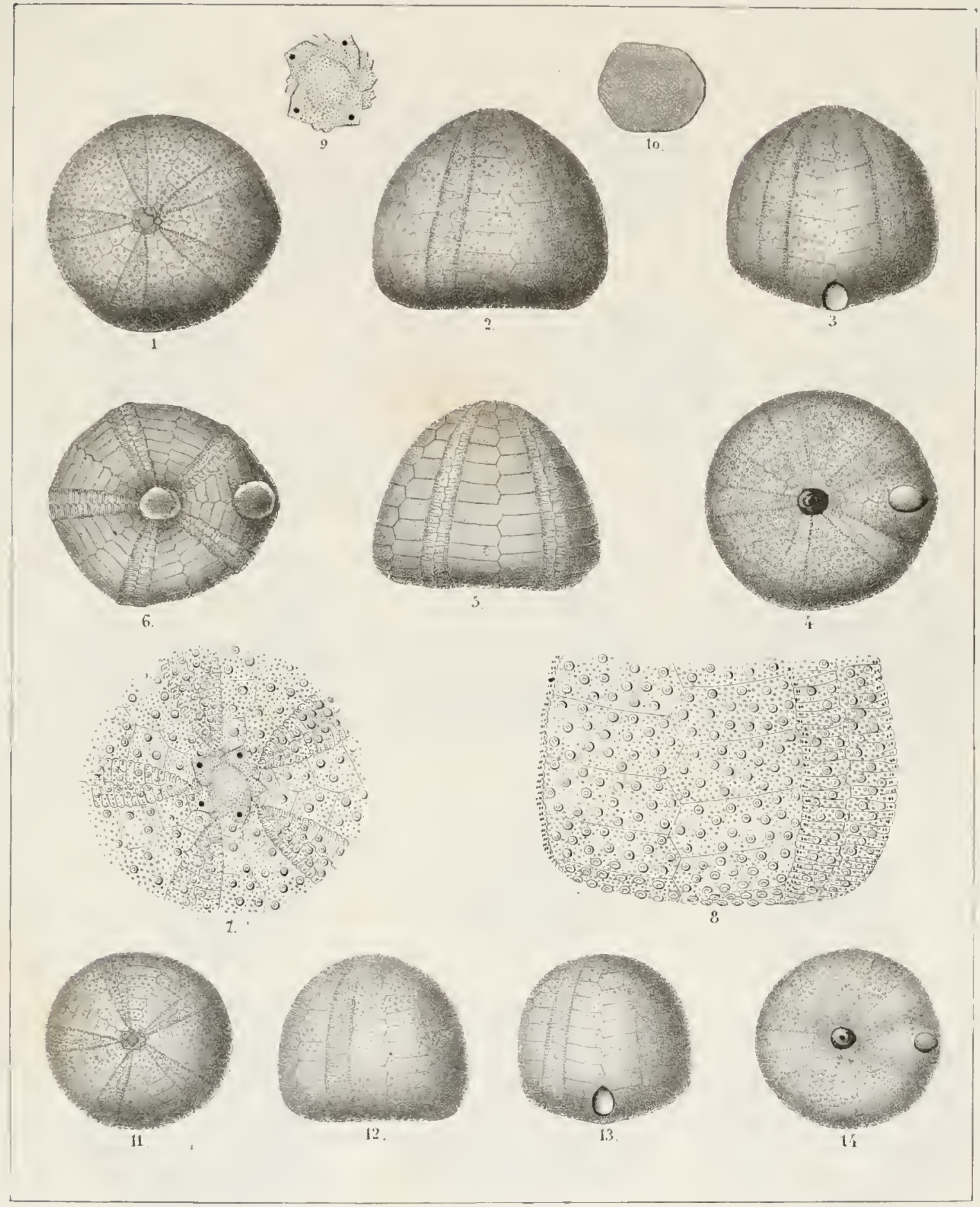

Dickemarm a..

Iutin de Nastet a Neucha:

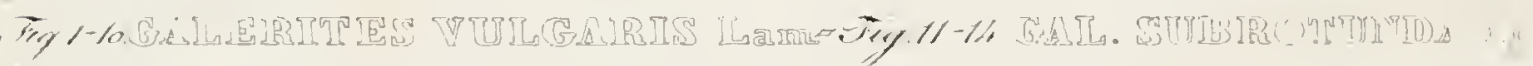





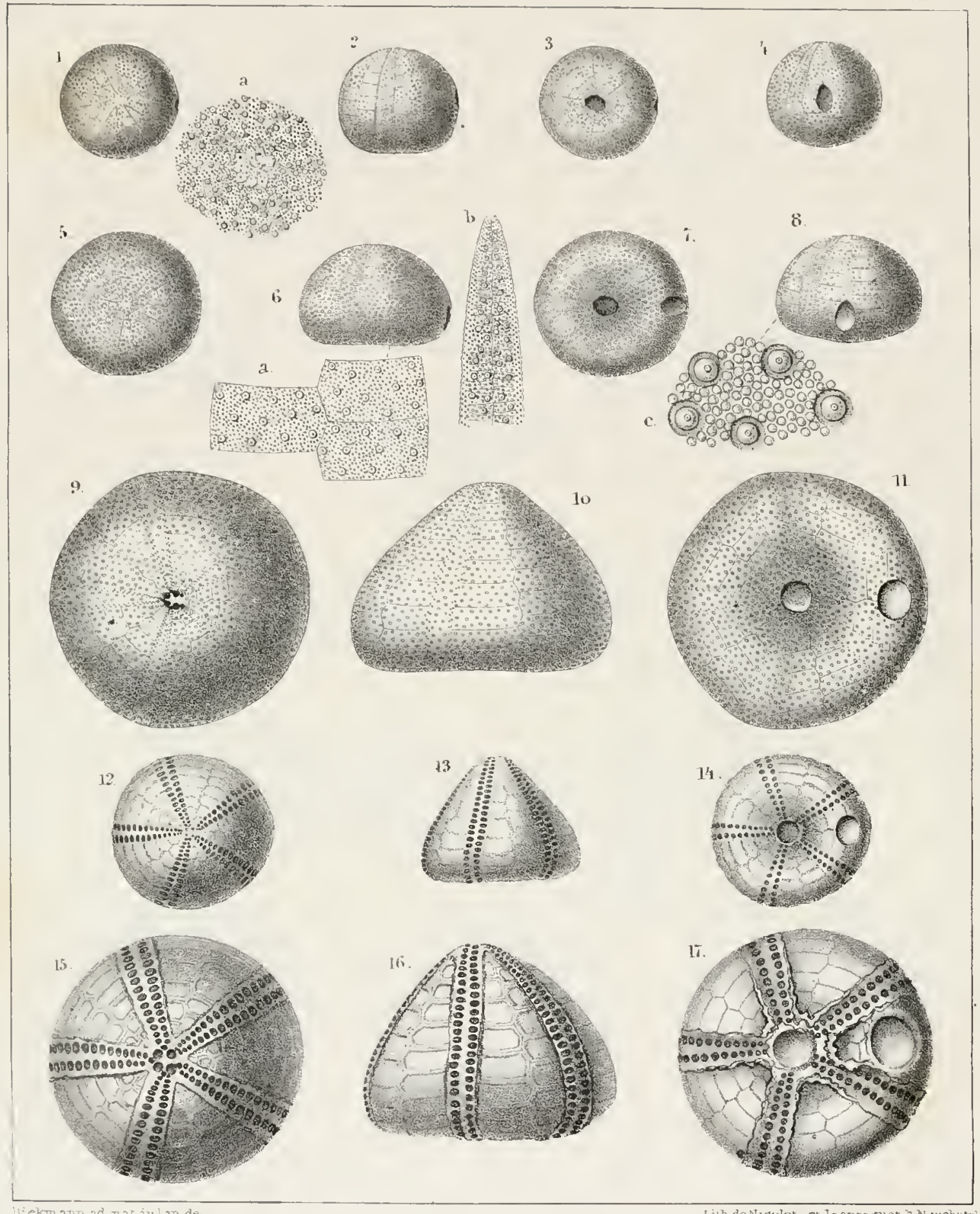

- Hy

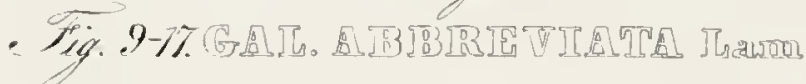




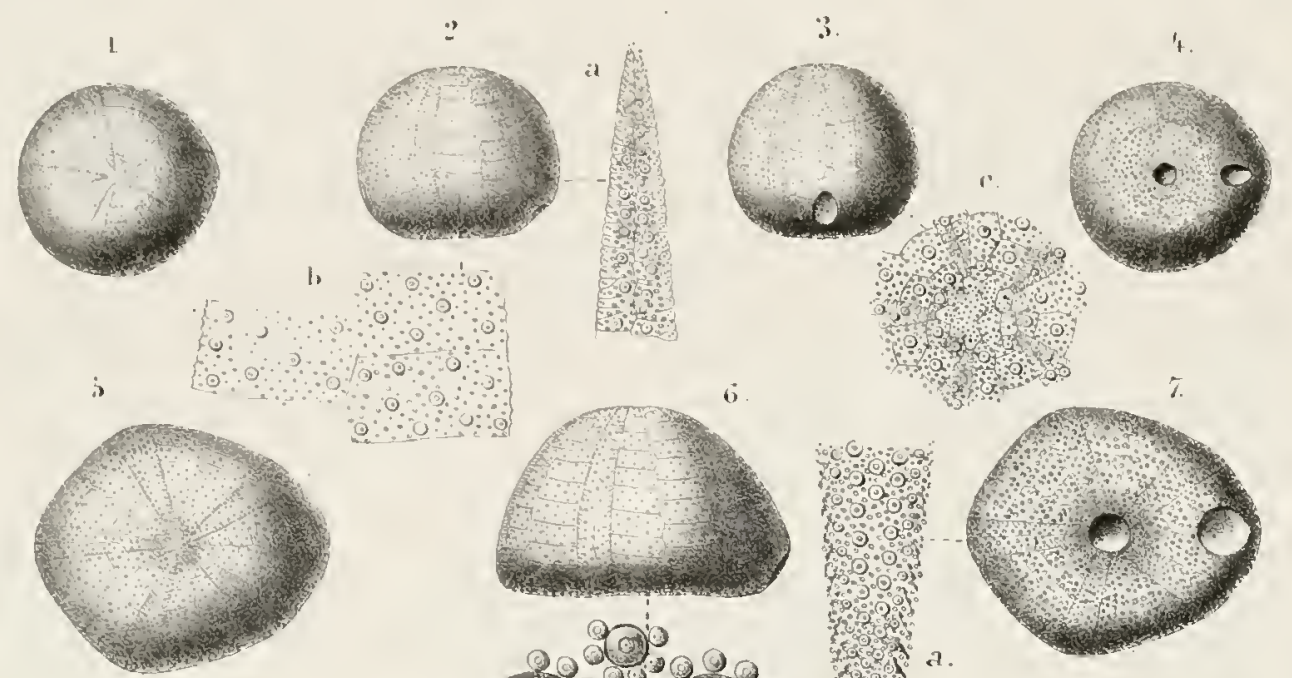

8

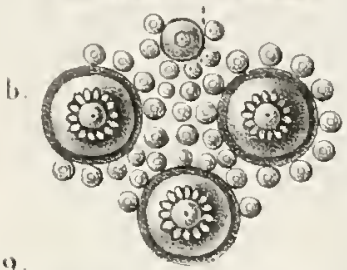

y.

20
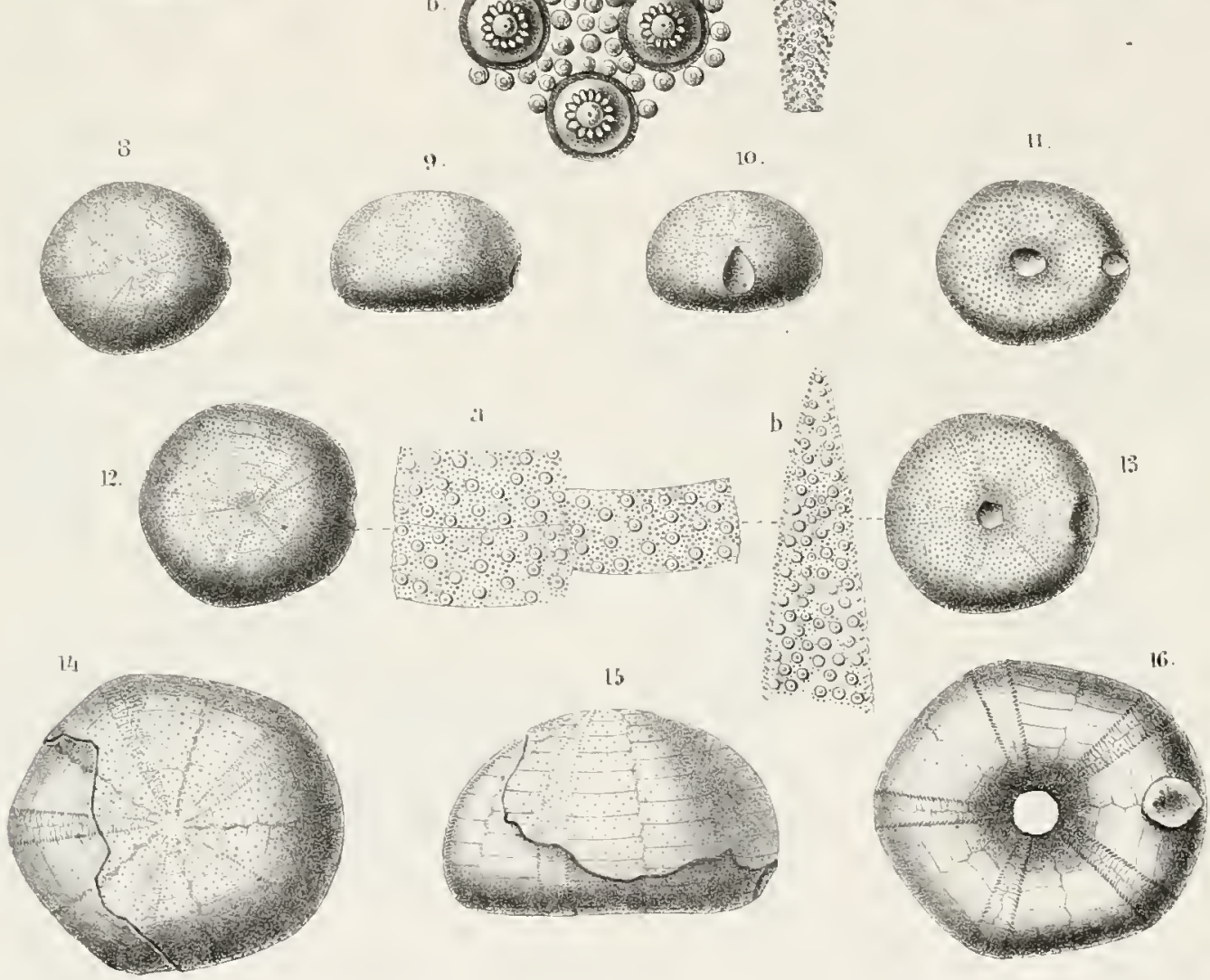

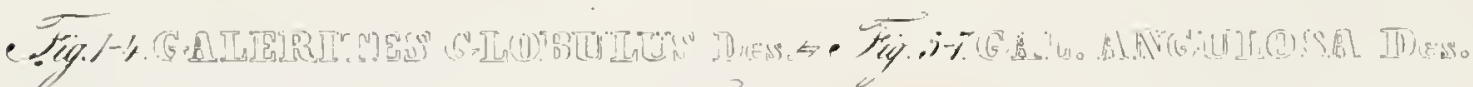

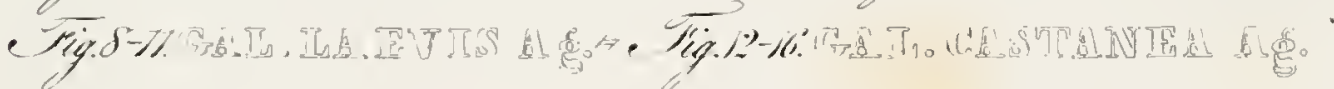




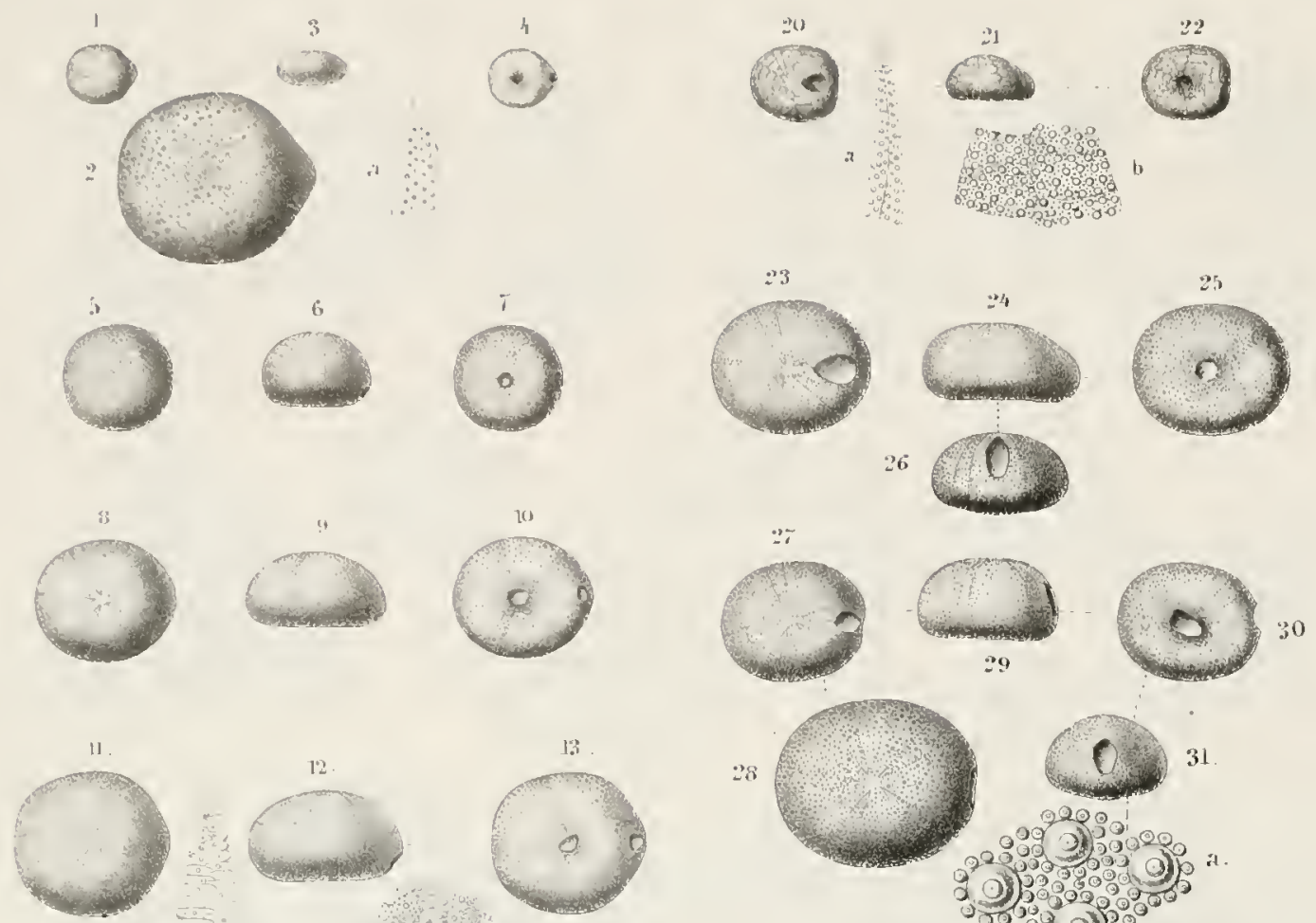

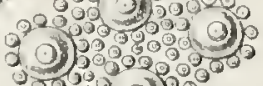
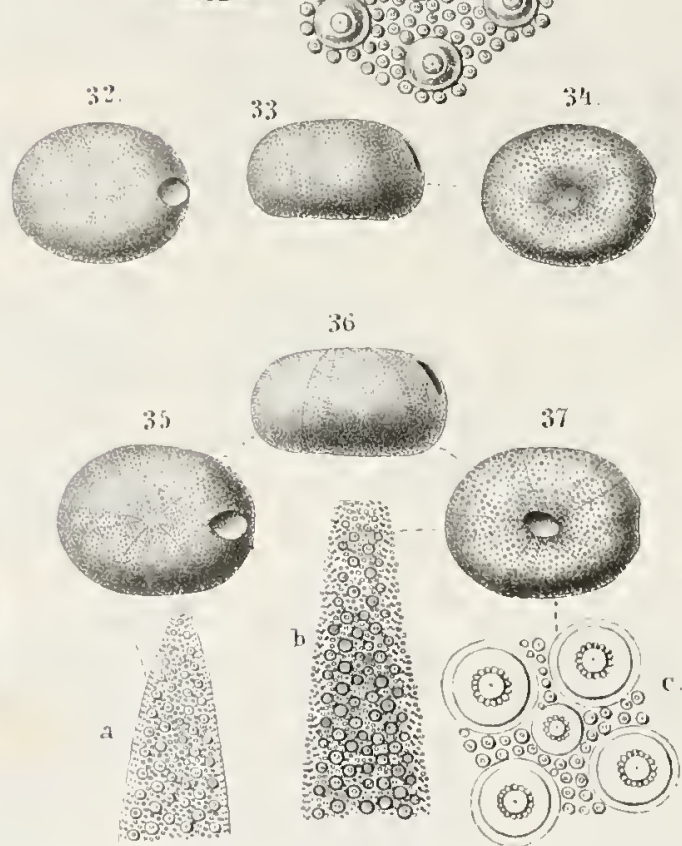

- Tig -

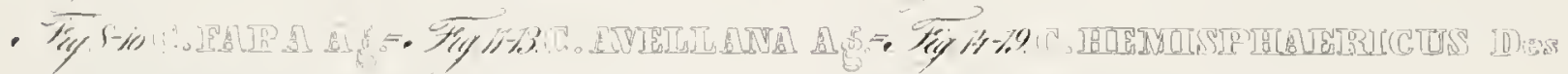

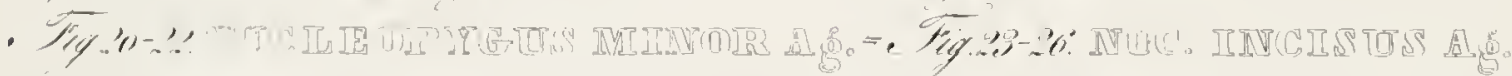

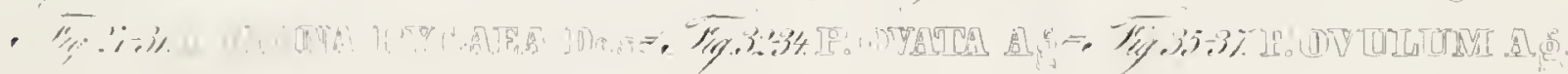





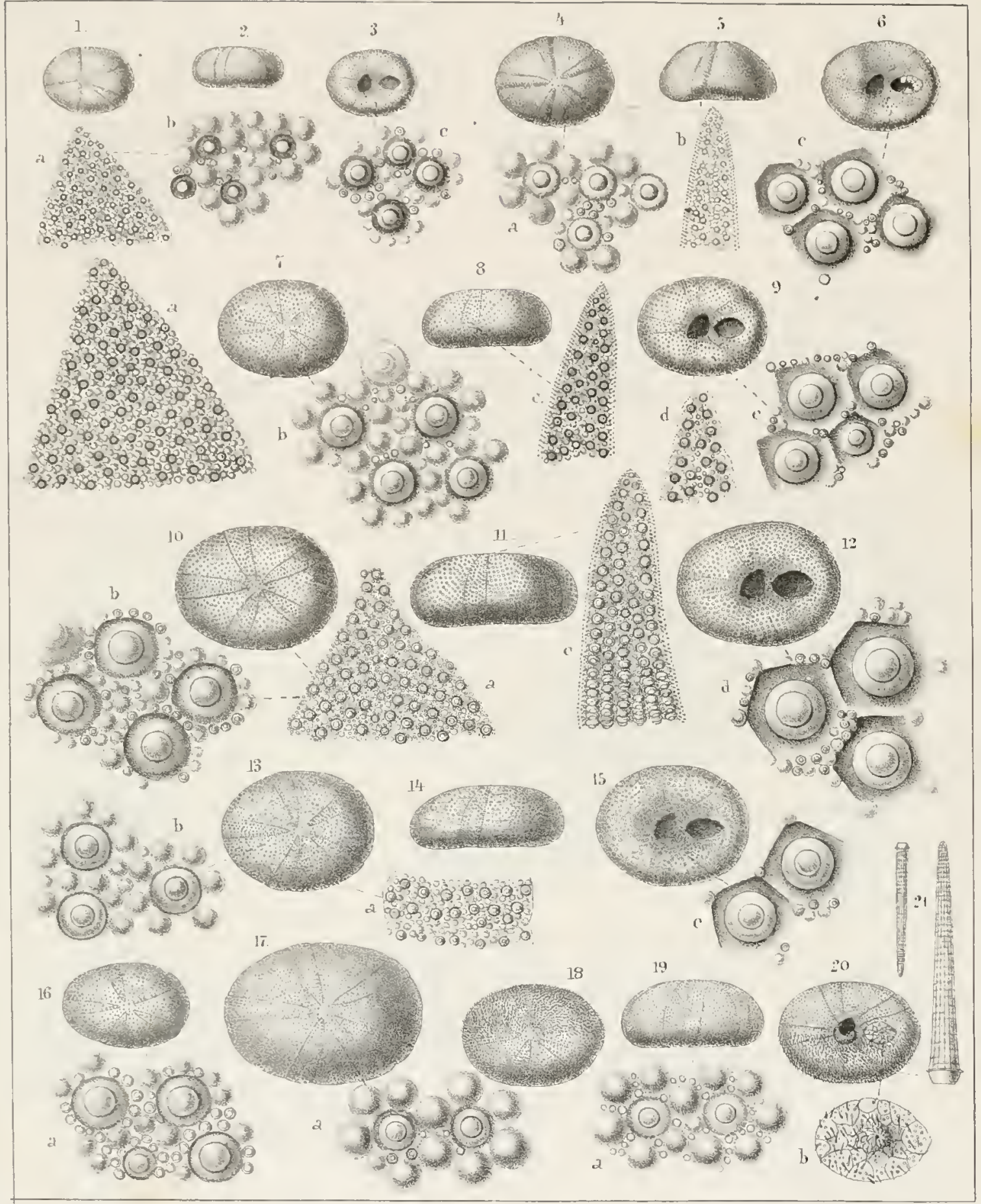

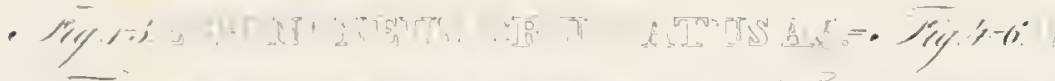

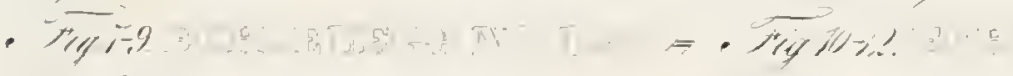

- Figle 



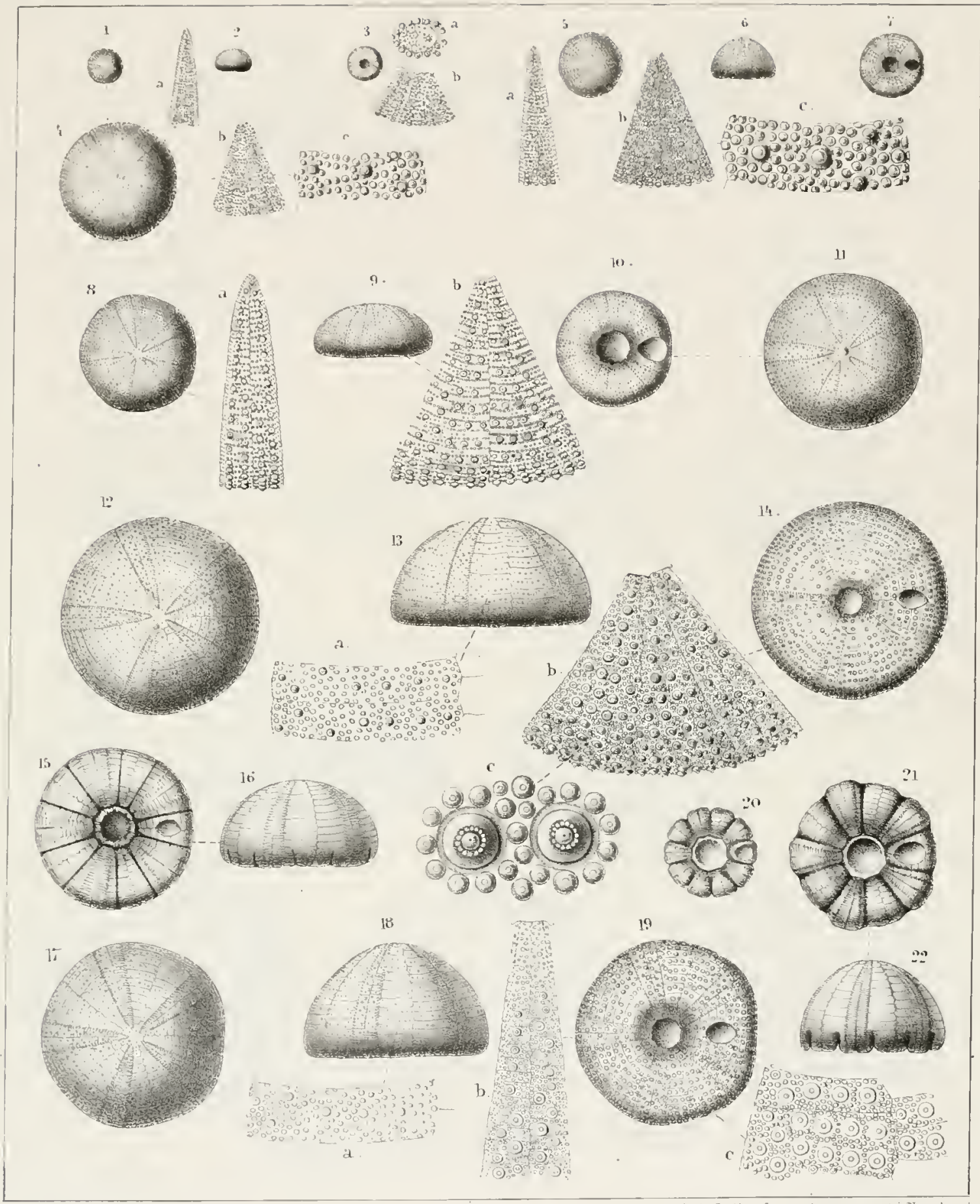

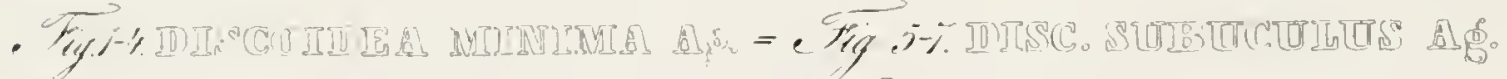

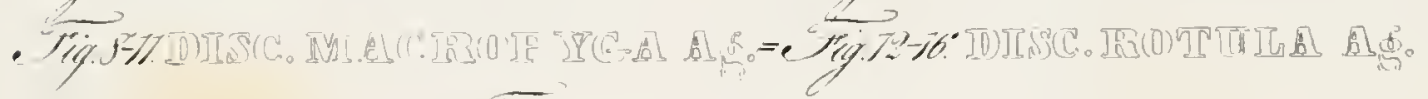

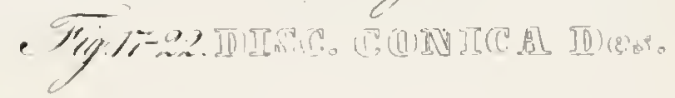




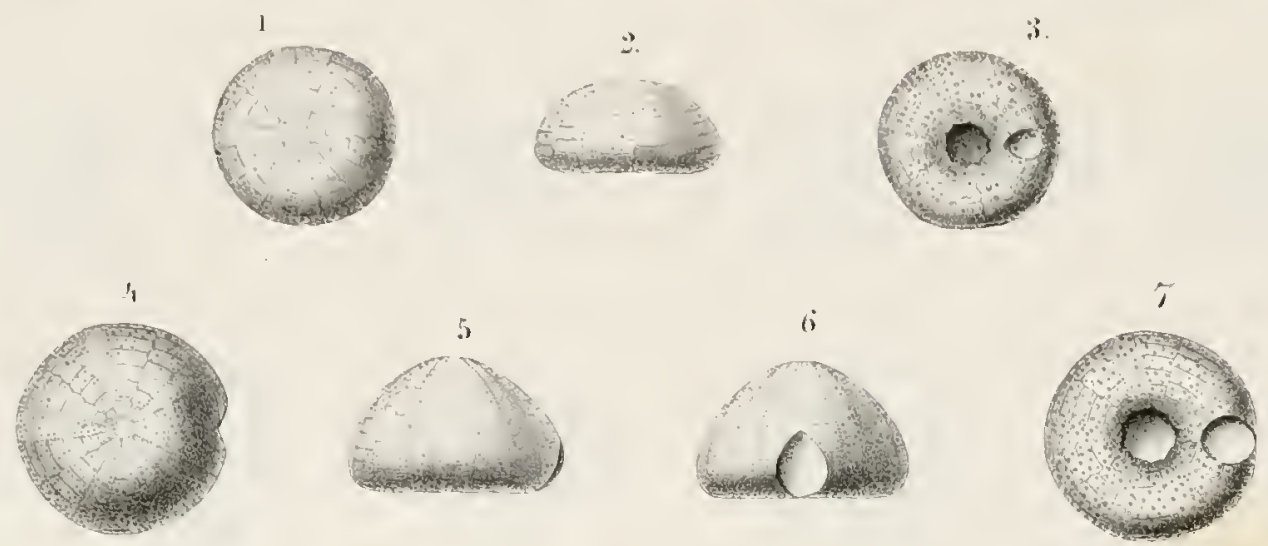

8.

10
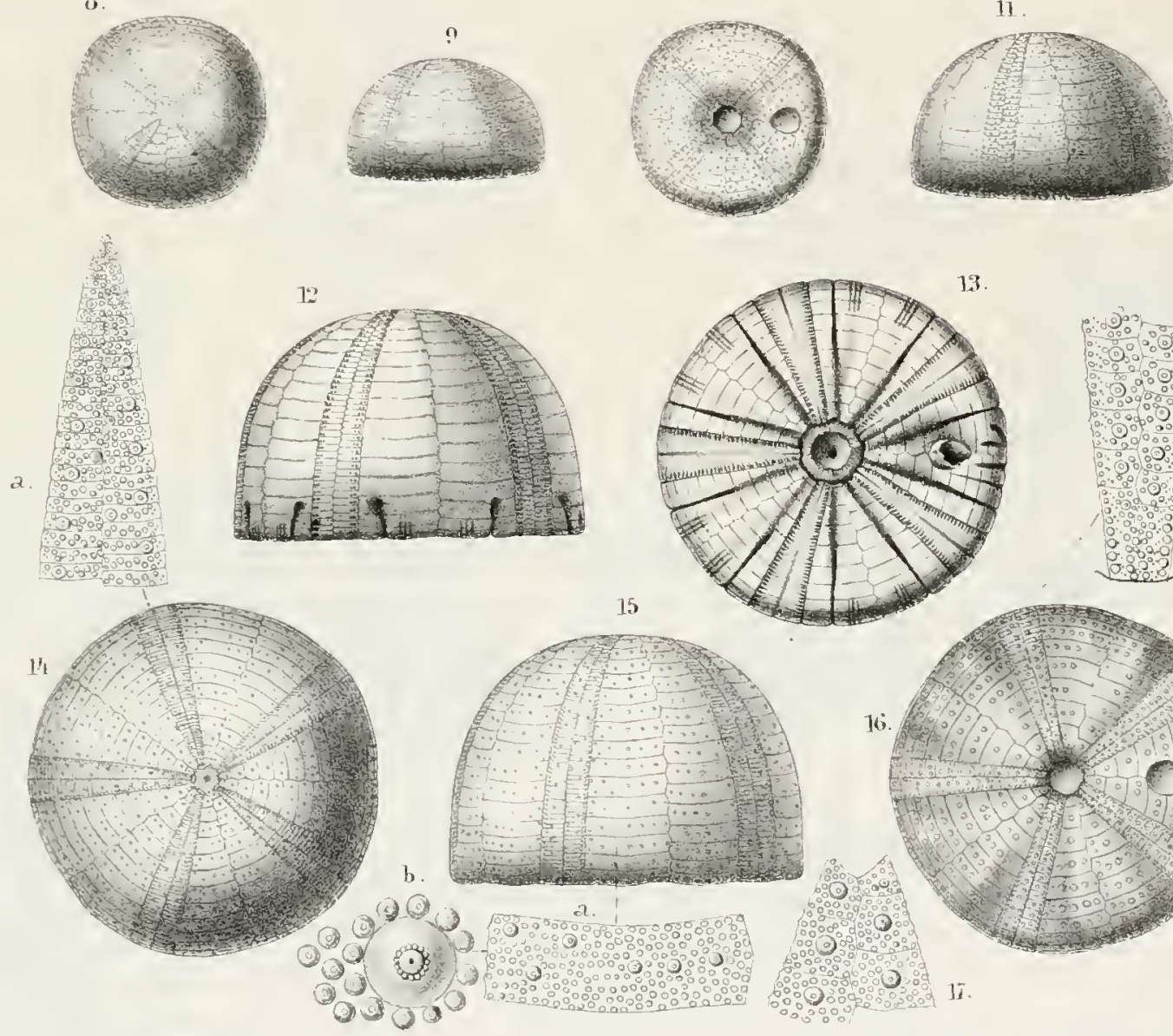

16.
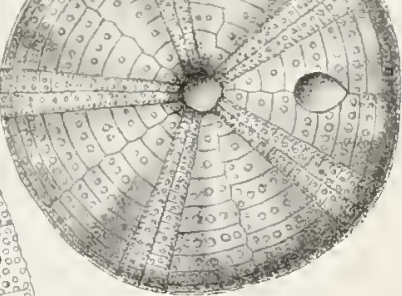
15.

- Hy

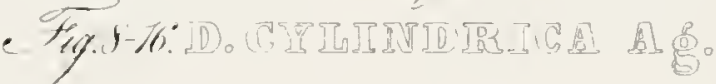





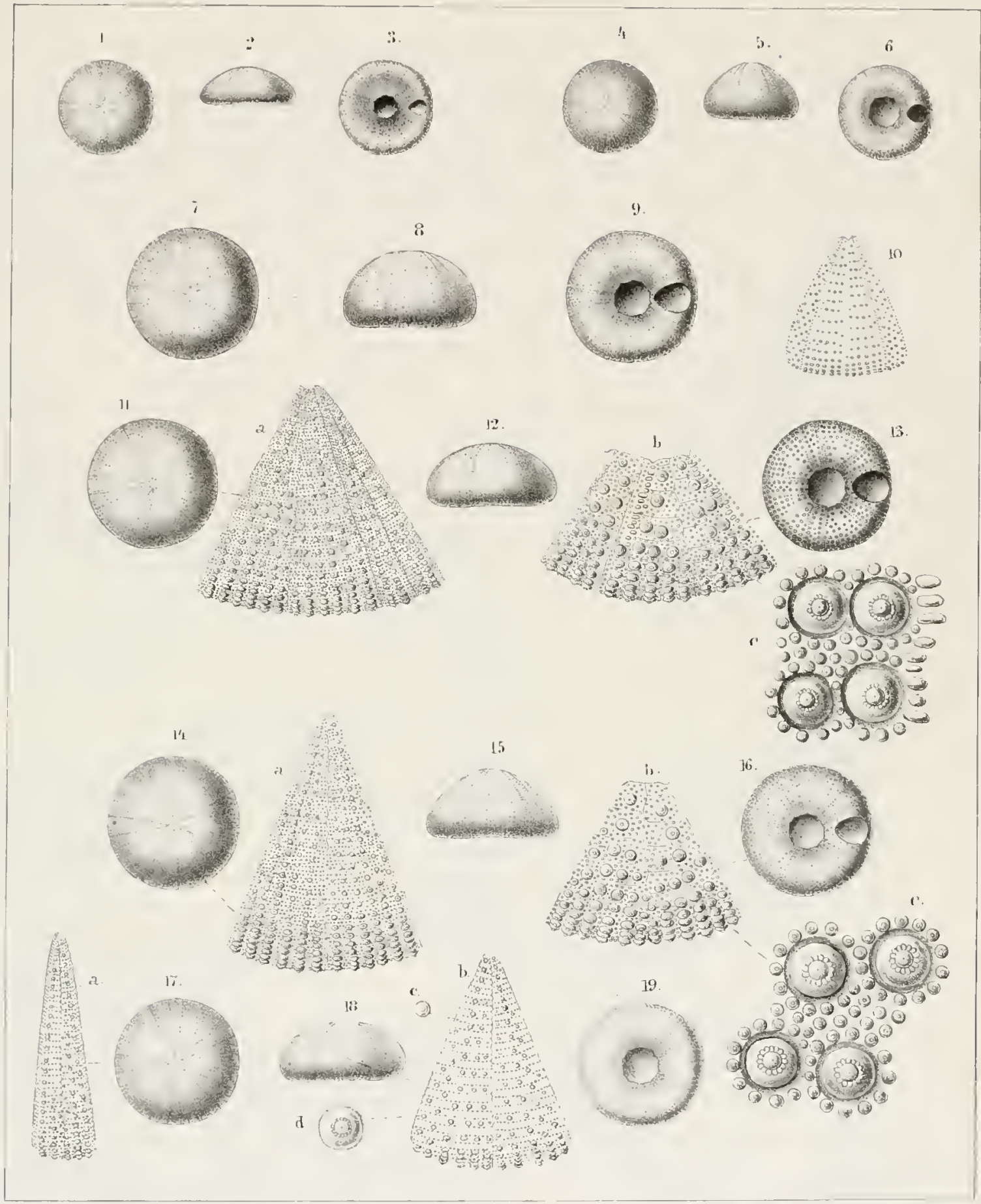
- Pij
- Iig. "
- jig. i-Al

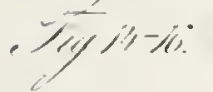
- Fing is

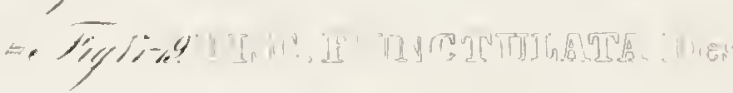





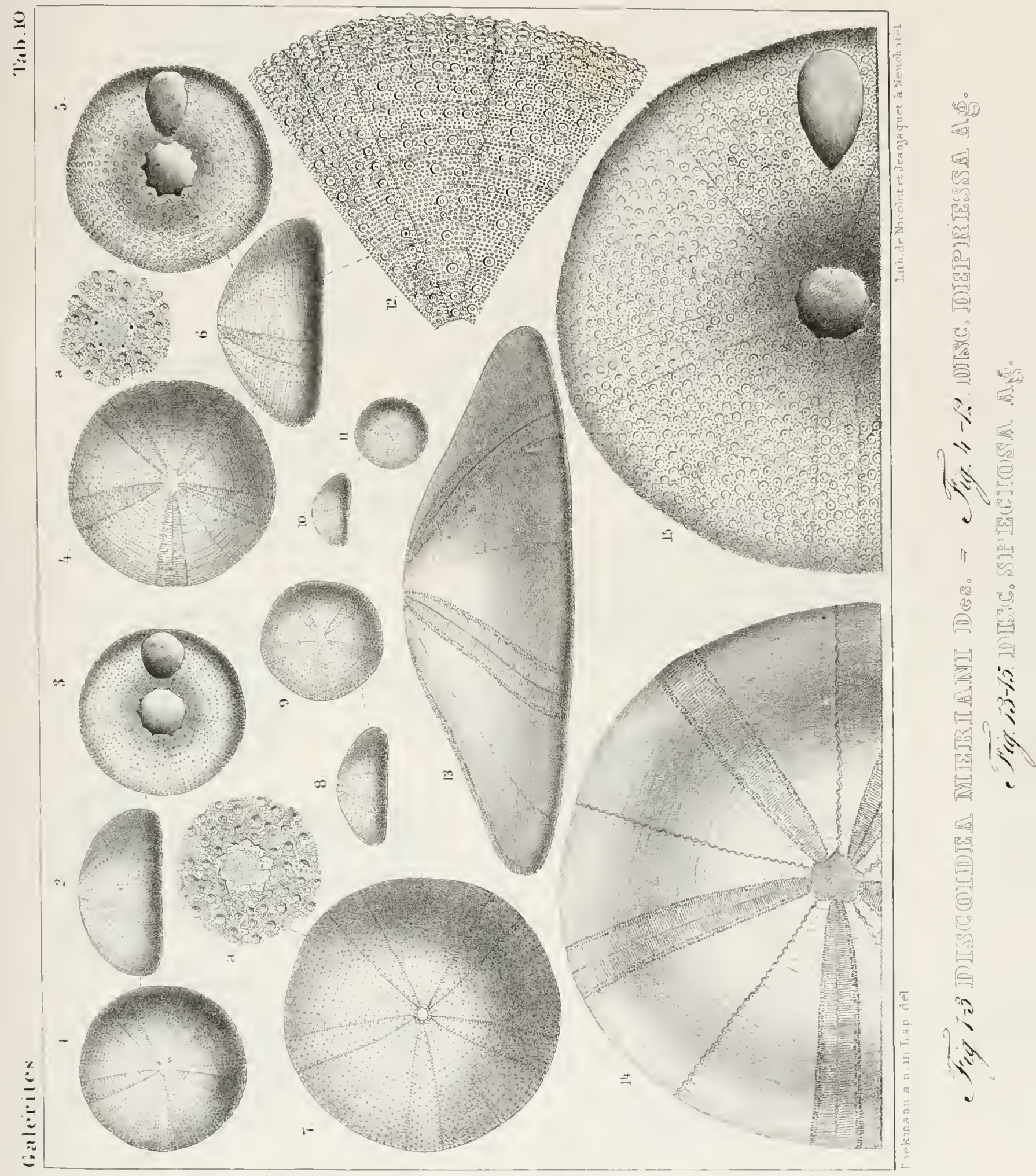





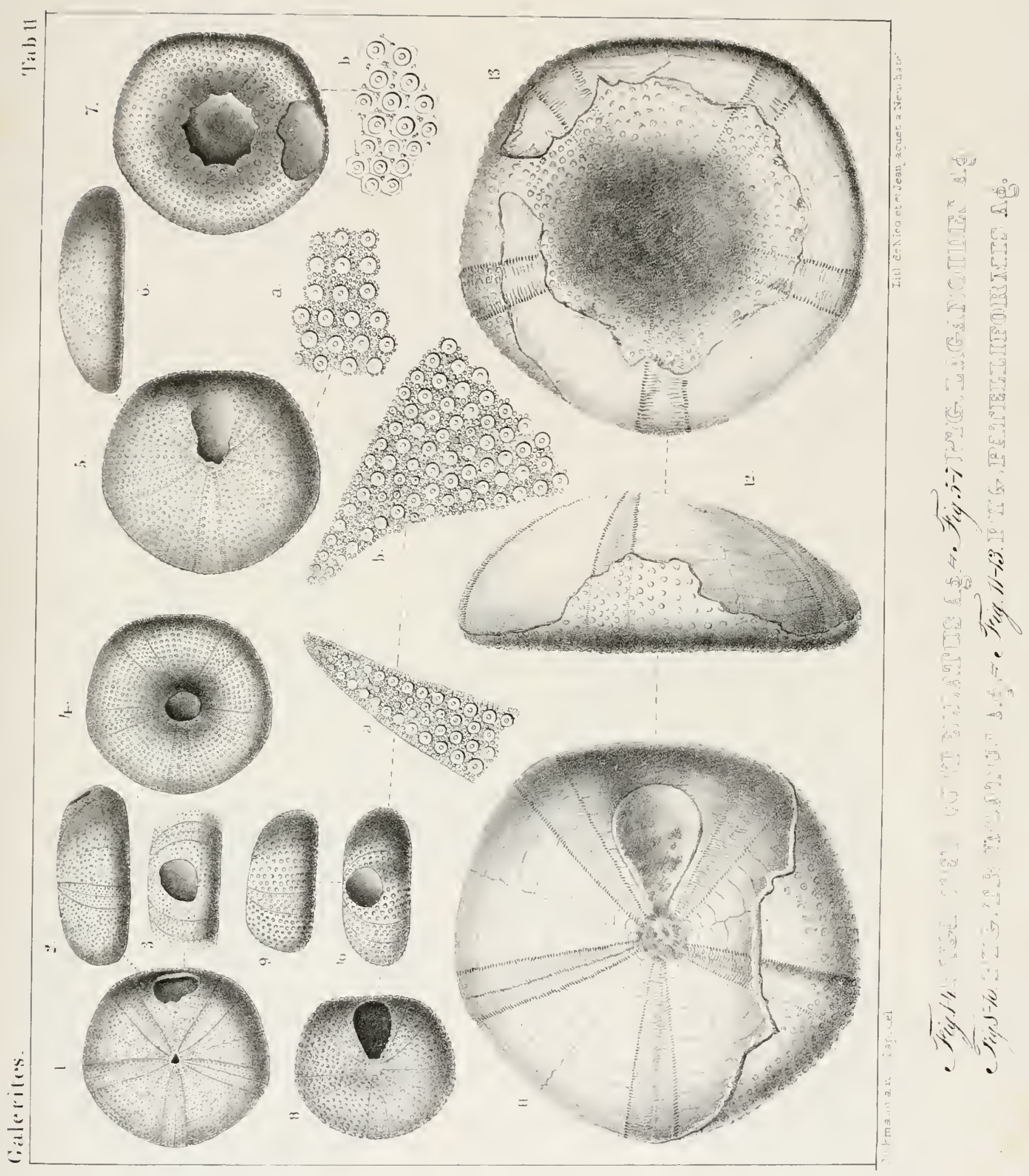





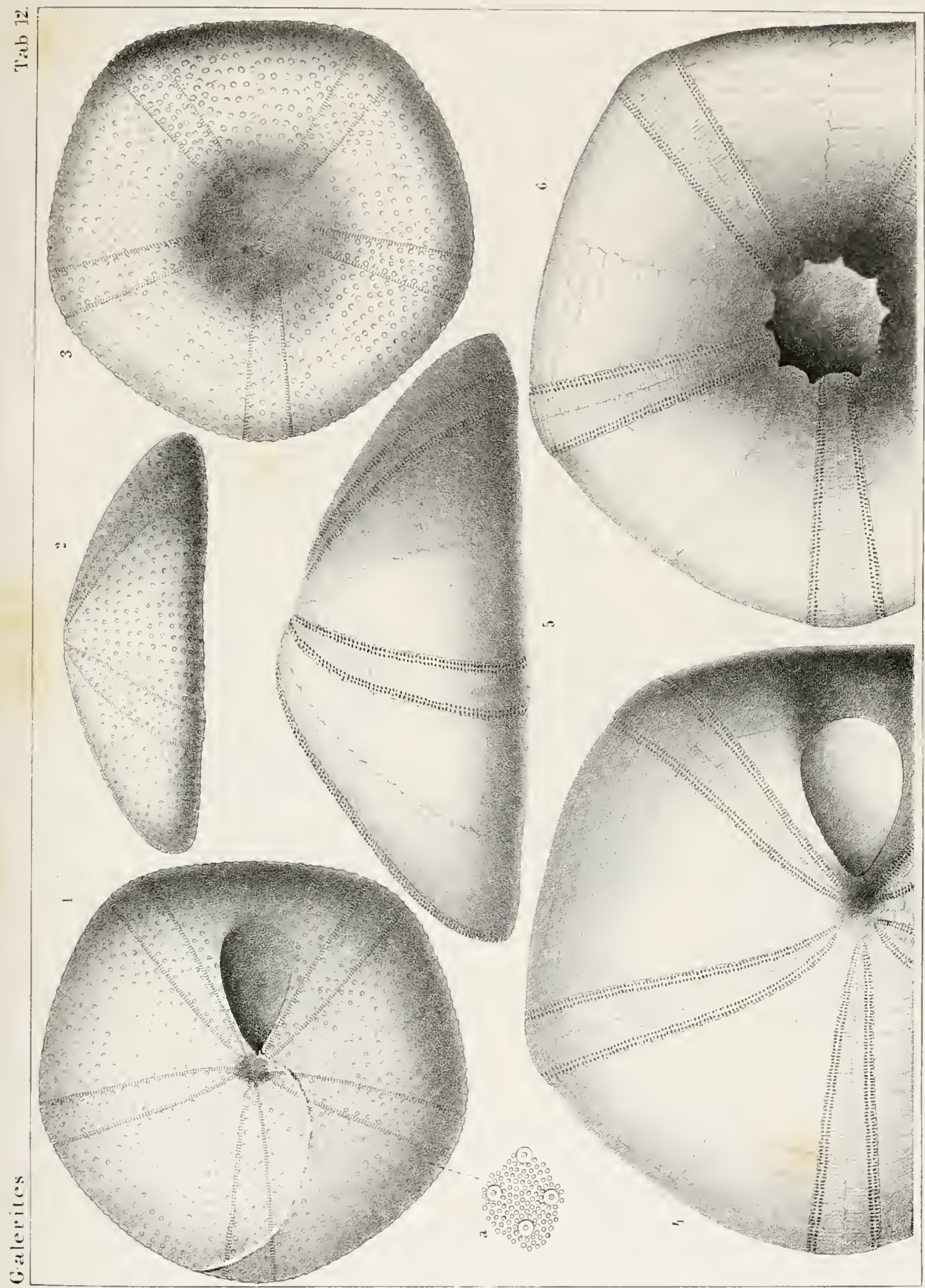

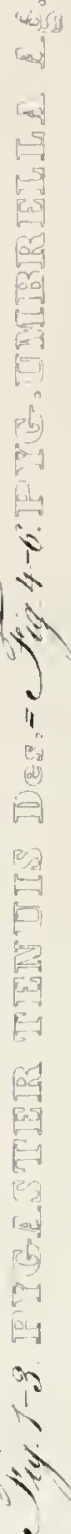





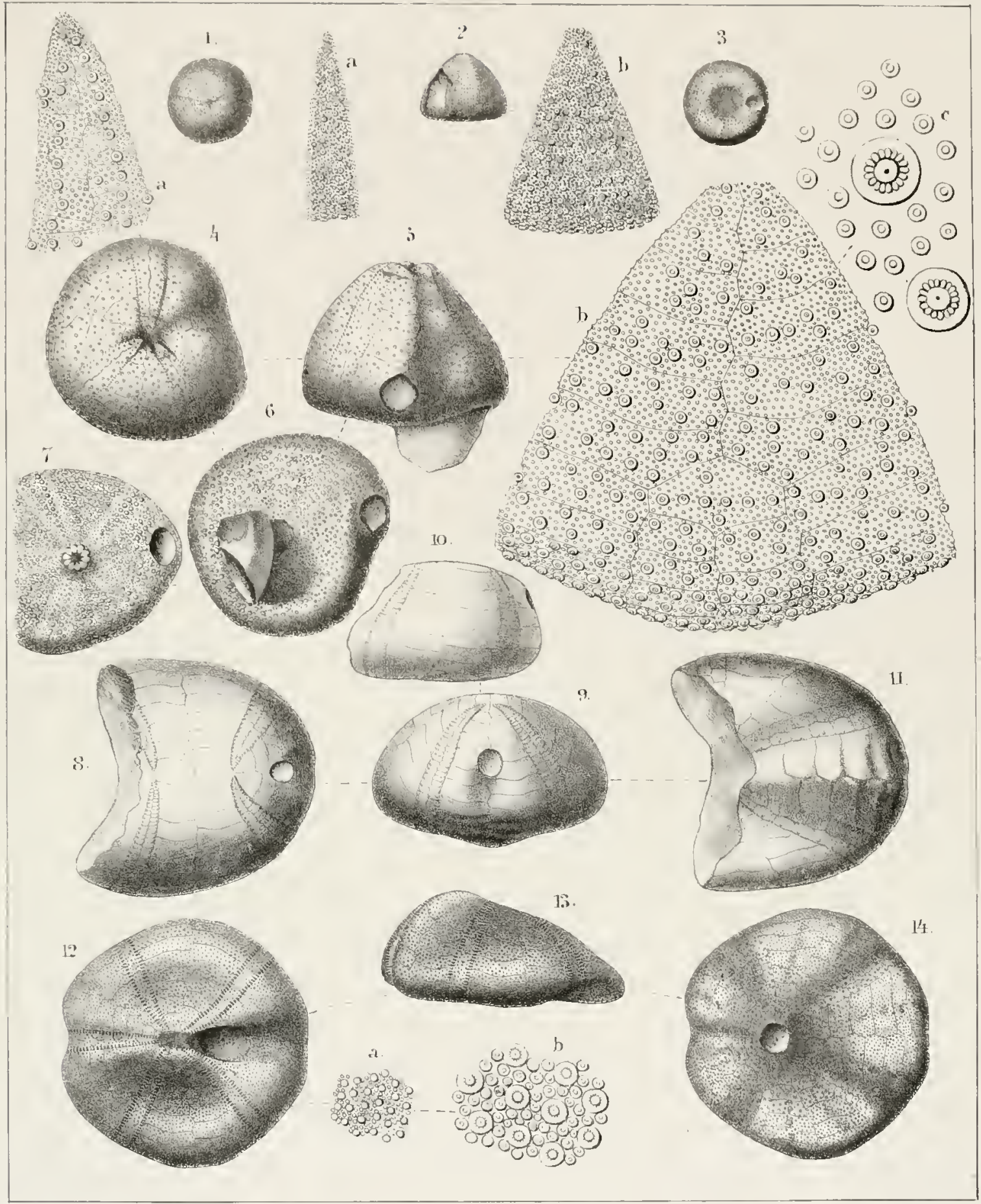

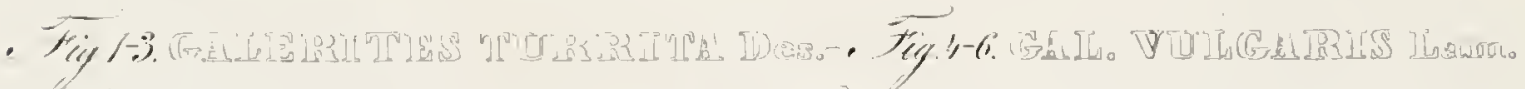
- Jint - Híf. 



\section{MONOGRAPHIES}

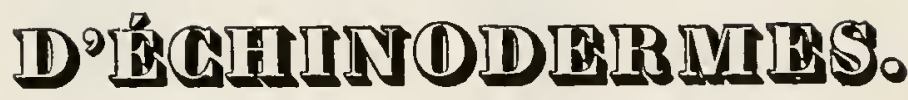




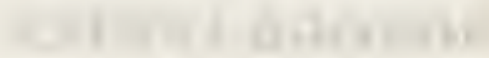

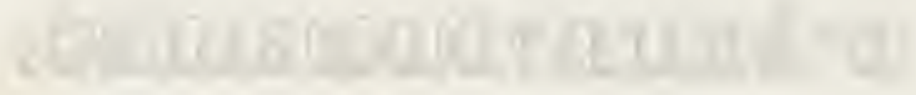




\section{ÉCHINITES.}

FAVILLLE DES CLYPÉASTROIDES.

(20)

\section{DES DYSASTER.}

PAI

IDDDESDIB

1842. 


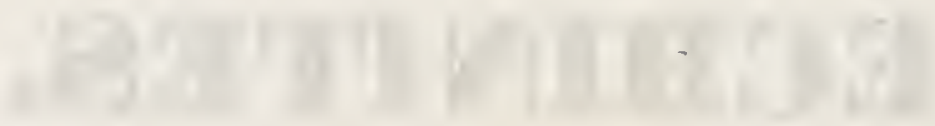

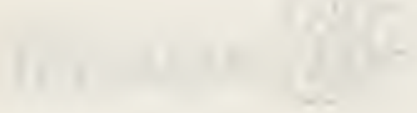




\section{IITRODLLCTIOI.}

Il u'y a pas long-temps que le type des Dysaster était ineonnu, comme tel, aux naturalistes. Le peu d'espèces qu'ils en ont décrites ont été ordinairement rangées par eux dans les Ananclyytes ou dans les Spatangues, dont elles se rapprochent en effet par leur forme extérieure. Mais cette ressemblance n'est que superficielle, et il suffit de jeter un coup d'œil sur les détails de leur lest pour y reeonnaitre des diffẻrences d'organisation profondes, différences qui engagèrent M. Agassiz à les séparer des Spatangues sous le nom de Dysaster, tandis que M. DesMoulins en faisait, à peu près à la même époque, son genre Collyrites.

Le caractère le plus saillant de ces Oursins consiste dans la présence de deux sommets aubulacraires, c'est-à-dire, que les cinq ambulacres, au lieu de converger tous vers le sommet du test, eomme cela se voit dans presque tous les autres Eehinites, se reneontrent sur deux points plus ou moins distans de la face supérieure, les trois ambulaeres antérieurs ordinairement un peu en avant du sommet, les deux ambulacres pairs postérieurs au dessus de lianus. Une pareille disposition des anbulacres implique nécessairement des modifications profondes dans le système respiratoire de ces animaux, qui, au lieu de se réunir, eomme d'ordinaire, au somnet, se trouve relégué sur les côtés antérieur et postérieur, et par eonséquent éloigné du système génital, avee lequel il est plus ou moins en eontact dans tous les autres genres. Or si nous avons pu nous croire autorisé à éloigner les Galérites des autres Clypéastroïdes, à cause de la forme particulière de leurs ambulaeres a la face supérieure, à bien plus forte raison n'lésiteronsnous pas à faire des Dysaster un groupe à part, dont le eachet réside également dans la nature de ses ambulacres.

Une question plus diffieile à résoudre, éest eelle de savoir à quelle famille les Dysaster appartiennent. M. Agassiz, dans son Prodrome, les place en lête des Spatangoüdes; Lamarck en fait des 


\section{$-6-$}

Ananchytes; Goldfuss des Spatangues, et Deslloulins les place, comme genre à part, entre les Nucléolites et les Ananchytes. Plus tard, Agassiz revint de sa première opinion et, dans son Catal. syst. des moules d'Echin., il rangea les Dysaster parmi les Clypéastroüdes. Une si grande diversité d'opinions à l'égard d'Oursins, d'ailleurs très-caractéristiques, prouve assez que les parties essentielles de leur organisation nous sont inconnues. De fait, la question se résume à ceci : Les Dysaster ont-ils un appareil masticatoire semblable ì celui des Clypéaströ̈des, ou bien cet appareil manque-t-il complétement, comme dans les Spatangoïdes. Par malheur, toutes les espèces sont fossiles, et il nous a été impossible de reconnaître dans aucune d'elles des traces d'un organe que l'on pût envisager comme faisant partie du système digestif. Les moules internes sont parfaitement unis; c'est à peine si l'on y distingue les articulations des plaques et les empreintes des pores ambulacraires. Le pourtour de la bouche est surtout très-uniforme. Nous en sommes par conséquent réduits aux caractères extérieurs qui seuls ne peuvent donner que des probabilités plus ou moins concluantes; après les avoir tous pesés, je suis porté à croire que les Dysaster ont en réalité plus d’affinité avec les Clypéaströ̈des qu'avec les Spatangoïdes; car šils ont la physionomie extéricure de ces derniers, leur bouche est conformée d'une toute autre facon: au lieu d'être allongẻe transversalement et bilabiée, comme dans les Spatangoüles, elle est anguleuse, conme dans les Galérites; ce qui me fait présumer qu’il existe au moins quelques rapports entre le système digestif de ces deux groupes.

Lorsqu'on songe que tous les Dysaster, a l'exception de trois, sont des fossiles de la formation jurassique, c'est-à-dire qu'ils vivaient à une époque oủ le type des Spatangues n'existait pas encore, on est en quelque sorte tenté de les envisager, ainsi que les Hyboclypes, comme un de ces types primitifs, dans lesquels se trouvent rẻunis des caractères qui, dans d'autres époques, n'appartiennent qu’à des groupes très-différens. On dirait que dans les Dysaster le type des Spatangues n'est pas encore séparé de celui des Galérites.

Jusqu'ici, ce groupe si remarquable ne se compose encore que d'un seul genre, qui est le genre Dysaster. 


\section{DU GENRE DYSASTER AG.}

Les Dysaster sont en général des Oursins de moyenne taille; quelques espèces atteignent des dimensions un peu plus considérables et ont jusqu’à deux pouces de longueur. Leur apparence est uniforme, et comme teurs tubercules sont peu développés et clair-semés, nous en concluons qu ïls étaient, comme les Galérites, des Oursins peu épineux.

La bouclie est centralc ou subcentrale en avant, sans cependant être aussi excentrique que celic des Spatangues ; mais ce qui constitue un caractère plus important que fa position de fa bouclıe , c'est sa forme qui, quoique en général d’apparence circulaire, est cependant, dans le principe, décigonałe; si elle paraît pentagonale dans certaines espèces, c'est ordinairement parce que le bord de l'ouverture correspondant aux aires interambulacraires est tellement restreint, qu'il disparaît à peu près complètement (*).

L'ouverture anale est de moyenne grandeur et invariablement située à la face postérieure, ordinairement au dessus d'un sillon évasé qui occupe le milieu de l'aire interanbulacraire impaire. Sa forme est elliptique de haut en bas.

It est à regretter que l’appareil génital soit ordinairement si mal conservé. Cependant, tout ce que j’ai pu en apprendre, d’après quelques exemplaires d'une meilleure conservation, c'est que cet appareil présente une structure particulière. On remarque, près du sommet ambulacraire antérieur, quatre pores formant entre eux un losange irrégulier; deux sont situés en avant des ambulacraires pairs antérieurs, et deux en arrière. Je n'ai pas pu massurer si les plaques dans

(*) C’est pour arvir accordé trop de confiance aux deseriptions ef aux figures souvent incorrectes des auteurs qui représentent les bysaster comme ayant la bouche ronde, que .1. Des.Ioulins a éte conduit à ranger daus son genre Collyrites, des Oursins complètement étrangers á ce groupe. En cela, M. Des.Houlins a cependant été conséquent avec son principe qui place lá forme de la bouche en première ligne, dans l'appréciation des caractères génériques. Mais à supposer mène que les Dysaster eussent la bouche ronde, cequi est une erreur, ce ne serait pas encore pour moi une raison d'associer aux bysaster des Oursins. il ambulacres convergens au sommet. Pour que le genre Collyriles de M. DesHoulins correspondit cxactement au genre Dy'saster, it faudrait en éloigner les Collyrites emygdula, C. brissoüles, C. Leteroclyfa, C. cunuliculata et C. depressa. Les trois premiers sont des spatangoides des genres Micraster et IIolaster; le C. conuliculata est notre Injoclipus canticulalus, et le C. depressa, le Pygrster costellatus Ig. J'ignore complètement ce que peut itre le Collyrites trigonalo. 
lesquelles ces pores s'ouvrent sont des plaques particulières; mais d'après tout ce que j’en ai vu, elles ne diffërent en rien extérieurement des plaques des aires interambulacraires. Quant aux plaques ocellaires, je n'en ai découvert aucune trace, quelque peine que je me sois donnée à cet effet.

Les aires ambulacraires n'ont guère que le tiers de la largeur des interambulacraires; aussi leurs plaques sont-elles beaucoup plus petites; il y en a cinq, et même six pour une plaque interambulacraire. Cependant, malgré leur petitesse, il est facile d'en connaitre le nonbre, puisque chaque plaque ne compte qu'une paire de pores, au moins à la face supérieure. A la face inférieure, les plaques ambulacraires sont plus hautes, ce qui fait paraître les pores plus distans. Ce n'est que sur le pourtour immédiat de l'ouverture buccale que l'on voit quelquefois des pores se dédoubler et former quatre rangées au lieu de deux (Tab. I, fig. 21). Les deux sommets ambulacraires de la face supérieure ne sont pas toujours ì égale distance l'un de l'autre; aussi leur éloignement plus ou moins considérable et la manière dont ils sont arqués, constituent-ils des caractères spécifiques importans. C'est ainsi que dans le $D$. bicordatus, les ambulacres postérieurs se rencontrent immédiatement au dessus de l'anus, tandis que dans le $D$. semiglobus (Tab. 4, fig. 10-12), ils s'élèvent fort haut et sont très-rapprochés des ambulacres antérieurs.

Les tubercules sont uniformément répartis sur toute la surface du test. Ils ne présentent aucune disposition régulière; ceux des aires ambulacraires ne diffèrent en rien de ceux des aires interambulacraires; seulement ceux de la face inférieure sont plus serrés et en général un peu plus développés que ceux de la face supérieure.

Quant à la forme générale, elle varie plus ou moins, suivant les espèces, mais toutefois dans des limites restreintes qui, jointes à la direction des ambulacres, constituent la physionomie des Dysaster. Quelques espèces sont très-déprimées, d’autres sont renflées; les unes sont tronquées en arrière, les autres pointues, les autres arrondies. La face inférieure est plus ou moins ondulée, suivant que les ambulacres sont logés dans des sillons plus ou moins profonds; mais une particularité qui se retrouve dans toutes les espèces, mème dans celles dont la face inférieure est le plus uniforme, et qui semble rappeler le type des Spatangues, c'est que l'aire interambulacraire est toujours plus renflée que le reste du test. Le sillon de l'ambulacre antérieur n'est pas seulement borné à la face inférieure; dans beaucoup d'espèces, il est encore très-marqué à la face supérieure et fait paraitre le côté antérieur bilobé.

Le nombre des espèces connues jusqu'à ce jour est de vingt; dans ce nombre il y en a plusieurs qui se trouvent en très-grande quantité dans certains terrains, et ordinairement par ni- 
chées de six, dix, vingt individus et mème davantage; d'on il résulte que ces animaux vivaient en sociélé. Jusquici toutes les espèces, à l'exception de trois, sont de l’époque jurassique, ensorte que l'on peut envisager, à bon droit, les Dysaster comme caractéristiques de cette formation. Les marnes à Ostrea acuminata (étage de l'oolite inférieure dans le Jura suisse et français), l'oxfordien et plus particulièrement le terıin à clıailles en ont fourni jusqu’à présent le plus grand nombre. Le $D$. oculum se trouve dans le néocomien, le $D$. excentricus et le D. Munsteri dans la craie. Les dépòts tertiaires n’en contiennent aucune trace.

\section{Dysaster bicondatus $\mathrm{Ag}$.}

Tab. 2, fig. 1-4.

Srr. Dysaster bicordatus Agr. Catal. syst. Ectyp. Suppl.

Ananehytes bieordatus Lam. III. p. 317 (excl. synt.).- E. Desl. Enc. T. 2, P. 162.

Spatangites ovalis Leske, p. 253 , Tab. 41, fig. 5 .

Collyrites elliptica DesMoul. Tabl. syn. p. 364.

D'Annone in Miner. Belus. T. 3, p. 161, Tab. 4, fig. 1, 2, 3.

Knorr. II , p. $15^{2}$, Tab. E. III, $11^{\circ} 6$.

Van Phelsum p. 32, sp. 3 (Egelschuitje twee top).

Il est peu d'espèces dont la synonymie soit aussi embrouillée que celle du $D$. bicordatus. Nous trourons le nom de bicordants dans la plupart des auteurs modernes, et presque toujours appliqué à une espèce diffẻrente, ou associé à d'autres synonymes. Leske donna d'alord le nom de Spatangites bicordatus à un moule des environs de St-Jacques, sur les bords de la Birse, moule qui, si les ambulacres sont exacts, n'est autre close que notre Dysaster propinquus. Lamarck reporta cette espèce dans son genre Ananchyte avec la plupart des autres Dysaster; mais l'on ne comprend pas comment Goldfuss a pu figurer sous le nom de bicordatus, en citant la figure de Leske, un Oursin si complètement différent de celui de cet auteur. C'est une espèce particulière que nous décrirons plus bas, sous le nom de $D$. Münsteri. M. Agassiz, lorsqu'il publia sa Descr. des Ech. foss. de la Suisse, pensait encore que le Spatangus ellipticus Lam. et le Sp. bicordatus pourraient bien n'être que des variétés d'une mème espèce; mais il revint plus tard de cette opinion, et admit deux espèces distinctes dans son Catalogue des Moules d'Echinodermes.

Cependant, à cỏtẻ de son Spatangites bicordauts, Leske avait décrit et figuré, d’après Konorr, sous le nom de Spatangites ovalis, une autre espèce originaire de Muttenz, près de Bàle, et que Parkinson et Philips identifient, à tort, avec une espèce analogue du Jura moyen de Kelloway. Cette fausse identification fut cause qu'on oublia peu à peu l'original de Leske et de Knorr, et que 
l'on prit l'habitude de se représenter sous le nom de Spatangus ou Dysaster ovalis une espèce du Jura moyen. Cependant les deux espẻces sont fort distinctes, comme le fait déjả présumer la différence de leur gisement; il devenait dès lors nécessaire de les différencier. A la rigueur, le nom d'ovalis eut dû être conservé à l'espèce de Leske; mais pour éviter de nouvelles confusions, M. Agassiz préféra le garder pour l'espèce anglaise; d'un autre côté, ne voulant pas que l'ancien nom de bicordatus fùt éliminé de la nomenclature, il le douna à l'espèce que Leslie avait décrite primitivement comme Spatangites ovalis.

L'espèce que nous appelons maintenant Dysaster bicordatus est de taille moyenne et diffère par sa forme élevée, du $D$. analis, qui se trouve dans le même terrain. Le côté antérieur est surtont haut et subtronqué (fig. 2); le côté postérieur est moins élevé et moins large, mais également tronqué obliquement. L'anus s'ouvre au bord supérieur de la face postérieure, et, au dessous, se voit un sillon évasé qui s’élend jusqu'à la base (fig. 3). La face inférieure est presque plane; la bouche est située au tiers de la longueur et séparée du côté antérieur par un sillon plat. Les ambulacres antérieurs se rencontrent un peu en avaut du sommet (fig. 1); les ambulacres postérieurs viennent se joindre immédiatement au dessus de l'anus (fig. 3). Coinme les détails du test sont très-bien conservés dans plusieurs exemplaires de cette espèce, j’ai profité de celle circonstance pour en donner des figures grossies. La fig. 2 a représente une plaque de l'aire interambulacraire postérieure impaire vue à la loupe; la fig. $2 b$ représente quelques tubercules de cette mème plaque vus au microscope; la fig. $4 c$ enfin montre quelques tubercules de la face inférieure, vus au microscope; comme à l'ordinaire, ils sont plus développés que ceux de la face supérieure.

C'est une espèce particulière des marnes à Ostrea acuminata (Oolite inférieure), et, comme les seuls exenplaires que j'en connais proviennent de la même localité que Knorr et Leske assignent au leur, il ne saurait y aroir de doute sur l'identité de l'espèce.

\section{Disaster amalis Ag.}

Tab. 2, fig. 8-10.

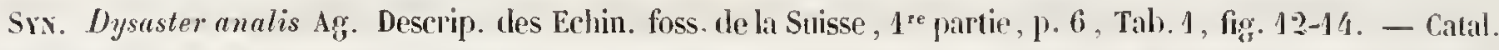
syst. Ectyp. p. 3. - Gressly, Jura soleurois, p. 76.

Collyrites analis DesHoul. Tabl. syn. p. 368 .

C'est l'espèce la plus répandue en Suisse; on la troure partout on les marnes à Ostrea acuminata sont i découvert. Sa forme est ovale, déprimée, élargie en avant, rétrécie en arrière. Le côté posté- 
rieur est tronqué. Le sillon sous-anal est à peine sensible; le sillon antérieur, correspondant à l'aire ambulacraire impaire, est un peu plus prononcé. La face inférieure est à peu près plane; car il n'y a que l’aire interambulacraire postérieure qui soit un peu plus renflée. L'ouverture bucrale est au tiers antérieur; j’ai été á même d'en examiner le pourtour, dans plusieurs exemplaires intègres, et je l'ai trouvé pentagonal (fig. 10 b) : cette forme est déterminée par la petitesse du bord correspondant aux aires interambulacraires, relativenent au bord des ambulacres. Si le bord des aires interambulacraires était un peu moins rétréci, louverture buccale serait décagonale, comme dans les Galérites et les Discoïdées; mais il est rare de rencontrer des individus dont la bouche soit intacte. L'anus est à peu près circulaire et situé au bord supérieur de la face postérieure; il est immédiatement recouvert par les ambulacres postérieurs, qui convergent en s'arquant au dessus de son bord supérieur. Les ambulacres antérieurs se rencontrent en avant du sommet et laissent par conséquent un espace très-grand aux aires interambulacraires postẻrieures paires; aussi, leurs plaques sont-elles beaucoup plus longues que celles des aires interambulacraires antérieures. La fig. $\mathbf{S}$ a représente une de ces plaques vue à la loupe, afin de montrer la disposition des tubercules. La fig. $\$$ b est un tubercule isolé, vu au microscope; comme tous les tubercules de Dysaster, il est mameloné, perforé et pourvu d'une collerette de plis très-accusés á la base du mamelon. Les tubercules miliaires qui les entourent sont également mamelonés. Les tubercules des aires ambulacraires ne diffèrent en rien de ceux des aires interambulacraires. La fig. 9 a représente l'ambulacre antérieur gauche vu à la loupe, montrant l'articulation des plaques et la disposition des pores qui sont invariablement situés à la base de ces derniers.

L'appareil génital est rarement conservé; il se compose de quatre pores formant entre eux un carré rhomboïdal. Deux sont en arant et deux en arrière des ambulacres antérieurs.

Le $D$. analis, ainsi délerminé, peut être envisagé comme l'un des fossiles les plus caractéristiques de cette couche de l'oolite inférieure que les géologues suisses appellent marnes à Ostrę acuminata. On le trouve ordinairement par nichées de quatre, huit, dix exemplaires et davantage, ce qui fait supposer que ces animaux vivaient en groupe. C'est la mème couche qui contient aussi le Discoidea depressa, le Dysaster ringens et le Dysaster bicordatus : ces deux derniers sont cependant moins fréquens. 


\section{Dysaster ellipticts Ag.}

Tah. 2, fig. 5-7.

Syn. Dysaster ellipticus Ag. Prodr. p. 16. - Catal. syst. Ectyp. p. 3.

Ananehytes elliptica Lam. III, p. 318. (exclud. syn.) - E. Desl. Enc. T. \&, p. 63.

Collyrites elliptica DesMloul. Tabl. syn. p. 364.

Lamarck a donné ce nom à une espèce très-voisine des $D$. analis et bicordatus, mais cependant différente de l'une et de l’autre. Elle est déprimée comme le $D$. analis, mais avec cette différence, que le côté antérieur, au lieu d'être ẻlargi, est, au contraire, un peu rẻtréci. Les ambulacres antérieurs remontent aussi plus haut et, de plus, il existe un espace libre entre les ambulacres postėrieurs et l'ouverture anale, ensorte que les aires interambulacraires postèrieures paires occupant l'espace entre les deux sommets ambulacraires sont moins larges que dans l'espèce précédente. C'est là à mon avis, le caractère essentiel du D. ellipticus. Le bord postérieur est arrondi, et c'est à peine si l'on y remarque une légère trace du sillon sous-anal. L'échaucrure antèrieure, correspondant à l'aire interambulacraire impaire, n'est que faiblement indiquée. Les ambulacres pairs antérieurs forment une courbe gracieuse en se rencontrant près du somnet (fig. 5). La fig. 5 a représente l'aire ambulacraire antérieure gaucle, vue á la loupe; or comme il n'y a jamais à la face supérieure qu'une paire de pores par plaque, et que les plaques diminuent de hauteur en approchant du sommet, il en résulte que les pores paraissent plus rapprochés en laut que sur la circonférence. La face infériẹre ne présente aucun caractẻre particulier; elle est à-peu-près plane comme daus le $D$. analis, et l'ouverture buccale est situẻe au tiers antérieur.

J'ai sous les yeux plusieurs exemplaires de celte espéce, provenant du département de la Sarthe; ce sont évidemmeut des fossiles jurassiques; mais jignore quel est l'étage dont il proviennent. L'exemplaire figuré fait partie de la collection de M. Michelin. 
IV. Drsisten Excextructs Des.

Tal. 4, fig. 1-3.

Srx. Nucleolites excentricus Münst. (dans Goldfuss Petref. p. 140 Tib. 49, fig. 7.)

Catopygus excentricus Ag. Prodr. p. 18.

Le D. excentricus, décrit et fignré par le comte de Münster, sous le nom de Nucleolites excentricus, a tout-ì-fait l'apparence d'un Dysaster jurassique, et cependant il provient, d'après l'indication de cet auteur, de la craie marneuse d'Essen, sur la Rohr. Par sa forme générale, il se rapproche le plus des $D$. bicordatus et ellipticus, et a même été confondu par les auteurs arec ce dernier, décrit ci-dessus. Il est, comme le D. bicordatus, court et large ; ses ambulacres postérieurs sont trẻs-arqués et se rencontrent immédiatement au dessus de l'anus; ses ambulacres antérieurs ne s’élèvent pas tout-ì-fait jusqu’au milieu du test, ensorte que les aires interambulacraires postérieures paires, comprises entre les deux sommets ambulacraires, sont trẻs-larges. Mais ce qui distingue notre $D$. excentricus de l'espèce que nous venons de mentionner, c'est sa forme bien moins ẻlevée; car, bien qu'il soit très-court, sa hautcur n’égale guère plus de la moitié de sa longneur, et le còté antérieur, au lieu d'être tronqué brusquement, est, au contraire, très-graduellement arrondi; l’anus est au hord supérieur de la face postérieure; le sillon sons-anal est large et très-évasé; la face inférieure est plane; la bouche est au liers antérieur; le sillon qui occupe l'espace entre cette ouverture et le bord est très-peu marqué; enfin, le test est très-mince comme dans tous les Dysaster; les tubercules et les pores des ambulacres n'offrent rien de particulier; la fig. 2 a représente quelques tubercules vus à la loupe. Ce grossissement est trop faible pour faire distinguer la perforation des tubercules; mais on peut s'assurer qu’ils sont réellement perforés, en examinant un tubercule au microscope.

M. le comte de Münster a eu l'obligeance de communiquer à M. Agassiz l'original de cette figure, ensorte que c’est le même individu qui est figuré lans les deux ouvrages. 


\section{Disaster propiveues Ag.}

Tab. 3, fig. 21-26.

SrN. Dysuster propinquus Agg. Descript. des Echin. foss. de la Suisse, the partie, P. 2, Tab. 1, fig. 1-3. Catal. syst. Ectyp.p. 3.

Spatangites bicordatus Leske p. 244, Tab. 47, fig. 6.

Andrea Litt. Helv. p. 16 , Tab. II, fig. $c$.

Cette espèce a tout-à-fait l'apparence extérieure du $D$. anulis, et c'est pour cette raison qu'en la décrivant pour la première fois dans sa Description des Echinodermes fossiles de la Suisse, II. Agassiz lụi donna le nom de propinquus. Elle est, comme le $D$. analis, déprimée et plus étroite en arrière qu'en avant; le còté postérieur est subtronqué ; la face inférieure est plus ou moins ondulée; l'aire interambulacraire impaire y est surtout renflée (fig. 25); le sillon anal est à peine indiqué; en revanclıe, le sillon antérieur est assez marqué ; l'ouverture buccale est trésrapprochée du bord antérieur, car elle est située au quart du diamètre longitudinal. Malgré cette conformité extéricure, le $D$. propinquus se distingue par un caractère essentiel, qu’il suffira de signaler pour en faire ressortir toute l'importance : les ambulacres postérieurs, au lieu de converger immédiatement au-dessus de l'anus, s’élèvent bien plus haut et ne se rencontrent qu’au tiers postérieur (fig. 24); de plus, ces ambulacres sont beaucoup plus larges que dans les espèces ci-dessus décrites, et l'ambulacre gauche s’élève plus haut que l'ambulacre droit. Ce dernier caractère m'avait d'abord paru insignifiant; mais l'ayant retrouvé, plus tard, sur un nombre considerable d'exemplaires de cette espéce, je crois pouvoir l'énumérer parmi les traits particuliers de l'espece.

Le D. propinquus, très-peu connu il y a quelques années, se trouve maintenant en nombre considérable dans plusieurs collections suisses, à tel point qu'on peut l'envisager comme un fossile caractéristique de l'étage oxfordien, et plus particulièrement du terrain à clıailles ou du corallien siliceux qui en forme la partie supérieure. M. Gressly en a recueilli de nombreux exemplaires dans le terrain à chailles du Fringeli, dans le canton de Soleure; près de Liesberg, dans le Jura bernois; à Largue, dans le département du Haut-Rhin, et à Wahlen, dans le Jura soleurois. Le Musée de Bàle en possède toute une série provenant du même terrain. Enfin, M. Parandier l'a aussi trouvé dans le terrain à clıailles du Mont-de-Bregille, près de Besançon. Dans le 


\section{$-1: 3-$}

nombre, on en trouve qui ont une taille double de celui que j’ai figuré: l'on remarque aussi que les vieux exemplaires sont en général plus déprimés que les jeunes.

Nous avons dit, en décrivant le D. bicordatus, que éest très-probalılement cetle espèce que Leske appela, dans l'origine, du nom de Sparangites bicordatus.

\section{Disisteik OVALis $\mathrm{Ag}$.}

Tab. 3, fig. 21-23.

Sw. Dysuster orcelis Ay. Calal. syst. Eetyp. p. 3.

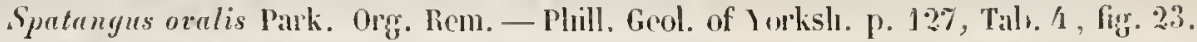

Collyrites oralis DesMoul. Tabl. s!n. p. 36 s.

Parkinson et Phillips ont décrit, sous le nom de Spatangus ovalis, une espèce de Dysaster du Calcareous grit de Scarborough, quils rapportent à tort au Spatangites ocalis de Leske, qui est, comme nous l'avous vu plus haut, notre $D$. bicordatus. La figure de Phillips n'est pas assez finie pour permettre une détermination rigoureuse, surtout lorsque, comme c'est ici le cas, les dilférences portent sur des caractẻres d'organisation en apparence imperceptibles. M. Studer ayant communiqué à M. Agassiz un exemplaire de Kelloway, provenant, selon toute apparence, du même terrain, j’ai cru pouvoir l'identifier avec l'espèce de Phillips, et c'est d'après cet exemplaire que jai fait représenter les figures ci-jointes. En comparant ces figures à celles du $D$. propinquus, on est frappé de leur tris-grande ressemblance. Les différences portent uniquement sur la forme du test; l'espèce anglaise est un peu plus renflée et plus plane à sa base. Quant aux ambulacres, ils présentent la mème disposition que nous avons décrite en traitant du $D$. propinquus, c'est-à-dire que les ambulacres postérieurs s'élèvent considérablement au dessus de l'anus , et sont en même temps très-larges. Il se pourrait done que le $D$. ovalis ne fùt qu'une variètè du D. propinquus. Mais comme je n'en possẻde encore qu'un seul exemplaire, je préfẻre attendre de plus amples informés pour me prononcer à cet égard.

L'exemplaire figuré étant très-bien conservè dans plusieurs de ses parties, j’ai pu y reconnaitre d'une manière distincte l'articulation des plaçues, non seulement dans les aires interambulacraires, mais aussi dans les aires ambulacraires. Les plaques ambulacraires sont beaucoup plus liautes i la face inférieure qu’ả la face supérieure, particuliẻrement celles des ambulacres postérieurs, et comme il n'y a qu'une paire de pores par plaque, il en résulte que ceux-ci sont beaucoup plus distans en dessous qu'en dessus. 
VII. Disaster malen Ag.

Tab. 2, fig. 11-13.

Srx. Dysaster Malum Ag̈. Catal. syst. Ectyp. p. 3.

La disposition des ambulacres nous fournit le caractère le plus important de cette espèce. Les ambulacres antérieurs atteignent à-peu-près le milieu de la longueur, et comme, de leur cótẻ, es ambulacres postérieurs s’élèvent aussi très-lıaut, il en résulte que les aires interambulacraires postérieures, ou l'espace entre les deux sommets ambulacraires, sont proportionnellement très-restreints. Cet espace n'a guère plus du quart de la longueur, tandis que, dans d'autres espèces, il équivaut presque à la moitié de la longueur. La forme générale du test est régulièrement ovoïde; la face inférieure est à-peu-près plane; le sillon antérieur est à peine indiqué; l'aire interambulacraire impaire elle-même est presque de niveau avec les autres parties du test; la bouche, située au tiers antérieur (fig. 13), est proportionnellement très-petite; l'on remarque aussi que les pores se rapprochent considérablement sur son pourtour, sans doute parce que les plaques sont moins lıautes. Il en est à-peu-près de même près du sommet, comme le montre la fig. $12 a$, qui représente la partie supérieure de l'aire ambulacraire antérieure gauche. La fig. $11 b$ représente une plaque de l'aire interambulacraire postérieure gauche, vue à la loupe : on y distingue les tubercules principaux et les tubercules miliaires, ces derniers occupant l'espace entre les tubercules principaux. La fig. $11 \mathrm{c}$, enfin, représente un tubercule isolé, vu au microscope, avec les tubercules miliaires qui l'entourent.

La principale différence qui existe entre cette espèce et le $D$. propinquus dont elle se rapproche le plus, consiste dabs la direction des ambulacres antérieurs qui s'élèvent bien plus haut. Les ambucracres postérieurs sont aussi proportionnellement plus étroits.

Je ne connais de cette espèce que le magnifique exemplaire qui est ici figuré. II fait partie de la collection de $\mathbf{1 1}$. DesHayes, et provient, selon toute apparence, du terrain jurassique de France. Son gisement ne m'est pas connu d'ume manière plus précise. 


\section{Drsasten trexcates DuBois.}

Tab. 13 des Galérites, fig. 8-11.

Srx. Dysuster truncatus Dubois. Yoy. an Cancase Sér. géol. Tab. I, fiģ. 1.

M. DuBois a figuré sous ce nom un moule de Dysaster recueilli par lui dans le terrain jurassique de Popilani, en Lithuanie. Mais comme le test est encore inconnu, il est assez difficile de l'identifier avec l'une ou l'autre des espèces mieux comnues, d'autant plus que nous ignorons ipeu-près complètement les rapports des moules avec le test dans les Dysaster. La figure que je donne ici du D. truncatus est faite d'après l'original de M. DuBois, et bien que le moule ne soit pas entier, il donne cependant une idée suffisante de sa forme générale, qui est ovale et médiocrement renflée; le côté postérieur est tronqué et l'on remarque, au dessous de l'anus qui en occupe le centre, un sillon évasé (fig. 9) ; les deux sommets ambulacraires sont rapprochés; les ambulacres eux-mêmes ne présentent rien de particulier dans leur direction; les postérieurs se rencontrent à une certaine distance au dessus de l'anus ; la face infërieure parait avoir été fortement ondulée; l'aire ambulacraire, au moins, forme un relief très-prononcé. En résumé, c'est des $D$. oralis et propinquus que ce moule se rapproclie le plus. Peut-être reconnaittra-t-on un jour, lorsque l'on aura étudié toutes les variétés d'àge de ces Oursins, que ces trois Dysaster ne forment qu'une seule espèce.

IX. Dysister gruxulosus Ag.

Tab. 3, fig. 18-20.

Sriv. Dysaster granulosus Ag. Prodr. p. 16. - Catal. syst. Ectyp. p. 3.

Collyrites granulosa DesMoul. Tabl. syn. p. 364.

Nucleolites granulosus Münst. (dans Gldf. Petr. p. 138, Tab. 43, fig. 4).

Cette espèce, décrite et figurée pour la première fois par Münster dans le grand ouvrage de Goldfuss, a une physionomie des plus caractérisées; aussi n'est-il guère possible de la confondre avec aucune de ses congénères. La troncature très-brusque du bord postérieur suffirait à elle seule pour la faire reconnaître entre tous les Dysaster. Sa forme générale est allongée et sensiblement renflée; sa face inférieure est parfaitement plane; il n'existe aucune trace d'un sillon anal, 
et même le sillon antérieur est à peine reconnaissable; les ambulacres antèrieurs n'atteignent pas le sommet; les ambulacres postérieurs se rencontrent immédiatement au dessus de l'anus; ensorte que l'espace intermédiaire est fort considérable et comprend plus du tiers de la longueur tolale. La fig. 19 a représente quelques tubercules de la face supérieure, vus au microscope, et montrant la manière dont ils sont entourés par les tubercules miliaires.

Le gisement de cette espèce n’ètait connu jusqu'ici que d’une manière vague. Goldfuss la cite dans les couches supérieures et moyennes du Jura d'Amberg, de Streitherg et de Vurgau, en Bavière. Récemment II. le comte de Mandelslohe m'en a communiqué plusieurs exemplaires provenant du corallien inférieur ou terrain à chailles des environs d'Urach, dans l'Alpe wurtembergeoise, où elle se trouve avec le Discoidea Mandelslohi. M. Gressly vient aussi de la rencontrer dans le terrain à chailles du Jura bernois, á Liesberg, dans le val de Laufon.

X. Drsister semi-globts Des.

Tab. 4, fig. 10-12.

Srx. Nucleolites semi-globus Mümst. (dans Goldf. Petref. p. 139. Tah. 49. fig. 6. )

Collyrites semi-globus DesHoul. Tilbl. syn. p. $36 \mathrm{~S}$.

Catopygus semi-globus ig. Prodr. p. is.

S'il est une espèce qui puisse faire naître l'idée d'un rapprochement entre les Spatangues et les Dysaster, c'est, à coup sùr, celle dont il est ici question. Lorsque j'ai examiné la figure qu'en a donnée Goldfuss, sous le nom de Nucleolites semi-globus, et en voyant les ambulacres convergeant vers un seul point du sommet, comme dans les Spatangues, tandis que la face inférieure n'est ni bilabiée, ni rapprochée du bord antérieur, comme cela devrait être, si c’était réellement un Spatangue, j'en étais à me demander söil ne serait pas convenable de faire de cette espèce exceptionnelle le type d'un nouveau genre; mais il mimportait pour cela de connaître l'original. M. Agassiz voulut bieu s'adresser à M. le comte de Münster, qui eut l'obligeance de le lui communiquer. Je me suis dès-lors assuré que les sommets ambulacraires, quoique très-rapprochés, sont cependant réellement distincts. Mais comme ils sont assez oblitérés près du sommet, le dessinateur les aura sans doute trop rapprochés; car, en réalité, les ambulacres antérieurs sont séparés des ambulacres postérieurs par un espace d'au moins deux à trois lignes (fig. 11). C'est donc lien réelle- 
ment à un Dysaster que nous avons í faire ici, el dès-lors la position presque centrale de l'ouverture buceale, et sa forme, que je crois anguleuse, quoique le contour en soil assez endommagé, n'ont plus rien que de très-normal.

Il est imutile de dire que éest la faible distance qui sépare les deux sommets ambulacraires qui constitue le caractère saillant de cette espèce. $\Lambda$ part cela, elle se fait encore remarquer par sa forme reuflée et semi-globuleuse qui luí a valu son nom spécifique; le côté antéricur est un peu plus large que le còté postérieur; l'anus est situé a la face postérieure el n’est pas visible d'en haut; la face inférieure est concave, et la bouche, qui est un peu excentrique en avant, paraît avoir été de grandeur moyenne. Les détails de la surface ont, pour la plupart, disparu. Le test est mince, comme on peut en juger par les lambeaux qui y sont adhérens.

II. le comte de Münster indique comme gisement le calcaire jurassique de Pappenheim ef de Monheim en Bavière.

\section{Dysasten acutus Des.}

Tab. 3, fig. 15-17.

Cette espèce tient en quelque sorte le milieu entre les espèces cordiformes, telles que les D. carinatus, capistratus, Buchii, etc, et les espèces plus elliptiques et plus aplaties, telles que les D. analis, propinquus, etc. Elle est déprimẻe et élargie en avant comme ces derniers, tandis que le côlé postérieur est pointu comme dans les premiers; le côté postérieur est sensiblement plus renflé que le côté antérieur ( fig. 16); la face inférieure est à peu près plane; le sillon antérieur est trẻs-marqué; la bouche est situče au quart antérieur; l'anus est à l'extrémité postérieure, de manière à être visible à la fois d'en has et d'en haut (fig. 15 et 17); les ambulacres antérieurs s'élèrent assez haut, ensorte que l'espace entre les deux sommets ambulacraires équivaut à peine au tiers de la longueur du test.

Je ue connais cette espèce que par un seul exemplaire qui fait partie du Musée de Neuclıatel ; son origine m'est inconnue; cependant je ne doute pas que ce ne soit un fossile jurassique. 


\section{Dysaster carisitus Ag.}

Tab. 3, fig. 1-4.

SN. Dysaster carinatus Ag. Prodr. p. 16. - Deser. Des Ech. foss. de la Suisse, p. 4, Tilb. 1, fig. 4-6. - Gatal. syst. Ectyp. p. 3. - Lam. III , p. 349.

Ananchytes carinata Lam. III, p. 318, - E. Desl. T. 2, p. 63.

Echinus carinatus L. Gm. p. 3299.

Spatangites carinatus Leske apud Klein p. 245, Tab. 51, fig. 3, 4.

Spatangus carinatus Gldf. Petref. p. 150, Tab. 16, fiğ. 4. - DeBl. Zoopl. p. 1Sä. - Bronn Letlaea, P. 286 , Tab. 1\%, fig. \%.

Collyrites carinata DesHoul. Tabl. sỹn. p. 366.

Echinus cordatus Val. Expl. des pl. de l'Encycl. métl. Tal. 158, figg. 1-2.

Echinus paradoxus Schlotl. p. 318.

Oursin en cceur Bosc. Déterv. T. 24, p. $28 \%$.

Baier Oryet. noric. Tab. 3 , fig. 43.

Valentin Mus. T. 2, Tal). 3, fịg. \%, № 1 .

On trouve eette espèce, sinon figurée et décrite, au moins mentionnée dans presque tous les auteurs, et sa forme très-earactèristique permet de la reconnaître faeilement. Elle a la forme d'un eœur de carte, e'est-à-dire qu'elle est échancrée en avant et pointue en arrière; son ¿paisseur est médioere; son nom lui vient sans doute de la présence d'une carẻue longitudinale qui s’étend sur la partie postérieure de la face supérieure, depuis le milieu du test jusqu’à l’anus; la face infériel.e est fortement pulvinée et l'aire interambulacraire impaire en particulier forme un relief très-saillant; l'ouverture buccale est siluée au quart antérieur de la longueur ; le sillon antérieur est fortement aceusẹ ; l'anus oeeupe l'extrémité du bord postérieur, de manière à n'être pas visible d'en liaut (fig. 1); les ambulacres antérieurs se rencontrent à peu près à l'opposite de la bouche, c'est-à-dire au tiers antérieur; les ambulacres postérieurs sont séparés de l'anus par un espace assez considérable (fig. 1); le plus souvent, ils sont très difficiles à reconnaitre.

C'est une espèce particulière à l'étage oxfordien, et c'est par erreur qu'elle est citée dans les Echinodermes fossiles de la Suisse, de M. Agassiz. comme appartenant au Lias. M. le comte de Mandelslohe m’en a communiqué récemment un exenplaire très-bien eonservé, provenant du corallien inférieur d'Urach, dans l'Alpe wurtembergeoise, oủ elle se trouve avec le Dysaster gramulosus et le Discoidea Mandelslohi. M. Gressly en a reeueilli plusieurs exemplaires dans le terrain à chailles de Günsberg daıs le eanton de Soleure, oủ elle parait remplacer le $D$. propinquıs. 


\section{Xill. Drsister capistratus Ag.}

Tal. 3 , fig. 12-1\%.

Srs. Dysaster capistratus Ag. Prodr. 1) 16. - Descr. des Ech. foss. de la Suisse, dre part. p. 7, Talb. 4 , fig. 1-3. - Catal. syst. Ectyp. p. 3. - Lam. III, p. 350.

Spatangus capistratus Munst. (dins Gldf. Petref. p. 151, Tab. 46, fig. 5.)

Collyrites capistrata Des.Ioul. Tilbl. syn. p. 366.

Spatangus carinatus var. $\beta$. Brom Lehhiea, p. $28 \%$.

La forme générale de cetle espéce est fort semblable à celle du $D$. carinatus; c'est-á-dire, qu’elle a le côté antérieur large et émarginé et le côté postérieur pointu. Cependant, un examen attentif nous fera bientôt connaitre les différences qui existent entre les deux espèces. Et d'abord: le D. capistratus n'a point cette carène remarquable du bord postérieur qui constitue l'un des caractères du $D$. carinatus; et par une conséquence nécessaire, l'anus, au lieu de n’ètre visible que d'en bas, ne l'est que d'en haut (fig. 13): la face inférieure n'est pas trés-accidentée, à l'exception cependant du sillon antérieur, qui est assez prononcé (fig. 14); l'aire interambulacraire postérieure n'est que légérement pulvinée; les ambulacres antérieurs s’ẻlèvent assez haut, et de même les ambulacres postérieurs; ce qui fait que l'espace intermédiaire est plus rétréci que dans beaucoup d'autres espèces, car il ne mesure guère plus du quart de la longueur totale. Les anıbulacres postérieurs ue sont pas parfaitement égaux. J'ai trouvé celui de gauche un peu plus élevé que celui de droite. La fig. 13 a représente quelques tubercules vus au microscope.

Cette espèce ne paraît pas être très-fréquente. Le Musée de Carlsrulıe en possède plusieurs exemplaires assez bien conservés, mais dont l'origine est inconnue. Tout me porte cependant á croire que c'est un fossile du Jura moyen, probablement du terrain à chailles. Münster se contente de dire que c'est un fossile jurassique.

\section{Disaster Bucrin Des.}

Tab. 3, fig. 9-11.

Cette petite espèce est voisine à la fois du $D$. carinatus et du $D$. capistratus, et l'on peut fort bien avoir des doutes sur sa valeur spécifique. Peut-être n'est-elle, en effet, que le jeune àge de l'une ou de l'autre de ces deux especces; cependant il ne faut pas perdre de vue que sa forme est plus 


\section{$-22-$}

renflée, et que le sillon antérieur est à peu près nul ; l'ouverture buccale est placée au liers antérieur: l'anus est à l'extrémité postérieure et placé de manière à n’ètre visilıle que d'en bas, comme dans le $D$. carinatus. Il existe aussi, à la partie postérieure de la face supérieure, une espèce de carène, comme dans cette dernière espèce.

L'exemplaire figuré a élé commuuiqué à M. Agassiz par M. de Buch el provient du calcaire a Nérinées de Stockach, dans le Grand Duché de Bade. Il existe dans la collection de II. de Mandelslohe plusieurs petits Dysaster fort semblables, provenant du corallien de Sirchingen, qui mont paru appartenir à la même espèce.

\section{Drsaster ovelum}

Tab. 3, fig. 5-8.

Celle espèce se distingue par une physionomie particulière, qui la fait remarquer au premier coup-d'œil entre tous les Dysaster, et qui provient essentiellement de sa forme très-renflée (fig. 6). N’ayant pu découvrir, dans l'origine, les ambulacres, j’ai élé long-temps dans le doute sur le genre auquel il conviendrait de rapporter cette espèce; car ce n'est qu'après avoir exposé un exemplaire à l'action de l'acide que j’ai réussi à mettre à jour ces organes; je me suis ainsi assuré qu'ils sont disposés comme dans les Dysaster et proportionnellement beaucoup plus larges que dans toutes les autres espèces; circonstance qui contribue sans doute à les rendre plus imperceptibles. L'espace intermédiaire entre les deux sonmets ambulacraires est très-restreint; c'est à peine s’il égale le quart de la longueur du test; le sillon antérieur n'est pas très-profond; la face inférieure est légèrement pulvinée; louverture buccale est située au quart antérieur; l'anus est a l'extrémité du bord postérienr et n'est pas visible d'en haut.

Le petil exemplaire de fig. 5,6 el 7 a été trouvé, ainsi que plusieurs autres semblables, par II. C. Nieolet dans l'élage néocomien de la vallée de la Chaux-de-Fonds. La fig. 8 représente un graml cxemplaire qui fail partie de la collection de H. DeLuc à Genève. 


\section{NVI. Drsaster Arellaxi Ag.}

Tab. 1, lig. 1-1.

Srx. Dysaster Arellana Ag. Catal. syst. Ectỵp. p. 3.

Cette petite espèce est ordinairement trẻs-renflée, ce qui lui donne l'apparence d'une noisette ; de lì son nom spécifique. Sa lıauteur égale au moins les trois quarts de sa longueur; le côté antérieur est non seulement plus élevé, mais aussi plus large que le còté postérieur; la face inférieure est plane; le côté postérieur est tronqué (fig. h), surtout lorsqu'on l'examine d'en bas; mais il n'en est pas moins pourvu d'un large sillon évasé, qui s'ètend de l'ourerture anale jusque au bord inférieur (fig. 3). Les ambulacres postérieurs se montrent immédiatement au dessus de l'anus; et, comme les ambulacres antérieurs n'atteiguent pas le milieu du test, il eı résulte que l'espace entre les ambulacres postérieurs et les ambulacres antérieurs est proportionnellement plus grand que dans aucune autre espèce, puisqu’il équivaut à la moitić de la longueur du test (fig. 1). Il en résulte, en outre, que les plaques des aires interambulacraires postẻrieures sont beaucoup plus grandes que celles des aires interambulacraires antẻrieures. Quant à l'aire iuterambulacraire impaire, comme elle est très-étroite, ses plaques sont naturellement petites. La fig. I a reprẻsente quelques tubercules vus à la loupe.

Cette espèce ne m'est encore connue que par quelques exemplaires du calcaire à polypiers de Normandie. Elle ne se trouve, à ce qu'il parait, ni dans le Jura suisse, ni dans le Jura français.

\section{Drsaster Eudesil Ag.}

\section{Tab. 1, fig. 5-12.}

Srix. Dysaster Eudesii Ag. Catal. syst. Ectỵp. p. 3.

Cette espèce semble être le représentant du $\boldsymbol{D}$. ringens dans l'oolite ferrugineuse de Normandie. Elle n'a été signalée jusqu'ici que dans le calcaire à polypiers de cette contrée; et comme c'est à II. Eudes Deslongchamps qu'en appartient la découverte, M. Agassiz l'a appelée du nom de cet infatigable géologue.

Le $D$. Eudesii a la face inférieure fortement pulvinée; les ambulacres y sont logés dans des sillons trẻs-marqués. La forme géenérale du test est allongée, ovoïde et fortement renflée 
(fig. 5, 7 et 8); mais on trouve aussi des exemplaires plus déprimés et presque circulaires, tel que celui de fig. 11 et 12 qui, pour avoir une physionomie un peu différente, n'en appartient pas moins, selon toute apparence, à la mème espèce. Un sillon assez marqué s'étend de l'anus au bord inférieur, et comme l'aire interambulacraire forme ici un coussinet très-renflé (fig. 9), le sillon n'en est que plus apparent. Les ambulacres postérieurs se rencontrent immédiatement au dessus de l'anus et sont élégamment arqués (fig. 7, 9, 11). Les ambulacres antérérieurs atteignent à peu près le milieu dı test et l'espace intermédiaire entre ces deux points équivaut à plus du liers de la longueur ( fig. 7). La fig. 7 a représente quelques tubercules de la face supérieure, entourés des tubercules miliaires. La fig. 11 a représente ces mèmes tubercules dans la variété circulaire, où ils sont un peu plus développés.

XVIII. Dysaster Rivgens Ag.

Tab. 1, fig. 13-17.

Sry. Dysuster ringens Af. Deser. des Ech. foss. de la Suisse, $1^{\text {re }}$ part. p. 5, Tab. 1, fig. 7-11. - Catal. syst. Eclyp. p. 3.

Collyrites ringens DesMoul. Tabl. syn. p. $36 \mathrm{~S}$.

Cette espèce frappe au premier coup-d'œil par l'apparence inégale et fortement pulvinée de sa face inférieure et par le renflement extraordinaire de l'aire interambulacraire impaire au dessus de l'anus (fig. 1't et 15). Sa forme est subcirculaire; car la différence de largeur entre le còté postérieur et le côté antérieur n’est que très-peu sensible; son épaisseur est peu considérable, surtout si l'on fait abstraction des inégalités de la face infërieure; peut-être mème est-ce l’espèce la plus plate de tout le genre. La face supérieure est très-uniformément arrondie ; les ambulacres antérieurs se rencontrent en général sur le milieu de la longueur; les ambulacres postérieurs recouvrent immédiatement l'anus (fig. 13, 15); les premiers sont proportionnellement très-étroits, et n'y eùt-il que ce caractère, il suffirait pour distinguer cette espèce de la variété circulaire du D. Eudesii; les ambulacres postérieurs sont plus larges. J'ai pu observer les pores génitaux dans plusieurs exemplaires, et je les ai toujours trouvés disposés de la même manière, c'est-à-dire au nombre de quatre, dont deux en avant et deux en arrière des ambulacres antérieurs, et formant entre eux un rhombe plus ou moins régulier (fig. 13). La fig. 13 a montre la disposition des tubercules vus à la loupe. Les tubercules principaux y sont nombreux el entourés d'une quantité de tubercules miliaires. 
Cette espèce est assez fréquente dans l'oolite infẻrieure (marne à Ostrea acuminata du Jura suisse), où on la trouve en société du Dysaster analis et du Discoidea depressa. Les exemplaires figurés ont été recueillis par M. Gressly, à Goldentlıal, dans le Jura soleurois.

\section{Xix. Drsister voltziI Ag.}

Tab. 1, fig. 1S-21.

Srx Dysaster Ioltzii Ag. Deser. des Ech. foss. de la Suisse. 1'e part. p. 8, Tab. 4, fig. 11-13.

On distingue aisément cette espèce ì sa forme circulaire. Sa face supérieure est uniformément bombée et, sous ce rapport, elle a la plus grande ressemblance avec le $D$. ringens; mais sa face inférieure est loin d’ètre aussi accidentée; à l'exception du rostre postérieur, elle est même à peu près plane. L'ouverture buccale est presque centrale, ce qui n’a lieu dans aucune autre espèce; les ambulacres antérieurs s'élèvent jusqu'au milieu de la face supérieure; les postérieurs recouvrent l'anus; les uns et les autres, très-êtroits à la face supérieure, s’élargissent considérablement à la face inférieure (fig. 21), et j’ai même pu m’assurer, par l'exemplaire figuré, que les pores, en approchant de l'ouverture buccale, se multiplient considérablement, à peu près comme dans beaucoup de Cidarides. Les tubercules ne présentent rien de particulier, ni dans leur structure, ni dans leur disposition (fig. 19a). C'est à feu M. Voltz qu'est due la découverte de cette espèce. Elle n'a été signalée jusqu'à présent que dans l'oxfordien des Voirons, près de Genève. Parmi les exemplaires que jai sous les yeux, il s'en trouve un qui a trois pouces et demi de diamètre, c'est-à-dire le double de la longueur de l'exemplaire figuré.

\section{Drsaster Mussteri Des.}

Tab. 4, fig. 4-7.

Srx. Spatangus bicordatus Goldf. Petref. p. 151, Tab. 46, fig. 6.

L'espèce dont il s'agit ici porte, dans Goldfuss, le nom de Spatangus bicordatus; mais nous avons déjà eu loccasion de faire observer qu’elle ne ressemble en rien au Spatangites bicordatus de Leske. En conséquence, nous arons dù changer le nom spécifique; et pour qu'elle ne fùt plus confondue arec le Dysaster bicordatus d'Agassiz, qui est de l'oolite inférieure, nous l'avons appelée D. Munsteri, du nom du célèbre et infatigable palćontologiste qui l'a découverte le prenier. 
Le $D$. Munsteri est l'espèce la micux caractérisée de tout le genre; elle ne ressemble en rien à toutes les espèces que nous avons décrites jusquiici : et d'abord, elle est à-peu-près aussi haute que longue; tandis que, dans aucun des autres Dysaster, le diamètre vertical n'excède les deux tiers du diamètre longitudinal: son bord antérieur est tronqué presque verticalement, et représente un triangle presque rectangle, au milieu duquel est creusé le sillon antéricur, qui est surtout profond près du bord inférieur : la face supérieure est comprimée et se termine en toit; le còté postérieur est beaucoup plus étroit que le côté antérieur. L'anus est situé au sommet de la face postérieure, mais recouvert par la carène dorsale, de manière à n'être pas visible d'en lauut (fig. 6) ; le sillon sous-anal est profond, et, en passant à la face inférieure, il détermine deux petiles protubérances marginales. A la face infêrieure, l'aire interambulacraire est fortement renflée, surtout en arrière (fig. 7); l'ouverture buccale est très-rapprochée du bord antérieur.

Les ambulacres antéricurs sont plus éloignés du milieu du test que dans aucune autre espèce ; et comme les ambulacres postérieurs recouvrent presque immédiatement l'anus, il en résulte que les aires interambulacraires postérieures paires qui occupent l'espace entre les deux sommets ambulacraires sont aussi beaucoup plus larges que celles d'aucun autre Dysaster.

Cette espèce parait être d'origine crélacée, d'après l'indication de M. le comte de Mïnnster. L'exemplaire figuré, qui est l'original même de Mlïnster, provient du Mecklenbourg. 


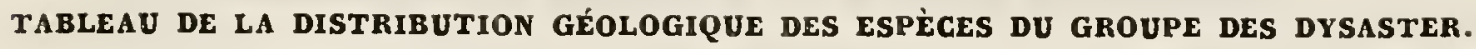

1. Esptécs de l’ípoQue jurassiQue.

i) Etage inférieur.

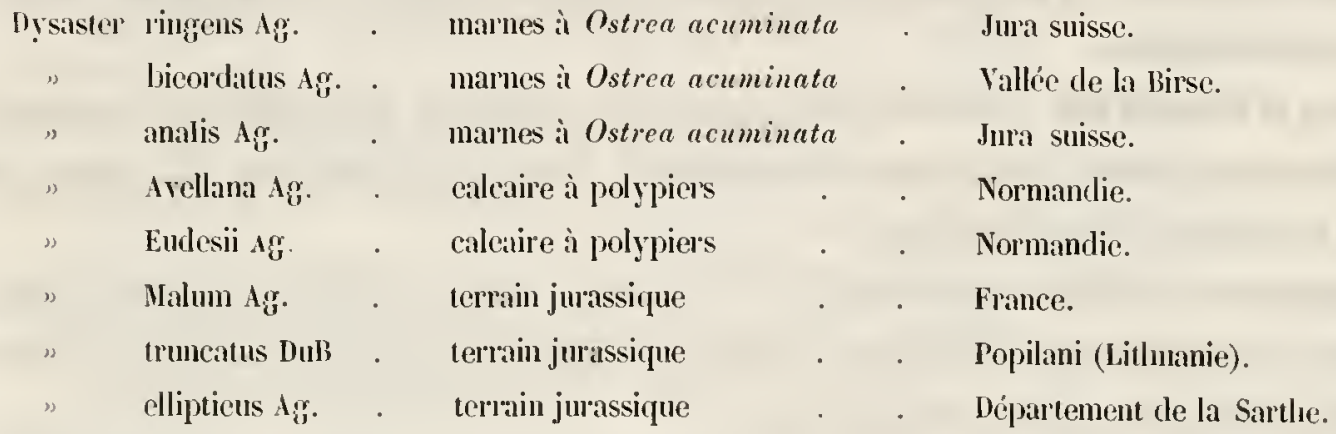

b) Etage moyen.

Dysaster Voltzii Af. carimatus A: propincpus $A \&$. gramulosus A $g$. eapistratus $A g r$. ovalis $A g$. acutus Des

c) Etage supérieur.

Dysaster Buchii Ar. semi-grlolus Des.

Dyssaster Münsteri Des. . excentricus Des. ovulum Des. oxfordien

oxfordien, terrain à chailles

terrain à clailles

terrain ì chailles

Jura moyen

ealcarcous grit

terrain jurassique

Jura supérieur ealcaire jurassique
Stockaclı (eant. de Scliafl'house).

Voirons près de Genc̀ve.

Giinslverg. (Jura soleurois).

(Liesberg (Jura Bernois), Fringeli, Walılen, (cant. de Soleure), Lillgute (départ. du Haut-Rhin), Besancon.

Urach (Wurtemberg).

Jura suisse.

Semborougylı, Kelloway.

Pappenleim et Monlıeim (Bavièrs).

\section{EsPĖCES DE L'ÉPOQUE CRÉTACE̊E.}

craie marneuse

eraie marneuse

nćocomien
Mecklembourg.

Essen sur la Roclir.

La Cliaux-dle-Fonds. 


\section{CONSPECTUS GENERUM ET SPECIERUM DYSASTERORUM.}

\section{Characteres gevtis Dysasterondy e famila Clypeastroideorum.}

Ambulacra simplicia, ad peripheriam divergentia, in vertice disjuncta, tria in summo vertice, duo postice convergentia.

Genus DYSASTER. Ambulacra disjuncta; ambitus ellipticus, subcordiformis ; os angulosum, obsolete decagonum, plus minusve excentricum; anus posticus ; tubercula non seriata, sel perforata et crenulata; testa tenuissina.

1. Dysaster bicordatus Ag. (Tab. 2, fig. 1-4). D. inflatus, antice subtruncatus, postice depressus, obtusus; ambitu ovato; basi plana; ambulacris anticis non ad verticem usque porrectis ; ambulacris posticis arcuatis, ano incumbentibus.

2. Dysastcr analis Ag. (Tab. 2, fig. 8-10). D. depressus, antice dilatatus, postice angustatus, subtruncatus; ambitu ovato ; basi plana; anbulacris posticis ano incumbentibus, al anterioribus maxime recedentibus.

3. Dysaster ellipticus Ag. (Tab. 2, fig. 5-7). D. subinflatus antice depressus, postice obtusus; ambitu ovato; basi plana; ambulacris posticis supra anum convergentibus, anticis in summo vertice conjunctis.

4. Dysaster cxcentricus Des. (Tab. 4, fig. 1-3). D. depressus, postice oblique truncatus; anbitu subquadrato; basi plana; ore à margine remoto; ambulacris posticis ano incumbentibus.

5. Dysaster propinquus $\Lambda_{\text {g. }}$. (Tab. 3, fig. 2\%-26). D. subinflatus vel depressus, antice truncatus, emarginatus; ambitu ovato; basi undulata, ad anum tumida; ambulacris posticis rectis, ah ano remotis.

6. Dysaster ovalis $\mathrm{Ag}$. (Tab. 3, fig. 24-26). D. inflatus, antice subtruncatus; ambitu ovato; basi undulata ; ore excentrico ; ambulacris posticis angustis, rectis, ab ano remotis.

7. Dysaster Malum Ag. (Tab. 2, fig. 11-13). D. inflatus; ambitu ovato; basi plana ; ore parvo; ambulacris anticis summum verticem adtingentibus; ambulacris posticis rectis, ab ano remotis.

8. Dysaster truncalus DuBois (Tab. 13 Galeritarum fig. 8-11). D. inflatus, elongatus, postice Iruncatus; basi undulata, ad anum tumida; ambulacris posticis rectis, ab ano remotis. Nucleus. 
9. Dysaster gramulosus $\mathrm{Mg}$. (Tab. 3, fig. 18-20). D. inflatus, elongatus, antice rotundatus, postice truncatus, quadratus; ambulacris posticis arcuatis, ano incumbentibus.

10. Dysaster semi-globus Des. (Tab. 4, fig. 10-12). D. inllatus, subhemisphaericus; ambitu ovato ; basi plana ; ore subcentrali ; ambulacris posticis rectis, ab ano remotissimis, sed ambulacris anterioribus proxinis.

11. Dysaster aeutus Des. (Tab. 3, fig. 15-17). D. inllatus, antice subdepressus, submarginatus, postice tumidus, subovatus; basi undulata; ambulacris posticis angustis, al ano remotis.

12. Dysaster carinaus Ag. (Tab. 3, fig. 4-1). D. cordatus, inllatus, postice acuminatus, superne carinatus; basi undulata; ambulacris posticis arcuatis, ab ano remotis.

13. Dysaster capistratus Ag. (Tab. 3, fig. 12-14). D. inflatus, elongatus, antice subtruncatus, emarginatus, postice acuminatus; (basi undulata; ambulacris posticis latis, rectis, al ano remotis.

17. Dysaster Buehii Des. (Tab. 3, fig. 9-11). D. inflatus, altus, cordatus, antice truncatus, submarginatus, postice coarctatus, acutus; superne rotundatus; ambulacris posticis rectis ; basi undulata.

15. Dysaster ocuhum Des. (Tab. 3, fig. 5-7). D. altus, tumidus, rotundato-ovatus, antice subemarginatus, postice subrostratus; ambitu cordato; basi undulata; ambulacris posticis latis, rectis, al ano remotis, subinconspicuis.

16. Dysaster Avellana Ag. (Tab. 1, fig. 1-4). D. inflatus, postice subtruncatus, subdepressus ; ambitu suborbiculari; ambulacris anticis summum verticem non adtingentilus, posticis ano incumbentibus; basi subplana.

17. Dysaster Eudesii Ag. (Tab. 1, fig. 5-12). D. inflatus, ovatus; basi valde undulata, sulcata, area postice tumida, sulco infraanali amplo; ambulacris anticis ad verticem summum porrectis, posticis arcuatis, ano incumbentibus : variat ambitu ovato, vel orbiculari.

18. Dysaster ringens Ag. (Tab. 1, fig. 13-17). D. depressus, superne sulbrotundatus, ambitu suborl,iculari; basi maxime undulata, sulcata area; postica tumida, subcarinata; ore sulmedio, poris creberrimis cincto; sulco infraanali amplo; ambulacris anticis angustis, ad summum verticem porrectis; posticis arcuatis ano incumbentibus.

19. Dysaster Voltzi Ag. (Tab. 1, fig. 18-21). D. depressus, superne subrotundatus ; ambitu orbiculari ; basi subplana, area postica tumida ; ore submedio, poris creberrimis circumdata ; ambulacris posticis ano arcuatis incumbentibus.

20. Dysaster Münsteri Des. (Tab, 4, fig. 4-7). altissimus, subcarinatus, antice et postice truncatus et utrumque sulcatus, lateraliter declivus ; basi umdulata, ad posticum marginem tumida ; ore antico, inframarginali; ano altissimo; ambulacris anterioribus anticis, posterioribus supra anum convergentibus, inde ab anteriorilus remotissimis. 



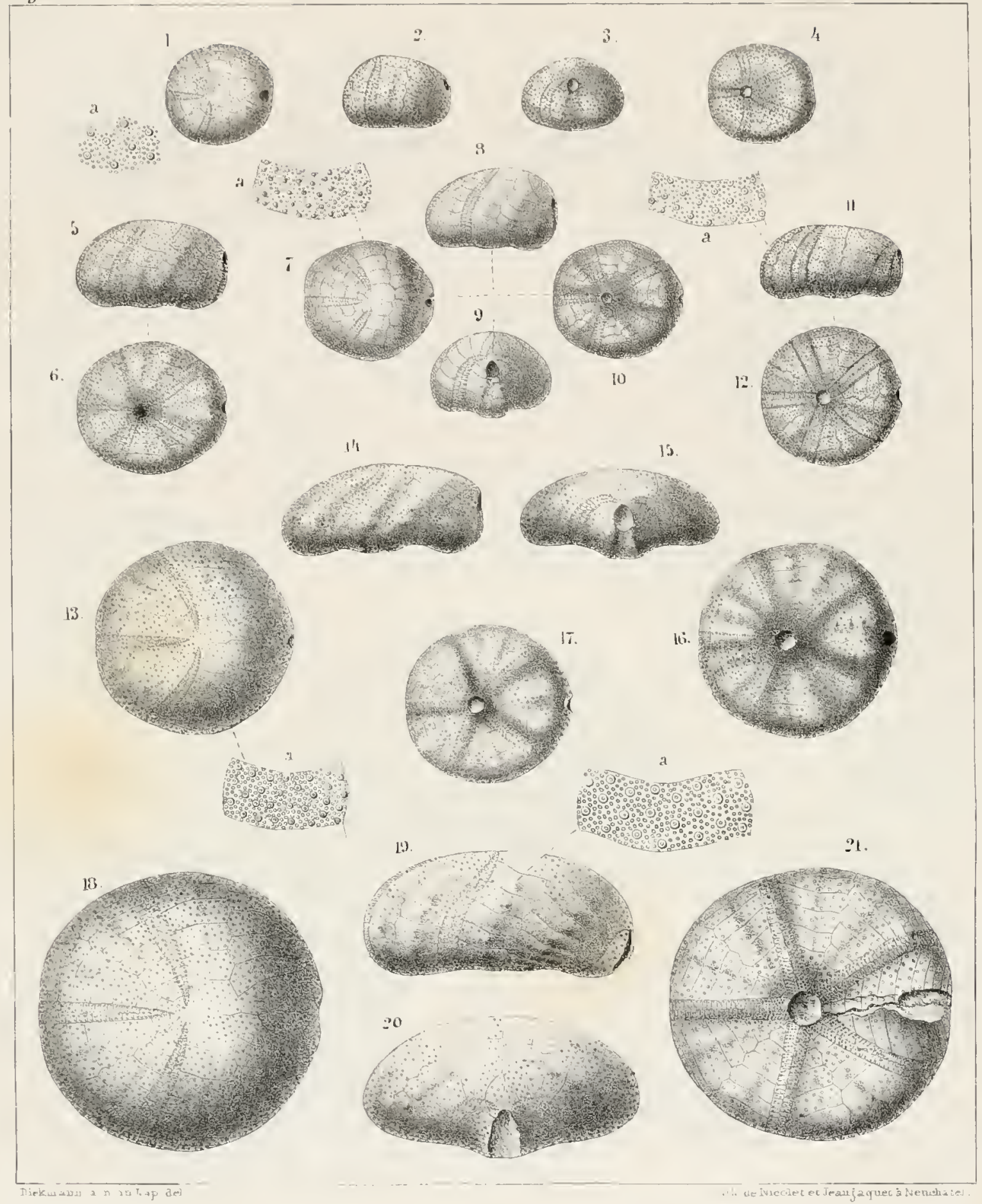

- Fiv-4.

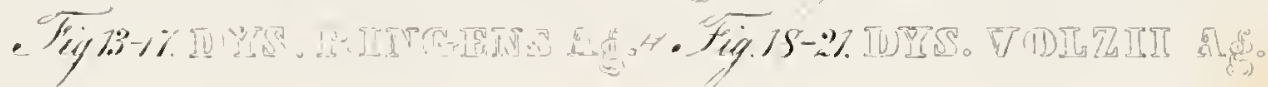





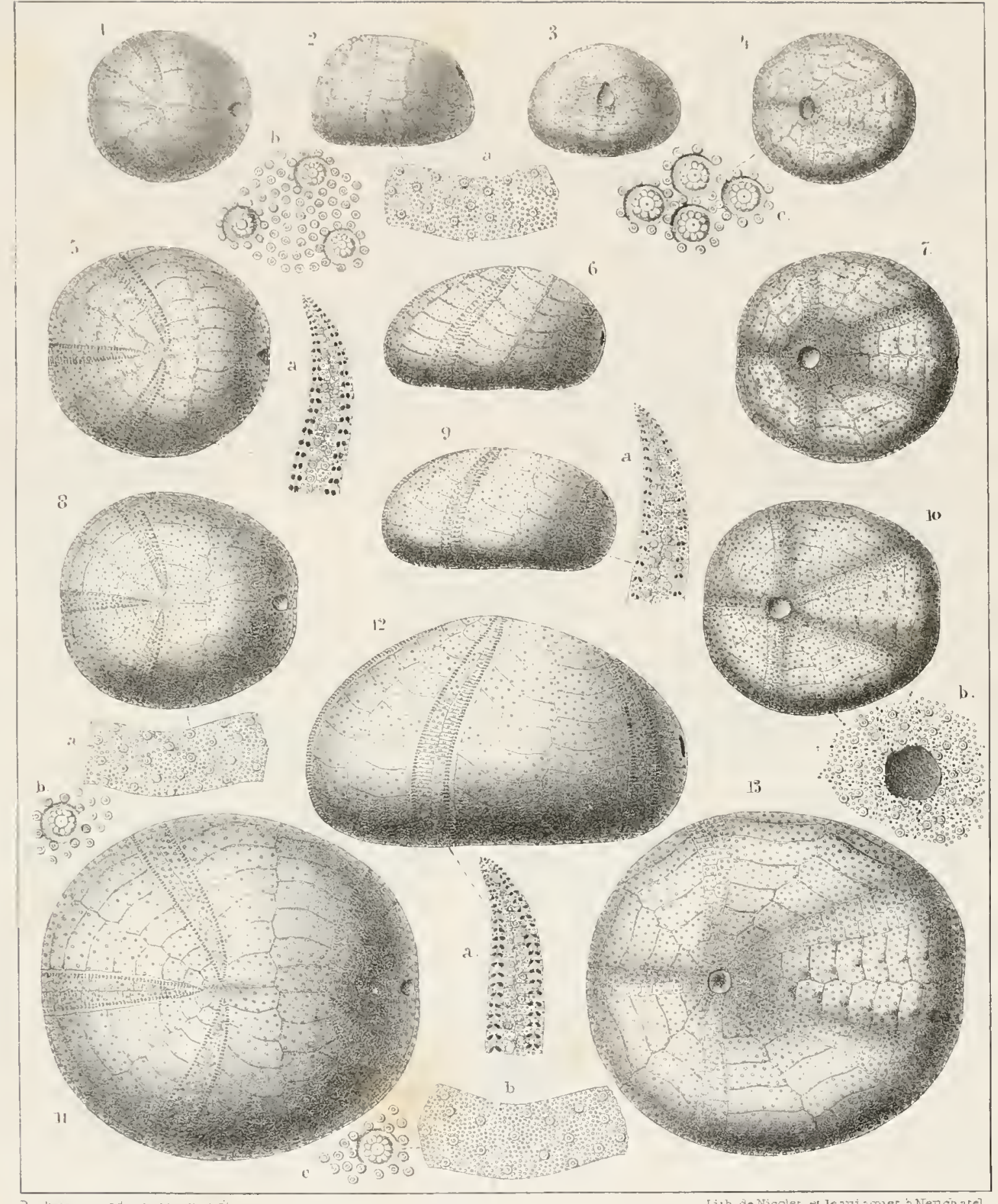

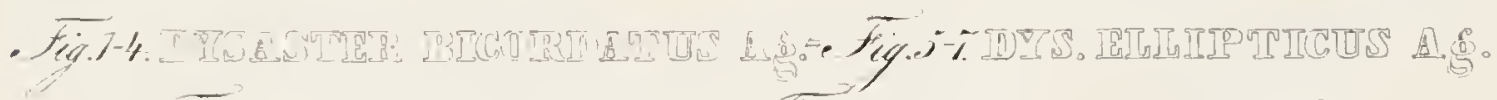

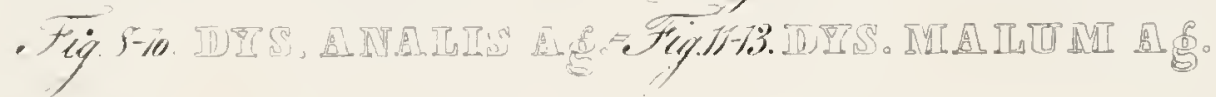





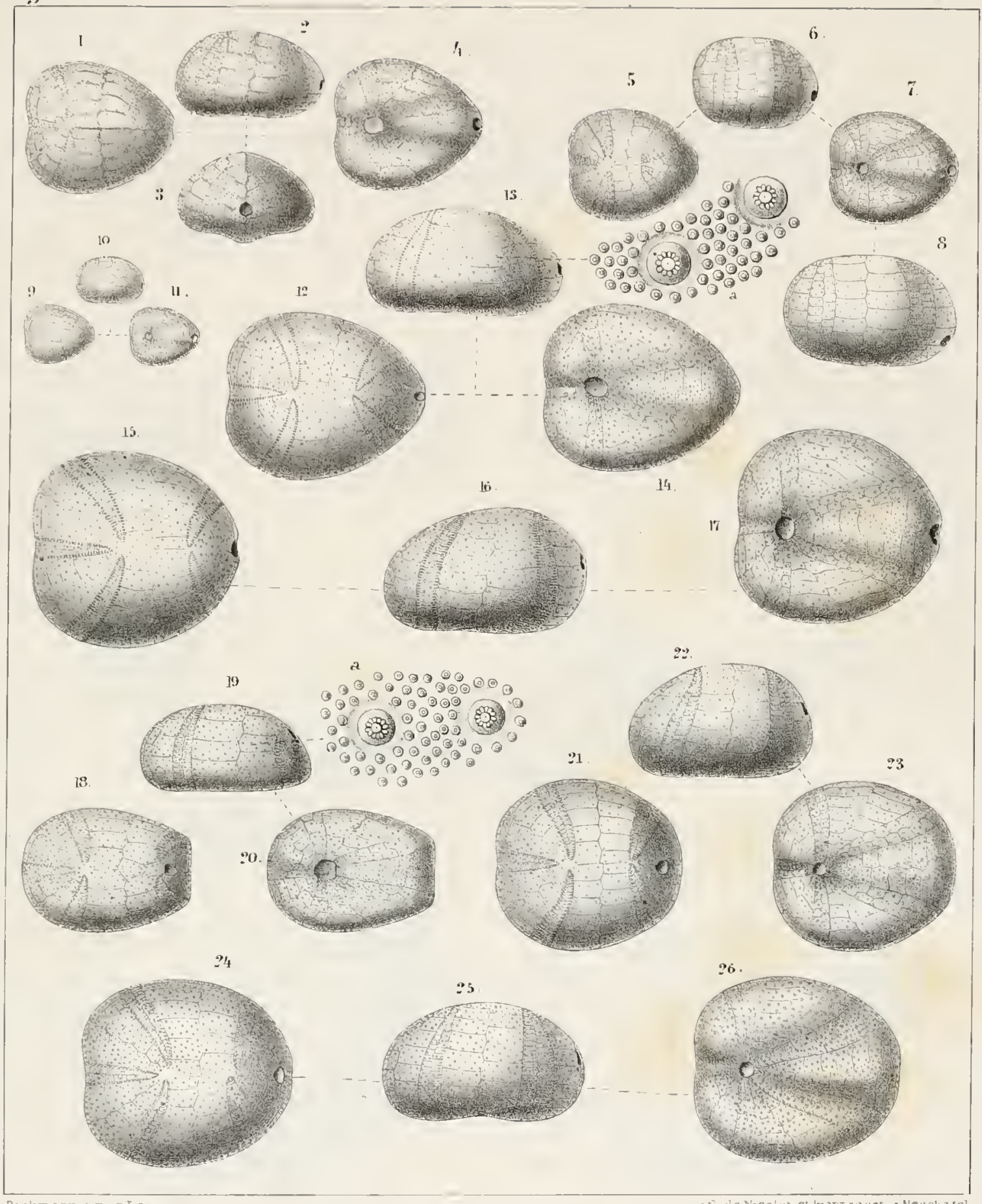

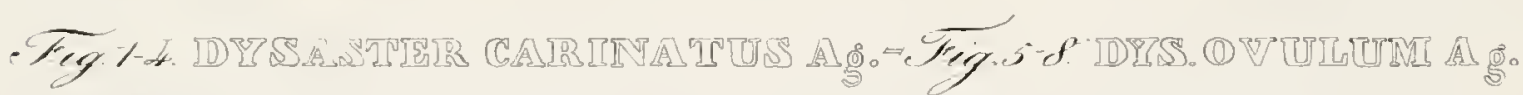

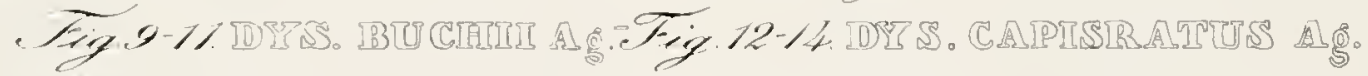

CFif

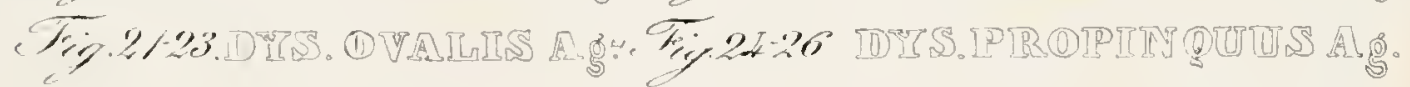





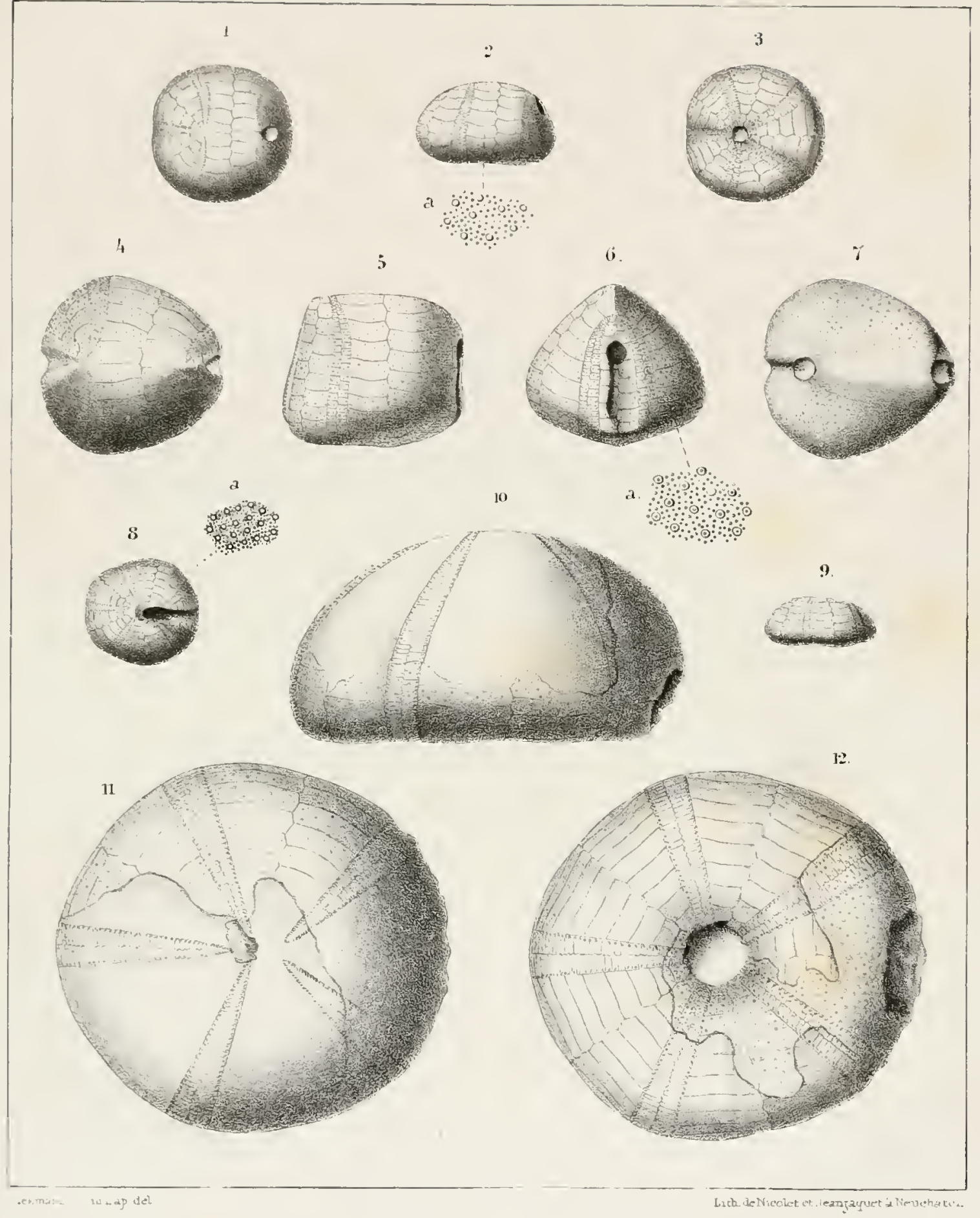

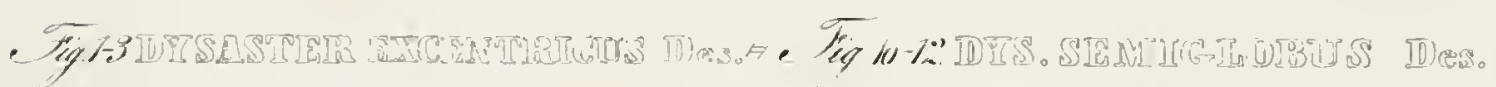

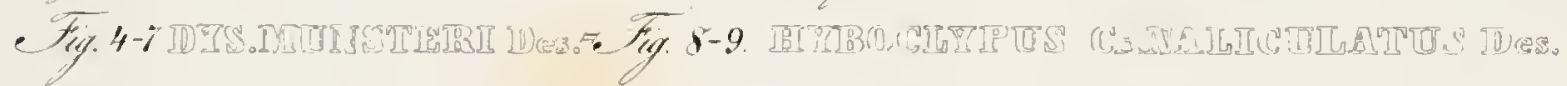





\section{MONOGRAPHIES}

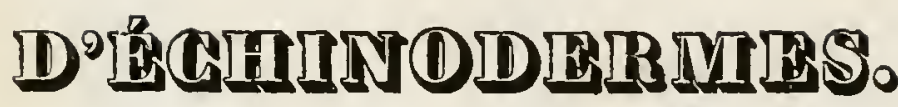





\section{ANATOMIE}

DES RCIIIYODERIIIS.

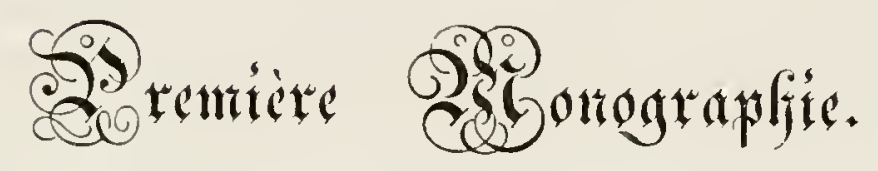

ANATOMIE DU GENRE ECHINUS.

PAR

G。 VALENTIII。

1841. 


\section{PRÉTCE.}

Lorsque j'ai entrepris la révision de la elasse des Eehinodermes, j’ai bicutôt senti que ce travail ne serait eomplet qu'autant qu'il embrasserait, dans un mème eadre, l'histoire naturelle des espèees vivantes et des fossiles et l'anatomie détaillée des principaux types de la classe. Mais ne pouvant espérer de remplir seul une tàche aussi diflieile, j'ai prié mon ami, M. le professeur Valentin, de bien vouloir se elıarger de cette dernière partie du travail. C'est la première de ses monographies anatomiques que je publie aujourd'hui. Il ne m'appartient pas de porter un jugement sur l'nuvre d'un auteur que ses travaux ont plaeé si haut parmi les anatomistes et les physiologistes de notre époque. Je me permettrai seulement de faire préeéder eette deseription anatomique du genre Eehinus de quelques observations sur les rapports génériques qui existent entre les espèees que M. Valentin a examinées, et les nombreuses espèees qui eonstituent le vaste genre Echinus des auteurs. Déjà Klein et Lamarek en ont séparé le genre Cidaris; plus tard, Gray a eneore distingué génériquement les Diadenua, les Astropyga, les Arbacia et les Salenia, et réintégré le genre Echinometra de Breynius. Dans ma description des Eehinodermes fossiles de la Suisse, et dans mon catalogue des moules d'Oursins fossiles du Musée de Neuchàtel, j'ai eneore établi plusieurs gences nouveaux, soit pour des espèees déjà eonnues, mais mal assoeiées, soit pour des types nouveaux qui auraient dù rentrer tous dans l'aneien genre Lehinus, tel que Lamarck le circonscrirait eneore, si on avait pu le conserver. Ce sont mes genres Hennicidaris, Acrocidaris, Acrosalenia, Tetragramma, Pedina, Echinopsis, Cyphosonua, Peltastes, Gouiophorus, Goniopygus, Acropeltis, Caloplenurus, Codiopsis et Glypticus. Cette multiplication des genres ne samait surprendre 
quand on saura qu'en les étallissant, j'ai basé mes distinctions sur un nombre d'espèces quadruple de celles qui sont mentionnées par les auteurs.Cependant, malgré toutes ces restrictions, le genre Echinus comprenait encore, parmi les espèces vivantes, sur lesquelles je n'ai point puhlié mes observations jusqu'à ce jour, des types assez différens pour que j’aie cru pouvoir le subdiviser de nouveau et ne conserver dans le genre Echinus proprement dit que les espèces voisines de l'Echiunus esculeutus, et qui ont, comme lui, les ambulacres formés de plusieurs séries arquées de pores disposés par paires.

C'est an genre Echinus, circonscrit dans ses limites les plus étroites, qu'il faut rapporter les quatre espèces mentionnées dans le travail de M. Valentin; il paraît même que toutes les espèces européennes appartiennent à ce genre. Je ne remarque, dı moins, aucune différence d'organisation importante entre celles que je connais, ni dans les parties solides du test, ni dans la structure des organes intérieurs, comme le montre le travail de M. Valentin.

La connaissance exacte des espèces est trop importante, lorsqu'il s'agit de vérifier les travaux des anatomistes, pour que je ne doive pas entrer dans quelques détails sur la synonymie de celles de nos côtes $\left(^{*}\right)$. Ces espèces sont :

1. Echinus sphera Müller. Zool. dan. Prod. Cette espèce ne parait se rencontrer que dans les mers du Nord de l'Europe où elle remplace l'Echinus esculentus de la Méditerranée qui n'existe pas dans le Nord. J'ignore cependant quelle est la limite exacte des deux espèces, el si l'Echimus Splıcera se trouve dans la Manche; mais ce que je puis affirmer positivement, c'est que l'Echinus globiforuis de Lamarck est synonyme de l'Echinus Sphreca de Müller, et qu'il faut par conséquent supprimer le nom de Lamarck. L'Echiuus au'anticus de BI., à peine différent de l'Echiuus globiforınis, doit aussi ètre rapporté à cette espèce. Enfin l'Echinus unariuus de Martin Lister, et l'Echinus esculeutus de Linné, ( $12^{\mathrm{me}}$ édition du Syst. nat.) de Pennant et de Fleming sont encore la même espèce. Un exemplaire original que je dois à l'obligeance de M. Fleming luimème ne me laisse aucun doute à ce sujet. Parmi les auteurs modernes, M. Ed. Forbes a été le premier à faire revivre les droits de l'espèce de Müller dans son History of bit. Starfishes p. 149 ; mais il se trompe en affirmant que l' $E$ -

$\left(^{*}\right)$ Dans le corps de son ouvrage U. Valentin s'est toujours servi des noms que j'ai adoptés; mais pour rapporter a leurs ty pes les fails relatifs aux especes qui sont simplenent citées d'apris d'autres auteurs, il importera d'avoir recours à la synonymie que j'ell doune. 
chinns Melo des auteurs du continent est synonyue de l'Echinus Sphrera de Miiller.

2. Echrosus Melo Link. C'est réellement une espèce très-distincte, propre à la Méditerranée; c'est la plus graude de toutes celles que je connais. J'en possède des exemplaires de six pouces de diamètre sur cinq pouces de hauteur. Les laguettes sont courtes, comme le dit MI. de Blainville; l'assertion de M. Ch. DesMoulins qu'elles sont an contraire fort longnes, provient sans doute de quelque confusion d'étiquettes dans sa collection. Celles de mon plus grand exemplaire ont à peine un pouce de long.

3. Echinus sardicus Lam. Synonyme de l'Echinlls Pseudo-melo De Blainv. Quoique très-voisin du Melo, cet oursin paraît cependant constituer une bonne espèce, qui se distingue de la précédente, plutòt par la petitesse de ses pores ambulacraires que par sa forme générale.

4. Echinus Fremingi Ball. Espèce très-caractéristique, mais fort rare, trouvée pour la première fois par M. le Dr Fleming aux Shetlands, et décrite dans son Brit. Anim. sous le nom d'Echinus miliaris, comme je m'en suis assuré par l'examen de l'exemplaire original. M. Ball l'a retrouvée depuis sur les côtes Sud-Ouest de l'Irlande, et lui a donné le nom qu'elle porte maintenant; elle est figurée p. 164, de Forbes Hist. of brit. Starfishes. Il importerait de comparer cette espèce avec l'Echinns quinquangnlatus DeBlainv., dont je n'ai pas pu me procurer d'exemplaire authentique. Ces quatre espèces ont cela de commun, que leurs piquans sont clairs-semés, à raison du petit nombre des grands tubercules, et que les pores ambulacraires sont par séries brisées de trois paires. L'ouverture inférieure du test est décagonale, sans profondes entailles, pour l'insertion des branchies externes.

La synonymie des autres espèces européennes est presque inextricable; cependant, étant parvenu à me procurer des exemplaires originaux de la plupart des espèces, j'cspère en venir à bout un jour; je dois faire remarquer dèsà-présent que les rapprochemens que j’ai à proposer diffèrent considérablement de ceux auxquels les auteurs modernes se sont arrètés.

5. Echinus lividus Lam. Quoique le plus commun de tous les Oursins d'Europe, c'est cependant celui qui a reçu les uoms les plus divers. Confondu avec plusieur's autres espèces, et en particulier avec l'Echinus uriliaris, sous les noms d'Echinus et Cidlaris saxatilis, et de Cidaris Basteri, il a été nettement ca- 
ractérisé par Lamarek, qui lui a donné le nom d'Echinns livirlus, qu'il porte maintenant, et qu'il devra conserver; ce qui n'a pas empêché DeBlainville de le décrire sous le nom nouveau d'Echinus vulgaris, et d'en distinguer le jeune àge sous le nom d'Echinus longispina, à-peu-près en mème temps que Risso l'appelait Echiuns purpuneus. De son côté, Leach l'a décrit sous le nom d'Echiuus tithophaguzs.Enfin Tiedemann, qui en a donné une très-bonne description anatomique, l'appelle Echinus saxatilis. J'en possède une série de nombreux exemplaires dont les plus petits ont à peine cinq lignes, et les plus grands près de trois pouces de diamètre. Les teintes varient du vert livide au vertbrun et au pourpre tirant au bleu. Cette espèce est earaetérisée par ses grandes épines acieulées, par des ambulacres plus ou moins rentrans, surtout chez les adultes, et par l'ouverture inférieure du test qui est déeagonale, sans entailles profondes.

6. Echinus neglectus Lam. On a voulu le rapporter à l'Echinus hividus; mais e'est une espèce très-distincte, figuréc par Leske, Tab. 38, fig. 2, $2 a, 3$ et $3 a$, et par Forbes dans son Hist. of Brit. Starf. p. 172. Fleming, la confondant avec l'Echinus subaugularis de Leske, l'a déerite sous ce dernier nom, comme j'ai pu m'en convainere par l'examen des exemplaires que je dois au savant professeur d'Aberdeen. Les piquans sont très-courts, sillonnés et dentclés; les ambulacres sont composés, dans toute leur longueur, d'ares serrés, composés de einq paires de pores et séparés par de petits tubercules; l'ouverture inférieure du test est décagonale, sans incisions profondes. Mes exemplaires proviennent du nord de l'Ecosse.

7. Echinus granularis Lam. Cette espèce, quoique très-distincte, a été négligée par les auteurs modernes, qui l'ont confondue avee l'Echinus cequituberculatus de M. DeBlainville et avec l'Echiuns brevispinosus de Risso, qui diffèrent également l'un de l'autre, eomme ils diffèrent l'un et l'autre de l'espèce de Lamarck. En revanche, l'Echiuns subglobifornis DeBlainville est synonyme de l'Echinus gianularis Lam. Possédant des exemplaires authentiques de ces trois espèces, je pourrai en préciser les caractères distinctifs.Anciennement on les a sans doute pris indistinetement pour l'Echiuus esculentus; mais depuis que l'on sait que l'Echinuts esculentus de Linné, qui est le sphcera de Müller, n'existe point dans la Méditerranée, il faut, ou supprimer complètement le nom d'Echinus esculentus, ou le restituer à l'espèce qui a 
été désignée la première sous ce nom, et laisser aux espèces de la Méditerranée les noms que leur ont donnés Lanarck, DeBlainville et Risso.

L'Echinus granularis paraît ètre la plus rare des trois; c'est celle qui a les plus gros tubercules et les plus grandes auricules qui sont en outre fortement obliques : le bord de l'onverture inférieure du test a dix fortes entailles; son test est très-épais; les piquans sont de moyenne grandeur, sillonnés, créneléset faiblement amincis à leur pointe qui est blanche, tandis que la base est d'un vert pourpré; les séries arquées des ambulacres sont formécs de cinq paires de pores, et séparées par un petit tubereule. Cette espèce paraît se trouver également dans la Méditerranée et dans l'Océan Atlautique; mais elle n'existe pas dans les mers du Nord.

8. Echinus brevispinosus Risso. C'est l'Echinus esculeutus des ouvrages de MII. de Lanarek et DeBlainville, et des auteurs qui ont décrit, sous ce dernier nom, des Oursins de la Méditerranée; mais il ne faut pas confondre cette espèce avec l'Echiruts esculentus des mers du nord de l'Europe, qui est le Splicera de Müller et de Forbes. L'Echinus brevispinosus a des tubercules plus petits et plus nombreux que l'Echinus granularis; ses piquans sont un peu plus gros et plus obtus; les auricules sont plus petites et moins obliques; l'ouverture inférieure du test a également de fortes entailles; les sćries arquées des ambulacres sont formées de cinq paires de pores, sans petits tubercules intermédiaires. Sa couleur est généralement violette; les piquans sont également violets ou pourprés à leur base et blanchàtres à leur sommet; il y en a mème dont la partic blanehe est plus considérable que la partie colorée. Lamarck et Risso citent une variété à piquans blancs; mais je erois que e'est une espèee distincte, dont je parlerai plus bas.

9. Echinus aequituberculatus DeBl. Cette espèce diffère des deux précédentes par l'extrème ténuité du test, par la grande uniformité des tubercules qui sc font remarquer par lcur blancheur sur le fond violet de l'épiderme; les piquans sont plus fins et aciculés, tantôt tout blaues, tantôt violets jusque près du sommet, qui est constamment blanc. Les auricules sont faibles, obliques, à ares plus grèles. Il n'y a constamment que quatre paires de pores dans chaque série arquée des ambulacres. Le bord de l'ouverture inférieure du test a de fortes entailles. Mes exemplaires proviennent de Sicile. 
10. Echinus albidus Agass. Cette espèee ressemble beancoup, par l'ensemble de ses caractères, à l'Echinus brevispinosus, e'est-à-dire qu'elle a les mêmes pores, les mèmes incisions au pourtour de l'ouverture inférieure du test; mais elle en diffère par des tubercules blanes, portant des épines également blanches, qui sont proportionnellement plus longues et plus acérées. Le test est violet.Les auricules sont grèles comme dans l'Echinus cequituberculatus. Des còtes de la Manche. Lamarck l'envisageait comme une simple variété de son Echinus esculentus, et Risso eomme une variété de son brevispinosus. Il se pourrait cependant que la variété blanche de Risso fût l'Echinus cequituberculatus DeBlainville.

Il ne me reste plus à mentionner, parmi les espèces d'Europe, que l'Echinus miliaris; mais avant d'en signaler les caractères, je dois faire remarquer que, sous cette dénomination, l'on a confondu plusieurs espèces très-distinetes, qui ont eela de commun, que la membrane buccale, loin d'être nue, est complètement couverte de plaquettes solides, imbriquées eomme des tuiles, semblables à eelles que l'on observe ehez les vrais Cidaris. Déjà Risso supposait que son Echinns miliaris n'était pas celui des anteurs. Une comparaison directe d'un grand nombre d'exemplaires provenant de la Méditerranée, de la mer du Nord et de la mer d'Irlande, m'a fait distinguer les quatre espèces suivantes :

11. Echinus mutiaris (Lesk. Lam.) Tuberenles des séries primaires assez gros et rapprochés; ouverture inférieure du test ample et faiblement échancrée; piquans aciculćs, allongés, pourprés à la pointe. Cette espèee se trouve sur les côtes de la Manche et sur celles d'Angleterre. Des exemplaires authentiques in'ont domné la certitude que e'est celle que Lamarck a décrite sous ce nom. C'est aussi celle que Forbes a figurée dans son Hist. of brit. Starf.

12. Echinus pustulatus Agass. Les tubercules sont plus petits et plus serrés que ceux de l'espèce précédente et ressemblent à de petites vésicules perlées; les piquans sont plus courts et moins acieulés. Les entailles de l'ouverture buceale sont peu marquées. Les exemplaires que je possède de cette espèce proviennent de la mer d'Irlande, et m'ont été eommuniqués par ML. Ed. Forbes.

13. Lchinus pulchellus Agass. Fort bien earactérisé par Risso sons le nom d'Echinus miliaris. Il ne m'est connu que de la Méditerranée, très-petit; déprimé, à très-petits tubercules; zones ambulacraires jaunâtres sur un fond ver- 
dâtre foncé; piquans grèles et petils, rosés à leur sommet, à base verdìtre ; ouverture inférieure du test petite, avec dix cntailles assez marquées.

14. Echinus decoratus Agass. Encore plus petit que le précédent, mais conoïde; les tubercules sont moins petits, et les miliaires surtout moins nombreux que dans l'espèce précédente; l'ouverture inférieure du test est plus petite, et les entailles moins marquées. Le fond de la couleur est pourpré ou vert, mais les zones ambulacraires sont d'un blanc jaunâtre très-clair, qui contraste très-fort avec le reste. Vu d'en haut, il paraît orné d'une étoile à dix rayons, ce qui lui a valu son nom.

Ce groupe comprend aussi de nombreuses espèces exotiques qui se distinguent toutes par la prépondérance des tubercules des séries primaires sur les autres tubercules, par des séries brisées de trois paires de pores dans les ambulacres, et par les plaques imbriquées de la membrane buccale; tels sont les Echinus variegatus, subangulosus et pentagonus de Lamarck, etc. L'existence, dans ces espèces, des plaques imbriquées de la membrane buccale qui caractérisent si bien les Cidaris proprement dits, et les distinguent des Diadèmes, me porte à croire qu'il faudra établir pour elles un genre à part, dont je connais déjà une dixaine d'espèces.

Plusieurs autres espèces exotiques offrent les mêmes caractères généraux que celles de nos côtes, qui se rapprochient de l'Echinus Melo, du Splıara, du lividus ou du brevispinosus, etc., et que nous avons exaninées plus haut; mais il en existe aussi un grand nombre qui ne présentent pas la mème uniformité de caractères et dont les ambulacres et la disposition des tubercules sont très-différens de ec que l'on observe généralement dans les espèces mentionnées cidessus. Ces différences coincïdent probablement avec des particularités de l'organisation intérieure assez tranchées pour justifier anatomiquement leur séparation générique; mais cela ne fût-il pas, les caractères extérieurs que je vais indiquer me paraissent motiver à eux seuls suffisamment l'établissement des genres que je propose ici.

L'Echinus toreuunaticus en particulier s'éloigne considérablement des Oursins ordinaires, par ses ambulacres simples et droits, qui sont très-semblables à ceux des Arbacia, des Tetrapygus et des Agarites; mais il en diffère par les ciselures de ses plaques; aussi en ai-je fait un genre à part sous le nom de Tемхopleurus. Ses piquans sont longs, grèles et comprimés. J'en connais une seconde 
espèee fossile, du Crag d'Angleterre, que je désigne sous le nom de Temn. Woodii. Je pense qu'il faudra assoeier ee genre au groupe des Arbaciens, plutôt qu'à celui des Ecliziviens. Il en est de même du genre Pleureehinus, dont le Cidaris bothryoüles de Leske est le type et dont j'ai vu un exemplaire dans la eolleetion de M. Stokes, qui lève tous les doutes sur l'existence de ee eurieux Oursin. Il est earaetérisé par des plaques en forme de eôtes horizontales, munies de tubereules uniformes. Le genre Microerphus est tout aussi extraordinaire. J'en connais deux espèees, toutes deıx inédites, que je désigne sous les noms de Micr.versicolor et maculatns, et qui se distinguent de tous les Oursins connus par la petitesse de leurs tubereules, qui sont groupés sur les aires ambulacraires, et au milicu et sur les bords internes des plaques intcrambulacraires, tandis que les bords externes ct les bords supérieurs et inféricurs de ees plaques en sont dépourvus. Je ne eonnais pas les baguettes de ee genre, ni cclles du genre préeédent.

Je erois eneore devoir élablir un genre partieulier, sous le nom de Salmacis, pour une espèce inćdite d'Oursin de l'Océan indien, intermćdiaire entre les Oursins proprement dits et lcs Arbacics, caraetérisé par des sérics horizontales de tubereules à-peu-près ćgaux sur ehaque plaque interambulacraire et ambulaeraire et disposćes de telle sorte que les sćries verticales ne ressortent point. Les piquans sont petits, mais ehaque piquant porte à son sommet une sorte d'aiguillc plus a eérée. Les ambulaeres sont formés, dans ehaque demi-aire, d'une quadruple rangée irrégulière de pores. J'appellc l'espìeeSalm. bicolor. Le test est brun, les piquans sont rouges et leur sommet est bleuâtre. Jc dois cet Oursin à l'obligeance de M. Valeneiennes. Quant à mes genres Tiripneustes, Amblypneustes, Toxopuenstes et Stomopnenstes, ils se rapprochent davantage des vrais Echinus; mais la strueture des ambulaeres et la disposition des tubercules me paraît en différer assez pour justifier l'établissement de gen res distincts. L'anatomie des parties molles devra eonfirmer ou infirmer l'induetion tirée de l'examen du test.

I.e genre Tripneustes est earaetérisć par trois rangées verticales et parallèles de donbles pores dans ehaque demi-aire ambulacraire et par une rangće principalc de tubereules aux bords internes des plaques interambulaeraires. La collerette des piquans est très-développée et la baguette fortement sillonnée d'un bout à l'autre. Ces Oursins ont de profondes entailles au pourtour de l'ou- 
verture inféricure du test. Il se pourrait que ce genre coïneidit avec le grenre Hipponoë de Gray qui n'est point encore décrit, mais simplcment cité dans le eatalogue dı Musée britannique. Dans ee cas, le nom de M. Gray devrait être préféré au mien. Les espèees quc je rapporte à mon genrc Tripneustes, sont Ics Echinus ventricosus, subccruleus, obuusangulus, ete. La facilité avec laquelle ees Oursins se fendent en segmens, embrassant ehaenn une aire anhulacraire au milieu, et une demi-aire interambulaeraire sur les deux eôtés, prouve évidemment qu'il faut eonsidérer l'Oursin comme formé de einq segmens scinblables.

Le genre ambly pneustes est également caraetérisé par de triples rangées de doubles pores dans ehaque demi-aire ambulaeraire; mais ces ıangées n'offrent pas le unême parallélisme verlical; l'ouverture inférieure du test est pelite simplement décagonale, sans entailles profondes; lcs tubercules sont très-petits et plus uniformément répartis sur les diverses parties de la surface; mais je ne connais pas la strueture des piquans; les ambulacres égalent en largeur les aires interambulacraires. Je rapporte à ee genre les Echinus Ovum, griseus, ete.

Je croyais, dans le principe, pouvoir rapporter au genre Antblypueustes le Cidaris granulata de Leske; mais un examen plus détaillé de cettc intéressante espèce un'a engagé à l'envisager eomme le typc d'un genre particulier que j'appelle Holopneustes. Dans ce genre, non sculement chaque demi-aire ambulaeraire égale en largeur une aire ambulacraire entière, mais les pores eux-mèmes sont disposés par paires formant deux séries marginales eontinues, entre lesquelles serpentent deux ou trois autres séries interrompues et irrégulières. Les ambulacres sont garnis de très-petits tubereules. Il y en a une série principalc sur ehaque demi-aire interambulacraire et entrc les deux demi-aires ambulaeraires. Je ne connais pas la nature des piquans. L'ouverture inférieure du test est très petite.

Le genre Toxopneustes a des ambulacres formés de séries arquées de doubles pores, convergeant vers le milieu des aires et séparées par des rangées parallèles de petits pores. Chaque séric arquée se compose de six à neuf paires de pores. Vers la bouche il y en a moins; mais elles sont plus rapprochées. Les tubercules des séries principales sont assez grands; l'ouverture inférieure du test 
offre dix échancrures peu profondes. Je prends pour type de ce genre l'Echinus tuberculatus; j'en connais quclques espèces inédites.

Le genre stomopneustes ne compte encore qu'une espèce; c'est l'Echinitus variolaris de Leske. Les tubercules sont très gros; il n'y en a qu'une rangée principale sur chaque demi-aire, tant des ambulacres que des interambulacres, ce qui fait ressembler cet Oursin à un Cyphosome. Les ambulacres sont formés de séries de trois paires de pores, disposés par bandes étroites dans la partie supérieure du test, grmais tellement élargies en-dessous, du còté de la bouche, que l'espace occupé par les tubercules est propor tionnellement petit; c'est ce caractère qui m'a fait donner ì ce genre le nom de Stomopneustes.

Je ne doute pas que, lorsqu'on connaîtra mieux les Oursins exotiques, il ne faille encore établir plusieurs genres dans cette famille. M. Ch. DesMoulins m'en a même déjà signalé un qui n'est point compris parmi ceux que je viens de caractériser et qu'il se propose de décrire.

Loin d'être nuisible aux vrais progrès de la science, cette multiplication des geures, lorsqu'ils sont établis sur des caractères précis, ne saurait avoir d'autre effet que de rapprocher de plus en plus les espèces que leurs caractères naturels lient le plus étroitement. C'est là le grand avantage des petits genres, et cet avantage est surtout sensible dans les familles dont toutes les espèces se ressemblent par leur aspect extérieur et par l'ensemble de leurs caractères.

Je dois à M. Valentin de déclarer ici que son travail était achevé dès le mois de nuai 1840 , et qu'il m'a remis son manuscrit à cette époque. La publication n'en a été retardée que par les soins qu'a réclamés l'exécution typographique des planches et la traduction du texte.

Neuchâtel, en décembre 1811 .

L. Agassiz. 


\section{IVTRondotros.}

L'espèce qui a servi à la description anatomique des Oursins, telle qu elle est contenue dans cette monographie est l'Echimus lividus("). Ce n'est qu'exeeptionnellement et pour rendre plus elairs certains détails, que parfois j’ai eu reeours aux Echimus Sphora et brevispinosus, en les employant eomme types de quelques figures. Tous les dessins ont étẻ exéentés sous mes yeux par M. Dickimann et lithographiés par le nême artiste distinguẻ, et jose espérer que, sous le rapport de liı préeision du moins, ils satisferont aux exigenees de la seienee. La plupart sont faits d'après des exemplaires conservés dans l'esprit de vin; les recherches anatomiques, au contraire, ont été faites en majeure partie sur des exemplaires vivans, à Marseille et à Niee, quelquefois à Berne, sur des exemplaires eonservés dans l'esprit de vin.

Les parties essentielles de l'Oursin ont déja été déerites avant moi, par d'autres naturalistes, entre autres par Cuvier, J. F. Meckel et surtout par Tiedemann et Delle Chiaje, aussi ne restait-il guère à étudier que quelques parties de l'organisation, tels que les organes situés à la face infẻrieure de la lanterne et les pédicellaires de la louehe, si earaetéristiques dans les Oursins, le systeme nerveux ("), des détails sur le système vaseulaire, ete. En revanche, l'observation mieroseopique de toutes ces parties était entièrement à faire; aussi m’a-t-elle fourni des résultats qui, ainsi que jai lieu de l'espérer, porteront leurs fruits dans lavenir. Abstraction faite de l'intérùt que présentent les parties molles de l'Oursin, eonme eelles de tous les animaux, lorsqu'on les

(“) C̈est la mème espẻce que Tiedemann a disséquée et qu'il désigne sous le nom d'Echinus saxatilis dans son ourrage.

(Agassiz).

(“) Depuis que ce travail a été Gni, MM. Krohn et Forbes ont ajouté des études approfondies sur le système nerveux et sur les yeux. 
examine au microscope, l'emploi de cet instrument est d'une importance toute particulière dans la classe des Echinodermes, à cause des squelettes calcaires si particuliers qui se trouvent lans leur intérieur. Les réseaux calcaires qui composent la charpente solide du test peuvent également être envisagés comme un trait caractéristique de ces animaux. Il existe en outre dans les organes mous, tels que ies tubes ambulacraires, la membrane buccale, les branchies externes, les pédicillaires de la bouche, ceux du corps, etc., de petits réscanx calcaires qui, quoique visibles seulement sous un grossissement plus ou moins fort, n'en sont pas moins les plus remarquables, par leur nombre aussi bien que par leur structure élégante. Pourquoi ces organes ne se seraient-ils pas conservés à l'élat fossile, anssi bien que le test lui-mème, la lanterne, les dents et d'autres organes? Aussi j’ai la conviction qu'ils deviendront un raste champ à cultiver pour la paléontologie microscopique des Echinodermes (*). C'est dans le but d'étalulir dès à présent quelques points de repaire pour l'étude paléontologique, que j’ai représenté dans ce travail la texture des parties solides ainsi que les petits squelettes microscopiques des organes de l'Oursin.

L'organisation de ces animaux est des plus compliquées; déjả leur test présente une variẻté extraordinaire de parties. Il est garni de piquans mobiles entre lesquels se cachent les tubes ambulacraires et les différentes espèces de pédicellaires. Au sommet du disque ( fig. 1), on remarque les cinq plaques génitales arec les ouvertures des cinq oviductes; à côté de celles-ci, les plaques ocellaires avec les yeux (fig. 4.) et à lintérieur les nombreuses plaques anales avec l'onverture anale. La face opposée (fig. 3) contient l'ouverture buccale avec l'extrémité des cinq dents qui lont plus ou moins saillie, la membrane buccale avec ses levres, les tubes buccaux et les divers pédicellaires qui s'y rattachent. Enfin l'on remarque sur la limite de la membrane buccale el du test, les cinq paires de branchies externes (fig. 57). A lintérieur, les organes digestifs, respiratoires, génitaux et locomoteurs, ainsi que le système vasculaire, présentent un développement trẻs-renıarquable. Le système nerreux paraît moins développé quant ì son volume; mais quant à ses fonctions, il ne le cède en rien au système nerveux des autres invertébrés.

Avant de passer à la description de toutes ces parties, nous derons nous entendre sur la manière lont il faut interpréter les différentes reggions du corps et sur le sens que nous altachons aux expressions de haut et de bas, d'avant et d'arrière, de gauche et de droite. On sait que dans sa position normale, lOursin a la face buccale en bas et la face anale en haut. C'est dans cette posi-

(") Déjà j’ai découvert des squelettes calcaires de Pédicellaires dans le terrain néocomien des environs de Neuchátel, depuis que les dessins de M. Valentin me les ont fait connaitre dans tous leurs détails. (Agassiz) 
lion qu il repose ou se meut an fond de la mer, et sur d'autres surfaces plus ou moins horizontales on mème perpendiculaires; car lorsquion le tient enfermé dans un vase en verre, il arrive trèsfréquenunent qu’il se met à ramper le longg des parois du vase pour arriver à la surface de l'eau, et éest toujours, comme l'ohserve trés-justement Gravenhorst ("), en ayant la bouche tournée contre les parois du rase (“). Il résulte des expériences de Bellonius et de Tiedemann ("..) que ces animaux se trourent dans une position très-gènée lorsqu'on les place la bouche en haut et l'anus en has; aussi font-ils tous leurs efforts ponr se retourner. En tenant compte de cette position de l'animal vivant, on trouve que Tiellemann (****), Meckel (****) et Sharpey (*****) ont été trèsconséquens en appelant inférieure la région buecale et supérieure la région anale. Ciest en effet de rette manière qu'il faut figurer ces animaux, si l'on ue veut pas se mettre en opposition avec l’impression que l'on en recoit à l'ètat vivant ; aussi n'ai-je pas liésité à représenter daus les fig. 2, 5, 9, 56 et 128 la bouche en bis et l'anus en haut.

Les déterminations de devant et derrière, de gauclıe et de droite, ont été introduites dans la science seulement depuis que M. Agassiz (*****), a fait la remarque que la partie antérieure est diamétralement opposée à la plus grande plaque génitale. Ce point une fois arrèté, il u’est pas difficile de dèterminer les autres réggions. C'est conformẻment à cette manière de voir que sont orientées les fig. $1,2,3,4,5,6,56,57,13$ ' et 161 ; et daus la description des divers organes je ne suis ioujours appliqué à indiquer d’une manière précise tous ces rapports de position, parce que c'esı le seul mojen d'obtenir un point de comparaison fixe pour lètude d'autres Echinites conformés diffẻremment ou dans lesquels le devant et le derrière sont naturellement indiqués, comme chez. les Spatangues.

Dans les mouvemens de l'animal, l'aire ambulacraire impaire antérieure semble jouir d'une sorte de prépondérance. Sans prétendre que les Oursins cheminent toujours dans une direction constante, je ferai cependant remarquer que cette position de l'ambulacre impaire en avant lenr

(*) Tergestina. Breslau, 1531 , in- $S^{\circ}$, p. 94.

(“) Chez MI. Forbes, à Edimbourg, j’en ai vu moi-nnème grimpant ainsi le long des parois d'un bocal. (Ag.)

(***) Anatomie der Rohren-IIolothurie, des pomeranzenfurbigen Seesterns und des Stein-Sec-Igel. Landshut, 1\$16. in-f*, 1. 70. Ouvrage couronué par l'Institut, en 1812.

(***) Anatomic etc., p. 72.

(***) System der vergleichenden Anatomie, 4. p. IIalle, 1829, 8*, p. 57.

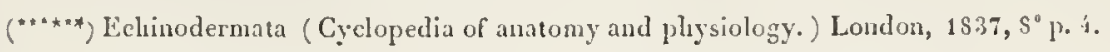

(******) Mémoires de la Société des Sciences naturelles de Neuchàtel. Tom. I. 1S36. 4, 1. 1;i. 
semble être très-habituelle, quoique souvent ils se dirigent latéralement on dans un sens opposé, Jorsqu'ils rencontrent des obstacles sur leur chemin.

Ėn terminant ces observations préliminaires, je dois encore ajouter un mot au sujet du texte. Il règne dans beaucoup de descriptions d'histoire naturelle une espèce de pédanterie qui embrouille plus qu'elle n'explique et qui est parvenue à son dernier terne dans l'ostéologie humaine, pédanterie qui consiste à décrire les moindres choses avec le plus grand détail et á confondre ainsi l'accessoire avec l'essentiel. Il est surtout difficile d'échapper à ce défaut dans une monographie qui traite d'un seul animal. Pour l'éviter j’ai tàchẻ de rendre mes planches aussi complètes que possible. Je pourrai ainsi me dispeuser d'entrer dans de longs détails sur des particularités d'organisation qui ressortent suffisanment de la simple inspection des figures. 


\title{
CHAPITRE I.
}

\author{
DU TEST.
}

Lorsquion examine un oursin dépouillé de ses piquans, on remarque au premier coup-d'cil que son test est divisé en zones verticales, d'inégale largeur, qu'on a distinguées sous le nom d'aires ambulacraires et d'aires interambutacraires. On en compte cing de chaque espèce; mais les interambulacraires sont en général les plus larges, et dans les espèces dont il est ici question, elles ont plus du double de la largeur des ambulacraires. Chaque aire en particulier se compose l'une double rangée de plaques. Ces diverses aires alternent entre elles et sont séparées par dix zones plus étroites, percées de petits pores, qui sont les zones porifêres ou les ambulacres proprement dits. Il résulte de-lả que le test de TOursin, comme celui de tous les Echinites en général, se compose extérieurement de vingt zones distinctes; c'est-ả-dire, de dix aires séparées par dix zones de pores. Hais telle n'est cependant pas sa véritable division; car en étudiant de plus près l'organisation de l'Oursin, on trouve qu'il se compose en réalité de cinq segmens d'égale grandeur, dont un impaire et quatre pairs. Le segment impaire est, comme l'a fort bien démontré M. Agassiz, l'antérieur; il est constamment opposé à la plus grande des plaques génitales. Les quatre segmens pairs sont le segment droit antérieur, le segment droit postérieur, le segment gauche antérieur et le segment gauche postérieur. Clacun de ces cinq segmens comprend une aire andulacraire, deux zones porifères et deux demi-aires interanbulacraires qui s’articulent entre elles au moyen de sutures en zigzag qu'on poursuit depuis le bord de l'ouverture buccale jusqu’à l'orifice anal (fig. 9.) ()

(*) En envisageant de cette manière la structure du test des Oursins, il est facile de saisir son analogie avec la charpente solide des Asteries. Chaque rayon de ces derniẻres peut dès-lors ètre comparè à un segment d'Echinite, et la conformité de leur organisation ressort d'elle-même.

(Agassiz) 


\section{De l'extérieur du test.}

Il existe à la surface de l'Oursin trois espèces de plaques calcaires: 1) les plaques dout sont formíes les aires ambulacraires et interambulacraires et que $\mathbf{H}$. DesMoulins désigne sous le nom de plaques earonales; elles occupent ì beaucoup près la plus grande partie du test et en constituent en quelque sorte la charpente; 2) les petites plaques dispersées sur la menbrane huccale (fig. 6); et 3) les plaques apieiales, ainsi appelées parce qu'elles occupent le sommet du disque, où elles forment deux anneaux distincts, l'un interne, comprenant les plaques anales proprement dites ( fig: $12 c$ ) et l'autre externe, entourant ces dernières et comprenant les plaques génitales (fig. 12 a) et les plaques ocellaires (fig. 12 b.) (*). Toutes ces plaques, a l'exception de celles de la membrane luccale, sont revêtues de tubercules sur lesquels s'articulent des piquans. A côlé des tubercules, se remarquent les pores ambulacraires, qui sont d'une importance capitale pour létude anatomique des Oursins.

Nous allons examiner succinctement ces différentes parties du test en commençant par les tuhercules. Nous traiterons ensuite des pores am!ulacraires et enfin des plaques de l'appareil génital, des yeux et de l'anus. Quant aux plaques de la membrane buccale, nous nous en occuperons en traitant de cette menlbrane et de sa structure.

Tous les tubercules ne sont pas de même grandeur: il y en a de gros, disposés en séries rigulières qui sont désignés sous le nom de tubercules prineipaux; ce sont ceux qui portent les grands piquans; et d'autres pius petits et moins réguliers qui portent de trẻs-petites épiues et occupent les espaces intermédiaires entre les tubercules principaux; ce sont ceux qu’on a appelés tuberrules miliaires. Le nombre des tubercules principaux varie dans les aires ambulacraires comme dans les aires interambulacraires suivant l'àge et la grandeur des individus. Dans l'Eelimus lividus et les espèces analogues, ils forment sur les aires ambulacraires quatre rangées i-peu-près iggales; toutefois les deux rangées externes, contiguës aux rangées de pores, et que jappelle rangées primaires (fig. $4 e$ ), en comptent un plus grand nombre que les deux rangées internes ( fig. 4. l). Enfin il y a encore, dans les aires ambulacraires, une troisième rangée de tubercules rudimentaires (fig. I $m$, fig. 6 n), qui u’existe guère qu'au milieu du test, même dans les 
exemplaires les plus grands: je nai jamais ru ces tubercules former une double rangée conıplete, car ils disparaissent bien avant d'atteindre l'ouverture buccale ou l'appareil génital.

Les aires interambulacraires comptent un plus grand nombre de séries de tubercules que les aires ambulacraires. Pour faciliter l'étude des différentes séries d'une aire, je les ai désignnées, dans les figures de Pl. 1, par des lettres différentes en réunissant, au moyen d'ares brisés, celles qui se correspondeut, ensorte que si l'on envisage les rangées les plus longues comme rangées primaires (fig. $4 \mathrm{~g}$, fig. $6 \mathrm{~g}$, fig. $9 \mathrm{~h}$ ), on pourra classer les autres dans l'ordre suivant : 1) les rangíes secondaires externes (fig. $7 \mathrm{~h}$, fig. $6 \mathrm{~h}$, fig. $9 \mathrm{i}$ ); 2) les rangées tertiaires externes (fig. $4 . i$, fig. $6 \mathrm{i}$, fig. $9 \mathrm{k}$ ); 3) les rangỉes quaternaires externes (fig. 9 I); li) les secondaires internes (fig. $4 \mathrm{k}$, fig. $6 \mathrm{k}$, fig. $9 \mathrm{~m}$ ), et 5) les tertiaires internes (fig. 4 , fig. 6 f, fig. $9 \mathrm{n}$ ) ("). Les deux rangées primaires atteignent seules le sommet et embrassent l'extrémité des plaques génitales, ensorte que les pores gènitaux s'ouvrent dans une échancrure de l'aire interambulacraire. De mène, ce sont les deux rangées jrincipales qui pénètrent seules dans le lobe compris entre les entailles de l'ouverture buccale. En considérant que toutes les rangées se répètent cinq fois sur la périphérie du test, nous aurons ainsi, dans $l \dot{E}$. lividus adulte, quatre-vingt-dix rangées de tubercules, savoir: pour les aires ambulacraires, dix rangées primaires, dix rangies secondaires et de cing à dix rangées tertiaires ; pour les aires interambulacraires dix rangées primaires, dix rangées secondaires internes, dix rangées tertiaires internes, dix rangées secondaires extornes, dix rangées tertiaires externes et dix rangées quaternaires externes. Mais toutes ces rangées n'existent que dans les individus qui ont atteint leur taille définitive, car nous verrons plus tard que le nombre en augmente avec l'ìge. Dans de petits exemplaires de l'E. miliaris, tel que celui de fig. 8 , qui n'a que six lignes de large et autant de haut, les rangées qui frappent le plus sont les rangées primaires des aires interambulacraires ; les rangées secondaires sont bien indiquées par de petites verrues, mais elles ne sont ni très-léveloppées, ni disposées en séries régulières. L.es rangées interambulacraires tertiaires, enfin, ne sont représenties que par quelques petites verrues, et les autres manquent complitement; il faut pour les apercevoir que l'Oursin ait atteint une taille double de celle de fig. 8 . On peut en conclure. sinon avec certitude, du moins avec la plus grande probabilité que les rangées primaires ambu-

(") Il pourrait paraitre plus naturel de décrire chaque aire interambulacraire comme un tout, et dans ce cas il faudrait appeler rnngéescrtoncs, celles que rous appelons ici internes; mais le test devant Atre envisagé comme formé de cinu segmens ayant une aire ambulacraire au milieu et deux demi-aires iuterambulacraires sur les cótés, tel que le représente la fig. 9 , il s'en suit que les rangées qui occupent le milieu des aires interambulacraires, sont en réalitẻ les rangẻes externes ḑu segment. 
lacraires et interambulacraires se développent et probablement se forment les premières et que les secondaires, tertiaires et quaternaires suivent successivement. L'observation d'une série nombreuse d'iudividus grands et petits m’a appris que les aires interambulacraires s'élargissent en effet de très-bonne lıeure et ménagent ainsi l'espace pour toutes les rangées secondaires, tertiaires et quaternaires qui viennent successivement s'y juxtaposer. Les aires ambulacraires restent au contraire bien plus étroites; aussi ne donnent-elles lieu qu'à des rangées secondaires. Il est inutile de dire que toujours les rangées secondaires apparaissent avant les tertiaires et celles-ci avant les quaternaires. On remarque aussi que daus les aires interambulacraires, les rangées externes se développent un peu plus tôt que les rangées internes. (Comp. fig. 7 et 8).

L'arrangement des gros tubercules, dont la régularité frappe au premier coup-d’oil, est soumis a des lois constantes que nous allons essayer d'exposer. On voit, au premier abord, que les tubercules de chaque demi-aire alternent avec ceux de la demi-aire voisine, mais que les rangées primaires, secondaires, terliaires el quaternaires d'une même demi-aire sont disposées sur uı seul rang. Examinons d'abord les tubercules des aires ambulacraires. Chaque plaque compte un tubercule primaire, un tubercule secondaire et un tubercule tertiaire, qui, lorsqu'ils ont acquis un certain développenent, sont disposés de manière à former une ligne ascendante qui part du tubercule de la rangée primaire, qui est toujours le plus bas, ou en d'autres termes le moins distant de l'ouverture buccale. Or comme les plaques alternent entre elles, il en résulte que les lignes de tubercules doivent présenter une alternance correspondante. Larrangement des tulercules des aires interambulacraires est un peu plus compliqué: il y a ici deux lignes montantes 'qui partent du tubercule de la rangée primaire, ou, en d'autres termes, chaque tubercule de la rangée primaire forme, d'une part avec les tubercules correspondans des rangées secondaires, ferliaires et quaternaires externes, et d'autre part avec les rangées secondaires et tertiaires internes, deux lignes montantes, dont l'externe est cependant la plus inclinée. Cette disposition régulière est surtout frappante lorsque les tubercules ont acquis un certain développenent; elle est moins distincte dans les individus qui ne sont pas encore parvenus au terme de leur accroissement.

Si l'on se rappelle que le test de l'oursin est composé de cinq segmens sur lesquels 'es tubercules sont disposés de diverses manières, et que l'on compare, dans les divers segmens, ceux qui sont rangés d'une même fagen, on ne manquera pas de découvrir entre eux certains rapports de position tout à fait conformes à la formation des tubercules et des plaques qui les portent. Que l'on marque, par exemple, d'un signe quelconque, les lubereules des rangées externes de l'aire interamlulacraire, compris dans une même plaque, savoir un tubercule de la rangée primaire, 
un de la rangée secondaire, unt de la rangée tertiaire el un de la ringée quaternaire externe, soit les lettres $h, i, k, l$, de fig. 9 ; que l'on saute la série correspondante de la même aire, les deux rangies de pores ambulacraires el tous les tubercules de l'aire ambulacraire, jusqu'i ce que l'ou arrive de nouveiu a lit rangée concordante de la procltaine aire interaubnlacraire, etl'on trouveral que la rangée qui s’aligne directement arec celle que l’on vient de narquer estégalement composee d'un tubercule printaire, secondaire, tertiaire et quaternaire, et quelle en forme en quelque sorte le prolongenent en spirale. En poursuivant plus loin cette filiation, l'on trouve que les lignes formées par les tubercules qui présentent ainsi une disposition analogue, s’èlèvent en spirale du pourtour de l'ouverture buccale jusqu'à l'appareil gẻnital, et qu'un tour est toujours termine avec la cinquième ligne. Ces lignes ascendantes comptent d'autant moins de tubercules qu' elles sont plus rapprochées de l'ouverture buccale et de l'appareil gẻnital. La mène chose a lieu pour les tuhercules de l'autre noitié de la plaque interambulacraire: mais comme ils sont lirigés dans un sens opposi, il faut tourner l'oursin dans le sens contraire; ensorte qu'en ne tenant compte que des tubercules externes de laire interambulacraire, nous aurions, sur tout le pourtour de l'oursin, dix spirales, dont cinq enroulées à gauche et ciuq à droite.

La mème chose s'applique aux tubercules des aires ambulacraires; nous avons ici également un double systeme de spirale, dont l’un est dirigé à gauche et l'autre à droite.

Ces spirales sont plus difficiles à poursuivre ì l'égard des rangées formées par le tubercule principal, secondaire et tertiaire interne de laire interambulacraire, puisque, avant d'arriver à la ligue correspondante, il faut sauter les lignes dirigées dans un sens opposé.

Il risulte de ceci que le test de l'oursin a trois systèmes de spirales dirigés à gauche et trois dirigés à droite, savoir un double système de tubercules interambulacraires externes, un double systeme de tubercules interambulacraires internes et un double systėme de tubercules ambulacraires. Louverture de ces angles augmente rapidement de has en haut et diminue igalement d'une manière très-rapide en approcltant de l'appareil génital.

Ce qui rend le tracé de ces lignes spirales difficile, ce n’est pas seulenent l'obligation dans laquelle on est de sauter les spirales intercalees, mais encore cette autre circonstance que de petits tubercules accessoires viennent souvent sinterposer entre ces tubercules principaux et déranger leur régularité. (*)

(`) Pour se rendre compte de celte disposition en spirale, il imporle d'étudier d'abord des Oursins qui ont un petit nombre de gros tubercules comme les Cidaris, oủ cet arrangement n'est point compliqué de tubercules secondaires, et où il est facile de reconnaitre l'ordre dans lequel ils se forment sur les plaques nouvelles autour de l'appareil génital. 
Les petits tubercules sont bien plus nombrenx que les gros; ils se rencontrent également snr les aires ambulacraires et sur les aires interambulacraires (fig. 9), ordinairement sur la limite des différentes plaques ou aux angles de ces dernières, on̉ ils sont même ordinairement un peu plus gros que sur les bords. Comme les plaques elles-mêmes, ils sont disposés en séries alternantes, ainsi que cela se voit surtout sur les aires interambulacraires, où ils sont en général plus nombreux et plus développés que sur les aires ambulacraires.

Les zones porifères ou ambulacres bordent de chaqne còté les aires ambnlacraires, quills séparent ainsi des aires interambulacraires. Ils s'étendent depuis le pourtour de l'ouverture buccale jnsqu'à l'appareil génital, en se rétrécissant à l'approche du sommet (fig. $4 d$ ). Le nombre des pores est sonmis à certaines variations dans les individns adultes. J'ai comptẻ, sur un test ayant $2^{\prime \prime} 9^{\prime \prime \prime}$ de diamètre et de $2^{\prime \prime} 1^{\prime \prime \prime}$ de haut, 640 pores dans une zone porifère; ce qui porterait leur nombre total à 3,200(*). En général, on compte pour clıque tubercule d'une rangée primaire de l'aire ambulacraire, cinq paires de pores formant une sorte de double arc autour du tubercnle ; mais souvent l'une des paires appartient à denx ares à la fois, ce qui nous explique pourquoi le nombre des pores des différentes zones porifẻres n'est pas lıabitueilement conforme à celui des tnbercnles primaires multiplié par dix. En tenant compte de certaines modifications, la disposition en spirale que nous avons signalée plus haut pour les tubercules, ponrrait bien aussi s'appliquer jnsqu’à un certain point aux pores ambulacraires.

Les plaques apiciales sont, comme nous l'avons vn plus haut, de deux sortes; elles forment anfour de l'ouverture anale un double anneau, dont l'un interne et l'antre externe (fig. 1, fig. 4, fig. 12). L'anneau externe se compose de dix plaques, savoir : cinq plaques génitales (fig. 12 a) et cinq plaques ocellaires ( fig. 12 b). Les plaques génitales seetendent depuis le sommet des aires nterambulacraires jusqu'au contact des plaques anales. Les plaqnes ocellaires correspondent aux aires ambulacraires; elles sont plus petites que les plaqnes gẻnitales et n’atteignent pas en général le bord des plaques anales. Cependant cette règle n'est pas sans exception, et l'on trouve des cas où quelques-unes de ces plaques sinsèrent entre les plaques génitales et font partie intégrante de l'anneau externe ( fig. 12 b).

Les plaques génitales sont d’inégale grandeur et la plus grande est toujours celle qui est opposée au segment antérieur; les quatre autres sont plus petites. La forme de ces plaques est pentagonale, lenr sommet est tourné en dehors, tandis que leur base, qui est fort large, et plns ou

(*) Dans un exemplaire de l'Echinus Spleara M. Forbes (a History of british Starfishes, London, 1841. 8. p. 152. 153) a calculé 3,720 pores. 
moins semilunaire entoure les plaques anales. Le trou génital est situé près du sommet de l'angle, tandis que près de la base on remarque toujours un ou plusieurs tubercules de grandeur moyenne entouré de plus petiles verrues.

Les plaques ocellaires (fig. $12 \mathrm{~b}$ ), sensiblement plus petites que les plaques génitales, sünsinuent en quelque sorte entre ces dernières avec lesquelles elles alteruent; leur forme est iggalement polygonale et mème pentagonale, en tant qu'on ne tient pas compte des dentelures du bord extérieur; mais ce qui les distingue surtout des plaques génitales, c'est que leur sommet au lieu d'ètre tourné en dehors, l'est en dedans; leur base présente ordinairement deux échancrures, et partant trois triangles qui s'articulent avec les dernières plaques des aires ambulacraires. Près dı sommet du triangle médian se trouve un petit trou a peine visible à l'wil nu. C'est dans ces trous que sont logés les organes que MIM. Forbes et Agassiz ont pris pour des yeux et dont nous aurons ì nous occuper en détail plus tard.

L a anneau apicial interne est formé par les plaques anales ( Tab. I, fig. 12c). Leur nombre est variable, ainsi que leurs dimensions. Les plus grandes occupent la périphérie, tandis que les petites sont au centre. Ces dernières sont ordinairement triangulaires, et peuvent se replier au grè de l'animal, pour éconduire les matières fécales. Ces diverses plaques sont tantòt unies et tantôt pourvues d'un tubercule, surtout les plus grandes, qui sont aussi plutôt pentagonales que triangulaires.

Quant au dẻveloppement et au mécanisme des différentes pièces du test, M. Agassiz (*) a fait à ce sujet de nombreuses recherches, d'où il résulte que les pièces coronales dans les individus de grande et de moyenne taille, sont moins intimement unies, et portent des piquans moins développès près du cercle des plaques anales et ocellaires, qu'ailleurs. On rencontre mème dans cette région des plaques de forme irrégulière, sans tubercules, ni piquans, et qui attestent en gènéral un développement moins avancé. Les très-jeunes plaques apparaissent comme des points d'ossification, qui s'agrandissent dans toutes les directions, mais d'une manière inégale, ce qui fait que le côté inférieur atteint beaucoup plutôt le terme de son accroissement, tandis que le lord supérieur est encore parfois tronqué, alors mème qu'un rudiment de tubercule commence à se montrer au milieu. La membrane externe est dans ces jeunes plaques plus molle que dans les plus anciennes, qui adhèrent dëjà intimement entre elles. Les piquans n'ont d'abord aucune mobilité, mais ils en acquièrent avec le temps, et ne dépassent pas un certain maximum de

\footnotetext{
(") Prodrome p. 175 ì 170.
} 
développement. Lorsqu'ils viennent ì se perdre, ils se renouvellent de la même manière, c'esta-dire par renflement et extension de la membrane externe. Pour se rendre compte de toutes ces particularités de l'accroissement, il importe de comparer des individus de différens âges, et e’est, entre tous les genres, celui des vrais Cidaris qui est le plus approprié á cel élude. On peut s'assurer que les jeunes individus nont qu'un petit nombre de plaques dans chaque rangée principale. Ces plaques s'accroissent au moyen d'une sécrétion calcaire, qui s'opère lentement sur leur périphérie jusqu’à ce que celles qui entourent la bouche aient acquis leur taille définitive et soient entièrement adhérentes entre elles. Pendant ce temps les plaques supérieures continuent à grandir et à augmenter en nombre, ensorte que le test de l'animal s'accroît de bas en laut, et de déprimé qu'il était, devient de plus en plus globuleux et même turrité. Au reste, l'accroissement des nouvelles plaques se fait en spirale. Quant aux piq̨uans, ce sont encore ceux qui avoisinent la bouchequi atteignent les premiers le terme de leur accroissement, comme on peut s'en assurer dans les Cidaris; les plus grands sont situés au tiers supérieur du test, el les incomplets a l'exlérieur des plaques génitales et ocellaires.

J’ai dì rapporter en détail ces ohservations de MI. Agassiz("), parce que je ne possède pas par devers moi des faits suffisans pour me rendre un compte exact de l'accroissement de l'Oursin. Il m'a cependant toujours semblé quil devait $\mathbf{y}$ avoir un double accroissement, l'un verlical et l'autre pẻriphérique : le premier me semblail être propre aux cinq segnens principaux el se manifester sur le pourtour de l'oviducte aussi hien que sur le pourtour de l'onverture buccale. C'est an moins ce qui m'avait paru résulter de l'examen des Cidaris, qui montrent, près de l'anneau apicial, des plaques de dimension inégale, tandis quil y en a de plus petites encore au pourtour de la bouche $\left({ }^{* *}\right)$. L'accroissement périphérique a lieu sur tous les bords des plaques el entre les sutures en zig-zag du milieu des aires ambulacraires et des aires interambulacraires. En tenant compte

(*) M. Philippi a aussi présenté quelques observations intéressantes sur l’accroissement du test des Echinites dans les Archives d'Hist. nat. de Wiegmann, 1837, p. 244.

(") Je crois que la divergeuce qui semble exister entre la manière de considérer l'accroissement des Oursins de M. Valentin et la mienne est plus appar renteque réelle. En effet, quoique les plaques et les tubercules qui entourent l'ouvertire buccale soient aussi petits et même souvent plus petits que ceux qui se développent dans la région anale, il n'est pas rigoureux d'en couclure qu'ils se sont formés plus tard que ceux du milieu du test et qu'ils sont par conséquent plus jeunes qu'eux. Leur aspect, leur épaisseur et leur liaison intime me paraissent au contraire devoir les faire envisager comme les plus ancienc, c'est-à-dire comme ceux qui se sont consolidés lorsque l'Oursin était très-jeune; et dès lors leur petitesse n’a plus rien qui puisse nous surprendre.

(Agassiz) 
de la formation des plaques, on est en quelque sorte autorisé ì en condure que l'accroissement périphérique cesse plutòt que l'accroissement vertical. Quant à l'accroissement des piquans, mes expériences confirment entièrement celles de M. Agassiz.

11 résulte de ceci que le nombre des plaques doit àtre différent, suivant l'ìge des individus: mais leur énumération est accompagnée de grandes difficultes. 11 est plus difficile de compter les gros tubercules et leurs piquans. Le nombre des petits tubercules qui entourent les gros est trèsconsidérable, mais il ne saurail être indiqué d’une manière précise, à cause de leur inconstance. Oı ne saurait pas davantage indiquer le nombre absolu que les tubercules d'un Oursin peuvent alteindre, par la raison que personne ne peut prétendre avoir eu en mains le plus grand individu d'une espèce. Une pareille énumération ne serait d'aillcurs d'ancune importance pour l'anatomie; en revinche l'énumération des tubercules, rclativenent à la grandeur de l'Oursin, conduit is quelques rapports intéressans, comme on peut le voir par le tableau suivant, où jai comparé huit individus de diffërente grandeur. Les chiffies sont en pouces et lignes duodécimales.

\begin{tabular}{|c|c|c|c|c|c|c|c|c|c|c|c|}
\hline \multicolumn{7}{|c|}{ liangèes internes. } & liangèes i & iternes. & \multicolumn{3}{|c|}{ Hangées ambulacraires. } \\
\hline$\therefore 0$ & Largenr. & El.tuteur. & primaire. & Seconduite. & Tertiaire. & Quaternaire. & Secondaire. & Tertiaire. & P'rimaire. & Sccondaire. & Tertiaire \\
\hline 1 & $2 / / 99^{\prime \prime \prime}$ & $2^{\prime \prime} 1^{1 / 1}$ & 29 & 26 & $18-19$ & 11 & 33 & 202 & $38-39$ & $30-31$ & 13 \\
\hline$\underline{2}$ & $2^{\prime \prime /} \mathbf{8}^{1115}$ & $2 / 13^{116}$ & 30 & 26 & $18-19$ & 12 & $31-35$ & 21 & 39 & $\overline{30-31}$ & 14 \\
\hline 3 & $\underline{2}^{2 / 2} \underline{2}^{1 / 1}$ & $1^{110211}$ & 23 & 21 & $13-14$ & $m m$ & 25 & $\overline{13-14}$ & 27 & 22 & $m " n$ \\
\hline 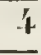 & $1^{\prime \prime} 11^{\prime \prime \prime}$ & 1"I & 19 & $17-18$ & $9-10$ & "1) & 21 & $\overline{11-19}$ & 25 & 18 & $n n$ \\
\hline 5 & $101 / 5$ & $5^{1115}$ & 13 & 10 & $n-n)$ & $m m$ & 13 & $m \geqslant-n$ & 15 & 8 & $m n$ \\
\hline 6 & $8^{\prime \prime \prime}$ & 4115 & 14 & 10 & $n-n "$ & $n n$ & $16-17$ & $\overline{m-n " n}$ & $16-17$ & $9-10$ & $11)$ \\
\hline 7 & $6^{111}$ & $5^{\prime \prime \prime}$ & 12 & 9 & $n-n n$ & $m "$ & 14 & $\overline{n \eta-\eta n}$ & $\overline{15-16}$ & 12 & $" n$ \\
\hline 8 & $5^{1 / 75}$ & $1^{111}$ & 10 & $9-10$ & $n-n \|$ & $" 1)$ & 13 & $m n-n n$ & $13-1.4$ & $m$ & $3 \prime \prime$ \\
\hline
\end{tabular}

Si nous réduisons maintenant le nombre des tubercules des autres rangées à celui de la rangée ambulacraire printaire, prise comme unité, nous aurons :

(*) La première colonne du tableau indique le numéro de l'exemplaire. Les seconde et troisième colonnes indiquent les dimensions transverses et verticales du test de ces exemplaires; tandis que les colonnes suivantes donnent le nombre de tubercules observés dans toutes les rangées, tant ambulacraires qu'interambulacraires, primaires et secondaires, internes et externes, comme le désiguent spécialement les titres des colonnes et les accolades qui les réunissent. 


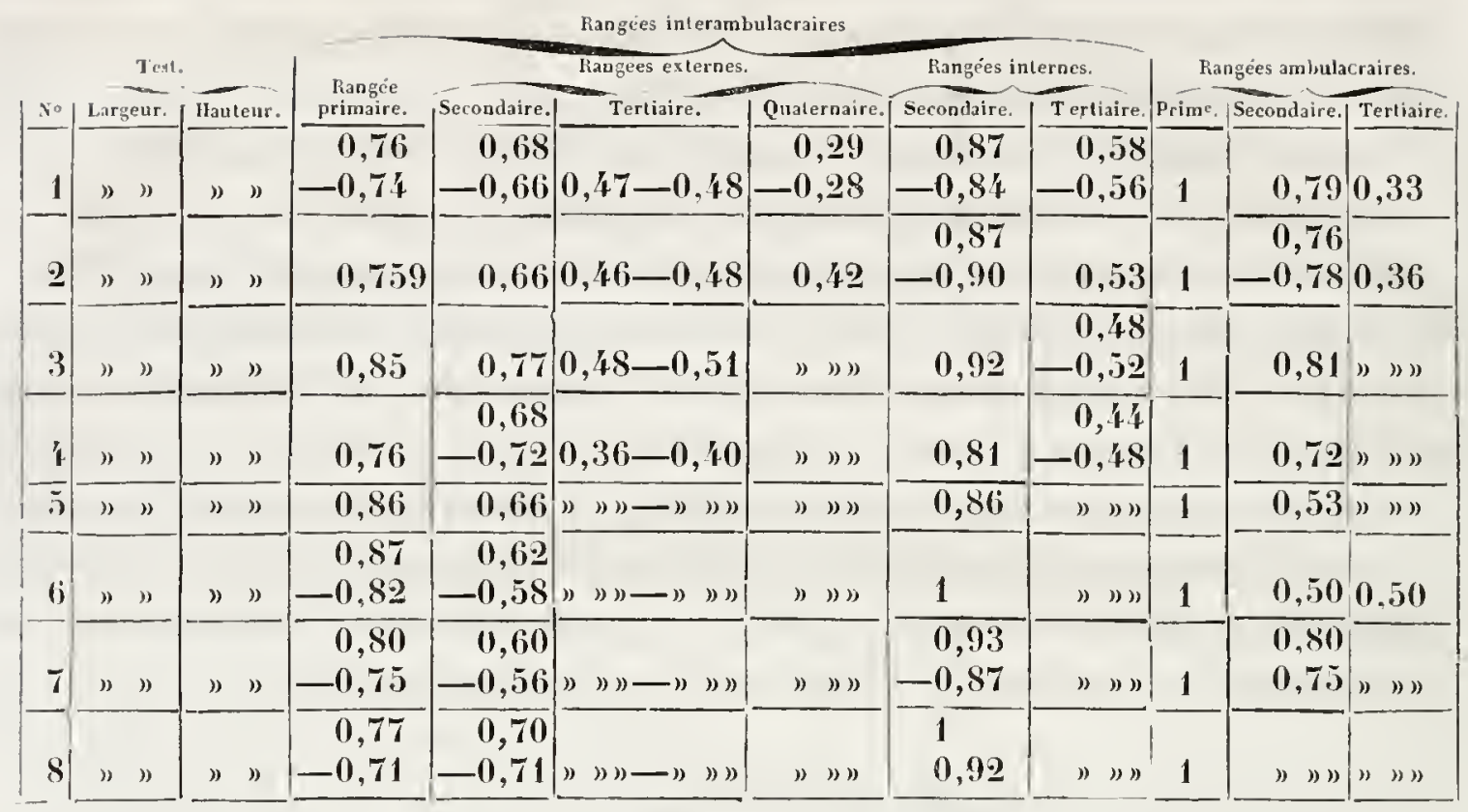

Il résulte de ce tableau :

$1^{\circ}$ Qu'abstraction faite des tubercules miliaires, qui sont encore plus nombreux, mais disposés trẻs-irréguliẻrement, le nombre total des gros tubercules et des tubercules de moyenne grandeur est dans la proportion suivante :

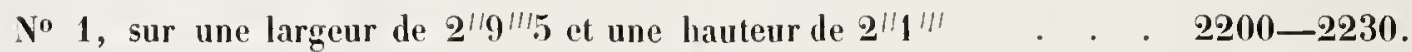

\begin{tabular}{|c|c|c|c|c|c|c|c|}
\hline ") 2 , & $"$ & $2^{\prime \prime} 8^{\prime \prime \prime} 5$ & $"$ & $2^{\prime / 3} 3^{\prime \prime \prime}$ & . & . & - $2240-2270$ \\
\hline$" 3$ & $"$ & $\mathbf{2}^{\prime \prime 2} / 1 / 5$ & $"$ & $1^{\prime \prime 2} \mathbf{2}^{\prime \prime \prime}$ & - & . & . $1440-1460$. \\
\hline " 1 & $"$ & $1^{\prime \prime} 11^{\prime \prime \prime}$ & $"$ & $1^{\prime \prime}$ & . & . & . $1200-1230$ \\
\hline$" 5$ & $"$ & $10^{\prime \prime \prime} 5$ & $"$ & $5^{\prime \prime \prime} 5$ & . & . & 590 . \\
\hline " 6 & $"$ & $8^{\prime \prime \prime}$ & " & $4^{1115}$ & . & . & $650-680$. \\
\hline$" 7$. & $"$ & $6^{\prime \prime \prime}$ & $"$ & $5^{\prime \prime \prime}$ & . & . & $620-630$. \\
\hline " 8 & 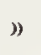 & $5^{11 / 75}$ & $"$ & $4^{\prime \prime \prime}$ & . & . & $450-470$. \\
\hline
\end{tabular}

Ces tubercules supposent maturellement un nombre égal de piquans.

$\mathfrak{2}^{\circ}$ Que c'est toujours l'aire ambulacraire primaire qui possède le plus grand nombre de tubercules.

$3^{\circ}$ Que la rangée qui tient le second rang sous le rapport du nombre des tubercules, n'est pas toujours la même. Dans les vieux individus, c'est ordinairement la rangée secondaire interne de 
l'aire interambulacraire; vient ensuite la rangée secondaire ambulacraire et la rangẻe primaire interanbulacraire, les rangées secondaire externe, et tertiaire interne de l'aire interanbulacraire, la rangée tertiaire ambulacraire et la rangée interambulacraire quatteruaire externe.

$4^{\circ} \mathrm{Que}$, même dans les jeunes individus, la rangée primaire de l'aire ambulacraire l'emporte sur toutes les autres sous le rapport de son développement.

$5^{0}$ Que dans l'accroissement de l'animal le nombre des tulsercules n'augmente ni proportionnellement il la hauteur, ni proportionnellement à la largeur du test.

$6^{\circ}$ Qu’en général le nombre des rangées interambulacraires se maintient dans une certaine proportion avec la largeur du test, proportion qui cependant n'est pas toujours rigoureuse.

$7^{\circ}$ Que les rangées secondaires et tertiaires sont subordonnées, quant au nombre de leurs piquans, de leurs tubercules et de leurs pièces coronales, à la forme gémérale du test. Leur proportion relative ressort du second tableau ci-dessus.

\section{DE LA FACE INTEINE U TEST.}

Autant l'extérieur du test de l'Oursin est rugueux et tuberculeux, autant sa face interne est lisse; ce qui fait que les sutures des différentes plaques y sont très-distinctes, et permettent uı examen bien plus rigoureux. De plus, on rencontre ici plusieurs particularités de structure qui ne se trahissent pas à l'extérieur, notamment sur le pourtour de la bouche, à la face interne des aires ambulacraires et interambulacraires, et en partie aussi sur le revers des apparcils génilal et anal; particularités qu’il inıporte d'étudier avec soin, si l'on veut se rendre un compte exact de la nature véritable du test et comprendre le mode d'insertion des parties molles et de l'appareil masticatoire en particulier.

Lorsquion a enlcvé toutes les pièces qui composent la lanterne d'Aristote ou l'appareil masticatoire, dont nous traiterons plus tard, on remarque sur le pourtour intérieur de l'ouverture buccale une sorte d'anneau renflé qui, de même que leepiderme, est entamé par les entailles de la bouche (Tab. II, fig. 14h). Aux angles des zones porifères, cet anneau s'élève en forme de deux liranches : ce sont les auricules destinées à supporter la lanterne. Le plus souvent ces auricules sont soudées à leur sommet, mais de manière à laisser entre elles une ouverture en forme de lunule, qui correspond à la suture des aires ambulacraires (fig. $14 \mathrm{~g}$ et fig. $15 \mathrm{~g}$ ).

Les pores ambulacraires se présentent à l'intérieur sous la forme de petits trous ronds, dont la disposition mérite une attention toute particulière. Tous sont percés obliquentent de dehors en 
dedans et en partie de haut en bas. C'est particulièrement le cas des pores internes, c'est-à-dire de ceux qui sont les plus rapprochés du centre de l'aire ambulacraire.

La forme générale des aires ambulacraires est à-peu-près la même qu’à la surface, c'est-ádire qu'elle se rétrécit en haut et en has, tandis que le milieu est élargi. 11 existe en outre, au milien de l'aire, une carène saillante qui en occupe toute la longueur et qui sert à l'insertion d'un genre particulier d’organes respiratoires. Cette carène, que j’appelle carène ambulacraire, part de l'appareil grénital, oủ elle est sensiblement rétrécie, descend en s’èlargissant le long de la sulure des plaques et se termine en face de la lunule des auricules. De chaque côté de cette carène, qui correspond à la ligne médiane des lıranchies internes, l'aire ambulacraire se déprime, de manière à atreindre sa plus grande profondeur en avant des pores internes; plus loin, elle se relève de nouvean, et il résulte de ce monvement une espèce de sillon aplati, destiné à loger les feuillets brancliaux.

De la carène ambulacraire partent en outre de zombreuses lignes horizontales, dirigées en dehors, et dont chacune atteint une paire de pores ou du moins le pore interne de l'une des paires. Ciest ordinairement la $6^{\circ}$, rarement la $7^{e}$ ou la $S^{e}$, et plus rarement encore la $4^{e}$ paire qui coïnride avec la suture de l'aire interambulacraire.

Il existe aussi sur la limite extrême des aires ambulacraires, mais en dehors des pores externes, une ligne quelque peu saillante qui augmente d'épaisseur ì mesure qu'elle approche de l'ouverture buccale. C'est le long de cette carène, un peu à l'intérieur, que sont les sulures en ziggzag qui unissent les plaques des aires ambulacraires a celles des aires interambulacraires.

La suture médiane ef les sutures des différentes plaques sont trop évidentes pour ne pas fixer de prime abord l'attention. La suture médiane s'étend depuis l'appareil génital jusqu au pourtour de louverture buccale, ou elle vient aboutir à la suture des auricules. Sa forme en zigg-zag résulte de l'enchevêtrentent des denx rangées de plaques dout se compose chaque aire. Les zigg-zag sont d'autant plus marqués que les plaques sont plus grandes, et l'on comprend dès-lors quïls soient moins sensibles près de l'appareil génital et aux abords de la bouche, qu'au milieu du test.

De même que dans l'aire ambulacraire, il existe aussi dans l'aire interambulacraire, le long de la suture médiane, une ligne légèrement renllée à laquelle se fixe le mésentẻre de l'ovaire. L'aire interambulacraire s'iplatit de chaque coté de cette ligne médiane pour se relever de plus en plus près de laire ambulacraire; ensorte que nous avons ici, conme dans cette dernière, de chaque còté de la suture médiane, une dépression en forme de sillon très-évasé. Ontre ces dépressions, on remarque souvent aussi, ì còté de la ligne médiane de laire interambulacraire, de petits 
creux plus ou moins appareus qui correspondent aux tubereules primaires des aires interambulacraires.

Les plaques de l'appareil śénital (fig. $13 e$ ) et celles de l'ouverture anale (fig. 13 g), sont articulées à la face interne à-peu-près de la même manière qu’à la surface du test. Il se forme ì la base des plaques génitales des renflemens, dont l'ensemble représente une espèce d'anneau saillant. Ces renflemens sont en général égaux dans les quatre plaques génitales paires; mais comme ils s'alliussent à leurs deux extrémités, il en résulte que cet anneau n'est pas continu, et l'on remarque de petites solutions de continuité au point de contact des diverses plaques. Le renflement de la plaque impaire est plus plat et plus large que les autres; il s’èargit surtout considérablement du còté du sommet de la plaque, en formant une sorte de bouton sur l'anneau. On distingue de plus à la face interne de cette mème plaque, notamment dans les grands individus, une structure fibreuse rayonnante d'une forme toute particulière, qui provient sans doute de la part que cette plaque prend à la carène annulaire ci-dessus.

Les pores génitaux sont disposés obliquement de dedans en dehors et de bas en haut; nais cette obliquité est en général bien moins sensible que dans les pores ambulacraires. Il existe aussi quelque chose de semblable dans les trous ocellaires.

Les plaques anales n'offrent rien de particulier à la face interne. De même que les plaques goénitales, elles ne montrent aucune trace de saillies ni de verrues.

\section{Structure du TEST.}

Les sutures au moyen desquelles les diverses plaques du test adhèrent entre elles s'aperçoivent parfois déjá à l'extérieur de l'Oursin ; mais la quantité de tubercules grands et petits dont la surface est revêtue empêchent de les poursuivre dans le détail. Leur articulation n'est hien distincte qu’à la face interne, oủ l'on voit au premier coup-d'ceil que toutes les pièces sont polygonales, plus ou moins pentagonales ou hexagonales, et qu'elles se laissent toutes ramener à deux systèmes, celui des aires ambulacraires et celui des aires interambulacraires. Chacun de ces systèmes est composé de deux rangées de plaques qui se répètent cinq fois sur le pourtour du test; ensorte qu'il y a constamment vingt rangées de plaques principales. Le ciment qui les tient réunies paraît être d'une nature organique, car il se dissout facilement dans la potasse.

Les plaques des aires interambulacraires sont les plus grandes; elles ont une forme plus ou moins lıexagonale, sont plus larges que hautes et limitées en haut et en bas par des lignes droites, 
plus ou moins arquées et en général parallèles entre elles; tandis que les bords latéraux internes et externes présentent au contraire des angles qui, en s'articulant entre eux, déterminent les lignes en zig-zag qui sont si distinctes à la face interne. L'angle du còté interne de chaque double série est plus aigu que celui du côtẻ externe; ce dernier est même trẻs-ouvert, mais il n'en existe pas moins, alors même que la suture ne présente en apparence qu'une ligne droite.

Les plaques des aires ambulacraires, également pentagonales ou lıexagonales dans le principe, ont leurs bords supérieur et inférieur droits et parallèles, et leurs bords externe et interne anguleux; mais les angles sont en général très-obtus, surtout les internes. C'est au bord cxterne de chaque plaque que s'ouvrent les pores ambulacraires, au nombre de quatre ou cinq paires pour chaque plaque. Le bord interne se relève graduellement, de maniẻre que la carène ambularraire dont nous avons parlé plus haut, coïncide à peu prẻs avec la suture de deux rangées de plaques ambulacraires. Celles-ci sont en général moins larges que les interambulacraires, mais leur liauteur est plus considérable proportionnellement à leur largeur.

En poursuivant une rangée de plaques dans toute sa longueur, on remarque qu'elles diminuent aussi bien vers la bouche que vers lanus, mais d'une manière différente. Du côté de l'ouverture buccale, elles perdent de leur hauteur, tandis que c'est plutôt leur largeur qui diminue du côté de l'appareil génital, de manière qu’elles sont ici plus hautes relativement à leur largeur qu'au milieu du test.

Lorsqu'ou brise un test d'Oursin, les brisures correspondent parfois aux sutures; mais plus gènéralement elles traversent en tout sens les plaques, et donnent souvent lieu à une cassure conchoïdale. Cette seule circonstance suffirait au besoin pour dèmontrer que les plaques adhèrent entre elles d'une autre manière que par la simple juxta-position; circonstance qui se troure pleinenent justifiée par l'observation microscopique; car nous verrons que le test de l'Oursin comme celui de tous les Echinodermes, contient des réseanx calcaires dont la substance se compose en majeure partie de sels calcaires et surtout de carbonate de chaux. Mais ces réseaux ont toujours pour base un squelette organique d'un tissu fibreux (Tab. II, fig. 18 et 23). En exposant le tout à la chaleur, on parvient ả éloigner ce squelette organique, et les parties inorganiques restent seules. Les acides produisent un effet contraire : ici c'est la substance inorganique qui est enlerée, tandis que le squelette organique seul reste intact; mais il faut, pour obtenir ce résultat, avoir soin de bien ménager les proportions, parce que le squelette organique est lui-même soluble dans l'acide un peu concentré.

ll suffit de faire une coupe transversale d'une plaque de l'aire interambulacraire pour s'assurer 
que la masse entière est composée d'une quantité de réseaux calcaires fort élégans (Tab. 2, ligg. 18), séparés par des mailles plus ou moins circulaires. On remarque quelquefois sur les coupes faites ì lia hâte des groupes de mailles qui semblent itre plus grandes que les autres; mais il est facile de se convaincre que cette différence est illusoire, an moins en ce qui concerne les coupes transversales. Ce sont certains piliers qui, par l'effet d'une trop forte pression, se sont détachés des autres pour se réunir artificiellement aux mailles adjacentes. Aussi, lorsque les réseaux calcaires plus petits se sont conservés soit au dessus, soit au dessous d'une assez grande maille, on les apergoit toujours distinctement au travers de ces dernières, et lorsque l'on a l'halsitude du mieroscope, l'on reconnaît bientôt que les mailles et les réseaux sont à des niveanx diffẻrens au foyer de linstrument. Il peut aussi arriver que lïnage perde de sa précision, lorsque certaines mailles se remplissent de matière pulvérisée par la friction; cependant cette circonstance donne rarenent lieu a des erreurs.

Le inoyen le plus sùr de connaître la structure intime des réseaux calcaires et la manière dont le test se brise, e'est d'examiner an microscope la poudre de friction après l'avoir préalablement lavée. Cette poudre ainsi traitée se montre composée de deux sortes de pièces, de fragmens de réseanx et d'esquilles plus petites, appartenant aux piliers qui composent les réseaux.

Les réseaux calcaires entrent constamment dans la composition du test, et présentent à peu prés partout la mème apparence générale. Les mailles comprises entre les piliers sont circulaires, plus souvent elliptiques et quelquefois aussi subtriangulaires. Leur diamètre varie plus ou moins suivant les individus. Je l'ai trouvé de 0,000525 a $0,001100 / /$ dans la couche externe d'une plaque de l'aire interambulacraire d'un grand Echinus; de 0,000375 à 0,000600", dans une plaque de l'aire ambulacraire et de $0,000,100$ " dans la plaque génitale impaire.

Les mailles des diffẻrentes couches superposées ne se recouvrent pas, mais alternent en quelque sorte, de manière que les piliers de la couche inférieure se voient à travers le milicu de la couche superposẻe. C'est ce dont il est facile de se convaincre par des coupes très-minces, ou cu lıumectant la masse avec de l'acide muriatique.

Vue au microscope, la substance des piliers qui constituent le réseau se présentent sous la forme d'une masse très-dure et cassante comme du verre. Elle est blanche ou d'un blanc jaunàtre; ses contours sont tranchans, fortement ombragés, et l'on y reconnaìt, en beaucoup d'endroits, des lignes arquées tantôt interrompues, tantôt continues, telles qu'on les observe dans les esquilles d'une masse de verre très-compacte (Voyez Tab. 2, fig. 20). Leurs bords sont tantôt anguleux, tantôt arrondis, tantôt droits ou arqués. Ces piliers sont adhérens entre eux dans toutes 
les direetions et à tous les niveaux; ce qui fait que, lorsque de petits fragmens se détaehent du réseau, il en résulte des saillies et des lignes qui pourraient faire supposer que les piliers sont. réunis entre eux par des sutures; eependant il ne faut qu'un peu d'attention pour reconnaitre la véritable eause de ces saillies.

Le mode de eassure tranchante des piliers détermine la forme même des plus petits fragmens, et toutes les esquilles microscopiques qui ne sont plus adhérentes entre elles affeetent les formes les plus variées et se distinguent par leur cassure conchoïlale, eomme le feraient de petites particules de substanee vitrée. Leurs contours sont pour la plupart arqués. Souvent ils se terminent d'un côté par une pointe saillante; d'autres fois ils sont plus arrondis, on bien ce sont de petits fragmens anguleux provenant d'un ou de plusieurs piliers. Au premier abord, on dirait que ces fragmens affectent des formes cristallines; mais l'on finit bientôt par se convainere que ce ne sont pas des cristaux, mais des fragmens à cassure conchoüdale. Celte apparence cristalline est surtout frappante dans la poudre des plaques anales et génitales.

Toutes les coupes horizontales, de quelque partie du test qu'elles proviennent, inontrent la continuité des réseaux dans le sens de la hauteur comme dans le sens de la largenr. La même continuité s'observe jusque dans les sutures qui se présentent au nicroscope sous la forme de bandes rectilignes (Tal. II, fig. 19); et il n'y a pas jusqu'aux bords des ouvertures oủ les réseaux ne soient parfaitement eirconscrits, par exemple, autour des pores ambulaeraires (fig. 19), sur le pourtour de l'ouverture buccale, etc.

Les coupes verticales sont encore bien plus instructives, car elles montrent la manière en laquelle les grands et les petits tubercules se forment et la différence qu'il y a, sous le rapport de la structure, entre la couche externe et la couche interne. La fig. 16 représente une partie d’une pareille coupe destinée à rendre ces rapports phus sensibles. Les trois renflemens prineipaux, l'un au milieu et les deux autres sur le bord, représentent la coupe de trois gros tubercules, séparés par des tubercules plus petits. On remarquera que les réseaux calcaires et leurs mailles sont plus petits et plus circulaires dans les couehes externes et à lintérieur des tubercules que dans les couches internes (fig. 16 et 17). La surface du mamelon est revêtue d'une bande circulaire qui se détache plus ou moins du reste de la masse. Les mailles du milieu du tubercule sont juxtaposées sans ordre apparent (fig. 16a), tandis qu'elles forment, sur ses flanes, des lignes symétriques et régulières, 'qui convergent de lıaut en bas, ou mieux de l'extérieur ì la base de l'axe idéal du tubercule. Les petits tubercules sont composés de réseaux plus uniformes; cependant l'on remarque encore ici des traces de lignes convergentes. Le mamelon des petits tubercules, 'orsqu'il existe 
(fig. 16 b), se fait remarquer par sa strueture vitrée. Dans les couches externes du test, les réseaux calcaires sont, ou disposés en lignes horizontales (lig. 17c) ou bien répartis d'une manière plus irrégulière (fig. 16); dans la couche interne, au contraire, ils se composent de grands réseaux allongés (fig. 16 e et fig. $17 d$ ), qui paraissent se relever parallèlement aux gros tubercules et s'abaisser dans les espaces intermédiaires (fig. 1(i). Bien que les réseaux calcaires passent d'une manière continue du test dans les tubercules, on n'en remarque pas moins, dans les coupes longitudinales de tests fortement cimentés, une bande plus foncée, rougeatre, qui passe sous les tubercules, et sépare en quelque sorte la substance de ces derniers de celle du test, circonstance qui semble expliquer pourquoi la base des tubercules est plus fortement pimentée que les tubercules eux-mêmes.

En soumeltant le test à l'action de l'acide muriatique, on voit les parties calcaires se dissoudre et occasionner une forte effervescence, qui est due à l'acide carbonique, qui devient libre. Pour peu que l'acide ne soit pas trop concentrẻ et que l'on ait soin de l'appliquer graduellement, on obtient par ce procédé un squelette mou, trẻs-délicat, qui, examiné au microscope, reflète d'une manière plus ou moins distincte les contours des réseaux calcaires, tout en montrant une structure fibro-granulaire et membraneuse (Tal. II, fig. 23). On obticut par ce procédé des squelettes mous aussi parfaits et aussi distincts que les réseaux calcaires eux-mèmes, lorsqu'on a soin d'appliquer avec précaution l'acide, et souvent mème on parvient à distinguer le mamelon (Tab. II, fig. 21).

En calcinant le test, on obtient des plaques avec leurs tubercules sans aucune altération. Cependant il arrive souvent que le test se délite en fragmens réguliers ou qüil se brise sous la moindre pression. Il ne saurait en être autrement, par la raison que le ciment organique que nous avons mentionné plus lıat, se trouvant réduit par l'action de la clıaleur à sa substance inorganique, perd sa force d'adhérence. Mais les rẻseaux calcaires se reconnaissent toujours de lit manière la plus distincte jusque dans la cendre, avec cette différence cependant qu'au lieu d'ètre vitrés et honogènes comme à l'élat frais, ils affectent une structure grenue, et conservent, lorsque l’incinération n'a pas été complète, une teinte roussàtre plus ou moins intense.

Les plaques génitales et les plaques anales noffrent rien de parliculier dans leur structure microscopique. Leurs réseaux calcaires sont petits et le pourtour des ouvertures génitales ct ocellaires présente la même apparence que celui des pores ambulacraires représenté Tab. II, fig. 19.

Quant a la composition chimique du test de l'Oursin, ce que nous venons de dire de sa struc- 
ture nous conduit á conclure de prime abord quî́l doit se trouver du carbonate de chaux parmi les substances inorganiques dont il se compose. Tiedemann déjả indique l'existence du carbonate et du phosphate de chaux. J'ai moi-même trouvé les proportions suivantes :

10) 3,384 grm. de test pris dans l'aire interambulacraire d'un grand Echimus lividus, domèrent $3,50 \mathrm{grm}$. de cendre, ce qui ètablit une proportion de $90,17 \%$ de cendre pour $9,83 \%$ de substance organique.

20) 1,624 grm. des aires ambulacraires du même Oursin donnèrent 1,505 de cendre, ce qui lait $92,67 \%$ de cendre et $7,33 \%$ de substance organique,

$\left.3^{\circ}\right)$ 2,170 grm. des aires anıbuacraires du mème Oursin donnèrent 2,021 de cendre, par conséquent $93,13 \%$ de cendre et $6,87 \%$ de substance organique.

La moyenne de ces trois expériences nous dome par conséquent $91,99 \%$ de matière inorganique sur 8,01 de substance organique.

II. le Professeur Brumner, de son còté, a obtenu les résultats suivans :

100 parties de cendre de même nature que celles mentionuées au $\mathrm{N}^{0} 1$ lui donnèrent :

$\begin{array}{lr}\text { Carbonate de chaux } & 96,27 \\ \text { Sulfate de chaux } & 1,53 \\ \text { Carbonate de magnésie } & 0,93\end{array}$

Des traces distinctes d'oxide de fer, mais point de vestiges d'acide phosphorique.

II. Brunner ne reconnut pas non plus la présence de la potasse. En revanche, il constata la présence du muriate et du sulfate de soude, qui cependant étaient en trop petite quantité pour quil pût en indiquer les proportions.

En appliquant ces résultats au test a l'élat frais, nous aurions :

Carbonate de chaux 86,81 .

Sulfate de chaux $\quad 1,38$.

Carbonate de magnésie 0,8 \%

Autres sels el perte 1,1\%.

Substance organique $\quad \mathbf{9 , 8 3}$.

100,00 .

Si dés-lors il est démontré que le test ainsi que les piquans ne contiennent qu'une très-miuime quantité d'acide muriatique et de chlorure de sodium, on en est à se demander, comme à l'égard des polypiers, pourquoi la nature n'emploie point pour la formation des animaux marins le dhore et le chlorure de sodium contenus en si grande abondance dans l'eau de mer. L'absence 
de phosphates est également un fait curieux à constater, ainsi que la quantité considirable de cendres comparativement à la substance organique.

Nous avons déjà mentionné plus haut le ciment qui sert à unir les différentes plaques du test. Les plaques anales jouissent en outre d'un mécanisme particulier : elles sont réunies par une membrane épaisse, contractile, qui se voit même à l'oil nu dans les interstices, et qui, en se contractant, déplace les plaques, ensorte que l’anus s'abaisse ou s’élève au gré de l'animal. Lorsqu'on soumet cette unembrane à l'action de la potasse pour la rendre plus transparente, on reconuaît daus son intérieur un tissu fibreux revêtu extérieurement par l'épithelium etla couche pimentée, et intèrieurement par une conche membraneuse très-mince. En ramollissant, au moyen de l'acide. la partic inférieure du test, on distingue en outre dans le squelelte organique plusieurs particnlarités dignes de fixer l'attention, el d'abord les contours des plaques et partant les divisions principales du test s'élèvent sous forme de carènes qui rendent les sutures d'autant plus distinctes: la membrane pimentée se laisse facilement enlever, et eII enlevant dans une préparation semblable l'anneau des plaques anales, on réussil aisément à mettre à jonr la membrane fibrense qui leur sert de support, et l'on y recomnaît distinctement de vigoureux faisceaux mnsculaires qui appartiennent a la classe des fibres mnsculaires composées (Voy. plus las les organes du mouvement). Ces muscles s'attachent probahlement à l'anus, et doivent à mon avis être envisagés comme les moteurs de cet organe (motores ani).

La face interne du test est revêtue, dans toute son étendne, par la membrane intérienre du test, qui entoure également l'intestin, les ovaires, l'oviducte et les branchies. Elle forme également le mésentère, qni entoure, ainsi que le péritoine des autres animaux dépourvus de diaplıragme, l'osophage, le cour, les artères et les veines, et communique en outre avec la membrane de la lanterne, dont nous traiterons à l'occasion des organes de la digestion. Celte même nuembrane forme sur chacune des sutures principales, un mésentère ovarien composé d'une double lamelle; clle enveloppe lovaire et loviducte, et est en un mot, dans le sens le plns étendu, un péritoine vibratile pour toute la cavite intestinale de l'Oursin.

La nembrane pimentée, enfin, revêt toutes les parties extérienres. Ehrenberge a prétendu avoir observé à sa surface un épithélium vilbratile; mais ni Forbes ni moi n’avons rien remarqué de semblable. 


\title{
CIIAPITRE II.
}

\author{
DES PIQUANS.
}

Les piquans qui recouvrent la surface des Oursins sont fixés sur les tubercules que nous venons de décrire dans le chapitre précédent; ils sont, comme ceux-ci, de grandeur variable, et l'on peut admettre qu'en gẻnéral leur taille correspond a celle des tubercules. Les uns et les autres atteignent leur plus grand développement sur le milieu du test, dans les aires ambulacraires et interambulacraires, ell diminuant plus ou moins vers la bouche et vers le cercle anal; et de mème qu'il existe entre les gros tubercules de plus petits tubercules (Tal. I , fig. 4, 5, 6, 9, 10 et 11), de même aussi l'on trouve entre les rangẻes des grands piquans primaires, secondaires, tertiaires et quaternaires, une quantité de petits piquans (Tab. I, fig. 1, 2 et 3).

Les piquans disparaissent autour de l'ouverture buccale, et la membrane buccale, au lieu d'ètre revêtue de véritables tubercules, ne porte que des plaques calcaires (Tab. V, fig. $73 e, d$ ). Il n'en est pas de mème des plaques anales et génitales, qui sont garnies de petits tubercules ( Tab. I, fig. 1, fig. ' $a$, fig. ' $b$, Tab. II, fig. 12, 12*,12**, Tab. IV, fig. $56 e, f$ ) portant des piquans de taille variable.

Dans tout piquant, qu'il soit grand ou petit, quil appartienne au test proprement dit ou aux plaques anales, l'on distingue une partie libre et une autre qui, cachée dans les tissus articulaires, sert uniquement à son articulation avec le mamelon du tubercule. La partie libre, conique, plus ou moins effilée, est à beaucoup près la plus considérable, et forme la baguette ou le piquant proprement dit (Tab. III, fig. $25 b, 28,29,39 d$ ). La partie inférieure, non libre, est cachẻe dans les membranes articulaires et les muscles des baguettes; elle comprend la tête ou la partie condylö̈de du piquant (fig. $25 a, 28$ et 29). Immédiatement au dessus de cette dernière, on remarque, ì la partie inférieure du piquant, un renflement annulaire qui sépare en quelque sorte la partic articulaire de la baguette proprement dite, et qui, is en juger par ses stries et par sa couleur, ressemble davantage à cette dernière qu'à la partie condyloïde; c'est la collerette du piquant. 
La longueur des piquans présente des variations trẻs-considérables dans le même individu; dans l'exemplaire de l'E. lividus, qui a servi à cette description, les plus grands piquans ambulacraires avaient une longueur de $10^{\prime \prime \prime} 5$, tandis que leur diamètre avait à leur base $0^{\prime \prime \prime} 5$; les plus longs piquans ambulacraires mesuraient de $8^{\prime \prime !}$ ì $8^{\prime \prime !} \mathbf{5}$; dans les premiers, le diamètre du bord de la collerette élait de $0^{\prime \prime \prime} \$ 3$, dans les deruiers de $0^{\prime \prime 75}$. La longueur des plus petits piquans des aires interambulacraires était d'un peu moins de $0^{\prime \prime \prime} 5$. Quant à la partie condyloïde, voici les dimensions que je lui ai trousées :

Longueur de la baguette. Longueur de la tête ou Rapport des deux longueurs. partie condyloïde.

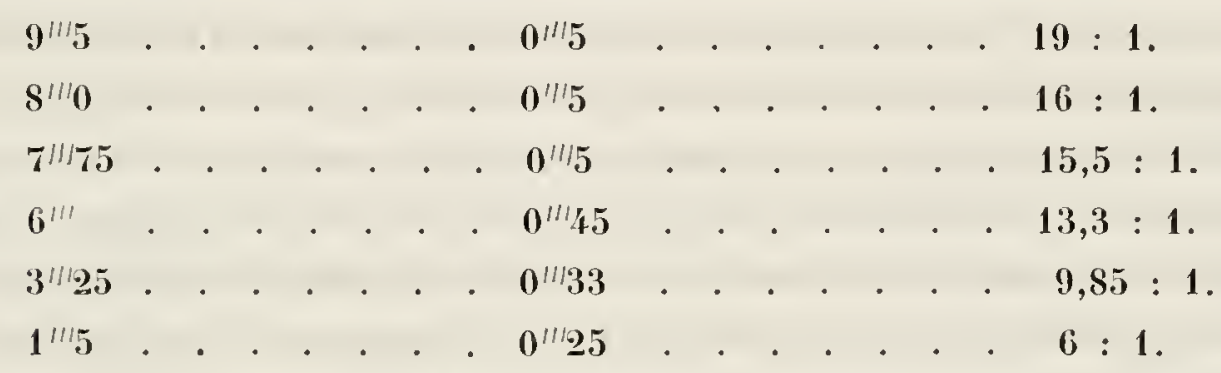

Il résulte de cet aperçu, que dans les petits piquans, la partie condylö̈le est relativement plus développée que dans les grands, Les jeunes piquans sont en général grèles; les grands, au contraire, et ceux de taille moyenne sont proportionnellement plus gros.

La forme des baguettes est cylindrique ou plutôt conique; elles atteignent leur maximum de largeur près de la tête, et se terminent ả leur extrémité par une pointe qui paraît émoussée à l'ail nu, au moins dans les exemplaires de grande et de moyenne taille (Tab. III, fig. 28), mais qui sous le microscope présente une forme arrondie (Tal. III, figg. 25 et 39). Une quantité de plis recouvrent le piquant dans toute sa longueur (Tab. III, fig. 25, 28, 29 et 39) et sont séparés par autant de sillons. Jaai souvent trouvé ces plis au nombre de $2 \mathfrak{5}$, nombre qui me paraît être le plus régulier; dans d'autres, j'en comptai 20, 21, 18, et parfois aussi sculement 12 ou 15. Le meilleur moyen de déterminer le nombre de ces plis est de prendre un piquant intact, de faire avec la pointe d'un couteau une incision sur l'un des plis, que l'on prend pour point de départ, et de tourner le piquant sur son axe en l'examinant à la loupe. De cette manière, tous les plis arrivent successivenent dans le cliamp de la loupe et se laissent très-facilement compter. Nous verrons plus bas, en traitant de la structure des piquans, qu'un moyen plus sûr encore, c'est de prendrc pour guide les coupes transversales, en les cxaminant au microscope. 
La baguette du piquant est toujours pimentée, sa couleur est brune dans l'E. lividus, et d'un bleu brunâtre passant au violet dans l' $E$. brevispinosus. La pointe est plus claire.

La collerette se présente extérieurement sous la forme d'un renflement de la partie inférieure de la baguette. Les sillons longitudinaux s'y continuent, mais en déviant horizontalement, de manière à former autant de divisions fort distinctes. Chacune de ces divisions se ternine ísolément et donne ainsi lieu à un petit renflement intermédiaire. C'est ce qui fait que, même à l'œil nu, mais surtout lorsqu'on vient à l'examiner à la loupe, l'anneau de la collerette se présente sous la forme d'une rosette d'autant plus distincte que le grossissement est plus fort (Tab.III, fig. 35). La plupart des renflemens de la rosette ont ả leur face supérieure uue dépression plus ou moins marquée, dépression qui n'est cependant pas également sensible sur tous les renflemens d'un même piquant. De leur face inférieure naît une arête qui se dirige obliquement en bas vers le condyle.

Le condyle se distingue par sa teinte blanche ou d'un blane verdàtre. Il n'est jamais pinıenté comme la baguette ou la collerette, parce que la peau externe ne le revêt plus; sa forme est cylindrique et légèrement rétrécie vers le bas; son bord supérieur est en contact avec les stries venant du bord inférieur de la collerette; sa face articulaire montre une dépression centrale ( Tab. III, fig. $36 b$ ), qui est entourée d'un bord circulaire renflé.

Pour bien connaître la structure intime des piquans, il importe en premier lieu d'en faire des cou pes minces et de les examiner ainsi au microscope, puis d'isoler le squelette organique par les acides. Ce dernier procédé m'a donné, pour les piquans, de neilleurs résultats que pour le test. Pour obtenir de fines lames transversales au moyen d'une fine scie, il est indispensable que le piquant ait été imprégné d'eau pendant un certain temps. A l’état sec, il est tellement cassant qu’il est impossible d'obtenir des coupes assez minces.

Si l'on vient á examiner une coupe du milieu d'un piquant de moyenne grandeur, l'on voit des lames rayonnantes diverger du centre vers la périphérie. En examinant cette coupe sous un faible grossissement et sur un fond noir, l'on voit partir du centre autant de rayons quil existe de sillons à la surface; en mène temıs les espaces intermédiaires sont occupés par des lamelles simples qui correspondent aux plis de la surface. Dans des coupes de jeunes piquans, il n'est même pas difficile de s’apercevoir que la substance centrale est formée de réseaux calcaires très-élégans.

Si l'on cxamine une coupe transversale, prise au milieu d'un piquant, el suffisamment mince pour être parfaitement transparente, même sous un fort grossissement (Tab. III, figg. 31), on remarquera que les bandes correspondant aux carènes de la surface (fig. 31 b) sont composées d'une sulstance calcaire simple, tandis que les espaces intermédiaires correspondant aux sillons 
( fig. 31 c) sont un réseau de mailles calcaires. On peut en outre se convaincre, au moyen de coupes tris-minces, que les rayons aree leurs réseaux calcaires ne sẻtendent pas tout à fait jusqu à la circonférence, mais qu'il y a entre deux renflemens de la rosette une incision ouverle et étroite en dehors, arrondie et élargie en dedans.

Les réseaux calcaires des sillons sont composés de mailles très-grandes accompagnées d'un certain nombre d'autres plus petites. Lia substance centrale en montre aussi d'inégale grandeur.

Une coupe longitudinale faite par le milieu du piquant (Tab. III, fig. 33) ma donné des résultats concordans. On y voit très-distinctement les couches de substance simple qui correspondent anx handes de la coupe transversale et aux carènes de la surface, et de mème les réseaux calcaires internédiaires entre ces bandes. La substance simple (fig. 33 et 3 i a) n'affecte aucune structure particulière. Il est vrai que souvent l'on y remarque de fines stries; mais elles ue sont quatcidentelles et dues au polissage. Souvent aussi cette substance montre, en diffẻrens endroits, des renflemens circulaires, tuberculeux, irrégulièrement fendillés, qui sont surtout nombreux près des feuillets du centre (fig. 3\%) et à la partie interne des deux lamelles extérieures ( fig. $34^{\circ}$ ). Iais il suffit d'un examen un peu attentif pour s'assurer qu'il ne s'agit point ici de véritables tubercules comme ceux de la surface du piquant, mais que ce ne sont que des piliers ronpus, intercalés entre les lamelles superposées.

Les rẻseaux calcaires intermédiaires entre les lames de la substance simple sont trẻs-distincts dans les coupes longitudinales, ce qui se concoit d'ailleurs, puisque leur direction est parallèle a l'axe du piquant. Les mailles du réseau sont ordinairement très-compliquées près de la pẻriphérie ( fig. $3^{\prime} c$, fig. $3 \%^{*}$ ), tandis que les lamelles du centre donnent lieu à des figures qui innitent un peu les bras d'une échelle (Tab. III, fig. 34). Les diffërentes lames d'un piquant ne sont pas toujours parfaitement parallèles dans les coupes longitudinales. En comparant entre elles une série de coupes, on voit qu'elles convergent un peu vers le haut, quoique d'une manière peu sensible. La convergence est plus marquée dans le has, ainsi que nous le verrons en traitant de la structure de la collerette et de la partie condylö̈le du piquant.

En traitant une coupe longitudinale d'un piquant à l'acide, on obtient, comme pour le test, un squelette organique trẻs-mince, qui montre encore la structure réticulée. Au lieu de la substance simple, on apercoit une masse délicate finement grenue. Les taches et la couche de piment de la peau externe ne disparaissent pas par l'action de l'acide; elles n'en deviennent au contraire que plus distinctes, et il faut tetre sur ses gardes pour ne pas confondre ou identifier la peau externe avec le squelette organique proprement dit. 
Il résulte de tout ceci que les piquans se composent de deux substanees ealeaires différentes; l'une que nous avons appelée la substance simple et l'autre qui est la substanee ealeaire réticulée. La sulstance simple est composée de lames disposées autour de l'axe central du piquant, et représentent autant de triangles qui s’élargissent vers la péripléric, oủ leur base, en s’arrondissant, détermine les earènes de la face extérieure. La sulsstance réticulée oecupe le centre du piquant et envoie des rayons entre les lames de la substanee simple, qu'elle sépare ainsi les unes des autres. Ces rayons réticulés s'élargissent également vers la périphérie; mais, eomme ils sont un peu moins longs que les lames de la substance simple, ils déterminent de légers sinus qui correspondent aux sillons longitudinaux de la surface du piquant.

Cette structure est commune à tous les piquans, aux jeunes comme aux vieux. Il u'y a que les proportions qui varient. La substance centrale augmente de volume avec l’àge. Je lui ai trouvé 0"0060 de diamètre sur une coupe de 0"0360; elle était par conséquent égale à un sixième du diauètre. Dans la coupe d'un petit piquant de 0/0022, la substanee centrale était de près d'un tiers. Il paraît aussi que cette substance n'est pas également développée dans toute la longueur d'un mène piquant; elle s’élargit du sonmet vers la base; ćest ansi que j’ai trouvé le diamètre d'une coupe transversale prise près du sonmet de 0/0120 et le diamètre de la substance centrale de $0^{1 / 046}$, par conséquent d'un tiers; au milieu du piquant, le diamètre de la eoupe était de 0//0280, celui de la substance centrale de $0 / / 006 \%$, par conséquent du quart; à la base, enfin, le diamètre de la eoupe éfait de 0 "0400 et celui de la substanee eentrale de 0 "060, par consé'juent de moins du sixième.

Une autre particularité des piquans consiste dans les stries eoneentriques et dans la coloration intérieure qui s'observent sur les coupes transversales. Les stries surtout se voient très-distinctenent, lorsquion a soin de faire une eoupe très-minec et de limbiber eonvenablement d'eau; elles se présentent alors sous la forme en laquelle je les ai représentées dans la eoupe de Tab. III, lig. 35. Cette circonstance nous permet de conclure que les piquans se forment par lames superposées. Il est probable que de nouvelles couches se déposent ainsi à des époques déterminées autour des anciennes, jusqu’a ce que le piquant ait atteint sa taille définitive. Ce mode d'accroissenent est rendu probable par le fait que ces lignes concentriques ne sont point des lignes circulaires; elles forment au contraire une série de segmens juxtaposès les uns aux autres et correspondant au contour du bord des lames du triangle de la substance simple. Si cette manière de voir est juste, il en résulterait que les diffẻrentes eouclıes ne devraient pas être d'égale épaisseur; et en effet, celles qui oeeupent le milieu de la couche sont plus larges que eelles qui sont 
plus voisines du bord. Si done il s'agissait d'établir une rẻgle à cet égard, on pourrait supposer que les couches extérieures sont plus minces, parce qu'elles sont obligées d'alimenter avec la même substance une plus grande surface; mais il est une circonstance qui s'oppose à cette explication, c'est que l'on trouve souvent entre deux couches également minces une couche beaucoup plus épaisse. Dans les piquans plus développés, le diamètre de ces couclies varie de 0,0012 " à $0,0035 "$ ".

La substance centrale montre une coloration d'un rouge très-intense, la partie colorée formant en quelque sorte un amneau dans lequel péuétre l'origine des rayons, ensorte quil en rísulte autant de divisions quiil y a de lames dans la substance sinte de la coupe. Chacune de ces divisions ressemble à un corps pyriforme, dont la convexité est touruće en dehors, et dont le bord correspond à celui des carènes extérieures du piquant, sans cependant lui être parallèle.

Les piquans de l' $E$. Sphera et brevispinosus montrent dans leurs parties essentielles la même structure que ceux de l'E. lividus, sauf quelques détails qui présentent des particularités de structure dignes de remarque. J'ai examiné de grands exemplaires de l'E. Sphara qui avaient longrtemps séjourné dans l'esprit de vin, et j'ai trouvé que leurs piquans, d'un bleu violet plus ou moins pâle, se distinguaient des autres en ce que la substance calcaire et les rayons réticulés élaient extraordinairement développés, comparativement aux lames de substance simple. C'est airsi que dans un piquant de même grandeur, dont la coupe prise au milieu du piquant mesurait $0^{1 / 0305}$, le diamètre de la substance centrale était de $0^{\prime \prime} 0160$, ce qui équivaut à plus de la moitié de la grandeur du premier. La substance centrale était entourée d'un anneau concentrique, les réseaux calcaires des rayons étaient larges et seublaient dẻborder en quelques endroits les lames de la substance simple. Je n'ai point aperçu de coloration particulière dans l'anneau central; en revanche, toute la masse du piquant et surtout la substance centrale montraient une teinte bleuàtre lorsqu'on l'examinait sur un fond noir. Les piquans de l'E. brevispinosus, qui ont la pointe blanche, tandis que leur hase est d'un hleu rougeàtre ou violet, lorsqu’ils ont séjourné quelque temps dans l'esprit de vin, m’ont semblé tenir le milieu entre l'E. lividus et l' $E$. Sphara relativement au développement de la substance centrale. Il est cependant digne de remarque que cette substance ne formait point un cercle, mais bien une sorte d'ellipse, et cette circonstance était sans doute due à la présence d'un cercle de mailles plus grandes que les autres. Les rayons étaient proportionnellement larges. Les lamelles simples en revanche présentaient une teinte d'un beau bleu violet qui formait un cercle a quelque distance de la périphérie.

Quant à la collerette, le meilleur moyen de l'étudier nous est offert par les coupes transversales. 
Une pareille coupe prise au milieu de la collerette d'un piquant de l'E. lividus montre au milieu tous les élémens du piquant, savoir : la substance centrale (Tab. III, fig. 35 a), les lames simples (fig, $35 c$ ) et les rayons composés de réseaux calcaires (fig. 35 b). Les ondulations du pourtour sont le résultat d’une accumulation de substance calcaire réticulée particulière (fig. $35 d$ ) qui délermine cette forme rosacée de la coupe, et est en outre remarquable par l'extrême petitesse de ses mailles. Quant aux dimeusions relatives des différentes parties, la substance centrale est proportionnellement trés-petite, les lamelles simples et les rayons se maintiennent dans les mêmes proportions qu'à la base de la baguette; Ja rosette en revanche est trés-large. J'ai mesuré une coupe de $0,0710^{\prime \prime}$ de diametre et j’y ai trouvé le diamètre de la substance centrale de $0 / 0070$, la longueur d'une lamelle de $0^{\prime \prime} 0195$ et la largeur de l'anneau extërieur de $0^{/ / 0125}$. Lorsque l'on examine la substance de l'anneau sous un fort grossissement et sur des coupes très-minces, on la trouve composée de réseaux calcaires d'une rare beauté ressemblant à ceux de la fig. $105 b$, de Tab. VI, qui appartiennent à une dent.

Les couleurs qui sobservent dans une coupe transversale de la collerette sont d'une rare beauté. J'ai vu au centre un anneau d'un jaune orange passant an rouge et, autour de celui-ci, un second anneau d'un beau jaune, puis un troisième qui était blanc, un quatrième d'un rouge écarlate, uı cinquième blanc, un sixième jaune, un septième błanc, un lıitième jaune et enfin un neuviẻme blanc ou d'un jaune mat qui touchait à l'anneau extéricur. Ces anneaux étaient surtout distincts sur un fond transparent. Sur un fond noir, on n'apercoit que les plus intenses, c'est-àdire quelques cercles rouges ou quelques jaunes; l'anneau extérieur était opaque sur un fond noir, mais d'une blancheur éclatante lorsque la lumière passait au travers du foyer.

Dans l'E. Sphxra, la collerette est extérieurement plus petite que dans l'E. lividus; aussi passe-t-elle plus insensiblement au condyle; mais on aurait tort d'en conclure qu'elle fùt plus mince. C'est tout le contraire qui a lieu; il suffit d'en examiner une coupe au microscope pour se convaincre que les lames simples sont étroites, tandis que les rayons réticulés sont considérablement developpés, et que le tout est enveloppé d’un anneau très-large d'une substance finement réticulée qui n'est point ondulée a son borl, comme c'est le cas des piquans de l'E. lividus. J'ai trouvé la largeur de cet anneau de 0/0070 dans une coupe transversale dont le diamètre était de 0 "0370. Sous le rapport de ses dimensions, l'E. brevispinosus tient le milieu entre l'E. lividus et l'E. Sphora. La collerette est un peu plus saillante que dans ce dernier; mais les petites carènes qui sont dirigées de la base vers la surface condyloüde ne sont pas moins développeies que dans l' $E$. licidus. Les lames simples sont plus larges, les rayons réticulés plus étroits 
que dans l'E. Sphxra; les mailles de la sulstance réticulée sont plus voisines de celles de ce dernier que de celles de l'E. lividus. En revanche l'anneau extérieur est également ondulé comme daus l'E. lividus; sa largeur était de 0//0110 dans une coupe d'un diamètre de 0"0530.

Quelquefois il se forme autour de la substance centrale, au moyen de masses calcaires intereilées transversalement, un second anneau qui partage les rayons de la substance simple en deux parties, l'une interne, centrale, qui est la plus petite, et l'autre externe et périphérique. Lorsque la coupe est très-mince, on voit cette substance calcaire oblique passer au moyen de piliers d'un rayon à l'autre, trahissant une disposition à former encore de nombreux anneaux semhables. Ces anneaux se renflent de distance en distance, et sont composés d'une quantité de parties juxla-posées, renflées au milieu et amincies aux extrémités. Sous un plus fort grossissement, l'on voit les renflemens des rayons réunis par de „petits piliers et près de la périphérie l'on remarque souvent, entre deux rayous, un réseau complet formé de petits piliers et de grandes mailles.

Quant à la formation de la collerette au moyen d'une substance finement réticulée, elle se trouve parfaitement confirmée par l'étude des coupes longitudinales (Tab. III, fig. 38).

\section{DE la tête ou parte condiloöde des plquans.}

La structure de la tète ou partic condyloïde des piquans est plus simple. Elle se compose d'une substance calcaire réticulée, á petites mailles et homogène dans toute son épaisseur. Une coupe faite par le milieu de la partic condyloïde, dans l'E. lividus, paraît blanche sur la circonfërence et forme au centre un anneau vert qui s'étend aussi quelquefois jusque vers la périphérie. Lorsque l'on examine cette coupe sous un grossissement médiocre (Tal. III, fig. 36), on trouve que la substance centrale foncée, correspondant par sa position à la facette articulaire du piquant ( fig. $36 b$ ), aussi bien que la substance périphérique (fig. $36 a$ ), se composent de réseanx calcaires a petites mailles, dont les petits piliers forment, par leur disposition génèrale, des lignes rayonıées, qui souvent ne sont pas entièrement droites, mais décrivent des courles plus ou moins sensibles du centre à la périphérie. On remarque entre la sulsstance centrale et le bord trois a cinq anneaux concentriques. Examinés sur un fond noir, la substance centrale et surtout l'anneau qui lui succède sont verts. Lorsque la coupe est suffisamment mince, on peut s'assurer, au moyen d'un plus fort grossissenent (Tab. III, fig. 37), que la substance centrale est conposée d'un réseau calcaire serréet très-ẻlégant, montrant sur ses bords des espaces arrondis libres. 
Lorsque la coupe transversale passe par la région inférieure de la partie condyloïde, on dirait au premier abord que les réseaux calcaires subissent une modification sensible au-dessus de la fossette : on voit des points noirs el des rayons d'apparence fibreuse, tantôt isolés, tantôt réunis par les rameaux latéraux. Cette apparence est déterminée uniquement par la poudre de friction qui remplit les intervalles entre les mailles dont la communication est alors beaucoup plus apparente qu'à l'état normal, lorsque les mailles des réseaux sont vides. Ces particularités sont les mèmes dans l'E. Sphæra et dans l'E. brevispinosus.

Les coupes longitudinales de la partie condyloïde ne sont pas moins intéressantes que les coupes transversales. On y voit, mème à l'xil nu, la partie brune de la baguette se continuer au delà de la collerette dans le domaine de la partie condylö̈de ef y devenir convexe, tandis qu'autour de ce dernier s'étend une bande verdâtre. Ce n'est qu'au dessous de celle-ci que se trouve la masse calcaire blanchequi forme la région inférieure de la partie condyloïde et la fossette articulaire. Cette disposition de la bande verte nous explique pourquoi, dans les coupes transversales, la teinte verte est tantôt centrale et tantôt s'étend jusqu’à la périphérie. Le premier cas a lieu lorsque la coupe transversale est prise très-bas, et le second lorsqu'elle est d'une région supérieure.

La fig. 38 de Tab. III représente une coupe longitudinale d'un piquant de l'E. lividus sous un faible grossissement. On voit ici les lames de la sulstance compacte avec leurs rayons intermédiaires se continuer dans l'in térieur de la partie condyloïde, la plupart et surtout celles du centre formant des lignes droites dans la plupart des coupes, tandis que les extérieures divergent plus ou moins. Dans d'autres, les rayons médians convergent en pointe; c'est ce qui se voit surtout lorsque la coupe est prise exactement par le milieu. Il y a divergence au contraire lorsqu'elle est plus ou moins latérale.

Antour de ces lames s'étend la bande verte et au dessous de celle-ci la bande blanche de la substance calcaire finement réticulée, qui d'ailleurs est la même dans les deux bandes; aussi passe-t-elle insensiblement de l'une à l'autre, ensorte qu'il n'y a que la couleur qui établisse une différence. Cette différence est moins sensible lorsqu'on fait passer la lumière dans le foyer; cependant l'on remarque que l'anneau vert prend une teinte plus ou moins bleuâtre qui passe parfois au violet, tandis que la bande blanche paraît sur certains points quelquefois entièrement verte.

La lande verte montre atissi, dans beaucoup de coupes, des divisions séparées par des sillons, comme le représente la fig. 38 de Tab. III. Mais elles ne peuvent pas être envisagées comme constantes. La bande b]anche ne montre rien de semblable. 


\section{$-55-$}

Dans tout le revêtement extérieur, qui forme les landes verte et blanche, les petits piliers des réseaux sont répartis avec une régularité adunirable, tantòt rayonnant vers le loord, tantôt prósentant une disposition plus lomogène; cette dernière se manifeste surtout ì lintérieur, et vers le liaut, tandis que la structure rayonnée se remarque de préférence á l'extérienr et par en bas. Souvent aussi l'une ou l'autre de ces deux formes sétend sur toute la coupe longitudinale, de mèue qüil arrive aussi qu’elles alternent daus certains piquans. La fig. 38 donnant un ilée juste des contours de la partie condyloüde et de la facette articulaire d'un piquant de l'E. lividus, ne dispensera d'entrer dans de plus amples détails sur ce sujet.

La coupe longitudinale du piquant de l'E. Splacera montre plusieurs particularités de structure, mais qui cependant, examinées au microscope, rentrent dans les formes que nous avons décrites ci-dessus. Les lames et les rayons de la baguette se prolongent un peu plus en avant dans la partie condylüde, et atteignent parfois la région qui, dans l'E. lividus, correspond au bord inférieur de la hande verle. A cóté des réseaux des rayons ordinaires, on remarque des réseaux intermédiaires ‘ue nous avons dejjà signalés dans les coupes transversales, et qui sont d’une rare magnificence dins les coupes longitudinales; ils se rapprochent sous plusieurs rapports des réseaux des dents (Tab. VI, fig. $10 j a$ ). La substance finement réticulée de la partie condyloïde est la même, mais moins développée, et forme dans sa disposition générale, d'une part, des rayons qui divergent vers la périphérie, et d’autre part des lignes arquées dont li convexité est dirigée vers la fossette articulaire. Celle-ci présente les mèmes réseaux réticulés que dans l'E. lividus; l'on y voit aussi quelquefois les espaces tubulaires se diriger perpendiculairement vers la surface de la fossette articulaire. Les coupes longitudinales de l'E. brevispinosus concordent parfaitemeut a vec celles de l' $\boldsymbol{E}$. lividus.

Si l'on examine la poudre d'un piquant sous un fort grossissement, on y reconnaîtra des débris de difiẻrentes formes et dimensions. La plupart ont l'apparence de bloes de rochers grands ou petits. Quelques-uns, surtout les petits, montrent la même forme et la même texture conchoïdale que les fragmens du test. Ceux de moyenne grandeur laissent souvent apercevoir des lignes droites ou courbécs d’une apparence assez élégante. Tantôt ces lignes sont à la face supérieure, tautot sur les brisures. Il y en a aussi sur lesquels on remarque des réseaux calcaires ou des fragmens de réseaux, et surtout des piliers brisés. Ces derniers (Tab. III, fig. 27) ressemblent en quelque sorte à des varices, et il faut ètre sur ses garles pour ne pas les envisager comme telles.

Quant à ce qui concerne la face supérieure des piquans, elle montre les mèmes stries longi- 
tudinales dont nous venons de parler à l'oceasion des fragmens. Les petits pirjuans qui reeousrent les plitques génitales et anales sont revêtus de petites arêtes ou dentelures très-élégantes qui s’aperçoivent déjả dans la fig. $25 \mathrm{c}$ de Tab. III, mais que l’on voit surtout bien dans la fig. 26 , qui représente le même piquant sous un fort grossissement. Elles sont disposées par lignes sur les carènes du piquant, et sont plus largés à leur lase qu'à leur sommet. Leurs détails s'aperçoivent surtout bien lorsque l'on comprime un piquant entre deux plaques de verre. On voit alors sur le bord de certains fragmens diverses bandes qui montrent a leur tour les lignes concentrigues déjả mentionnées ei-dessus, et les parties transparentes permettent de distinguer les arètes ou dentelures dont elles sont revêtues: les petites soies du test ont les mêmes arètes; mais je ne saurais dire si elles se trouvent sur les piquans plus développés. La substamee de ces petites arètes est du calcaire compacte sans réseaux ni cellules.

L'analyse chimique des piquans m’a donné les résultats suivans : $1^{\circ}, 1,235 \mathrm{grm}$. de piquans d'un Echimus lividus ayant 10 lignes de large et 3 lignes et demie de laut, donnèrent 1,115 grm., ce qui fait par conséquent $90,28 \%$ de eendres et $9,72 \%$ de substance organique; $2^{\circ}, 5,009$ grm. de piquans d'un Eehinus de $2^{\prime \prime} 2^{\prime \prime \prime}, 5$ de large et $1^{\prime \prime} 2^{\prime \prime \prime}$ de haut, donnèrent $4,629 \%$ de cendres, ce qui fait 92,41\% de eendres et $7,59 \%$ de substance organique.

Cent parties de cendre du $n^{\circ} 2$ comparées à cent parties de piquans frais, donnèrent à M. Brumer : 100 parties.

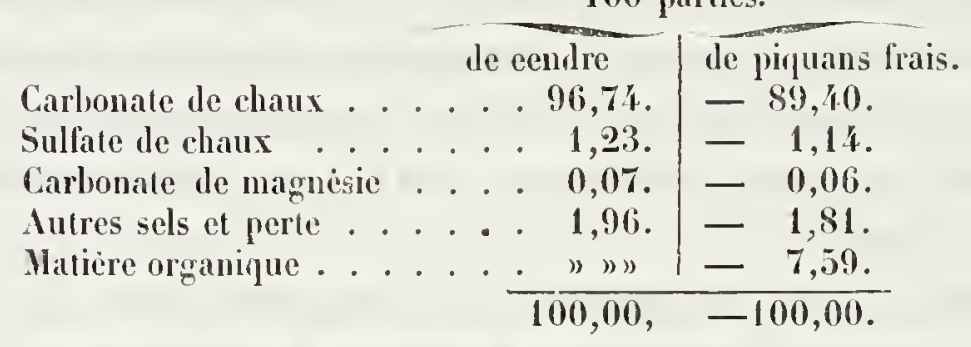

Il s'y trouva aussi des traces évidentes d'oxide ferreux. En revanche, on n’y retronva aucune trace d'acide phosphorique ni de potasse.

11 résulte de la simple comparaison du piquant et des tubercules eorrespondaus, que la fossette articulaire du prenier doit itre susceptible de se tourner sur le tulpercule. Comment cette rotalion s'opère-t-elle? C'est ce que nous apprend l'étude des parties molles qui entourent le piquant.

L'articulation du piquant (articulatio aculci) (Tab. III, fig. 28 et 29) entoure le piquant fixé sur le renflement articulaire du tubereule, et s’étend en s'élargissant depuis la eollerette jusqu'au pourtour extérieur du tubercule. Les parties qui la eomposent sont : la membrane cxtęne pimentée, les muscles et la capsule articulaire. 
$1^{\circ}$ La membrane externe pimentée sétend comme peiu extérienre par dessus l'articulation du piquant, et de lí par dessus le piquant lui-même, oủ l'on peut quelquefois l'enlever avec le coutcau, en grattant les endroits qui montrent des taclies de piment. Mais elle se remarque surtout bien sur les piquans qui ont séjourné quelque temps dans l'acide muriatique el qui se trouvent privés de leurs parties calcaires, comme j’en ai représenté un Tal). III, fig. 39. Celte couclıe de piment pénètre aussi, à ce qu’il parait, l’intérieur du piqnant; du noins l'on tronve, lorsque l'on enlève les parties calcaires d'une coupe longitudinale ou transversale, une membrane criblée de petites boules et de taches grenues. La même membrane s'olsserve aussi d'une manière trèsdistincte sur les fragmens des plus petits piquans.

C'est surtout sur l'articulation que la membrane pimentée se laisse enlever facilement. Elle montre iei des taches de piment plus ou moins grandes, repose immédiatement sur la surfaee des muscles, et se continue plus ou moins dans la couche pimentée du test.

פo Les muscles du piquant (musculi s. motores aculei) sont recouverts immédiatement par la memlorane pimentée et se dirigent du bord, et surtout de la fossette articulaire du piquant vers le pourtour extérieur du tubercule. En général, il y a autant de museles, ou plutôt de faiseeaux musculaires, qu’il existe de prolongemens des stries à la collerette. Leur direction vers la périphérie du tubereule s'observe surtout hien lorsqu'on coupe un piquant immédiatemeut au dessus de la collerette el que l’on déploie les parties antérieures de l'articulation. La mème opération peut. aussi se faire sur des piquans ramollis par l'acile (roy. Tab. III, fig. 39). Chacun de ces faisceaux, séparé des faisceanx voisins auxquels il envoie parfois cependant une ou deux fibres musculaires, se compose d'autres faisceaux plus petits et très-nombreux, qui montrent des fibres distinctes et souvent aussi des indices de stries transversales, comme nous le verrons plus las en traitant des muscles.

$3^{\circ}$ La capsule articulaire est une menbrane ligamenteuse très-forte, composie de deux couches distinctes qui unissent la partic articulaire du piquant avec le tubercule, mais de telle sorte cependant, que la fossette articulaire du prenier et le sommet du second demeurent libres. Le feuillet intéricur naît inmédiatement au dessus du bord qui entoure la fosselte articulaire du piquant; le feuillet extérieur, au contraire, sur la face externe de larticulation (fig. 396 ); l'un et l'autre s'attachent autour du tubercule proprement dit.

La capsule articulaire se distingue par sa solidite ainsi que par sa couleur hlanche. Examinée au microscope, elle se montre composée de fibres très-fortes ayant 0,/001 jusqu'à 0,"003 de diamètre, qui se eomposent i leur tour de filets plus fins encore, et se distinguent par leur appa- 
rence particulière des fibres musculaires et de celles du ligament extérieur oblique de la charpente masticatoire. On aperçoit entre elles de fins filets qui correspondent aux filets du tissu cellulaire de l'Oursin.

On le voit, il existe entre le piquant et le test une sorte d'arthrodie : lorsque tous les muscles agissent simultanément, ils doivent nécessairement serrer le piquant contre le tulsercule. Reste à savoir maintenant si une contraction simultanée de tous les muscles est possible, ou sill n'est pas plutôt indispensable qu'une partie soit en repos, tandis que l'autre se contracte. Si ce dernier cas a lieu, le piquant devra toujours être ramené vers le côté oủ s'opère la contraction, et, par le fait, le mouvement circulaire aura son plus grand contour au sommet, et sera le plus petit it la base du piquant. Si les muscles se contractent et se relàchent successivement, il devra en résulter un mouvement de rotation. Il décrira ainsi un cône dont la base correspondra au sommet du piquant et le sommet à sa base, à-peu-près comme les cils vibratiles dans leurs mouvemens infondibuliformes.

L'extrême solidité de la capsule articulaire explique pourquoi l'articulation ne se disloque pas lorsque l'animal, après avoir contracté ses tubes ambulacraires, fait reposer sur quelques pirquans tout le poids de son corps. Elle empèche en même temps que des secousses trop violentes n'occasionnent une désarticulation de ces mêmes piquans.

Jusquả quel point les piquans contribuent-ils à la locomotion? C'est ce que nous verrons plus bas, en traitant des fonctions des tubes ambulacraires. 


\section{CHAPITRE III.}

DES TUBES AMBULACRAIRES.

Avant de commencer la description de ces organes qui jouent un si grand rôle dans les Oursins, nous derons nous entendre sur la signification des divers noms qu'on leur a donnés. Les anciens naturalistes employaient le nom d'ambulacres pour désigner les zones porifères qui séparent les différentes aires; il y en a même qui comprennent dans cette appellation non seulement les zones porifères, mais aussi l'aire ambulacraire que ces zones embrassent. Les anatomistes, au contraire, ont transféré ce nom aux tubes ou suçoirs membraneux qui sortent par les trous des zones porifères. On me fera peut-être le reproche de ne pas suivre l'exemple de mes prédécesseurs; mais comme ce Iravail fait partie d'une série de inonographies publiées par M. Agassiz, j’ai dù avant tout rechercher la confornité des termes; et pour éviter toute confusion, jappelle tubes ambulacraires les organes dont il est traité dans ce chapitre : quant au nom d'ambulacres, je l'emploierai avec M. Agassiz, comme synonyme de zone porifère.

Les tubes ambulacraires frappent d'une manière toute particulière dans les individus vivans, parce que, comme l'a déjà fait remarquer Della Chiaje *, ils atteignent et dépassent mème, dans les vrais Echinus, la longueur des plus grands piquans, et parce que l'animal en étend et en retire alternativement une partie, soit pour toucher les objets qui l'entourent, soit pour se mouvoir. Dans les exemplaires conservés dans l'esprit de vin, ils sont constamment contractés et trés-courts ( Tab. IV, fig. 56 et 5T); ce qui fait qu'on ne les remarque pas aussi facilement, à moins que les piquans n'aient été enlevés préalablement. Ceux de ces tubes qui s'ouvrent dans les pores des ambulacres sont cylindriques et ont, à leur extrémité libre, des ventouses, et dans leur intérieur, une cavité qui communique avec les cavités des branchies internes : ce sont les tubes ambulacraires proprement dits. D'autres, en bien moins grand nombre, sont fixés à la membrane luc- 
cale, et portent pour eette raison le nom de tubes ou sucoirs buccaux : ils diffèrent sous plusieurs rapports des tubes ambulacraires, et comme ils sont intimement liés à l'appareil buceal, nous ne nous en occuperons pas ici ; nous réservant de les étudier en détail au chapitre de la membrane buccale. Quant aux rapports qui existent entre ces deux sortes de tubes et les branclies, nous en traiterons en parlant de ces derniers organes.

Comme les tubes anthulaeraires eorrespondent par leur nombre et leur position aux pores des ambulacres, ils sont aussi comme eux disposés par doubles séries (Tab. IV, fig. 56 et 57), qui s’étendent de l'ouverture buccale à l'appareil génital. Ordinairement petits autour de la bouclıe, ils s'agrandissent vers le milieu du test pour diminuer sensiblement à l'approclıe des plaques génitales. Quant à eeux qui entourent l'ouverture buccale, ils ne sont disposés en séries qu'autant que les pores qui leur donnent passage le sont eux-mêmes.

Dans les exemplaires conservés dans la liqueur, on trouve souvent les tubes ambulacraires renflés à leur hase; dans les exemplaires vivans, ils m'ont paru être plus uniformément cylindriques, sans que je puisse cependant affirmer qu'il n'existe aucune trace de renflement. La partie eylindrique ou la tige du tube est au reste molle, eontractile, flexible et s'affaisse quelquefois sur elle-même par l'effet de la eontraction du canal central qui la traverse. La ventouse est un peu plus dure; elle paraît quelquefois eontractée dans les individus morts; mais souvent aussi elle est étalée et dure : ćest une eonséquence de la présence d'un squelette calcaire qui se trouve à l'intérieur, et qu'Alex. Monro paraît avoir remarquẻ le premier. Essayons d'étndier ee squelette avant de passer à l'examen de la structure des parties molles.

Lorsqu'on place une ventouse isolée dans de l'eau, sur un fond noir, el qu'on l'examine au microseope, sous un faible grossissement, on y reconnait la présence de plaques ealeaires, même à travers les membranes de la ventouse. Mais les différentes pièees s'observent plus distinctement lorsqu'on comprime la ventouse. Pour obtenir le squelette ealeaire complètement intact, on sounet la ventouse pendant quelque temps à l'aetion d'une solution de potasse qui, en rongeant peu à peu les parties molles, les rend transparentes, à tel point qu'on finit par voir le squelette entier dans toute sa perfection. Ce squelette se compose de deux parties distinetes, une supérieure, que j’appelle la rosace (Tab. IV , fig. 61), et une inférieure, l'amean calcaire (Tab. IV, fig. 62). Ce dernier se trouve à la base de la ventouse; le premier, au eontraire, est placé près de la surface.

Dans l'E. lividus, la rosace se distingue par un caractère général (Tab. IV, figg. 59, 60 et 61), qui consiste en ce que les plaques dont elle se compose forment un cercle complet, au milieu 
Iluquel se trouve une grande ouverture circulaire; de cette ouverture partent des fissures linéaires qui se prolongent entre les différentes plaques, et s’élargissent sur le milieu de leur longueur eI une vacuole allongée et ouverte en dehors. Le pourtour de la rosace est formé par les aspérités des plaques.

Le nombre des plaques n'est pas le même dans toutes les ventouses; le nombre normal cepenlant paraît être de cinq (Tab. IV, fig. 60); ensorte qu'il y eu aurait une impaire antérieure, fleux gauches et deux droites. Fréquemment ces cinq plaques sont de grandeur inégale ; souvent aussi il n'y en a que quatre (Tab. IV, fig. 59 et 61); mais il est rare d'en rencontrer trois, six ou sept. En général, on pourrait croire quil n’y a rẻgulièrement que quatre plaques de grandeur inégale; mais en examinant la rosace de près, on trouve que l'une des plaques est divisée en deux, ensorte qüil y en a réellement cinq; mais dans ce cas, il faut être bien sur ses gardes pour ne pas prendre pour une suture quelque brisure accidentelle. Celles-ci se reconnaissent toujours it l"irrégularité de leurs lords, et, en employant un plus fort grossissement, on apercoit ordinairement de petites esquilles caleaires qui s'en sont détachées.

Les vieux exemplaires de l' $E$. brevispinosus montrent sonvent sept plaques. On en rencontre aussi fréquenment six dans les grands exemplaires de l'E. Sphora. Il se pourrait par consé'luent que le nombre elı augmentàt avec l'àge; ce qui se trouverait justifié par cette autre circonstance, que la grandeur des plaques, ainsi que nous l'avons vu plus haut, est variable.

La position de ces plaques calcaires, relativement à la bouche et à l'anus, est très-difficile à déterminer, parce que l'on ne peut jamais savoir avec certitude si la tige du tube n'a pas été dérangée. J'ai cependant cru remarquer que dans les tubes des ambulacres anlérieurs impairs, la plaque impaire antérieure ètait dirigée dans l'axe de la zone porifére.

Ces plaques sont aplaties, et clıacune d'elles présente quatre bords différens : $1^{\circ}$ le bord interne, qui est arqué et contribue ainsi pour sa part à former l'ouverture centrale; $2^{\circ}$ les deux bords latéraux, qui divergent de dedans en dehors, chacun d'eux prẻsentant un ou plusieurs petits sinus qui forment les vacuoles intermédiaires entre deux plaques; les sutures aboutissent tantòt lans une aspérité de la circonférence, tantòt dans un espace intermédiaire entre deux aspérités ; $3^{0}$ le bord externe enfin, qui est liẹrissé d'aspérités obtuses, mais assez saillantes. Il m’a paru que les plaques diminuaient d'épaisseur de dehors en dedans.

Les plaques de la rosace se composent d'un réseau de mailles présentant une disposition particulière (Tab. IV, fig. 60). Les mailles sont plus ou moins arrondies, et les piliers ordinairement disposés de telle maniëre quiune partie (ceux qui sont les plus forts et qui peuvent ètre envisagés 
comme les principaux piliers longitudinaux) diverge plus ou moins de l'intérieur à l'extérieur, et se termine au bord extérieur en saillies arrondies, qui rappellent certains ornemens des édifices gothipues. Quelquefois l'on apercoit une petite plaque calcaire, placée transversalement entre deux saillies; mais le plus souvent ces saillies sont séparées par un sinus plus ou moins profond. Parfois aussi, l'on remarque que l'une ou l'autre est garnie, mais d'un côté seulement, par le tissu calcaire; d'autres fois on voit de petites carẻnes les entourer, et enfin il arrive aussi qu'elles sont complètement dégarnies. Le bord interne des plaques est tellement mince, que ce n’est qu’à grand peine que l'on y aperçoil quelques traces de piliers longitudinaux. Le tout ne forme qu'une couclıe très-mince de petites mailles calcaires.

J'ai mesuré le diamètre d'une ventouse prise dans l'ambulacre d'un grand exemplaire de l'E. lividus, et je l'ai tronvé être de $0^{\prime \prime}, 0480$; le diamètre de la rosace était de $0^{\prime \prime}, 0340$ el la longueur d'une plaque isolée, de $0 ", 0115$.

L'ammeau calcaire est situé au dessous de la rosace, à la base de la ventouse et près du sommet de la tige du tube, ensorte qu'on l'aperçoit déja en partie à travers les plaques calcaires, ainsi que cela est représenté Tab. IV, fig. 59 et 60 . Nais pour l'examiner convenablement, il faut renverser la ventouse. Cet anneau est un organe calcaire très-délicat qui, lorsquón l'examine sur uı fond noir, se distingue par sa blancheur, non seulement des parties molles environnantes, mais encore de la rosace. Comme cette dernière, il augmente d'épaisseur de dedans en dehors; son bord externe forme un carré ou un polygone à cinq, six, sept ou lunit côtés, qui, au lieu d'ètre rectilignes, sont plus ou moins arqués. Le bord interne laisse bien aussi apercevoir des traces de cette disposition polygonale; mais, en somme, il se rapproche davantage de la forme circulaire.

Cet anneau est composé d'une plaque calcaire criblée de trous (Tab. IV, fig. 62), se prolongeant jusque près du loord interne, mais sans s'ouvrir dans la cavité intérieure; ils sont, au contraire, toujours fermés jar de petites poutres transversales, ensorte qu'on dirait que le bord interne est ourlé d’un fil calcaire circulaire. Vers le bord externe, la substance calcaire est en général moins trouée et plus contiguë. Jai trouvé son diamètre de $0^{\prime \prime} 0185$, son épaisseur moyenne de $0 / 100030$.

Exposés à l'action de l'acide muriatique, les squelettes calcaires dégagent, en se décomposant, une quantité d'acide carbonique; ensorte quils contiennent, sans aucun doute, un carbonate quelconque, vraisemblablement du carbonate de chaux; car il est à présumer qu'en génẻral leur 
substance chimique ne diffëre point de celle des autres tissus calcaires. Leur cendre contient également les formes essentielles des réseaux calcaires.

Il est très-possible que ces squelettes se soient également conservés dans les espèces fossiles ; les observations microscopiques ne manqueront pas de nous fournir, avec le temps, des renseignemens positifs ì cet égard (Voyez pag. 2).

Avant de passer aux parties molles des tubes ambulacraires, 11 me reste encore à mentionner quelques tissus calcaires particuliers que jai observés dans leur tige, en disséquant des individus conservés dans de l'esprit de vin: c'étaient, dans l'E. lividus, de petites aiguilles calcaires en forme de croissant (Tab. V, fig. 65), qui, entièrement isolées les unes des autres, ćtaient accunulées en nombre plus ou moins considérable, le plus souvent sous la menbrane pimentée de la tige. Dans l'E. brevispinosus (Tab. V, fig. 66), ces aiguilles se ramifient à leur extrémité; on les trouve dans cette espèce, comme dans la précédente, sous la couche de piment dans la tige du tube (Tab. V, fig. 67). Quelquefois aussi on en rencontre dans les ventouses ainsi que dans les autres organes intérieurs et extérieurs. M. Miescher les a même trourées dans les ovaires de l'E. lividus. Ils résistent i l'action de la potasse, mais se dissolvent dans l'acide muriatique, en dégageant de lacide carbonique. Reste à savoir si ces petits corps calcaires sont des produits artificiels, ou bien s'ils existent aussi dans l'animal vivant. J'ai trouvé leur longueur de $0^{\prime \prime}, 00110$ et leur largeur de 0,"00015, dans l'E. livilus.

Quant aux parties molles de la ventouse, sou entonnoir terminal, d'apparence lisse, présente une quantité de renflemens (Tab. IV, figg. 59) séparẻs par autant de dépressions. Cette disposition est surtout frappante dans l'E. brevispinosus : de chaque renflement part un pli saillant qui se dirige vers le centre en se rétrécissant de plus en plus (fig. 59c); il en est de même des dépressions correspondantes (fig. 59 d). Nous verrons plus bas à quel usage sert sans doute celte organisation particulière de la ventouse.

Lorsqu'on veut étudier les parties molles situées sous l'épithélium et la couche de piment, il est indispensable de traiter plusieurs ventouses a l'acide muriatique, pour lissoudre leur squelette calcaire, tandis que d'autres devront ètre exposées à l'action de la potasse, afin de donner aux parties molles une plus grande transparence. Dans les préparations ramollies par l'acide, on reconnaît très-distinctement, surtout vers le bord de la ventouse, l'épithélinn, dont on apercoit même quelquefois les carreaux, et sous celui-ci la couche de piment. Dans quelques préparations, on distingue encore des fibres rayonnées recouvertes par la couche de pinent, ce qui s'explique par ce fait, que l'ouverture de l'anneau calcaire est plus grande que l'ouverture du canal central 
du tube (Tab. IV, fig. 59a). II existe en effet entre ces deux ouvertures (celle de l'anneau calcaire et celle du canal central), dans la plupart des tubes, un tissu membraneux, composé de fibres trèsdistinctes qui rayonnent en divergeant du centre vers la périphéric (fig. 596 ). Les plaques du squelette calcaire empêclsent ordinairement d'observer la direction ultérieure de ces fibres dans les exemplaires frais, ainsi que dans ceux qui n'ont pas été rendus suffisamment transparens. Mais si l'on est parvenu à dissoudre ce squelette sans léser les parties molles de la ventouse, l'on voil des fibres rayonnées s'étendre jusqu'à la périphérie, entre la couche de piment et les plaques calcaires. J'ai trouvé qu'en gẻuéral l'E. brevispinosus s'appropriait le mieux à ces sortes de recherches. Dans plusieurs exemplaires de l'E. Sphera, j’ai en outre, parfois remarqué, au dessus de cette couche fibreuse, une couche grenue que je suis cependant disposé à regarder comme un produit artificiel.

On peut admettre par avance qu'il existe aussi des fibres circulaires dans la ventouse ; cependant je ne suis pas en état de donner à leur igard des renseignemens bien délaillés. Dans bon nombre de préparations exposées à l'action des acides et de la potasse, elles ne sont pas visibles du tout. En revanche, l'on aperçoil quelquefois sur les plaques calcaires qui ont été rendues transparentes par la potasse, des stries circulaires qui sont très-probablement des impressions de fibres musculaires circulaires. On en découvre également dans les déchirures fraîches du tuhe. Ces fibres sont extrêmement fines; leur épaisseur n'est que de 0",0002; mais elles n'en portent pas moins tous les caractères des fibres musculaires.

Les plis, ainsi que les fibres musculaires superposés aux plaques de la rosace, semblent deslinés à fixer la ventouse; peut-c̀tre les premiers se dilatent ef se contractent-ils dans ce but. Le squelette calcaire fournit sans doute à tout l'appareil un point d'appui, et lui permet ainsi de sattacher plus fortement. Celte supposition semble justifice par le fait que dans les tubes buccaux, qui, à raison de leur position, ne contribuent que peu ou point à la succion, ainsi que nous le dẻmontrerons au chapitre de la membrane buccale, la rosace est plus imparfaite, tandis que l'anıeau calcaire manque complètement.

Le traitement par la potasse nous a en outre fail connaître plusieurs autres points de l'organisation de la ventouse: les plis de sa surlace deviennent peu ì peu transparens, tout en se raccourcissant (sans doute par l'effet de la dissolution), de manière quïls affectent en quelque sorte la forme de cornets répartis à la circonférence de la ventouse. Il ne s'agit donc pas ici de nouveaux organes; mais l'on acquiert par ce moyen la certitude qüil existe réellement des tissus memliraneux au dessus des plaques calcaires, ce qui ne s'aperçoil pas dans les autres méthodes 
de préparation. Je ne saurais décider si ces tissus que jai représentés, Tab. V, figg. 64 $c$, d’aprẻs un tube buccal, sout des matrices pour les plaques calcaires et en particulier pour leurs dentelures, on s’ils servent à un autre usage.

Les parois de la partie cylindrique du tube montrent, à l'état de contraction, une quantité de plis trausverses et circulaires (Tab. IV, fig. 58) qui disparaissent lorsque le tube se dilate. Ces parois elles-mèmes sont composées de l'épithelium externe, de la pean, y compris la coucle de piment, de la couche musculaire et de la couclıe intérieure avec son épitlıelium, ses vaisseanx sanguins et probablement aussi ses nerfs.

Lépithelium semble être un épithelium vibratile. Ia couche de piment et la peau sous-jacentes ont ensemble une épaisseur assez. considérable; elles se laissent en partie détacher des couches inférieures, et leurs lambeaux montrent d'une manière très-distincte, à leur face externe, les plis circulaires mentionnés ci-dessus, lesquels sont bien moins distincts à la surface des couclıes internes. Ces lambeaux permettent en outre d'observer la superposition de la couche de piment sur le corium fibreux qui représente les plis. J'ai trouvé en général ce corium fibreux plus distinct dans les tubes de l'E. brevispinosus que daus ceux de l'E. lividus. Il est lors de doute qu’il existe également, dans les couches sous-jacentes à la couche pimentée, des fibres musculaires longitudiuales et transversales; c'est ce dont on peut s'assurer en examinant l'extrémité inférieure d'un tube arraché de sa base, ou bien la tige, après en avoir enlevé la couche de piment. Les fibres longiludinales formeut de longs faisceaux dirigés de bas en haut. Les fibres transversales, plus extérieures, forment de petits faisceaux dont plusieurs correspondent aux plis transverses ci-dessus mentionnés. Quelquefois l'on croit aussi apercevoir des plis obliques; mais ils ne semblent être qu’apparens et résulter du déplacenent des fibres transverses de la paroi opposée ("). Le diamètre moyen des fibres musculaires que jai observé est de 0",0003. La potasse les rend égalemeut transparens. Immédiatement au dessus se trouve la couche interne avec son épithelium, qui, selon toute apparence, est aussi viloratile.

Dès qu'on a enlevé la couche de piment avec la couche externe de la peau, on remarque sur les tiges des tubes intacts une ligne qui s’étend le long du milieu de leurs faces antérieure et poslérieure, accompagnée parfois de deux lignes latérales secondaires. Lorsqu'on réussit à rendre la tige transparente au moyen de la potasse, on voit que la ligne médiane contient un vaisseau renfermé dans une gaine et s'étendant sur toute la longueur du tube, depuis sa base jusqu'à la

(") Par fibres obliques, j’entends ici des fibres qui remonteraient obliquement ou en spirale, mais non pas celles qui sinterposent entre les fibres longitudinales et transversales, sous la forme de branches obliques anastomosées. 
ventouse. Dans les tubes de moyenne grandeur, la largeur moyenne de ce vaisseau est de 0 ",0011, et le diamètre moyen de sa gaine de $0 ", 0038$. J'ai cru aussi reconnaître parfois des vaisseaux transverses dans les plis du tube, notamment dans l'E. brevispinosus.

L'ouverture extérieure du canal central se voil très-bien à l'oil nu, au milieu de la ventouse. A l'état de contraction, son diamètre paraît être un peu plus petit que le diamètre de la cavité de la tige. Cette dernière s'élargit lorsque le tube est contracté vers sa base. Mais si l'on ouvre un tube et qu'on l'examine par sa face interne, l'on y voit fort bien les faisceaux de fibres musculaires longitudinales faire saillie, dès qu'on a enlevé la membrane interne. Je ne saurais dire si la mêne rlose a lieu à l'état vivant.

Cette organisation des tubes explique parfaitement leur fonction telle qu'on l'observe dans l'animal vivant. La dilatabilité et la contractilité si considérables de la tige sont dues principalement au jeu des fibres musculaires longitudinales et transversales. Lorsque la tige est le plus dilatée, les fibres musculaires longitudinales sont à l'élat de repos. Lorsque les fibres circulaires se contractent, l'intérieur du cylindre se rétrécit, et ces fibres contrilsuent ainsi probablement d'une manière indirecte à allonger le tube. Le contraire a lieu dans les deux sortes de fibres musculaires, lorsque la tige se raccourcit. Le squelette calcaire de la ventouse, sert évidemnent à donner à cette dernière une plus grande solidité. La succion s’opère d’après le mécanisme commun à toutes les ventouses en général, ćest-à-dire par l’action des muscles qui la revêtent, jointe à la dilatation des plis. Nous traiterons plus bas des rapports des tubes avec l'extension et la contraction des organes branchiaux.

Jusqu'ici je me suis en vain appliqué à trouver des nerfs dans les cylindres et dans les ventouses des tubes; ni les exemplaires vivans, ni ceux conservés dans l'esprit de vin ne m’en ont fourni la moindre trace. Et cependant je ne doute pas qu'ils n'existent, et même en grande quantité; car l'animal se sert de ses tubes comme d'organes du toucher, et il paraît qu'il discerne de cette manière fort bien les objets qui l'entourent; il les retire dès qu'on les touche avec une aiguille.

Les tubes servent en outre à la locomotion. Il est vrai que les opinions des auteurs sur ce point sont très-contradictoires. Aristote, Réaumur, Al. Monro ( $\left.{ }^{1}\right)$ et Agassiz $\left({ }^{2}\right)$ ont envisagé les piquans comme servant a la locomotion, tandis que Gondolph $\left(^{3}\right)$ remarqua le premier que ces animaux se servent de leurs tubes dès qu'ils veulent changer de place. Ce fait a été plus tard

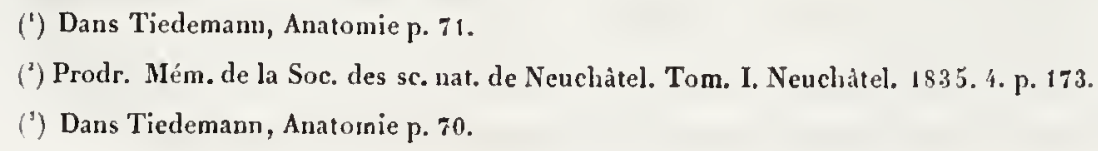


confirmé par Baster, Bianchi, Spallanzani, Tiedemamn('), Della Chiaje $\left({ }^{2}\right)$, Gravenhorst $\left({ }^{3}\right)$, Forbes $\left({ }^{4}\right)$, et je m’en suis assuré noi-même sur des animaux vivans $\left({ }^{5}\right)$. L'animal se fixe ilu moyen des ventouses de ses tubes aux objets avoisinans. Veut-il progresser, il reconnaît au moyen d'autres tubes les oljets adjacens, s'y fixe et reliche ceux qui adhéraient les premiers. Les piquans ne semblent avoir pour but que de faciliter la rotation du corps en agissant á peu prìs comme des balanciers ou des gouvernails; ils ne deviennent de véritables appuis que lorsque tous les tubes sont retractés, comme cela arrive peu de temps avant la mort, lorsque l'animal est ì sec. Mais mène dans ce cas, il n'y a point de locomotion; les piquans entrent, au contraire, en mouvement lorsque l'on excite l'animal, qu'on le retire de l'eau pour le mettre à sec, etc. Les tubes ambulaaraires sont par conséquent les principaux organes locomoteurs, ainsi que cela résulte des expépériences détaillées de 'Tiedemann, expériences qu’il est très-facile de répéter. Je n’ai jamais vu nager les vrais Oursins; ils ne font que ramper sur le fond de la mer, ensorte que l'on est forcément obligé dabandonmer lhypothèse que les piquans agissent comme des rames. Si l'on jette un Oursin dans la ner ou dans un vase rempli d'eau, il ne s'y maintient nullement en suspens, unais tombe aussitot au fond.

(') Anatomie p. 70 .

(') Mémorie vol. II, p. 339. Instituzioni di anatomia e fisiologia comparata, Tom. I, Napoli, 1832. 8. p. 61.

(3) Tergestina. Breslau, 1531. S. p. 94, 95.

(4) History of brit. Starf. London, 1S41.8. p. 143.

(3) Depuis la publication de mou Prodrome, je me suis également convaincu que les tubes ambulacraires sont les principaux organes du mouvement. Voyez ma Monographie des Scutelles : Observations sur les progrès récens, etc., pag. 11 et 12. 


\title{
CHAPITRE IV.
}

\author{
DES PËDICELLAIRES.
}

Il existe à la surface extérieure de l'Oursin des appendices pédicellés qui ont été décrits pour la première fois par $\mathbf{O}$. F. Müller (*) sous le nom de Pédicellaires (**). On en distingue trois sortes qui sont 1) les pédicellaires gemmiformes, 2) les pèdicellaires tridactyles, 3) les pédicellaires ophicephales. Comme ces derniers prédominent et sont surtout dèveloppès sur le pourtour de la bouche, je les appelle aussi pédicellaires buceaux, bien qu ils se trouvent également sur d'autres régions du test. Ces trois espèces de pèdicellaires ont un caractère commun qui consiste dans la présence d'un squelette calcaire intérieur entouré de tissus mous et composé de deux parties fort distinctes, la tête qui est à l'extrémité libre, et la tigge. Nous n’aurons à nous occuper ici quue des pédicellaires gemmiformes et des tridactyles. Les pédicellaires oplbicéphales étant trop intimement liés à la membrane buccale pour pouvoir en être séparés, nous en traiterons au chapitre de cette dernière. Les uns et les autres entourent les piquans; mais comme ils sont beaucoup p'us courts et plus grẻles que ces derniers, on ne les voit bien que lorsque le test est entièrement dèbarrassé de ces épines, et même, dans ce cas, il est encore bon de tenir le test sous l'eau, pour qu'ils n'échappent pas à l'observation.

$1^{\circ}$ Les pédicellaires gemmiformes (Tab. IV, fig. 10-13) sont placés tout autour des tubercules, surtout des plus gros, sur les aires ambulacraires aussi hien que sur les aires interambulacraires

(*) Otto F. Müller Zool. danica Fasc. 1, p. 16 (Edt. allemande p. 53-55). Ce naturaliste les envisageait comme des animaux parasites particuliers, dont il décrit trois espèces sous les noms de Pedicellaria globifera, triphylla et tridens. Probablement la première correspond a mes pédicellaires gemmiformes, la seconde aux oplicćphales, et la troisième aux tridactyles.

(") Depuis la rédaction de ce travail, Sars et Forbes ont aussi fait des observations sur les Pédicellaires. Voy. Forbes History, etc, p. 156, 174, 186. Voyez anssi parmi les anteurs plus anciens, Tiedemann p. 98, et Della Cliaje Memorie Vol. 2, p. 324 . 
et même quelquefois sur les zones poriféres. Ils sont composés d'une tige longue et grèle, sur laquelle est fixé un renflement que jappelle le bouton, et que l'on reconnaît facilement à sa couleur qui est d'un rouge brun. La longueur moyenne de la tige, dans les exemplaires conserves dans l'esprit de vin, est de 1/20 a 1//8. La longueur de la base du bouton est d’à peũ près $0 ", 005$, relle du bouton lui-même de $0 ", 020$.

Le squelette calcaire contenu dans le bouton est, ainsi que nous l'avons dit plus haut, séparè de celui de la tige. Le premier est désigué sous le nom de téte, l'autre sous celui de massue. Ces deux squelettes sont moins éloignès l'un de l'autre dans les pédicellaires gemmiformes que dans les deux autres espéces. Leur position relative est représentée sous un fort grossissement dans la lig. 40, Tab. IV. La ligne qui forme le contour indique les parties molles. Pour en bien saisir tous les détails, il importe de les préparer préalablement à la potasse.

La tête est composée, dans l' $E$. livillus, de trois parties igales fixées sur une base commune et correspondant clıacune à l'un des bras en forme de pince (Tab. IV, fig. 4'. e). Cette base s'appuie elle-mème sur une pièce calcaire (figg. 4. f $f$ ) qui correspond à la partie que je désigne dans les pédicellaires buccaux sous le nom d'arc ou de canal semicirculaire. Chacun des trois bras de la pince (fig. $44 c$ ) est composé d'une lame aplatie, allongée, à peu près quadrangulaire, linitéc par des carẻnes ou nervures latẻrales, et percée d'une quantité de petites ouvertures. Clıaque bras est en outre armé d'une double paire de dents, l'une supérieure (lig. $44 d$ ), l'autre inférieure (fig. f f e), qui sont dirigées en dedans et se terminent plus ou moins en pointe. $\Lambda$ la base de la tête, les trois bras alternent avec les pièces basilaires. Celles-ci sont au nombre de trois (fig. 44 b) et se composent chacure de deux plaques paires poiutues en haut et arrondies en bas, entourant de leurs carènes une plaque calcaire élégamment celluleuse. Ces pièces basilaires adhèrent ellesmêmes à la pièce arquée, triangulaire (fig. 44 ), qui est ici très-simple, ayant sa base tournée en haut et sa pointe en bas.

Les trois bras de la pince peuvent opérer des mouvemens de va et vient, c'est-à-dire s'ourrir et se fermer sans inconvénient, comme cela se voit sur l'animal vivant. Les dents se rapprorhent dans ce cas et peurent mème saisir et réduire certains oljets. La longueur moyenne de r'es têtes est de $0 ", 020$.

La massue (Tab. IV, lig. 4. $\mathrm{f}$ ) est très-longue et très-grèle, et pénètre jusque daus l’intérieur du bouton, ensorte qu'elle est beaucoup plus rapprochèe des pièces basilaires que dans les deux autres espèces de pédicellaires. C'est au milieu qu'elle est le plus grèle; elle s’èlargit graduellement vers le tıat, et surtont vers le bas. Son extrémité supèrieure se termine par un renflement assez unar- 
'jué que jappelle la tête de la massuc, et qui, relativement à la partie moyenne, est plus développée que dans les deux autres espèces. L'extrémité inférieure est également renflée et tronquée lrusquement. La substance de la massue se compose, comme dans les deux autres espèces de pèdicellaires, de fines ramules calcaires longitudinales, ou de bandes séparées par des espaces transparens. Si l'on examine cette partie sous un fort grossissement, l'on remarque que les bandes calcaires qui font une légère saillie à la surface sont réunies par des piliers transverses qui, sous un moindre grossissement, font l'effet de stries transversales. Ces bandes calcaires longitudinales, ‘ui ordinairement se brisent en travers et donnent lieu à de petites saillies sur les brisures, s’ètendent du bord de l'extrémite inférieure jusqu'à l'origine du bouton qui termine la massue. Sur celui-ci, les piliers transverses deviennent plus forts et plus nombreux, et se cliangent en véritables réseaux calcaires.

Les parties molles qui entourent la massue n’ajoutent guère à son diamètre. Il n'en est pas de même de la tête, dont elles augmentent considérablement le volume; aussi le bouton se présente-il sous la forme de trois lobes réunis, dont les extrémités sont rapprochées comme la corolle d'une fleur dormante pendant la nuit (Tab. IV, fig. 40 et 41). La figure 42 représente une coupe transversale prise par le milieu des trois lobes. Vers le sommet, les trois lobes du bouton s'écartent considérablement et prennent en quelque sorte la forme d'une dent (fig. 43), et c’est dans l’intërieur de ces lobes renflés que sont logées les trois pinces qui se trouvent ainsi revêtues par les parties charmues de l'organe.

Lorsque l'on est parvenu à rendre ces pédicellaires transparens, au moyen de potasse très-étendue, l'on voit un épithẻlium s'étendre de la massue sur les lobes du bouton; mais la forme renflée de ce dernier n'en est pas moins due à une masse particulière, d'une apparence grenue, quelquefois légèrement fibreuse, et que je crois devoir envisager comme composée de nuscles, quoique je n'y ai pas aperçu d'une manière distincte des fibres musculaires. Une masse semblable se voit à la base du bouton et entoure la tête de la massue. La tige, en revanche, n'est revêtue que d'une mince couche de parties unolles, composées, à ce qu'il m’a paru, d'un èpithélium, d'une couche de piment et d'une membrane fibreuse au dessous de cette dernière.

Nous avons dẹjà dit plus lıaut que les lobes du bouton peuvent s'ouvrir et se fermer sans qu’il en résulte aucun dommage pour le squelette calcaire. On peut s'assurer que les mênes mouvemens s'opèrent aussi pendant la vie.

$2^{\circ}$ Les pèdicellaires tridactyles sont remarquables par leur grandeur; ce sont sans doute ceux 
que Baster connaissait dẹjà. Tiedemann (") et Della-Chiaje (“*) les mentionnent également. Il est facile de les distinguer des deux autres espẻees, même à l'oil nu; mais ec qui les earactérise surtout, e'est leur structure mieroscopique et particuliẻrement leur squelette. Comme les pédieellaires genmiformes, ils entourent les tubereules, partieulièrement eeux des aires interanbulaeraires; mais jusqu'ici je n’ai pas pu reconnaitre pourquoi l'on trouve de préférenee en tel endroit des pédicellaires gemmiformes, et en tel endroit des pédicellaires tridaetyles. La longueur moyenne de tout l'organe, sur des éehantillons eonservés dans de l'esprit de vin, est de $2^{\prime \prime \prime}$ i $2^{\prime \prime \prime}, 2$; la longueur de la tête $2^{\prime \prime}, 5$ ì $0,55^{\prime \prime}$.

La fig. 45 de Tab. IV représente la forme de la tête ealeaire d'un pédicellaire tridactyle. Trois pinces eonvergentes (b), séparées par des interstiees vides, en forment, eonjointement avec le renflement de la base (a), les élémens essentiels. Chaque pinee se compose de deux pièees fortement dentelées à l'extérieur, et d'une pièee moyenne plus profonde et à jour: la tête est par eonséquent eoneave à l'intérieur, et très-étroite, comparativement à sa longueur. La forme du renflement basilaire ressort mieux de la figure ei-jointe que ne pourrait le faire une deseription détaillée. Il est inutile de dire qu'il existe aussi iei trois pièees eorrespondant aux trois pinees ; elles sont triangulaires, eonvergent sous un angle de $120^{\circ}$ et présentent chacune une grande ouverture près de l'angle de eonvergenee. Les pièces correspondantes aux ares semieireulaires ne paraissent pas exister. La massue ressemble, par sa forme et ses dimensions, à la massue des pédicellaires buceaux (Tab. IV, fig. 46); elle se eompose de filets ealeaires et, à son extrénité près de la tète, de réseaux ealeaires, absolument semblables à eeux des deux autres sortes de pédicellaires. Les parties molles qui l'entourent sont plus développées que dans les pédicellaires gemmiformes, et peut-être même que dans les pédicellaires buecaux; elles se eomposent, ainsi que nous le verrons en traitant de ees derniers, d'un épithélium externe, d'une couehe de piment et de fibres longitudinales et transversales.

$3^{\circ}$ Les pédicellaires oplicéphales qui se trouvent ça et lả à la surfaee du test ressemblent si forl, par leur squelette ealeaire, de mème que par leurs parties molles, aux pédicellaires buecaux, que nous pouvons en renvoyer la deseription au ehapitre suivant, qui traite de ees derniers. J'ai trouvé quelquefois de très-petits pédieellaires dont les pinees sont larges, en forme de feuilles arrondies ou échancrées dans le haut, mais dont la base est peu saillante et dépourvue de piẻees

\footnotetext{
(*) Anatomie p. 98.

(**) Mémoire Vol. II. p. 324.
} 
analogues aux canaux semicirculaires. Je n'ai pu m'assurer si ce sont des pédicellaires d'une espèce particulière, ou s'ils ne sont que le jeune âge des pédicellaires ophicéplaales.

La première idée qui se présente à l'esprit, éest que les diverses espèces de pédicellaires dont nous venons de traiter ne sont que des formes variées d'un seul et même organe. Cependant, je crois devoir envisager la chose différemment, parce que je n'ai point trouvé de formes transitoires, et parce que les différences m’ont paru assez prononcées pour justifier l'idée que ce sont des organes indépendans les uns des autres.

$J$ 'ai cru remarquer que dans les individus adultes de l' $E$. brevispinosus, les tridactyles et les ophicéphales prédominent. Leurs pinces se font remarquer en ce qu'elles s'élargissent et deviennent lancéolées vers la partie supérieure; tandis qu’elles ont à l'intérieur une carène, et à l'extéricur, aiusi que sur les flanes, des réseaux calcaires très-élégans qui s’étendent presque jusqu'au bord: les carènes sont proportionnellement étroites, et leurs dents petites. A la base, chacune des pinces se transforme en une large plaque, qui conserve encore à l'intérieur sa carène moyenne. La face inférieure de la pièce basilaire des pédicellaires est conformée, dans l'E. brevispinosus, de la même manière que dans l'E. lividus. Les massues, ainsi que les parties calcaires des pédicellaires ophicéphales ne se distinguent que par leur plus grand développement. Il existe aussi de petits pédicellaires ophicéphales absolument analogues à ceux de l' $E$. lividus.

L'E. Sphara montre les trois espèces de pédicellaires. Leurs parties calcaires et leurs parties molles sont les mêmes que dans l' $E$. lividus.

L'usage de ces petits organes n'est pas encore connu d'une manière précise. On est naturellement porté à les envisager comme des organes de préhension, d'autant plus qu'ils s'ouvrent et. se ferment comme les doigts de la main, comme Monro (") l'a observé le premier. Cette hypothèse est surtout vraisemblable à l'égard des pédicellaires genmiformes, dans lesquels les trois parties de la tête s'ouvrent et se ferment, tandis que les parties extéricures très-épaisses servent peut-être de moteurs, si toutefois il est vrai que ce soient des muscles. Cette interprétation offre moins de vraisemblance à l'égard des tridactyles et des ophicéphales, parce qüil n'existe pas un appareil aussi vigoureux de parties molles (contractiles). On peut même ouvrir les pinces jusqu'à un certain degré, sans les endommager. Mais s'il est vraisemblable que ce sont des organes de préhension, leur utilité n'en est pas encore démontrée, attendu qu’il n'existe dans leur voisinage aucun canal par lequel ils pussent faire passer les objets qu'ils auraient saisis. Les transmettent-ils

(*) Vergleichung des Baues und der Physiologie der Fische, mit dem Baue der Menschen und der ührigen Thiere, tihersetzt von J. J. Schneider. Leipzig 1787. 4. p. 88. 
de l'un ì l'autre pour les faire arriver jusqu'i la bouche? Cette hypothèse est peu vraisemblable, attendu qu'il existe à la base de la membrane buccale, à côté des branchies externes, une interruption dans leur succession. Peut-être pourrait-on admettre que, dans le mouvement de transmission, cette lacune est remplacée par un mouvenent vibratile de la surface des branchies externes. Quoi qu’il en soit, que l’on envisage les pédicellaires comme des organes de préliension, ou qu'on leur assigne d'autres fonctions, leur nombre et la constance de leur disposition suffisent pour nous convaincre de leur importance. Leurs tissus mous leur donnent en mème temps la faculté de s’allonger et de se rẻtrécir considérablement, et par conséquent d'exécuter des mouvemens sensibles dans l'eau. Les pédicellaires gemmiformes sont, sous ce rapport, moins favorisés, tandis que les tridartyles et les oplicéplıales sont douies de celte faculté à un très-lıut degré.

(*) L'incertitude qni a rígné jusqu' ici sur la nature des P'́diceltaires et la diversilé d'opintions que professent uncore à leur snjet les naturalistes, montrent assez les difficultés que présente la solntion de ce probleme. Cet enbarras provient sans. doute de l'igurance complète dans laquelle on se trouve sur le diveloppement des embryons les oursins. En effet, si l'on arait pu poursuivre tous les clangemens que l'auf de l'Oursill sulit, depuis la ponte jusyu'ì l'entier accroissement de l'animal, on saurait si les Pédicellaires sont des organes formés par l'animal . et quel rapport nalurel les lie à l'onveloppe extérienre du corps à laquelle ils sont attachés, ou, s"ils sont parasites, à quelle c'poque đu développenent de l'onrsin ils commencent à s'y liser, et sons quelle forme ils s'y attichent. Xe pourant dans ma position faire des recherches successives sur cette intiressante question, je me permels de sommettre ici à l'attention des naturalistes qui habitent le roisinage des côtes maritimes, quelques considérations qui les engageront peut-être à de nourelles recherches. Et d'abord les Pédicellaires existent-ils sur les plus petits exemplaires d"Oursins comme sur les plus grands? existent-ils à toutes les saisons de l'année? présentent-ils à toutes les saisons les mèmes caractìres? les mâles en sont-ils ununis comme les femelles? Une réponse posilive à ces diverses đuestions acheminerait sans doute vers la solution du problime. Je me les suis adressćes, parce que je ne puis me défendre de l"idée que les Pédicellaires ne soient des embryons d'Oursins, qui après leur éclosion se fixeraient sur le test de leur mére. La ressembance frappante qu’ont les arceaux des Pédicellaires arec l'appareil masticatoire des oursins m’a donné cette idée qui ne paraîtra pentêtre pis un paradoxe, si l'on considère la diversité de formes qu’affectent les Pédicellairea sur le mème Oursine et surtout si l'on se rappelle que les Conatules, avant de devenir libres, sont aussi pédiculées, comme nous l'a appris M. Thompson, et sil'on considere en mème temps que certains Echinodermes subissent les changemens de formes les phus itranges, comme l'a dímontré Sars pour l'Asterias sanguinolenta. Le peu que l'on connait du mode de déreloppenent des animax rayonnés est bien fait pour pịuer notre curiosité et nons préparcr aux découvertes les plus inattendues.

(Agassiz.) 


\section{CIIAPITRE V.}

\section{DE LA MEHBRANE BUCCALC ET IES ORGANES QUI EN DÉPENDENT.}

Il règne tout autour du bord de l'ouverture inférieure du test une memlirane très-solide qu'on désigne sous le nom de membrame buccale (membrana oris) (Tab. I, fig. 3 et Tab. IV, fig. 57). Elle est renflée au milieu, plus ou moins déprimée ou aplatie sur les bords, et percée au centre par l'ouverture buccale (orificium oris), qui est occupée par l'extrémité des cinq dents. Suivant qu'elles sont plus ou moins distantes, ces dents laissent entr'elles un passage plus ou moius large qui conduit au pharynx et au canal intestinal.

On s'apercoit, au premier coup d'wil, particulièrement dans les grands exemplaires de l'E. brevispinosus, moins distinctenıent dans l' $E$. lividus, que l'ouverture buccale, qui paraît circulaire, ne l'est cependant pas parfaitement, mais qu'elle est au contraire légèrement pentagonale, et que la membrane buccale y adhère par cinq lambeaux ou lèvres (labia). Ces lèvres sont peu prononcées et en apparence simples dans $E$. lividus; dans l'E. brevispinosus elles sont, au contraire, divisées en deux lambeaux montrant une organisation différente. Les lèvres internes (labia oris interna) composées de plis très-minces et légèrement adlérens par leur surface opposée, ont leur plus fort renflement dans l'espace intermédiaire entre deux dents. Ce renflement, qui alterne par conséquent avecles dents, ainsi qu'avec les ambulacres buceaux, et, par la ıtême raison, avec les aires ambulacraires, correspond aux aires interambulacraires. De plus, ce renflement est divisé en deux parties par une iucision longitudinale plus ou moins profonde, qui correspond à l'espace intermédiaire entre deux dents. Enfiı, ces mêmes lèvres se distinguent encore par la présence d’une quantité de petits renflemens ronds ou anguleux ressemblant fort aux galets d'un pavé. Les lèvres externes (labia oris externa) forment cing lambeaux triangulaires en forme de croissant, dont le renflement semble correspondre plus ou moins à ceux des lèvres internes, avec cette seule différence qu'ils sont dirigés en dehors, tandis que ces derniers le sont en dedans. Elles sont également marquées, du còté de l'ouverture buccale, de tubercules qui passent sans modifications aux tu- 
bercules de la lévre interne à laquelle ils sont contigus, tandis que la partie dirigée vers la périphẻrie de l'animal a la mème apparence que le reste de la membrane buccale. Je dois cependant faire observer ici que jïinore si cette duplicature des lèvres est complète, ou si elle ne se montre qu'après la nort, comme e'est par exemple le cas des paupières de l'Octopus. Dans l'E. lividus, cette disposition des lèvres est moins compliquée. Nous avous ici de grandes lèvres simples garnies de très-petits tubercules (Tab. V, fig. $68 \mathrm{~b}$ ), mais présentant des plis rayonnants très-développés qui s'étendent vers la périphérie, tandis que dans l' $\boldsymbol{E}$. brevispinosus, ils sont bien plus faibles, presque indistincts et n'existent qu’à la face extérieure dés lèvres externes.

Les lèvres juxta-posées se confondent à leur base et passent ainsi à la membrane buccale interne pour ne former qu'une seule membrane qui se divise en deux régions : $1^{\circ}$ la région interne, s'étendant de l'ouverture buccale au cercle interne des pédicellaires buccaux, et $2^{\circ}$ la région externe, s’ětendant du cercle interne des pédicellaires buccaux jusqu’à la soudure de la membrane buccale av'ec l'ouverture ou le bord du test.Vue à l'œil nu, la première région paraît complètement molle et sans trace de dépòts calcaires; tandis que c'est tout le contraire dans la région externe. Sous le microscope, il en est tout autrement, ainsi que nous le verrons plus bas. La région interne est plus libre que la région externe et n’adhère pas immédiatement à. la charpente dentaire. Enfin, la membrane buccale forme une saillie plus ou moins prononcée au milieu, et sa surface extéricure est plus ou moins colorẻe; elle est gẻnéralenent brune dans l'E. lividus et violette dans $\boldsymbol{T} \boldsymbol{E}$. brerispinosus. Ces teintes résultent d'une couche de piment adhérente à la face extérieure de la membrane buccale.

Sous un faible grossissement, les renflemens tuberculeux de la membrane buccale de l'E. brevispinosus apparaissent comme de petites touffes plus ou moins claviformes au sommet, mais en général molles; leur largeur est de $0 ., 0040$ à $0^{\prime \prime}, 0060$ et à $0^{\prime \prime}, 0110$, dans la partic renflée en forme de massue. A l'ẻtat frais, ces renflemens sont entourés d’un épithélium, qui ne perntet pas de les étudier en détail sans préparation préalable. Leur forme cependant rappelle, sous le microscope, les villosités du canal intestinal des animaux supéricurs. Lorsqu'on est parvenu à rendre ces renflemens transparens, au moyen d'une solution de potasse, l'on remarque, à l'intérieur de la couche épithélienne, une masse fibreuse dont les fibres rayonnent de l'axe du renflement vers les bords (Tab. V, fiğ. 69); circonstance qui rappelle, jusqn'à un certain point, la structure des villosités intestinales. Ces fibres rayonnantes sont fines, délicates et de couleur jaunâtre, après avoir été exposées à l'action de la potasse. On apercoit parfois entre elles des fibres isolées plus fortes, plus développées, qui, par leur couleur, rappellent un tissu élastique, 
mais qui ne se ramifient pas d'une manière aussi caractéristique que les autres. Leur signification in'est demeurée inconnue jusqu'ici.

Ces renflemens tuberculeux semblent n'être autre chose que des excroissances de la membrane buccale. Je ne saurais dire s'ils contiennent un réseau de vaisseaux ; cependant la chose me parait probable; car dans les endroits oủ la base des renflemens passe aux plis, l'on voit des cylindres isolés qui ont tout-a-fait l'apparence de vaisseaux sanguins, et dont la largeur est d'environ 0",00065. Ces cylindres ne s'apercoivent que lorsque l'organe a été rendu transparent par la polasse.

De la face interne de chaque lèvre interne, une paire de carènes, qu'on désigne sous le nom de ligamens labiaux dentaires internes (ligamenta labiorum dentalia interna) (Tab. V, fig. 75), s’étend vers l'espace intermédiaire entre deux dents. Ces carẻnes sont garnies latéralement d'appendices, tandis que leur surface interne, qui occupe l'espace entre deux dents, montre des collicules disposés en séries, comme on les observe sur l'ésophage de beaucoup de reptiles.

Dans la membrane buccale elle-même, les plus petits vestiges des réseaux calcaires s'étendent jusque dans le domaine des lèvres internes.

Les livvres externes, qui, sans alterner avec les lèvres internes, sont cependant disposées différemment, sont formées de doubles plis qui se continnent, d'une part, dans le fenillet externe les lèvres internes correspondantes, et, d'autre part, dans la partie avoisinante de la membrane huccale; elles sont épaisses et marquées de taches de piment à leur face externe, moins, à ce qu’il paraît, sur leurs bords, et encore moins à leur face interne. On les isole très-facilement, et l'on distingue alors parfaitement les lèvres internes, leurs ligamens labiaux dentaires et leurs rapports avec les dents et la charpente dentaire. Leur structure correspond parfaitement a celle des parties buccales, et compte le même nombre de pièces constitutives; elles ont le même épithélium, la même couche pimentée, les mêmes couches fibreuses, et l'on y remarque aussi de nombreux fragmens très-distincts de réseaux calcaires. Les lèvres simples de l'E. lividus (Tab. V, fig. 68), examinées à l'neil uu, ont tout-a-fait l'apparence de la membrane buccale, bien qu'clles soient garnies d'une quantité de plis et de bandes (fig. 68 a) qui divergent vers la périphérie et ne disparaissent que lả oủ commencent les pédicellaires buccaux, c'est-à-dire à l'intérieur du cercle des tubes ambulacraires buccaux. Leur fice interne est en général brune; mais elle affecte aussi Jes teintes plus claires, et l'on y reconnaît, ainsi que dans l'E. brevispinosus, les plis labiaux dentaires (plicae labii dentales), les renflemens pairs et les sillons principaux situés entre ces derniers. En revanche, les tubercules en pavé sont moins développés, plus limités dans leur répar- 
tition, et entourés, à l'extrémitè de la surface interne des lèvres, d'une rangée de tubercules plus grands et nıoins colorés : le bord des lèvres lui-même paraît être festonné; au moins les festons buccaux cylindriques de couleur noire sont-ils ici disposés par séries saillantes.

Le double pli des lèvres se laisse déployer très-facilement, et sa liaison avec la membrane buccale, qui est retroussée près de l'ouverture buccale, est très-faille. On voit très-bien les plis longitudinaux de la face externe de la lèvre se prolonger jusqu'au bord de l'ouverture buccale, ct en partie sur la face interne de la lèvre, en donnant lieu à des verrues en pavé et polygonales, colorées en brun ou en noir par le piment. Sous un grossissement considérable, chacune de ces verrues en pavé apparaît sous la forme d'un corps isolẻ polygonal, opaque, jaunâtre, revètu de piment, à borls distincts, et séparé des corps environnans par des espaces transparens dans lesquels on reconnaît quelquefois des troncs de vaisseaux. Traitées à la potasse, ces mèmes verrues se montrent scus la forme de festons buccaux mous (Tab. V, fig. $71 b$ ), reconnaissables à leur enveloppe épithélienne et à leurs fibres rayonnées, comme dans l'E. brevispinosus, et garnis de petits amas rayonnés de piment très-élégans.

La membrane pimentée qui revèt la surface des lèvres ne se laisse pas isoler facilement; mais l'on remarque, dans les fragmens que l'on est parvenu à détacher, une disposition très-élégante du piment qui suit tantôt les sillons longitudinaux, tantôt les fibres de la membrane buccale, et d'autres fois affecte une disposition plus rayonnée; par exemple, ả la surface des festons buccaux. Au dessus du piment sont les couches épithéliennes.

Lorsque la membrane pimentée est enlevée, la couche qui forme la substance de la lèvre apparaît ì nu à la surface du feuillet externe. On y remarque, même sans préparation, particulièrement dans les vieux exemplaires, les réseaux calcaires (") que nous décrirons plus loin en traitant en détail de la membrane buccale. On y distingue en outre diverses couches de fibres : $1^{\circ}$ les fibres musculaires du contracteur des lèvres (musculi decurtatores labiorum) qui rayonnent de l'ouverture buccale vers la périphérie, en formant leurs plexus; $2^{\circ}$ des fibres s'cntrecroisant olliquement et d'une manière irrégulière, mais qui, au lieu d'être de nature musculaire, semblent plutòt former la masse tendineuse des lèvres et de la membrane buccale. Je ne saurais dire s'il existe eu réalité des fibres musculaires circulaircs sur les lèvres. J'en ai cependant vu quelquefois à l'extrémité supérieure de la membrane labiale interne; mais il me reste de forts doutes sur la memlorane labiale externe.

(*) Sans préparation, les mailles paraissent au premier coup d'œil si transparentes, qu'on pourrait ètre tenté de les comparer à certaines glandes cutances des reptiles; mais il suffit d'un examen un peu attentif pour reconnaitre leur véritable structure. 
Desséchée, la membrane buccale montre dans son intérieur (Tab. V, fig. 73), une quantité de pièces calcaires. Dans le nombre, il y a dix grandes plaques, les plaques ambulacraires buccales ( fig. 72 et $73 c$ ), dont chacune est percée au milieu d'une ouverture ( fig. $72 b$ ), destinée a faciliter la communication du tube ambulacraire buccal avec les branchies buccales internes. Autour de ces plaques ambulacraires buccales se voient de nombreuses plaques isolées (fig. 72 c), disposées en cercle autour de l'ouverture buccale, et qui, examinées sous un fort grossissement, se montrent composées de réseaux calcaires. Mais ce ne sont pas là les seuls tissus calcaires de la membrane buccale. En traitant celle-ci à la potasse, on remarque qu'il existe, en tre les grandes plaques calcaires, de nombreuses pièces réticulées grandes et petites; de semblables pièces calcaires s'étendent aussi vers les lèvres à l'intérieur des plaques ambulacraires butcales (Tab. V, fig. 71), mais sans atteindre, au moins dans l' $E$. lividus, ces dernières; cela n'a lieu que dans les grands exemplaires de l'E. Sphara. Il est évident que les plus intérieures de ces plaques (fig. $71 d$ et $d^{\prime}$ ), sont les moins développées; elles se composent de simples piliers plus ou moins rameux, qui cependant augmentent de grosseur et sont de plus en plus rapprochés a mesure qu’on les poursuit à l'extérieur. Les réseaux qui en résultent paraissent de plus en plus compliqués, ainsi que le montre la fig. 71 . Il en résulte, qu'il se forme constamment de nouveaux dépòts de réseaux calcaires à l'intérieur, et il semble permis d'en conclure que même l'accroissement des parties molles de la membrane buccale a lieu de l'extérieur à l'intérieur.

Les parties qui entrent dans la composition de la membrane buccale sont : 1) l'épithélium externe, 2) une couche pimentée assez considérable, 3) la couche substantielle compacte, 4) le revètement intérieur, y compris son épithélium vibratile. La structure de la couche substantielle est assez difficile à observer; en en déchirant une parcelle on en voit sortir des fibres particulières qui ne ressemblent en rien aux fibres nusculaires, et diffẻrent également des fibres tendineuses de l'animal, mais que je crois pouvoir paralléliser avec les fibres du corion des autres animaux; on y remarque en outre de petits filamens cellulaires très-fins. Les filbres du corion s'entrecroisent et ont une direction oblique tantôt circulaire, tantôt rayonnante.

Le revêtement interne de la membrane buccale ne s'ẻtend que jusqu'à l'origine des lèvres, d'où il passe sur la surface de la pyramide dentaire; ce passage est marqué à la partie supérieure de la pyranide, par de fines stries transversales, telles qu'elles sont indiquées dans la fig. 75.

Nous allons maintenant passer aux organes situés sur la membrane buccale, qui sont les tubes ambulacraires buccaux et les pédicellaires buccaux.

Il existe dans le domaine de la membrane buceale, à-peu-près au milieu de sa largeur, cinq 
paires de tubes que jappelle tubes ambulacraires buccaux et que Tiedemann désignait comme de petits processns terminés par une ventonse ronde. Ces tubes situés dans le milieu des plaques ambulacraires buccales, sont composés, comme les autres, d'un disque libre et déprimé; ils sont supportés par une tige et percés à l'intérieur; cependant cette tige est plus courte et plus large que dans les tubes ambulacraires du corps de l'animal; le disque lui-même est ordinairement un peu plus grand, et le tuhe entier plus court et plns mou. Je lui ai trouvě, dans les exemplaires conservés dans lesprit de vin, une longueur d'environ $1^{\prime \prime \prime}$, depuis son insertion sur la membrane buccale jusqu'au milieu du disque de la ventouse. Ces tnbes buccaux sont situés dans le prolongement des ambnlacres (Tab. I. fig. 3, Tab. IV, fig. 57), et forment entre eux un cercle dont le diamètre moyen est de $4^{\prime \prime \prime}$ a $4^{\prime \prime \prime} 5$. Chaque paire est à une distance de $1^{\prime \prime \prime} \mathbf{2 5}$ a 1 , $^{\prime \prime \prime}$ 50 de la paire voisine.

En comparant entre eux les tubes bnccaux tels qüils se présentent dans les exemplaires conservés dans l'esprit de vin, l'on trouve que le disque de la ventouse, quoique uni et aplati dans quelqnes-uns, est cependant en gẻnẻral plus ou moins déprimé. On pourrait ètre tentẻ d'attribuer cette particnlarité à l'alssence de piquans et admettre, que n'étant pas protégés comme les tubes ambulacraires proprement dits, ils auraient fléchi sous le poids du corps. Qnoi qu’il en soit, on est en droit de supposer que leur squelette calcaire est relativement plus petit que dans ces derniers ; supposition qui se trouve pleinement confirmée par l'observation. En revanche, les parties organiques annulaires qni entourent le squelette à l'extérieur sont un peu plus larges. J'ai trouvé dans une ventouse de 0 ", $0 \$ 130$ de large, la largeur dn squelette de $0^{\prime \prime}, 00808$ et de $0^{\prime \prime}, 00700$. Le reste était occupé par les parties organiques.

Lorsqu'on est parvenu à rendre la ventouse d'un tube transparente, au moyen de la potasse, on remarque que la rosette calcaire, là où elle est le plus simple, se compose de quatre pièces isolées que j’ai trouvées disposées ainsi que suit dans le tube gauche de la paire correspondante aux zones porifères antẻrieures : une pièce impaire regardait l'intérieur; deux pièces paires correspondaient aux flancs, et la quatrième pièce était dirigée en dehors.

Les pièces latérales et notamment celle de ganche étaient semi-circulaires; dans celle de droite, le bord interne du croissant était singulièrement aminci. La pièce interne et la pièce externe étaient plns allongẻes et la première avait une épaisseur plus considérable sur certains points. Le plus grand diamètre des pièces interne et externe était de $0^{\prime \prime}, 0141$; le diamètre transversal du croissant latéral gauche mesurait 0 ",0193; celni du croissant droit $0^{\prime \prime}, 0185$. La plus grande largenr de la pièce interne était de $0^{\prime \prime}, 0066$; celle de la pièce externe de $0^{\prime \prime}, 0091$; celle de la pièce 
latérale droite de 0 ",0092; celle de la pièce latérale gauche de 0 ",010\%. Le nombre quatre n'est cependant pas constant : jai trouvė des tubes qui comptaient jusqu’à six pièces remarquables par leurs pointes saillantes au bord, tandis que lorsqu'il n'y en avait que quatre, elles se distinguaient ordinairement par leurs pointes peu marquées et par leurs réseaux calcaires plus épais. Dans quelques cas rares, la ventouse ne compte que trois pièces, dont deux grandes, semi-lunaires, correspondant aux pièces latérales que nous venons de mentionner, et une autre impaire plus longue.

Lorsque la ventouse a passé quelque temps dans la potasse, il est facile d'en détacher avec le scalpel une membrane foncée, et la rosette apparait sous la forme d'une tablette blanclıe. Examinée au microscope, elle se montre entourée d'épines (Tab. V, fig. 64c) semblables à celles que nous avons dèjá mentionnées dans les tulıes ambulacraires du corps. La fig. 67 représente un squelette ralcaire composé de trois pièces et hérissé d’ëpines sur ses bords. Quelquefois ces épines sont aussi très-distinctes au bord interne. Je les ai surtout trouvées développées dans les grands exemplaires de l'E. brevispinosus.

Je n’ai pas pu remarquer, dans les tubes ambulacraires buccaux, l'anneau poreux, aplati et quadrangulaire des tubes ambulacraires ordinaires. L'absence de cet anneau, joint au peu de développement de la rosace, la prédominance des parties molles et l'ouverture plus grande du canal intérieur déterminent une plus grande mollesse du tube non-seulenıent dans la tige, mais encore dans la ventouse.

A l'ètat frais, les tubes buccaux sont trop peu transparens pour que l'on puisse en observer les différentes parties sans préparation préalable. C'est tout au plus si l'on réussit à se faire une idèe daire de l'épithélium qui le recouvre et de la couche pimentée qui est au dessous. Quant aux parlies intėricures, il est indispensable d'employer la potasse pour les reconnaître, et il importe surtout de répéter les expériences si l’on veut bien saisir tous les détails. La ventouse est composée des mêmes élémens que nous avons signalés daus les tubes aubulacraires du corps. On y reconnaît les bourrelets entourant les aspérités du squelette calcaire, les entonnoirs renversés et les fibres musculaires, surtout les rayonnantes. J'ai en outre remarqué, sur quelqques points situés à l'extérieur du squelette calcaire d'un $\boldsymbol{E}$. brevispinosus, des cellules remplies de petites granules, sur la signification desquelles je n’ai pas une idée hien claire : elles ressemblent i-peu-près, par leur forme, à ces cellules particulières qui servent à former dans l'embryon du cheval la substance cornée du sabot. Je ne les ai rencontrées que rarement et toujours groupées en petits amas.

La partie cylindrique du tube a des parois proportionnellement très-minces ct une cavité inté- 
rieure assez grande, qui solserve à l'ceil nu et dans laquelle on parvient sans peine ì introduire une soie. Quant aux filıres musculaires renfernées, d'une part, entre l'épithélium externe el la couche pimentée, et d'autre part, entre cette dernière et l'épithélium interne, il est assez diflicile de les observer; mais il parait cependant qu'elles suivent lit même direction que dans la partie cylindrique des tubes ambulacraires du corps.

J'ai olsservé en outre, dans les exemplaires à l'esprit de vin de l'E. brevispinosus, au dessous de la couche pimentée, de petits corps calcaires linéaires, légèrentent arqués on semi-lunaires, réunis en amas et pourvus d'un ou de plusieurs rameaux latéraux à leurs extrémités; on les reminrquait quelquefois aussi dans la ventouse. Rendus transparens au moyen de la potasse, ils ne dégageaient point d'air au contact avec l'acide acétique, mais se dissolvaient dans l'acide muriatique. Cus mêmes petits corps calcaires se retrouvèrent aussi dans l'E. lividus; mais c'étaient de petits croissans plus simples, sans épines ni rameaux latéraux. L’acide muriatique les dissolvait égilement en dégageant une quantité d’acide carbonique. Ce sont évidemment des organes analogues à ceux que nous avons étudiés en traitant des tubes ambulacraires du corps.

Lorsqu'on injecte de mercure le canal intérieur d'un tube buccal, le métal s'introduit dans la cavité correspondante des branchies buccales. C'est un sujet sur lequel nous reviendrons en traitant des branchies internes.

A la limite externe des lèvres, lả où celles-ci passent dans le prolongement de la membrane buccale, commencent les pédicellaires buccaux (Tab. I, fig. 3, et Tab. IV, fig. 57), qui sont trèsserrés jusque près de la partie périphérique de la uembrane buccale. Tiedemann (*) les appelle des appendices filiformes se terminant en trois pointes. Della Chiaje (") et Sharpey ("*) semblent les avoir envisagés de la même manière. Ils correspondent parfaitement aux pédicellaires ophicèphales que nous avons mentionnés dans le chapitre précédent, et montrent mème à l'œil nu une petite tète renflée, portée sur une tige grèle. Leur couleur blanche et leur dureté sont une preuve quils contiennent, au moins à leur sommet et a leur base, des parties calcaires plus dures. En même temps, l’on s'aperçoil qüil existe dans ces mèmes pédicellaires deux squelettes calcaires différens, la tête et la massue, qui tous deux se dessinent d'une manière très-nette lorsqu'on est parvenu à rendre les parties molles transparentes au moyen de la potasse. La partie moyenue de ces pédicellaires est flexible, car elle ne se compose que de parties molles sans squelette calcaire. Ce-

(') Anatomie p. 98.

(') Memoric p. 576 . Tab. sxïi, fig. ‥ 6,7, 8, 9.

(') Echinoderunato p. 4. 
pendant ces dernières sont également très-fragiles, bien qu'on rencontre aussi des pédicellaires plus élastiques qui reprennent en se détendant leur ancienne position lorsqu'on les en a dérangés.

La tête calcaire se compose de trois parties constamment adhérentes : les cuillers, les pièces renflèes et les ares semicirculaires.

A létat parfaitement intact, les trois pinces ou cuillers qui se trouvent dans claque tête de pédicellaire sont rapprochées, ensorte que l'extrémité supérieure est arrondie et fermée au sommet (Tab. IV, fig. 49). Suivant la position de la tête, il peut arriver que l'on ne voie que la principale partic d'une cuiller et le bord ou plutôt le profil d'une autre (Tab. IV, fig. 47); ou bien l'on voit deux cuillers avec leurs bords qui se regardent; dans ce cas, la troisième cuiller n'est visible qu'autant que les deux premières sont plus ou moins béantes (Tab. IV, fig. 49 et 50); ou bien l'on distingue les carẻnes médianes saillantes des trois cuillers par leur face postérieure, ou seulement une cuiller avec sa carène médiane et ses deux carènes marginales (Tab. IV, fig. 48). Dans ce dernier cas, les trois carènes médianes convergent en un dôme arrondi au sommet. Dans le premier de ces cas, on distingue déjà les découpures du bord latéral de la cuiller, et même les fines dentelures qui les bordent (fig. 47). Quelquefois même on reconnaît aussi les bords découpés de deux cuillers voisines.

En soumettant la tête à une faible pression, on voit les cuillers en sortir à-pen-près comme une paire de mandibules. Cette opération peut se répéter plus ou moins sans que lorgane en souffre; et c'est par l'étude réitérée des cuillers, ainsi poussées au dehors, que l'on parvient à se faire une juste idée de leur structure.

Chaque cuiller représente en quelque sorte une nacelle dont le fond est occupé par une carène longitudinale saillante que j'appelle la carène médiane (Tab. IV, fig. 51 et 52); les parties latérales de la nacelle sont occupées par un réseau calcaire très-élégant, entre les mailles duquel on aperçoit souvent de petites carènes transversales (fig, 48 et 51 ). Il existe en outre une carène latérale, près du bord de la paroi latérale; mais elle n’a point de réseaux calcaires, et ne converge qu'au sommet avec les autres carènes latérales et la carène médiane; les bords présentent une série d'entailles garnies de très-fines dentelures. Il m'est arrivé de distinguer quelquefois, dans la masse calcaire de ces entailles ou découpures, une structure fibreuse rayonnant dı centre vers les dentehres du bord; mais peut-être sont-ce moins des fibres que des sillons.

Les découpures des deux bords d'une seule et même cuiller sont presque toujours assymétriques; souvent celles de l'un des bords sont plus saillantes ou plus plates que celles de l'autre, et vice versa; quelquefois aussi on dirait que la cuiller n'a de découpures que d'un côté, et des 
épines de l'autre; cependant je crois m’ètre assuré que cette différence u’est qu’une conséequence de la position oblique des déconpures de l'autre bord.

Les carènes transversales donnent quelquefois lieu il des dẹpressions isolées plus profondes près de la base des cuillers. De lì les trois cuillers passent dans les reuflemens basilaires qui en sont les prolongemens immédiats, et qui souvent sont si rapprochés quils ont l'air de se confondre en une seule pièce. J'ai cependant vu dans quelques cas rares une séparation distincte et dentelée, formant la continuation de la séparation entre les cuillers. Chaque cuiller présente, sous ce rapport, la disposition indiquée dans la fig. 53 de Tab. IV; les deux carènes laterales et la carẻne médiane se continuent immédiatement dans le renflement correspondant qui est criblé de petites ouvertures, quelquefois disposées par séries longitudinales et plus grandes au milieu que sur les bords; le bord inférieur est limité par une carène transversale.

Les ares semicirculaires sont des processus plus ou moins développés, dont les convexités sont renflèes à peu près comme les ampoules des canaux semicirculaires de l'organe auditif (Tab. IV, fig. 47). Ils sont composés d'une masse calcaire compacte, et il n'y a que leurs extrémités renflèes qui montrent des trous; cependant ces trous manquent aussi parfois. Ces arcs semicirculaires sont ordinairement disposés de telle sorte qu'ils paraissent recouverts par trois pilastres d'une cuiller recourbée en arrière.

En tournant la tête du pèdicellaire et en l'examinant sous ses différentes faces, on s'aperçoit qu'à chaque cuiller de la partic antérieure correspond une portion de la pièce renflée de la régrion postérieure; mais il est très-difficile de placer la tête dans une position telle, que les deux parties de l'organe puissent être vues en même temps. Quant au renflement, les carènes fines et épaisses que l'on remarque sur ses parois divisent sans doute l'intérieur en une quantité de cavités latérales régulières correspondant aux saillies de la surface.

Çả et là on rencontre aussi de petites têtes isolées, à trois pinces semblables à celles du test. J'ai, de plus, rencontré dans l'E. brevispinosus, une autre forme de tête qui correspond à celle des pédicellaires ophicéphales.

Les tiges des pédicellaires buccaux sont absolument de même nature que dans les autres pédicellaires. La tête comme la massue se dissolvent dans l'acide acétique, en dégageant une quantité d'acide carbonique. Quant aux parties molles, l'on reconnait, sans la moindre préparation, qu'elles enveloppent également la massue et la tête; il existe entre les deux une cavité centrale qui semble se former à l'extrémité de la massue, entourer celle-ci et se prolonger jusqu'ả l’insertion du pédicellaire dans la membrane buccale. Les, parois sont composées, à l'inté- 
rieur, de filbres qui se tordent facilement; l'épithélium et la couche pimentée sont l'un et l'autre Pxtérieurs. Quelquefois l'on voit à l'intérieur des parois des canaux longitudinaux qui ont l'apparence de vaisseaux sanguins.

En traitant les pédicellaires buccaux à l'acide acétique, le canal intérieur affecte une transparence toute particulière, après que le carbonate de chaux de la tête et de la massue s'est transformé en acétate de chaux. Il a tout-à-fait l'apparence d'un tissu isolé, ayant ses parois composées de filbres longitudinales et transversales, et sa surface garnie d'un épithélium distinct; ensorte que nous aurions ici la même disposition des tissus que dans les petits vaisseaux sangruins de l'homme el des animaux supérieurs; comme dans ces derniers, leurs contours forment aussi parfois des ondulations très-distinctes. On remarque de plus, autour de la lase des têtes, et surtout de celles ì trois pinces, un large anneau de fibres transversales, qui paraissent être de nature musculaire et servent peut-être á fermer la pince et les cuillers. Les réseaux calcaires de la tête ainsi que ceux de la massue présentent un squelette organique grenu, de couleur grise, qui correspond exactement, par sa forme, aux contours extérieurs, et dont l'intérienr contient souvent de petits corpuscules globuleux renfermant un petit noyau.

Il est évident que les pédicellaires buccaus jouissent aussi de la faculté de s'allonger et de se rétrécir, et probablement même de saisir de petits objets au moyen de leurs pinces; mais en tout cas ils ne semblent pas s'ouvrir autant que les autres pédicellaires.

Enfur, il existe encore a la surface de lit membrane buccale de petits piquans nicroscopiques (Tal. V, fig. T2), dont la structure ne differe en rien de celle des autres piquans. 


\section{CHAPITRE VI.}

\section{WES ORGINES DIGESTIYS}

Le canal alimentaire de l'Oursin se compose du pharyux, de l'esopheage, de l'intestin proprement dit et du rectum. Le pharynx est renfermé dans la charpente dentaire connue sous le nom de lanterne d'Aristote. L'ésophage est placé verticalement dans la cavité intérieure. L'intestin se déploie le long des parois du test; le rectum, enfin, est dirigé vers l'ouverture anale. Mais pour bien comprendre la disposition et les fonctions des parties molles des organes digestifs, il importe que nous connaissions préalablement la structure et les muscles de la lanterne.

La charpente dentaire se compose de cinq parties symétriques, dont chacune comprend, outre la dent proprement dite et la plume dentaire, plusieurs autres organes qui sont : la pyramide, la fuux et un corps particulier en forme d'Y que je propose d'appeler le compas.

$1^{\circ}$ La pyramide (Tab. V, fig. $76 b, 77 b, 78,79,80,81,82$ ) forme la partie essentielle de l'appareil masticatoire. C'est elle qui contient, dans son intérieur, la dent proprement dite, qui fait saillie à son extrémité inférieure. Sa charpente se compose d'une pièce pyramidale á trois faces, dont une extéricure et deux latérales, toutes plus larges en haut qu'en bas. La face extérieure est convexe vers le bas (planum longinedinale cxtermum fig. $76 b$ et 78); une suture longitudinale la divise en deux branches et détermine à sa partie infẻrieure deux protubérances symétriques. Plus haut, les côtés de cette même face sont déprimés et forment la grande fossette (fovea magna externa fig. 78 a) qui est circonscrite par le bord extéricur saillant (margo proeminens extermus fig. 78 b). C'est ici, à l'endroit le plus profond, qu'elle donne lieu à un sillon particulier, le grand sillon longitudinal externe (sulcus longitudinalis extermus major fiğ. 78 c). A lintérieur de ce dernier, se trouve, ả la partie supérieure de la pyramide, un second sillon plus court et moins marqué, qu'on appelle le petit sillon longitudinal externe (sulcus longitudinalis extermus minor fig. $78 d)$, qui atteint à peu près le sommet de la lanterne. On voit en outre, á la partie inférieure du grand sillon, un renflement longitudinal bordé extérieurement par un petit sillon 
(suleus longitudinalis externus minor) qui est surtout distinct dans les grands exemplaires de l'E. Sphara. Enfin l'on remarque aussi, près de l'extrémité inférieure du grand sillon externe, une échancrure semilunaire (incisura semilunaris) limitée extérieurement par une petite pièce calcaire, la demi-line ( fig. 78 e).

L'arc transverse (arcus transversus pyramidis fig. 78f) limite la pyramide à sa partie supérieure. Il se compose de deux demi-arcs symétriques dont la séparation est indiquée par une suture médiane. Sa face extérieure est surmontée d'une carène particulière, la carène arquée (crista arcuata), qui se termine, en haut, à la partie médiane de l'arc et s'applique, en bas, contre le bord saillant de la pyramide, en un endroit qui correspond ì une petite dépression (fovcola arcualis), mais qui n'est pas également marqué dans toutes les espèces. Enfin, il existe, à la partie supérieure de l'arc transverse, près de la suture médiane, un léger renflement (colliculıs arcualis), qui est particulièrement distinct dans l' $E$. Sphora et l'E. lividus.

Le grand ereux (foramen magmem pyramidis fig. $78 i$, fig. $82 d$ ), est une grande ouverture situèe à la partie supérieure de la pyramide. Sa forme est celle d'un triangle isocèle à base légèrement arquée, tandis que les deux côtés sont plus droits. Son sommet, qui est tourné en bas, est échancré d'une manière particulière et coincïde avec le sommet de la suture médiane de la face externe de la pyramide. Il est limité latéralement par les prolongemens des parois des deux grands creux externes, tandis que sa base est formée par le grand arc externe.

Les deux faces latérales de la pyramide ( fig. 79 b, et fig. 81 a) sont symétriques et se correspondent jusque dans les plus petits détails; elles convergent intérieurement et déterminent ainsi la forme pyramidale de l'organe. Elles ne sont nullement continues dans toute leur longueur; mais l'on remarque, vers le haut, une grande et une petite cavité. Claque paroi se divise en outre en une partie supérieure triangulaire, qui se rétrécit en bas et sẻlargit en haut, ef en une partie inférieure plus petite; l'une et l'autre sont limities extérieurement par le bord de la face externe de la pyramide. Leur bord interne n'est pas entièrement droit et paraît inégal, par l'effet des carẻnes transversales; il détermine de plus une légère échancrure concave près du bord inférieur, au contact du sillon dentaire et de la dent. Les bords des deux faces se rapprochent davantage en haut, mais sans cependant se joindre complètement; ils divergent de plus en plus vers le bas et sont le plus distant à leur extrémité inférieure. Leur surface est revêtue d'une quantité de stries transversales (eminentic transiersce) légèrement onduleuses, it-peu-près comme les lignes transversales de filores nuusculaires striées transversalement.

La partie supérieure de la pyranide est plus compliquée et peut-ètre est-elle même complète 
ment isolée dans le jeune âge. On y remarque tout d'abord l'échancrure destinée à recevoir la faux (fovea falcis fig. $80 c$ ), échancrure profonde et triangulaire extérieurement plate, et étroite intérieurement. Au dessus de cette échanerure s'élève l'are transverse; sa fice interne a, de chaque còté, une dépression, le trou vide (fovea racua) qui est dirigé en dedans et en bas. Entre ces deux dèpressions, se remarque une éminence composée de deux parties symétriques, l'éminence mẻdiane (eminentia media), qui embrasse une échancrure seni-circulaire, l'échancrure dentaire (incisura dentalis fig. $\$ 0 d, 82 c$ ), destinée à recevoir la partie de la dent qui passe par cet endroit.

Le petit creux de Ia pyramide (foramen mims pyramidis fig. $80 e$ ), communique avec le grand creux et conduit directement daus la cavité intérieure de la pyramide (cavitas pyramidis), ensorte que cette dernière s'ouvre extérieurement dans le grand creux, supérieurement dans le petit creux de la pyranide, et intérieurement enfin par i'écartement des deux feuillets latéraux. De l'origine du grand creux, jusqu’à l'extrémité inférieure, s’étend le sillon dentaire (sulcus dentalis fig. 82 b), bordé par les deux carènes dentaires (linece eminentes dentales fig. 82 a), qui dépassent même, sous la forme d'un prolongement (processus s. crista dentalis, fig. 82 a), le bord inféricur du grand creux. Le sillon dentaire lui-même est plus ou moins strié dans le sens longitudinal.

$2^{\circ}$ La faux ( $/ a l x$, fig. $77 c, 84,85,86$ et $90 a$ ), est une petite piece allongée et aplatie, fixée entre deux pyramides et par conséquent inférieure au compas. Son bord interne est échancré en forme de croissant; son bord externe est rectiligne. Dans l'E. Sphara, les deux bords latéraux montrent en outre chacun une petite échanerure résultant d'un sillon dirigé obliquement de la face supérieure à l'extérieur et en bas. En général, la partie moyenne de la faux est plus ou moins onduleuse, tandis que vers le centre de la lanterne, ses bords sont obliques et droits.

La partie inférieure de la faux s'adapte exactement dans l'espace qui lui est réservé entre deux pyramides; ensorte que ses renflemens correspondent à des dépressions de cette derniẻre et vice versa. Son bord externe est marqué de deux profonds sillons latéraux déjả mentionnés ci-dessus , qui sont dirigés obliquement en bas et forment une espèce de triangle, correspondant à une proćminence anguleuse de la pyramide destinée à supporter la faux. Les autres reliefs Iatéraux s’adaptent tout aussi exactement aux parties correspondantes de la pyramide. La partie moyenne de la faux qui est unie, prend une forme sillonnée vers l'échancrure semi-lunaire de l'extrémité interne. Sa face supérieure est plus unie encore et se courbe en dehors et en bas (fig. $76 d$, fig. $77 d$, fig. $87,88,89,90 b$ ).

Dans les vieux exemplaires de l'E. brevispinosus, les faux sont dirigíes obliquement d'en liaut 
et de dehors en dedans et en bas. Dans les jeunes individus de l'E. lividus, elles sont plus horizontales.

$3^{\circ}$ Le compas ou corps en forme $d ' Y$ (pars Y formis fig. $76 d, 77 d, 87,88,89,90 b$ ), situé au dessus de la faux, est arqué ; le côté convexe de l'arc est dirigé en lıaut et le côté concave en bas. II est pointu en dedans, tandis que son extrémité extérieure est large, réfléchie, aplatie et forme leux prolongemens en forme d'Y. Il est de plus comprimé latéralement au milieu, ce qui rend son bord tranchant en bas. Ses flancs sont marqués de légers renflemens et d'impressions alternatives qui sont les impressions musculaires (impressiones musculares fig. 87, 85, 89a). Sa face inférieure est concave et montre des renflemens et des dépressions qui correspondent exactement à la face ondulée de la faux contre laquelle ils s'adaptent.

La charpente de la lanterne est ainsi composée: des cinq pyramides dont cliacune est formée de deux piẻces intimement soudées, des cinq faux et des cinq compas, en tout quinze, ou si l'on compte les pyramides pour deux pièces, vingt pièces, auxquelles il faut encore ajouter :

$4^{\circ}$ Les cinq dents logées à l’intérieur des cinq pyramides.

Chaque dent (fig. $76 a, e, 79 c, d, 81 b$ ) est composée de deux parties intimement unies, et dont l'extérienre qui représente la partie la plus dure est la dent proprement dite (dens sensu strictiori), l'autre, d'une substance plus molle, porte le nom de plume dentaire (pluma devtalis).

La dent proprement dite (fig. 91, 92, 93) est une longue pièce dure, dont la face externe est lisse, tandis que la face interne est marquece d'une carène médiane renflée, la carène dentaire (crista dentalis fig. $91 a 92 a, 93 a$ ). Logée dans le sillon de la pyramide, elle devient molle et passe à l'état de plume dentaire au dessus de ce sillon (fig. $76 e$ et $77 e$ ). Ses deux faces, surtout l'extérieure, sont lisses et luisantes; mais cette dernière est séparée en deux moitiés symétriques par un sillon médian, qui est lui-même bordé, de chaque côté, par un renflement, auquel succède un autre sillon et, plus loin, le bord qui est renflé, ensorte que l'on dirait que la dent est striée longitudinalement. La face interne est divisée en deux parties déprimées à l'intérieur et relevées a l'extérieur. Toute la dent, y compris la plume et la carène dentaire, est arquée en dedans, sa convexité étant dirigée en dehors. La face latérale et la face interne de la carène sont unies; mais vers l'extrémité inférieure, la carène se tronque obliquement, de maniẻre à se terminer un peu avant le bout de la dent; la dent elle-même est pointue et l'on aperçoit souvent, à sa surface, une ligne longitudinale qui la divise en deux parties égales.

La plume dentaire est située le long et à l'intérieur de la ligne médiane du grand crenx de la pyranide; plus loin, elle se loge dans le sillon dentifëre de l'arc transverse; libre au dessus 
de ce dernicr, elle se replie sur elle-même et se termine, en s'amincissant, dans les vésicules ovales remplies de liquide. Dinıs les grands exemplaires de l' $E$. brevispinosus, elle forme plusieurs plis en avant de son extrúmiti. La carène dentaire se prolonge en s'annincissant ì-peu-près jusqu'à son extrémité, où elle est tronquée obliquenent.

Quant à leur structure microscopique, la faux et le compas contiennent des réseaux calcaires d'une forme particulière, tels quiils existent aussi daus le test, dans les piquans, à l'extrémité de la massuc, etc. Les pyramides ont les mêmes réseaux calcaires, auxquels s'ajoute parfois une substance plus dure qui correspond, dans sa partie essentielle, à la substance jaune des dents. Les dents contienuent, outre quelques réseaux calcaires, des filres et de l'émail. Les plumes dentaires se composent de lames calcaires d'une structure particulière très-régulière; et l'on peut en conclure que la composition de la partic dure de la dent est analogue.

Lorsqu'on fait une coupe transversale d'une pyramide, on s'aperçoit, en sciant, que les lames latérales sont bien moins dures que le centre, surtout dans la partie supérieure jusqu'à la région du grand creux.On sent de plus que cette plus grande durete, qui est si considérable qu'elle émousse en très-peu de temps les meilleures scies, n'est pas répartie d'une manière uniforme dans toute la substance, mais qu'elle est en quelque sorte localisée. Elle se trahit sur les coupes transversales par des stries jaunes, et on la voit former, de chaque còté du sommet, une bande longitudiuale dirigée à-peu-près dans le sens des feuillets latéraux de la pyramide. Plus bas, dans l'épais-seur de la lame externe de la pyramide, se trouvent deux bandes encore plus fortement plisscées, d'où partent deux lignes convergeant vers la surface extéricure de la pyranide, et se réunissant sur la suture médiane. Ces lignes divergent de plus en plus vers le sommet et se terminent dans les flanes latéraux du grand creux de la pyramide, où la substance jaune se reconnaît facilement lorsque la pyramide est intacte. Eufin on les voit aussi se continuer jusqu'aux arcs transverses. On voit en outre, sur chacun des bords saillans latéraux de la pyramide, d'autres bandes de cette même substance.

L'élude microscopique de cette substance dure et jaune m'a donné des résultats particuliers. La fig. 111, Tab. VI, montre quelle est son apparence dans une coupe transversale. On n'y reconnait aucune structure réelle, car les stries que l'on remarque à sa surface sont produites uniquement par le polissage. Mais au dessus de cette substance, l'on remarque, dans les coupes longitudinales comme dans les coupes verticales, des réseaux calcaires tantôt continus, tantôt partiels, ensorte qu’il paraît que, dans les endroits oủ cette structure est visible, la substance jaune pénètre la substance des réseaux calcaires. Exposés aux acides, les réseaux calcaires se conservent 
très-bien et deviennent même plus nombreux et plus apparens qu’ils n’ẻtaient auparavant. Mais ce traitement ne m'a fourni aucune donnée sur la nature de la substance jaune. La potasse ne provoque non plus aucune modification.

Le reste de la substance calcaire se présente, à la surface de la pyramide, sous la forme de réseaux polygones à mailles arrondies. Nous avons dẻja fait remarquer plus haut que la suture longitudinale qui se voit à la surface de la pyramide, la pénètre de part en part et divise ainsi son revêtement extéricur et sa masse entière en deux moitiés symétriques. Sur les côtés de celte ligne médiane, on aperçoit une figure arquée, symétrique, pointue à l'extérieur et qui s'évase à l’intérieur en se terminant en deux côtés symétriques. Je désignerai celte partie sous le nom de région centrale par opposition à la région latérale. Dans la région centrale, les piliers principaux des réseaux calcaires sont rangés horizontalement et leurs mailles sont plus petites que dans les régions latẻrales. Dans ces dernières, en effet, les piliers principaux et secondaires se confondent davantage, divergent d'une manière plus uniforme vers la périphérie et sont en général plus uniformes. Là oủ les deux substances sont en contact, elles se présentent au microscope sous la forme de la fig. 105 de Tab. VI. Dans les régions latérales, le diamètre moyen des mailles est de 0",0008; dans la région moyenne de 0",0004.

La substance jaune existe également au centre des parties latérales de la pyramide. On l'apercoit même à l'œil nu et mieux encore, à la loupe, sous la forme de bandes jaunâtres. Sur les coupes transversales, elle se fait remarquer par la présence de piliers calcaires proportionnellement plus grands que les autres, qui s'étendent sur les parties claires de la coupe. A ces piliers d'une taille supérieure, on en voit adhérer d'autres plus petits, également pourvus de petits trous et qui communiquent par des rameaux très-minces. Les autres réseaux calcaires sont plus homogènes; leurs piliers n'atteignent des dimensions extraordinaires que sur quelques points du bord extérieur de la pyramide et ne donnent lieu qu'ì de grandes mailles isolées. Les carènes de la surface montrent les mêmes réscaux calcaires; seulement l’on remarque qu’à leur lord extẻrieur ils se prolongent en formant de fines pyramides très-délicates, destinées à l'insertion des faisceaux musculaires interpyranidaux (Tab. V, fig. $102 d$.) Les faux se composent de réseaux semblables, mais l'on y aperçoit en outre de longs piliers transverses quelquefois isolés, quelquefois ramus, parfois aussi anastomosés, qui se remarquent surtout ì la face supérieure. I.es compas ont des réseaux calcaires, rẻpartis d'une manière uniforme dans toutes les directions; cependant ils sont un peu plus allongés à l’intérieur et prennent une direction oblique près de sa lifurcation. Il paraît que dans les très-vieux exemplaires de l'E. brevispinosus, quelques traces de la substance jaune adhèrent encore à la face intérieure. 
Lorsqu'on vient à examiner la surface d'une dent, le sillon médian paraît un peu jaunâtre, le reste est plus homogène. La dent se brise transversalement ou plutôt obliquement avec une grande facilité, mais jamais longitudinalentent. Ủne coupe transversale, prise à la partie supérieure, montre une figure en forme de marteau (Talb. VI, fig. 106) dont le manche correspond à la carène dentaire. On voit, au milieu du marteau, une ligne transversale plus claire, flexueuse à ses extrémités, de laquelle partent des lignes d'apparence fibreuse (Tah. VI, fig. 108 b). Sur quelques points, ordinairement à l'opposite de cette bande claire, on remarque un tissu plus ou moins distinct (Tab. VI, fig. 109), qui paraît provenir de réseaux calcaires. Enfin, l'extérieur est bordé d'une bande en forme d'anneau (Tal. VI, figg. 107, $108 a, 109 a$ ), qui est plus claire et contient des cellules analogues à celles des plantes. Les flancs de la carẻne dentaire montrent, des deux côtés, la même disposition; le milieu est moins distinct. Ces différentes parties de la dent se voient d'une manière plus distincte dans les coupes longitudinales : au bord, la substance émaillée se présente comme une masse transparente, séparée par une quantité de doubles lignes en forme de fibres; viennent ensuite les fibres extérieures obliques (Tab. VI, fig. $110 a$ ), que l'on pourrait envisager au besoin comme des fibres de l'émail. A celles-ci succèdent les fibres intérieures ou fibres dentaires proprement dites ( fig. $110 c$ ), dont quelques-unes débordent à l'extrénité de la coupe, sous la forme de filets déchirés. Entre ces fibres dentaires et les mailles, se trouve une ligne de démarcation très-tranchée, dont les bords sont ordinairement plus transparens que le reste, et quelquefois jaunes. Nous aurions ainsi, dans la partie compacte de la dent, deux substances fibreuses, une intérieure et une extérieure, et une substance de revêtement. Les fibres des deux premiẻres substances sont dirigées obliquement de bas en haut; celles de la substance extérieure vont de dehors en dedans; celles de la substance intérieure de dedans en dehors. Les divisions de la substance de revêtement suivent la même direction que les fibres de la substance dentaire; mais elles se dissolvent plus vite et d'une manière si complète dans l'acide muriatique, que je n'ai pu en obtenir le squelette organique, quoique j’aic la conviction quill existe. Lorsque l'on expose la dent entière à l'action de l'acide, il n'en reste qu'une pellicule très-mince, sans aucune trace des fibres précédentes. En revanche, on y remarque de grandes taches claires, d'une disposition assez régulière, à bords renflés en haut et en bas, mais confluant latéralement. Le diamètre moyen transversal des divisions de la substance de revêtement est de $0^{\prime \prime}, 0008$, la largeur des fibres de la substance dentaire ex térieure de 0 ",,00035 et la largeur des fibres de la substance dentaire interne de 0 "',0007.

Les divisions en forme de fibres de la sulstance de revêtement se présentent souvent sous la 
forme de petites colonnes dans lesquelles on croit parfois remarquer des subdivisions fibreuses. Quant aux fibres de la substance dentaire externe, quoiqu'elles soient trẻs-serrées, elles sont cependant réunies par une substance intermédiaire simple, mais dure. Les fibres de la substance interne montrent parfois des lignes brisées et irrégulières, tantôt isolées, tantôt formant des réseaux très-élégans analogues à ceux des plantes. On peut s’assurer, par l’inspection du bord interne de la coupe, que ces lignes brisées n'appartiennent pas aux fibres dentaires elles-mêmes, mais bien à une mince lame calcaire étendue par dessus. Les extrémités des fibres qui font ici saillie, sont entièrement lisses; en quelques endroits, les brisures de la lame supérieure sont très-distinctes, car non-seulement celle-ci revêt l'extrémité des fibres, mais elle les dépasse mêne. Nous reviendrons plus bas sur la cause de cette structure particuliẻre.

Pour bien connaître les rapports de la plume dentaire avec la partie dure, il importe d'en poursuivre l'extrémité supérieure vers la partie solide de la dent.

Nous avons déjả fait remarquer plus haut que la plume dentaire a aussi sa carène, qui disparaît à une petite distance du bord supérieur. Lorsqu’on examine la partie supérieure de la plume dentaire de l'E. lividus, sous un fort grossissement, on voit à-peu-prẻs une figure comme celle qui est représentée Tab. VI, fig. 113 ; c'est-à-dire que l'on aperçoit un corps allongé, séparé en deux moitiés par une bande longitudinale moyenne, et paraissant même disjoint à son extrémité. Tout prẻs de là, la masse est transparente, mais plus l'on redescend le long de la plume dentaire, plus l'on voit la partie centrale de la carẻne devenir distincte (Tab. VI, fig. $113 d$ ). La lig. 114 de Tab.VI, représente l'extrémité de la plume dentaire sous un grossissement plus fort, pour montrer qu’il s'agit ici de plaques arquées, symétriques, qui diminuent de plus en plus vers l'extrémité, et que ces mèmes plaques s'entrecroisent de la manière la plus régulière dans la partie mojenne. Si I'on examine une portion de cette même plume prise plus bas, on s'apercoit que la carène dentaire ('Tab.VI, fig. 115 c), résulte uniquement de ce que les lames obliques s'élèvent en arc vers le milieu de la face interne, tandis qu'elles sont droites des deux côtés de ce renflement oủ elles forment les parties latérales planes de la face interne de la plume (fig. 115). L'entrecroisement a lieu de la manière la plus régulière, ainsi qu'on peut le voir dans la fig. $115 \mathrm{~b}$. Un fragment plus mince de la partie supérieure de la plume dentaire se présente sous la forme de fig. 116, Tab. VI: les lames conservent leur forme ailée, mais elles montrent en même temps un tissu d'apparence fibreuse, qui semble appartenir à une lamelle intermédiaire, et qui, lorequ'on la brise, montre une cassure grossièrement fibreuse. Plus la région du fragment que l'on examine sera infërieure, plus ses fibres seront nombreuses et indépendantes et plus aussi elles s’étendront sur les flancs, ensorte que 
l'on aura de la peine à distinguer, au premier coup d'oil, les lames intermédiaires transparentes qui cependant existent, comme on peut s'en assurer par une reclierche plus minutieuse. Les fragmens de ces lames ont mème une tendance à affecter une forme rlombique ou au moins rhomboïlale. J'ai représenté, dans la fig. 117 de Tab. VII, quelques-unes de ces formes anguleuses, et quelques fragmens des fibres. Au contact de la plume dentaire et de la dent, ces fibres correspondent entièrement aux fibres de la substance dentaire intéricure, et par leur forme, leur taille et par leur disposition. Nous asons dẹjà fait remarquer plus haut qu'il existe, en outre, entre elles de minces lames régulières et homogènes.

Les rapports de la substance dentaire extérieure sont moins distincts; aussi importe-t-il de faire de nouvelles recherches sur la manière dont leurs fibres se développent. Quant à la substance inteirieure, nous possédons maintenant une listoire complète de toutes ses parties, depuis l'extrémité supérieure de la plume dentaire jusque dans la substance dentaire elle-méme.

Si l'on fait une section horizontale d'un Oursin, de manière à couper l'ésophage et que l'on vienne à examiner la lanterne, on aperçoit au prenier coup d'œil, outre les muscles de la charpente dentaire, une membrane très-mince, qui revêt la plupart des parties intérieures et que l'on désigne sous le nom de membrane de la lanterne. Voici à peu près quelle est sa manière d'ètre dans les parties latérales de la lanterne de l'E. lividus: elle est étendue entre les muscles interarcaux de la pyramide, revêt la surface de chacun de ces muscles et le ligament oblique extẻrieur; de là elle se prolonge sur une partie correspondante des muscles interarcaux, passe près du bord externe saillant de la pyramide, revèt la moitié de la surface du muscle interpyramidal et le ligament interne correspondant, si elle se rencontre avec l'extrémité opposée de la membrane de la lanterne, ou bien elle se poursuit dans une direction opposée. Vis-it-vis du grand creux externe de la pyramide, cette membrane est dẻjà mince et bursiforme; mais en passant par dessus l'arc transverse, elle forme de petits sacs ou vessies particulières, de forme à peu près ovale, (Tab. VII, fig. $118 \mathrm{c}$ ), qui font saillie à l'intérieur vers le centre de la lanterne ou vers l'ésophage, oủ elles correspondent à l'extrémité des carènes dentaires. Ces petits sacs, déji connus de Monro (*), sont les mêmes que Tiedemann a figurẻs dans son ouvrage, Tab. X, fig. $1 a$, fig. 2 f., et qu'il met en correspondance avec les branchies internes. L’intérieur de ces petits sacs communique, d'une part, avec la cavité de la pyramide qui s'ouvre dans l'espace étroit entourant l'ésophage; d'autre part, avec l'espace qui, intérieurement, est limité par la pyramide, par les muscles interpyramidaux, 
par l'arc transverse du test, et plus bas par la partie latérale de la membrane de la lanterne et les deux ligamens externes obliques; d'où elle passe dans la cavité des branchies externes. Ces petits sacs sont remplis d'eau claire; quelquefois aussi, surtout dans les exemplaires conservés dans l'esprit de vin, l'eau est remplacée par de l'air. A partir de ces petits sacs, la membrane de la lanterne se replie à l'intérieur, revêt les muscles transverses ainsi que les appendices veineux et les vaisseaux de la lanterne et passe enfin à la limite de l'ésophage et du pharynx, où elle se confond avec le revètement glandulaire de l'ésophage pour tapisser probablement aussi le pharynx.

La membrane de la lanterne est très-mince et transparente; sa structure est finement fibreuse, et sa surface vibratile des deux côtés.

Au nombre des autres tissus mous de la lanterne, il nous reste à mentionner les tendons et les muscles. Quant aux premiers, nous les distinguons en ligamens externes obliques et en ligamens internes droits. Les muscles sont de plusieurs sortes: les muscles interarcaux et les muscles arcaux, les muscles interpyramidaux, les muscles transverses et quelques tissus problématiques de la face supérieure de la lanterne.

Examinons d'abord les ligamens : le ligament oblique externe (ligamentum obliquum extermum Tab.V, fig. $95 h$ et $98 k$ ) se répète dix fois sur la circonférence de la lanterne. Il naît par paires entre les auricules, vis-a-vis des aires interambulacraires, se dirige obliquement en dehors et en haut pour se fixer à l'extrémité de l'axe des branches du compas. Ce ligamenl, qui parait blanc et quelque peu brillant à l'cil nu, montre sous le microscope plusieurs faisceaux longitudinaux (de trois à six). Les filets primitifs du ligament affectent les mèmes ondulations caractéristiques qui les distinguent aussi dans les animaux supérieurs.

Tiedemann (") signale les ligamens externes au nombre des muscles de la lanterne servant à mouvoir les arcs semi-circulaires; mais déjả Meckel ("*) les envisageait comme de simples ligamens; et l'observation microscopique ne permet pas de douter que ces pièces ne soient réellement des ligamens et non pas des muscles.

Le ligament oblique interne (ligamentum internum obliquum) se répète cinq fois sur le pourtour de la lanterne. On voit, près de chacune des ouvertures auriculaires, un ligament partir du milieu des branchies internes, se diriger à l’intérieur et se prolonger jusqu'à l'extrémité intérieure de la faux et du compas (Tab. VII, fig. $135 d$ ). Le bord externe de cette partie (que nous appelons peut-être à tort le ligament, car il est formé d'une double lamelle qui renferme peut-être en-

(*) Anatomie p. 75 .

$\left.{ }^{* *}\right)$ System der vergleichenden Anatomic IV, p. 38. 
core des organes glanduleux) est linité par une ligne blanche, d'apparence plus ligamenteuse : cependant, lobservalion microscopique démontre que c'est un vaisseau qui communique avec la branche principale des vaisseaux branchiaux, ainsi que l'avait déjà olsservé Tiedenann; aussi, cette partie n'est-elle pis compose de fibres ligamenteuses particulieres, mais bien d'une double lamelle molle de la membrane de la lanterne.

Les muscles de la lanterne ont dẹja été indiqués d’une manière assez complète par Tiedemann ("); un seul muscle lui a ichappé, le muscle de la plume dentaire qui n'est bien distinct que dans les grands exemplaires de l'E. brevispinosus. L'ètude microscopique nous a appris que quelques ligamens, que l'on avait envisagés à tort comme des muscles, n'en sont point. Nous allons maintenant eximiner successivement les différens muscles de la lanterne.

$1^{\circ}$ Les muscles interarcaux (musculi pyramido-interarcuales s. commumitores ciborum Tab. V, fig. $75 f$ et fig. 98 $i$ ). Ce sont des muscles très-vigoureux qui partent, par paires, de lanneau auriculaire, entre les auricules, et montent en d'oite ligne, mais obliquement de dehors en dedans, pour se fixer au bord renflé de l'are transverse de la pyramide. Le ligament oblique externe est presque contigu à chacun de ces muscles et les divise en quelque sorte en deux portions, l'une qui naì du bord saillant intermédiaire entre deux auricules et s̈insère à la partie supérieure du bord externe de l'arc transverse, et l'autre, qui vient du bord interne des auricules elles-mêmes et se fixe au bord saillant externe de la pyramide. Chaque pyramide a ainsi un muscle droit et un muscle gauche, qui correspondent à l'espace intermédiaire entre deux auricules et par conséquent à une aire interambulacraire.

Le muscle, en se contractant, attire la partie supérieure et latérale de la pyramide obliquement en dehors et un peu en bas, refoule de cette manière la pointe de la pyramide et celle de la dent qu’elle contient, à lintéricur, ensorte que l'extrẻmité des dents devient apte à ronger, à broyer et à couper les alinens. Si le muscle n’agissait pas des deux côtés, ce mouvement serait diflérent; si éétait la partie fixée à l'are transverse de la pyramisle qui agît seule, la dent serait mue d'une manière plus simple de dehors en dedans. Si c'était au contraire la partie fixée au bord externe saillant de la pyramide qui fùt seule en activité, nous a urions un léger mouvenent latéral de la dent. Ces dix muscles sont par conséquent les muscles masticatoires et, comme tels, ils jouissent d'une grande force. Lorsqu'ils agissent tous simultanement, ils refoulent la lanterne contre la membrane buccale, la renflent, et, en faisant saillir davantage l'extrémité des dents, ils favorisent la 
prélension des alimens. Dans plusieurs jeunes exemplaires de l'E. lividus, la partie du musele qui s'atlaclıe au bord saillant externe de la pyramide est moins développée que l'autre. De la face interne des muscles s'élèvent plusieurs faisceaux ligamenteux fort remarquables (Voy. I'E. brerispinosus).

2o. Les muscles arcaux ou les dilatateurs de l'ouverture dentaire (musculi pyramido-arcuales dititatores orificii dentium) (Tab.V. fig. $75 \mathrm{~g}$ et $99 h$ ) sont petits, mais très-gros proportionnellement à leur longueur et également au nombre de dix. Tandis que les muscles interarcaux naissent de l'anneau auriculaire, entre les auricules, ceux-ci naissent, par paires, sur la face interne des auricules elles-mêmes et se dirigent vers deux pyramides voisines. Chacun de ces muscles est large à son origine et se courbe sur lui-même dans son cours ultérieur, ensorte que sa direction, au lieu de correspondre à l'axe vertical, coïncide avec l'axe transversal et se fixe à la demi-lune de la face externe de la pyramide. Ces muscles, en attirant la partie inférieure de la pyramide à eux, èloignent les dents, dilatent l'otverture dentaire et sont par conséquent les antagonistes des muscles interarcaux.

$3^{\circ}$. Les muscles interpyramidaux (musculi interpyramidales) (Tab.V. fig. 99 au-dessous de $c$ ) sont au nombre de cinq et se logent entre les faces latérales de deux pyramides; ils sont par conséquent plus longs en bas qu'en lıaut. Ils s'attachent aux stries transversales de la face latéraledes pyramides, ainsi que nous l'avons vu par l'étude microscopique de ces parties. Leur fonction est de rapprocher les pyramides et, partant, les bords latéraux des dents. En agissant tous simultanément, ils doivent nécessairement rétrécir la lanterne, mais davantage, à ce qu’il paraìt, en haut qu'en bas, et agir ainsi d'une manière indirecte sur l'ésoplıage situé au milieu de la lanterne, ou du moins l'empêcher de se dilater outre mesure. Meckel peut donc avoir raison, sous un certain rapport, en envisageant l'ensemble de ces muscles comme une sorte de sphincter.

$4^{\circ}$. Les muscles transverses (musculi transversi) (Tab. V. fig. 97 d). Ce sont cinq muscles en forme de ruban dont chacun s'étend de l'impression de l'un des compas a celle du compas voisin. Leur fonction est de rapprocher les compas et peut-être de ramener leur extrémité interne en bas et leur extrẻmité externe en haut. Quelles sont les fonctions de ces cinq muscles, lorsquilils agissent ensemble? c'est ce qui n’est pas encore dénontré d'une manière certaine. Meckel pense qu'ils sont destinés à rapprocher les arcs des pyramides, à éloigner les dents et à faciliter ainsi la prélıension des alimens; mais la grande mobilité du compas me fait douter de la vérité de cette explication.

Il me reste à mentionner encore quelques bandes musculaires qui sont particulièrement distinctes dans les grands exemplaires de l'E. brevispinosus. Toutes sont situées dans la membrane éten- 
due an bord supérieur de la lanterne, entre le bord externe formé par les ares transverses des pyramides et les muscles transverses. Cinq de ces bandes sout situées dins les échancrures des cinq pyramides; elles sont disposées par paires et se dirigent toujours du borl interne de la partie inférieure du muscle interarcal vers l'éclancrure de la pyramide, se subdivisant ici en plusieurs faisceaux qui aboutissent à la membrane qui entoure la plume dentaire. Les cinq autres bandes sont aussi par paires; elles partent également du muscle interarcal, passent ì côté el même sur le bord du compas el envoient à l'intérieur plusieurs fibres dirigées en partie vers le compas et en partie vers la membrane entourant la carène dentaire (Voy. Tab. V. fig. 97). Examinées à la loupe et même à l'oil nu, ces bandes ont l'applarence de fibres musculaires; mais le nicroscope y montre de larges fibres simples et contiguës, qui semblent mettre en doute leur nature musculaire. Cependant, si ce sont réellement des nuscles, leur action principale doit ètre dirigée sur la plume dentaire. La paire située près de l'échancrure dentaire serait alors destince a l'amener en dehors, et l'autre paire servirait à la fixer. Si l'un des muscles agissait isolément, la plume dentaire serait attirée latéralement et en dehors. Mais, en tous cas, ces bandes musculaires sont trop délicates pour produire des effets quelque peu considérables.

Le pharynx de l'Oursin commence immédiatement au-dessus de l'extrénité des dents et de la cavité de la bouclı ou du vestibule, avec les bourrelets pharyngiens, qu il faut bien distinguer des lèvres de la membrane buccale. Il occupe la cavité centrale de la lanterne et, en quittant celle-ci, passe immédiatement à l'ésophage. La différence entre ce dernier et le pharynx n'est pas seulement déterminée par leur posilion relativement à la lanterne; elle repose aussi sur la forme extérieure, qui est pentagonale dans le pharynx, sur la nature des membranes et surtout sur les particularités que présente la membrane muqueuse. Lorsquaprès avoir dẻtaché l'appareil masticatoire avec une partie de l'esophage, l'on en enlève une ou plusieurs pyramides (Tab. VII. fig. 121 , Tab. IX, fig. 182 et 183) on découvre d'abord le pharynx el, à côté de celui-ci, plusieurs autres organes particuliers que nous allons decrire en premier lieu, parce que l'ignorance dans laquelle nous sommes de leurs fonctions, ne nous permet pas, pour le moment, de leur assigner physiologiquement leur place. Au bas de la coupe de fig. $121 \mathrm{~h}$ et de fig. 122 e de Tab. VII, nous remarquons les bourrelets pharyngiens qui ressemblent quelque peu à de simples petits cécums situés à la partie inférieure de l'ésophage. $\Lambda u$-dessus de ces bourrelets, on voit cinq paires de filets blanes ou de ligamens longitudinaux ( Tah. VII. fig. $121 g, 122 g$ et 12 ' $c$ ) remonter vers l'ésophage et se rattacher à l'extrémité interne de la faux. Un peu a lintérieur de ces filets, lon aperçoit cinq 
organes allongẻs, fusiformes (fig. $122 h$ et $12 \% d$ ) qui sont recouverts, dans le bas, par les bourrelets pharyngiens. Enfin, il existe, à l'extérieur, cinq renflemens longitudinaux et plus ou moins larges de la membrane pharyngienne, qui est ici plissée transversalement. Les plis sont tantòt visibles à l'coil nu, tantôt on ne les aperçoit qu’à la loupe.

L'étude microscopique des ligamens longitudinaux nous apprend que ce ne sont autre chose que de simples ligamens revêtus de la membrane interve de la lanterne. Ils se composent de fibres analogues à celles des ligamens extérieurs de la lanterne et servent peut-être ả élargir le pharynx, lorsque les pièces de la pyramide sont distendues. Peut-être aussi servent-ils uniquement ì fixer le pharynx à la lanterne. Tiedenann déjả a fait la remarque que ce ne peuvent être des nerfs.

Les organes fusiformes pourraient plutôt ètre envisagés comme des tissus nerveux, à en juger l'aprẻs leur couleur, leurs renflemens, leur tenacité et leur structure microscopique. Examinés au microscope, ces organes montrent, dans les exemplaires conservés lans l'esprit de vin (malleureusement je n'ai pas eu l'oceasion de les étudier sur le vivant), une masse grenue avec des fibres qui les traversent et qui ont quelque ressemblance avec les fibres primitives des invertébrés. Mais le fait que, plus haut, ces organes fusiformès ne se réunissent pas en un anıcau pliaryngien envoyant des rameaus dans plusieurs directions, nous empêche d'admettre cette liypothese. Souvent on dirait, en effet, que chaque organe fusiforme se prolonge dans le renflement correspondant du pharyux avec lequel il est en contact; mais, en examinant de plus pres, on voit quili ne se termine en filet qu'en haut.

Si l'on ouvre le plarynx dans le sens de sa longueur, on verra qu il est divisé en cinq zones à l'intérieur comme à l'extérieur. Cette division s'opère au moyen de simples plis longitudinaux qui partent des cinq lèvres pharyngiennes et s'élendent jusquä l'ésophage (Tah. VII, fig. 123d). Chaque pli est accompagné de còtes obliques très-élégantes, qui alternent avec de petits sillons. Au reste, ce plissement oblique, que l'on remarque aussi souvent à l'extérieur, avant que l'on ouvre le pharynx, n'est pas simple, mais par paires; car l'on voit, au milieu de chacune des cinq zones, une bande saillante longitudinale d'oú partent en quelque sorte les plis symétriques obliques. Dans le bas, ces plis obliques se confondent avec ceux bien plus compliqués des bourrelets pharyngiens (Tab. VII, fig. $123 \mathrm{c}$ ), et l'endroit oủ ce passage s'effectue est indiqué par un are composé de deux moitiés, qui disparait à l'endroit correspondant aux sillons intermédiaires entre les plis longitudinaux.

La membrane muqueuse du pharynx est trés-solide. La membrane musculaire est peut-être encore plus développée; elle se compose de filıres musculaires aplaties formant tantôt des couclıes 
transversales, tantôt des couches longitudinales (Tab. VIII, fig. 156). La membrane dont ces fibres sont revêtues extérieurement parait correspondre exactement à la membrane extérieure et intérieure de la lanterne dont elle n'est peut-être que le prolongement.

A l'extérieur, le passage du pharynx à l'úsophage est marqué par un étranglement transversal (Tab.VII, fig. 121 el 122). A lintérieur, cette séparation est encore beaucoup plus prononcée (Tal. VII, fig. 123) : la membrane muqueuse du pharynx que nous venons de décrire se termine brusquement pour faire place à celle de lésophage, qui est d’une structure toute particulière.

Liésophage comprend cette partie du canal intestinal qui s'étend entre la lanterne et la portion de lintestin qui se déploie le long de la face interne du test. Pour bien voir sa position, il faut enlever soigneusement la partie moyenne de l'aire ambulacraire antérieure impaire arec une parlie des aires interambulacraires adjacentes, comme cela est représenté dans la fig. 128, Tah. VII. L'ésophagge est ici suspendu dans l'espace intermédiaire entre la face inférieure et l'appareil gènital, a-peu-près comme une corle détendue faisant plusieurs contours plus ou moins prononcés. II y a deux contours principaux, qui tous deux sont dirigés obliquement de bas en haut, d'arrière en a vant et de ganche a droite, et dont l’un, l'inférieur, est un peu plus petit que le supérieur. De lá l’ésophage se tourne à droite el en arrière pour passer à la partie plus renflée de lintestin.

L'ésophage se distingue à l'extérieur par une apparence toute particulière. Sans tenir compte de ses renflemens et de ses étranglemens, de ses contours et de ses détours, l'on aperçoit, à sa surface, une quantítẻ de stries longitudinales irrégulières, auxquelles correspondent des tissus folliculés non moins réguliers (Tab. VII, fig. $119 k, 122 i$, Tab.VIII, 14 fe, 159 et 160). En ouvrant l'ésophage, on voit que ces tissus folliculés sont disposés par rangées longitudinales, simples ou bifurquées, s’entrecroisant arec des rangées transversales non moins réguliëres. La figg. 126 , de Tab. VII, représente une partie de l'ésophage vue sous un faible grossissement, dans le but de donner une idée de cette structure. Cliaque follicule représente un renflement plus ou moins aplati. Les interstices intermédiaíres sont déprimés et transparens, tandis que les renflemens sont opaques. Sont-ce de véritables glandes ou non, c'est ce dont je n'ai pu m'assurer d'une manière positive. Je dois cependant ajouter que l'on voit au milieu de la plupart de ces follicules des points clairs correspondant au canal sécréteur d'une glande ou à son ouverture. Dans d'autres, on ne remarque, il est vrai, aucune trace d'une organisation semblable, ni aucuns canaux glandulaires. En exposant une coupe de l'ésophage à l'action de l'acide muriatique, on obtient, en revanche, une image qui fait supposer la présence de vastes cavités intérieures. Les parois montrent des fibres rayonnantes , 
semblables à celles que nous avons décrites en traitant des appendices de la membrane buccale ( Tab. V, fig, 69); seulement leur position détermine des formes plus rcnflées.

L'ésopluage a aussi ses trois membrancs: $1^{\circ}$ la membrane musculaire composée de nombreuses couches de fibres longitudinales et transversales. $2^{\circ}$ La membrane celluleuse, qui esi superposée ì la précédente. $3^{\circ}$ La lame mésentérique qui sert d'enveloppe générale et dont la surface entière est vibratile: nous en parlcrons ci-dessous.

C'est près de l'oraire postérieur correspondant à la principale plaque génitale (Tab. VII, fig. 127 et 128), que l'ésophage passe à l'intcstin. Je n'ai pas pu observer de trace d'une valvule en cet endroit. En revanche, lintestin présente, dans son prolongement ultérieur, une espèce d'appendice cécal (fig. 127 p), qui porte dẹjà tous les caractères du grand intestin et est par conséquent complètement différent de l'ésophage.

L'intestin proprement dit longe les parois internes du test, auxquelles il est attaché par des filets et des membrancs extérieurs (Tab. VII, fig. 129), ensorte qu'il est suspendu à l'intérieur du test commc un rideau à ondulations nombrcuses (Tab. VII, fig. $128 \mathrm{~m}$, fig. $130 \mathrm{~b}, c$ ). Ses premiers contours, qui sont en mème temps les inférieurs, vont de gauche à droite et d'arrière en avant, puis reviennent en avant et repassent de nouvenu sur l'arrière. Les seconds sont dirigés de droite à gauche, d'arrière en avant, et de nouvcau d'avant en arrière. Vis-ả-vis de clraque aire ambulacraire, lintestin est arqué vers le haut et plus ou moins latéralement. Le contraire a lieu visà-vis des aircs interambulacraircs; ici la courbe est dirigée en bas. Celte disposition est la même dans les deux principaux contours de lintestin; ensorte que cliacun d'eux présente dix ares. Quant aux portions d'ares correspondant aux aircs interanbulacraircs, ceux du contour intérieur de l'intestin sont plus élevés que ceux du contour extérieur; ce qui fait que lorsquon les examine d'en has, ces derniers cachent les premiers. Le contraire a lieu pour les arcs correspondant aux aires ambulacraires; ccux du contour inférieur sout plus rapprochés du nilieu et un tant soit peu plus has que ceux du contour supérieur, ce qui fait qu’ils les recouvrent en partie. Quand le sccond coutour cst ainsi arrivé jusqu’à la région de la rangée branchiale postérieure gauche, il se recourbe en dcdans et en Iraut, et passe au rectum qui va aboutir à l'anus.

Pour bien voir ces contours de l'inteslin en place, ce qu'il y a de mieux à faire, c'est de détacher la membrane buccale ou bien de faire une incision circulaire dans le test en deliors des auricules; on soulève ensuite la partie aiısi détacliée, et, en regardant dans l’intéricur, on a l'image qui est ici représentée ( Tab. VII, fig. 12T). Della Chiaje a dẻjả douné une senblable figure, mais je n'ai jamais réussi à diviser le test en deux parties, de manière à avoir, dans l'une, les contours 
principaux de la partie supérieure, el, dans l'autre, ceux de la partie inférieure, comme l'a fait Tiedentann ( ${ }^{1}$ ).

Tous les anteurs qui se sont occupés de l'anatonie des Oursins out ohservé que l'intestin est très-large, mais qu'en revauche ses membranes sont excessivement minces. En beaucoup d'endroits, et surtout sur les arcs du contour inférieur qui correspondent aux aires anbulacraires, il est marqué de plis et de sillons alternans, (Tab. VIl, fig. 128 et 130) à-peu-près comme un colon. Sa lace interne est assez unie, bieu que l'on y apercoive de petits plis transverses correspondant a ceux de la surface extérieure, et qui, eu plusieurs endroits, augmenteut d'épaisseur. Le microscope permet en outre d'apercevoir, à la face interne, une quantité d'alvéoles (Tab. VII, lig. 131) eu général peu développées et dirigées priueipaleunent dans le sens des plis transverses. Ces alvéoles sont séparées par des lignes plus claires el plus minces. Les trois membranes de l'intestin sont distinctes el ne présentent rien de particulier, si ce n'est que la membrane museulaire est trẻs-mince; la meubrane muqueuse, en revauche, est très-épaisse. Daus les exeuplaires conservés à l'esprit de vin, les deux couclıes alternantes de fibres musculaires et les restes altérés de cellules épithéliales prenueut l'aspect qu'on leur voit dans Tab. IX, fig. 179. La mème disposition des membraues existe dans toute la lougueur de rintestin jusquả l'extrémité du rectum; seulement, dans cette derniẻre région, les plis longitudinaux paraissent ètre plus saillans. Quant aux muscles moteurs de l'anus, nous en avons déjả parlé en traitant du test.

Toute la surface du canal intestiual, depuis les bourrelets pharyngiens jusqu'à l'extrémité du rectum, est revêtue d'un épithélium viloratile. Les organes digestifs et surtout l'intestiu proprement dit contiennent de nombreux débris d'alimens, sous forme de globules blancs semi-terreux que Rondelet déji comparait á des pillules, et qui s’échappent sous la forme d'excrémens. Il s’agissait d'étudier, à l'aide du microscope, la nature de ces matières fécales, afin d'appreudre si l'Oursin se nourrit de plantes ou de matiẻres animales, ou sil est omnivore. Tiedemann $\left({ }^{2}\right)$ trouva dans ces matières fécales des fragmens de testacés et mène parfois de petits tests d'uvivalves parfaitement conservés. Blaiuville doute que l'Oursin se nourrisse de substances animales; il n'envisage pas l'assertion de Tiedemaun comme suffisamment démontrẻe, quoiqu’il ajoute, sous forme de reuseignement, que Bosc vit un jour un Oursin dévorer un petit crustacé. Sharpey trouva, dans l'E. Sphara, des fragmeus de plantes marines, pour la plupart incrustés de flustres. Les matières fécales contenaient en outre des fraguens de coquilles, à l'égard desquels il eùt cepeudaut été difficile de dire

(') Anatomie Tal. X, fig. 1.

(') Anatomie p. 77. 
s’ils provenaient de mollusques, dont l'Oursin aurait fait sa pâture, ou s'ils avaient été ingérés avec le sable marin. Je dois convenir que, sous ce rapport, les résultats de mes observations ne sont pas entiẻrement concordantes. L'intestin des Spatangues contient, ainsi que l’a déjà fait remarquer 11. Desor ( ${ }^{1}$ ) toute une faune de débris testacés, les Polypiers, des Mollusques, des Echinodermes, elc., et parmi ces derniers mème des tests de jeunes Spatangues. Il n'en est pas de même de l'intestin de l'E. lividus, dont le contenu se compose de matières arénacées ou calcaires, accompagnẻes de nombreux dẻbris végẻtaux, tantòt détruits, tantôt plus ou moins conservés. Je n’ai pas trouvé une seule loule de matière fécale qui ne contînt un bon nombre de débris de varecs et de conferves marines. J'ai représenté (Tab. V1I, fig. 132), quelques échantillons de ces débris végétaux qui sont au reste très-variables. Au premier abord, quelques-uns ( fig. 132, fig. $g$ ), ressemblent fort à des tests de Mollusques $\left({ }^{2}\right)$; mais en les examinant de prẻs, on finit par s'assurer qu’ils sont de nature purement végétale. Je n’ai jamais olsservé avec certitude des débris de Mollusques, ni d’autres grands animaux, dans les E. lividus et brevispinosus. Je n'y ai rencontré que de petites navicelles (fig. $132 g$ ) et d'autres infusoires qui y sont assez nombreux.

Quelle que soit en définitive la manière de se nourrir de l'Echinus, on ne saurait en tout cas repousser l'idée qu'il ingère des matières inorganiques en quantité, hypothèse qui s'explique d'ailleurs par l'énorme sécrétion calcaire de ces animaux; car, abstraction faite du calcaire du test et des piquans, nous trouvons encore, dans toutes les parties un peu solides de l'animal, une quantité énorme de matière calcaire.

Le canal intestinal est revêtu d'une sorte de mésentẻre qui sert à le fixer à la face interne du test. Les points d'adhérences se laissent rapporter à des lignes qui se tronvent sur les aires interanbulacraires, entre la limite des hranchies el les principales sulures des plaques, el qui correspondent, pour la plupart, aux tubercules interambulacraires primaires de la face externe. Là où l’intestin est plus libre, par exemple, dans les concavilés de son pourtour, le mésentère revêt, comme double lamelle, l'artère intestinale et se termine par un bord libre. Une semblable surface affran-

(1) Verlandl. der Scliweizerischen uaturforschenden Gesellschaft bei ilirer Versammlung zu Bern. 1859, S. 170.

(") Pendant que je faisais ces observations, 11 . Sluttleworth trourait de nombreuses traces de ce méule nouveau genre de végretaux, fixés à des tiges de Callitricle, dans des mares tourbeuses d'eau douce, non loin de la ner, sur la cóte occidentale A'Irlaude, daus le coute de Calwag. M. Sluttleworth décrira en détail te genre, sons le nou de Lecanidium. D’apris ce savant, les caractires essentiels de ce genre consistent dans sa forme concave-conveve; il se raproche le plus du genre Microsterias. dont il diffère cependant par l'irrégularité de ses formes et par les proportions numéripues et la position de ses cellules. Ces corps sattachent aux tiges des plantes aquatiques, comne des Patelles. 
$-81-$

chie du mésentère se voit aussi au milieu de la convexité du tour superieur ('Tal. VII, fig. 130), car ici le mésentère est empêché de se fixer au test par les branchies internes.

Il se compose d'une double lamelle de simple construction, pimentée en quelques endroits et contenant des vaisseaux sanguins, surtout entre ses fenillets. Les lanes du misentère sont vibratiles dans toute leur étendue de contintent dans les membranes internes du test. 


\section{CHAPITRE VII.}

DES ORGANES RESPIRATOIRES.

Il y a deux classes d'organes respiratoires, les extérieurs libres et les intérieurs cachés. Les premiers se remarquent déja à la surface de l'animal; les seconds correspondent aux tubes ambulacraires avec lesquels ils communiquent.

$1^{\circ}$ Les branchies cxtérieures libres ou branchics buccales externes ont été décriles pour la première fois par Tiedemann $\left({ }^{1}\right)$ et Della Chiaje $\left({ }^{2}\right)$; Neckel, au contraire, n'en fait aucune menlion. Placées au bord externe des aires interambulacraires, elles correspondent, par leur position, aux entailles du test, et sont par conséquent au nombre de dix. Un connaisseur les reconuaîtra toujours sur l'animal vivant; mais ils ne sont bien distincts que quand on a enlevé les piquans (Tab. IV, fig. $57 \mathrm{c}$ ). Ce sont des organes branchus; leur tige principale naîl de la membrane buccale, dans les entailles du test, se ramifie et se termine enfin par des filets cécaux, ainsi qu'on le voit dans notre fig. 142 (Tab VIII), qui représente une branchie de l'E.lividus. Le canal principal, composé d'une membrane très-solide, se divise en une quantité de rameaux 'jui se subdivisent ả leur tour, et se terminent à leur extrémitẻ en petites grappes. Lorgane entier est creux, et les cavités secondaires s'étendent d'une manière continue jusqu'aux cécums terminaux. La cavité principale communique, par une très-grande ouverture située à côté ou devant les auricules (Tab. VII, fig. 135, $l$; Tab. IX, fig. 181), avec l'espace intérieur qui est entre la lanterne et l'ésophage, d'une part, et le test avec sa membrane, l'intestin et les organes sexuels, d'autre part.

En introduisant du mercure dans la cavité principale de l'organe, tous les vaisseaux s'en remplissent facilement jusqu’à l'extrémité des filets cécaux. Tiedemann $\left({ }^{3}\right)$ dit même avoir vu le

(') Inatomie p. 78 .

$\left.{ }^{2}\right)$ Memorie vol. 11, p. 558. Institntioni, p. 932-68.

(') Anatomic p. 78 . 
nercure sortir par l'extrémité de ces vaisseaux ; mais je crois pouvoir affirmer avec certitude que ce n’élait que l'effet d’une rupture oceasionnée probablement par la trop forte pression du métal injecte; car, lien que jaie réussi à introduire du mercure jusque dans les ramifications cécales, je n'en ai jamais vu s'échapper la moindre parcelle; bien plus, je n’ai jantais pu apereevoir, sous le microscope, la moindre trace diune ouverture. L'existence de pareilles ouvertures serait d'ailleurs contraire au type de la structure glanduleuse, telle que nous l'observons partout dans la nature. Della Chiaje (') trouva, dans liutérieur de ces branchies, du sang et un liquide épais semblable à celui qui existe dans la vessie de Poli ou dans le cœur; mais ce fait, ainsi que nous le verrons plus bas, a igalement besoin d'ütre confirmé.

La surface extérieure de ces organes est très vibratile. A l'épithélium suceède une couche de piment qui recouvre la substance branchiale proprement dite, qui probablement est aussi revêtue it l'intérieur d’un épithélium vibratile. Celte substance branchiale contient, dans les individus adultes des $E$. lixidus, brevispinosus et Sphara, un tissu calcaire très étendu, mais isolé, qui existe jusqu’aux extrémilés des ramifications cécales. Dans le canal principal, ces réseaux calcaires sout mème très développés, compliqués et souvent disposés par feuillets. J'en ai figuré une parlie (Tab. VIII, fig. 113). Ils deviennent toujours plus simples à mesure qu’ils se ramifient dans les parois de l'organe. La plupart ne sont composés que de quelques mailles; d'autres ne sont que légèrement ramifiés et d'autres encore ne forment que de simples massues. Ils diminuent en général vers le haut, à-peu-prẻs de la mème manière que cela a lieu pour la membrane huccale (Tab. V, fig. 71). Cependant, on trouve encore de nombreux réseaux calcaires trỉs-développés, même à l'extrémité des filets cécaux. On ne saurait douter que ces organes ne contiennent aussi de nombreux vaisseaux sanguins; cependant je dois à la vérité de eonvenir que je n’ai pas pu les distinguer d'une manière précise.

2o. Branchies intérieures. Il existe, à côté des rangées de pores ambulacraires, à la face interne du test, cinq rangées paires d'organes connus depuis longtemps (Tab. VII, fig. $127 \mathrm{~F}, 130 \mathrm{k}$ et 134 f) et que je propose d'appeler branchies intérieures. Ces organes sont effilés vers l'appareil génital et anal, où ils viennent se terminer au bord des plaques ocellaires; ils sont larges vers le milieu du corps, s’étendent jusqu’à l'anneau auriculaire et se prolongent même, sous une autre forme, au deli de cette région, pour apparaitre de nouveau, en contact avec la membrane buccale, sous forme de branchies buccales intérieures. Chacun de ces organes présente, sur la ligne médiane, une bande blanche (Tab. VII. fig. $136 \mathrm{~b}$ et Tab. VIII, fig. $139 \mathrm{~d}$ ) a laquelle

(1) Memorie vol. II, p. 558 Institutioni. p. $262-65$. 
sont attachés latéralement, comme autant d'ailes, les feuillets branchiaux (fig. 136 a et 139 a) 'qui flottent pendant la vie de l'animal, mais que l'on trouve ordinairement surperposés et dirigés en bas après la mort. En soulevant ces feuillets branchiaux, on remarque qu’ils sont attachés rlans le prolongement de leur membrane, aux pores ambulacraires internes, ou plutôt qu’ils embrassent (ces derniers (Tab. VIII. fig. 139 c).

Lorsqu'on examine les feuillets branchiaux à l'ëtat libre, dans l'eau, on remarque que cliaque fruillet renferme une large cavité. Dans des Oursins conservés dans l'esprit de vin, la partie qui conslitue les parois latérales montre seule une quantité de lignes in terrompues, mais plus ou moins concentriques. Le bord libre interne se présente, au contraire, généralement sous la forme de figg. 139, Tilb. VIII, surtout dans les vieux individus de l'E. livilus. Si l'on exanine un pareil feuillet branchial sous un plus fort grossissement, l'on aperçoit, sur ses parois, des fibres qui montrent une disposition régulière (Tab. VIII, fig. 137 et 138). Ces fibres sont réunies par une membrane transparente sans structure, ou plutôt elles sont adhérentes à la face interne d'une pareille membrane; elles n'ont aucune ressemblance arec les fibres élastiques plus fines des animaux supérieurs; cependan t elles se réunissent souvent en réseau (fig. 1 1 1 a) et paraissent être contractiles pendant la vie. On aperçoit même souvent, sur les parois de ces membranes, des canaux et des réseaux qui ont tout-î-fait l'air de vaisseaux sanguins; mais il faut être sur ses gardes pour ne pas les confondre avec des plis, tels qu'on en voit souvent sur' les membranes délicates. D'après les observations de Della Chiaje (') ef de hrolın $\left({ }^{2}\right)$, il existe un réseau vasculaire dans le feuillet branchial, tandis qư un vaisseau plus grand en parcourt le bord. Ce vaisseau envoie deux rameanx vers le trou ambulacraire. On y reunarque aussi souvent des glohules de sang (Voy. fig. 178), altérés par l'esprit de vin $\left({ }^{3}\right)$. Les faces exterues et internes de ces feuillets branchiaux sont vibratiles.

Il importe, avant tout, de se faire une juste idée de la conformation des cavités de ces feuillets Iranchiaux et de leurs rapports avec les tubes ambulacraires. Déja Monro ( $\left.{ }^{\dagger}\right)$, et plus tard Tiedemann $\left(^{5}\right)$, ont fuit la remarque, que du mercure introduit dans la cavité des tubes ambulacraires pénètre dans les feuillets loranchiaux, el jai souveni répété ces expériences arec un plein succès;

\footnotetext{
(') Memorie rol. II, p. $55 \mathrm{~s}$,

(3) Muller's Archiv fül Anatomie. 1841 , p. 3̈.

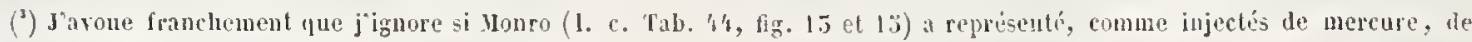
veritables vaisseaus sanguins.

(') Anatomic p. 92.

(3) Antomie p. 81 .
} 
aussi je ne doute pis que toutes les cavités des tubes d'une zone porifère n’aboutissent dans les branches de la cavité du feuillet branchial, situé à la même hauteur. Je ne mets pas non plus en doute que les cavités des feuillets branchiaux ne correspondent entre elles, ayant fait l'observation que parfois le mercure se répand dans les stries longitudinales, de mène que daus les feuillets branchiaux de la rangée opposée. Or, à moins d'admettre une extravasation du mercure, on est uaturellement conduit à supposer que toutes ces cavités communiquent entre elles.

Les branchies interieures ont en général la forme de fig. 139, Tab. VIII ; mais elles se rétrẻcissent et s’arrondissent un peu (lig. $135 h$ ) vers le bas, et prennent même la forme de petits sacs (fig. 135i). Près des auricules et sous ces dernicies, elles ressemblent aux branchies buccales intérieures. Enfin, il existe un espace dépourvu de branchies entre les branchies intérieures et la membrane buccale. Il résulte de la position des branchies intérieures, qu'elles alternent, sur la membrane buccale, avec les branchies extérieures, les premières étant situées dans le rayon des aires ambulacraires; les branchies exterieures, au contraire, dans les aires interambulacraires. Lorsque les branchies intérieures affectent la forme de petits saes, comme c'est le cas près des auricules, elles sont dégagées, plus ou moins effilées et, vues au microscope, elles ressemblent à peu près à un poumon de Salamandre. Leur structure est absolument la mème que celle des branchies ordinaires, ainsi que le montre la fig. 140 de Tab. VIII. Les fibres quion remarque sont capables de les dilater et de les contracter.

Les branchies intérieures, ainsi que les tubes auxquels elles sont adhérentes, ont eu le sort d'ètre rangées par plusicurs naturalistes dans le systėme vasculaire. Monro (') les désigna sous le nom de vaisseaux absorbans; dénomination qui paraît assez convenable, en tant qu'on ne les parallélise pas avec le systėme lymphatique des animaux supérieurs. Tiedemann $\left({ }^{2}\right)$, considérant l'appareil entier comme le système vasculaire des tubes ou petits pieds, crut devoir proposer la théorie suivante: Il y a dans la cavité des branchies intérieures un liquide non salé; dés que les branchies se contractent, ce liquide est poussé par les ouvertures des tulıes ambulacraires dans la cavité de ces derniers, qui s'élargissent et s'étendent à cet effet; tandis qu'ils se contractent du moment que le liquide rentre dans les branchies. Cette supposition ne serait possible qu'autaut. que les tubes n'auraient pas d'ouverture ì l'extérieur, et c'est en effet ce qu'il admet en combattant les observations d'Alex. Monro, qui soutient que le canal des tubes s'ouvre à l'extérieur, au

\footnotetext{
(') Anatomie p. 90-91.

(2) Inafomie p. 8:-84.
} 
milieu d'une ventouse ( $\left.{ }^{1}\right)$. Mes observations confirment celles de Monro, el je ne puis par conséquent partager l'hypothèse de Tiedemann. Je crois en effet m'être assuré, par un examen scrupuleux, que la ventouse des tubes ambulacraires est percée par le milieu, et qu'elle communique avec la cavité des branchies internes au moyen d'un canal. C'est tout au plus si ce canal se montre un peu rétréci au dessous de la ventouse, et encore ce rétrécissement pourrait-il n'être qu'un effet de l'irritation ou de la mort. S'il en est ainsi, il est évident que la dilatation des tubes ambulacraires ne peut pas s'opérer par l'action d'un liquide, suivant la théorie ci-dessus, attendu que l'eau de mer pénètre librentent par les tubes dans les branchies intérieures. Tout en confirmant la contraction des tubes et des branchies intérieures, je ne puis cependant porter un jugement définitif sur leür contenu, et jabandonne aux recherches futures de déterminer si ce contenu est salé ou non.

Je ne puis également partager l'opinion de Tiedemann sur un autre point. Cet auteur affirme $\left(^{2}\right)$ que l'eau de mer arrive dans l'intérieur de l'animal, par des ouvertures dont seraient percées les branchies extérieures. J'ai dẹja fait remarquer plus haut que je n’ai jamais vu de pareilles ouvertures et que, dans ma conviction, l'eau de mer ne saurait s'introduire par cette voie dans l’intérieur du corps.

Cherchons maintenant à nous rendre compte de la respiration elle-même. L’Oursin a très-probablement une double respiration, une extérieure et une intérieure. Cette première a lieu par les hranchies extérieures, si toutefois il est vrai qu'elles contiennent un réseau de vaisseaux sanguins. En revanche, je ne pense pas que les tubes ambulacraires soient des organes respiratoires. Ils ne sont, à mon avis, que les médiateurs de la respiration. Si la manière dont nous avons exposé la structure du canal des tubes est exacte, l'eau doit s’introduire par leur entremise dans les cavités des branchies intérieures, dont les parois sont tapissées de nombreux raisseaux sanguins. Ces deux sortes d'organes respiratoires rempliraient ainsi en mème temps les fonctions de la respiration intérieure. Nous savons en effet que l'intérieur de l'animal renferme constamment une certaine quantité d'eau contenue entre la lanterne et l'ésophage d'une part, et le test avec ses membranes internes, les branchies intérieures, le canal intestinal et les ovaires d'autre part. Cette eau est en contact avec la surface libre des branchies intérieures, et pénètre en mème temps dans les cavités des branchies extérieures, ainsi que nous l'avons démontré plus haut; ensorte qu'elle est extérieure relativement aux branchies intérieres, et intérieure relativement aux branchies cxtérieures; mais

(') Anatomie p. 83
(') Anatomic p. 78 . 
les rapports de ces deux sortes de branchies sont diamétralement opposés relativement au milieu servant à la respiration. Les branchies extérieures flottent dans l'eau de mer, tandis que c'est l'eau contenue dans l'animal qui pénètre dans leurs cavités. Les branchies intérieures, au contraire, reçoivent dans leur intérieur l'eau de mer, tandis qu'elles sont entourées par l'eau intérieure.

C'est ici le lieu d'ajouter quelques mots sur cette eau intérieure que l'on appelle le système aqueux de l'Oursiu. On a observé a plusieurs reprises qüil existe toujours, dans l’intérieur du test, une grande quantilé d'eau baignant les organes intérieurs de l'animal. Nous avons dejả fait remarquer que nous ne partageons pas l'opinion qui prétend que cette eau y est introduite par des ouvertures situćes à l'extrémité des loranchies extérieures; opinion qui semble aussi être celle de R. Wagner $\left({ }^{1}\right)$. Della Chiaje $\left({ }^{2}\right)$, en parlant du système aqueux des Echinodermes, ne dit rien de particulier à l'égard des Oursins.

Il n'y a que deux voies par lesquelles l'eau de mer puisse s’introduire dans l'intérieur du corps : ou lien elle s'y infiltre ì travers les tissus membraneux de la surface de I'animal, ou bien elle y pénètre par des pores ou des canaux. Rien ne serait plus naturel que d'admettre que cette transpiration a lieu, d'une part, par la menbrane buccale, d'autre part par les membranes qui unissent les plaques génitales aux plaques anales, si leur épaisseur et leur texture compacte ne s'opposaient à cette supposition. Il se pourrait également qu’il s’introduisit de l'eau par l'espace à-peuprès triangulaire que l'on remarque entre deux dents, etc.; encore ne serait-ce que pas endosmose. Dans le second cas, on admet que l'eau de mer pénètre par des tubes ambulacraires, dans les cavités des branchies où elle est employée à la respiration, et que de là elle pénètre par exosmose dans l'intérieur du corps. La nature salée ou non salée ne prouverait ni pour ni contre cette lıypothèse, attendu que la respiration n'enlève à l'eau que des parties gazeuses telles que l'oxigène, mais en aucune facon son contenu de sel. Mais la supposition, que l'eau intérieure est introduite par endosmose, est contraire à l'analogie ; car nons savons qu'il existe dans d'autres Echinodermes, par exemple, dans les Astérites et les Ophiures, de véritables fissures ou d'autres ouvertures par lesquelles l'eau de mer pénètre dans lintérieur du corps.

L'eau occupe deux cavités distinctes dans l'intérieur de l'animal; celle de l'une de ces cavités, que je voudrais appeler l'eau du corps, baigne la face extérieure de la lanterne, l'ésophage, le

(') Lehrbuch der vergleichenden Anatomie I, p. 195, 194.

(') Ilemorie Vol. II, p. 270. 272. Institutioni Tom. I, p. 286. 
$-88-$

canal intestinal, les ovaires, les branchies intérieures et la membrane du test; celle de l'autrecavité, que l'on pourrait appeler l'eau de la lanterne, occuperait l'espace circonscrit par la membrane de la lanterne, la lanterne elle-même et ses muscles latéraux, espace que nous avons décrit plus haut en parlant de la membrane de la lanterne et des vésicules ovales qui entourent l'extrémité de la plume dentaire. 


\title{
CIAPITRE VIII.
}

\author{
I)U SYSTHME VASCULAIRE
}

Nous arrivons ì la partie la plus olseure de l'anatomie des Oursins. Les recherches que nous avons faites dans le but de connaître le systène vasculaire de ces animaux, sont loin d'avoir résolu les difficultés qui se présentent. Cependant, pour faciliter les voies et préparer les matériaux ¿̀ ceux qui s'occuperont ultérieuremnnt de cette question, je vais essayer de donner ici un aperçu succinct de tout ce qui a élé fait dans ce domaine.

Al. Monro $\left({ }^{1}\right)$ trouva, au bord inférieur du mésentère, deux vaisseaux d'égale grandeur et dépourvus de valvules. Ces vaisseaux se laissèrent facilement injecter de mercure, et l'on vit en même temps, au bord du tube intestinal, et sur la membrane qui unit ce dernier au test, un réseau de vaisseaux se remplir de métal. Les deux troncs principaux ne communiquaient point entre eux, ni avec aucun organe que l'on eùt pu prendre pour le ceur. Cependant il y avait, près de l'anus, un organe en apparence creux, et qui était réuni au gros intestin. Je ne pense pas que lorgane ainsi décrit par Monro soit identique avec ce que Tiedemann décrit comme élant le cour. La figure qu’en a donné Monro $\left({ }^{2}\right)$ s'y oppose de toute manière. Il paraît que l’espèce sur laquelle Monro fit ses observations était l'E. Sphara; mais peut-être a-t-il emprunté les appendices de l'anus à un E. melo, puisque ses successeurs n'ont pas pu y retrouver l'organe en question.

Cuvier $\left({ }^{3}\right)$ dit que dans les Oursins, comme dans les Étoiles de mer, l'artere et la veine principales longent l’intestin. Les artères de l'enveloppe (les artères qui se distribuent tout i l'entour dans l'enveloppe) viennent d'un vaisseau annulaire entourant l'ésophage. En sortant de cette enveloppe le sang retourne de noureau à lintestin au moyen du mésentère; «mais, dit-il, c'est au dehors que se fait la respiration, et les tubes respiratoires communiquent avec les vaisseaux de

(1) Anatomie p. 89 .

(') Anatomie Tab. XLVHI, fig. 2, 10.

(') Lecons d'anatomie comp. Première édition. Tom. 1 , Paris 1805 , 8' p. 416-17. 
l'enveloppe et non pas avec un trone placé entre les plis du canal. Dans les Oursins, on voit plus particulièrement les grandes artères de l'enveloppe détacher un petit rameau pour le faire passer au travers de chacun des petits trous, et aller nourrir les pieds des muscles des épines et les autres parties molles extérieures. Je pense que ce sont ces vaisseaux-là que Monro a pris pour des absorbans. "

Suivant Tiedemaun ('), le canal intestinal a deux vaisseaux principaux, l'un à son bord interne, l'autre à son bord externe. Il existe de plus, autour de l'extrémité de l'intestin, et à l'extrémité inférieure des cinq oviductes, un vaisseau circulaire duquel naît un petit vaisseau qui descend vers la lanterne et va aboutir à un canal de couleur brune, de forme ovale, ayant à-peuprès $2^{\prime \prime \prime}$ de long et pourvu de fibres musculaires croisées, se contractant et se dilatant pendant la vie. De ce canal naissent plusieurs vaisseaux, l'un qui envoie des rameaux à l'ésoplage, au pharynx ef aux muscles de la peau et de la lanterne; un second longe l'ésophage jusqu'à son embouchure dans la partie renflée de l'intestin, où il se continue dans un vaisseau situé au bord interne de ce dernier. Ce vaisseau se dilate vers le hant, longe le bord interne de la première courbure, puis se retrouve encore à la seconde, d'oủ on le poursuit jusqu'au rectum ; c'est donc vraisemblablement l'artėre intestinale. Pendant la vie, elle contient un liquide d'un jaune foncé presque orange, qui se coagule très-promptement dans l'esprit de vin. Il existe en outre, au bord externe de l'intestin, un grand vaisseau, contenant un liquide d'un blanc jaunàtre : ce canal qui a sa plus grande largeur au milieu, se rétrécit des deux côtés et peut par conséquent être envisagé comme veine intestinale. Dans le bas, cette veine se prolonge le long de l'ésophage jusqu'à la lanterne; dans le haut, elle se poursuit jusqu'au voisinage de l'intestin, en suivant tous les contours du canal intestinal; elle recoit, dans son trajet, de nombreux rameaux des parois de ce dernier et en envoie d'autres en grande quantité à la peau qui tapisse l’intérieur du test. Ces derniers vaisseaux se terminent là où le mésentère maintient l'intestin dans sa position flexueuse. La veine intestinale ne se contracte ni se dilate lorsqu'on l'irrite avec une aiguille. Au moyen d'un rameau qu'elle envoie à la membrane interne du test, où l'eata de mer aspirće par l'animal sert à oxider le sang, la veine intestinale devient en même temps une artère servant à la respiration. Le vaisseau annulaire de l'intestin qui recoit à son bord externe plusieurs vaisseaux venant de la membrane interne du test, fonctionne probablement comme veine de respiration en déversant le sang dans l'artère intestinale et de là dans le cœur. Quant au système vasculaire des branchies 
internes, Tiedemann les met en rapport avec sa numière d'envisager la contraction et la dilatation des tubes ambulacraires.

Suivant Della Chiaje, la yeine intestinale commence à lis partie terminale de l'intestin, qu'elle longe jusqu’à l'ésophage, à l'extrémitè duquel elle passe dans un anneau vasculaire. Eille s'inastomose, au moyen de réseaux vaseulaires, avec la sulsslance même de l'intestin, et envoie des rameaux dans le mésentère. Le sang qu'elle contient est, dans l'E. neapolitamus et dans le Spatangus, d'un rouge violet tirant au jauntutre, el dans le Cidaris hystrix, verdàtre. Du vaisseau annulaire de l'ésophage naissent non seulement l'artère intestinale dout le cour's est parallèle á celui de lintestin, avec lequel elle communique au moyen de réseaux capillaires, mais encore les cinq arteres pharyngiennes qui, avant d'atteindre les bourrelets plaryngiens, sanastomosent, au moyen d'un rameau qui traverse les muscles de la lanterne, avec les cinq artëres dorsales qui se dirigent vers l'anus, en longeaut les liranchies internes. Ici, ces cinq artères dorsales forment uı anneau autour de l'anus. Le cœur ou la vessie de Poli part du vaisseau annulaire pharyngien ; sa forme est tubulaire, son cours est simueux, et il se termine en s'ëlargissant el en se fixant a l'ésophage, au moyen du mésentère qui s'étend jusque prẻs de l'anus. Le vaisseau, qui se dirige du fond du ceur vers la face interne de la grande plaque génitale, communique avec un corps vésiculeux composé d'une quantité de grains, et rempli d’une liqueur semblable à celle qui se trouve dans la vessie de Poli (').

Depuis les travaux de ces deux derniers savans, Tiedemann et Della Chiaje, il n'a point été fiit de tentatives importantes pour concilier ces opinions contradictoires. Meckel $\left({ }^{2}\right)$, R. Wagner $\left({ }^{3}\right)$, Sharpey $\left({ }^{4}\right)$, Duvernoy $\left({ }^{5}\right)$, ne font que rapporter les observations de Tiedemanu et Della Chiaje, en ajoutant çi et là leur manière de voir individuelle, qui cependant n'est pas basée sur l'expérience. Allen Thompson $\left({ }^{6}\right)$, en particulier, traite la circulation des Echinodermes d'une manière très-brève.

Nous allons maintenant dire ce que nous avons observé nous-même, en y ajoutant la théorie que nous nous sommes faite de la circulation dans l'Echinus.

\footnotetext{
(') Memorie Vol, 1I, p. 540. Inslitutioni Tom. 1, p. 505.

$\left.{ }^{3}\right)$ System der vergleichenden Anatomie Vol. 3,1851 1. 54-56.

(3) Lehrbuch der vergleichenden Anatomic Part. I, 1. 156-158.

(') Echinodermata p. 14.

(") Curier, Lecons d'anatonie comparée Scconde Edl. Ton. VI, Paris 1859, p. 467-470, cte.

(") Todd Cyclopaedia of anatomy and physiology rol. 1, p. 6.5.
} 
Le cœur(Tab. VII, fig. 125 f, 127 o, $128 h$, et Tab. VIII, fig. 144 f) est situé près de l'ésophage, et entouré par la double lanelle du mésentère. C'est un organe allongé, un peu effilé en haut et plus renflé en bas (fig. 145), mais dont le relief varie plus ou moins, suivant les individus. L'une de ses faces est à peu près lisse; tandis qu’a la face opposée, on remarque un corps semblable à un vaisseau (Tab. VIII, fig. 144, 146 et 147). Quoique la position de res deux faces varie un peu dans les diffẻrens individus, la face lisse est cependant en général dirigée en avant et à Jroite dans la direction de l'ovaire antérieur droit, tandis que la face opposée est tournée en arrière et à gauche, à peu près dans la direction de l'ovaire postéricur gauche. Au reste, sa position est telle, que le plus grand diamètre est à peu prẻs dans le sens vertical.

On remarque, à la surface du cour, plusieur's parties plus ou moins distinctes et limitées par des étranglemens, tels qu'on les voit dans la figg. 147 de Tab. VIII, qui est dessinée de profil. Lorsque toutes ces parties sont bien accusées, on peut reconnaître trois régions principales dans le cour : une supérieure, une moyenne et une infërieure, dont chacune présente plusieurs renflemens en forme de petits sacs. L'organe entier est évidemment en spirale, particularité qui se reconnaìt aussi assez distinctement dans ses fibres musculaires, comme on peut s'en assurer en le dégageant de son enveloppe mésentérique et de ses vaisseaux extéricurs. En examinant, au contraire, la surface du cour dans son état d'intégrité, ả la loupe, on y remarque une série de petits vaisseaux qui, en partic, se ramifient à la surface, et en partie forment des figures réticulées plus ou moins irrégulières, mais très-élégantes.

Le corps, qui ressemble a un vaisseau et qui, comme nous venons de le dire, sètend sur l'une des faces du cour (Tab. VIII, fig. 147), occupe une espèce de sillon tout près de la double lamelle du mẻsentère, qui lui-même pénètre dans ce sillon, pour de là s’étendre plus loin sur la surface du cœur.

Il est très-difficile de se faire une idée juste et claire de l'intérieur du cour. Ce n’est nullement un ventricule simple; l'on y rencontre, au contraire, plusieurs espaces limités soit par des parois ınusculaires, soit par de fines parois cutanées. Il m'a mênıe semblé que, dans le cour de certains E. brevispinosus, l'espace entier n'était limité qu'extéricurement en certains endroits, particulièrement près du sillon longitudinal. Les fig. 148 a 152 de Tab. VIII, représentent une série de coupes transversales qui montrent, qu'en aucun endroit du cœur, le ventricule n'est simple, et que, vers le haut, les cavités sont plus petites, et leur nombre plus considérable qu'en bas. On se fera une idée approximative de ces rapports en supposant une ou deux cavités principales au milieu et de petites cavités particulières dans les parois. Une circonstance très-remarquable, c'est que 
le vaisseau qui occupe le sillon du cour ne pénètre point dans son intérieur; il ne fait quadhérer à sa surface au moyen de l'enveloppe mésentérique qui l'entoure de trois côtés.

Les fibres du corur sont reconnaissables, même i la loupe. Sous le microscope, on distingue de très-fines fibres au milieu d'une substance abondamment fournic de globules de piment. Les cavités sont revêtues d’une membrane interne. La membrane externe, qui se continue dans le mésentère du cour, est vibratile comme le mésentère lui-mıeme. L'organe entier esi susceptible de se contracter et de se dilater.

De la partie inférieure du cour part un trone vasculaire, qui se dirige vers la lanterne, envoie peut-être quelques rameaux fius à l'ésophage, ef forme, à la limite entre l'ésophage et le pharynx, au sommet de la lanterne, une espèce de vaisseau circulaire (Tab. VII, fig. 119 et Tals. VIII, fig. 1 4 \%) qui envoie des rameaux dans l'intérieur de la lanterne et des tissus environnans. J'appelle provisoirement ce vaisseau annulaire artériel de la lanterne. Un autre vaisseau se dirige en sens opposé vers les plaques anales et envoie encore, à ce qu'il paraît, des rameaux à la partie supérieure de l'ésophage. Il m'a paru que ce même vaisseau formait, dans l'E. brevispinosus, prẻs du cercle anal, un vaisseau annulaire artériel d'où partaient cinq ar tères génilales.

L'artère intestiuale (Tab. VII, fig. 127, 128 et 130) longe le bord de l'intestin, et son trone principal s'étend jusque vers le rectum en envoyant de nombreux rameaux à l'intestin. La lanterne a, outre le vaisseau annulaire artériel, un second vaisseau plus grèle qui recoit des rameaux de la lanterne, el alimente à son tour les veines ésophagiennes qu'on remarque à la surface de l'ésophage. Un autre vaisseau veineux se dirige le long de la surface externe de l'intestin, envoie de nombreux ranieaux à la nembrane du test, remonte avec le rectum, el pénètre, par de nombreux filets, dans le vaisseau annulaire du rectum. Enfin, il y a près des branchies internes, dans la bande médiane, deux vaisseaux, probablement une artère et une veine branchiales, d'oú partent des rameaux dans les deux directions. Il existe probablement aussi dans la membrane branchio-lanternale (Tab. VII, fig. $135 d$ ) un vaisseau venant des branchies, et qui peut-être aboutit à l'un des vaisseaux anuulaires de la lanterne.

L'observation, on le voit, est loin d'avoir embrassé tous les organes de la circulation; aussi est-il bien difficile de se faire une juste idée de l'ensemble de leurs fonctions, alors que nous ne savons pas même encore distinguer d’une manière précise les artères et les veines. Cependant, comme la forme monographique de ce travail moblige en quelque sorte à m'expliquer aussi sur ce point obscur de l'anatomie des Oursins, je tâcherai de suppléer au défaut d'observations par 
une hypothèse que je crois conforme à l'état actuel de la science. On conviendra sans peine que les idées que l'on se faisait autrefois de la circnlation de l'Oursin ne pouvaient être que trèsincompletes, puisqu'elles ne tenaient compte ni des branchies externes, ni des branchies internes, el que ces organes ont certainement des vaisseaux, comme toutes les autres parties de l'animal. Voici donc quelle est à-peu-près ma manière d'envisager la circulation:

Le cour envoie du sang artériel à l'artère qui descend à la lanterne; ce sang passe, au moyen de l’annean circulaire de la lanterne et de ses rameaux, dans les parties molles de la lanterne, et en particnlier dans le pharynx et la membrane buccale. Le ramean artériel, descendant dans la lanterne, alimente en outre directement la partie inférieure de l'ésophage. De la membrane bnceale, du pharynx et des parties molles de la lanterne, le sang rentre dans l'anneau annulaire veineux de la lanterne, et de là dans la veine intestinale, oủ, se mùlant avec le sang veineux qui vient de l'intestin, il passe dans le vaisseau annulaire du rectum et y recoil encore le sang veinenx des ovaires. De là il se rend dans les cinq trones qu’il faut, à mon avis, envisager comme artères branchiales. Ceux-ci distribuent le sang dans les branchies intérieures, où il se transforme de nouvean en sang artériel. Cette transformation opérée, le sang, redevenn artériel, se rend de nonveau, par la veine branchiale, dans le vaissean annulaire artériel de l'anus, d'oủ il se répand, d'une part, dans les artères des ovaires, et d'autre part, dans l'artère intestinale, pour de là regagner le cour. Les vaisseanx qui se rendent de la membrane interne du tesi dans la veine intestiuale, peuvent avoir une double fonction : ou bien ce sont des veines simples venant de la peau et se mêlant au sang veinenx de la lauterne el de l'intestin, ou bien ce sont des veines artérielles qui condnisent du sang veinenx dans la membrane interne du test, pour ly oxider au contact avec l'eau marine intérieure qui baigne continnellement cette membrane.

On pourrait encore supposer un autre mode de circulation dans lequel les artères et les veines auraient la même importance que dans la première lıypothèse, mais qui en différerail en ce que la circulation se ferait dans un sens opposé : du cour, le sang artériel arriverait dans l'artère intestinale, alimenterait l'ésoplıage, l'intestin et le rectum, remonterait vers les plaques génitales et anales, pourvoirait les artères des ovaires et peut-être aussi celles de la membrane du test. Le sang veineux s'assemblerail de tout l'intestin dans la veine intestinale qui, arrivée au rectum, se transformerait en vaisseau anuulaire veineux de l'anus, recevrait les veines de l'ovaire et répandrait le sang dans les cinq veines branchiales; celles-ci le rẻpartiraient dans les fenillets branchiaux, où il serait oxidé. Le sang des branchies, redevenu ainsi artériel, redescendrait par ia veine branchiale vers les auricules, et se continuerait, par leurs ouvertures, dans le vaisseau 
du ligament intérieur oblique, remonterait le long dı pharynx, regagnerait le vaisseau annılaire artéricl de la lanterne, et de lá rentrerait dans le cour par l'artère qui remonte de la lanterne. Quant aux vaisseaux sanguins observés dans les tubes ambulacraires, ils communiquent, comme Krolnu l’a égalenent ohservé, avec ceux des hranchies interues.

Je le répète, celte explication de la circulation n'est autre chose qu'une hypothẻse hasardèe; pent-ètre même est-elle dénuće de tout fondement: ućanmoins elle me senble être en larmonie avec ce que l'on remarque dans d'autres animaux, et ne contredit en rien les observations inconplètes, il est vrai, que nous possédons sur les vaisseaux sanguins de l'Oursin.

S'il est vrai, comme nous l'avons admis, que le vaisseau anmulaire externe de la lanterne soit récllement une veine, nous aurions, dans la structure de cet organe, un appareil qui corresponIrait ou au moins serait analogue aux appendices veineux des Céplnalopodes. En effet, si dans une lanterne intacte, on souleve les cinq vésicnles remplies de liquide ou en partie d'air, qui sont situées a l'extrémité des plumes dentaires, on y voit cinq organes vésiculeux appliquès contre la face supérieure de la lanterne; organes qui se font remarquer par des points noirs répartis à leur surface ( Tab. VII, fig. 118). Ces organes, entourés de la membrane de la lanterne, sont libres à l'extérieur, tandis qu’à l’intèrieur ils adlıèrent à un vaisseau annulaire à parois très-minces, que nous venons de désigner sous le nom de vaisseau ammlaire veincux de la lanterne. Chacun de ces cinq organes correspond par sa position à la ligne médiane d'une pyramide, par conséquent au milieu d'une aire interambulacraire; il se trouve donc au milieu de l'espace compris entre deux faux et deux compas, et à l’intérieur des muscles transverses. En observant à l'oil nu, on dirait souvent que le vaisseau annulaire, auquel se rattachent ces organes, communique d'une part avec la veine intestinale, et, d'autre part, avec l'artère intestinale; mais un examen microscopique plus exact m'a convaincu qu'il n'existe de véritable communication qu'arec le vaisseau annulaire veineux.

Chacun de ces organes montre, au microscope, une structure glanduleuse (Tab.VII, fig. 120). Du vaisseau annulaire veineux part un large rameau, qui se divise en has en plusieurs branches latérales, et c’est sur ces dernières que l'on remarque les vésicules glandulaires. Les rameaux principaux sont les plus transparens; les vésicules et leurs tiges le sont moins. Ces derniers montrent sous le microscope un épithélium en pavé, tel qu'il existe dans les vésicules salivaires des embryons des mammifères et des oiseaux. Un épithélium semblable se remarque aussi daus les rameaux principaux; mais il paraît être d'une structure plus fine dans l'anneau annulaire veineux. 
Cette structure glanduleuse est tout-id-fait en rapport avec les observations faites par Krohı sur les appendices veineux des Céphalopodes, et de plus nous y remarquons aussi quelques corpuscules rouges que je n’ai cependant eu l'occasion d'observer que sur des exemplaires conservés dans l'esprit de vin. Ces corpuscules, tantôt entièrement globuleux, tantôt irréguliers, ne dégragrent point d'acide carbonique au contact avec l'acide hydrochlorique qui ne fait que les blanchir. Au premier abord, cette circonstance nê concorde pas avec les expériences faites par lírolın sur les Céphalopodes, puisque cet observateur a trouvé les points rouges en question composés de cristaux colorés. Hais d’un autre côté, j’ai remarqué sur des exemplaires de Sepia officinalis conservés à l'esprit de vin, des globules rouges tout-à-fait semblables à ceux de l'Oursin, ensorte que l'analogie n'en existe pas moins.

Les organes décrits par Della Chiaje $\left({ }^{1}\right)$, sous le nom de grappoli vesicolosi, sont probablement analogues ou identiques avec les organes glanduleux qui nous occupent ici.

Tiedemann $\left({ }^{2}\right)$ trouva le sang, dans l'artère intestinale d'un jaune foncé ; dans la veine intestinale, au contraire, d'un blanc jaunàtre. Les globules du sang sont granulaires et souvent, ả ce qüil paraît, irréguliers ; ils contiennent aussi fréquemment un noyau. Leur circulation mentionnée par Della Chiaje ${ }^{3}$ ) el Carus (') est évidemment déterminée par le mouvement vibratile de la memlorane interue du test $\left(^{5}\right)$.

(') Voici comnent il sexprime dans les Istiluzioni Toun. 2 p. 340 : 11 vasellino clie dal fondo dell Ampolla Poliana si dirige verso la fovea corrispoudente alla faceia interna dello sendetto maggiore dellano, communica con un corpo vescicoloso risulfante da numerosi granelli, ne quali si contiene un umore identico a quello dell'Ampolla Poliana o sia del ruore. L'E. spatayus, che perfellamente ne manca, ed avendo l'ampolla accennata semza vaso di conmunicazione nel suo fondo, offre sul mesenterio vari grappoli vascolosi provenienti dalle diverse diramazioni dell'arteria meseraica minore e pendenti sul mesenlerio. Esplorata sifatta sostanza al microscopio l’ho riuxenuta licolma di globetti sanguigni. L'E. cidaris è sfornito delle sucecennate produzioni rasculose: e chi sa con queste e co corpi sfragiali delle bran chic non abbiano relazione igruppi vescicolosi alle asterie?

(2) Anatomie l. c.

(3) Menorie Vol. 11, p. 545 .

(") Analecten fïr Nalur und lleilkunde 1829 in-8", p. 152

(") Comp. sur les observations de behla-Chiaje R. Nigner de la whysologie du sang Cah. 1. 1853, p. 28, et son manuel d'anatomie compario 1, 1. e. 


\section{CIIAPITRE IX.}

\section{DU SYSTEME NERVEUX.}

Plusieurs travaux ont été publiés sur le systène nerveux de l'Oursin. Tiedemann (1) vit de très-fins filets blancs à la face interne de très-grands exemplaires de l'E. saxatilis, conservés dans de l'esprit de vin. Il vit aussi, à plusieurs reprises, des filets semblalles a la face externe de la lanterne et aux environs des muscles interpyramidaux; d'autres fois il remarqua des filets blancs sur les branchies internes. Cependant il ne réussit pas à découvrir la connexion de ces filets entre eux. Il lui parait qu'un anneau nerveux existe à la face interne de la membrane buccale. Van Beneden et Grant $\left({ }^{2}\right)$ mentionnent un anneau pharyngien qui enverrait de funs filets descendaut à la lanterne, et d'autres montant au plarynx et ả l'ésophage. Enfiu, Krohn ( $\left.{ }^{3}\right)$ a publié , dans ces derniers temps, des études très-détaillées sur ce sujet. Suivant cet anatomiste, l'amnean pharyngien qui entoure le pharyux forme un pentagone situé à quelques lignes de la bouche, au dessus de la cavité buccale, entre les impasses de cette dernière et l'extrémité des pyramides. On le reconnait, dans l' $E$. subglobiformis de Blainville et dans beaucoup d'exemplaires de l'E. livilus, à une teinte violacée: dans le Cidaris hystrix, il est d'un vert foucé sale; dans les E. aquituberculatus et miliaris, il est encore plus apparent. De cet anneau partent, à l'endroit où les cinq pièces annulaires se rencontrent, cinq rameaux nerveux, dont chacun sort entre deux pyramides, seetend sur la membrane buccale, traverse l'auricule par le milieu et se continue sur la ligue médiane entre les branchies internes, pour aboutirà l'ouverture de la plaque ocellaire, c'esta-dire à l'organe que MII. Forbes et Agassiz envisagent comme l'nil. Le nerf branchial, étroit à ses extrẻmités, large et aplati au milieu, se divise, au moyen d'uu sillon qui est surtout distinct

(') Anatomic p. $89,90$.

(') Inatomie comparée, traduction allemande par C. C. Schmidt, p. 219.

(3) Müller's Archiv 1841 , p. 2 à 7. 
près de la membrane buccale, en deux branches qui envoient des rameaux aux feuillets transverses des branchies. Ces rameaux arrivent par les pores dans les tubes ambulacraires, et se poursuivent, sous la forme de filets extrêmement délicats, jusqu'au disque de la ventouse. Il en est de même des filets qui se détachent avant les auricules pour gagner les branchies et les tubes buccaux. Ordinairement le nerf est coloré jusque près de l'auricule, et l'on ne saurait douter que cette coloration ne provienne des grains de piment.

Je n'ai que peu de chose à ajouter à ces résultats obtenus par Krohn. C'est sur de grands exemplaires de l'E. Sphara conservés dans l'esprit de vin, que ces détails n’ont paru le plus distincts. La fig. 181 de Tal. IX contient un dessin de Ianneau pharyngien, tel qu'il se présente lorsque la lanterne, les pyramides et le pharynx sont enlevés. On y distingue le pentagone nerveux $(b)$ formé d'arcs concaves en dehors, ainsi que les branches principales $(a)$ qui s'en détachent, et que nous proposons de désigner sous le nom de ner/s branchiaux, puisqu'ils sétendent sur tout le long de la ligne médiane des branchies. J'ai représentẻ, dans la fig. 180 de Tab. IX, deux nerfs $(a)$ avec l’arc pentagonal correspondant $(b)$, d'après une préparation faite avec beaucoup de soin, tandis que la fig. 181 contient un dessin plus idéal fait d'après les différentes parties que l'on a pu observer. C'est à dessein que, dans la fig. 180, l'on a enlevé l'une des pyramides, landis que l'arc pentagonal adhère encore à la partie supérieure du pharynx; car, comme les rameaux nerveux longent les sutures médianes des aires ambulacraires, et que chacun des ares du pentagone correspond à l'espace intermédiaire entre deux nerfs branchiaux, il en résulte que chacun des ares du pentagone correspond, par sa position, à une aire interambulacraire, plus, deux demi-aires ambulacraires. Leur position, relativement aux parties de la lanterne, est déslors facile à saisir. De chaque arc du pentagone naissent de nouveaux filets destinés aux muscles interpyramidaux ( fig. $180 c, 183 c$,) et ả l'ésophage (fig. 182c). En passant à la surface de la membrane buccale, et avant de traverser l'auricule, le nerf branchial détache des filets pour les branchies buccales internes et les tubes buccaux, conme aussi pour les muscles de la lanterne qui s'attachent aux ares des auricules, ou s'insèrent entre ces derniers. II est probable que d'autres filets se répandent dans la membrane buccale et dans les branchies externes; cependant je nai pas encore pu les voir. En suivant la ligne médiane des branchies internes, le nerf branchial alimente les différens feuillets branchiaus interues, et les tubes ambulacraires, ainsi que l'a déjả démontré lírohn. Après s’être aminci à son extrémité supérieure, le nerf entre enfin dans l'orifice de la plaque ocellaire (fig. 185 b). Je ne saurais dire si des feuillets latéraux vont gagner les testicules et les ovaires. En revanche, j’ai cru remarquer, dans de jeunes exemplaires 
frais de IE. lividus, des traces diun systeme nerveux intestinal: plusieurs filets anastomosés (Tab. VIII, ligg. 159 et 160), dont l'un paraissait même pourvu de renflemens, longent l'úsophatre. Il est hors de doute qüils proviennent du pentagone nerveux; peut-être même procèdentils des rameaux pharyngiens de ce dernier (Tab. IX, fig. 182c); et c'est sans doute le cour et l'esophage qu'ils alimentent en premier lieu. Il résulte de ceci, qu'il existe des nerfs pour tous les principaux organes. Ce qui étonne, r'est le peu de développement de la substance ganglionaire. Quant à la structure pintentée, clle n'est pas étrangère au système nerveux : on la remarque surtuut dans le domaine du pentagone et de la membrane buccale. Des anas de piment $(b)$ sont épars sur les fibres nerveuses $(a)$, comme cela se trouve représenté dans la fig. 186. La lig. 187 montre les débris du contenu des nerfs. 


\section{CHAPITRE X.}

\section{DES ORGANES DES SENS.}

Il est faeile de s'assurer que les Oursins sont doués en plusieurs endroits de leur corps, d'un toucher très délicat. Les tubes ambulacraires sont sans doute des organes du toueher, comme nous l'avons démontré plus hant; mais les pédieellaires et les piquans n'en réagissent pas moins aussi sur l'aninal lorsqu'ils entrent en contact avec des eorps irritans. La sensation se manifeste également tantôt à la membrane extérieure du test, tantòt à la membrane bueeale ou ả celle de l'appareil génital et ocellaire.

Nous n'avons encore aucune trace de l'odorat ni de l'ouïe chez ees animaux. En revanehe,

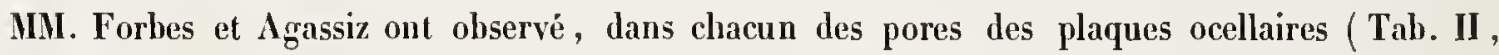
fig. $12 b$ ), un organe pimenté entouré d'un eercle plus clair ( Tab. IX, fig. 188a, $188 b, 189 a$ ). C'est cet organe qu'ils envisagent eonme l'cil, et cette opinion est en effet eorroboréc par l'analogie des yeux des Astéries observés par Ehrenberg et Siebold. Il est évident que le canal qui traverse la plaque ocellaire est occupé par un organe. Nous avons vu que le nerf branchial vient y aboutir et qu'il recoit aussi plusieurs vaisseaux sanguins, eomme l'a dẹjà fait remarquer Della Chiaje. Je dois cependant avouer que, jusqu'à présent, toutes mes tentatives pour découvrir une lentille dans cet organe ont été vaines. Je n'y ai trouvé qu'un eorps pimenté, eomposé de différens tissus fibreux et celluleux. Une seule fois j’ai cru y déeouvrir, dans un exemplaire de l'E. lividus, conservé dans l'esprit de vin, un organe globuleux, adhérent à une tige, ainsi qu'il est représenté dans la fig. 190 de Tab. IX; au reste je n'ai pas non plus reneontré de lentille dans les taehes rouges qu'on dit être les yeux des Astéries. 


\section{CIIAPITRE XI.}

DES ORGANES LOCOMOTEURS.

Les organes aetifs et Ies organes passifs du monvement sont disposés de telle sorte dans l'Oursin, que nous avons jugé eonvenable, pour éviter toute eonfusion, de les traiter indépendamment l'un de l'autre. Au nombre des organes passifs du mouvement qui, par leur eonsistanee et leur eontenu ealeaire font en quelque sorte partie du squelette, nous eomptons : le test, les piquans, les plaques génitales et anales, la lanterne, les tissus ealeaires des tubes ambulaeraires, eeux des pédieellaires et la menlbrane bueeale. Les organes tendineux sont prineipalement: les ligamens principaux fixés à la lanterne, moins eependant l'un des ligamens intérieurs que le ligament extérieur. Les organes aetifs du mouvement sont, abstraction faite des fibres museulaires contenues dans les différens organes de l'animal, les museles des piquans, eeux de la lanterne, de la membrane buecale, de la membrane anale (motores ani), les museles des tubes ambulaeraires, des pédicellaires et eeux des branehies internes.

Nous avons traité de la substanee des diverses parties du squelette, des ligamens, des museles et des membranes ả l'oceasion de ees différens organes. Les parties ealeaires du squelette sont eomposées en partie de réseaux ealeaires, en partie de pièees ealeaires plus simples; mais il n'existe nulle part unestrueture osseuse conme dans les animaux vertẻbrés. Les ligamens sont composés de fibres ligamenteuses que nous avons caraetérisées en traitant du ligament extérieur oblique (Tab. VIII, fig. 157 et 158). Les fibres museulaires sont de quatre sortes. Il y a : $1^{\circ}$ des fibres museulaires composées. Ce sont des faisecaux montrant des lignes transversales distinetement espaeées(Tab.VIII, fig. 154), à-peu-près eomme on en remarque dans les fibres museulaires des inseetes. Ils sont d'un jaune rongeàtre très-intense: la eassure n'en est point rhomboïdale. Quelquefois l'on remarque entre les lignes transversales fonećes les plus distantes, des stries transversales qui, dans quelques fibres, rappellent les tissus analogues des Vertébrés (Tab.VIII, fig. 155). Les fibres primitives, 


\section{$-102-$}

'ylindriques et homogènes, font partout saillie; c'est en particulier le cas de tous les muscles de li lanterne, des moteurs des piquans, peut-ìtre aussi des muscles des ambulacres et en tout cas des moteurs de l'anus.

$2^{\circ}$ Des fibres musculaires simples. Ce sont des fibres primitives, étroites, allongées et aplaties qui, isolées, se recoquillent facilement et prennent ainsi l'apparence trompeuse de renflemens rhomboïdaux (Tab. VIII, fig. 156). Cette sorte de fibre existe dans la membrane musculaire du pharyux, de l'ésoplıage et de l'intestin. Peut-être faut-il aussi ranger dans cette catégorie une partie des filbres des ovaires (Tab. IX, fig. 172).

$3^{0}$ Des fibres contractiles en réseaux. Elles existent dans les branchies, sont fines, très-plates, ì ce qu’il parait, et attachées aux parois des branchies, à-peu-près comme les filıres ligneuses s'attachent aux parois cellulaires primaires des cellules végélales primitives en formant entre elles un réseau (Tab. VIII, fig. 141), ou en se bifurquant.

$4^{\circ}$ Des fibres contractiles ondulées, plus ou moins arquées, cylindriques, se contractant et se dilatant pendant la vic. Tels sont les muscles de la membrane buccale et des lèvres, des pédicellaires buccaux et des pédicellaires du corps. Peut-être faut-il aussi ranger ici, plutôt que dans la première classe, les fibres musculaires des tubes ambulacraires.

La contraction des muscles s'opère d'une manière très-énergique, quoique assez lente. Il suffit de se rappeler avec quelle force les dents agissent, avec quelle vigueur les piquans sont mus, et combien les tubes ambulacraires adhèrent fortement. L'irritabilité continue longtemps après lat mort. J'ai vu, à Nice, au mois de septembre, des Oursins coupés en deux el même des parties d'Oursins mouvoir leurs piquans avec la plus grande énergie, le second jour après avoir été disséqués. 


\title{
CHAPITRE XII.
}

\author{
DES ORGINES DE LA GENEIRTION.
}

La dualité des sexes dans les Oursins était admise par le peuple long-temps avant qu'elle ne fiit constatée par les savans. De tout temps les habitans des côtes méridionales de l'ltalie ont distinguè des Oursius rouges et des Oursins blancs. D’après ces indications, M. Risso un'apprit qu'en automne, l'on trouvait, dans quelques Oursins, un liquide blanc, et dans d'autres un liquide jaune foncè dans le voisinage de l'anus. M. Peters (") reconnut en effet, par l'ètude microscopique, 'que la liqueur blanche contient des animaux spermatiques en très-grande quantitẻ et que c'est parr consèquent le véritable sperme, tandis que ceux qui ne sont point pourvus de cette liqueur blanche, sont évidemment garnis d'ovaires. En comparant numériquement toute une sẻrie d'exemplaires, il trouva sur 98 individus 43 màles et 55 femelles, en sorte que la fréquence des mâles ne le cède pas de beaucoup à celle des femelles. Cependant il est probable que les mâles ne se voient en aussi grand nombre, sur les côtes, qu'ì l'époque de l'accouplement et, quà toute autre époque, ils habitent les grandes profondeurs; car sur un nombre assez considèrable d'individus (plus de trente) que je recus en $\mathbf{1 8 3 9}$ du golfe de Villa-franca, il n'y avait pas un mâle; tous ont étẻ reconnus être des femelles, et cependant je recueillis dans le mème golfe de nombreuses Holothuries parmi lesquelles il y avait presque autant de mìles que de femelles.

Les organes de la génération sont très-ressemblans dans les deux sexes et, suivant M. Peters, les testicules diffërent à peine des ovaires dans leur forme extérieure. N'ayant point eu l'occasion d'examiner des testicules, je me bornerai ici à la description des ovaires, en ajoutant, pour terminer, quelques détails sur le sperme.

Les ovaires sont au nombre de cing : ce sont des corps aliongès (Tab.VII, liğ. 127/, fig. 128 , fig. $130 \mathrm{~g}$, et Tab. VIlI, fig. $161 d, e, f, g)$, entourés d’un mẻsentẻre très-délicat et resserrè.

(*) Müller's Irehiv, 1840, p. 145. 


\section{$-104$}

C'est au moyen d'une double lame de ce mésentère, se détachant de la surface externe (Tal. VIII, fig. 163), que les ovaires sont fixés au test. Les endroits oủ le mésentère se fixe au test correspondent aux sutures principales de ce dernier, ensorte que les ovaires ont la mème position que les plaques génitales auxquelles ils correspondent.

Chacun des cinq ovaires se termine, à son extrémité supéricure, par un canal cylindrique et indépendant qui vient aboutir aux plaques génitales. Monro (*) pense que ces cinq canaux se réunissent autour de l'anus en un vaisseau circulaire; mais cette indication repose évidemment sur une erreur; car, abstraction faite du mésentère, il existe aussi des vaisseaux sanguins de l'ovaire qui, en se réunissant en un anneau autour de l'anus, représentent un polygone. Mais si l'on vient à examiner de près ce prétendu anneau, on voit que chaque oviducte se continue au-delà et va aboutir directement à l'un des pores génitaux, sans communiquer en aucune façon avec les oviductes voisins.

On pourrait supposer que, comme la plaque génitale postérieure surpasse les autres en grandeur, il devrait aussi en être de mème de l'ovaire. Cependant mes observations ne confirment nullement cette supposition. Dans les très-petits Oursins, qui n’ont qu'un pouce de diamètre, les ovaires sont à peine assez longs pour atteindre la moitié de la hauteur du test; ils sont un peu plus longs dans les individus adultes (Tab.V'III, fig. 161). Lorsqu'ils ont atteint toute leur turgescence, immédiatement avant l'époque du frai, ils s'étendent bien au delà du milieu de la hauteur et se prolongent à-peu-près jusquà la cloison inférieure; mais dans tous ces états, ils ne montrent entre eux aucune différence de grandeur constante et assez importante pour qu'il soit permis d'en tirer aucune conclusion. Une différence particulière qui s'observe surtout dans les individus de moyenne taille, et d'une manière moins frappante dans l'E. lividus et l'E. brevispinosus que dans l'E. Sphœra est celle-ci : les ovaires pairs sont tellement dẻveloppés qu’ils se touchent, tandis que celui de l'ambulacre impair postérieur demeure plus isolé, comme je l'ai indiqué dans la fig. 161 de Tab. VIII. J'ai trouvé cette mème différence chez des Oursins qui n’ẻlaient point dans l’époque du frai, et dans lesquels les ovaires n’étaient que médiocrement renflés. J'ignore si la même particularité se retrouve dans tous les états de son développement; mais j’ai tout lieu de le supposer. De plus l'ovaire, lorsqu'il est rempli d'aufs, est convexe ou aplati à sa face externe, tandis que sa face interne est renflée de chaque côté du sillon mèdian. Sa structure est glanduleuse ; on remarque, mème sans préparation préalable, à sa face externe (Tab. VIII, fig. 163) comme à sa face interne (Tab. VIII, fig. 16\%), les renflemens cécaux par lesquels se termine la

(*) Anatomie p. 90 . 
structure grlanduleuse. Ces petits cécums ont, ì leur sommet, des lignes transversales plus ou moins distinctes; ces lignes sont paires et linilíes, à la fatce externe, par le mésentère, et à la face interne par le sillon longitudinal de l'ovaire, auquel elles viennent aboutio des deux côles. Un canal médian (Tal. VIII, fig. 165) reçoit de nombreux rameaux latẻraux qui se ramilient plus ou moins el se terminent á leur extrẻmité par des impasses arrondis, comme c'est par exemple le cas des $E$. licilus et brecispinosus. Dans les exemplaires de l'E. Sphrra, dont les ovaires ne sont pas entièrenent remplis, le sillon médian est moins distinct et l'aplatissement latéral moins symélrique el moins déclive.

Les formes particulières des tubes cécaux sont reprísentées aussi fidẻlement que possible, dans les fig. 165 et $166^{\circ}$ de Tab. VIII. Ces ramifications se voient très-distinctement dans les ovaires à moitié remplis de I'E. brevispinosus. Leurs parois se composent d'un épithélium vibratile interne, d'une couclıe fibreuse mèdiane (Tah. IX, fig. 171), et d'une membrane externe qui paraît être idenlique avec le mésentère. Ces trois membranes se reproduisent aussi dans l'oviducte. Il est presque inutile d’ajouter que le mésentère de l'ovaire est également vibratile. Les canaux glandulaires de l'ovaire sécrètent leurs aufs depuis le fond des tubes cécaux (Tab. VIII, fig. 162) jusque dans le canal sécréteur principal. Ici tous les wufs, même les plus petits, peuvent ètre facilement étudiés au microscope, grâce à leur transparence : ils ne montrent rien de particulier dans leur structure, mais se composent de la membrane vitellienne, du vitellus, qui est huileux et grenu, et dont les grains sont souvent agglomérés dans les exemplaires conservés dans la liqueur (Tab. IX, fig. 170) de la vésicule germinative, qui est transparente, et de la tache germinative, qui est en général simple. Dans la tache germinative solide, on distingue en outre souvent encore un corps rond et parallélement à lui un lıalo simple ou multiple. Dans les aufs d'un certaiı àge, la quantité du vitellus devient toujours plus considérable, comme dans les autres aninaux; ce qui rend rétude de la vésicule germinative d'autant plus difficile (") (voyez Tab. IX, fig. 169. Tab. VIII, fig. 16 T).

Les animalcules spermatiques contenus dans le sperme et que l'on retronve ì côté de corpuscules germinatifs, ont été observés, ainsi que je l'ai dit plus haut, par M. Peters. Ils ont le corps allongé et ovale, plus ou moins arrondi en avant et pointu en arrière, et probablement une très-

(*) A rétat frais, je n'ai jamais rencontré que des oufs ronds. Mais des Oursins conservés daus l'esprit de in üen ont souvent offert d’allongés et de clavellés. Quoique cette forme doive être attribuée en premier lieu à l'influence de l'esprit de vin, il n'en serait pas moins digne de l’attention des naturalistes de voir sil n'existe pas réellement diverses formes docufs dans len Oursins frais. 
fine queue qu'il ne put cependant reconnaître avec certitude. Leurs mouvemens sont très-vifs. J'ai représenté dans la figg. 168 de Tab.VIII les diverses formes de ces animalcules d'après un dessin original que je dois à l'obligeance de M. Péters. Je me suis permis d'y ajouter les queues qui certainement doivent exister.

Kœlliker (") a observé depuis lors les zoospermes des Asterias rubens, violaeea et papposa, de même que ceux des Eehinus saxatilis et esculentus. Tous ont le corps allongé, une très-fine queue en forme de cheveux, et exécutent des mouvemens très-rapides. De son côté, il s'est assuré de la grande ressemblance de structure des testicules et des ovaires dans ces deux ordres d'Echinodermes. Dans l' $E$. saxatitis, les testicules sont d'un brun foncé et mème quelquefois noirs. Les aufs sont d'un brun clair passant au jaune. La liqueur spermatique est blanche; les animalcules avaient $0^{\prime \prime \prime}, 0015$ de ligne de long, étaient pyriformes et paraissaient déprimés sur un point de leur surface, lorsqu'on les examinait de profil; ils se mouvaient soit en serpentant, soit par des contractions saccadées de leur queue filiforme. Kolliker a également trouvé dans la liqueur spermatique d'un $\boldsymbol{E}$. eseulentus des cellules de $0^{\prime \prime \prime}, 001$ à $0 ! . !, 018$, dont quelques-unes contenaient de nombreux corpuscules ayant de $0^{\prime \prime \prime}, 0005$ à $0^{\prime \prime \prime}, 001$ et d'autres globules libres, assez semblables à ces dernières, mais pourvus d'un appendice filiforme de $0^{\prime \prime \prime}, 005$ à $0^{\prime \prime \prime}, 01$ de long. Quelques-unes des plus petites cellules avaient un appendice dont l'extrémité présentait un élargissement circulaire ou bien un renflement au milieu.

A l'époque de l'accouplement, le sperme ainsi que les œufs sont excrétẻs par les ouvertures gẻnitales de l'appareil génital, où l'on en trouve souvent des traces très-marquées. Nous sommes encore dans une ignorance à-peu-près complète du mode d'accouplement et de fécondation des Oursins, ainsi que de leur embryologie.

${ }^{*}$ ) Beitræge zur Kenutniss der Geschlechtsverhaltnisse und der Sanenflüssigkeit wirbelloser Thiere, nebst einem Versuch iiber das Wesen und die Bedeutung der sogenannten Samenthiere. Berlin 1841. 4º p. 57-59. 


\section{EXPLICATION DES PLANCHES.}

TAB. I.

Fig. 1-3. Exemplaite femelle de moyeme taille de l' $E$. lividus avec tous ses piquans, que j’ai représentés hérissés dans tons les sens, tels qu’ils étaient sur un individu que je fis monrir en le mettant dans l'esprit de rin. J'ai vu d'autres individus morts de lit même manière, dont les piquans présentaient une disposition si rẻgulière, qu’on eut dit des chereux peignnés soigneusement.

Fig. 1. L'animal vu par sa faee anale. On voit les piquans, les tubes ambulaeraires, les platques géuitales et ocellaires, les pliques amales et l'ouverture anale.

Fig. 2. L'animal, ru de profil, dans sa position naturelle, l'ouverture buecale étant lournée en bas et lonverture anale en haut. On y voit les piquans et les tulyes ambulaeraires.

Figg. 3. L'animal vu par sa faee buceale; on voit les piquans, les tubes ambulacraires, la membrane bueeale, les tubes bueeaux, les lèvres, lonverthre lneeale et l'extrémité des dents faisant saillie par' cette dernière.

Fig. 4-6. Test d'un oursin adulte de l'espèee de l'Echimes brerispinosus, pour faire voir les diffírens systòmes de tuberenles.

Figy. 4. Face inale du test.

An centre se voient les plaques aniles et les plaques génenitales.

c $1, c 2, c 3, c 4, c 5$. Sutures entre les deux séries des aires interambulacraires.

$d 1, d 2, d 3, d 4, d 5, d 6, d \%, d s, d 9, d 10$. Les dix ambulacres ou zones porifères, enclavant entre $d \leq$ et $d$ ? l'aire ambulactaire impaire; cntre $d 3$ et $d 4$, l'aire ambulaeraire antririeure gauche; entre $d 5$ et $d 6$, l'aire ambulacraire postérien'e gauche; entre $d 10$ et $d 9$, l'aire anbulacraire antéricure droite, et entre $d \mathrm{~S}$ et $d \%$, l'aire ambulacraire postérieure droite.

$e 1, e 2, e 3, e 4, e 5$. Les dix rangées primaires des aires ambulaeraires.

$f 1, f 2, f 3, f 4, f 5$. Les dix rangres tertiaires internes des aires interambulacraires.

$g 1, g 2, g 3, g 4, g 5$. Les dix rangées primaires des aires interambulaeraires.

$h 1, h 2, h 3, h 4, h 5$. Les dix rangées secondaires externes des aires interambulacraires.

$i 1, i 2, i 3, i 4, i 5$. Les dix rangées tertiaires externes des aires interambulaeraires.

$k 1, k 2, k 3, k 4, k$ o. Les dix rangíes secondaires internes des aires interambulaeraires.

$l 1, l 2, l 3, l 4, l 5$, Les dix rangéés seconthires tes aires ambulaeraires.

$m 1, m 2, m 3, m 4, m 5$. Les rangées rudimentaires tertiaires des aires anbulacraires aver la suture médiune.

Figr. 5. Le test, vu de profil, la face buceale ćtant tournée en bas et la fiee anale en traut.

a. Les aires ambulaeraires.

$b b$. Les aires interambulacraires.

Fig. 6. Faee buecale du test. 
Au centre se voil l'ouverture buecale, avee la membrane buccale déchirée par la dessieation. Quelques fragmens calcaires sont visibles dans la membrane buccale dessćchéc.

$c 1, c 2, c 3, c 4, c 5$. Les sutures entre les deux séries de plaques des aires interambulaeraires.

$e 1, e 2, e 3, e 4, e 5$. Les deux rangées primaires des aires ambulacraires.

$f 1, f_{2}, f 3, f /, f b$. Les dix rangées tertiaires internes des aires interambulacraires.

g $1, g 2, g 3, g$ 4, g 5. Les dix rangées primaires des aires interambulacraires.

$h 1, h 2, h 3, h 4, h 5$. Les dix rangées secondaires externes des aires interambulacraires.

$i 1, i 2, i 3, i$ 4, $i$ b. Les dix rangées tertiaires externes des aires interambulacraires.

$k 1, k 2, k 3, k 4, k b$. Les dix rangées quaternaires externes des aires interambulacraires.

$l 1, l 2, l 3, l 4, l 5$. Les dix rangées secondaires internes des aires intermblulacraires.

$m$ 4, $m 2, m 3, m$ 4, $m$ b. Les dix rangées secondaires des aires ambulacraires.

$n$ 1, $n 2, n 3, n$ 4, $n$ :. Les dix rangées tertiaires des aires ambulacraires.

Fig. \% et 8 . Faces anales de deux petits oursins, de l'espèce de l'Echinus miliaris, montrant que les rangres primaires apparaissent tonjours les premicres.

a représente dans les denx figgures l'anus entouré dles plaques gónitales.

hh. Le segument antérieur impair du test.

cc. Les rangées primaires de l'aire ambulacraire.

dd. Les ramgies primaires de l'aire interambulacraire.

Fig. 9. Segment antérieur impair du test de fiģ. 4, 5 et 6., vue sous un failıe gुrossissement et montrant uns les lubereules, les grrands comme les petits, ainsi que Ia disposition des pores ambulacraires.

a. Echancrure correspondant à la plaque génitale.

bb. Deux entailles luccales.

$c c$. Les deux ambulacres ou zones porifères.

d. La sutmre médiane.

$e$. La ranfée primaire de l'aire ambulacraire.

$f$. La rangée sccondaire de l'aire ambulacraire.

g. La rangée lertiaire de l'aire ambulaeraire.

$h$. La rangóe primaire de l'aire interambulaeraire.

$i$. La ranģée secondaire exlerne de l'aire interambulaeraire.

$k$. La rangée tertiaire externe de l'airr interaml nulacraire.

l. La rangée quaternaire externe de l'aire interambulacraire.

$m$. La rangíe secondaire interne de l'aire interambulaeraire.

$n$. La rangée tertiaire interne de l'aire interaml sulacraire

Figg. 10. Un tulercule isolé de la rangée primaire de l'aire interambulacraire, considérablenent gyrossi et wi le profil.

a. La zone lisse ou la colline du tubereule.

b. Le mamelon.

c. Les tubereules miliaires entourant le gros tubercule.

TAIR. II.

Fiğ. 11. Le même tuhereule vu d'en haut. La signification des lettres est la même que dans la fiğ. 10.

Fig. 12. Appareil apjicial d'm E. lividus.

Fig. 12.* Le même applareil faiblement gọrossi.

Fig. 12. Appareil apicial d'un autre individu faiblement grossi. 
a. Plaques rgénitales.

b. Plirpues oecllaires.

d. Onverture anilc.

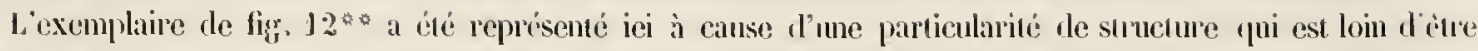
généuale, e'est que la plaque neellaire antérieme fait partio de l'ammean apicial et touche aux placpues anales.

Fig. 13. Moilić du test de l'exemplaire de ligg. 4 , 5 et 6 vin en dediuns.

Portion du test comprise entre äj et al. Segument antéricur impair.

\begin{tabular}{|c|c|c|}
\hline " & $"$ & $a 1-a^{2}$. Segment intririeur droit. \\
\hline " & $"$ & $a_{2}^{2}-a_{2}$. Segmont postélicur droit. \\
\hline ") & ") & a:j-ak. Segment antcicieur gaurle. \\
\hline " & $"$ & $a^{\prime} \mathbf{1}-a 3$. Segment postérieur granche. \\
\hline
\end{tabular}

$b \mathbf{1}, b 2, b 3, b$ 亿, $b$. Aires ambulicraires formant te milieu des segunens.

c. Sultures transversales des plarpues interambulaeraires.

d. Sulures transrersales des plaques ambulacraires.

$e, e, e, e, e$. Les plaques génitales. Entre elles sont situćes les plarpues ocellaires, dont les trois anterieures font partic du cercle apicial, et au milien sont les plapues anales.

Fig. 14. Moitié inférieure du test de fig. 13.

$a, b, c$ et $d$ ont la même signifieation que diuns la fiğ. 13.

$f, f, f, f, f$. Les cinq aurieules.

$y, g, g, g, g$. L'ouverture des auricules.

$h, h, h, h, h$, etc. Les dix entailles de l'ourerture inférieure du test.

$i, i, i, i, i$. Partie de l'anneau auriculaire correspondant aux aires interanlunlacraires.

Fig. 15. L'anneau auriculaire, vu de profil.

$e, f, g, h, i$, ont la même siognilication que dans la fiợ. précédente.

$k$. Sulmres verticales d'une auricule.

Fig. 16. Coupe verticale d'une plaquette du test.

$a, a, a$. Trois tulserenles grossis.

$b$. Un tubereule miliaire.

$c, c$. Tubereules de la plus petite dimension.

$d, d$. Simples renflemens.

$e$. Réseau calcaire de la face interne du test.

Fig. 17. Une semblable conpe sous un plus fort grossissement.

a. Mamelon du tuberculc.

b. Colline du ulsercule.

$c$. Sulsstance externe du test.

d. Substance interne du test, ayant de plus grands réseaux caleaires.

Fig. 18. Coupe transtersale de la substance interne ì grrands réseaux.

Fig 19. Coupe transtersale de la partie externe d'une aire ambulacraire, afin de rendre pilis sensible li forme des pores ambulaeraires et des sutures.

$a, a, a, a$. Pores anbulicraires.

b. Sultures.

Figy. 20. Fragmens détaehés eonstituant la poudre du test.

$a$. Fraģment qui contient eneore une maille du réseau.

b. Fragymens du réseau montrant une eassure plus ou moins conehoïdale; 
c. Fragmens de dimension moyenne.

d. Fragmens plus pelits.

e. Fragmens de la plus petite dimension, qui quelquefois pervent induire l'olservateur en erreur par lem apparence crystalline.

Fig. 21. Tubercules ramollis par l'acide muriatique, le mamelon étant enlevé.

Fig. 22. Un semblable tubercule vu an microscope.

Fig. 23. Coupe trinsversale d'un fragment de test ramolli par l'acide muriaticue.

TAB. III.

Fig. 24. l'etit piquant de l'appareil génital d'un $\boldsymbol{E}$. lividus, de moyenne taille.

a. La partie condylö̈le.

b. La baguelle.

Fiğ. 25. Le même piquant garossi.

a. La partie condyloïde.

b. La bagntlte avec les carènes qui la caractérisent.

c. Quelques traces des fines aspérités des carènes.

d. Les muscles du piquant (motores aculeorum).

Fiğ 26. Partie supérieure libre du même piquant grossi, ponr montrer les fines épines des carc̀nes.

Fig. 27. Fragment du mème piquant encore plus fortentent grossi, pour montrer sa cassure conclioidale, sil sulnstance simple et les épines de sa surface.

Fị̂. 28. Piquant de gyrande taille du même animal de grrandeur naturelle, arce une portion dù test.

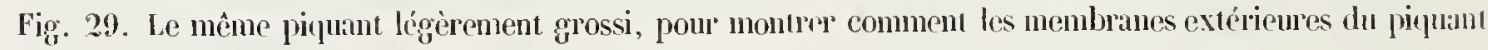
sont fixées au tubercule.

Fig. 30. Coupe transrersale du piquant par le milien.

a. La substance centrale.

b. La substance simple.

$c$. Les rayons de la substance réticulée.

Figg. 31. Coupe transversale par le milieu du piquant. La signitication des leures est la même que daus la figg. 30.

Figg. 32. Portion grossie de la substance réliculée.

Fig. 33. Coupe longitudinale par le milieu du piquant.

a. Feuillet de la sulstance simple.

b. Sulstance réticulée.

Fig. 34. Fragment de la coupe longitudinale sons un plus for' grossissement.

a. Sulastance simple.

b. Sulsstince réliculée extérieure.

c. Sulbstance réticulće intérienre.

Fig. 34* Réseanx de la coupe longitudinale fortement grossis.

Fiş. 35. Coupe transversale de la tête d'm piquant de grande liille.

a. La sulustance centrale.

b. La substince simple.

$c$. La substance réliculéc.

$d$. La rosette de la collerette.

Fig. 36. Coupe transversale de la partie articulaire du condyle, avec sat cavitu médliane.

a. La partie périphérique. 
b. La cavité articulaire.

Fig. 37. Substanee de la partic eentrale dı coulyle, legèèement grossi.

Fig. 3S. Conpe longitudinale de la partie infériene du piqnint. On voit les fenillets de la sulstanee simple, ainsi que la sulstanec réticulée, converger vers le has. On y voil également de quelle inanière la collerette s" forme et eonment sa sulsstance curtonre la lète du piipnant et forme la cavité articnlaire.

Fig. 39. Piquant de moyenne grandeur ramolli par l'acile.

a. La cavité artienlaire.

b. La membrane interne de la capsule; eelle-ci est enlevio d'un còté pour laire voir l'origine des motores aculeorum.

c. Les motores aculeormm.

TAB. IV.

Figy. 40 et 亿1. Pédicellaires gemmiformes vits de côté.

a. La tige.

Ђ. Le renflement lasilaire.

c. Le bouton.

Fig. 4\%. Le bonton rin d'en liant.

Fig. 43. Bouton ramolli par l'acide montrant ses renflemens et sa eavité.

Fî̧. 44. Pédicellaire ģemmiforme traité à la potasse pour montrer le squelette ealeaire. Les parties molles qui entourent ce dernier sont indiquées dans leur position naturelle.

$a$. La massne.

b. Base des pinces.

c. Pinces.

$d$. Dents externes, et $e$, dents internes des pinces.

Figy. 45. Squeletle calcaire d'un pédicellaire tridactyle.

$a$, renflement basilaire.

$b$, bras des pinces.

Fiyg. 46. Pédicellaire buccal rendı un peu transparent par la potasse.

a. La tige.

b. Le bonton.

c. Canal eentral des parties molles entre la tige et le bouton.

d. Fibres longitudinales des parties molles, sur lesquelles on remarque extéricurement la conehe pimentée.

e. Fibres transversales près du renflement du bonton.

Fiß̧. 47, 4S, 49, 50. Têtes de piquans buccaux dans différentes positions.

a. Bras des pinces.

b. Pièces luasilaires.

c. Ares semicirculaires.

Figg. 51, 52, 53. Pinces isolées, tirées des boutons représentés dans les figurures précédentes.

Fig. 51, vues en grande partie en dedans.

Fig. 52, rues de profil et un pen obliquement.

Fig. 53, vies par la face externe.

a. La nervure margyinale.

b. La nervure médiane.

$c$. Nervire transversale. 
d. Partie des pièces basilaires correspondant à la base des pinces.

Fig. bُ. Missuc des filets buccanx.

a. Partic clavellée libre.

h. Base de la massue.

Fig. 53. Partie du test d'm petit $E$. lixidus prise dans le voisinage de l'anns, et montramt la disposition des pélicellaires tridactyles el gemmiformes.

a. Tube ambulacraire.

b. Pédicellaire gemmiforme.

c. Pédicellaire tridactyle.

Fig. 56. Profil d’um tesi d'E. lividus dégagé de ses piquans, pour montrer la saillie de l'ame et la direciou des ambulacres.

a. Les aires interambulacraires.

b. Les aires ambulacraires.

c. Les tubes ambulacraires.

d. Lorifice anal.

e. Les plarplnes anales.

$f$. Les plaques rénitales.

Fig. 5\%. Face inférieure dı même Oursin.

a. Aire ambulacraire impaire antérienre.

b. Tulhes ambulacraires.

c. Branchies buceales.

d. Membrane buccale.

e. Tubes luccaux.

$f$. Onverture bnceale arec les cinq dents qui en surgissent.

Fig. 5s. Tulve ambulacraire grossi, rendu nu pen transparent par li potisse.

a. Squelette de la ventouse.

b. Faroi externe plissée transversalement.

c. Cantal central.

d. Faiscean principal de fibres longitudinales.

Firg. 59. Veutouse d'un tube ambulacraire, rendue légèerement transparente jar la potasse.

a. Ouverture centrite de la ventonse.

b. Filores rayonnantes entourant l'ouverture.

c. Squelette calcaire de la rentouse.

d. Plis de la surfice des parties molles.

Fig. 60. Rosace de la ventonse d'm tube ambulacraire. On voit l'anneau calcaire au thavers des cing pièces te la rosace.

Fig. 61. Rosace de la rentouse d'un tulve ambulacraire composé de quatre pièces.

Fig. 62. Anueau calcaice d'mu tube ambulacraire.

Fig. 63 Tube ambulacraire buceal rendu semi-transparent par lacide acélique, vin de profil.

a. La ventouse.

b. La membrane externe revêtue de piment.

c. La grande cavité centrale.

d. Fibres misculaires de la lige.

e. Ces mêmes filıres surguissimt par faisceatux à l'endroil oì elles ont été déelinées. 
TAB. Y.

Fig. 64. Squelette calcaire d'un tube buceal de l'E. lividus.

a. L'onverture centrule.

b. Le résean calcaire.

c. La substince molle qui l'entome.

Fig. 65. Corps semi-eireulaires calcaires de la partic cylindrique d'un tube buceal de l'E. lividus.

Firy. 60. Les mêmes corps pris sul' III E. brevispinosus.

Fiy. 6\%. Les mèmes corps vus en place, avec la menbline pimentéc yni les recourre.

Fiğ. 6S. Membrune étaléc d'une lève de là inembrane buceale de l'E. lividus.

a. La couche extorne.

b. La conche interne.

c. Les membranes et muscles adjacens de la lanterne.

Figig. 69. Feston isolé de la lève rendu transparent par la potasse.

a. L'épithélium.

b. Les fibres rayonnées.

Fig. 70. Conche externe de pineut de la mombrane luccule.

Fig. 71. Conche externe de la levre de la membrane buceale de l'E. lividus, tuitée ì la potasse.

$a$. Le bord libre de la lève.

b. Le piment en pavé.

c. La couche substantielle filorense de la membrane lunceale.

$d^{\prime} d^{\prime \prime} d^{\prime \prime \prime} d^{\prime \prime \prime \prime}$. Différentes formes do réseaux calcaires. Les internes sont les moins développés. Les externes sont plus compliqués.

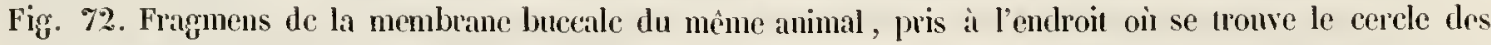
tubes ambulacraires buccaux, et rendus transparens par la potasse.

a. Placines des tubes buceanx.

b. Trou destiné à l'insertion d'un tulse lniceal.

c. c. c. Petits fragumens de la membrane buceale.

d. Réscaux calcaires dispersés dins la membrane buccale

On remarque en outre, dans cette fig̛ure, de plus petits pịuans et des massues de différens pédicellaires. Figु. 73. Profil de la membrane buccale desséchéc de l'E. lividus, avee les patties adjacentes du test.

$a$. L'ouverture buceale avec l'extrémité des dents qui font saillie.

b. Les plis rayonne's de la nembrane luncale.

c. Les plaques des tubes buccaux.

d. La partic externe de la membrane lunceale avec ses plaques calcaires.

$e$. Les entailles dı test.

Figig. Th. Face inférieure d'un $E$. lividus.

Une partic de la membrane buccale est enlevée pour faire voir la position des pyramides el des rlents, relativenent à l'omertme buccale.
a. La pyramide.
$b$. L'extrínité des dents.
c. Les lèvres.

Fiğ. 75. Face imférieure du même animal. La membrane luccale est en partie enlevéc jusqu’à son insertion dans le test.

a. La lyramide. 
b. L'extrémité des dents.

c. Le bord des lèvres.

d. La plume dentaire apparaissant à travers le grrand erenx de la pyramide.

$e$. Les aurieules.

$f$. Les museles interareaux.

$g$. Les museles extenseurs de l'ouverture dentaire.

Fig. 76. Lanterne d'Aristote de l'E. Sphera, vile de profil.

a. L'extrémité des dents faisant saillie en dehors des pyramides.

b. Les pyramides.

c. Le grand ereux ou trou de la pyramide.

d. L'extrémité des eompas.

$e$. La plume dentaire.

Fiğ. 7\%. Le même appareil, vu d'en liaut.

a. Les auricules.

$b$. La pyramide.

c. La fanx.

d. Le eompas.

e. La plume dentaire.

f. L'ouverture ésophagienne de la pyramide.

Fig. 78. Pyramide vie par sa faee externe.

a. La grande fossette de la pyramide (fovea magna exterma).

b. Le bord externe (margo procminens externa).

c. Le grand sillon longitudinal externe (sulcus longitudinalis externus major).

d. Le petit sillon longitudinal externe (sulcus longitudinalis externus minor).

e. La demi-lune (semi-luna).

f. L'are transverse de la pyramide (arcus transversus pyramidis).

g. L'éelanerure de l'are (fovea arcuatis).

$h$. Le grand ereux ou trou de la pyramide (foramen magnum pyramidis).

$i$. Le gyrand ereux on tron de la pyramide vue obliquement.

Fig. 79. Pyramide avee la dent qu'elle eontient vue de profil.

a. Le grand ereux (foramen nagnum pyramidis).

b. La faee latérale de la pyramide avec ses stries transversales.

c. L'extrémité de la dent finisant saillie.

d. La plume dentaire.

Fig. So. Pyranide vue par' sa face interne.

a. Le côté latéral.

b. Le sillon dentaire.

c. L'échanerure destinée à loger la faux.

d. L'éeltanerure dentaire.

e. Petit erenx de la pyramide (foramen minus pyramidis).

Fig. 81. Pyramide avee sa dent, vue par la faee interne pour faire voir li manière dom la dent est renfermée dans la pyramide.

$a$. Stries transversales.

b. Lá dent,

c. Le sommet de la plume dentaire. 
Fig. S2. La pyramide vue par sa face interue, la dent et une partie des parois latérales étant enlevées, afiu de montrer le sillon dentaire et les earènes qui le bordent.

a. Les earènes saillantes de la pyramide (linex eminentes pyramidis).

b. Le sillon dentaire (sulcus dentalis).

c. L'échancrure dentaire (incisura dentalis).

d. Le grand tron de la pyramile (foramen magnum pyramidis).

Fig. 83. Pyramicle vue d'en hant.

a. Le petit crenx de la pramide (foramen minus pyramidis).

b. Le trou vide de l'are transverse (foveae racuae areus transversi).

c. Le grand ereux de la pyramide (foramen magnum pyramidis).

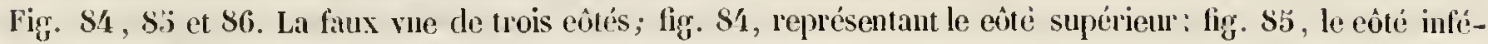
lieur, et lig. s6, le profil.

Fig. S7, S8 et S9. Le eompas, vu en dessis (fig. S\%), en dessous (figy. S8), et de profil (fig. S9).

an. Les impressions musculaires (impressiones musculares).

Fig. 90. Profil de la faux et du eompas rémis pour montrer leur superposition.

a. La fitlx.

b. Le eompas.

Fig. 91, 92 et 93. Partie supérieure d'une dent vue de trois côtés.

Fig. 91. Faee externe.

a. La earène moyenne.

b. Les denx surfuees planes.

c. Les firees inelinées.

Fig. 92. La fize interne.

Fig. 93. Le profil.

Fig. 94. La face interne de la plume dentaire.

a. Son extrémité.

$b$. La earène de la plume dentaire.

Fig. 95. La lanterne d'un $\boldsymbol{E}$. Sphera avec ses miseles et ses membranes, vie de profil.

a. L'intestin soltant de lia linter'ue.

$b$. L'atère prineipale qui longe l'iutestin.

c. La pyramide.

d. L'extrémité des dlents.

e. Le eompas.

$f$. Les plumes dentaires.

g. Les museles eomminateurs (musculi comminatores ciborum).

$h$. Le ligament externe oblique (ligamentum externum obliquum).

Fig. 96. La lanterne avee ses museles, vie d'en haut et légèrement grossie.

a. L'intestin sortant de la lanterne.

b. Les aurieules.

c. Les ares transverses des pyramides.

d. Les eompas.

e. Les museles eomminateurs.

f. Le liģament externe oblirjue.

$g$. Les extenseurs de l'ouverture dentaire.

h. Les museles transverses (musculi transversi). 
Fig. 9\%. Face supérieure de la lanterne d'm grand $E$. brerispinosus de grandeur naturelle, afun de montrer les fines stries qui servent peut-être à mouvoir les plumes dentaires, si toutefois ce sont des museles.

$a$. L'origine de l'intestin sortant de la lanterne.

b. Les pyramides.

c. Les compas.

$d$. Les muscles transverses.

$e$. Les museles internes de la plume dentaire.

$f$. Les muscles externes de la plume dentaire.

g. Les plumes dentaires.

Fig. 9S. Face intérieure du test, avec la lanterne, dans la position dans laquelle elle se trouve dans l'animal vivant, qui a son ouverture bueeale tournée en bas, et l'ouverture anale tournée en laut. Cette figure est deslince à faire voir la disposition des museles comminateurs et des muscles obliques externes.

a. Branclies internes.

b. Plaques interambulaeraires.

c. Auricules.

c. Pyramides.

e. Entailles de la pyranide.

$f$. Les faux.

g. Les compas,

h. Pelite eavité de la pyramide, laissant apereevoir la partie supérieure de la grande cavité.

$i$. Les museles comminateurs.

$k$. Ligament externe oblique.

l. Les extenseurs de l'ouverture dentaire.

Fig. 99. Face interne du test avec la lanterne. On a enlevé les muscles comminateurs et les ligamens exrermes obliques, afin de donner une idée de la position des extenseurs de l'ouverture dentaire.

a. Les branelies internes.

b. Les aires interambulaeraires.

c. Les inricules.

d. Les pyramides.

e. Les compas.

$f$. Les plumes dentaires.

g. L'ouverture interne des carités des hranchies externes.

$h$. Les extenseurs de l'ouverture dentaire. On voit distinetement leur' double insertion sur' les auricules rt la demi-lune de la face externe des prramides.

Fig. 100. Cette fiøure est destince à représenter les museles interpyramidaux, l'une des einq pyramides de la lanterne étant enlevée. ainsi que l'ésoplagege.

a. La pyramide.

b. La grande eavité de la prramide.

c. L'extrémité des dents.

d. Les plumes dentaires.

c. Les fiux.

$f$. Les compas.

g. Les bords de la pyramide.

$h$. Les muscles interpyramidaux ocenjant l'espace entre denx pyramides.

Fig. 101. Les stries transversales des faces latérales des priramides avee les faisceaux des muscles interpy- 


\section{$-117$}

ramidaux, pour montrer que les fibres museulaires ne s'attaehent qu'anx earènes, et nullement aux sillons intermédiaires entre ces earènes.

a. Les stries transverses.

$b$. Les espaees des sillons entre les stries.

c. Les faisceaux musculaires des muscles interpyramidanx.

Fig. 102. Conpe minee des stries transversales des faces latérales des pyramides montrant leur forme er leurs réseanx enlcaires.

a. Les stries.

b. Les sillons intermédiaires.

c. Le bord de la partie latérale de la pyramide.

d. Partie saillante des stries transverses.

TAB VI.

Fig. 103. Coupe transversale de la partie inférieure d'une dent de l'E. Sphoera, légèrement grossie à la loupe.

Fig. 104. La même coupe, plus fortement grossie.

a. Réseaux fibreux verticaux.

b. Réseaux calcaires sans disposition sériale.

Fiğ. 105. Partie supérieure de fiğ. 104 sous un très-fort ģrossissement.

a. Réseaux fibreux verticaux.

b. Ríseann calcaires sans disposition sériale.

Fig. 106. Coupe transversale, de grandeur naturelle, d'une dent d'oursin prise à la partie supérieure, lit où elle est revêtue d'émail.

Fig. 10\%. La même coupe grossie.

Fig. 108. Une portion de la fig. $10 \%$, plus fortement gुrossie.

a. La substanee externe.

b. Les fibres.

Fig̣. 109. Antre partie de fig. 10\%, sons le même grossissement que figg. 1.08 .

a. Substanee externe.

$b$. Réseaux en pavé.

c. Substince simple.

Fig. 110. Fraginens d'une eoupe longitudinale d'une dent montrant les trois substanees fibreuses prineipales.

a. La couche externe.

b. Filres dentaires externes.

c. Fibres dentaires internes.

Fig. 111. Coupe transversale prise an milieu d'une pyramide près de l'endroit où l'on remarque, an milieu de la substanee, une couehe émaillée jaunâtre.

a. Sulstance réticulée.

b. Sulstance simple.

Fìg. 112. Coupe prise à l'endroit même où eette substanee jaunâtre se voit à l'intérieur de la pyramide.

a. Sulstiunce en paré.

b. Sulstance réticuléc.

Fig. 113. Partie inférieure de la faee externe de la plume dentaire d'un jeune $k$. lividus.

a. La pointe.

b. La substanee latérale plus mince et transparente. 
c. La suture médiane.

d. La carène dentaire située à la face interne.

Figg. 114. L'extrémité inférieure de la plume dentaire d'un individu plus jenne de la même espèce, mais plus fortement grossi.

a. Lil pointe.

b. La sulustance latérale.

c. L'extrémité de la carène dentaire.

Fig. 115. Fraggmens du milieu de la plume dentaire d'un E. lividus de moyenne grandeur. La face iuterne est ici représcntée pour faire roir comment les lames se relèvent pour former la carène.

a. Parties latérales.

b. Suture médiane.

c. Carène de la plume dentaire.

Fig. 116. Fragnens minces pris sur' le milieu de la plume dentaire d'un plus grand exemplaire d'un $E$, $l i-$ vidus, faisant roir la forme des lames qui composent la plume dentaire. La signification des lettres est lit même que dans la fiğure précédente.

TAB. VII.

Fig. 11\%. Différentes formes de lames détachées d'ume plume dentaire.

a. Plaques rhomboidales.

b. Plaques moins régulières.

c. Frigmens aciculaires.

Fig. 118. Lanterue d'um jeune $\boldsymbol{E}$. lividus, vu ì la loupe, montrant les vessies ovites remplies de liquide it travers lestuelles on décourre l'extrémité des plumes dentaires.

a. Les pyrumides.

b. Les compas entre lesquels on roit en partie les muscles transverses.

c. Les vésicules ovales.

d. Les parties supérieures des plumes dentaires se voyant à travers les vessies.

e. L'origine du canal intestinal.

Fig. 119. Fuce supericure de la liuterne d'un $\boldsymbol{E}$. lividus de taille moyenne, montrant les oryanes grandul'ux situés à l'extéricur du vaisseau annulaire de la lanterne.

«. Les pyramides.

h. Les échinncrures dentaires.

$c$. Les faux.

$d$. Les compas.

e. La petite ourerture des pyramides.

$f$. Les muscles transrerses.

y. L'artère descendint à la lanterne.

h. Le vaisseau artéricl annulaire de la lanterne.

l. Les orģanes gylancluleux situés à l'extérieur du vaisseıu annulaire de la lanterne.

k. La partie du canal iutestinal sortaut de la lituterne.

Fig. 120. Les organes glanduleux.

a. La partie correspondaute du vaisseau annutaire artériel de la lanterne.

$b$. Le canal principal de cet organe.

cc. Les caurax secondaires.

d. Les sacs cécaux avec les taches de piment dont ils sont reconverts. 
e. Lc canal latéral.

Figy. 121. L'ésophage avce les renflemens ésophaģicns ct les liggamens longeant l'ésophage. Les deux pyramides postérieures sont entières; les dcux latéralcs sont séparées par le milicu, ct l'antérieure ne montre: que sa partic inféricure renversée.

a. Partic inféricurc.

b. Partic supéricurc des deux pyramiles latérales.

c. Partie inféricure renversćc de la pyramide antéricure.

d. La fimx.

c. Le eompas.

f. L'ésophage.

y. Les ligamens longyitudinaux longeant l'ésophage.

$h$. Les renflemens ésophaģiens.

$i$. Les organes blanes filiformes.

$k$. Origine du eanal intestinal sortant de la lanterne.

l. L'artère descendant à la lantcrnc.

Fig. 122. L'ésoplage avce lcs renflemens ésophaģiens d'un $E$. lividlis. Les pyramides sont tellcment écartécs que les inscrtions supérienres des ligamens longent l'ésoplage se voicnt sur les pyramides.

$a$. La face externe de la pyramide.

b. La faee latérale avec ses strics transversales.

c. L'extrémité des dents.

d. La partic supéricure de la plunc dentairc.

$e$. Les renflemcns ésophagyiens qui, vus de dehors, ont l'apparence de petits sacs.

$f$. L'ésophage.

g. Les ligamens longeant l'ésophage.

h. Les organes en spiralc.

$i$. L'oriģine du canal intestinal sortant de la lanternc.

$k$. L'étranglement cntrc le canal intestinal et le pharynx.

Figg. 123. Le pharynx arce lc eommencement de l'ésophage d'un $E$. lividus, l'un et l'autre ouverts, aliu de montrer la face interne.

a. La pyramide.

b. Les dents.

c. Lcs renflcmens pharyngicns avec lcurs bourrelets.

d. La faec interne de l'ésophage avec ses fibres obliques et ses cinq divisions longitudinales, dont une postćrieurc et dcux latérales sont visibles, tandis que les denx antéricures sont enlevées.

$e$. La face interne de la partic supćrieure de l'ésophagc.

$f$. La partie supéricure de l'ésophage.

Fig. 124. Le pharynx d'un jeunc $E$. lividus isolé, vu à la loupc.

a. Le pharynx.

$b$. Les renflemens plaryngicns.

c. Les ligamens longeant le plarynx.

$d$. Les organes cn spirales.

Figg. 125. Faec supérieure de la lanterne d'un jeune $E$. lividus avec l'ésophage qui lui cst adhérent, montrant lcur rapport avee lc cour, cn grandeur naturelle.

a. La pyramide.

b. La petite ouverturc de la pyramide. 
c. La fiux.

$d$. Les compas.

e. L'ésoplage.

$f$. La face postérieure du coeur.

g. L'artère descendant à la lanterne.

$h$. Le vaisseau annulaire artériel de la lanterne.

Fig. 126. Une partie de Ia membrane séreuse de l'ésophage d'un $\boldsymbol{E}$. lividus, sons un fort grossissement.

a. Les renflemens.

b. Les espaces entre les renflemens.

$c$. Les taclies claires.

d. Les renflemens.

Fig. 12\%. Cette figure représente le cours total du canal intestinal, à l'exception du pharynx, d'après un exemplaire de l'E. Sphcera. La membrane buccale a été enlevée avec une partie dı test, et la lanterne avec l'ésophage qui en dépendent sont ici repliés en dehors de manière que l'on voit l'intérieur de l'0ursin par' en laas. La couche inférieurc de l'intestin est déplacée au moyen d'un crochet, afin de faire voir les tours supérieurs.

a. Le test débarrassé de ses piquans, de ses tubercules ambulacraires et de ses pédicelliires.

b. Les auricules.

$c$. Les trous des auricules.

d. Les sutures médianes des auricules.

$e$. Les pyramides.

$f$. Les faux.

g. Les compas.

h. Les nuscles comminateurs.

$i$. Le ligament oblique externe.

l. Les muscles transverses.

$m$. L'ésophage.

$n$, Le vaisseau longeant l'ésophinge.

$o$. Le cocur.

$p$. L'appendice.

$q, r, s, t, u$. Les cinq tours inférieurs de l'intestin.

$v, w, x, y, z$. Les cinq tours supérieurs de l'intestin.

A. Les filets attachint l'intestin à la membrime de la face interne du test.

i. Le vaisseau intesinal interne.

c. Le vaisseau intestinal externe.

D. La lamelle mésentérique entre le vaisseau intestinal exterue et l'intestiu.

E. Ovaires. (Le trait indlique ici l'ovaire postérieur droit).

F. Branchies internes correspondant aux tulses anbulacrairés.

G. Le rectum.

i.. L'anneau circulaire de l'anus.

Fig. 128. L'intestin, vu de profil, d'un $\boldsymbol{E}$. lividus de taille ordinaire (l'aire interambulacraire ganche extírieure et les parties aroisinantes du test sont enlevées, et les parties correspondantes de l'intestin sont coupées).

a. Le tesi.

b. L'extrémité des dents surgissant de la membrane buccale.

$c$. Les auricules.

d. L'ouverture des auricules. 
c. La suture longitudinale des aurienles.

$f$. La lanterne, dont les différentes parties sont faeiles ì recomnaitre d'après les dítails de la fiģure préridente.

g. L'ésopliage.

h. Le eœur.

i. L'appendice céeal de l'intestin.

$k$. Partie du premier tour de l'intestin qui est iei comper vertiealenent.

l. Tours supérieurs de l'intestin.

$m$. Tours inferieur's de l'intestin.

$n$. Les ovaires.

Fig. 129. Profil de l'intérieur d'un jeune E. liridus; une aire interambulaeraire est enlevée pour firire voir les fils d'attache de l'intestin.

a. Le test.

b. L'extrémité des dents surguissant de l'ouvertur'e bueenle.

c. La membrane buecale.

d. Une aurieule.

c. La linterne.

f. L'intestin.

y. Les fils d'attaele de l'intestin.

$h$. Vaisseaux internes de l'intestin.

i. Vuisseaux externes de l'intestin.

Fig. 130. Profil de l'intérieur d'un E. lividus.

L'un des eôtés du test, la lanterne, les tomrs eorrespondans de l'intestin, l'ésophage et le rectum sont enlevés, afin de faire voir, d'une part, le rapport des tours supérieur's avee les inférieur's, et, d'autre part, les oviduetes aloutissant à l'amean anal.

a. Le test.

b. Les tours inférieurs de l'intestin.

c. Les tour's supérieur's de l'intestin.

d. Les fils d'attaelie.

e. Le vaisseau intestinal interne.

$f$. Le raisseau intestinal externe.

g. Les ovaires.

$h$. Les oviduetes.

i. L'annean anal.

$k$. Les branehies intermes.

Fiģ. 131. Membrane séreuse de l'intestin, légèrement grossie.

Fig. 132. Contenu de l'intestin d'un E. lividus et d'un E. Sphcera, pour montrer que ees animanx se nourrissent essentiellement, sinon exelusivement, de plantes.

a. Fragoment d'une plante.

$b$. et $c$. Frammens de plantes marines, probablement des varees.

l, e. Fragomens ressemblant à des eonferves.

$f$. Fragmens ressemblant à des eoruilles; mais trahissaut leur nature végétale quand on les examine de près.

g. Squelette d'une Diatomée.

Fıg. 133. Nembrane séreuse, légèrement grrossie, du reetum d'un E. lividus. 


\section{$-122$}

«. Les renflemens formant des séries régulières.

b. Les espaces intermédiaires entre les renflemens.

Figg. 134. Rérgion supérieure du test, vue intérienrement et dépouillée de ses parties calcaires au moyen do l'acide hydrochloriøue, de mauière qu’il ne reste que le stuelette organique.

a. Les plaques iuterambulacraires.

b. Les sutures entre Ies plaques interambulacraires.

c. Les plaques génitales.

d. Les trous donnant passage anx oviductes.

e. Les plaques ocellaires.

$f$. Les plaques ambulacraires.

g. Le rectum.

$i$. Les carènes ambulacraires.

Fig. 135. Lanterne arec les parties a voisinantes du test d'um E. Sphere, légèrement grrossie. Les auricules et les muscles de li lanterne sont enlevés, afiu de faire voir les formes diverses fu'afleetent les tubes ambulicraires inférieurs el les tubes buccaux; on voit anssi les ourertures des branchies externes et la membrane branchio-lanternale.

a. La pyramide.

b. La faux.

c. Le compas.

d. Le ligament oblique externe.

e. L'anneau auriculaire.

$f$. La membrane buceale.

g. Le test.

$h$. Les branchies ordinaires.

$i$. Les branchies plus renflées des environs de l'annean auriculaire.

$k$. Les branchies burcales intericines.

l. Les ouvertures des branchies externes.

m. L'amnetu circulaire.

Fig. 136. Branchies internes d'un $\boldsymbol{E}$. lividus de moyenne grandeur', rendues transparentes par l'acide, et lé:èrement gुrossies.

a. Les feuillets branchiaux.

b. Le vaisseau lranchial longitudinal.

c. Les vaisseaux transwerses.

TAB. VIII.

Figg. 13\%. Extrémité d'un feuillet branclial fortement grossi, montrant la direction des fibres.

Fị̧. 138. Partie latérale de la hase d'un feuillet branchial, vu sous le même grossissement.

Fig. 139. Branchies internes d'un $E$. Sphera légèrement gorossies, montrant leur eavité interne et leurs rapports avec les trous ambulacraires

a. Face latérule d'un fenillet.

b. L'épaisseur d'un feuillet.

c. La rangée externe des pores ambulacraires.

d. Le vaisseau longitudinal.

c. Les raisscaux transver'saux.

Fig. 140. Branchie luccale interne, fortement grossie, montrant ses filıres entrecroisées. 
rig. 141. Ces mèmes filores, plus fortement grossies.

a. Les réseaux de filres.

$b$. Un vaissean traversant le résean de fibres.

Fig. 142. Branchie externe d'un E. lividus, légèrement grossie.

a. L'ouverture interieure de la branchie.

b. Le trone principal.

c. $c$. Les branches latérales.

d. Les cócunns des extrémités.

Figg. 143. Partie de la membrane du tronc principal d'ume branchie externe, rendue transparente parr la potasse, afin de montrer ses réseaux calcaires.

a. Partic interne tourné vers la membrane buecale.

$b$. Purtie externe tournée ver's l'extrémité des branchies.

Fi⿱⺈. 141. Partie antérieure du eoeur en place et adlıérent à l'ésophlage.

a. La pyranide.

b. La faux.

c. Le eompas.

d. Les museles transverses.

$f$. La face antériente du cœur.

g. L'artère descendant à la lanterne.

$h$. Le vaissean artériel eirculaire de la lanterne.

$i$. Filet nervenx intestinal (probablement le rameau impair) montant le long te l'ésoplnage.

Figy. 145. Le eceur vil par sa faee postérieure.

a. Le cocur.

b. L'artère montante.

$c$. Le raisseau inférienr.

Fig. 146. Le coeur vir de profil.

Fig. 147. Le cœur vu en face.

Fig. 14S. Coupe transversale du cocur prise en $a . b$, ( fig. 147).

Fig. 149. Coupe transversale prise en $c$. $d$.

Fig. 150. Coupe transversale prise en $e . f$.

Fig. 151. Corpe transversale prise en $g . h$.

Fiơ. 152. Partie inférienre dı eœur placée de manière à ee que l'on voie sa eavité de haut en bas.

Tontes ces figures sont dessinces à l'aide d'une forte loupe.

Fig. 153. Faiseeaux musculaires d'ın muscle transrersal de la lanterne, légèrement gyrossis.

Fiğ 154. Les mèmes faisceaux museulaires plus fortement grossis, afin de faire ressortir les liģnes trausversales qui sont plus distantes.

Fig. 15̉. Quelques fibres museuaires fortement grossies, montrant leurs filets longitudinaux et parfois leurs stries transversales.

Fig. 156. Filıres museulaires simples de l'ésophage.

a. Les fibres transversales.

$b$. Les renflemens apparens des fibres transversales.

$c$. Les fibres longitudinales.

Fig. 157. Ligament oblique externe légỳrement grossi montrant ses faisceaux ligamenteux dans toute leul citendue. 
a. Les faisceaux ligamenteux.

b. La membrane transparente de la lanterne et des museles eomminateurs.

Fig. 15s. Quelques faiseeaux fortement grossis.

Fig. 159. Anneau pharyngien d'un petit $\boldsymbol{E}$. lividus légèrement grossi.

a. La pyramide.

b. La faux.

c. Le eompas.

$d$. Les museles transverses.

e. L'anneau pharyngien.

$f$. Le vaisseau artériel eireulaire de la lanterne. L'ésophage qui est représenté sortant de la lanteme montre, à sa surfaee, le commeneement du système nerveux intestinal.

Figg. 160. Système nerveux intestinal du même animal sous un failble grossissement.

a. La pyramide.

b. La faux.

c. Le comipas.

d. Les museles transverses.

e. L'ésophage.

$f$. Les rameaux latéraux du système nerveux intestinal.

y. Les rameaux moyens ganglionaires du même système nerveux.

$h$. Nerfs aceompagnant l'artère qui deseend à la lanterne.

$i$. Le eœur.

Fig. 161. Faee anale du test de l'E. Sphcera montrant les ovaires après s'être déehargés d'une partie de leurs oufs.

a. Le test.

b. Les aires interambulaeraires.

c. Les branehies internes.

d. L'ovaire postérieur impair.

e. L'ovaire postérieur droit.

f. L'ovaire antérieur droit.

g. L'ovaire antérieur ganelie.

h. L'ovaire postérieur ganelıe.

$i$. Le rectum.

$k$. Le vaisseau sanguin du rectum.

1. L'anneau anal.

Figg. 162. Céeuns terminaux d'un ovaire eontenant de très-jeunes œufs.

Fig. 163. Ovaire rempli d'oeufs d'un $\boldsymbol{E}$. livichus, vu par sa faee postériemre et légèrement ggrossi. On voit les divisions transversales, l'oviduete, les ećeums terminaux et la liggne médiane anxquels se rattache la membrane de l'ovaire.

Fig. 164. Le même ovaire vu par sa face antérieure. On distingue les divisions transrersales, le sillon nédian longitudinal qui est en partie débordé par de petits eéeums ovifères.

Fig. 163. Partie supérieure du même ovaire eoupée vertiealement par le milieu, de manière que la moitié interne de l'ovaire se trouve enlevée. On voit l'origine du eanal prineipal et les ramifieations des branelies latírales juşư'à l'extrémité des eéeums.

Fig. 166. Coupe transversale prise au milieu du même ovaire. On distingue le eanal prineipal et de nom- 


\section{$-123$}

brenx canaux laterax coupes transversalement; en revanche, il y a beaucoup de céeums terninaux intacts. On voit également la coupe transwersale du profond sillon de la fitce interne.

Fig. 16\%. Un ouf ale l'E. lividus avec la ressie germinative et la tache germinative.

a. La membrane du jaune.

b. Le jalune.

c. Lat ressie germinative.

d. La tache germinative.

Fig 16s. Animax spermatiques de l'E. purpureus.

TAB. 1X.

Figy. 169. Diflérens aufs tirés de l'ovaire d'un E. Spherert.

a. OEuf très-jeme.

b. OEuf un peu plıs dévelopjé.

c. OEuf encore plus avancé.

Fig. 170. Amas de golnthles vitelliens d'un ouf du même animal.

Figg. 1\%1. Fibres de la membrane médiane des parois de l'ovaire th méme animal.

Fig. 172. Fibre isolée, plus fortement grossic. Quelques endroits sont marqués de stries ou d'anneux particulicrs.

Figg. 173. Plissement de la membrane des branchies internes avec des filbres réticulces faisant saillie.

Fiơ. 1\%. Autre plissement de la mếme espèce.

Fig. 175. Filres de la memlırane des branchies internes.

Fiơ. 176. Fibres et débris de l'épithélium de la membrane des branchies internes, tels qu’ils se présentent dans des exemplaires conservés à l'esprit de vin.

Fig. 17\%. Une seule de ces fibres plus fortement grossic.

Fiq̛. 17S. Corpuscules sanģuins altérés, trourés dans les vaisseaux brancliaux.

Fiæ. 179. Fibres et débris de l'épithélium de la membrane de l'intestin.

Fig. 180. Partic inférieure du test d'un E. Sphcera, vue en dedans arec la lanterne onverte et le pharynx, montrant une partie de l'auncau pharynģien.

a. Le nerf loranchial.

b. Partie correspondante de l'anncau plaryngyien.

c. Rameau destiné au musele interpyramidal correspondant.

Fig. 1S1. L'anneau plaryngien avec les nerfs branchiaux.

$a$. Les nerfs branchiaux.

$b$. L'anneau plar'ynģicn.

Fig. 1S2. Rameaux de l'amneau pharyngien destinćs au pharynx.

a. Origgine des nerfs brancliaux.

b. L'anneau pharyngien.

c. Rameaux destinés au pharynx.

Figg. 183. Rameaux nerveux destinés aux museles interpyranidaux et aux autres parties de la lanterne.

$a, b, c$. Ont la mème signification que diuns fig. 182.

d. Rameau destiné à certaines parties de la lanterne.

Fig. 184. Rameaux nerveux destinés aux muscles arcaux.

a. Nerf loranchial.

b. Rameaux nerreux des muscles arcaux. 
Figy. 185. Extrémité des nerfs branchiaux.

a. Le nerf branehial.

b. La branehe terminale du nerf branehial allant aboutir au eanal de la plarque ocellaire.

c. Le rectum renversé.

Fig. 186. Dessin mieroscopique d'un faiscenu nerveux avec des taelies de piment.

a. Les filmes nerveuses.

b. Le piment.

Fig. 15\%. Fibres nerveuses arec des débris du contemı nerveux, tels qu'ils se présentent daus des exemplaires conservés à la liqueur.

Fig. 185 et 159. Les yeux tels qu'ils se présentent dans des exemplaires vivans de l'E. lividus, d'après un dessin de M. Forbes.

Fig. 188 a. La rosette apieiale composée des plaques génitales, des plaques ocellaires et dés plaques iniales.

Fig. 158. $b$. La mème rosette fortement grossie. Un ceil se voit dans le tron ocellaire $c$.

Fig. 189. Le même ail plus fortement gुrossi.

Fig. 190. Dessin gुrossi de l'organe visuel tel qu'il a été observé une senle fois au microscope. 


\section{TABLE DES MATIÈRES.}

\begin{tabular}{|c|c|c|c|c|}
\hline Préfice & · & - & 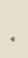 & page \\
\hline INTRODUCTION & . & . & $\cdot$ & . \\
\hline Cilapitre 1. Du test & . & . & . & . \\
\hline Cur.t. II. Des piquans & . & . & * & . \\
\hline CirsP. III. Des tubes ambulacraires & . & . & . & . \\
\hline Chap. IV. Des Pédicetlaires & . & . & . & . \\
\hline Citup. V. De la membrane buccale et de & es organes qui & en dépendent. & $\cdot$ & • \\
\hline CinAP. VI. Des organes digestifs. & . & . & $\cdot$ & - \\
\hline Chisp. VII. Des organes respiratoires. . & . & . & . & . \\
\hline Cinsp. VIIl. Du système vasculaire. & . & . & - & . \\
\hline Cintp. IX. Du système nerveux. & . & . & . & . \\
\hline Cunp. X. Des oryanes des sens & . & . & . & \\
\hline Cunp. XI. Des orgyanes locomoteurs & . & . & . & - \\
\hline Ciltp. XII. Des orģanes de la génération & . & . & . & - \\
\hline Explication des Plancies. & . & 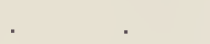 & . & \\
\hline
\end{tabular}




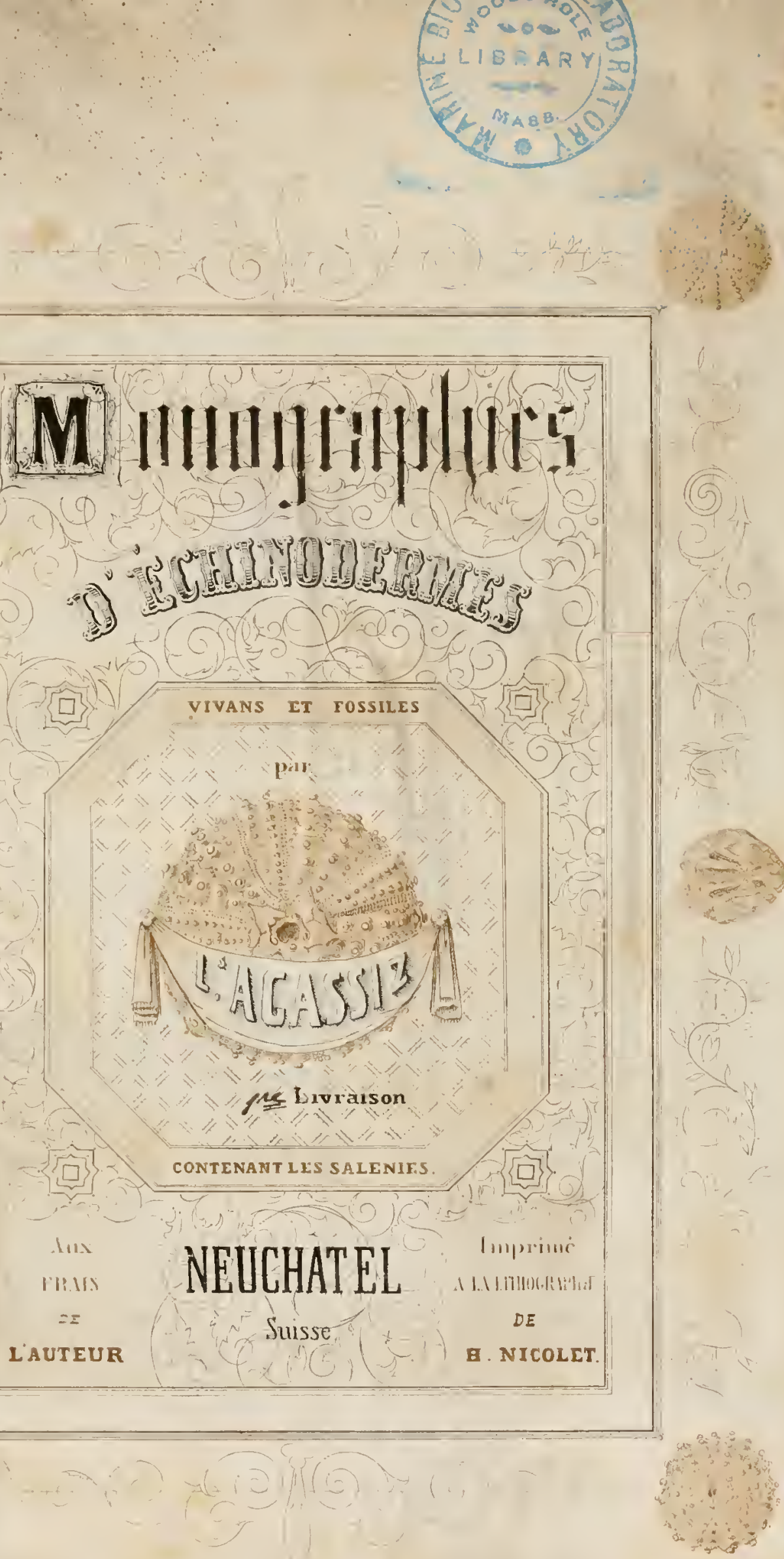


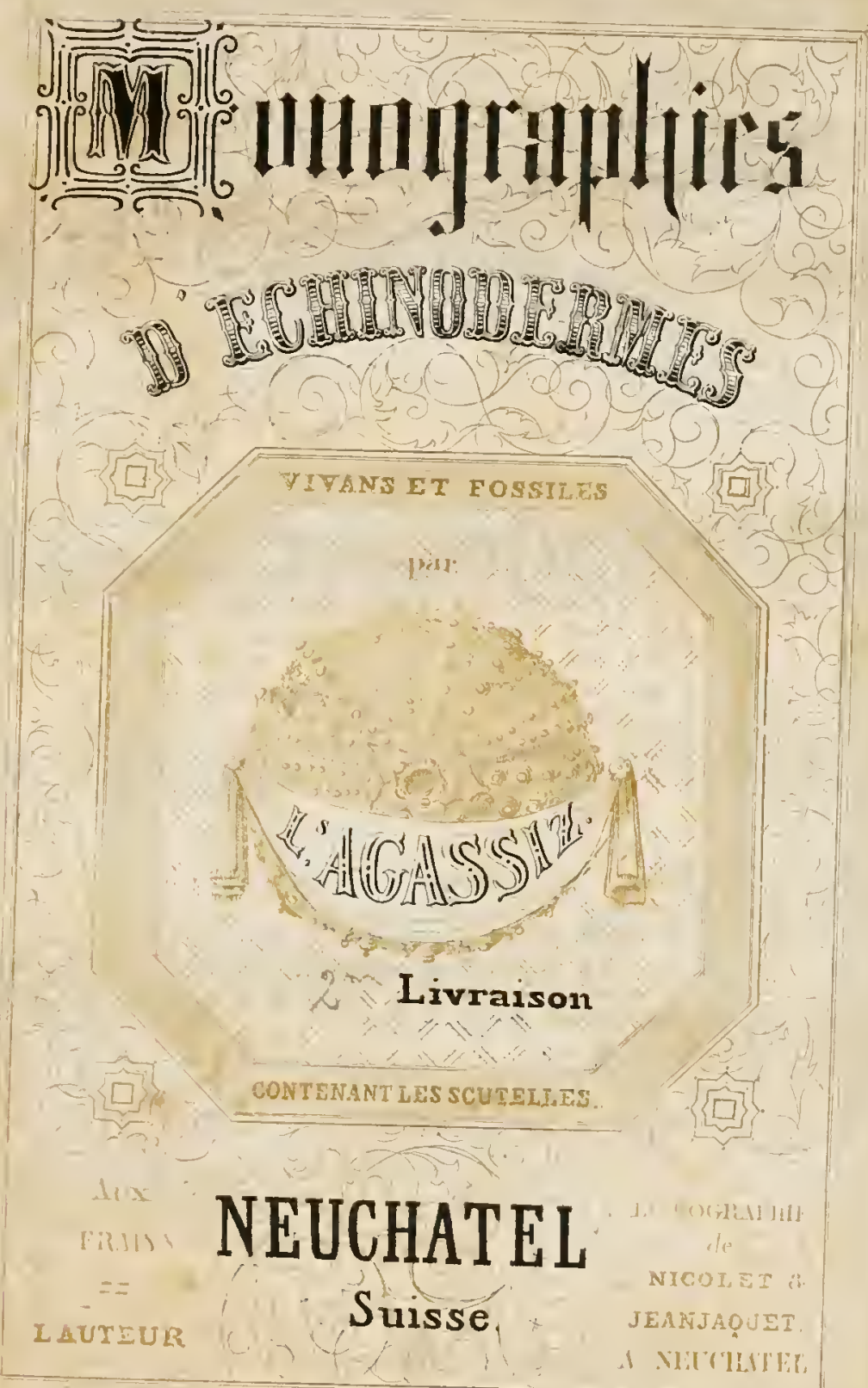




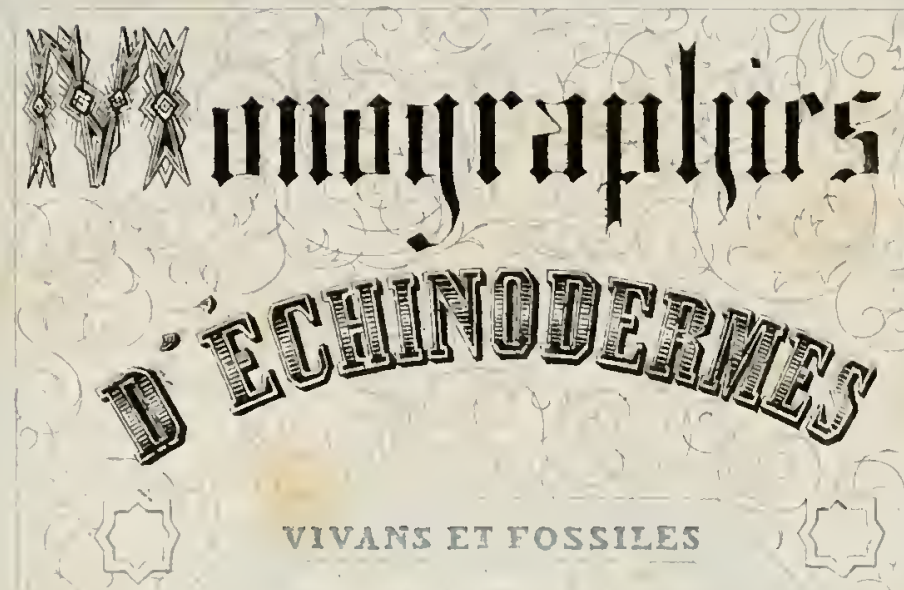

pins:
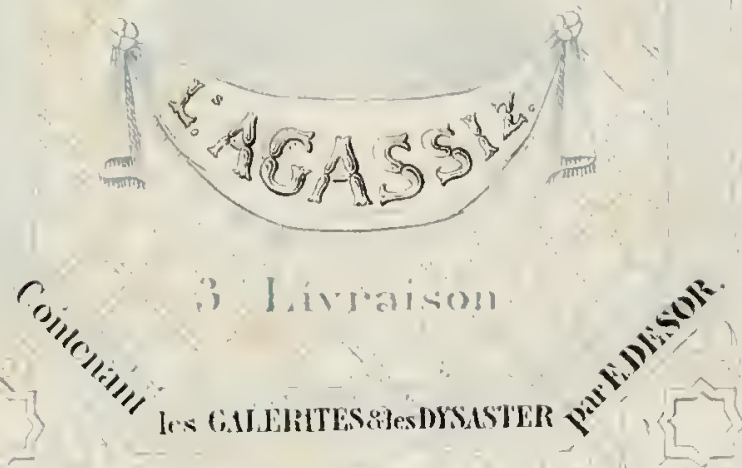

\section{NEUCHATEL Sulisse?}

NICOIET

JEANJAOUET

L AUTEUX

(a)

SOLOTIURX

HCi JENT S GASSMANX. 





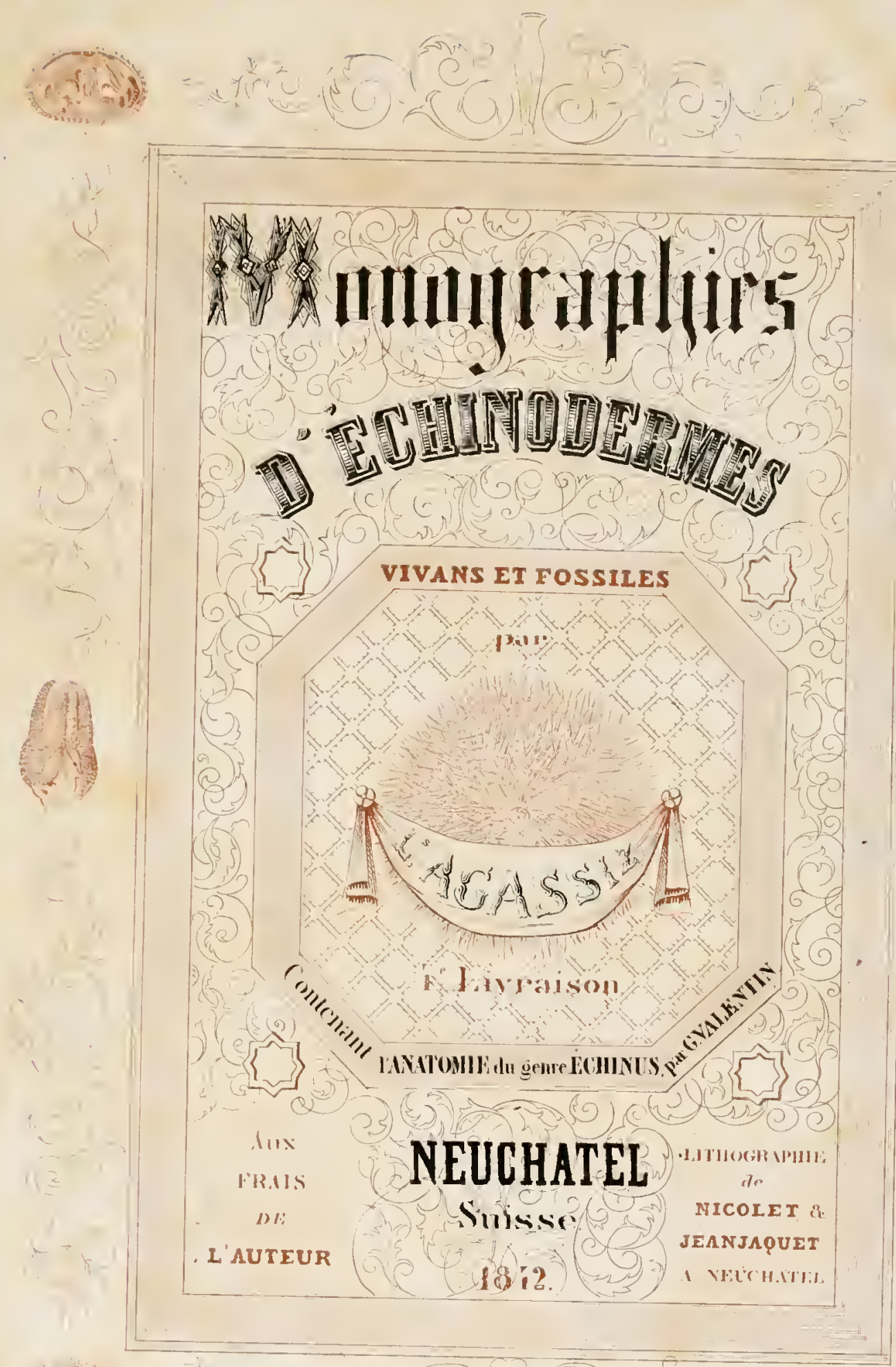










